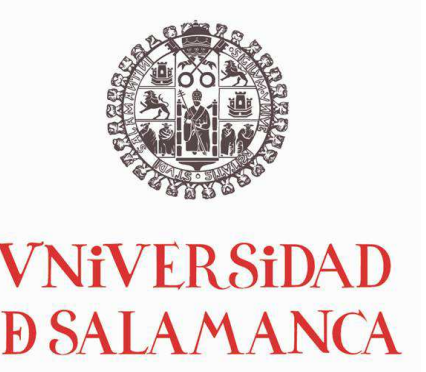

\title{
NECESIDADES PERCIBIDAS EN EL PROCESO DE ENVEJECIMIENTO DE PERSONAS CON DISCAPACIDADES
} INTELECTUALES Y DEL DESARROLLO

\author{
Tesis doctoral
}

\author{
Autora: Andrea Payo Sánchez \\ Directores: Antonio-León Aguado Díaz y \\ Miguel Ángel Verdugo Alonso
}

Facultad de Psicología

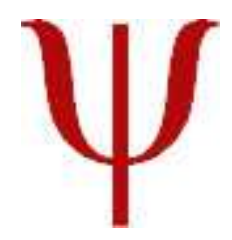

Junio 2017 

D. MIGUEL ÁNGEL VERDUGO ALONSO Y D. ANTONIO LEÓN AGUADO DÍAZ

Profesores Doctores del Área de Personalidad, Evaluación y Tratamiento Psicológicos de la Universidad de Salamanca y de la Universidad de Oviedo.

Hacen constar que el trabajo de investigación:

NECESIDADES PERCIBIDAS EN EL PROCESO DE ENVEJECIMIENTO DE PERSONAS CON DISCAPACIDADES INTELECTUALES Y DEL DESARROLLO,

Que presenta $D^{\mathbf{a}}$. ANDREA PAYO SÁNCHEZ, ha sido realizado bajo nuestra dirección y supervisión y reúne, a nuestro juicio, los méritos suficientes de originalidad y rigor para que la autora pueda optar con el título de Doctora.

Oviedo, mayo de 2017.

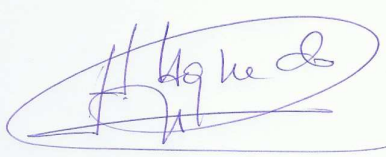

Fdo.: Dr. D. Antonio León Aguado Díaz

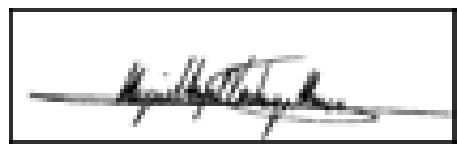

Fdo.: Dr. D. Miguel Ángel Verdugo Alonso

ILMO. SR. PRESIDENTE DE LA COMISIÓN DE DOCTORADO DE LA UNIVERSIDAD DE SALAMANCA 

A mis padres, por su apoyo incondicional. A Alfonso, por estar conmigo en todo momento. A Carmen, por ser una persona muy especial. 



\section{ÍNDICE GENERAL}

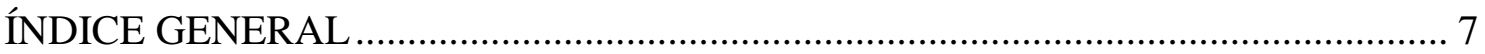

ÍNDICE DE GRÁFICOS, TABLAS Y FIGURAS ………………………………...... 15

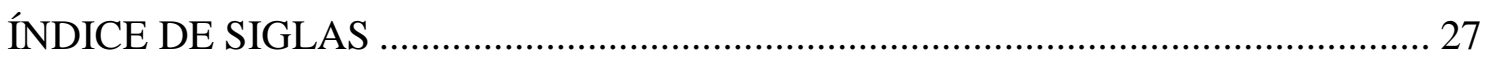

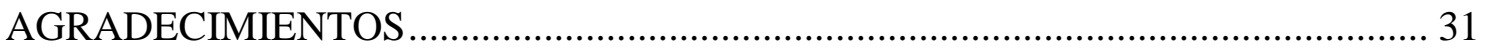

1. RESUMEN GENERAL Y PALABRAS CLAVE ……………………………….... 33

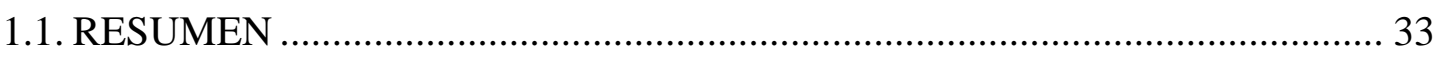

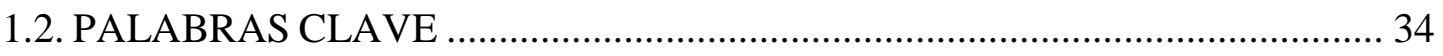

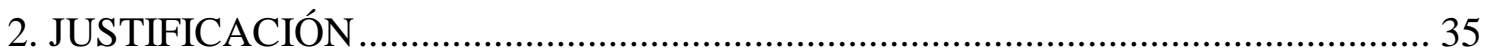

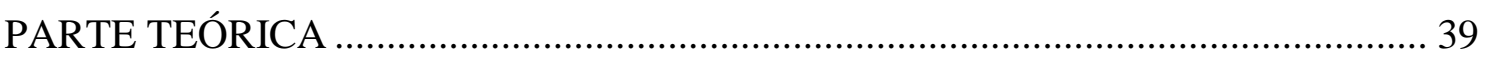

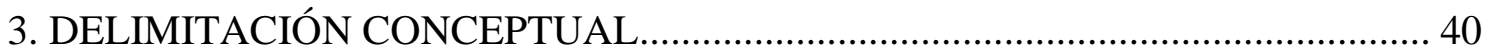

3.1. DISCAPACIDAD INTELECTUAL Y DEL DESARROLLO ............................. 40

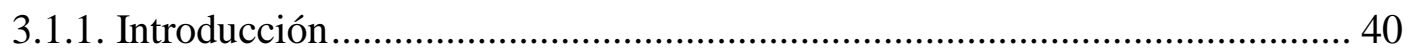

3.1.2. Evolución del concepto de discapacidad intelectual y del desarrollo ........... 40

3.1.3. Características de la Discapacidad Intelectual y del Desarrollo.................... 46

3.1.4. Implicaciones de la nueva definición de discapacidad intelectual y del

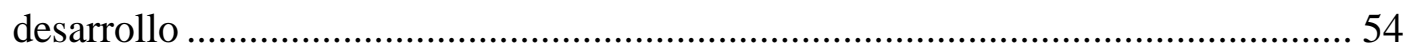

3.1.5. Líneas de investigación en discapacidad intelectual y del desarrollo ........... 57

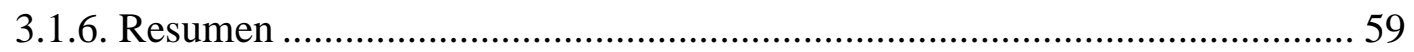

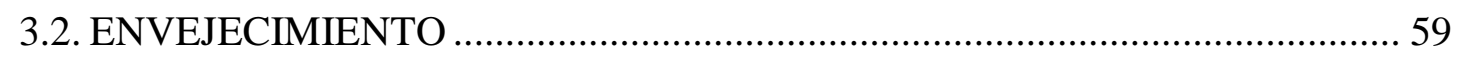

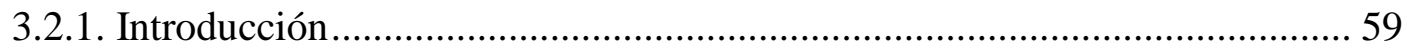

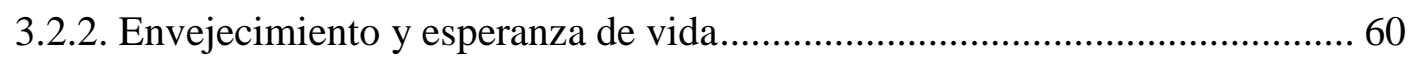

3.2.3. Envejecimiento y discapacidad vs discapacidad y envejecimiento............... 62

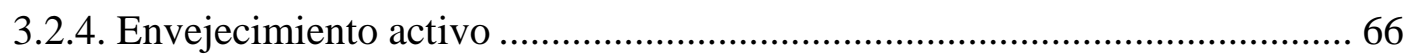

3.2.5. Envejecimiento en personas con discapacidades intelectuales y del desarrollo

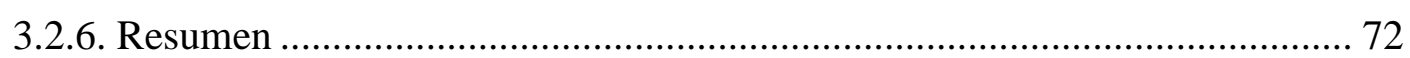

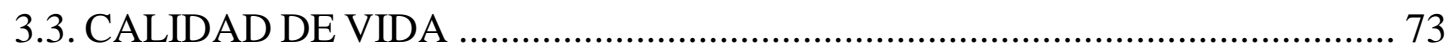

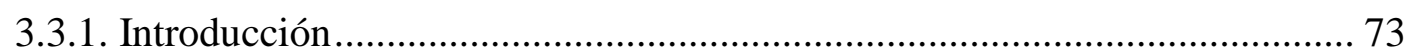

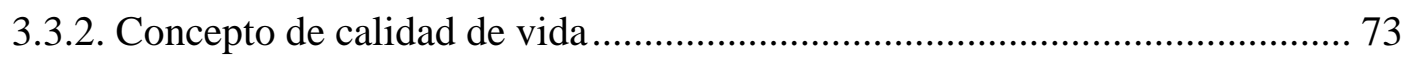

3.3.3. Investigaciones sobre calidad de vida ........................................................ 76

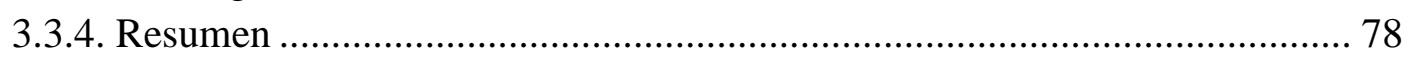

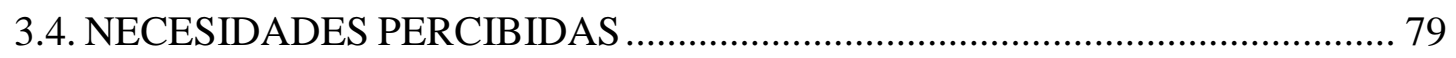

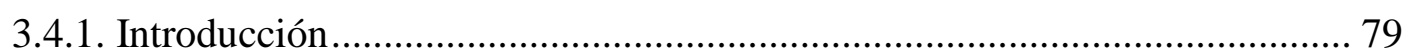

3.4.2. Concepto de necesidades percibidas......................................................... 79

3.4.3. Investigaciones sobre necesidades percibidas ............................................. 80

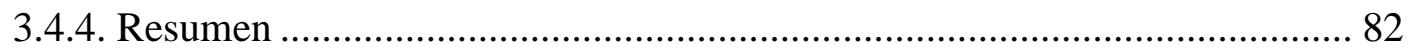




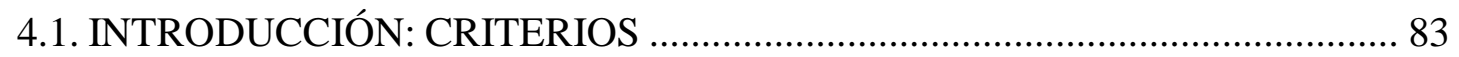

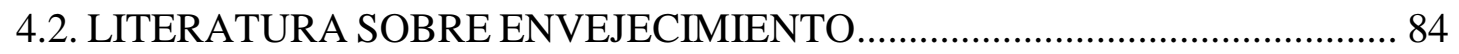

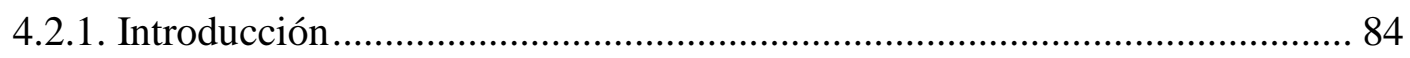

4.2.2. Envejecimiento en la población general .................................................. 84

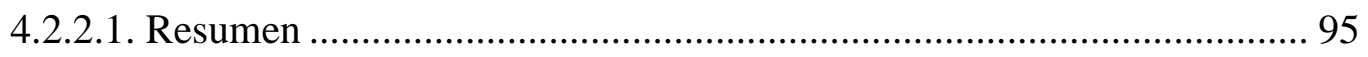

4.2.3. Envejecimiento en personas con discapacidad .......................................... 96

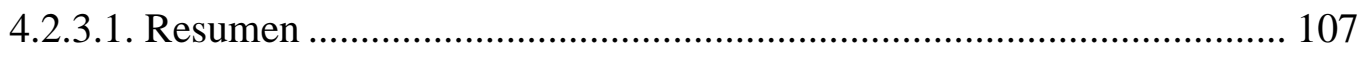

4.2.4. Envejecimiento en personas con discapacidades intelectuales y del desarrollo

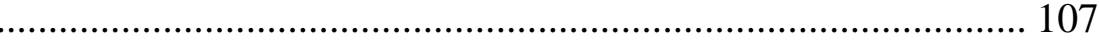

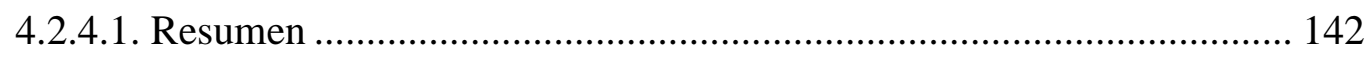

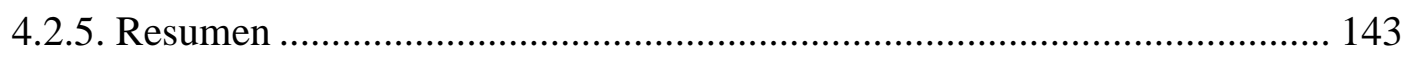

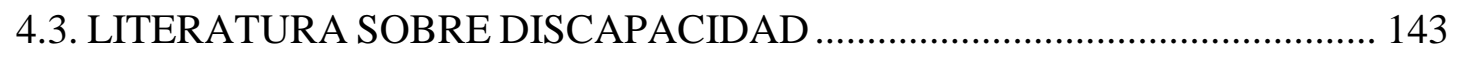

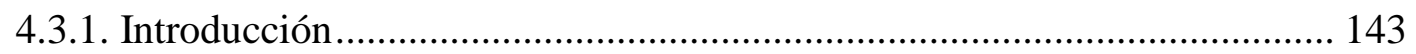

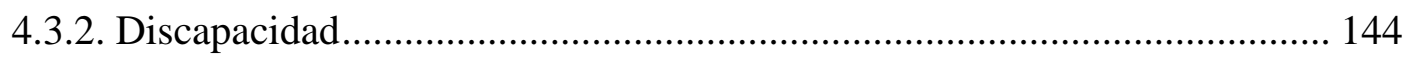

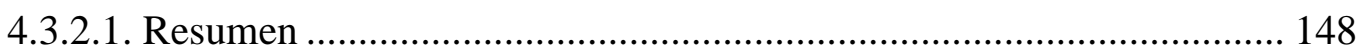

4.3.3. Discapacidades intelectuales y del desarrollo ........................................... 148

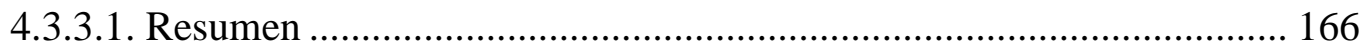

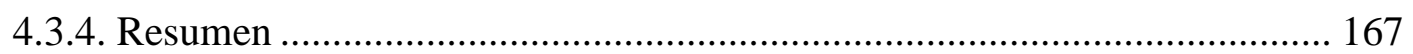

4.4. LITERATURA SOBRE CALIDAD DE VIDA .............................................. 168

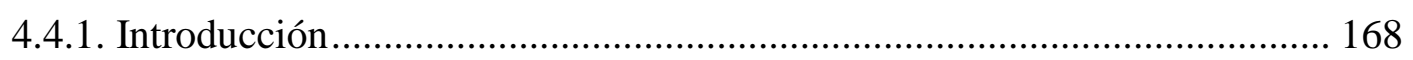

4.4.2. Calidad de vida en la población general ................................................... 168

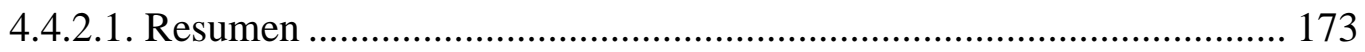

4.4.3. Calidad de vida en personas con discapacidad ....................................... 173

4.4.3.1. Resumen ..................................................................................... 175

4.4.4. Calidad de vida en personas con discapacidades intelectuales y del desarrollo

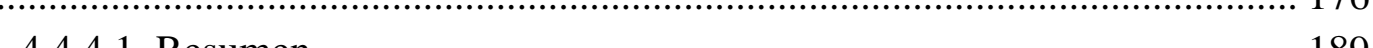

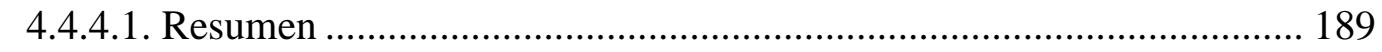

4.4.5. Calidad de vida en el envejecimiento de la población general................... 189

4.4.5.1. Resumen ................................................................................ 203

4.4.6. Calidad de vida en el envejecimiento de las personas con discapacidad ... 203

4.4.6.1. Resumen ...................................................................................... 206

4.4.7. Calidad de vida en el envejecimiento de las personas con discapacidades

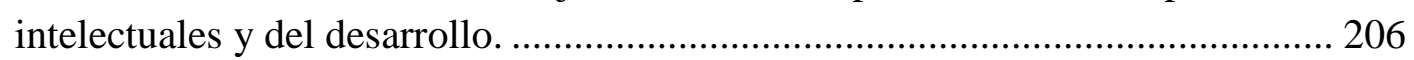

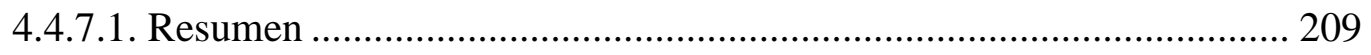

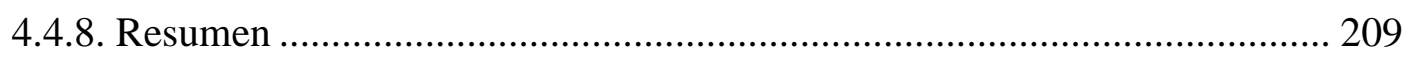

4.5. LITERATURA SOBRE NECESIDADES PERCIBIDAS ............................. 210

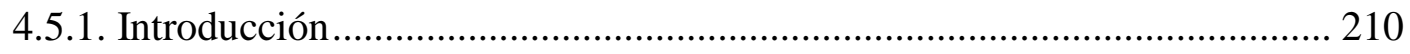

4.5.2. Necesidades percibidas en personas con discapacidad ............................ 210

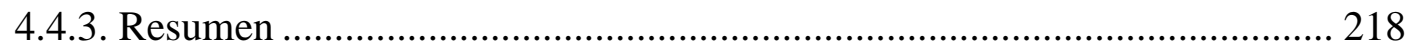

4.6. DISCUSIÓN DE LOS RESULTADOS DE LA REVISIÓN ............................ 218

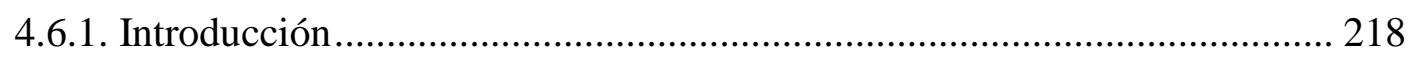

4.6.2. Resumen de los resultados de la revisión ............................................... 219 
4.6.3. Conclusiones y discusión de los resultados de la revisión 219

PARTE EMPÍRICA 223

5. INTRODUCCIÓN 224

6. OBJETIVOS E HIPÓTESIS 224

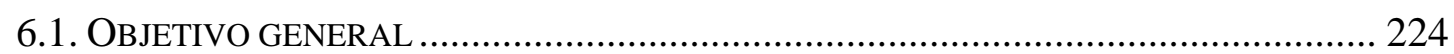

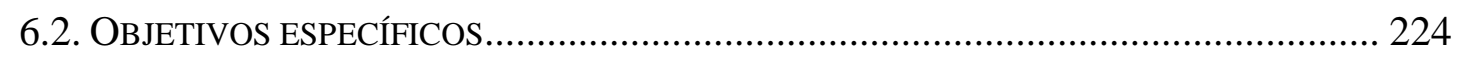

6.3. HIPÓTESIS DE TRABAJO............................................................................... 225

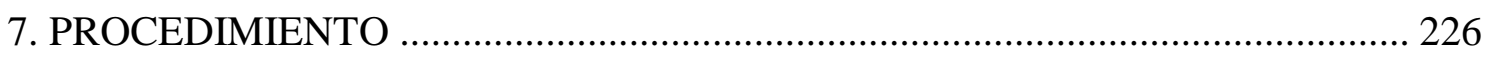

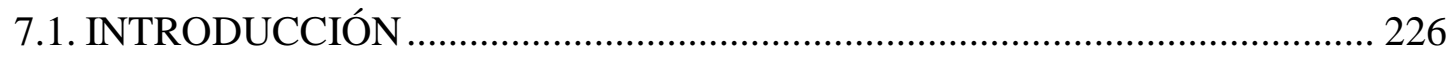

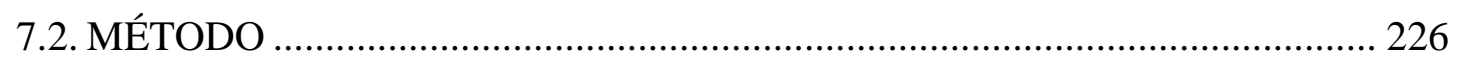

7.3. INSTRUMENTOS DE EVALUACIÓN ….................................................... 228

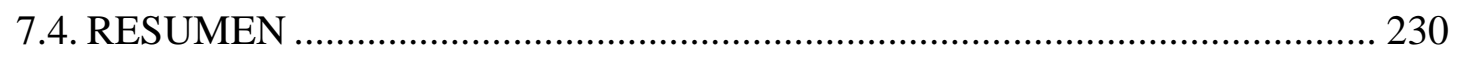

8. ANÁLISIS DE LA ENTREVISTA PERSONAL ................................................... 230

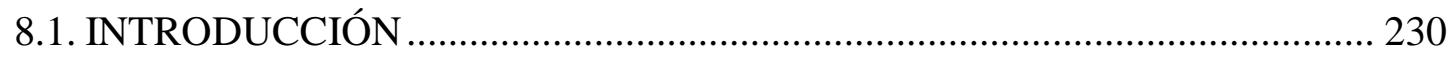

8.2. DESCRIPCIÓN DE LA MUESTRA DE PERSONAS CON DISCAPACIDAD

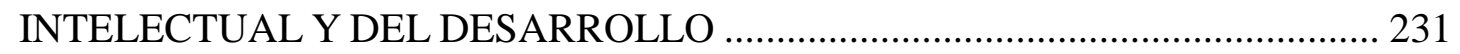

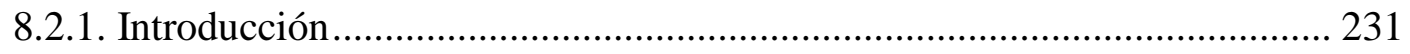

8.2.2. Descripción de la muestra de personas con discapacidad intelectual y del

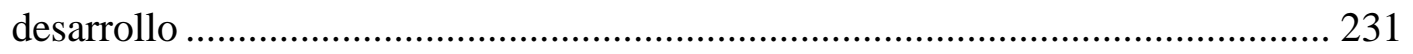

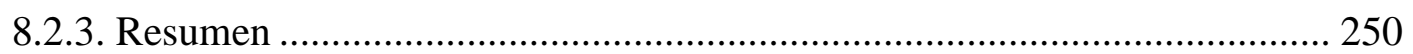

8.3. DESCRIPCIÓN DE LAS FRECUENCIAS DE LAS NECESIDADES

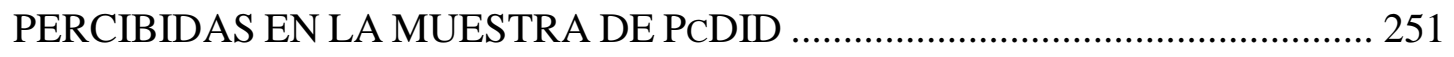

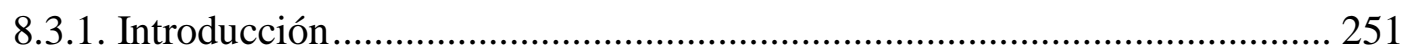

8.3.2. Preocupaciones y necesidades percibidas en la muestra de personas con

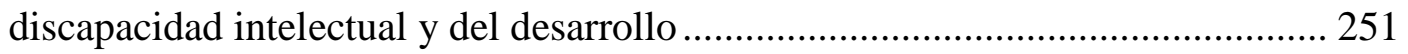

8.3.2.1. Necesidades de salud personal ......................................................... 257

8.3.2.2. Necesidades sobre recursos económicos ........................................... 258

8.3.2.3. Necesidades sobre recursos sanitarios ............................................... 259

8.3.2.4. Necesidades sobre recursos de servicios sociales.............................. 260

8.3.2.5. Necesidades sobre la existencia de barreras ....................................... 261

8.3.2.6. Otras necesidades y preocupaciones................................................. 262

8.3.3. Soluciones propuestas por la muestra de personas con discapacidad intelectual y del desarrollo............................................................................... 263

8.3.4. Medidas y apoyos institucionales requeridos por la muestra de personas con discapacidad intelectual y del desarrollo ........................................................ 267

8.3.5. Pensamientos sobre el futuro de las personas con discapacidad intelectual y

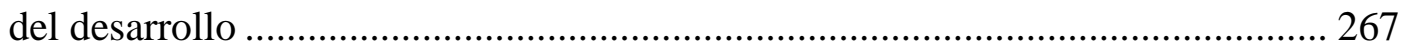

8.3.6. Problemas señalados de las personas con discapacidad intelectual y del

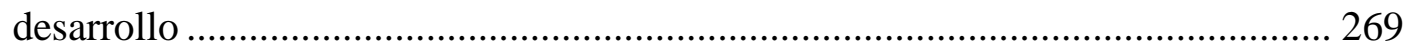

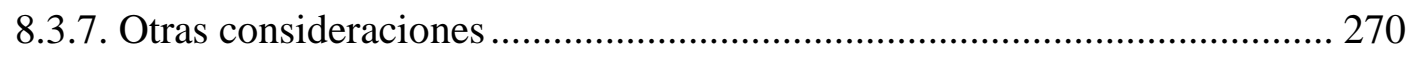

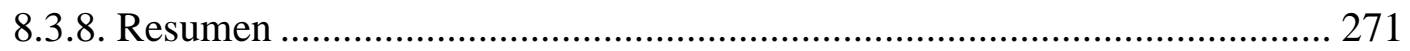




\subsection{ANÁLISIS DE LA RELACIÓN ENTRE PREOCUPACIONES Y}

NECESIDADES Y LAS VARIABLES PREDICTORAS: MUESTRA DE PCDID 272

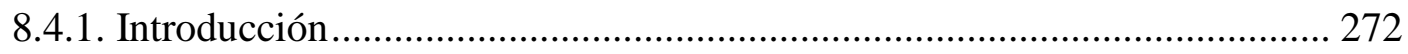

8.4.2. Prueba de normalidad de las distribuciones ............................................. 273

8.4.3. Variable persona que cumplimenta la entrevista ..................................... 275

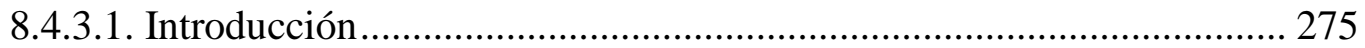

8.4.3.2. Resultados sobre la variable persona que cumplimenta la entrevista.. 276

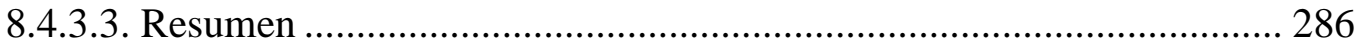

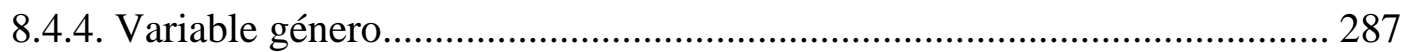

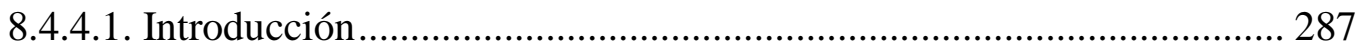

8.4.4.2. Resultados sobre la variable género .................................................. 287

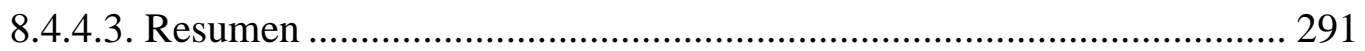

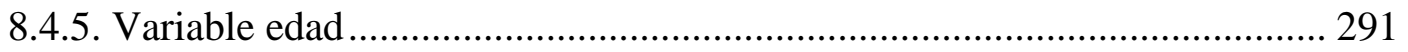

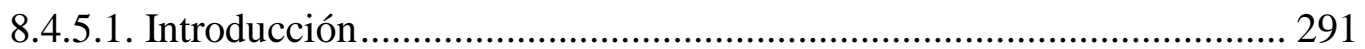

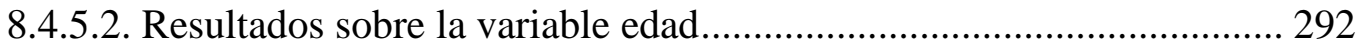

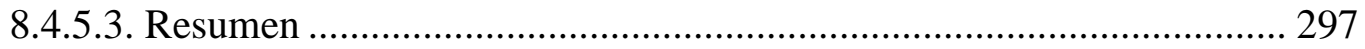

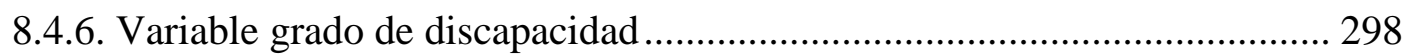

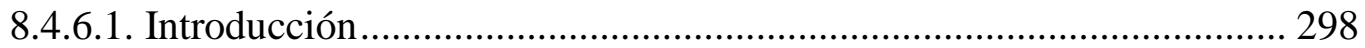

8.4.6.2. Resultados sobre la variable grado de discapacidad........................... 298

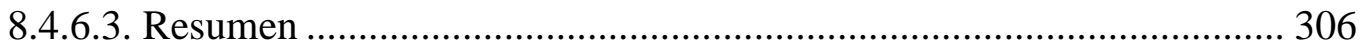

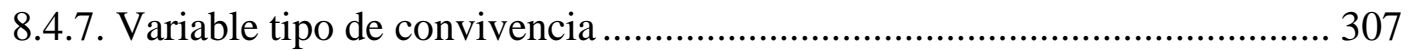

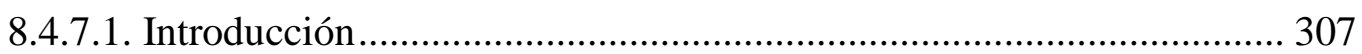

8.4.7.2. Resultados para la variable tipo de convivencia................................ 307

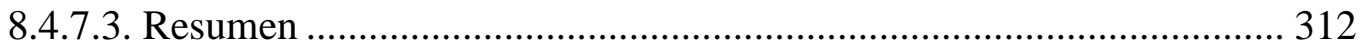

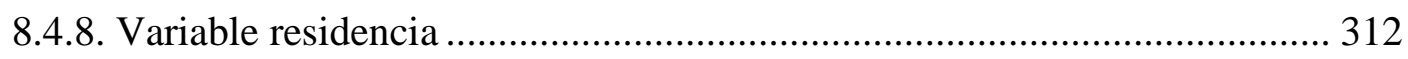

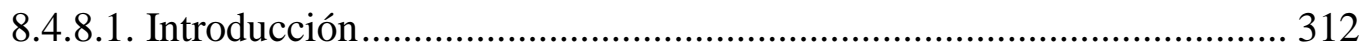

8.4.8.2. Resultados sobre la variable residencia .......................................... 313

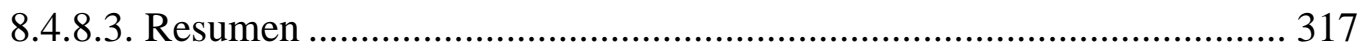

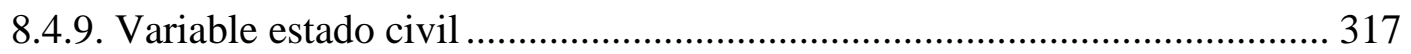

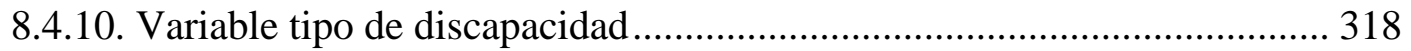

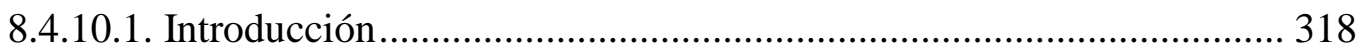

8.4.10.2. Resultados para la variable tipo de discapacidad ............................. 318

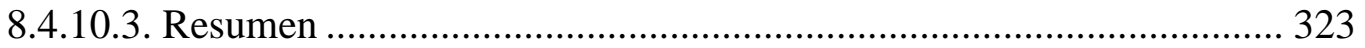

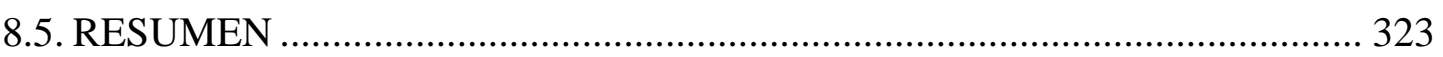

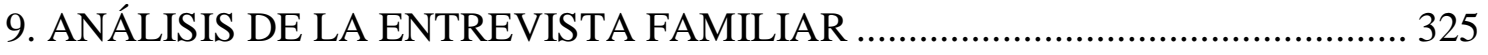

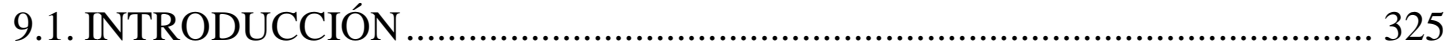

9.2. DESCRIPCIÓN DE LA MUESTRA FAMILIAR …....................................... 325

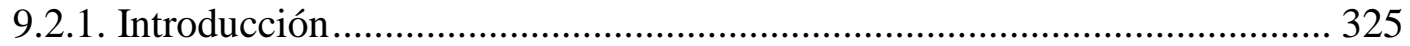

9.2.2. Descripción de la muestra de familias ...................................................... 325

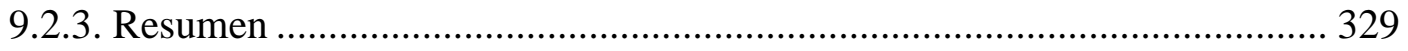

9.3. DESCRIPCIÓN DE LAS FRECUENCIAS DE LAS NECESIDADES

PERCIBIDAS EN LA MUESTRA DE FAMILIAS .............................................. 329

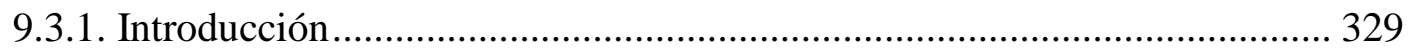


9.3.2. Preocupaciones y necesidades percibidas en la muestra de familias.......... 330

9.3.2.1. Necesidades sobre salud personal................................................... 334

9.3.2.2. Necesidades sobre recursos económicos .......................................... 335

9.3.2.3. Preocupaciones sobre recursos sanitarios.......................................... 336

9.3.2.4. Preocupaciones sobre recursos de servicios sociales ......................... 337

9.3.2.5. Preocupaciones sobre la existencia de barreras ................................. 338

9.3.2.6. Otras preocupaciones y necesidades............................................... 339

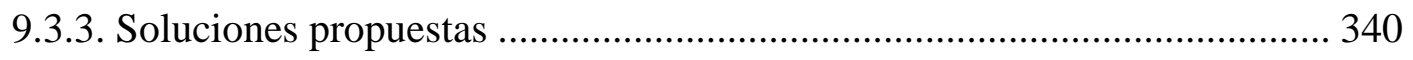

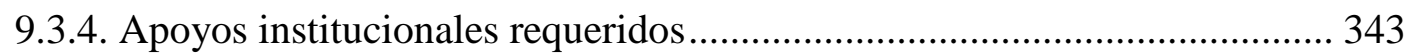

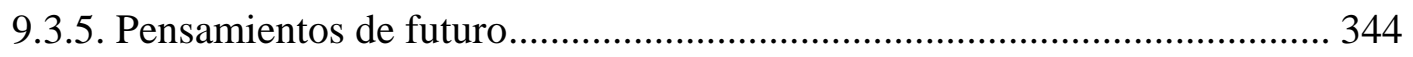

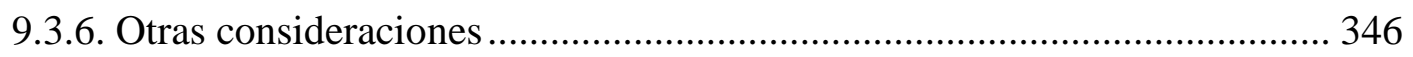

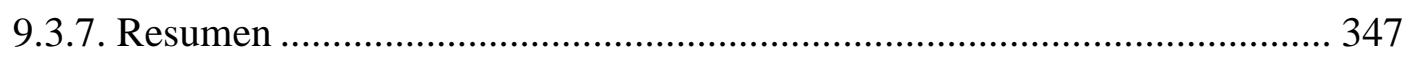

9.4. ANÁLISIS DE LA RELACIÓN ENTRE PREOCUPACIONES Y

NECESIDADES Y LAS VARIABLES PREDICTORAS. MUESTRA FAMILIAR

348

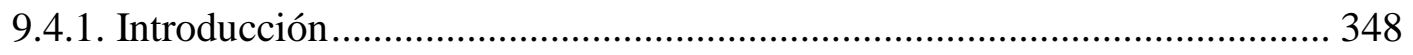

9.4.2. Prueba de normalidad de las distribuciones ............................................ 349

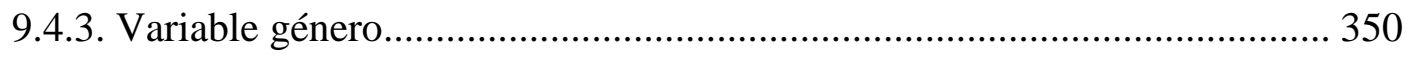

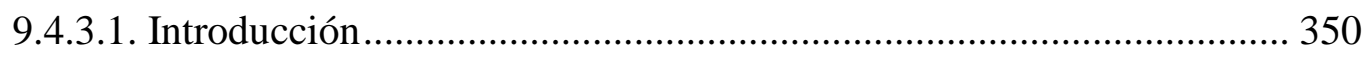

9.4.3.2. Resultados sobre la variable género …............................................ 350

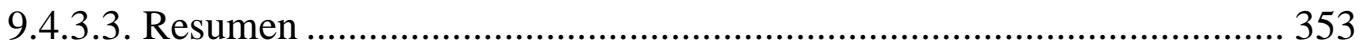

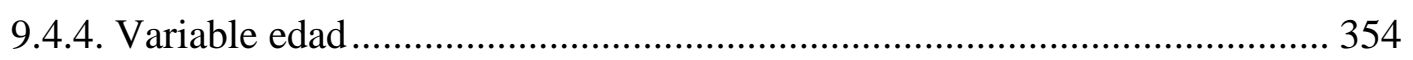

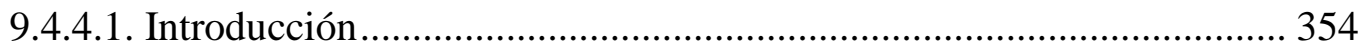

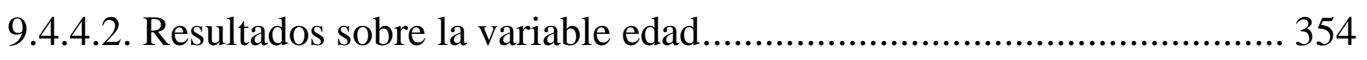

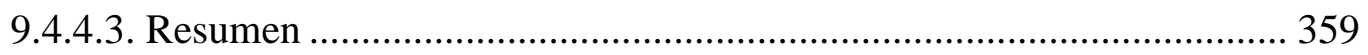

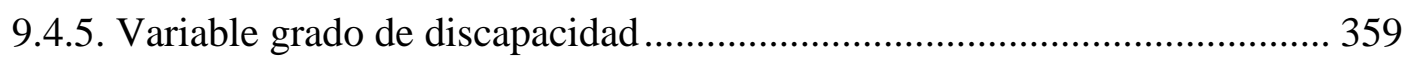

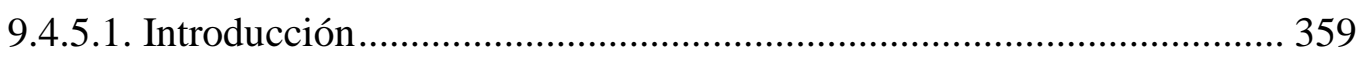

9.4.5.2. Resultados sobre la variable grado de discapacidad........................... 360

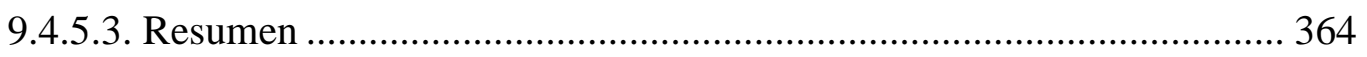

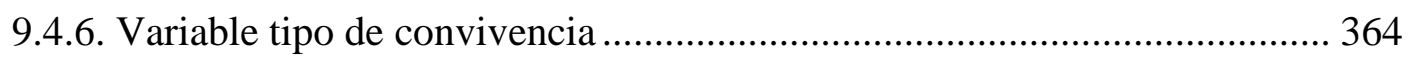

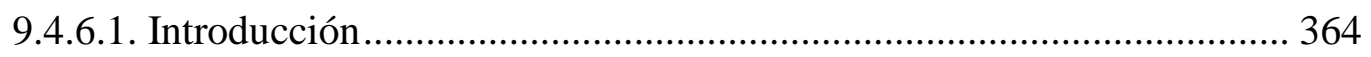

9.4.6.2. Resultados sobre la variable tipo de convivencia............................. 365

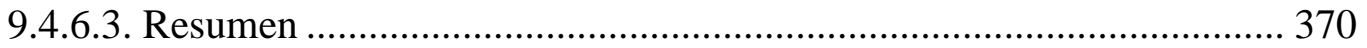

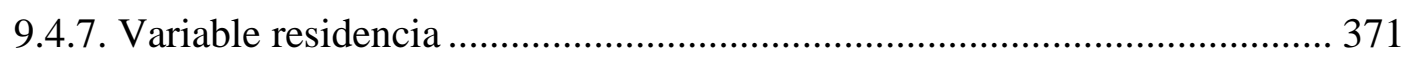

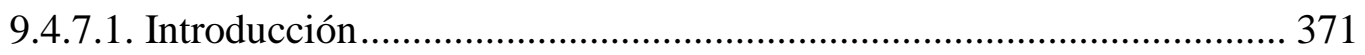

9.4.7.2. Resultados sobre la variable residencia ............................................ 371

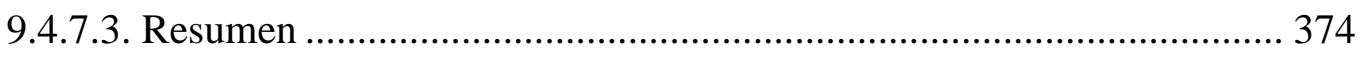

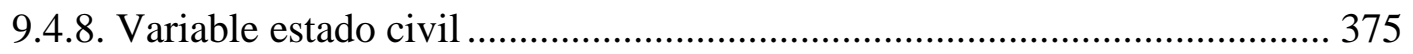

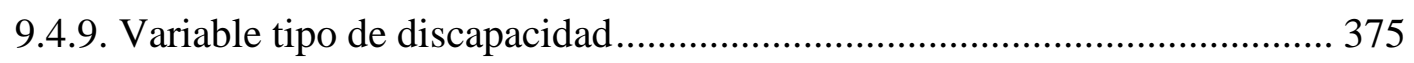

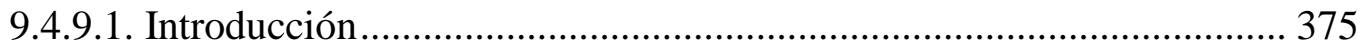

9.4.9.2. Resultados sobre la variable tipo de discapacidad ............................ 375

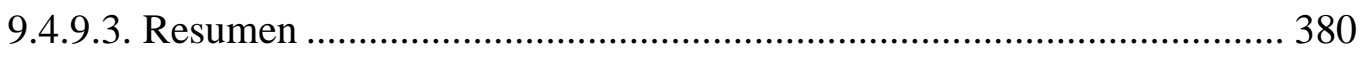

10. ANÁLISIS DE LA ENTREVISTA INSTITUCIONAL ....................................... 382 


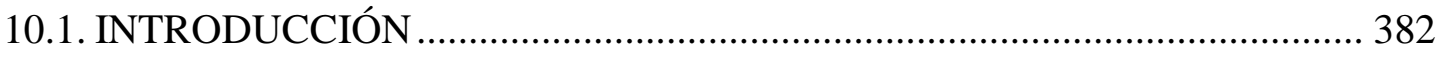

10.2. DESCRIPCIÓN DE LA MUESTRA INSTITUCIONAL ................................ 382

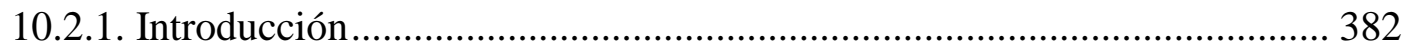

10.2.2. Descripción de la muestra de instituciones ........................................... 382

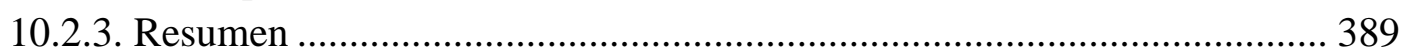

10.3. ANÁLISIS DE LAS NECESIDADES DE LAS INSTITUCIONES ............... 390

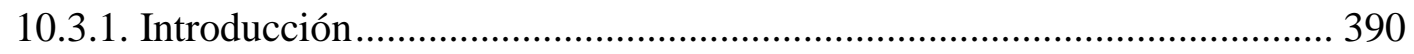

10.3.2. Análisis de las necesidades percibidas. Muestra institucional. ................ 390

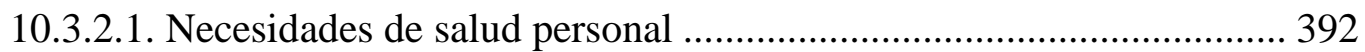

10.3.2.2. Preocupaciones sobre recursos económicos .................................... 393

10.3.2.3. Preocupaciones sobre recursos sanitarios .......................................... 394

10.3.2.4. Necesidades sobre recursos de servicios sociales ............................ 394

10.3.2.5. Necesidades sobre existencia de barreras ...................................... 395

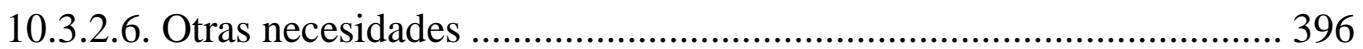

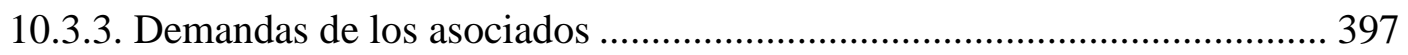

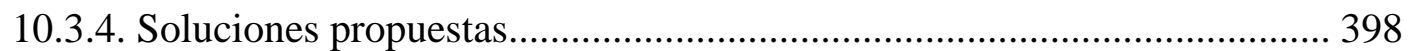

10.3.5. Medidas y apoyos institucionales requeridos ........................................ 403

10.3.6. Pensamientos sobre el futuro de los asociados ...................................... 404

10.3.7. Pensamientos de futuro de las personas con discapacidad mayores ........ 406

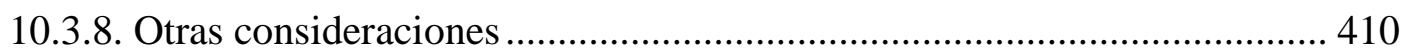

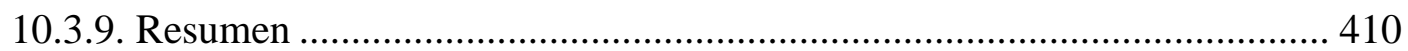

10.4. ANÁLISIS DE LA RELACIÓN ENTRE PREOCUPACIONES Y

NECESIDADES Y LAS VARIABLES PREDICTORAS. MUESTRA

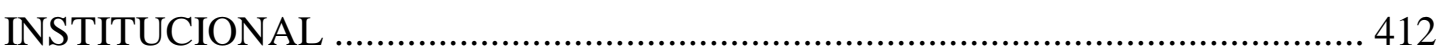

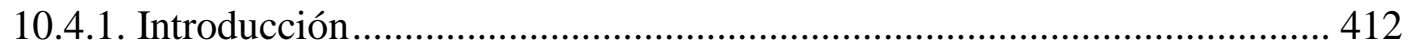

10.4.2. Prueba de normalidad de las distribuciones .......................................... 412

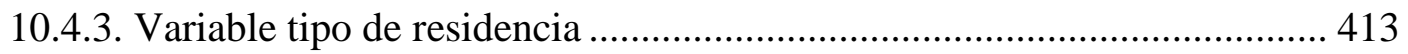

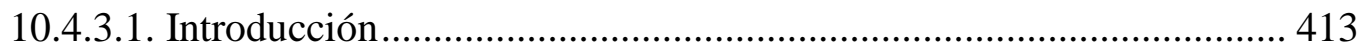

10.4.3.2. Resultados sobre la variable tipo de residencia ................................ 414

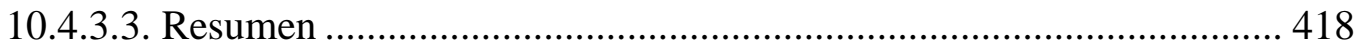

10.4.4. Variable tipo de institución................................................................. 418

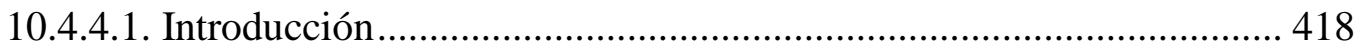

10.4.4.2. Resultados sobre la variable tipo de institución ............................... 419

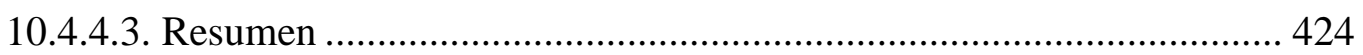

11. PERSONAS, FAMILIAS Y PROFESIONALES: CONVERGENCIAS Y

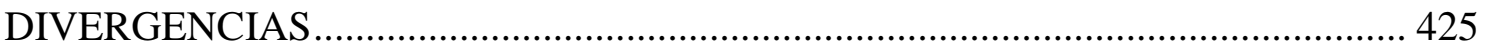

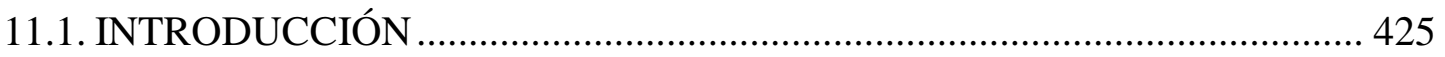

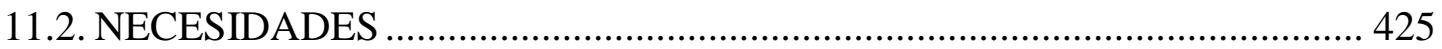

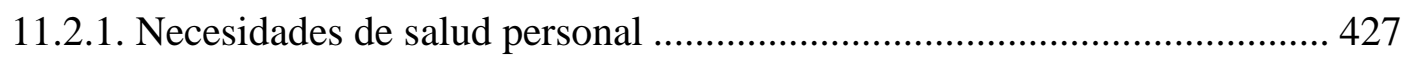

11.2.2. Necesidades sobre recursos económicos ................................................ 428

11.2.3. Necesidades sobre recursos de los servicios sanitarios .......................... 429

11.2.4. Necesidades sobre recursos de servicios sociales.................................. 430

11.2.5. Necesidades sobre la existencia de barreras .......................................... 431 


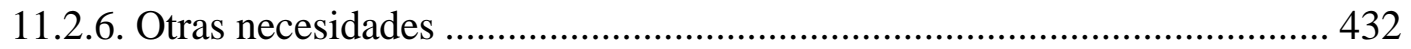

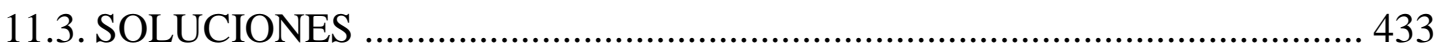

11.4. APOYOS INSTITUCIONALES REQUERIDOS …................................... 435

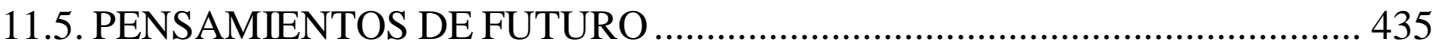

11.6. RESPUESTAS SUPERIORES AL 40\% DE ELECCIÓN ............................... 437

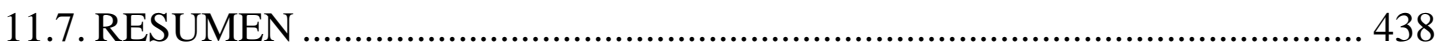

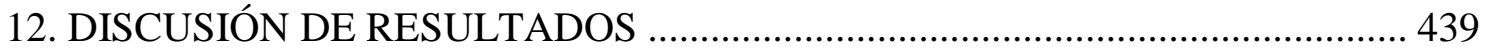

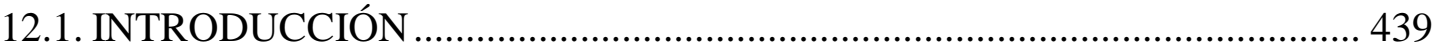

12.2. DISCUSIÓN DE RESULTADOS DE LA ENTREVISTA PERSONAL ........ 439

12.3. DISCUSIÓN DE RESULTADOS DE LA ENTREVISTA FAMILIAR ......... 447

12.4. DISCUSIÓN DE RESULTADOS DE LA ENTREVISTA INSTITUCIONAL

12.5. COINCIDENCIAS Y DIVERGENCIAS ENTRE LAS TRES MUESTRAS . 455

13. CONCLUSIONES Y POSIBLES LÍNEAS DE ACTUACIÓN ............................ 459

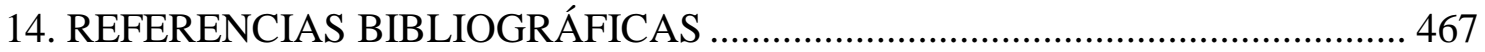

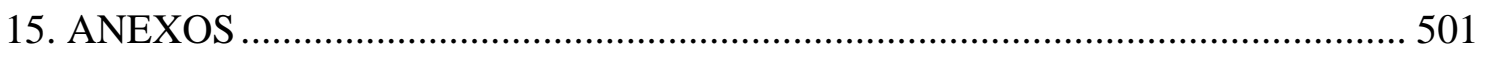

15.1. ANEXO 1: ENTREVISTA PERSONAL Y FAMILIAR .................................. 501

15.2. ANEXO 2: ENTREVISTA INSTITUCIONAL ........................................... 516 



\section{ÍNDICE DE GRÁFICOS, TABLAS Y FIGURAS}

Figura 1: MODELO TEÓRICO DEL FUNCIONAMIENTO HUMANO. ADAPTADO DE SCHALOCK

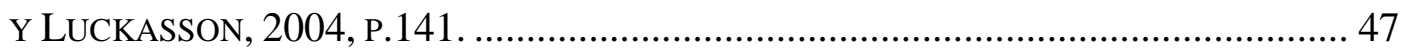

TABlA 1: FACTORES DE RIESGO DE LA DI. TOMADO DE AAIDD, 2011, P.103 ................ 51

Figura 2: ModELO DE APOYOS. AdAPTADO DE THOMPSON ET. AL., 2009, P.137........... 53

GRÁFICO 1: ESPERANZA DE VIDA Y PROYECCIÓN AL NACER POR GÉNERO EN ESPAÑA.

FUENTE: INE: PROYECCIÓN DE LA POBLACIÓN DE ESPAÑA 2014-2064. NOTAS DE

PRENSA, 28 DE OCTUBRE DE 2014.

GRÁFICO 2: COMPARACIÓN DE LAS TASAS DE DISCAPACIDAD POR EDAD DE LA POBLACIÓN ESPAÑOLA (POR MIL HABITANTES), DE LAS ENCUESTAS EDDES (1999) Y EDAD

(2008). TOMADO DE EDAD, 2008, P.2.

TABLA 2: SISTEMAS EN LOS QUE INFLUYE EL ENVEJECIMIENTO Y PRINCIPALES SÍNTOMAS.

ADAPTADO DE FEAPS MADRID (2007): LAS PERSONAS CON NECESIDADES DE

APOYO GENERALIZADO: GUÍA DE IDENTIFICACIÓN DE INDICIOS DE ENVEJECIMIENTO Y ORIENTACIONES PARA LA DETERMINACIÓN DE APOYOS. CUADERNOS DE ATENCIÓN DE DÍA, N`3, PP. 26-31. 70

TABLA 3: DIMENSIONES Y PRINCIPALES INDICADORES DE CALIDAD DE VIDA. ADAPTADO

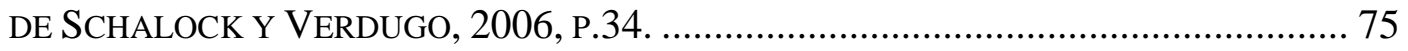

TABLA 4: LITERATURA SOBRE ENVEJECIMIENTO EN LA POBLACIÓN GENERAL................. 85

TABLA 5: LITERATURA SOBRE ENVEJECIMIENTO EN LAS PERSONAS CON DISCAPACIDAD. 97 TABLA 6: LITERATURA SOBRE ENVEJECIMIENTO EN PERSONAS CON DISCAPACIDAD

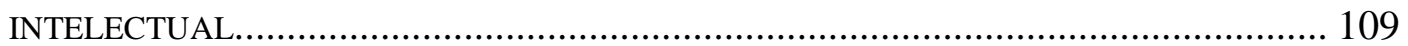

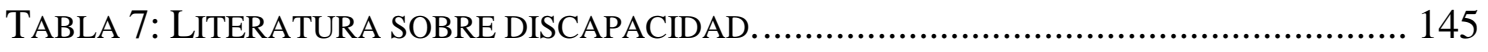

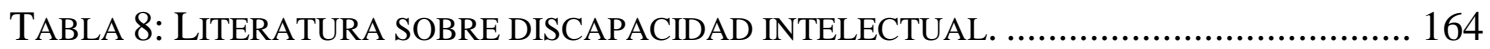

TABLA 9: LITERATURA SOBRE CALIDAD DE VIDA EN LA POBLACIÓN GENERAL............... 172

TABLA 10: LITERATURA SOBRE CALIDAD DE VIDA EN LAS PERSONAS CON DISCAPACIDAD.

TABLA 11: LITERATURA SOBRE CALIDAD DE VIDA EN LAS PCDID. ............................. 177

TABLA 12: LITERATURA SOBRE CALIDAD DE VIDA EN EL ENVEJECIMIENTO DE LA

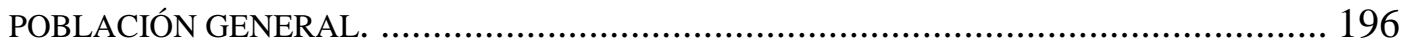

TABLA 13: LITERATURA SOBRE CALIDAD DE VIDA EN EL ENVEJECIMIENTO DE PCD...... 204

TABLA 14: LITERATURA SOBRE LA CALIDAD DE VIDA EN EL PROCESO DE ENVEJECIMIENTO

DE LAS PERSONAS CON DISCAPACIDAD INTELECTUAL Y DEL DESARROLLO. ........... 208

TABLA 15: LITERATURA SOBRE NECESIDADES PERCIBIDAS. …....................................... 216

TABLA 16: CARACTERÍSTICAS DESCRIPTIVAS DE LA MUESTRA POR GÉNERO ................. 231

TABLA 17: CARACTERÍSTICAS DE LA MUESTRA POR EDAD Y GÉNERO.......................... 232

TABLA 18: CARACTERÍSTICAS DE LA MUESTRA POR LA EDAD EN FUNCIÓN DEL TIPO DE DISCAPACIDAD DESGLOSADO POR TIPO DE DISCAPACIDAD Y POR GÉNERO............. 233

TABLA 19: CARACTERÍSTICAS DE LA MUESTRA POR EDAD AGRUPADA POR PERCENTILES Y GÉNERO. 
TABLA 20: CARACTERÍSTICAS DE LA MUESTRA POR TIPO DE CUMPLIMENTACIÓN DE LA

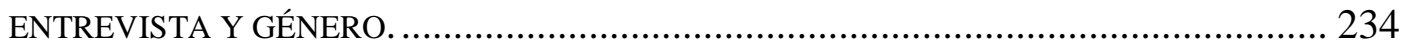

TABLA 21: SÍNTESIS DE LAS CARACTERÍSTICAS DE LA MUESTRA POR TIPO DE CUMPLIMENTACIÓN DE LA ENTREVISTA Y GÉNERO.

TABLA 22: SÍNTESIS DE LAS CARACTERÍSTICAS DE LA MUESTRA POR TIPO DE INFORME DICOTOMIZADO DE LA ENTREVISTA Y GÉNERO.............................................. 235

TABLA 23: CARACTERÍSTICAS DE LA MUESTRA POR LUGAR DE APLICACIÓN Y GÉNERO. 235

TABLA 24: CARACTERÍSTICAS DE LA MUESTRA POR RESIDENCIA Y GÉNERO.................. 236

TABlA 25: CARACTERÍSTICAS DE LA MUESTRA POR COMUNIDAD AUTÓNOMA DE

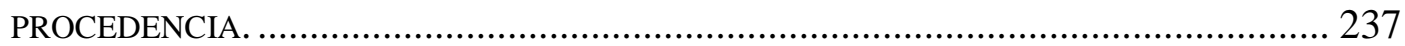

TABLA 26: CARACTERÍSTICAS DE LA MUESTRA POR ESTADO CIVIL Y GÉNERO................ 237

TABLA 27: CARACTERÍSTICAS DE LA MUESTRA POR ESTADO CIVIL RECODIFICADO Y GÉNERO.

TABLA 28: CARACTERÍSTICAS DE LA MUESTRA POR NIVEL CULTURAL ALCANZADO Y GÉNERO.

TABLA 29: CARACTERÍSTICAS DE LA MUESTRA POR EL NIVEL O CUALIFICACIÓN PROFESIONAL Y GÉNERO.

TABLA 30: CARACTERÍSTICAS DE LA MUESTRA POR SITUACIÓN LABORAL ACTUAL Y GÉNERO.

TABLA 31: CARACTERÍSTICAS DE LA MUESTRA POR NIVEL DE INGRESOS Y GÉNERO...... 240

TABLA 32: CARACTERÍSTICA DE LA MUESTRA POR PRESENCIA DE LOS PADRES Y GÉNERO.

TABLA 33: CARACTERÍSTICAS DE LA MUESTRA POR NÚMERO DE HERMANOS Y GÉNERO.

TABLA 34: CARACTERÍSTICAS DE LA MUESTRA POR LA PRESENCIA DE HIJOS/AS Y GÉNERO.

TABLA 35: CARACTERÍSTICAS DE LA MUESTRA POR EL TIPO DE DISCAPACIDAD.

TABLA 36: CARACTERÍSTICAS DE LA MUESTRA POR LA ETIOLOGÍA DE LA DISCAPACIDAD.

TABLA 37: CARACTERÍSTICAS DE LA MUESTRA POR LA EDAD DE ADQUISICIÓN DE LA DISCAPACIDAD.

TABLA 38: ESTADÍSTICOS DESCRIPTIVOS DE LOS AÑOS CON DISCAPACIDAD EN FUNCIÓN DEL GÉNERO DE LOS PARTICIPANTES.

TABLA 39: CARACTERÍSTICAS DE LA MUESTRA EN FUNCIÓN DEL GÉNERO Y DEL RECONOCIMIENTO OFICIAL DE LA SITUACIÓN DE DISCAPACIDAD.

TABLA 40: CARACTERÍSTICAS DE LA MUESTRA POR LA SEGUNDA DISCAPACIDAD......... 245

TABLA 41: CARACTERÍSTICAS DE LA MUESTRA POR LA TERCERA DISCAPACIDAD. ......... 246

TABLA 42: DESCRIPCIÓN DE LA MUESTRA POR EL GRADO DE DISCAPACIDAD RECONOCIDO Y GÉNERO.

TABLA 43: DESCRIPCIÓN DE LA MUESTRA POR EL GRADO DE DISCAPACIDAD RECONOCIDO DICOTOMIZADO Y GÉNERO.

TABLA 44: DESCRIPCIÓN DE LA MUESTRA POR EL GRADO DE DISCAPACIDAD RECONOCIDO AGRUPADO POR PERCENTILES Y GÉNERO.

TABLA 45: CARACTERÍSTICAS DE LA MUESTRA POR TIPO DE CONVIVENCIA Y GÉNERO.. 248 
TABLA 46: CARACTERÍSTICAS DE LA MUESTRA POR TIPO DE CONVIVENCIA RECODIFICADO

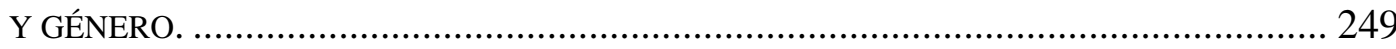

TABLA 47: CARACTERÍSTICAS DE LA MUESTRA POR LA CONVIVENCIA RECODIFICADA Y DICOTOMIZADA EN DOS CATEGORÍAS Y GÉNERO.

TABLA 48: CARACTERÍSTICAS DE LA MUESTRA POR TIPO DE DISCAPACIDAD Y POR TIPO DE CONVIVENCIA RECODIFICADO.

TABLA 49: ESTADÍSTICOS DE LAS PREOCUPACIONES Y NECESIDADES PERCIBIDAS DE LA MUESTRA DE PERSONAS CON DISCAPACIDAD INTELECTUAL GENERAL. 252

GRÁFICO 3: No TOTAL DE PREOCUPACIONES Y NECESIDADES PERCIBIDAS DE LA MUESTRA DE PCDID GENERAL. 253

TABLA 50: ESTADÍSTICOS DE LAS PREOCUPACIONES Y NECESIDADES PERCIBIDAS DE LA MUESTRA DE PERSONAS CON SÍNDROME DE DOWN. 254

TABLA 52: ESTADÍSTICOS DE LAS PREOCUPACIONES Y NECESIDADES PERCIBIDAS DE LA MUESTRA DE PERSONAS CON PC. 255

TABLA 53: FRECUENCIAS Y PORCENTAJES (DE RESPUESTAS Y DE CASOS) DE PREOCUPACIONES SOBRE SALUD PERSONAL DE LAS PCDID. 258

TABLA 54: FRECUENCIAS Y PORCENTAJES (DE RESPUESTAS Y DE CASOS) DE PREOCUPACIONES SOBRE RECURSOS ECONÓMICOS DE LAS PCDID.

TABLA 55: FRECUENCIAS Y PORCENTAJES (DE RESPUESTAS Y DE CASOS) DE PREOCUPACIONES SOBRE RECURSOS SANITARIOS DE LAS PCDID.

TABLA 56: FRECUENCIAS Y PORCENTAJES (DE RESPUESTAS Y DE CASOS) DE PREOCUPACIONES SOBRE RECURSOS DE SERVICIOS SOCIALES DE LAS PCDID........ 261

TABLA 57: FRECUENCIAS Y PORCENTAJES (DE RESPUESTAS Y DE CASOS) DE PREOCUPACIONES SOBRE EXISTENCIA DE BARRERAS DE LAS PCDID.

TABLA 58: FRECUENCIAS Y PORCENTAJES (DE RESPUESTAS Y DE CASOS) DE PREOCUPACIONES SOBRE OTRAS PREOCUPACIONES Y NECESIDADES DE LAS PCDID.

TABLA 59: FRECUENCIAS Y PORCENTAJES (DE RESPUESTAS Y DE CASOS) DE LAS SOLUCIONES PROPUESTAS POR LAS PCDID. 264

TABLA 60: FRECUENCIAS Y PORCENTAJES (DE RESPUESTAS Y DE CASOS) DE LAS SOLUCIONES PROPUESTAS POR LAS PCDID EN FUNCIÓN DE LA TEMÁTICA. 266

TABLA 61: FRECUENCIAS Y PORCENTAJES (DE RESPUESTAS Y DE CASOS) DE APOYOS REQUERIDOS POR LAS PCDID.

TABLA 62: FRECUENCIAS Y PORCENTAJES (DE RESPUESTAS Y DE CASOS) DE PENSAMIENTOS SOBRE EL FUTURO DE LAS PCDID.

TABLA 63: FRECUENCIAS Y PORCENTAJES (DE RESPUESTAS Y DE CASOS) DE PENSAMIENTOS SOBRE EL FUTURO EN FUNCIÓN DE LA TEMÁTICA DE LAS PCDID. . 269

TABLA 64: FRECUENCIAS Y PORCENTAJES (DE RESPUESTAS Y DE CASOS) DE PENSAMIENTOS SOBRE EL FUTURO DE LAS PCDID.

TABLA 65: FRECUENCIAS Y PORCENTAJES (DE RESPUESTAS Y DE CASOS) DE OTRAS CONSIDERACIONES DE LAS PCDID.

TABla 66: PRUEBA DE KOLMOGOROV-SMIRNOV PARA UNA MUESTRA EN FUNCIÓN DE LAS NECESIDADES Y SOLUCIONES GENERALES. MUESTRA DE PCDID. 
TABLA 67: PRUEBA DE KOLMOGOROV-SMIRNOV PARA UNA MUESTRA EN FUNCIÓN DE LAS NECESIDADES ESPECÍFICAS. MUESTRA DE PCDID.

TABLA 68: RANGOS PROMEDIOS EN FUNCIÓN DEL TIPO DE INFORME DICOTOMIZADO EN NÚMERO TOTAL DE PREOCUPACIONES Y NECESIDADES GENERALES. MUESTRA DE PCDID.

TABLA 69: ESTADÍSTICOS DE CONTRASTE EN FUNCIÓN DEL TIPO DE INFORME DICOTOMIZADO DESGLOSADO EN NÚMERO TOTAL DE PREOCUPACIONES Y SOLUCIONES GENERALES. MUESTRA DE PCDID.

TABLA 70: RANGOS PROMEDIOS EN FUNCIÓN DEL TIPO DE INFORME DICOTOMIZADO EN NÚMERO TOTAL DE PREOCUPACIONES ESPECÍ́FICAS. MUESTRA DE PCDID.

TABLA 71: ESTADÍSTICOS DESCRIPTIVOS EN FUNCIÓN DEL TIPO DE INFORME DICOTOMIZADO EN NÚMERO TOTAL DE NECESIDADES ESPECÍFICAS. MUESTRA DE PCDID

GRÁFICO 5: RANGOS PROMEDIO EN FUNCIÓN DEL TIPO DE INFORME DICOTOMIZADO EN NÚMERO TOTAL DE PREOCUPACIONES GENERALES Y ESPECÍFICAS. MUESTRA DE PCDID.

TABLA 72: RESUMEN DE DIFERENCIAS EN FUNCIÓN DEL TIPO DE INFORME DICOTOMIZADO EN NÚMERO DE NECESIDADES Y SOLUCIONES GENERALES Y NECESIDADES ESPECÍFICAS. MUESTRA DE PCDID. 280

TABLA 73: RANGOS PROMEDIOS EN FUNCIÓN DEL TIPO DE INFORME RECODIFICADO EN NÚMERO TOTAL DE PREOCUPACIONES Y SOLUCIONES GENERALES. MUESTRA DE PCDID

TABLA 74: ESTADÍSTICOS DESCRIPTIVOS EN FUNCIÓN DEL TIPO DE INFORME RECODIFICADO EN NÚMERO TOTAL DE PREOCUPACIONES Y SOLUCIONES GENERALES. MUESTRA DE PCDID.

TABLA 75: RANGOS PROMEDIOS EN FUNCIÓN DEL TIPO DE INFORME RECODIFICADO EN NÚMERO TOTAL DE PREOCUPACIONES ESPECÍFICAS. MUESTRA DE PCDID. 284

TABLA 76: ESTADÍSTICOS DE CONTRASTE EN FUNCIÓN DEL TIPO DE INFORME RECODIFICADO EN NÚMERO TOTAL DE PREOCUPACIONES ESPECÍFICAS

GRÁFICO 6: RANGOS PROMEDIO EN FUNCIÓN DEL TIPO DE CUMPLIMENTACIÓN RECODIFICADO EN NÚMERO TOTAL DE PREOCUPACIONES GENERALES Y ESPECÍFICAS. MUESTRA DE PCDID. 285

TABLA 77: RESUMEN DE DIFERENCIAS EN FUNCIÓN DEL TIPO DE INFORME RECODIFICADO DE LA MUESTRA DE PCDID. 286

TABLA 78: RANGOS PROMEDIOS EN FUNCIÓN DEL GÉNERO EN NÚMERO TOTAL DE PREOCUPACIONES Y SOLUCIONES GENERALES. MUESTRA DE PCDID . .................... 288

TABLA 79: ESTADÍSTICOS DE CONTRASTE EN FUNCIÓN DEL GÉNERO EN NÚMERO TOTAL DE PREOCUPACIONES Y SOLUCIONES GENERALES. MUESTRA DE PCDID. .................... 289

TABLA 80: RANGOS PROMEDIOS EN FUNCIÓN DEL GÉNERO EN NÚMERO TOTAL DE PREOCUPACIONES Y NECESIDADES ESPECÍFICAS.

TABLA 81: ESTADÍSTICOS DE CONTRASTE EN FUNCIÓN DEL GÉNERO EN NÚMERO TOTAL DE PREOCUPACIONES ESPECÍFICAS. MUESTRA DE PCDID. 290

GRÁFICO 7: RANGOS PROMEDIO EN FUNCIÓN DEL GÉNERO EN NÚMERO TOTAL DE PREOCUPACIONES GENERALES Y ESPECÍFICAS. MUESTRA DE PCDID. 
TABLA 82: RESUMEN DE DIFERENCIAS EN FUNCIÓN DEL GÉNERO. MUESTRA DE PCDID.

TABLA 83: RANGOS PROMEDIOS EN FUNCIÓN DE LA EDAD RECODIFICADA EN NÚMERO TOTAL DE PREOCUPACIONES Y SOLUCIONES GENERALES. MUESTRA DE PCDID . ... 293

TABLA 84: ESTADÍSTICOS DE CONTRASTE EN FUNCIÓN DE LA EDAD RECODIFICADA EN NÚMERO TOTAL DE PREOCUPACIONES Y SOLUCIONES GENERALES. MUESTRA DE PCDID

TABLA 85: RANGOS PROMEDIOS EN FUNCIÓN DE LA EDAD RECODIFICADA EN NÚMERO TOTAL DE PREOCUPACIONES ESPECÍFICAS. MUESTRA DE PCDID.

TABLA 86: ESTADÍSTICOS DE CONTRASTE EN FUNCIÓN DE LA EDAD RECODIFICADA EN NÚMERO TOTAL DE PREOCUPACIONES ESPECÍFICAS. MUESTRA DE PCDID.

GRÁFICO 8: RANGOS PROMEDIO EN FUNCIÓN DEL GRUPO DE EDAD RECODIFICADA EN NÚMERO TOTAL DE PRECUPACIONES GENERALES Y ESPECÍFICAS. MUESTRA DE PCDID.

TABLA 87: RESUMEN DE DIFERENCIAS EN FUNCIÓN DE LA EDAD RECODIFICADA. MUESTRA DE PCDID.

TABLA 88: RANGOS PROMEDIOS EN FUNCIÓN DEL GRADO DE DISCAPACIDAD DICOTOMIZADO EN NÚMERO TOTAL DE PREOCUPACIONES Y SOLUCIONES GENERALES. MuestRA DE PCDID.

TABLA 89: ESTADÍSTICOS DE CONTRASTE EN FUNCIÓN DEL GRADO DE DISCAPACIDAD RECODIFICADO EN NÚMERO TOTAL DE PREOCUPACIONES ESPECÍFICAS. MUESTRA DE PCDID. 299

TABLA 90: ESTADÍSTICOS DE CONTRASTE EN FUNCIÓN DEL GRADO DE DISCAPACIDAD DICOTOMIZADO EN NÚMERO TOTAL DE PREOCUPACIONES ESPECÍFICAS. MUESTRA DE PCDID. 300

TABLA 91: ESTADÍSTICOS DE CONTRASTE EN FUNCIÓN DEL GRADO DE DISCAPACIDAD DICOTOMIZADO EN NÚMERO TOTAL DE PREOCUPACIONES ESPECÍFICAS. MUESTRA DE PCDID. 301

GRÁFICO 9: RANGOS PROMEDIO EN FUNCIÓN DEL GRADO DE DISCAPACIDAD DICOTOMIZADO EN NÚMERO TOTAL DE PREOCUPACIONES GENERALES Y ESPECÍFICAS. MuESTRA DE PCDID. 301

TABLA 92: RESUMEN DE DIFERENCIAS EN FUNCIÓN DEL GRADO DE DISCAPACIDAD DICOTOMIZADO. MUESTRA DE PCDID.

TABLA 93: RANGOS PROMEDIOS EN FUNCIÓN DEL GRADO DE DISCAPACIDAD RECODIFICADO EN NÚMERO TOTAL DE PREOCUPACIONES Y SOLUCIONES GENERALES. MUESTRA DE PCDID.

TABLA 94: ESTADÍSTICOS DE CONTRASTE EN FUNCIÓN DEL GRADO DE DISCAPACIDAD RECODIFICADO EN NÚMERO TOTAL DE PREOCUPACIONES Y SOLUCIONES GENERALES. MuestRA DE PCDID. 304

TABLA 95: RANGOS PROMEDIOS EN FUNCIÓN DEL GRADO DE DISCAPACIDAD RECODIFICADO EN NÚMERO TOTAL DE PREOCUPACIONES ESPECÍFICAS. MUESTRA DE PCDID. 
TABLA 96: ESTADÍSTICOS DE CONTRASTE EN FUNCIÓN DEL GRADO DE DISCAPACIDAD RECODIFICADO EN EL NÚMERO TOTAL DE PREOCUPACIONES ESPECÍFICAS. MUESTRA DE PCDID.

GRÁFICO 10: RANGOS PROMEDIO EN FUNCIÓN DEL GRADO DE DISCAPACIDAD RECODIFICADO EN NÚMERO TOTAL DE PREOCUPACIONES GENERALES Y ESPECÍFICAS. MUESTRA DE PCDID.

TABLA 97: RESUMEN DE DIFERENCIAS EN FUNCIÓN DEL GRADO DE DISCAPACIDAD RECODIFICADO. MUESTRA DE PCDID. 306

TABLA 98: RANGOS PROMEDIOS EN FUNCIÓN DEL TIPO DE CONVIVENCIA EN NÚMERO TOTAL DE PREOCUPACIONES Y SOLUCIONES ESPECÍFICAS. MUESTRA DE PCDID . .. 308

TABLA 99: ESTADÍSTICOS DE CONTRASTE EN FUNCIÓN DEL TIPO DE CONVIVENCIA EN NÚMERO TOTAL DE PREOCUPACIONES Y SOLUCIONES GENERALES. MUESTRA DE PCDID.

TABLA 100: RANGOS PROMEDIOS EN FUNCIÓN DEL TIPO DE CONVIVENCIA EN NÚMERO TOTAL DE PREOCUPACIONES ESPECÍFICAS. MUESTRA DE PCDID.

TABLA 101: ESTADÍSTICOS DE CONTRASTE EN FUNCIÓN DEL TIPO DE CONVIVENCIA EN NÚMERO TOTAL DE PREOCUPACIONES ESPECÍ́FICAS. MUESTRA DE PCDID.

GRÁFICO 11: RANGOS PROMEDIO EN FUNCIÓN DEL TIPO DE CONVIVENCIA EN NÚMERO TOTAL DE PREOCUPACIONES GENERALES Y ESPECÍFICAS. MUESTRA DE PCDID . ... 311

TABLA 102: RESUMEN DE DIFERENCIAS EN FUNCIÓN DEL TIPO DE CONVIVENCIA RECODIFICADO.MUESTRA DE PCDID.

TABLA 103: RANGOS PROMEDIOS EN FUNCIÓN DE LA RESIDENCIA EN NÚMERO TOTAL DE PREOCUPACIONES Y SOLUCIONES GENERALES. MUESTRA DE PCDID.

TABLA 104: ESTADÍSTICOS DE CONTRASTE EN FUNCIÓN DE LA RESIDENCIA EN NÚMERO TOTAL DE PREOCUPACIONES Y SOLUCIONES GENERALES. MUESTRA DE PCDID ... 314

TABLA 105: RANGOS EN FUNCIÓN DE LA RESIDENCIA EN NÚMERO TOTAL DE PREOCUPACIONES ESPECÍFICAS. MUESTRA DE PCDID.

TABLA 106: ESTADÍSTICOS DE CONTRASTE EN FUNCIÓN DE LA RESIDENCIA EN NÚMERO TOTAL DE PREOCUPACIONES ESPECÍFICAS. MUESTRA DE PCDID.

GRÁFICO 12: RANGOS PROMEDIO EN FUNCIÓN DE LA RESIDENCIA EN NÚMERO TOTAL DE PREOCUPACIONES GENERALES Y ESPECÍFICAS. MUESTRA DE PCDID.

TABLA 107: RESUMEN DE DIFERENCIAS EN FUNCIÓN DE LA RESIDENCIA. MUESTRA DE PCDID

TABLA 108: RANGOS PROMEDIOS EN FUNCIÓN DEL TIPO DE DISCAPACIDAD INTELECTUAL Y DEL DESARROLLO EN NÚMERO TOTAL DE PREOCUPACIONES Y SOLUCIONES GENERALES. MUESTRA DE PCDID.

TABLA 109: ESTADÍSTICOS DE CONTRASTE EN FUNCIÓN DEL TIPO DE DISCAPACIDAD EN NÚMERO TOTAL DE PREOCUPACIONES Y SOLUCIONES GENERALES. MUESTRA DE PCDID

TABLA 110: RANGOS PROMEDIOS EN FUNCIÓN DEL TIPO DE DISCAPACIDAD INTELECTUAL Y DEL DESARROLLO EN NÚMERO TOTAL DE PREOCUPACIONES ESPECÍFICAS. MUESTRA DE PCDID.

TABLA 111: ESTADÍSTICOS DE CONTRASTE EN FUNCIÓN DEL TIPO DE DISCAPACIDAD EN NÚMERO TOTAL DE PREOCUPACIONES ESPECÍFICAS. MUESTRA DE PCDID. 
GRÁFICO 13: RANGOS PROMEDIO EN FUNCIÓN DEL TIPO DE DISCAPACIDAD EN NÚMERO TOTAL DE PREOCUPACIONES GENERALES Y ESPECÍFICAS. MUESTRA DE PCDID. . .. 322

TABLA 112: RESUMEN DE DIFERENCIAS EN FUNCIÓN DEL TIPO DE DISCAPACIDAD. MuESTRA DE PCDID.

TABLA 113: RESUMEN DE LOS RESULTADOS SIGNIFICATIVOS EN CADA UNA DE LAS VARIABLES PREDICTORAS EN LA MUESTRA DE PCDID.

TABLA 114: TOTAL DE PERSONAS DE LA MUESTRA QUE HAN COMPLETADO LA ENTREVISTA FAMILIAR.

TABLA 115: PARENTESCO DE LAS PERSONAS QUE HAN COMPLETADO LA ENTREVISTA FAMILIAR. 326

TABLA 116: CARACTERÍSTICAS DE LA MUESTRA FAMILIAR POR LA EDAD Y EL GÉNERO DE LAS PCDID.

TABLA 117: LUGAR DE APLICACIÓN DE LAS ENTREVISTAS FAMILIARES.

TABLA 118: CARACTERÍSTICAS DE LA MUESTRA FAMILIAR EN FUNCIÓN DE LA PROCEDENCIA DE LAS PCDID. 328

TABLA 119: CARACTERÍSTICAS DE LA MUESTRA FAMILIAR POR LUGAR DE RESIDENCIA DE LAS PCDI.

TABLA 120: CARACTERÍSTICAS DE LA MUESTRA FAMILIAR EN FUNCIÓN DEL ESTADO CIVIL DE LAS PCDID.

TABLA 121: ESTADÍSTICOS DE LAS PREOCUPACIONES Y NECESIDADES PERCIBIDAS DE LA MUESTRA DE FAMILIAS EN GENERAL

GRÁFICO 14: № TOTAL DE PREOCUPACIONES Y NECESIDADES PERCIBIDAS DE LA MUESTRA DE FAMILIAS EN GENERAL

TABLA 122: ESTADÍSTICOS DE LAS PREOCUPACIONES Y NECESIDADES PERCIBIDAS DE LA MUESTRA DE FAMILIAS DE LAS PERSONAS CON SD.

TABLA 123: ESTADÍSTICOS DE LAS PREOCUPACIONES Y NECESIDADES PERCIBIDAS DE LA MUESTRA DE FAMILIAS DE LAS PERSONAS CON OTROS TIPOS DE DID.

TABLA 124: ESTADÍSTICOS DE LAS PREOCUPACIONES Y NECESIDADES PERCIBIDAS DE LA MUESTRA DE FAMILIAS DE LAS PERSONAS CON PC.

GRÁFICO 15: COMPARACIÓN DE LAS NECESIDADES ESPECÍFICAS DE LAS FAMILIAS EN FUNCIÓN DE LAS PCDID CON SD, OTROS TIPOS DE DID O PC

TABLA 125: FRECUENCIAS Y PORCENTAJES (DE RESPUESTAS Y DE CASOS) DE PREOCUPACIONES SOBRE SALUD PERSONAL DE LAS FAMILIAS.

TABLA 126: FRECUENCIAS Y PORCENTAJES (DE RESPUESTAS Y DE CASOS) DE PREOCUPACIONES SOBRE RECURSOS ECONÓMICOS DE LAS FAMILIAS.

TABLA 127: FRECUENCIAS Y PORCENTAJES (DE RESPUESTAS Y DE CASOS) DE PREOCUPACIONES SOBRE RECURSOS SANITARIOS DE LAS FAMILIAS.

TABLA 128: FRECUENCIAS Y PORCENTAJES (DE RESPUESTAS Y DE CASOS) DE PREOCUPACIONES SOBRE RECURSOS DE SERVICIOS SOCIALES DE LAS FAMILIAS. ... 338

TABLA 129: FRECUENCIAS Y PORCENTAJES (DE RESPUESTAS Y DE CASOS) DE PREOCUPACIONES SOBRE EXISTENCIA DE BARRERAS DE LAS FAMILIAS.

TABLA 130: FRECUENCIAS Y PORCENTAJES (DE RESPUESTAS Y DE CASOS) DE PREOCUPACIONES SOBRE OTRAS PREOCUPACIONES Y NECESIDADES DE LAS FAMILIAS. 
TABLA 131: FRECUENCIAS Y PORCENTAJES (DE RESPUESTAS Y DE CASOS) DE LAS SOLUCIONES PROPUESTAS POR LAS FAMILIAS.

TABLA 132: FRECUENCIAS Y PORCENTAJES (DE RESPUESTAS Y DE CASOS) DE LAS SOLUCIONES PROPUESTAS POR LAS FAMILIAS EN FUNCIÓN DE LA TEMÁTICA.

TABLA 133: FRECUENCIAS Y PORCENTAJES (DE RESPUESTAS Y DE CASOS) DE APOYOS REQUERIDOS POR LAS FAMILIAS.

TABLA 134: FRECUENCIAS Y PORCENTAJES (DE RESPUESTAS Y DE CASOS) DE PENSAMIENTOS SOBRE EL FUTURO DE LAS FAMILIAS.

TABLA 135: FRECUENCIAS Y PORCENTAJES (DE RESPUESTAS Y DE CASOS) DE PENSAMIENTOS SOBRE EL FUTURO EN FUNCIÓN DE LA TEMÁTICA DE LAS FAMILIAS.

TABLA 136: FRECUENCIAS Y PORCENTAJES (DE RESPUESTAS Y DE CASOS) DE OTRAS CONSIDERACIONES DE LAS FAMILIAS.

TABla 137: PRUEBA DE KOLMOGOROV-SMIRNOV PARA UNA MUESTRA EN NÚMERO TOTAL DE PREOCUPACIONES, SOLUCIONES, APOYOS REQUERIDOS, PENSAMIENTOS DE FUTURO Y OTRAS CONSIDERACIONES.

TABLA 138: PRUEBA DE KOLMOGOROV-SMIRNOV PARA UNA MUESTRA EN NÚMERO TOTAL DE PREOCUPACIONES SOBRE SALUD PERSONAL, RECURSOS ECONÓMICOS, RECURSOS SANITARIOS, RECURSOS DE SERVICIOS SOCIALES, EXISTENCIA DE BARRERAS Y OTRAS PREOCUPACIONES.

TABLA 139: RANGOS PROMEDIO EN FUNCIÓN DEL GÉNERO EN NÚMERO TOTAL DE PREOCUPACIONES Y SOLUCIONES GENERALES. MUESTRA DE FAMILIAS.

TABLA 140: ESTADÍSTICOS DE CONTRASTE EN FUNCIÓN DEL GÉNERO EN NÚMERO TOTAL DE NECESIDADES GENERALES. MUESTRA DE FAMILIAS.

TABLA 141: RANGOS PROMEDIO EN FUNCIÓN DEL GÉNERO EN NÚMERO TOTAL DE NECESIDADES ESPECÍFICAS. MUESTRA DE FAMILIAS.

TABLA 142: ESTADÍSTICOS DE CONTRASTE EN FUNCIÓN DEL GÉNERO EN NÚMERO TOTAL DE PREOCUPACIONES ESPECÍFICAS. MUESTRA DE FAMILIAS. 352

GRÁFICO 16: RANGOS PROMEDIO EN FUNCIÓN DEL GÉNERO EN NÚMERO TOTAL DE PREOCUPACIONES GENERALES Y ESPECÍFICAS. MUESTRA DE FAMILIAS.

TABLA 143: RESUMEN DE DIFERENCIAS EN FUNCIÓN DEL GÉNERO. MUESTRA DE FAMILIAS.

TABLA 144: RANGOS PROMEDIO EN FUNCIÓN DE LA EDAD RECODIFICADA EN NÚMERO TOTAL DE PREOCUPACIONES Y SOLUCIONES GENERALES. MUESTRA DE FAMILIAS. 355

TABLA 145: ESTADÍSTICOS DE CONTRASTE EN FUNCIÓN DE LA EDAD RECODIFICADA EN NÚMERO TOTAL DE PREOCUPACIONES Y SOLUCIONES GENERALES. MUESTRA DE FAMILIAS.

TABLA 146: RANGOS PROMEDIO EN FUNCIÓN DE LA EDAD RECODIFICADA EN NÚMERO TOTAL DE PREOCUPACIONES ESPECÍFICAS. MUESTRA DE FAMILIAS.

TABLA 147: ESTADÍSTICOS DE CONTRASTE EN FUNCIÓN DE LA EDAD RECODIFICADA EN NÚMERO TOTAL DE PREOCUPACIONES ESPECÍFICAS. MUESTRA DE FAMILIAS......... 358 358

GRÁFICO 17: RANGOS PROMEDIO EN FUNCIÓN DE LA EDAD EN NÚMERO TOTAL DE PREOCUPACIONES GENERALES Y ESPECÍFICAS. MUESTRA DE FAMILIAS. 
TABLA 148: RESUMEN DE DIFERENCIAS EN FUNCIÓN DE LA EDAD RECODIFICADA.

MUESTRA DE FAMILIAS.

TABLA 149: RANGOS PROMEDIO EN FUNCIÓN DEL GRADO DE DISCAPACIDAD DICOTOMIZADO EN NÚMERO TOTAL DE PREOCUPACIONES Y SOLUCIONES GENERALES. MUESTRA DE FAMILIAS.

TABLA 150: ESTADÍSTICOS DE CONTRASTE EN FUNCIÓN DEL GRADO DE DISCAPACIDAD DICOTOMIZADO EN NÚMERO TOTAL DE NECESIDADES GENERALES. MUESTRA DE FAMILIAS. 361

TABLA 151: RANGOS PROMEDIO EN FUNCIÓN DEL GRADO DE DISCAPACIDAD DICOTOMIZADO EN FUNCIÓN DEL NÚMERO TOTAL DE PREOCUPACIONES ESPECÍFICAS. MUESTRA DE FAMILIAS.

TABLA 152: ESTADÍSTICOS DE CONTRASTE EN FUNCIÓN DEL GRADO DE DISCAPACIDAD DICOTOMIZADO EN NÚMERO TOTAL DE PREOCUPACIONES ESPECÍFICAS. MUESTRA DE FAMILIAS.

GRÁFICO 18: RANGOS PROMEDIO EN FUNCIÓN DEL GRADO DE DISCAPACIDAD DICOTOMIZADO EN NÚMERO TOTAL DE PREOCUPACIONES GENERALES Y ESPECÍFICAS. MUESTRA DE FAMILIAS. 363

TABLA 153: RESUMEN DE DIFERENCIAS EN FUNCIÓN DEL TIPO DE INFORME DICOTOMIZADO DE LA MUESTRA DE PCDID.

TABLA 154: RANGOS PROMEDIO EN FUNCIÓN DEL TIPO DE CONVIVENCIA EN NÚMERO TOTAL DE PREOCUPACIONES Y SOLUCIONES GENERALES. MUESTRA DE FAMILIAS. 366

TABLA 155: ESTADÍSTICOS DE CONTRASTE EN FUNCIÓN DEL TIPO DE CONVIVENCIA EN NÚMERO TOTAL DE PREOCUPACIONES Y SOLUCIONES GENERALES. MUESTRA DE FAMILIAS.

TABLA 156: RANGOS PROMEDIO EN FUNCIÓN DEL TIPO DE CONVIVENCIA EN NÚMERO TOTAL DE PREOCUPACIONES ESPECÍFICAS. MUESTRA DE FAMILIAS.

TABLA 157: ESTADÍSTICOS DE CONTRASTE EN FUNCIÓN DEL TIPO DE CONVIVENCIA EN NÚMERO TOTAL DE PREOCUPACIONES ESPECÍFICAS. MUESTRA DE FAMILIAS.

GRÁFICO 19: RANGOS PROMEDIO EN FUNCIÓN DEL TIPO DE CONVIVENCIA EN NÚMERO TOTAL DE PREOCUPACIONES GENERALES Y ESPECÍFICAS. MUESTRA DE FAMILIAS. 369

TABLA 158: RESUMEN DE DIFERENCIAS EN FUNCIÓN DEL TIPO DE CONVIVENCIA.

MUESTRA DE FAMILIAS

TABLA 159: RANGOS PROMEDIO EN FUNCIÓN DE LA RESIDENCIA EN NÚMERO TOTAL DE PREOCUPACIONES Y SOLUCIONES ESPECÍFICAS. MUESTRA DE FAMILIAS.

TABLA 160: ESTADÍSTICOS DE CONTRASTE EN FUNCIÓN DE LA RESIDENCIA EN NÚMERO TOTAL DE NECESIDADES GENERALES. MUESTRA DE FAMILIAS

TABLA 161: RANGOS PROMEDIO EN FUNCIÓN DE LA RESIDENCIA EN NÚMERO TOTAL DE PREOCUPACIONES ESPECÍFICAS. MUESTRA DE FAMILIAS.

TABLA 162: ESTADÍSTICOS DE CONTRASTE EN FUNCIÓN DE LA RESIDENCIA EN NÚMERO TOTAL DE NECESIDADES ESPECÍFICAS. MUESTRA DE FAMILIAS.

GRÁFICO 20: RANGOS PROMEDIO EN FUNCIÓN DE LA RESIDENCIA EN NÚMERO TOTAL DE PREOCUPACIONES GENERALES Y ESPECÍFICAS. MUESTRA FAMILIAR. 374

TABLA 163: RESUMEN DE DIFERENCIAS EN FUNCIÓN DE LA RESIDENCIA. MUESTRA DE FAMILIAS. 
TABLA 164: RANGOS PROMEDIO EN FUNCIÓN DEL TIPO DE DISCAPACIDAD EN NÚMERO TOTAL DE PREOCUPACIONES Y SOLUCIONES GENERALES. MUESTRA DE FAMILIAS. 376

TABLA 165: ESTADÍSTICOS DE CONTRASTE EN FUNCIÓN DEL TIPO DE DISCAPACIDAD EN NÚMERO TOTAL DE PREOCUPACIONES Y SOLUCIONES GENERALES. MUESTRA DE FAMILIAS. 376

TABLA 166: RANGOS PROMEDIO EN FUNCIÓN DEL TIPO DE DISCAPACIDAD EN NÚMERO DE PREOCUPACIONES ESPECÍFICAS. MUESTRA DE FAMILIAS.

TABLA 167: ESTADÍSTICOS DE CONTRASTE EN FUNCIÓN DEL TIPO DE DISCAPACIDAD EN NÚMERO TOTAL DE PREOCUPACIONES ESPECÍFICAS. MUESTRA DE FAMILIAS. .

GRÁFICO 21: RANGOS PROMEDIO EN FUNCIÓN DEL TIPO DE DISCAPACIDAD EN NÚMERO TOTAL DE PREOCUPACIONES GENERALES Y ESPECÍFICAS. MUESTRA DE FAMILIAS. 379

TABLA 168: RESUMEN DE DIFERENCIAS EN FUNCIÓN DEL TIPO DE DISCAPACIDAD. MUESTRA FAMILIAR. 380

TABLA 169: RESUMEN DE LOS RESULTADOS SIGNIFICATIVOS EN FUNCIÓN DE LAS VARIABLES PREDICTORAS EN LA MUESTRA DE FAMILIAS ....

TABLA 170: CARACTERÍSTICAS DE LA MUESTRA INSTITUCIONAL POR LUGAR DE APLICACIÓN DEL CUESTIONARIO.

TABLA 171: CARACTERÍSTICAS DE LA MUESTRA INSTITUCIONAL POR PERSONA QUE CUMPLIMENTA EL CUESTIONARIO.

TABLA 172: CARACTERÍSTICAS DE LA MUESTRA INSTITUCIONAL POR SEDE DE LA INSTITUCIÓN.

TABLA 173: CARACTERÍSTICAS DE LA MUESTRA INSTITUCIONAL POR PROCEDENCIA. ... 384

TABLA 174: CARACTERÍSTICAS DE LA MUESTRA INSTITUCIONAL POR TIPO DE INSTITUCIÓN.

TABLA 175: CARACTERÍSTICAS DE LA MUESTRA INSTITUCIONAL POR TIPO DE DISCAPACIDAD ATENDIDA.

TABLA 176: CARACTERÍSTICAS DE LA MUESTRA INSTITUCIONAL POR ESPECIALIZACIÓN DEL PERSONAL

TABLA 177: CARACTERÍSTICAS DE LA MUESTRA INSTITUCIONAL POR TIPO DE SERVICIOS.

TABLA 178: CARACTERÍSTICAS DE LA MUESTRA INSTITUCIONAL POR EL TIPO DE ALOJAMIENTO DE LOS USUARIOS.

TABLA 179: ESTADÍSTICOS DESCRIPTIVOS DE LAS NECESIDADES ESPECÍFICAS SEÑALADAS POR LA MUESTRA INSTITUCIONAL.

GRÁFICO 22: FRECUENCIA DE NECESIDADES ESPECÍFICAS PERCIBIDAS POR LA MUESTRA INSTITUCIONAL.

TABLA 180: FRECUENCIAS Y PORCENTAJES (DE RESPUESTAS Y DE CASOS) DE PREOCUPACIONES SOBRE SALUD PERSONAL DE LA MUESTRA INSTITUCIONAL.

TABLA 181: FRECUENCIAS Y PORCENTAJES (DE RESPUESTAS Y DE CASOS) DE PREOCUPACIONES SOBRE RECURSOS ECONÓMICOS DE LA MUESTRA INSTITUCIONAL.

TABLA 182: FRECUENCIAS Y PORCENTAJES (DE RESPUESTAS Y DE CASOS) DE PREOCUPACIONES SOBRE RECURSOS SANITARIOS DE LA MUESTRA INSTITUCIONAL. 
TABLA 183: FRECUENCIAS Y PORCENTAJES (DE RESPUESTAS Y DE CASOS) DE PREOCUPACIONES SOBRE RECURSOS DE SERVICIOS SOCIALES DE LA MUESTRA INSTITUCIONAL

TABLA 184: FRECUENCIAS Y PORCENTAJES (DE RESPUESTAS Y DE CASOS) DE PREOCUPACIONES SOBRE EXISTENCIA DE BARRERAS DE LA MUESTRA INSTITUCIONAL.

TABLA 185: FRECUENCIAS Y PORCENTAJES (DE RESPUESTAS Y DE CASOS) DE PREOCUPACIONES SOBRE OTRAS PREOCUPACIONES Y NECESIDADES DE LA MUESTRA INSTITUCIONAL.

TABLA 186: FRECUENCIAS Y PORCENTAJES (DE RESPUESTAS Y DE CASOS) DE DEMANDAS DE LOS ASOCIADOS DE LA MUESTRA INSTITUCIONAL. 398

TABLA 187: FRECUENCIAS Y PORCENTAJES (DE RESPUESTAS Y DE CASOS) DE LAS SOLUCIONES PROPUESTAS POR LA MUESTRA INSTITUCIONAL 400

TABLA 188: FRECUENCIAS Y PORCENTAJES (DE RESPUESTAS Y DE CASOS) DE LAS SOLUCIONES PROPUESTAS POR LA MUESTRA INSTITUCIONAL EN FUNCIÓN DE LA TEMÁTICA......

TABLA 189: FRECUENCIAS Y PORCENTAJES (DE RESPUESTAS Y DE CASOS) DE APOYOS REQUERIDOS POR LA MUESTRA INSTITUCIONAL.

TABLA 190: FRECUENCIAS Y PORCENTAJES (DE RESPUESTAS Y DE CASOS) DE PENSAMIENTOS SOBRE EL FUTURO DE LA MUESTRA INSTITUCIONAL.

TABLA 191: FRECUENCIAS Y PORCENTAJES (DE RESPUESTAS Y DE CASOS) DE PENSAMIENTOS SOBRE EL FUTURO EN FUNCIÓN DE LA TEMÁTICA DE LA MUESTRA INSTITUCIONAL.

TABLA 192: FRECUENCIAS Y PORCENTAJES (DE RESPUESTAS Y DE CASOS) DE PENSAMIENTOS SOBRE EL FUTURO DE LA MUESTRA INSTITUCIONAL.

TABLA 193: FRECUENCIAS Y PORCENTAJES (DE RESPUESTAS Y DE CASOS) DE PENSAMIENTOS SOBRE EL FUTURO EN FUNCIÓN DE LA TEMÁTICA DE LA MUESTRA INSTITUCIONAL.

TABLA 194: FRECUENCIAS Y PORCENTAJES (DE RESPUESTAS Y DE CASOS) DE OTRAS CONSIDERACIONES DE LA MUESTRA INSTITUCIONAL

TABlA 195: PRUEBA DE KOLMOGOROV-SMIRNOV PARA UNA MUESTRA EN NÚMERO DE PREOCUPACIONES Y SOLUCIONES GENERALES. MUESTRA DE PROFESIONALES....... 413

TABLA 196: PRUEBA DE KOLMOGOROV-SMIRNOV PARA UNA MUESTRA EN NÚMERO DE PREOCUPACIONES ESPECÍFICAS. MUESTRA DE PROFESIONALES.

TABLA 197: RANGOS PROMEDIO EN FUNCIÓN DEL TIPO DE RESIDENCIA EN NÚMERO TOTAL DE PREOCUPACIONES Y SOLUCIONES GENERALES.

TABLA 198: ESTADÍSTICOS DE CONTRASTE EN FUNCIÓN DE LA RESIDENCIA EN NÚMERO TOTAL DE NECESIDADES GENERALES. MUESTRA DE PROFESIONALES. ................... 416

TABLA 199: RANGOS PROMEDIO EN FUNCIÓN DEL TIPO DE RESIDENCIA EN NÚMERO TOTAL DE PREOCUPACIONES Y SOLUCIONES GENERALES. MUESTRA DE LOS PROFESIONALES.

TABLA 200: ESTADÍSTICOS DE CONTRASTE EN FUNCIÓN DE LA RESIDENCIA EN NÚMERO TOTAL DE PREOCUPACIONES ESPECÍFICAS. MUESTRA DE PROFESIONALES. 
GRÁFICO 23: RANGOS PROMEDIO EN FUNCIÓN DE LA RESIDENCIA EN NÚMERO TOTAL DE PREOCUPACIONES Y NECESIDADES ESPECÍFICAS. MUESTRA DE PROFESIONALES.... 417

TABLA 201: RESUMEN DE DIFERENCIAS EN FUNCIÓN DE LA RESIDENCIA. MUESTRA DE PROFESIONALES

TABLA 202: RANGOS PROMEDIOS EN FUNCIÓN DEL TIPO DE INSTITUCIÓN EN NÚMERO DE PREOCUPACIONES Y SOLUCIONES GENERALES. MUESTRA DE PROFESIONALES....... 420

TABLA 203: ESTADÍSTICOS DE CONTRASTE EN FUNCIÓN DEL TIPO DE INSTITUCIÓN EN NÚMERO TOTAL DE PREOCUPACIONES Y SOLUCIONES GENERALES. MUESTRA DE PROFESIONALES

TABLA 204: RANGOS PROMEDIO EN FUNCIÓN DEL TIPO DE INSTITUCIÓN EN TIPO DE NECESIDADES ESPECÍFICAS. MUESTRA DE PROFESIONALES.

TABLA 205: ESTADÍSTICOS DE CONTRASTE EN FUNCIÓN DEL TIPO DE INSTITUCIÓN EN NÚMERO TOTAL DE PREOCUPACIONES ESPECÍFICAS. MUESTRA DE PROFESIONALES.

GRÁFICO 24: RANGOS PROMEDIO EN FUNCIÓN DEL TIPO DE INSTITUCIÓN EN NÚMERO TOTAL DE PREOCUPACIONES Y NECESIDADES ESPECÍFICAS. MUESTRA DE PROFESIONALES

TABLA 206: RESUMEN DE DIFERENCIAS EN FUNCIÓN DEL TIPO DE INSTITUCIÓN. MUESTRA DE PROFESIONALES.

TABLA 207: RESUMEN DE LOS RESULTADOS SIGNIFICATIVOS EN LA MUESTRA INSTITUCIONAL.

TABLA 208: FRECUENCIAS DE LAS NECESIDADES ESPECÍFICAS SEÑALADAS POR LA MUESTRA DE PCDID, FAMILIAS Y PROFESIONALES.

GRÁFICO 24: FRECUENCIA DE LAS NECESIDADES ESPECÍFICAS SEÑALADAS POR LA MUESTRA DE PCDID, FAMILIAS Y PROFESIONALES.

TABLA 209: PORCENTAJES DE CASOS DE PREOCUPACIONES SOBRE SALUD PERSONAL DE LAS TRES MUESTRAS. 428

TABLA 210: PORCENTAJES DE CASOS DE PREOCUPACIONES SOBRE RECURSOS ECONÓMICOS DE LAS TRES MUESTRAS. 429

TABLA 211: PORCENTAJES DE CASOS DE PREOCUPACIONES SOBRE RECURSOS DE SERVICIOS SANITARIOS DE LAS TRES MUESTRAS.

TABLA 212: PORCENTAJES DE CASOS DE PREOCUPACIONES SOBRE RECURSOS DE SERVICIOS SOCIALES DE LAS TRES MUESTRAS.

TABLA 213: PORCENTAJES DE CASOS DE PREOCUPACIONES SOBRE EXISTENCIA DE BARRERAS DE LAS TRES MUESTRAS.

TABLA 214: PORCENTAJES DE CASOS DE PREOCUPACIONES SOBRE OTRAS NECESIDADES DE

LAS TRES MUESTRAS.

TABLA 215: PORCENTAJES DE CASOS DE SOLUCIONES DE LAS TRES MUESTRAS. 434

TABLA 216: PORCENTAJES DE CASOS DE APOYOS INSTITUCIONALES REQUERIDOS DE LAS TRES MUESTRAS.

TABLA 217: PORCENTAJES DE CASOS DE PENSAMIENTOS DE FUTURO DE LAS TRES MUESTRAS. 436

TABLA 218: PORCENTAJE DE RESPUESTAS SUPERIORES AL 40\% EN LAS TRES MUESTRAS. 


\section{ÍNDICE DE SIGLAS}

3MS

AAIDD

AAMR

ABVD

ACG

ACPQ

ADLs

AIVD

AVD

BI

BMI

C2Ist

CAII-R

CES-D10

CI

CQOL-ID

CSIC

CV

DC-LD

DI

DSM-IV-TR

EBEAP

ECEMC

EDAD

EDDES

EQ-5-D

EQLI

ESAP

ESI
Test Minimental Modificado.

Asociación Americana de la Discapacidad Intelectual y del Desarrollo. Asociación Americana del Retraso Mental (actualmente AAIDD).

Actividades Básicas de la Vida Diaria.

Escala de Morbilidad de Hopkins.

Escala de Participación Comunitaria

Actividades Instrumentales de la Vida Diaria.

Actividades Instrumentales de la Vida Diaria.

Actividades de la Vida Diaria.

Índice de Barthel.

Índice de Masa Corporal.

Evaluación de la Salud, Comportamiento, Desarrollo y Enfermedad Mental.

Índice de Cambios en la Actividad e Intereses Revisado.

Escala del Centro Epidemiológico de Estudios de Depresión.

Cociente Intelectual.

Cuestionario de Calidad de Vida para Personas con Discapacidad Intelectual de China.

Consejo Superior de Investigaciones Científicas.

Calidad de Vida.

Criterios Diagnósticos para la Discapacidad Intelectual.

Discapacidad Intelectual.

Manual Diagnóstico y Estadístico de los Trastornos Mentales Revisado.

Escala Breve para la Apreciación del Estado de Ánimo Positivo en personas adultas con discapacidad intelectual.

Estudio Colaborativo Español de Malformaciones Congénitas.

Encuesta de Discapacidad, Autonomía personal y situaciones de Dependencia.

Encuesta de Discapacidades, Deficiencias y Estado de Salud.

Cuestionario de Calidad de Vida de 5 Dimensiones.

Instrumento de Evaluación de la Calidad de Vida.

Encuesta Europea sobre el Protocolo de Envejecimiento.

Instrumento de Evaluación de la Autodeterminación. 
ETAM Red Europea de Asesoramiento en Tecnología.

FEISD Federación Española de Instituciones del Síndrome de Down.

FQOLS Entrevista de Evaluación de la Calidad de Vida Familiar.

GPS Sistema de Posicionamiento Global.

GWBS Cuestionario de Bienestar general.

IASSID Asociación Internacional para el Estudio Científico de la Discapacidad Intelectual.

ICAP Inventario para la Planificación de Servicios y Programación Individual.

ICD-10 Clasificación Internacional de Enfermedades.

ICD-10-DCR Clasificación Internacional de Enfermedades - Criterios Diagnósticos para la Investigación.

ICF Clasificación Internacional de Funcionamiento, Discapacidad y Salud.

INE Instituto Nacional de Estadística.

INICO Instituto Universitario de Integración en la Comunidad.

Life-H Evaluación de los hábitos de Vida.

MCS Encuesta de Componente Mental.

MMSE Test Minimental.

MQE Medida de la Calidad del Entorno.

NHI-D Encuesta Nacional de Salud.

NHP Perfil de Salud de Nottingham.

NIDD Base de datos nacional de discapacidad intelectual de Irlanda.

NP Necesidad Percibida.

NPs Necesidades Percibidas.

OMS Organización Mundial de la Salud.

PALS Encuesta de limitaciones en la participación y la actividad.

PAS-ADD Instrumento de Screening de Trastorno Mental en Personas con Discapacidad Intelectual.

PBC Apoyo Conductual Positivo.

PcD Personas con Discapacidad.

PcDI Personas con Discapacidad Intelectual.

PcDID Personas con Discapacidad Intelectual y del Desarrollo.

PCP Planificación Centrada en la Persona.

PcSD Personas con Síndrome de Down.

PELEA Protocolo de Estudio Longitudinal sobre Envejecimiento.

PDA Asistente Digital Personal

PMs Personas mayores 
PPSALD Estado Psiquiátrico Actual para Adultos con Discapacidad Intelectual.

PRS Programa de Apoyos Individualizados en Residencias.

QLI Índice de Calidad de Vida de Ferrans y Powers.

QOL-PMD Cuestionario de Calidad de Vida para Personas con Múltiples Discapacidades Profundas.

QOL-Q Cuestionario de Calidad de Vida.

RAND Entrevista de Salud.

RHSS Encuesta del Estado de Salud de Rochester.

RMI Índice de movilidad del test Rivermead.

SAAC Sistemas Aumentativos y Alternativos de Comunicación.

SAI Inventario de Envejecimiento Satisfactorio.

SD Síndrome de Down.

SERA Sistema de Evaluación de Residencias de Ancianos.

SF-12 Encuesta Corta del Estado de Salud.

SF-36 Encuesta del Estado de Salud.

SIS Escala de Intensidad de las Necesidades de Apoyo.

SMAF Sistema de Medida de la Autonomía Funcional.

SNAC Cuestionario de Calidad y Cantidad de Sueño.

SSSQ Cuestionario de Habilidades de Supervivencia en la Calle.

SWH-HRA Programa "Estar Bien y Sano" para la Evaluación de los Riesgos para la Salud en Personas con Discapacidad Intelectual y del Desarrollo.

SWLS Escala de Satisfacción con La Vida.

TUG Test de Levantarse y Caminar

VAS-ARM Escala de Evaluación de Habilidades Sociales para Adultos con Discapacidad Intelectual.

VFQ-ID Cuestionario Viena de Fragilidad para Personas con Discapacidad Intelectual.

WHODAS 2.0 Entrevista de la Discapacidad de la Organización Mundial de la Salud.

WHOQOL Medida de Calidad de Vida.

YAQOL Cuestionario de Calidad de Vida en Adultos Jóvenes. 



\section{AGRADECIMIENTOS}

En primer lugar, quiero dar las gracias a los Profesores Antonio Aguado y a Ángeles Alcedo por haberme permitido formar parte de su equipo de investigación y darme la oportunidad de llevar a cabo este trabajo. Asimismo, quiero agradecer la enseñanza que me han proporcionado durante mis años de formación, ya que ambos contagian el entusiasmo con el que se adentran a formarnos en el mundo de la discapacidad. También quiero dar las gracias a todos los miembros de este equipo porque de todos ellos, en mayor o menor medida, he aprendido algo.

Gracias también a los profesionales y miembros del INICO, dirigidos por D. Miguel Angel Verdugo, por su excelente trabajo en la formación de nuevos profesionales y su repertorio investigador y práctico, que nos proporciona cada día nuevas líneas para mejorar la vida diaria de las personas con discapacidad.

Gracias a todas las Asociaciones, familias, personas con discapacidad y profesionales que han participado en la investigación.

No podría dejar de agradecer a mis padres todo el apoyo que me han brindado y que me ha permitido llegar hasta aquí. No tendría ni el espacio, ni las palabras suficientes para agradecerles todo lo que han hecho por mí. Así como también agradecer al resto de mis familiares cercanos su comprensión, afecto y compañía durante toda mi existencia. Muchas gracias a todos. Gracias a Olaya y Ana por aguantar mis discursos, apoyarme, animarme y simplemente por estar ahí. Y por supuesto, gracias a mi equipo de ASPRONA de Tobarra, con quienes sigo formándome como persona, como profesional y aprendiendo cosas nuevas cada día. 



\section{RESUMEN GENERAL Y PALABRAS CLAVE}

\subsection{RESUMEN}

Este trabajo se enmarca dentro de la línea de investigación sobre envejecimiento, necesidades percibidas y calidad de vida en personas con discapacidad, dirigida por el Dr. D. Antonio-León Aguado Díaz, Profesor del Departamento de Psicología de la Universidad de Oviedo. El objetivo principal de esta investigación es conocer las necesidades percibidas por las personas con discapacidades intelectuales y del desarrollo españolas, por sus familias y por los profesionales que les atienden, y relacionarlas con las características sociodemográficas de los participantes así como con otras variables intervinientes.

En un primer momento, se lleva a cabo una revisión sobre las publicaciones más relevantes y actuales, para concretar y operacionalizar los conceptos con los que se van a trabajar. Así, se exponen las investigaciones principales más actuales sobre el envejecimiento, tanto en población general, como en personas con discapacidad y en personas con discapacidad intelectual; sobre la calidad de vida, nuevamente en los tres colectivos de personas y de las necesidades percibidas. Asimismo, también se incluye una revisión actualizada sobre las investigaciones más novedosas en el campo de las personas con discapacidad y con discapacidad intelectual.

Posteriormente, se expone el trabajo empírico realizado. A través de tres entrevistas semiestructuradas paralelas, se analizan de forma análoga las principales preocupaciones y necesidades percibidas por este colectivo, sus familias y los profesionales que les atienden, así como las principales medidas institucionales que echan en falta en 
los servicios, las soluciones propuestas y los pensamientos acerca del futuro. Todo ello con el objetivo de identificar los indicadores de calidad de vida y las necesidades percibidas en la población estudiada y determinar la demanda de servicios de este colectivo en constante crecimiento.

\subsection{PALABRAS CLAVE}

Envejecimiento, calidad de vida, necesidades percibidas, discapacidad, discapacidades intelectuales y del desarrollo. 


\section{JUSTIFICACIÓN}

La tesis que se presenta se enmarca dentro de la línea de investigación iniciada y dirigida por el Dr. D. Antonio-León Aguado Díaz acerca de la calidad de vida (CV) y necesidades percibidas (NPs) por personas con discapacidad (PcD) en proceso de envejecimiento (Aguado, Alcedo, Fontanil, Arias y Verdugo, 2001; Aguado y Alcedo, 2003, 2004; Aguado, Alcedo y Arias, 2005; Aguado, Alcedo, Arias y Rueda, 2006; Aguado, Alcedo y Fontanil, 2005, 2012; Aguado, Alcedo, Rozada, González, Real y Fontanil, 2010). A raíz de esta investigación ya se han publicado numerosas tesis doctorales entre las que se enmarcan la tesis de Souto (2015) sobre las necesidades percibidas por las personas con Parkinson, y la de Solís (2014), referente también a las necesidades percibidas por las personas con discapacidad intelectual.

El objetivo de este trabajo estriba en conocer las características sociodemográficas y las NPs de una muestra española de personas con discapacidades intelectuales y del desarrollo (PcDID) que se encuentran en proceso de envejecimiento. Con todo ello, se pretende aportar la suficiente información a los servicios dirigidos al colectivo de PcDID en proceso de envejecimiento para que puedan organizar y planificar los recursos con el fin de incrementar su eficacia en la mejora de la calidad de vida de esta población.

El aumento de la esperanza de vida de la población general producido por los avances sanitarios, económicos y sociales se ha expandido también a la población de PcD, que ahora debe hacer frente a los nuevos retos y desafíos que supone el proceso de envejecimiento, sumados a los que ya presentaban las limitaciones funcionales preexistentes ligadas a la discapacidad. Esta conjunción les sitúa en una situación de doble vul- 
nerabilidad, también denominada doble experiencia. Dicho fenómeno en la actualidad ha dado lugar al desarrollo y la promoción de medidas y programas para mejorar la calidad de vida de las personas con discapacidad intelectual que envejecen, y a la elaboración de diferentes instrumentos para medir objetivamente el impacto que las actuaciones profesionales tienen en la calidad de vida de este colectivo.

Los enfoques recientes que estudian el proceso de envejecimiento en la población con PcDID se centran en el estudio de las necesidades relativas a la calidad de vida percibidas por los propios afectados, dando especial relevancia en la actualidad al aspecto subjetivo de la calidad de vida.

En la tesis que se expone, en primer lugar se aplica una entrevista semiestructurada paralela (Aguado y Alcedo, 2003; 2004; Aguado, Alcedo, Arias y Rueda, 2006; Aguado, Alcedo y Fontanil, 2012; Aguado, Alcedo, Rozada, González, Real y Fontanil, 2010) a una muestra de PcDID, así como a sus familiares y a los profesionales que les atienden, entrevista paralela que recogerá datos personales, datos sobre el lugar y la persona que cumplimenta la entrevista; datos clínicos relativos a la discapacidad, datos sobre la convivencia; datos sobre las preocupaciones y necesidades percibidas sobre salud personal, recursos económicos, recursos asistenciales sanitarios, recursos de servicios sociales, existencia de barreras y otras preocupaciones y necesidades; las soluciones que consideran necesarias, las medidas y apoyos institucionales que echan en falta, los pensamientos sobre el futuro, los problemas señalados y una última pregunta abierta por si hubiera alguna consideración que añadir.

Una vez aplicados los instrumentos descritos anteriormente, se exponen los análisis de las variables sociodemográficas y las variables intervinientes, así como de las NPs por las PcDID, sus familiares y los profesionales, y se establecen relaciones entre 
las mismas, y también se estudia en qué puntos convergen y divergen las tres muestras participantes. 
PARTE TEÓRICA 


\section{DELIMITACIÓN CONCEPTUAL}

\subsection{DISCAPACIDAD INTELECTUAL Y DEL DESARROLLO}

\subsubsection{Introducción}

Aunque la discapacidad intelectual ha existido siempre, la visión que ha tenido el resto de la sociedad hacia este colectivo ha variado considerablemente entre décadas. Asimismo, la forma en que el concepto de DI se ha estudiado desde la investigación también ha cambiado y se ha ido mejorando con el paso de los años con el fin de acercarse a una mejor comprensión de la situación en la que viven las personas con DI, de los desafíos a los que se enfrentan, con el objetivo último de poder ofrecerles las ayudas necesarias para poder desarrollarse y vivir de la manera más autónoma e independiente posible.

En este apartado titulado "la discapacidad intelectual" se trata de llevar a cabo un análisis de los cambios que han tenido lugar tanto desde la historia de la humanidad, como de los avances que se han producido en la investigación, sobre el concepto, características y líneas actuales de investigación en este campo ampliamente estudiado.

\subsubsection{Evolución del concepto de discapacidad intelectual y del desarrollo}

El concepto de discapacidad ha sufrido constantes cambios. Como recoge Verdugo (1995) sobre Wodrich, la discapacidad intelectual, previamente denominada "retraso mental", fue considerada en un principio como una incapacidad para hacerse cargo de sus propios bienes, es decir, cuando una persona con DI era beneficiaria de una herencia, ésta pasaba directamente a pertenecer a la realeza debido a que la persona con 
DI no era capaz de gestionarla. Esta era la ley King's Act promulgada en el año 1324, época en la que el actual concepto de DI era conocido como "idiocia" (Verdugo, 1995). Esta ley también distinguía entre la "idiocia" permanente, y un estado de "idiocia" transitoria, en cuyo caso la persona pasaba a considerarse "lunática".

No fue hasta finales del siglo XIX cuando se atribuyó la discapacidad intelectual a un origen orgánico, considerando a la vez una cierta influencia ambiental, apareciendo con ello varios sistemas clasificatorios basados en criterios anatómicos, categorías clínicas e influencias etiológicas y dando lugar al establecimiento de conceptos tales como la educabilidad, la modificabilidad, y algunas características de la DI como la complejidad o la necesidad de varios enfoques terapéuticos, o de varios tratamientos (Aguado, 1995, p.118).

Aparecen avances en la descripción y clasificación de la DI, así como en la identificación de formas clínicas asociadas a ella (Aguado, 1995, p.118). Por un lado, en cuanto a la descripción, Esquirol a principios del siglo XIX distingue entre la demencia y la amencia para hacer referencia al trastorno mental o a la DI respectivamente, en su obra Enfermedades mentales: tratado de la locura (Aguado, 1995, pp. 119,120).

Seguin por la misma época establece cuatro tipos de idiocia, a saber, idiocia, imbecilidad, debilidad mental y simpleza, en función de los problemas en el desarrollo moral e intelectual y Down, también contemporáneo, propone una nueva clasificación basada en la etiología de lo que actualmente denominamos DI (Aguado, 1995, p.119), de donde surge el actual término "Síndrome de Down", denominado por el propio Down como "mongolismo". 
Ireland publica un tratado donde recoge aspectos de la llamada "deficiencia mental”, como la definición, etiología, incidencia, educación y legislación; y además muestra un elevado interés por las causas perinatales de la DI, sobre todo el empleo de los fórceps. Asimismo, fue el primer autor que determinó la medida del perímetro craneal, estableciéndola en $42 \mathrm{~cm}$. Ireland se adelantó a épocas posteriores, considerando que para el diagnóstico era imprescindible comparar la las personas con DI con las personas sin DI, y que debía tenerse en cuenta la edad, cuestión retomada por Binet años más tarde (Aguado, 1995).

Bourneville basándose en la anatomía propone otra clasificación que fue aceptada tanto en el continente europeo como en el americano, así como realizó una descripción de la esclerosis tuberosa conocida como el Síndrome de Bourneville-Pringle. Otra de sus aportaciones fue el crear un modelo de instituto psicopedagógico en el Bicêtre de París (Aguado, 1995). Por último, Duncan y Millar publican en 1866 una clasificación basada en la conducta (Aguado, 1995).

En cuanto a los avances realizados en la identificación de la actual DI, en 1940 se crea la Asociación de Directivos Médicos de las Instituciones para Idiotas y Débiles Mentales de EEUU de la mano de Seguin, posteriormente se conocería como la American Journal on Mental Retardation.

Hasta 1959, la actual DI no deja de ser considerada desde una perspectiva prácticamente biologicista (Verdugo, 1995). Es en ese año cuando aparecen las aportaciones de la Asociación Americana de la Deficiencia Mental (AAMD), conocida posteriormente como Asociación Americana del Retraso Mental (AAMR), y actualmente como Asociación Americana de la Discapacidad Intelectual y las Discapacidades del 
Desarrollo (AAIDD). Esta asociación ha llevado y sigue llevando a cabo actualizaciones constantes acerca de la definición, la etiología y otros aspectos de la actual DI.

La primera definición aportada por la AAMD en los años 60 sobre el entonces llamado "retraso mental" fue propuesta por Heber, y relacionaba el retraso mental con un funcionamiento intelectual general por debajo de la media, que se origina en el período del desarrollo, y se asocia con deficiencias en el comportamiento adaptativo (Verdugo, 1995, p.520). Hay que hacer varias consideraciones en lo que respecta a esta definición. En primer lugar, lo referido al funcionamiento intelectual se considera como la obtención de una puntuación por debajo de la media en un test de inteligencia (se empleaba el Stanforf-Binet, en función del cual se clasificaba a las personas con retraso mental en cinco subgrupos dependiendo del CI: límite, ligero, moderado, severo y profundo). El período de desarrollo hacía referencia a que el "retraso" se manifestaba antes de los 16 años. Por otro lado, hay que considerar que esta definición hace hincapié en los problemas de la persona en el comportamiento adaptativo en el momento actual, y que ya no alude a una imposibilidad de prevención, cura o mejora del retraso mental y de las consecuencias asociadas (Verdugo, 1995, p.520).

Grossman en 1973 revisa la definición anterior y añade algunos matices, definiendo el "retraso mental" como un funcionamiento intelectual significativamente inferior a la media que existe concurrentemente con déficits en conducta adaptativa, y que se manifiesta durante el período de desarrollo (Verdugo, 1995). A raíz de la definición de Heber, el concepto de "retraso mental límite" hacía referencia a una puntuación de CI entre 87-60, de manera que el "retraso mental" se consideraba a partir de una desviación típica por debajo de la media. Al introducir "significativamente" para hablar de la inteligencia en la definición de Grossman, el tipo límite desaparece de la clasificación 
de retraso mental, y el funcionamiento intelectual (la puntuación de CI) debía estar al menos dos desviaciones típicas por debajo de la media. Asimismo, la clasificación da un pequeño giro quedándose reducida a cuatro categorías, que son ligero, medio, severo y profundo (Verdugo, 1995).

Esta definición se mantuvo hasta 1983, fecha en que Grossman vuelve a revisar la anterior, y propone que el retraso mental se refiere a un funcionamiento intelectual general significativamente inferior a la media que resulta o va asociado con déficits concurrentes en la conducta adaptativa, y que se manifiesta durante el período de desarrollo (Verdugo, 1995). Con las definiciones anteriores se introducen mejoras en la identificación del entonces llamado "retraso mental"; se introduce el concepto de conducta adaptativa, la puntuación de CI se establece por debajo de 70, dejando de ser considerado "retraso mental" el caso de las personas que obtengan un CI de 70 a 85 (pasan a denominarse personas de inteligencia baja), se amplía la edad de diagnóstico y se elimina la condición de "retraso mental" como algo permanente (Verdugo, 1995).

Paralelamente al desarrollo de las definiciones de "retraso mental" también se producen avances en la intervención con este colectivo en la línea de una concepción más optimista, debido en parte a la eliminación del concepto de "retraso mental" como algo permanente. Papel en ello han jugado movimientos como la desinstitucionalización (Verdugo, 1995).

En 1992 se produce un cambio de paradigma en el campo del "retraso mental" con la aparición desde la AAMR de una definición más precisa de la mano de Luckasson, quien dice que el retraso mental hace referencia a limitaciones sustanciales en el funcionamiento actual. Se caracteriza por un funcionamiento intelectual significativa- 
mente inferior a la media, que generalmente coexiste junto a limitaciones en dos o más de las siguientes áreas de habilidades de adaptación: comunicación, autocuidado, vida en el hogar, habilidades sociales, utilización de la comunidad, autodirección, salud y seguridad, habilidades académicas funcionales, tiempo libre y trabajo. El retraso mental se ha de manifestar antes de los 18 años de edad (Verdugo, 1995, p.528). Esta nueva definición tiene varias implicaciones. Cobra gran importancia la interacción del individuo con los entornos en los que se desenvuelve, de manera que el objeto primordial será realizar una evaluación multidimensional de dichas interacciones para poder establecer así los tratamientos adecuados y las necesidades de servicio requeridas (Verdugo, 2003). Asimismo, se elabora una nueva clasificación basada en los apoyos, donde se especifican el apoyo intermitente, limitado, extenso y generalizado (Verdugo, 1995). Además, en esta última definición se fija y operativiza el concepto de conducta adaptativa, ya que se alude a este punto como limitaciones en dos o más áreas de las habilidades de adaptación, y se especifican diez de ellas (Verdugo, 2003).

Nuevamente en 2002 la AAMR publica la definición que se emplea actualmente, revisada y actualizada en 2007, propuesta por Luckasson:

"La discapacidad intelectual se caracteriza por limitaciones significativas en el funcionamiento intelectual y la conducta adaptativa tal como se ha manifestado en habilidades prácticas, sociales y conceptuales. Esta discapacidad comienza antes de los 18 años”. (Schalock y Luckasson, 2007, p.118).

Con esta última definición se pasa a inaugurar el siguiente apartado, donde se exponen las implicaciones que de ella se han derivado y la situación actual de la DI. 


\subsubsection{Características de la Discapacidad Intelectual y del Desarrollo}

La AAIDD define la discapacidad intelectual como limitaciones significativas en el funcionamiento intelectual y la conducta adaptativa tal como se ha manifestado en habilidades prácticas, sociales y conceptuales. Esta discapacidad comienza antes de los 18 años (Luckasson, 2002; AAIDD, 2011, p.33).

Esta definición no tendría significado sin el contexto que le aportan las premisas siguientes (AAIDD, 2011):

- Las limitaciones que la persona muestra en su funcionamiento actual deben ser tenidas en cuenta en relación al contexto de sus iguales en edad y cultura.

- La evaluación de la DI debe considerar los aspectos culturales (diversidad cultural), comunicativos (diversidad lingüística), motores, sensoriales y conductuales de la persona.

- Las PcDI tienen limitaciones, pero también capacidades, y éstas debes ser tomadas en consideración.

- La descripción de las limitaciones de la persona tiene por finalidad la elaboración de un perfil de necesidades de apoyo.

- Si se proporcionan los apoyos adecuados durante un tiempo determinado, la PcDI mejorará su funcionamiento.

Esta definición hace hincapié no sólo en las limitaciones de las personas con discapacidad, sino también en las capacidades, y sitúa las limitaciones dentro del contexto socio-cultural en el que la persona se desenvuelve, siendo necesario también con- 
siderar la diversidad lingüística y cultural. El objetivo de la identificación de las limitaciones es programar un perfil de apoyos adecuado para que el funcionamiento de la persona con discapacidad intelectual pueda mejorar (Schalock y Luckasson, 2004).

El modelo teórico que sustenta la definición anterior se basa en la perspectiva ecológica de la OMS y se centra en el funcionamiento de la persona, haciendo referencia además a su ambiente y a los apoyos (Schalock y Luckasson, 2004). Además, este modelo propone cinco dimensiones del funcionamiento humano, como son la capacidad intelectual, la conducta adaptativa, la participación, interacción y roles sociales, la salud y el contexto ambiental de la persona (Figura 1).

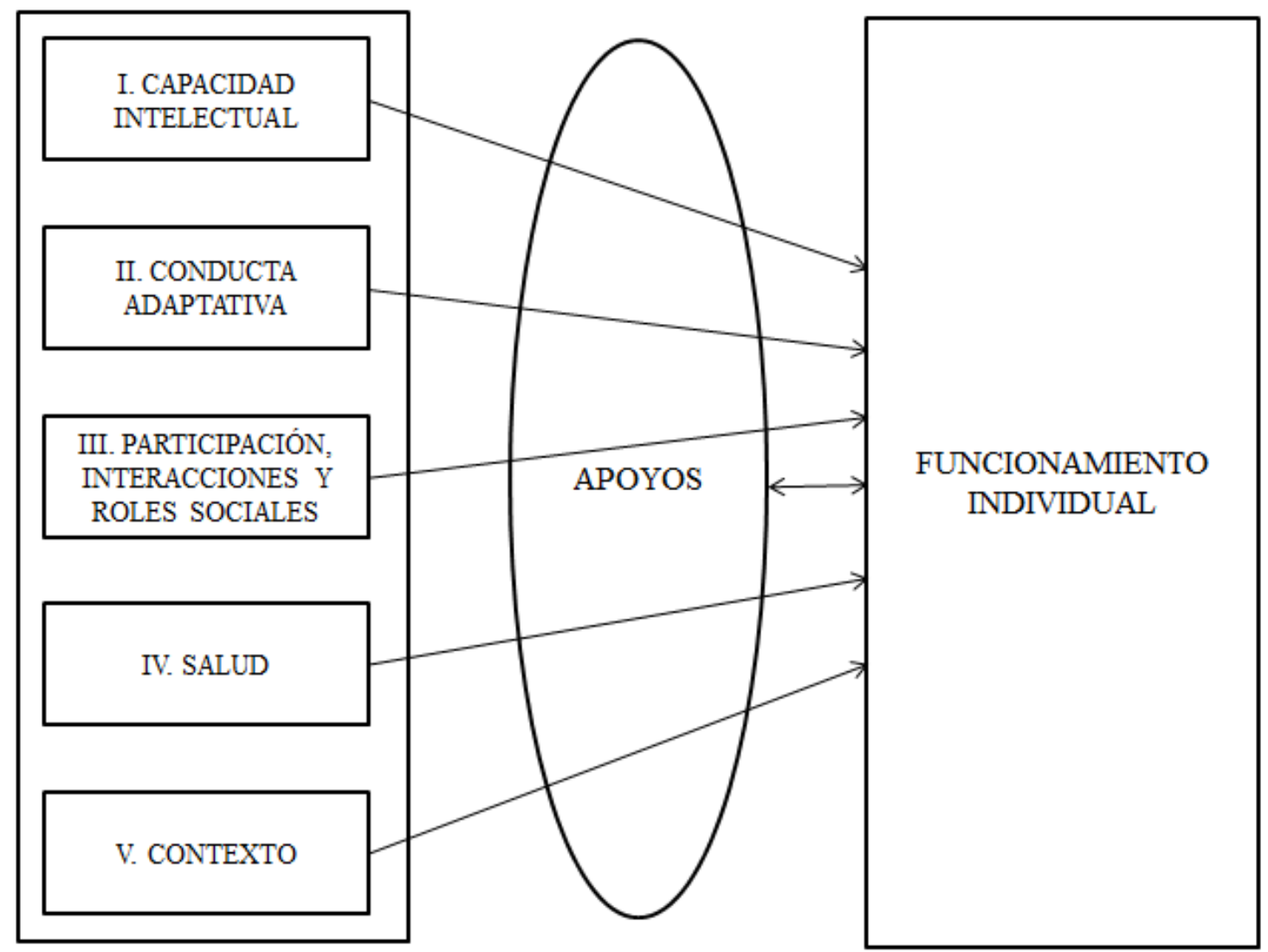

Figura 1: Modelo teórico del funcionamiento humano. Adaptado de Schalock y Luckasson, 2004, p.141. 
La inteligencia es definida por Luckasson como la habilidad mental general que incluye el razonamiento, la planificación, la solución de problemas, el pensamiento abstracto, la comprensión de ideas complejas, el aprendizaje rápido y el aprendizaje de la experiencia; y debe ser evaluada mediante pruebas estandarizadas (Schalock y Luckasson, 2004). Asimismo, el criterio para el diagnóstico de DI es de dos desviaciones típicas por debajo de la media de la población general (Schalock y Luckasson, 2004).

Por su parte la evaluación de la conducta adaptativa también debe realizarse con pruebas estandarizadas, que hayan incluido para su validación tanto personas con DI, como personas sin DI, y el criterio diagnóstico es, al igual que en la inteligencia, de dos desviaciones típicas por debajo de la media de la población general. La conducta adaptativa es definida por Luckasson como el conjunto de habilidades conceptuales, sociales y prácticas que han sido aprendidas por el individuo para su funcionamiento diario (Schalock y Luckasson, 2004).

La participación y la interacción deben observarse en las interacciones cotidianas de la persona con su entorno social, mientras que el rol social hace referencia al conjunto de actividades normativas de un rango de edad específico (Schalock y Luckasson, 2004).

Por otro lado, la dimensión que alude a la salud, debe ser considerada desde la definición de este término por parte de la OMS, donde se dice que la salud es un estado de bienestar físico, mental y social (Schalock y Luckasson, 2004).

La última dimensión se refiere al contexto en que la persona se desenvuelve e incluye el contexto social inmediato, incluyendo la persona, la familia, personas próximas y personal de apoyo directo (microsistema); los vecinos, la comunidad, los centros 
educativos y los servicios de apoyo (mesosistema); también la cultura, la sociedad, el país o las influencias socio-políticas (macrosistema). Esta dimensión hace referencia al modelo ecológico de los sistemas propuesto por Bronfenbrenner (Schalock y Luckasson, 2004).

En cuanto a la etiología de la DI, hay que distinguir entre los factores de riesgo y el momento en que se han producido. En cuanto a los factores de riesgo, por un lado estarían los biológicos o biomédicos, que harían referencia a desórdenes genéticos o de nutrición, por ejemplo la presencia en el feto del síndrome de alcoholismo junto a una anomalía cardíaca congénita. Otros factores de riesgo pueden ser sociales, que tienen que ver con la interacción con las personas adultas responsables del niño y la estimulación por parte del adulto que éste recibe, esto ocurre por ejemplo cuando las habilidades parentales no son adecuadas. Entre los factores educativos que deben proporcionar los apoyos necesarios para el desarrollo de las distintas habilidades (de inteligencia, de adaptación, etc.), estaría una inadecuada intervención temprana con el niño. Por último, otro factor de riesgo sería de tipo comportamental, en el caso de que la mujer embarazada realizase conductas perjudiciales para el feto, por ejemplo, en el caso del abuso de sustancias o de la negligencia hacia su hijo (Schalock y Luckasson, 2004). Otro aspecto a tener en cuenta es el momento en el que se produce ese factor de riesgo. Se destacan tres momentos, prenatal, perinatal y postnatal (tabla 1), dependiendo de si el problema se da antes, durante o tras el parto respectivamente (Schalock y Luckasson, 2004). La etiología de la DI debe considerarse para mejorar en la prevención de futuros casos posibles, y no como un punto a favor de la condición de estabilidad de la DI.

Si la concepción de la DI como algo estable y permanente a lo largo del tiempo se mantuviese hoy día, no podríamos hablar de algo tan imprescindible como es actual- 
mente el sistema de apoyos. Los pasos que se establecen desde el ámbito clínico para la evaluación de la DI son tres; en primer lugar, el diagnóstico mediante pruebas estandarizadas, punto que ya se ha tratado anteriormente; un segundo punto dentro del diagnóstico es la clasificación, que debe recoger diferentes aspectos, como la intensidad del apoyo requerida, el nivel de DI, los factores de riesgo etiológicos, el nivel de conducta adaptativa, en general, la clasificación se realiza en función de todas las áreas que se han evaluado previamente (las cinco áreas del modelo); y como último paso del diagnóstico, estaría la planificación de los apoyos (Schalock y Luckasson, 2004). 


\begin{tabular}{|c|c|c|c|c|}
\hline Fase & Biomédicos & Sociales & Conductuales & Educativos \\
\hline $\begin{array}{l}\text { Prena- } \\
\text { tal }\end{array}$ & $\begin{array}{l}\text { Trastornos cro- } \\
\text { mosómicos. } \\
\text { Trast. asociados a un } \\
\text { único gen. } \\
\text { Síndromes. } \\
\text { Trast. metabólicos. } \\
\text { Disgénesis cerebral. } \\
\text { Enfermedades ma- } \\
\text { ternas. } \\
\text { Edad parental. }\end{array}$ & $\begin{array}{l}\text { Pobreza } \\
\text { Malnutrición } \\
\text { materna. } \\
\text { Violencia } \\
\text { doméstica. } \\
\text { Falta de acceso a } \\
\text { cuidados paren- } \\
\text { tales. }\end{array}$ & $\begin{array}{l}\text { Consumo de } \\
\text { drogas por los } \\
\text { padres. } \\
\text { Consumo de } \\
\text { alcohol por los } \\
\text { padres. } \\
\text { Consumo de } \\
\text { tabaco por los } \\
\text { padres. } \\
\text { Inmadurez pa- } \\
\text { rental. } \\
\end{array}$ & $\begin{array}{l}\text { Discapacidad cog- } \\
\text { nitiva de padres } \\
\text { (in contar con } \\
\text { apoyos. } \\
\text { Falta preparación } \\
\text { para paternidad. }\end{array}$ \\
\hline $\begin{array}{l}\text { Perina- } \\
\text { tal }\end{array}$ & $\begin{array}{l}\text { Prematuridad. } \\
\text { Lesiones en momen- } \\
\text { to del nacimiento. } \\
\text { Trastornos neonata- } \\
\text { les. }\end{array}$ & $\begin{array}{l}\text { Falta de cuida- } \\
\text { dos parentales. }\end{array}$ & $\begin{array}{l}\text { Rechazo por } \\
\text { padres a cuidar } \\
\text { al hijo. } \\
\text { Abandono del } \\
\text { hijo por los pa- } \\
\text { dres. }\end{array}$ & $\begin{array}{l}\text { Falta de derivación } \\
\text { hacia servicios } \\
\text { de intervención } \\
\text { tras el alta médi- } \\
\text { ca. }\end{array}$ \\
\hline $\begin{array}{l}\text { Posna- } \\
\text { tal }\end{array}$ & $\begin{array}{l}\text { Traumatismo cra- } \\
\text { neoencefálico. } \\
\text { Malnutrición } \\
\text { Meningoencefalitis. } \\
\text { Trast. epilépticos. } \\
\text { Trast. degenerativos. }\end{array}$ & $\begin{array}{l}\text { Pobre interac- } \\
\text { ción niño- } \\
\text { cuidador. } \\
\text { Falta de estimu- } \\
\text { lación adecua- } \\
\text { da. } \\
\text { Pobreza familiar. } \\
\text { Enfermedad } \\
\text { crónica en la- } \\
\text { familia. } \\
\text { Institucionaliza- } \\
\text { ción. }\end{array}$ & $\begin{array}{l}\text { Maltrato y aban- } \\
\text { dono infantil. } \\
\text { Violencia } \\
\text { doméstica. } \\
\text { Medidas seguri- } \\
\text { dad inadecua- } \\
\text { das. } \\
\text { Deprivación } \\
\text { social. } \\
\text { Cond. problemá- } \\
\text { ticas del niño. }\end{array}$ & $\begin{array}{l}\text { Deficiencia en } \\
\text { crianza. } \\
\text { Diagnóstico tardío. } \\
\text { Atención temprana } \\
\text { inadecuada. } \\
\text { Servicios educati- } \\
\text { vos inadecuados. } \\
\text { Apoyo familiar } \\
\text { inadecuado. }\end{array}$ \\
\hline
\end{tabular}

Tabla 1: Factores de riesgo de la DI. Tomado de AAIDD, 2011, p.103

El modelo de los apoyos (figura 2) tiene fundamento al diferenciar lo que son los apoyos de lo que son las necesidades de apoyo. Los apoyos hacen referencia a determinados recursos y estrategias que tienen por objetivo promover el desarrollo, la educación, los intereses y el bienestar personal de la persona y que mejoran el funcionamiento individual, mientras que las necesidades de apoyo es un constructo psicológico referido al patrón y la intensidad de los apoyos necesarios para que una persona par- 
ticipe en actividades con un funcionamiento humano normativo, tal y como recogen los mismos autores (Thompson, Bradley, Buntinx, Schalock, et. al., 2009).

La AAIDD especifica cómo debe realizarse la evaluación, planificación y valoración de los apoyos para las personas con DI. El modelo de apoyos describe la relación entre el desajuste entre las competencias personales y las demandas ambientales y la provisión de apoyos individualizados que conducen a mejores resultados personales (AAIDD, 2011, p.170). Este modelo tiene cuatro implicaciones importantes que debemos tener en cuenta (AAIDD, 2011): (a) el desequilibrio (desajuste) entre las competencias o capacidades de la persona y las exigencias o demandas del entorno van a dar lugar a las necesidades de apoyo, que van a hacer referencia a su vez a una intensidad y un tipo de apoyo determinado; (b) si la planificación de los apoyos es la adecuada, se conseguirá una mejora de los resultados personales; (c) el objetivo de los servicios de atención pasa a ser las necesidades de apoyo de la persona y no sus limitaciones; (d) este enfoque dirigido a reducir el desequilibrio entre las capacidades de la persona y las demandas del entorno debe dirigirse a identificar, desarrollar y organizar los apoyos adecuados que permitan la mejora de los resultados personales. El concepto de apoyos individualizados tiene dos funciones básicas, la primera de ellas es identificar los cambios que hacen posible la mejora del funcionamiento de la persona que disminuyen la discrepancia entre la capacidad de la persona y las exigencias del entorno; la segunda es que a través de esa mejora del funcionamiento humano se consiga la mejora de los resultados personales (AAIDD, 2011). Es decir, tan importante es proporcionar los apoyos adecuados como mejorar los resultados personales de la persona. Centrarse sólo en uno de estos dos aspectos sería completamente erróneo, porque bien no estaríamos con- 
siderando las necesidades que tiene la persona, bien no estaríamos teniendo en cuenta las preferencias y el proyecto de vida de la misma.

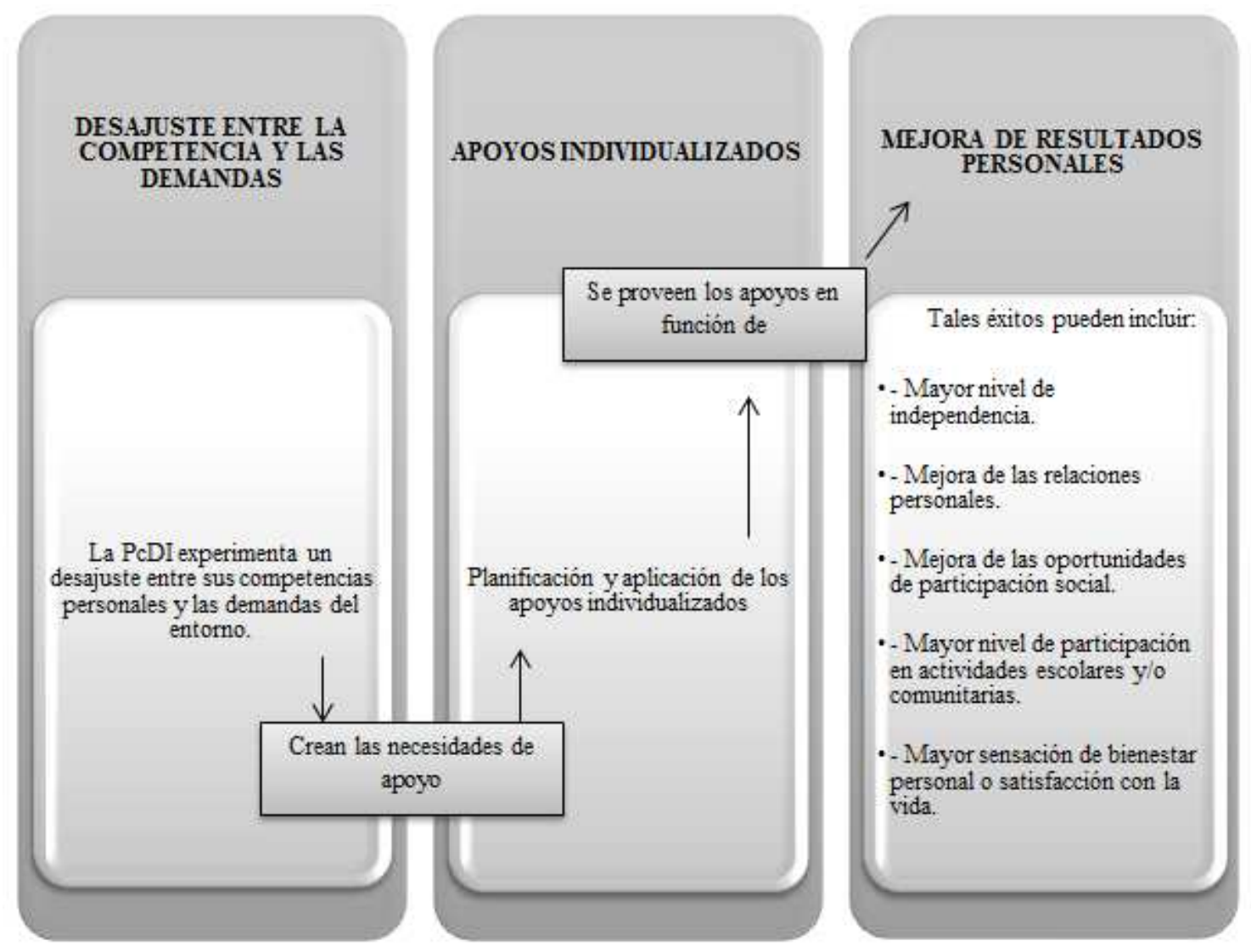

Figura 2: Modelo de apoyos. Adaptado de Thompson et. al., 2009, p.137.

En la figura 2, se reflejan los pasos que incluye el modelo del funcionamiento humano. En primer lugar, se deben identificar las metas y expectativas de la persona para luego continuar con la evaluación de las necesidades de apoyo que se van a requerir. Es importante que los apoyos se establezcan en función de aquello que la propia persona quiere y espera. En tercer lugar, se desarrolla y se implementa el plan individualizado de apoyos, priorizando las preferencias que la persona ha expresado en los pasos anteriores, poniendo énfasis en sus objetivos personales y en las necesidades de apoyo. Se redacta el plan individualizado especificando el patrón y los tipos de necesidades de apoyo que la persona requiere para realizar actividades específicas, y se im- 
plementa dicho plan. Un cuarto paso versaría sobre el proceso de monitorización del plan que se ha implementado, y por último, en una quinta fase se realizaría la valoración en función de la mejora de los resultados personales (Thompson et al., 2009).

Como se puede observar en las líneas precedentes, la discapacidad intelectual ha sido objeto de múltiples investigaciones que han ayudado a su definición, caracterización y evaluación, si bien aún existen "vacíos" por ejemplo a la hora de evaluar algunas de las áreas que propone la AAIDD, como es el caso de la dimensión referida a la participación y roles sociales, ya que en años anteriores la investigación ha girado en torno a la evaluación de la inteligencia y de la conducta adaptativa, que a fecha de hoy, están ampliamente documentadas y existen numerosas pruebas válidas para evaluarlas. Asimismo, los criterios para el diagnóstico de DI están muy claramente definidos en el caso de la inteligencia y de la conducta adaptativa, pero no ocurre lo mismo con las tres áreas posteriormente propuestas por la AAIDD.

En cuanto al sistema de evaluación e implementación de los apoyos también existen investigaciones que han dado lugar al reciente modelo de los apoyos expuesto anteriormente. Además se han estipulado los pasos para evaluar, planificar y valorar la implementación de esos apoyos que van dirigidos a posibilitar que la persona con DI pueda vivir con la mayor independencia y autonomía posible.

\subsubsection{Implicaciones de la nueva definición de discapacidad intelectual y del desa- rrollo}

La nueva definición de DI planteada por la AAIDD recientemente, va a tener una serie importante de implicaciones tanto en las políticas públicas, como en el ámbito educativo y en las organizaciones proveedoras de apoyos (AAIDD, 2011). Aunque los 
tres ámbitos son de sobrada importancia, para la línea que sigue este trabajo sólo voy a tratar dos de ellos, las repercusiones sobre las políticas públicas y sobre las organizaciones que proveen los apoyos.

En cuanto a las políticas públicas es sabido que influyen en los sistemas de clasificación de la DI, y por tanto, también de su evaluación, ya que son las políticas públicas quienes determinan los criterios diagnósticos en este sentido. Por otro lado, los sistemas de clasificación también repercuten en las políticas públicas, ya que influyen en la percepción de necesidades que tienen las propias PcDI, y esto es importante a la hora de planificar y programar servicios de apoyo. Ambos, tanto las políticas públicas como los sistemas clasificatorios están bajo la influencia de la visión social de la discapacidad. De la interacción entre las políticas públicas y los sistemas clasificatorios ha surgido, por ejemplo, el interés en la prestación de apoyos individualizados (AAIDD, 2011). Todo ello influye en los resultados personales, ya que todos los servicios y los sistemas diagnósticos y clasificatorios van dirigidos a mejorar los resultados personales de las PcDI. El esquema para entender las influencias comentadas anteriormente, constaría de unos inputs, que podrían ser sociales (movimientos sociales y políticos, cambios actitudinales en la sociedad, las decisiones judiciales que proclaman la igualdad de derechos de las PcDI, etc.), conceptos básicos sobre la política en discapacidad (tanto referentes a la persona, ya sean el empoderamiento, la autodeterminación, etc., como las referentes al sistema en la prestación de servicios y apoyos) o las concepciones de discapacidad cambiantes (modelo multidimensional de comprensión del funcionamiento humano). Estos tres tipos de factores influirían directamente en las políticas públicas, que establecen las reglas, normativas, los estatutos y los requisitos de financiación. Las políticas públicas a la vez que influirían en las prácticas clasificatorias que se llevan a cabo, también se verían influenciadas por ellas, como ya se ha explicado anteriormente. Y serían 
por último las prácticas quienes tendrían repercusión sobre los resultados tanto personales, familiares, sociales como de cambio en los distintos sistemas (AAIDD, 2011).

A partir de la nueva concepción de la DI, se ha observado la aparición de distintas tendencias en este ámbito, como por ejemplo el abandono de métodos tradicionales de evaluación a un diagnóstico más sistemático y posteriormente reflejado en pautas concretas de actuación; un incremento en la flexibilidad de los sistemas de apoyo; orientación de las gestiones en la dirección de la gestión por resultados y dirigir la investigación desde una perspectiva multidisciplinar que involucre a todas las personas que rodean a la PcDI (AAIDD, 2011).

Asimismo, la AAIDD (2011) recoge las pautas de actuación mediante las que la nueva concepción propuesta puede repercutir en el desarrollo de las políticas públicas: (a) establecer buenas prácticas en el campo de la DI, en el sentido de cumplir los tres criterios propuestos para el diagnóstico, de emplear varios sistemas de clasificación, de considerar las necesidades de apoyo de las PcDI y proporcionarles los apoyos necesarios y del empleo del juicio clínico; (b) empleo universal para los tres pasos propuestos en la evaluación: (c) reconsiderar la actual descoordinación existente entre los diferentes sistemas; (d) dirigirse a la mejora de los resultados personales; (e) recoger información sistemática de los resultados personales para valorar la eficacia de los servicios.

Por otro lado, las organizaciones que proveen los apoyos a las PcDI son muy variadas y de distinta índole, por ejemplo, comprenderían todos los tipos de residencia o alojamiento existente, los centros especiales de empleo, centros ocupacionales, colegios de educación especial, centros de día, incluso centros sanitarios. En este campo, cobra absoluta importancia la concepción de la atención personalizada que conlleva el sistema de apoyos individualizados con el objetivo último de la mejora de los resultados perso- 
nales. Con estas pinceladas, las organizaciones dirigidas a proveer los servicios de apoyo debe orientar sus acciones hacia la mejora de la calidad de los mismos, en el sentido del empleo de buenas prácticas, por ejemplo en los procesos de evaluación de la CV de las PcDI, coordinación de todos sus recursos y estrategias de actuación, la recogida de información sistemática y multidimensional, considerando todos los contextos en los que la persona se desenvuelve y las preferencias que ésta tenga sobre los asuntos que le conciernen, teniendo como referencia un grupo de apoyo significativo para la persona implicada (AAIDD, 2011).

\subsubsection{Líneas de investigación en discapacidad intelectual y del desarrollo}

En la conferencia europea IASSID celebrada en Roma en 2010, se estipularon 20 temas recurrentes en las investigaciones sobre las personas con discapacidad intelectual. Estos temas iban desde la calidad de vida en el envejecimiento de estas personas, pasando por los temas bio-conductuales, la educación, la capacitación o empowerment, tanto de las familias como de las personas con discapacidad intelectual, la ética, etc. La discapacidad intelectual se aborda ya desde múltiples áreas profesionales, y la mejor forma de enfocarla es hacerlo aunando todas y cada una de estas perspectivas (Holland, 2011).

Algunos de los aspectos más discutidos en la investigación son el peso que tiene la investigación biológica contra una investigación más de carácter social; el rol participativo de las personas con discapacidad intelectual en las investigaciones frente a las investigaciones tradicionales, entre otros. Todos los temas de discusión han producido un gran avance en la investigación acerca de este colectivo de personas, de forma que el estudio de la discapacidad intelectual se ha acordado que debe llevarse a cabo integran- 
do el conocimiento que nos aportan todas las disciplinas, como bien he dicho anteriormente (Holland, 2011).

Los principales desafíos a los que se enfrenta la investigación en este campo serían garantizar el desarrollo y mantenimiento de las aportaciones necesarias académicas y de los servicios, así como asegurarse de que los nuevos conocimientos hallados en las investigaciones se difunden y utilizan por los profesionales dedicados a este campo, mejorando los servicios de apoyo existentes en cada país dirigidos a mejorar la calidad de vida de estas personas. Como líneas futuras, debemos tener claro cuáles son los problemas susceptibles de ser tratados a través de las metodologías y tecnologías existentes en la investigación y los que no pueden ser tratados por el momento temporal en que nos encontramos (Holland, 2011).

Como investigadores, se trata de integrar los conocimientos que provienen los diferentes tipos de estudios, tanto conceptuales, sociológicos, biológicos y psicológicos, así como las teorías del desarrollo. Los estudios acerca de las políticas deben esforzarse por interpretar los resultados de las investigaciones para extraer conclusiones dirigidas a los proveedores de los servicios de apoyo a las personas con discapacidad intelectual; los documentos conceptuales deben incluir reflexiones filosóficas, centradas en el modelo bio-psico-social. Los estudios clínicos deben dirigirse a la investigación aplicada, es decir, a la identificación de nuevas intervenciones y al desarrollo de buenas prácticas profesionales. Estos estudios, además de ser interdisciplinares, deben incluir opiniones y experiencias de expertos. El mensaje de futuro tendría que girar en torno a la construcción de conocimientos interdisciplinares, los investigadores debemos dirigirnos a explorar nuevas ideas explorando las tecnologías de investigación que se han desarrollado en otros lugares y campos, para aplicarlas al nuestro y debemos esforzarnos por conseguir llevar a la aplicación práctica y política los resultados de investigación (Holland, 2011). 


\subsubsection{Resumen}

Mediante los apartados anteriores hemos visto que la discapacidad intelectual se ha ido delimitando y definiendo con el paso de los años, si bien, esto no debe ser más que un pretexto para continuar la investigación en este campo con el objetivo último de que cada día este colectivo pueda tener la mayor autonomía e independencia posible. Por otro lado, no podemos olvidar que el colectivo de personas con DID es tan heterogéneo como el colectivo de la población general, de manera que aunque se hayan estipulado los pasos tanto de evaluación, como de implementación del sistema de apoyos, etc., cada persona va a tener sus propias características, sus propios objetivos, sus propias necesidades, y por lo tanto requerirá unas medidas (o apoyos) que no tiene por qué requerir otra persona con DID. El objetivo último de la etiqueta "discapacidad intelectual", del diagnóstico clínico de la misma y de la clasificación, debe ser siempre mejorar los aspectos necesarios y proporcionar los apoyos necesarios para que la persona pueda vivir completamente integrada en nuestra sociedad, y como ya he dicho anteriormente, de forma autónoma e independiente.

\subsection{ENVEJECIMIENTO}

\subsubsection{Introducción}

En este apartado se exponen diferentes epígrafes para tratar temas como la esperanza de vida de la población general y con DID, la diferencia existente entre el envejecimiento con discapacidad y la discapacidad con envejecimiento, así como unas pinceladas sobre el envejecimiento activo y las líneas de investigación recientes en este campo. 


\subsubsection{Envejecimiento y esperanza de vida}

Con el aumento de la esperanza de vida, se incrementa la prevalencia de población mayor y aumenta también la de la población dependiente. España será uno de los países más envejecidos del mundo dentro de unas décadas, y se hace patente la necesidad de un cambio en las políticas dirigidas a este colectivo, como por ejemplo, en el sistema de pensiones y en los sistemas de atención sanitaria y de cuidados, tanto formales como informales.

El envejecimiento se define como el proceso natural e irreversible de cambios biológicos, psicológicos y sociales que experimenta toda persona desde su vida intrauterina, a lo largo de toda su existencia, para culminar con la muerte (Instituto de Normalización Previsional, 2004). Se pueden distinguir dos tipos de envejecimiento, uno primario y otro secundario. El envejecimiento primario hace referencia al proceso de envejecimiento sin la presencia de enfermedad, es decir, al envejecimiento a causa de la edad que ocurre en los individuos de una especie, mientras que el envejecimiento secundario se produce en el individuo cuando diversos factores interaccionan con los mecanismos y cambios propios del envejecimiento dando lugar a los problemas asociados a este proceso, por ejemplo los problemas de salud (Alonso, Sansó, Díaz-Canel, Carrasco y Oliva, 2007).

Para encontrar una edad en la que se pueda hablar de población que está envejeciendo se suele emplear el límite de la edad de jubilación, alrededor de los 65 años. En España la proporción de personas mayores de 64 años se estima alrededor de un 17\%, mientras que la media de edad de la población española se sitúa aproximadamente en 40,3 años (INE, 2011). Se estima que en el año 2050 más de un 40\% de la población 
española será mayor de 60 años (Otero, Zunzunegui, Rodríguez-Laso, Aguilar y Lázaro, 2004). Un factor causal de ello es el aumento de la esperanza de vida que se ha producido a raíz de diversos avances médicos, tecnológicos, sociales y económicos (Otero et. al., 2004). La esperanza de vida desde el nacimiento en la población española actualmente se estima en 78 años para los hombres y en 84 para las mujeres (INE, 2009). En el gráfico 1, podemos observar la proyección del Instituto Nacional de Estadística de la esperanza de vida de los españoles hasta el año 2064, especificado a través del género.

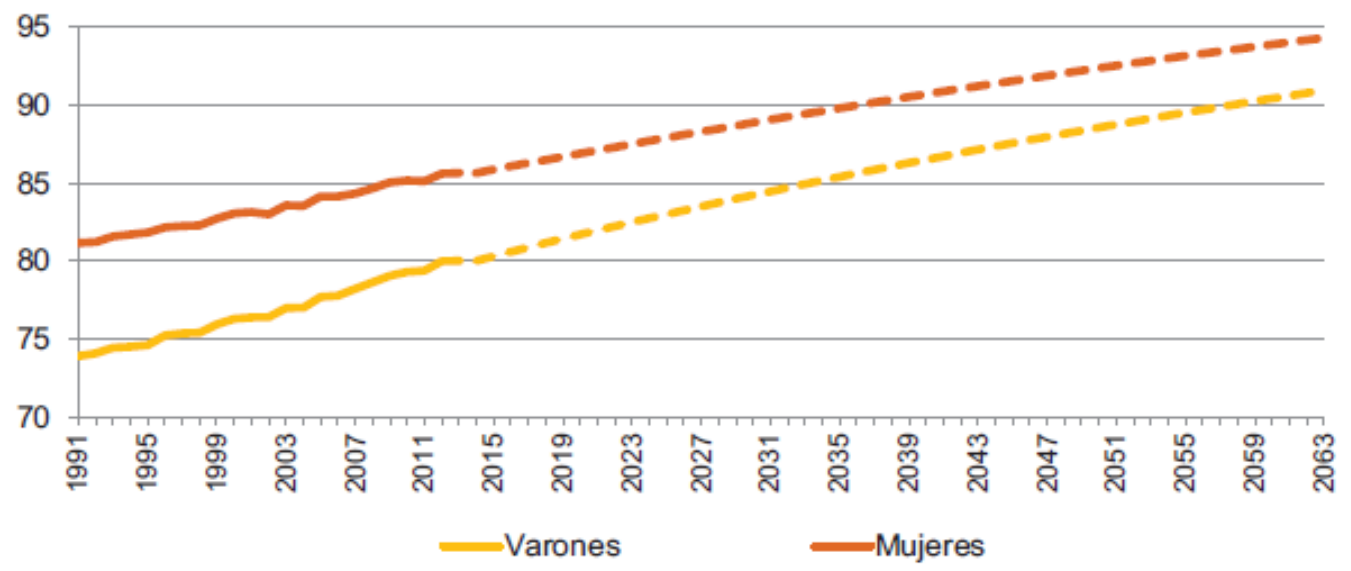

Gráfico 1: Esperanza de vida y proyección al nacer por género en España. Fuente: INE: Proyección de la población de España 2014-2064. Notas de Prensa, 28 de Octubre de 2014.

El aumento de la esperanza de vida produce un aumento del porcentaje de población mayor y un aumento en la proporción de personas dependientes, no sólo en los casos en los que aparecen enfermedades graves, sino también a causa de los propios procesos asociados al envejecimiento, de manera que se incrementa la demanda de recursos sociales para asegurar el bienestar físico, social y psicológico de este colectivo.

La OMS, en su 69ª Asamblea llevada a cabo en mayo de 2016, reconoce que se está produciendo un envejecimiento acelerado de la población a nivel mundial. Por ello, 
insta a los Estados Miembros para que lleven a cabo medidas que aseguren a la población mayor un adecuado nivel de salud y bienestar, así como a prevenir posibles discapacidades, la dotación de oportunidades que procuren una mayor longevidad al colectivo de personas mayores, a intervenir en las situaciones de menores niveles socioeconómicos que derivan en un menor nivel de salud, y destaca, principalmente, la importancia del entorno saludable, accesible y propicio para poder envejecer en un lugar apropiado y donde las personas mayores puedan realizar actividades que valoren y hagan que sean valoradas. Asimismo, la OMS reconoce la aportación que las personas mayores hacen a la sociedad, y por ello, destaca que este colectivo debe tener las mismas oportunidades y derechos que el resto de la población.

\subsubsection{Envejecimiento y discapacidad vs discapacidad y envejecimiento}

No es lo mismo hablar del envejecimiento y discapacidad que de discapacidad y envejecimiento. El envejecimiento y discapacidad hace referencia a aquellas personas en las que la discapacidad ha aparecido en la infancia o incluso anteriormente, mientras que hablar de discapacidad y envejecimiento alude a aquellas personas que han tenido un desarrollo normativo y una vida libre de discapacidad, pero que en un momento puntual y por el motivo que sea, han adquirido una discapacidad (Verbrugge y Yang, 2002). No es lo mismo por tanto haber nacido con una discapacidad y haber aprendido a vivir con ella, que haber tenido una vida sin ninguna limitación significativa y llegado un momento tener que aprender a vivir con ella. Las implicaciones son completamente distintas. Es decir, las PcD que envejecen ya cuentan con limitaciones previas de la propia discapacidad, a las que se van a unir las consecuencias del envejecimiento en sí, es lo que se ha denominado la doble experiencia (Verdugo, Rodríguez y Sánchez, 2009). 
Según datos de la encuesta EDDES, la proporción del tiempo vivido sin discapacidad en España era en 1999 del 91\% para los hombres y del 87.7\% para las mujeres (Gispert, Ruíz-Ramos, Barés, Viciana y Clot-Razquin, 2007). La edad media de personas con discapacidad en el año 2008 se sitúa alrededor de los 64 años, si bien se puede observar un descenso en las tasas de discapacidad en la población de 65 a 90 años, mientras que a partir de los 90 años esta tasa se ha incrementado si comparamos los años 1999 y 2008 (gráfico 2).

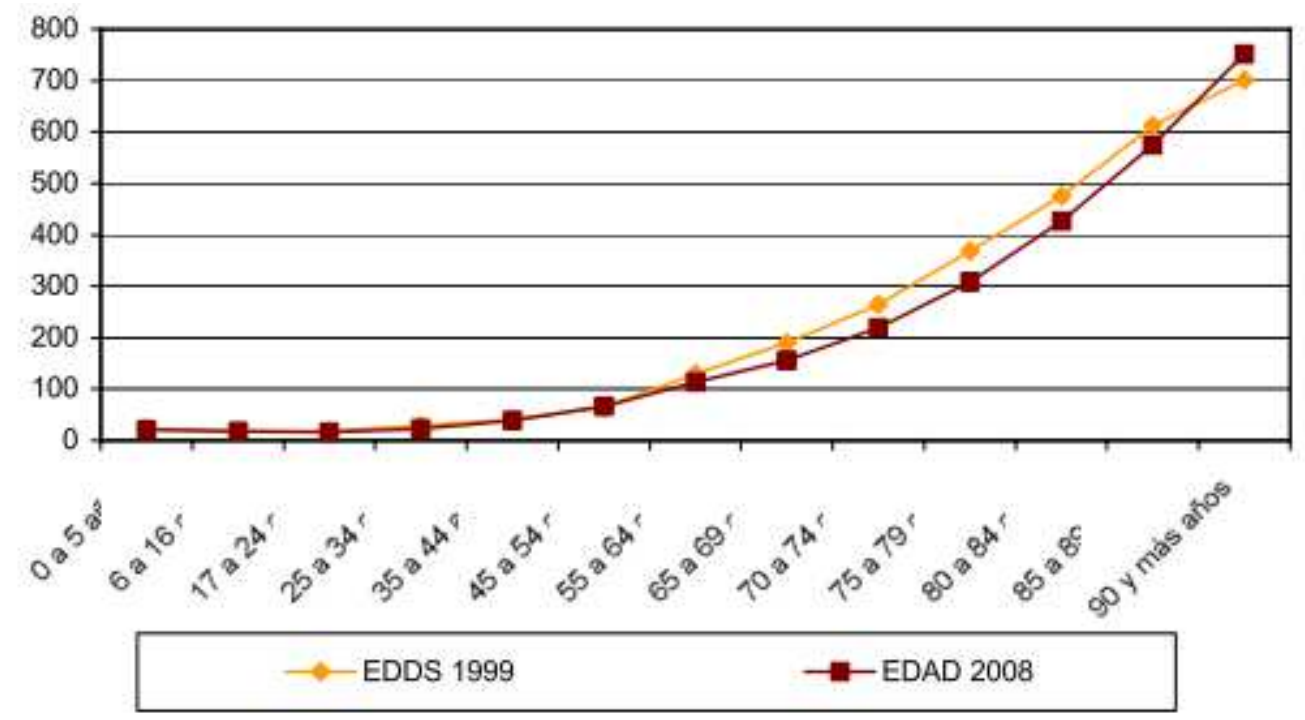

Gráfico 2: Comparación de las tasas de discapacidad por edad de la población española (por mil habitantes), de las encuestas EDDES (1999) y EDAD (2008). Tomado de EDAD, 2008, p.2.

A medida que avanzamos en edad se sabe que nos exponemos a un mayor riesgo de tener algún tipo de discapacidad, debido en parte al incremento de la prevalencia de trastornos crónicos, por lo que se introduce el concepto de la dependencia (EDAD, 2008). La dependencia es definida en el Libro Blanco de la Dependencia como el no poder realizar, sin ayuda, alguna de las actividades básicas de la vida diaria relacionadas con el cuidado personal, la movilidad dentro del hogar o las funciones mentales básicas (Gispert, Clot-Razquin, Rivero, Freitas, Ruíz-Ramos, Busquets y Argimón, 
2008, p.654). Asimismo, se sabe que el colectivo principal que presenta mayores tasas de dependencia son las mujeres mayores de 85 años, y que sus principales dificultades giran en torno a las ABVD; algunos factores que explicarían esta tendencia son el estilo de vida de este colectivo, que suele restringirse al ámbito del cuidado doméstico, por lo que favorece un estilo de vida sedentario, mayores niveles de aislamiento y depresión que en el grupo de los varones (Otero et. al., 2004). Además, que la tasa de prevalencia de dependencia sea mayor en las personas mayores puede explicarse porque tienen mayores niveles de morbilidad, que suelen acompañarse de un deterioro cognitivo asociado a la edad, por lo que la rehabilitación es más compleja (Otero et. al., 2004). Asimismo, algunos estudios que investigan los grados de gravedad de las discapacidades relacionan las limitaciones funcionales en las ABVD y en las AIVD con los niveles más graves de discapacidad, mientras que señalan que las limitaciones sensoriales y de movilidad se asociarían con niveles más bajos de la misma (Gispert et. al., 2008). Al asociarse distintos niveles de gravedad con los distintos tipos de discapacidad, se conforman los distintos grados de dependencia (Gispert et. al., 2008).

En conclusión, la población española dependiente está constituida principalmente por mujeres mayores, que requieren cuidados para la realización de las $A B V D$, y que tienen limitaciones en la movilidad, por lo que tiene implicaciones importantes para $\mathrm{el}$ futuro de las pensiones, las reformas laborales y los sistemas de servicios de salud y cuidados de larga duración (Otero et. al., 2004).

Por otro lado, en lo que respecta a las personas con discapacidad que envejecen, los investigadores acostumbran a fijar una edad a partir de la cual aparecen una serie de cambios tanto físicos, como psicológicos y sociales, que caracterizan esta etapa del ciclo vital, apareciendo un llamado envejecimiento prematuro. Así, la edad establecida para la 
población normal se sitúa entre los 60 y 65 años (Madrigal, Pereyra, Calvo y Uría, 2007), mientras que en las personas con discapacidad intelectual esta edad se fija entre los 40 o 50 años, según la misma fuente; sin embargo esto no es así para aquellas personas con discapacidad intelectual moderada o leve, ya que la edad se sitúa alrededor de los 60-70 años; mientras que en el Síndrome de Down la edad se suele fijar en 35 años. Por lo tanto, la edad estimada de aparición del proceso de envejecimiento varía para cada colectivo, si bien esto no ocurre en todos los tipos de discapacidad. Los avances médicos, tecnológicos y económicos que han producido un incremento de la esperanza de vida en la población general, también han producido que las personas con discapacidad cada vez lleguen a vivir más años. El proceso de envejecimiento ha sido muy estudiado en la población con discapacidad intelectual, debido a que son en gran medida personas dependientes, bien de sus padres, bien de otros cuidadores, y también son más propensos a padecer una demencia a edades avanzadas. En las personas con discapacidad, debemos tener en cuenta que envejecer puede suponer una doble discapacidad, en el sentido de que los problemas relacionados con la vejez se unen a las dificultades de la propia discapacidad que la persona ya tenía (Madrigal et. al., 2007). Todo esto se traduce en un aumento de la situación de dependencia y con ello, una limitación mayor en su autonomía. Es por esto por lo que se hace patente la necesidad en el ámbito de las personas con discapacidad que envejecen, la adecuación de los recursos necesarios, tanto sociales como sanitarios, para lograr una reducción del grado de dependencia y una reducción del deterioro tanto cognitivo como de otro tipo que pueda darse en estas personas, teniendo siempre en cuenta la aportación de los apoyos que se estimen oportunos. 


\subsubsection{Envejecimiento activo}

Hoy en día la investigación sobre el envejecimiento de población con y sin discapacidad se centra en el concepto del "envejecimiento con éxito", o también "saludable”, “activo”, "productivo”, “óptimo” o "positivo”, que se considera un término multidimensional que abarca, transciende y supera la buena salud y que está compuesto por un amplio conjunto de factores bio-psico-sociales, y que incluye tanto aspectos objetivos (baja prevalencia de enfermedad y discapacidad asociada, buen estado físico y psicológico, alta participación social), como aspectos subjetivos, como la propia satisfacción con la vida de la persona mayor (Fernández-Ballesteros, Zamarrón, López, Molina, Díez, Montero, Schettini, 2010, p.641). La OMS (2016) indica que el envejecimiento saludable es el proceso de fomentar y mantener la capacidad funcional que permite el bienestar en la vejez. Y sobre la capacidad funcional dice que está determinada por la capacidad intrínseca de la persona, los entornos en que habita y sus interacciones. Asimismo, comenta que el envejecimiento es un proceso de toda la vida de la persona, y que por lo tanto, envejecer de forma saludable no sólo es oportuno en las personas que en estos momentos padecen algún tipo de enfermedad, sino en todo el resto de individuos.

Fernández-Ballesteros et. al. (2010) señalan los siguientes predictores de un envejecimiento con éxito en la población de personas mayores:

- Variables sociodemográficas (sexo, nivel educativo, nivel de ingresos, edad): los hombres con más frecuencia se incluyen dentro del grupo de personas mayores que envejecen con éxito, así como aquellas personas con un nivel educativo alto, un mayor nivel de ingresos o que son más jóvenes. 
- Estilos de vida (zona geográfica y entorno cultural): una dieta saludable (la dieta mediterránea) y el bajo consumo de bebidas alcohólicas de alta graduación, así como la práctica regular de ejercicio físico también predicen que la persona está envejeciendo con éxito.

- Estado físico (salud física): se ha comprobado que los predictores más fuertes de un envejecimiento saludable son la fuerza y la capacidad pulmonar, así como la rapidez y el índice de masa corporal; si bien estos predictores parecen estar más asociados con los varones, que tienen más fuerza y capacidad pulmonar en general que las mujeres.

- Estado psicológico (inteligencia, personalidad, nivel afectivo): los autores encuentran la inteligencia como un predictor consistente a la hora de envejecer con éxito, sobre todo la tarea denominada dígito-símbolo, que es una tarea de aprendizaje y coordinación psicomotriz. En cuanto a la personalidad, se ha observado que puntuaciones normativas en neuroticismo y una buena valoración del estado físico son predictores del envejecimiento óptimo. Además, un balance emocional positivo, la extraversión y la autoeficacia para envejecer son también indicadores importantes.

Sin embargo, los autores también señalan que los factores que apenas parecen tener relevancia en el envejecimiento satisfactorio son los que aluden a la relación familiar y social, así como a la participación social. Esto en mi opinión podría ser debido a la pérdida de las personas significativas que se suele producir en la vejez. 


\subsubsection{Envejecimiento en personas con discapacidades intelectuales y del desarrollo}

El envejecimiento en las PcDID tiene similitudes y diferencias con respecto al envejecimiento de la población general. En este caso, a las limitaciones previas ligadas a la propia discapacidad se unen ahora las ligadas al envejecimiento.

Es lógico que si la discapacidad intelectual se evalúa en diferentes áreas, a saber, capacidad intelectual, conducta adaptativa, participaión, interacción y roles sociales, salud y contexto, se evalúen las consecuencias del envejecimiento en cada una de ellas.

En el área de la capacidad intelectual, se dice que entre el 10 y el $15 \%$ de las PcDID que envejecen conservan su destreza intelectual, pero sí es cierto que específicamente hay tareas que se realicen peor en función del individuo; se sabe, por ejemplo, que disminuye los tiempos de reacción o la atención selectiva, mientras que se suelen conservar la atención mantenida o el uso de conocimientos adquiridos (FEAPS, 2007).

En lo referente a conducta adaptativa, se puede decir que disminuye las capacidades motrices (el equilibrio, la coordinación, fuerza, resistencia y tono), así como el interés por actividades lúdicas. Hay una mayor necesidad de períodos de descanso y en algunos casos, incrementa la dependencia de otra persona para realizar las actividades de vida diaria. Otras cuestiones que pueden producirse son un aumento en las dificultades para orientarse y desplazarse, dificultades en el lenguaje, menor capacidad de decisión y toma de elección, menor capacidad de frustración, interpretaciones erróneas de la realidad, menor uso de recursos comunitarios y menor interés por los mismos, disminución de la autoconfianza por la percepción subjetiva de una mayor dependencia, labilidad emocional y menor adaptación al cambio (FEAPS, 2007). 
En el ámbito de la participación, el rol activo de la persona en la sociedad puede disminuir por aparecer conductas de tipo desafiante, agresiva, impulsiva o irritable; puede incrementarse el tipo de apoyo y la intensidad del mismo o necesitar ayudas técnicas para poder participar, asimismo, puede tener mayores problemas para reconocer y discriminar personas y espacios, suele cambiar el tipo de intereses. En otros casos puede darse cierto retraimiento social o una dificultad para adaptarse a los cambios en el entorno (FEAPS, 2007).

En cuanto a la salud, los principales cambios se reflejan en la tabla 2. 


\begin{tabular}{|c|c|}
\hline Área & Cambios principales \\
\hline $\begin{array}{l}\text { Sistema Ner- } \\
\text { vioso }\end{array}$ & $\begin{array}{l}\text {-Pérdida de neuronas, conexiones interneuronales y velocidad de la } \\
\text { conducción nerviosa. Disminuye el riego sanguíneo. } \\
\text {-Déficit cognitivo: disminuye la atención, la memoria y la capacidad } \\
\text { de aprendizaje de cosas nuevas; desorientación espacio-temporal. } \\
\text { Todo ello puede llevar a la demencia. } \\
\text {-Alteraciones en la marcha: tono muscular más rígido, problemas de } \\
\text { equilibrio... } \\
\text {-Pérdida de mecanismos de control de la sed y temperatura. } \\
\text {-Alteración en la regulación de la deglución, y la función cardiorres- } \\
\text { piratoria. }\end{array}$ \\
\hline $\begin{array}{l}\text { Sistema Sen- } \\
\text { sorial }\end{array}$ & $\begin{array}{l}\text {-Se modifican los órganos de los sentidos y puede llevar a una depri- } \\
\text { vación sensorial, con el riesgo de sufrir caídas, aislamiento social y } \\
\text { confusión en la orientación. } \\
\text {-Vista: pueden aparecer cataratas y presbicia. } \\
\text { - Oído: disminuye la capacidad auditiva y el sentido del equilibrio. } \\
\text {-Gusto y olfato: se van perdiendo. Hay menor segregación de saliva, } \\
\text { lo que lleva a menor satisfacción con la comida. Mayores dificultades } \\
\text { en la deglución, por la tos, el atragantamiento, sobre todo con líqui- } \\
\text { dos. } \\
\text {-Tacto: disminuye la sensibilidad térmica, pueden sentir más el frío y } \\
\text { llevar más ropa de lo normal aunque haga calor, lo que incrementa el } \\
\text { riesgo de deshidratación. }\end{array}$ \\
\hline $\begin{array}{l}\text { Sistema Os- } \\
\text { teoarticular }\end{array}$ & $\begin{array}{l}\text {-Pérdida en la calidad del tejido óseo, disminuye el líquido sinovial y } \\
\text { fibrosis de las articulaciones, lo que conlleva una disminución de la } \\
\text { función articular. } \\
\text {-Pueden aparecer enfermedades como la artrosis, la osteoporosis, el } \\
\text { síndrome del hombro doloroso, las cervicalgias y lumbalgias. } \\
\text {-La masrcha es más lenta y menos segura, hay nuevos patrones post- } \\
\text { urales flexores y cabeza y tronco se inclinan hacia delante. } \\
\text {-Mayor riesgo de caídas. } \\
\text {-Cansancio, dificultades para coordinar los movimientos y lentitud. }\end{array}$ \\
\hline Piel y anexos & $\begin{array}{l}\text {-Piel: se atrofia y deshidrata, lo que lleva a que haya lesiones por pre- } \\
\text { sión, escaras y manchas por exposición al sol. } \\
\text {-Aparecen arrugas y manchas en cara, manos y antebrazos. } \\
\text {-El pelo se hace más fino. } \\
\text {-Las uñas pueden sufrir hiperqueratosis, en concreto las de los pies. }\end{array}$ \\
\hline
\end{tabular}

Tabla 2.1.: Sistemas en los que influye el envejecimiento y principales síntomas. Adaptado de FEAPS MADRID (2007): Las personas con necesidades de apoyo generalizado: Guía de identificación de indicios de envejecimiento y orientaciones para la determinación de apoyos. Cuadernos de Atención de Día, No3, pp. 26-31. 


\begin{tabular}{|c|c|}
\hline Área & Cambios principales \\
\hline $\begin{array}{l}\text { Sistema Car- } \\
\text { diovascular }\end{array}$ & $\begin{array}{l}\text {-Se reducen las células miocárdicas, aparece la fibrosis, disminuye la } \\
\text { freceuencia cardíaca, la capacidad de bombeo de sangre a los órganos } \\
\text { y hay dificultades en la respuesta al estrés. } \\
\text {-Pueden aparecer insuficiencia cardiaca y arritmias. } \\
\text {-Puede haber un engrosamiento y pérdida de la elasticidad de las pa- } \\
\text { redes de las arterias, porque se depositan en ellas grasa y calcio, lo } \\
\text { que produce un aumento de la presión arterial sistólica. } \\
\text {-Dilataciones en el sistema venoso, por lo que pueden aparecer ede- } \\
\text { mas y varices en las piernas. }\end{array}$ \\
\hline $\begin{array}{l}\text { Aparato Res- } \\
\text { piratorio }\end{array}$ & $\begin{array}{l}\text {-Menor distensión de la pared torácica y del tejido pulmonar por la } \\
\text { fibrosis. } \\
\text {-Disminución del volumen respiratorio. } \\
\text {-Disminución de efectividad del mecanismo de la tos. } \\
\text {-Puede conllevar a mayores infecciones y/o a insuficiencia respirato- } \\
\text { ria. }\end{array}$ \\
\hline $\begin{array}{l}\text { Aparato Di- } \\
\text { gestivo }\end{array}$ & $\begin{array}{l}\text {-Pérdida de piezas dentarias. } \\
\text {-Disminución de producción de saliva. } \\
\text {-Enlentecimiento del tránsito digestivo. } \\
\text {-Puede aparecer disfagia motora y estreñimiento; gastritis y hemorra- } \\
\text { gias. } \\
\text {-Menor tolerancia a algunos fármacos y menor absorción de los nu- } \\
\text { trientes de los alimentos. }\end{array}$ \\
\hline $\begin{array}{l}\text { Aparato Uri- } \\
\text { nario }\end{array}$ & $\begin{array}{l}\text {-Disminución de la filtración del riñón, lo que altera la eliminación de } \\
\text { sustancias tóxicas y el mantenimiento del equilibrio de sustancias } \\
\text { importantes en el medio interno. } \\
\text {-Disminución de la capacidad de la vejiga, del tono de su musculatura } \\
\text { y esfínteres. } \\
\text {-En varones aumenta el tamaño de la próstata y en mujeres se debili- } \\
\text { tan los músculos del periné. Puede haber más infecciones. }\end{array}$ \\
\hline $\begin{array}{l}\text { Aparato Geni- } \\
\text { tal }\end{array}$ & $\begin{array}{l}\text {-Con la menopausia en las mujeres se puede producir la osteoporosis, } \\
\text { y se quedan igualadas a los hombres en el riesgo de padecer infartos. } \\
\text { Conlleva un aumento de peso y mayor riesgo de depresión, así como } \\
\text { de padecer cáncer de mama y endometrio. } \\
\text {-En hombres se produce la andropausia, con una disminución de la } \\
\text { frecuencia de las erecciones y menor producción de hormonas mascu- } \\
\text { linas. Hay un agrandamiento de la próstata que favorece el aumento } \\
\text { de infecciones o incluso aumenta el riesgo de cáncer de próstata. }\end{array}$ \\
\hline Salud Mental & $\begin{array}{l}\text {-Mayor riesgo de padecer problemas comportamentales o mentales } \\
\text { que la población general. } \\
\text {-Elevada prevalencia de demencia tipo Alzheimer en PcSD. } \\
\text {-Posibilidad de demencia senil en PcDID. }\end{array}$ \\
\hline
\end{tabular}

Tabla 2.2.: Sistemas en los que influye el envejecimiento y principales síntomas. Adaptado de FEAPS MADRID (2007): Las personas con necesidades de apoyo generalizado: Guía de identificación de indicios de envejecimiento y orientaciones para la determinación de apoyos. Cuadernos de Atención de Día, N³, pp. 26-31. 
Por último, en cuanto al área relativa al contexto (FEAPS; 2007), se produce una mayor necesidad de adaptaciones en cuanto a la accesibilidad física (barreras, prevención de caídas...), así como una mayor necesidad de ayudas técnicas (sillas, bastones, etc.). También hay una necesidad de accesibilidad cognitiva en los entornos, de manera que se facilite la comprensión, la orientación espacio-temporal... Por otro lado, se sabe que con el envejecimiento pueden verse reducidas las interacciones y la red de apoyo social; y asimismo, puede aparecer una mayor dificultad para adaptarse a los cambios de residencia, de personas de apoyo, y de situación de vida en general, que suelen ocurrir durante esta etapa de la vida. Por último, también suele darse una disminución del número de actividades de ocio en las que participa la persona dentro de la familia, por el propio envejecimiento de los familiares o por el agravamiento de la propia discapacidad de la persona.

Para finalizar este apartado, es adecuado mencionar el manual de Navas, Uhlmann y Berástegui (2015). Estas autoras estudian el envejecimiento activo en las PcDID desde una perspectiva de $\mathrm{CV}$, dividida en 8 dimensiones, a saber, bienestar físico, bienestar emocional, desarrollo personal, inclusión social, autodeterminación, derechos, relaciones personales y bienestar material, y proponen una serie de buenas prácticas en cada área respaldadas por la investigación científica.

\subsubsection{Resumen}

El aumento de la esperanza de vida debido a diversos avances médicos, tecnológicos y económicos produce un envejecimiento de la población en los países desarrollados. A medida que las personas envejecemos, somos más propensas a sufrir algún tipo de discapacidad y de tener algún grado de dependencia, de hecho, el perfil de la población dependiente en nuestro país estaría conformado por las mujeres mayores de 85 
años, con problemas para realizar las ABVD y con problemas de movilidad. Por otro lado, las personas con discapacidad que envejecen también tienen hoy día una mayor esperanza de vida, y en muchos casos, los problemas o cambios asociados al envejecimiento constituyen para ellas una segunda discapacidad, haciendo que tengan que enfrentarse a una doble situación de dependencia y viendo aún más mermada su autonomía. Este panorama, deja entrever la necesidad de unos servicios y sistemas de prestación que deben ser sensibles ante estas dificultades, que pueden ir en la línea de las actuaciones preventivas de un mayor deterioro (físico, cognitivo, etc.) o de un mayor grado de dependencia.

\subsection{CALIDAD DE VIDA}

\subsubsection{Introducción}

En este apartado se presenta el concepto de calidad de vida, así como sus dimensiones e investigaciones más actuales.

\subsubsection{Concepto de calidad de vida}

El concepto de calidad de vida surge a finales de los años 50 debido al interés por el bienestar de las personas como consecuencia de la industrialización. Se desarrolla por tanto en el ámbito de las ciencias sociales para medir objetivamente ese bienestar a través de determinados indicadores, en su mayor parte estadísticos (Gómez-Vela y Sabet, 2000).

La calidad de vida es un constructo multidimensional y por ello es un término difícil de operacionalizar (Rodríguez-Marín, Pastor y López-Roig, 1993). Realizando un análisis de los términos que conforman el concepto de calidad de vida, "calidad" haría 
referencia a la excelencia en cuanto a valores humanos, como la felicidad, el éxito, la riqueza, la salud y la satisfacción, mientras que "de vida" se referiría a los aspectos esenciales de la existencia humana (Schalock, Brown, Brown, Cummins et. al., 2002, p.458).

En la actualidad el concepto de calidad de vida se emplea como una noción sensibilizadora, que ofrece como referencia la perspectiva de la persona y de su ambiente; como un tema unificador que aporta el patrón para la conceptualización, medición y aplicación de la CV; y por último, como un constructo social, para la mejora del bienestar de la persona y para introducir mejoras en los programas, en la comunidad y en la sociedad (Schalock, 2004).

Aunque no exista una definición consensuada de la calidad de vida, sí que hay aspectos en los que hay consenso a lo largo de las investigaciones. En primer lugar, está plenamente aceptada la multidimensionalidad del término, así como la universalidad de sus componentes. También hay consenso en que sus componentes son tanto objetivos como subjetivos, y en que la autodeterminación, los recursos, el propósito de vida y el sentido de pertenencia influyen positivamente en la CV (Schalock y Verdugo, 2006, p.31).

Como contructo multidimensional, la calidad de vida se ve influenciada por los factores personales y ambientales, las relaciones íntimas, la vida familiar, las amistades, el trabajo, el vecindario, el lugar de residencia, la educación, la salud, el estilo de vida y el estado de la nación (Schalock et. al., 2002), es por esto por lo que actualmente se está empezando a contemplar la calidad de vida desde el modelo ecológico de Bronfenbrenner (Schalock, 2004). 
Schalock y Verdugo (2006) elaboran un modelo de calidad de vida basado en 8 dimensiones con sus principales indicadores. Cada vez son más los estudios que investigan los efectos de los factores que se asocian a una mejor calidad de vida. Schalock (2004) realiza una revisión de los estudios dirigidos a encontrar los indicadores de la calidad de vida y encuentra 125. Las dimensiones y los indicadores propuestos por Schalock y Verdugo (2006) se agrupan en 8 dimensiones reflejadas en la tabla 3.

\begin{tabular}{|l|l|}
\hline \multicolumn{1}{|c|}{ Dimensión } & \multicolumn{1}{c|}{ Indicadores principales } \\
\hline Bienestar emocional & Alegría, autoconcepto, ausencia de estrés. \\
\hline Relaciones interpersonales & Interacciones, relaciones de amistad, apoyos. \\
\hline Bienestar material & Estado financiero, empleo, vivienda. \\
\hline Desarrollo personal & Educación, competencia personal, realización. \\
\hline Bienestar físico & Atención sanitaria, estado de salud, actividades de la vida, ocio. \\
\hline Autodeterminación & $\begin{array}{l}\text { Autonomía/control personal, metas y valores personales, elec- } \\
\text { ciones. }\end{array}$ \\
\hline Inclusión social & $\begin{array}{l}\text { Integración y participación en la comunidad, roles comunita- } \\
\text { rios, apoyos sociales. }\end{array}$ \\
\hline Derechos & Legales y humanos (dignidad y respeto). \\
\hline
\end{tabular}

Tabla 3: Dimensiones y principales indicadores de calidad de vida. Adaptado de Schalock y Verdugo, 2006, p.34.

Los indicadores tienen diversas funciones, por ejemplo, son imprescindibles a la hora de evaluar programas y/o tomar decisiones en cuanto a un programa de mejora de la calidad de vida.

En el ámbito de la discapacidad intelectual el concepto de CV se aplica para el desarrollo de servicios y para la evaluación de los resultados personales (Schalock y Verdugo, 2007). Cada vez más, este concepto está siendo el eje de la planificación cen- 
trada en la persona, la evaluación de resultados y la mejora de la calidad de los servicios dedicados a este colectivo (Schalock y Verdugo, 2006, p.30). Una cuestión a tener en cuenta es que en las personas con DI la calidad de vida se compone de los mismos factores que en las personas sin DI (Schalock, Brown, Brown, Cummins, Felce, Matikka, Keith y Parmenter, 2002), de manera que en este colectivo también se basa en las necesidades, el control y las elecciones personales, aspecto muy interesante ya que en muchos casos las personas con DI carecen de esa libertad de elección que todos deberíamos tener.

\subsubsection{Investigaciones sobre calidad de vida}

En la última década se ha incrementado el número de publicaciones destinadas al área de la calidad de vida. Gómez-Vela y Sabet (2000) clasifican las líneas de investigación sobre calidad de vida en función del ámbito en el que se han desarrollado:

- Medicina: el aumento de la esperanza de vida y con ella, el incremento de las enfermedades crónicas han facilitado que en la investigación apareciese un nuevo concepto denominado calidad de vida relativa a la salud. Este concepto hace referencia a la percepción de los pacientes sobre su propia enfermedad, y básicamente, de la incidencia de sus consecuencias en el bienestar físico, social y psicológico. Este nuevo concepto ayuda en la evaluación de las intervenciones y éstas van dirigidas a mejorar la calidad de vida de los pacientes. Existen numerosas publicaciones hoy día acerca de los efectos del cáncer, sida, asma, esclerosis múltiple, etc., sobre la calidad de vida.

- Psiquiatría y psicología: la calidad de vida en estos campos se emplea como medio para evaluar las intervenciones con personas con depresión mayor o esquizofrenia. Otra línea de estudio investiga los efectos que ha tenido la desinstitucio- 
nalización en los sujetos y sus familias. Otras investigaciones se han dirigido a estudiar los efectos del apoyo social, del funcionamiento individual y del nivel de autonomía sobre la calidad de vida de la persona.

- Educación: es el área en que se ha realizado un menor número de investigaciones sobre calidad de vida. Las que se realizan, tienen que ver con los alumnos con necesidades educativas especiales y la efectividad que tiene la enseñanza en su calidad de vida. Los currículum se centran más en la formación integral de la persona y la mejora de su calidad de vida. También existen estudios acerca del uso de las nuevas tecnologías como apoyo a los escolares con discapacidad. El sistema educativo actualmente basa su criterio de calidad en la satisfacción del estudiante.

- Discapacidad: en el ámbito de la discapacidad hoy día se elaboran numerosos programas dirigidos a mejorar la calidad de vida de estas personas. Por ejemplo, en la discapacidad intelectual, existen numerosos estudios dedicados a investigar cómo influye el empleo con apoyo en la calidad de vida de este colectivo, también una línea gira en torno a la influencia de la desinstitucionalización en personas con discapacidad que han pasado de estar en los llamados hospitales psiquiátricos a las residencias comunitarias. Todos estos programas ponen el acento en la planificación centrada en el individuo, la autodeterminación, el modelo de apoyos y las técnicas de mejora de la calidad.

La calidad de vida depende de la etapa evolutiva en la que se encuentre la persona, de manera que se han estudiado por separado las etapas de infancia, adolescencia y vejez. En la infancia y adolescencia se investiga acerca de cómo influyen determinadas situaciones, que no suelen ser comunes en esta etapa del ciclo vital, en la satisfacción de 
los niños y adolescentes con la vida. En las personas mayores se investigan los efectos que la participación social, los servicios asistenciales, el estado de salud, las actividades de tiempo libre, tienen sobre su calidad de vida (Gómez-Vela y Sabet, 2000).

Por último cabe decir que el estándar de la calidad de vida se está llevando a las investigaciones en el campo del trabajo, conceptualizándose la idea de una calidad de vida laboral.

\subsubsection{Resumen}

En el presente apartado se ha visto cómo el término calidad de vida surgió para evaluar de manera objetiva el bienestar de las personas. Con el aumento de la esperanza de vida y el incremento de la prevalencia de las enfermedades crónicas, así como de las discapacidades, hoy en día se ha convertido en el punto central de numerosas investigaciones dirigidas a evaluar cómo influyen todo tipo de factores en diversos colectivos.

Numerosas han sido las investigaciones dedicadas a definir y clarificar el concepto, así como a establecer los indicadores que revelen una buena calidad de vida. A través del modelo propuesto por Schalock y Verdugo (2006) acerca de la calidad de vida, se proporcionan las dimensiones de este concepto y sus indicadores objetivos para determinar con precisión la satisfacción con la vida de las personas con enfermedades crónicas, con discapacidad, etc. Aunque ha sido un concepto que se ha llevado a diversos ámbitos, como el de la medicina, en forma de calidad de vida relativa a la salud, o al ámbito del trabajo, en forma de calidad de vida laboral, el tema que nos ocupa en este trabajo es la discapacidad intelectual.

La calidad de vida en el ámbito de la discapacidad intelectual es el criterio mediante el cual se realizan la planificación y la evaluación de numerosos programas. Exis- 
ten numerosas investigaciones acerca de cómo afectan el empleo con apoyo y el empleo normalizado a la calidad de vida de este colectivo. Asimismo, también se estudian los efectos de la desinstitucionalización, por ejemplo en personas con DI que han pasado de vivir en un hospital psiquiátrico a hacerlo en una residencia comunitaria.

Son numerosas las posibilidades del empleo del estándar de calidad de vida aplicado a los programas de apoyo a las personas con DI, siempre con el objetivo último de que este colectivo pueda llevar una vida independiente y autónoma, que son principios centrales de una buena calidad de vida.

\subsection{NECESIDADES PERCIBIDAS}

\subsubsection{Introducción}

En este apartado se trata de realizar una exposición del concepto de necesidades percibidas, así como de las investigaciones más relevantes que anteceden al estudio presente.

\subsubsection{Concepto de necesidades percibidas}

Cuando una persona percibe que tiene una necesidad, tiene una sensación de carencia que puede ser de varios tipos, por ejemplo física, si dicha carencia es de alimentación, vivienda, etc.; social, si tiene que ver con el sentido de pertenencia, entre otros muchos tipos. Bradshaw estableció una tipología de cuatro tipos de necesidades (AAIDD, 2010):

- Necesidad normativa: son los niveles de satisfacción que establecen los profesionales y expertos a través de las investigaciones para una situación determinada. 
- Necesidad expresada: es aquella necesidad que la persona manifiesta tener, también se denomina demanda. Es la acción de la necesidad percibida.

- Necesidad percibida o experimentada: es lo que una persona o grupo de personas perciben como necesario. Es subjetiva y está condicionada por factores psicológicos o psicosociales. Cuando es experimentada por un amplio colectivo de personas pasa a convertirse en una realidad social.

- Necesidad comparativa: es aquella necesidad que un agente externo visualiza en función de la situación en la que se encuentran dos grupos similares. Se establece a partir del estudio de las características de una población que recibe un servicio concreto.

El trabajo presente y la investigación que lo sustenta se centran en las necesidades percibidas o experimentadas, puesto que lo que se intenta poner de relieve son las carencias que percibe el grupo de personas con discapacidad que envejecen con respecto a los servicios, prestaciones y recursos dirigidos a mejorar su calidad de vida.

\subsubsection{Investigaciones sobre necesidades percibidas}

Como ya se adelanta en la introducción de este apartado, existe escasa investigación acerca de las necesidades que las personas con discapacidad perciben sobre los servicios que se dirigen a ellos, si bien se llevan a cabo investigaciones sobre necesidades percibidas en población general, o en población mayor.

Algunos autores, como por ejemplo Meadows, Harvey, Fossey, Burguess (2000), Meadows, Burguess, Bobevski, Fossey, Harvey y Liaw (2002) y Meadows y Burguess (2009), se dedican a estudiar la necesidad percibida acerca del cuidado de salud mental en población general australiana. 
Por otro lado, Dubois, Dubuc, Raîche, Caron y Hêbert (2008) llevan a cabo un estudio acerca de la necesidad percibida de institucionalización de personas mayores de 75 años.

Más en relación con el presente trabajo, el equipo del Dr. D. Antonio Aguado en la Universidad de Oviedo lleva a cabo desde hace algunos años una investigación basada en detectar las necesidades percibidas de las personas con discapacidad (Aguado y Alcedo, 2004). A través de entrevistas semiestructuradas personales para las personas con discapacidad y entrevistas paralelas para sus familiares y para los profesionales que les atienden, este equipo ha recopilado una serie de resultados en tres publicaciones principales. La primera de ellas, centrada en las necesidades percibidas de las propias personas con discapacidad (Aguado y Alcedo, 2004) y las dos siguientes acerca de las necesidades percibidas de sus familiares (Aguado, Alcedo y Arias, 2004) y de las necesidades percibidas de los profesionales que atienden a este colectivo (Aguado, Alcedo, Fontanil, 2005). En tales investigaciones no sólo se recogen las necesidades que son percibidas por los participantes en lo referente a su calidad de vida, sino también las posibles soluciones que podrían darse ante esas necesidades y los pensamientos que tienen sobre el futuro (Aguado et. al., 2004). Un resultado importante a tener en cuenta de esta amplia investigación es que las necesidades que perciben tanto las personas con discapacidad, como sus familiares, como los profesionales que trabajan con ellos son consistentes, por lo que es un punto importante a tener en cuenta a la hora de programar y reestructurar los servicios disponibles.

Destacables son las recientes investigaciones realizadas por el equipo de Aguado y sus colaboradores en Bizkaia (2006) y Castilla y León $(2010,2012)$ acerca de las necesidades percibidas y calidad de vida de las personas con discapacidad intelectual en 
proceso de envejecimiento. En la investigación llevada a cabo en Bizkaia con PcDI que envejecen (Aguado et. al., 2006), los resultados entre las necesidades y preocupaciones y las soluciones que aportaban tanto las PcDI, como sus familiares y los profesionales de atención directa tienden a coincidir. De hecho, las preocupaciones de los tres colectivos entrevistados giraban en torno a la salud personal, la existencia de barreras y de recursos de servicios sociales. La concordancia era mayor entre los resultados encontrados en las entrevistas de las PcDI y las de sus familias, siendo la de los profesionales un complemento a ambas. Lo mismo ocurre en lo referente a las soluciones propuestas, mientras que las familias y las PcDI valoran con mayor prioridad la subida de pensiones, los profesionales sitúan como primaria la supresión de barreras arquitectónicas. Resultados similares fueron encontrados posteriormente en la investigación realizada en Castilla y León (Aguado y cols., 2010, 2012).

\subsubsection{Resumen}

Si bien existen servicios, prestaciones y recursos destinados a favorecer la calidad de vida de las personas con discapacidad, no siempre se ajustan a lo que este colectivo considera como cuestiones necesarias. Las investigaciones acerca de las necesidades que las personas con discapacidad perciben en dichos servicios son escasas pero necesarias para lograr que los servicios continúen optimizándose y atendiendo realmente las demandas de este colectivo de personas, y puedan continuar su acción en la mejora de su calidad de vida. 


\section{REVISIÓN}

\subsection{INTRODUCCIÓN: CRITERIOS}

El objetivo de la revisión es obtener una visión amplia del panorama investigador en el ámbito de las PcDID que envejecen. Para la búsqueda se han empleado las bases de datos PsycInfo, ERIC y Medline, así como Dialnet y el buscador Google Scholar. Las palabras clave empleadas en dicha búsqueda fueron envejecimiento, necesidades percibidas, calidad de vida, discapacidad y discapacidad intelectual. Los resultados se han agrupado en 4 bloques:

- Envejecimiento: se incluyen investigaciones dedicadas al envejecimiento de la población general, de las PcD y de las PcDI.

- Discapacidad: se incluyen estudios realizados en el ámbito de la discapacidad en general y de la DI en particular.

- Necesidades percibidas: debido a la escasa investigación en este campo, tan sólo se recogen aquellas publicaciones acerca de las NPs en las PcD.

- Calidad de vida: en este bloque aparecen estudios dedicados tanto a la población general, como a la población con discapacidad y con DI, así como a la población mayor y población mayor con discapacidad.

En la búsqueda se emplea un criterio temporal, tras haber revisado los estudios publicados en la última década para poder obtener una visión actualizada del estado de la investigación en las NPs y la CV de las PcDI que envejecen. En el caso de las NPs, el criterio empleado es la proximidad de las investigaciones con el estudio que se presenta. 


\subsection{LITERATURA SOBRE ENVEJECIMIENTO}

\subsubsection{Introducción}

En este apartado se incluyen las publicaciones que tratan sobre el envejecimiento en la población general, en las personas con discapacidad y en las personas con discapacidad intelectual.

\subsubsection{Envejecimiento en la población general}

A continuación se presenta la tabla 4 que recoge el resumen de las investigaciones revisadas acerca del envejecimiento en la población general.

Adams, Roberts y Cole (2011) llevan a cabo una investigación sobre los cambios en la actividad y su relación con las limitaciones de salud y la depresión. Aplican cuestionario CAII-R a 178 personas de edades superiores a los 64 años. Este colectivo señala una menor actividad instrumental y social, en favor de un incremento de la actividad espiritual social pasiva. Los mayores de 80 años indican mayores limitaciones en la actividad instrumental que entre 64 y 79 años. La reducción de la actividad social muestra mayor asociación con depresión. Los autores sugieren adaptar las terapias ocupacionales al estadio de vida en que se encuentra la persona, ya que cada grupo de edad dentro de las propias personas mayores tiene sus propias necesidades. 


\begin{tabular}{|c|c|c|c|c|}
\hline Autor/es & Temática & Resumen & Estudio & Observaciones \\
\hline $\begin{array}{l}\text { Adams et. al. } \\
(2011)\end{array}$ & $\begin{array}{l}\text { Actividad, } \\
\text { salud y depre- } \\
\text { sión en PMs }\end{array}$ & $\begin{array}{l}\text { Actividad social media } \\
\text { la relación salud- de- } \\
\text { presión }\end{array}$ & $\begin{array}{l}\text { Trans- } \\
\text { versal }\end{array}$ & $\begin{array}{l}\text { Se debe adecuar la } \\
\text { terapia según grupos } \\
\text { edad }\end{array}$ \\
\hline $\begin{array}{l}\text { Bergland et. } \\
\text { al. (2011) }\end{array}$ & $\begin{array}{l}\text { Vivienda, re- } \\
\text { des sociales, } \\
\text { salud, movili- } \\
\text { dad en PMs }\end{array}$ & $\begin{array}{l}\text { Mujeres solas, proble- } \\
\text { mas de movilidad y } \\
\text { menores niveles edu- } \\
\text { cativos }\end{array}$ & $\begin{array}{l}\text { Trans- } \\
\text { versal }\end{array}$ & $\begin{array}{l}\text { No se ha comparado } \\
\text { la variable género }\end{array}$ \\
\hline $\begin{array}{l}\text { Carbonell et. } \\
\text { al. (2009) }\end{array}$ & $\begin{array}{l}\text { Ejercicio físico } \\
\text { en PMs }\end{array}$ & $\begin{array}{l}\text { Por cambios físicos del } \\
\text { envejecimiento, no se } \\
\text { deben entrenamientos } \\
\text { de fuerza y resistencia }\end{array}$ & Revisión & $\begin{array}{l}\text { No todos los tipos de } \\
\text { ejercicio son adecua- } \\
\text { dos en el envejeci- } \\
\text { miento }\end{array}$ \\
\hline $\begin{array}{l}\text { Díaz et al. } \\
\text { (2002) }\end{array}$ & $\begin{array}{l}\text { Trastornos } \\
\text { afectivos en el } \\
\text { anciano }\end{array}$ & $\begin{array}{l}\text { Relación entre trastor- } \\
\text { nos afectivos y varia- } \\
\text { bles biológicas y psi- } \\
\text { cosociales }\end{array}$ & Revisión & $\begin{array}{l}\text { Más vulnerables a } \\
\text { trastorno afectivo; } \\
\text { atención socio- } \\
\text { sanitaria específica }\end{array}$ \\
\hline $\begin{array}{l}\text { Fernández- } \\
\text { Ballesteros } \\
(2001)\end{array}$ & $\begin{array}{l}\text { Condiciones } \\
\text { ambientales y } \\
\text { salud }\end{array}$ & $\begin{array}{l}\text { Factores ambientales y } \\
\text { salud y satisfacción de } \\
\text { PMs en residencias }\end{array}$ & $\begin{array}{l}\text { Trans- } \\
\text { versal }\end{array}$ & $\begin{array}{l}\text { Factores ambientales } \\
\text { externos predicen } \\
\text { variables personales }\end{array}$ \\
\hline $\begin{array}{l}\text { Fernández- } \\
\text { Ballesteros et. } \\
\text { al. (2010) } \\
\end{array}$ & $\begin{array}{l}\text { Criterios enve- } \\
\text { jecimiento con } \\
\text { éxito }\end{array}$ & $\begin{array}{l}\text { Criterios y predictores } \\
\text { del envejecimiento con } \\
\text { éxito }\end{array}$ & $\begin{array}{l}\text { Trans- } \\
\text { versal }\end{array}$ & $\begin{array}{l}\text { La muestra no es re- } \\
\text { presentativa }\end{array}$ \\
\hline $\begin{array}{l}\text { I. Normaliza- } \\
\text { ción Previsio- } \\
\text { nal }(2004)\end{array}$ & $\begin{array}{l}\text { Deficiencias } \\
\text { propias del } \\
\text { envejecimiento }\end{array}$ & $\begin{array}{l}\text { Deficiencias y vulne- } \\
\text { rabilidad en el enveje- } \\
\text { cimiento }\end{array}$ & Revisión & $\begin{array}{l}\text { Se necesitan cambios } \\
\text { específicos en los } \\
\text { servicios de atención }\end{array}$ \\
\hline $\begin{array}{l}\text { Lim et. al. } \\
\text { (2011) }\end{array}$ & $\begin{array}{l}\text { Servicios so- } \\
\text { ciosanitarios }\end{array}$ & $\begin{array}{l}\text { Relación servicios } \\
\text { sanitarios y sociales }\end{array}$ & $\begin{array}{l}\text { Trans- } \\
\text { versal }\end{array}$ & \\
\hline $\begin{array}{l}\text { Martínez et. } \\
\text { al. (2006) }\end{array}$ & $\begin{array}{l}\text { Evolución en- } \\
\text { vejecimiento } \\
\text { poblacional }\end{array}$ & $\begin{array}{l}\text { Legislación y atención } \\
\text { socio-sanitaria a PMs }\end{array}$ & Revisión & $\begin{array}{l}\text { Coordinación de ayu- } \\
\text { das sociosanitarias }\end{array}$ \\
\hline $\begin{array}{l}\text { Ministerio de } \\
\text { Sanidad e } \\
\text { IMSERSO } \\
(2015)\end{array}$ & $\begin{array}{l}\text { Estudio es- } \\
\text { tadístico }\end{array}$ & $\begin{array}{l}\text { Perfil de personas ma- } \\
\text { yores en España }\end{array}$ & Revisión & \\
\hline $\begin{array}{l}\text { Momtaz et. al. } \\
\text { (2011) }\end{array}$ & $\begin{array}{l}\text { Bienestar psi- } \\
\text { cológico en } \\
\text { PMs }\end{array}$ & $\begin{array}{l}\text { El sexo, la edad, el } \\
\text { estado civil, los ingre- } \\
\text { sos predicen el bienes- } \\
\text { tar psicológico }\end{array}$ & $\begin{array}{l}\text { Trans- } \\
\text { versal }\end{array}$ & $\begin{array}{l}\text { Las mujeres solteras } \\
\text { de bajos ingresos, } \\
\text { más riesgo de bajo } \\
\text { bienestar psicológico }\end{array}$ \\
\hline $\begin{array}{l}\text { Olesen et. al. } \\
(2011)\end{array}$ & $\begin{array}{l}\text { Participación } \\
\text { comunitaria y } \\
\text { salud mental } \\
\end{array}$ & $\begin{array}{l}\text { La participación co- } \\
\text { munitaria es positiva } \\
\text { de cara a la jubilación }\end{array}$ & $\begin{array}{l}\text { Trans- } \\
\text { versal }\end{array}$ & $\begin{array}{l}\text { Debería realizarse en } \\
\text { lugares con otras eda- } \\
\text { des de jubilación }\end{array}$ \\
\hline $\begin{array}{l}\text { Otero et al. } \\
(2004)\end{array}$ & $\begin{array}{l}\text { Prevalencia } \\
\text { dependencia }\end{array}$ & $\begin{array}{l}\text { Prevalencia de depen- } \\
\text { dencia en mayor de } 65 \\
\text { años }\end{array}$ & $\begin{array}{l}\text { Longitu- } \\
\text { dinal }\end{array}$ & $\begin{array}{l}\text { Dependencia asociada } \\
\text { al envejecimiento } \\
\text { cada vez se da a eda- } \\
\text { des más tardías. }\end{array}$ \\
\hline
\end{tabular}

Tabla 4.1.: Literatura sobre envejecimiento en la población general. 


\begin{tabular}{|l|l|l|l|l|}
\hline \multicolumn{1}{|c|}{ Autor/es } & \multicolumn{1}{|c|}{ Temática } & \multicolumn{1}{|c|}{ Resumen } & Estudio & \multicolumn{1}{c|}{ Observaciones } \\
\hline $\begin{array}{l}\text { Pin et. al. } \\
(2011)\end{array}$ & $\begin{array}{l}\text { Religión y } \\
\text { salud mental }\end{array}$ & $\begin{array}{l}\text { PM's con religión, más } \\
\text { trastornos, menos tra- } \\
\text { tamiento }\end{array}$ & $\begin{array}{l}\text { Trans- } \\
\text { versal }\end{array}$ & $\begin{array}{l}\text { Se necesita investigar } \\
\text { el esa frecuencia más } \\
\text { baja }\end{array}$ \\
\hline $\begin{array}{l}\text { Richardson et. } \\
\text { al. (2011) }\end{array}$ & $\begin{array}{l}\text { Ansiedad en } \\
\text { los servicios } \\
\text { dad son elevados en } \\
\text { personas que acuden a } \\
\text { los servicios de aten- } \\
\text { ción }\end{array}$ & $\begin{array}{l}\text { Trans- } \\
\text { versal }\end{array}$ & $\begin{array}{l}\text { Una menor edad co- } \\
\text { rrelaciona significati- } \\
\text { vamente con ansie- } \\
\text { dad. }\end{array}$ \\
\hline $\begin{array}{l}\text { Troutman et. } \\
\text { al. (2011) }\end{array}$ & $\begin{array}{l}\text { Envejecimien- } \\
\text { to satisfactorio }\end{array}$ & Escala válida & $\begin{array}{l}\text { Trans- } \\
\text { versal }\end{array}$ & $\begin{array}{l}\text { Prueba exclusiva para } \\
\text { población mayor ne- } \\
\text { gra. }\end{array}$ \\
\hline $\begin{array}{l}\text { Turner et. al. } \\
(2010)\end{array}$ & $\begin{array}{l}\text { Salud percibi- } \\
\text { da en mayores }\end{array}$ & La salud es subjetiva. & $\begin{array}{l}\text { Trans- } \\
\text { versal }\end{array}$ & $\begin{array}{l}\text { No tienen en cuenta } \\
\text { percepciones de PMs }\end{array}$ \\
\hline $\begin{array}{l}\text { Urquijo et. al. } \\
(2008)\end{array}$ & $\begin{array}{l}\text { Estilos de } \\
\text { afronta-miento } \\
\text { en PMs }\end{array}$ & $\begin{array}{l}\text { Relación entre estilos } \\
\text { afrontamiento con esti- } \\
\text { los de personalidad }\end{array}$ & $\begin{array}{l}\text { Trans- } \\
\text { versal }\end{array}$ & $\begin{array}{l}\text { Sería interesante rea- } \\
\text { lizarlo con varones } \\
\text { para comparar los } \\
\text { resultados. }\end{array}$ \\
\hline $\begin{array}{l}\text { Walter et al. } \\
(2011)\end{array}$ & $\begin{array}{l}\text { Bienestar en } \\
\text { pareja }\end{array}$ & $\begin{array}{l}\text { Bienestar en mujeres } \\
\text { se transmite a los ma- } \\
\text { ridos }\end{array}$ & $\begin{array}{l}\text { Trans- } \\
\text { versal }\end{array}$ & $\begin{array}{l}\text { Factores influyentes } \\
\text { no considerados. }\end{array}$ \\
\hline
\end{tabular}

Tabla 4.2.: Literatura sobre envejecimiento en la población general. (Continuación).

Bergland y Engedal (2011) realizan un estudio para comprobar el estado de salud, la participación en redes sociales, la movilidad y la estructura de la vivienda en 307 mujeres noruegas de 75 y más años. Para ello realizan una entrevista y aplican el TUG. Los resultados indican que la mayoría de las mujeres tienen una media de 80 años y viven solas. Los años de escolarización, la baja participación en redes sociales, la dificultad para caminar, que sienten que su corazón late con fuerza y sufren falta de aliento, se sienten más solas y tienen menores puntuaciones en el TUG son factores asociados a vivir solo. La asociación más fuerte se daba entre los sentimientos de soledad y el vivir solas. Los autores concluyen que las mujeres que viven solas informan con mayor frecuencia de sentimientos de soledad, tienen menores años de escolarización, son más 
frágiles y tienen más problemas de movilidad que las mujeres mayores que viven con su pareja.

Carbonell, Aparicio y Delgado (2009) estos autores realizan un estudio con el objetivo de revisar la literatura existente sobre los cambios físicos producidos en el envejecimiento y sobre las implicaciones que ello tiene en las recomendaciones de realizar ejercicio físico en personas mayores. Los autores indican que con la edad se pierde flexibilidad en piernas y brazos, aparecen los problemas de articulación y disminuye la masa corporal. Asimismo, también disminuye la capacidad pulmonar y son frecuentes los problemas de equilibrio. Las investigaciones que estos autores revisan reportan que los programas de ejercicio diseñados para las personas mayores se centran básicamente en la flexibilidad y el equilibrio, la fuerza y la resistencia, mientras que en este estudio se propone que los programas de ejercicio físico en este colectivo no deberían incluir entrenamiento en fuerza y resistencia si se tienen en cuenta los cambios físicos que produce el envejecimiento.

Díaz, Martínez y Calvo (2002) estos autores afirman que con el proceso de envejecimiento se reducen las facultades físicas, se incrementa la probabilidad de enfermar, de sufrir enfermedades crónicas, disminuyen los recursos económicos, etc., es decir, confluyen una serie de variables que exponen a la persona a la vulnerabilidad de padecer un trastorno afectivo, en concreto, en este colectivo los más acusados son los trastornos emocionales, como la ansiedad o la depresión. Todo ello conlleva un descenso en la calidad de vida. Entre los factores que determinan los trastornos afectivos en las personas en proceso de envejecimiento, destacarían los biológicos (el estado de salud, las enfermedades médicas crónicas, los trastornos sensoriales...), los sociodemográficos (sexo, edad, estado civil...) y los psicosociales (la muerte de un cónyuge, niveles so- 
cioeconómicos bajos, etc.). Los autores concluyen que en las personas mayores se dan una serie de factores de riesgo que aumentan su vulnerabilidad a padecer un trastorno afectivo, por ejemplo la dependencia funcional, el deterioro cognitivo, la escasez de recursos económicos, el aislamiento social y la institucionalización.

Fernández-Ballesteros (2001) esta autora afirma que la edad es una variable explicativa de la salud en el proceso de envejecimiento. Empleando una muestra de 1403 personas mayores que viven en 12 residencias de 12 Comunidades Autónomas españolas, analiza los factores ambientales que pueden influir o predecir el estado de salud y de satisfacción de este colectivo. La autora alude que determinados factores ambientales influyen en la variabilidad de formas de envejecer, por ejemplo las ayudas sociorecreativas, la accesibilidad a la comunidad, las expectativas de funcionamiento, la tolerancia y el clima social son predictores de la salud o de la satisfacción de las personas mayores que viven en residencias. Todo ello repercute asimismo en la calidad de vida de este colectivo. Las variables físicas y arquitectónicas, las características organizacionales o las dimensiones del clima social, bien por sí mismas o interactuando con los factores personales predicen la salud y la satisfacción de las personas mayores que viven en residencias.

Fernández-Ballesteros, Zamarrón, López, Molina et. al. (2010) estos autores investigan cuáles pueden ser los criterios y predictores de un envejecimiento con éxito. Con una muestra de la población de Madrid de 55 a 75 años independientes para realizar las actividades de la vida diaria, a quienes se les pasó el PELEA observan que la prevalencia del envejecimiento con éxito depende de los criterios empleados para evaluarlo, de manera que los indicadores subjetivos como la satisfacción y la salud subjetiva elevan la tasa de prevalencia (según la satisfacción 8/10 personas entre los 55 y 75 
años estaría envejeciendo con éxito), mientras que esto no ocurre con los indicadores objetivos como la enfermedad o productividad. Por otro lado, entre los predictores que encuentran estos autores del envejecimiento activo estarían las variables sociodemográficas como los más consistentes; por otro lado los estilos de vida (beber habitualmente, práctica ejercicio físico), las condiciones psicológicas (dígitos símbolo, que también es un consistente predictor cognitivo), variables de personalidad (neuroticismo con un peso negativo) y variables emocionales (extraversión y autoeficacia para envejecer). Como conclusión, los autores insisten en la búsqueda de una definición empírica del envejecimiento activo y en la continuidad de la investigación acerca de sus predictores, y en la aplicación posterior de los datos empíricos en la promoción del envejecimiento activo.

El Instituto de Normalización Previsional (2004) define el envejecimiento como un proceso natural e irreversible de cambios biológicos, psicológicos y sociales que experimenta toda persona desde su vida intrauterina, a lo largo de toda su existencia, para culminar con la muerte. Asimismo se presenta este proceso como diferente a nivel individual, y se le da especial importancia debido al aumento de las expectativas de vida en las últimas décadas. De todo ello se deriva la vulnerabilidad de este colectivo, el difícil acceso que tienen a los servicios sociales y la falta de oportunidad, y se presenta la necesidad de cambios los servicios de atención a este colectivo para promover la salud, tanto física como mental y la prevención para una vejez libre de discapacidad, desde la perspectiva de la OMS de que el estado de salud de los adultos mayores viene dado por la presencia o ausencia de autonomía física, psíquica y social. Otros temas que se tratan en este artículo giran en torno a los mitos y estereotipos sobre la vejez, que habitualmente culminan en ofrecer una imagen de incapacidad, inutilidad social y rigidez de este colectivo, lo que va a influir en nuestras actitudes y nuestro trato hacia ellos, lle- 
gando, en algunos casos al maltrato o la negligencia tanto por parte de familias, como de servicios e instituciones.

Lim, Lee y Hwang (2011) realizan un estudio para investigar la confianza en el médico y el uso de los servicios sociales y sanitarios por parte de las personas mayores. Para ello emplean datos recogidos en una entrevista coreana realizada a personas mayores de 65 años. Se evalúa si el nivel de capital social afecta a los individuos en el empleo de los servicios sanitarios. Los resultados indicaron que el nivel de capital social produce un efecto positivo indirecto en el uso de los servicios sanitarios por parte de las personas mayores a través de su efecto positivo en el nivel de confianza en los médicos.

Martínez, Alonso y Calvo (2006) revisan el marco legislativo y las nuevas prestaciones de los servicios sociosanitarios para atender a las personas mayores. Para ello hacen referencia al porcentaje de personas mayores en la población española y su evolución en los últimos años. En el ámbito de la familia refieren que las principales cuidadoras de las personas mayores son las mujeres, que en muchos casos tienen dificultades para compaginar la vida laboral con los cuidados. Del mismo modo, también aluden que las personas mayores han perdido el rol que desempeñaban en la familia, pudiendo quedar aislados en muchos casos. Por otro lado, desde el contexto legislativo, se dice que desde los años 80 ha habido avances positivos para mejorar la situación de este colectivo, y ejemplo de ello es el Plan de Acción Internacional sobre el Envejecimiento aprobado en 2002, así como se han llevado a cabo programas con el mismo fin, por ejemplo el Programa de Salud y Envejecimiento de la OMS. Por otro lado, estarían los recursos comunitarios y la institucionalización. En lo referente al primero, existen actualmente numerosos recursos sociosanitarios de atención al colectivo de personas mayores, como el programa de atención a domicilio; mientras que en cuanto a la institucionalización, 
existen unidades de dependencia geriátrica, de media estancia y convalecencia en hospitales de agudos. Estos autores concluyen que las medidas comunitarias existentes para la atención a este colectivo deben articularse entre sí para incrementar su eficacia.

El Ministerio de Sanidad, Servicios Sociales e Igualdad y el IMSERSO (2015) publican un informe sobre las personas mayores en España. En el mismo se recogen datos sociodemográficos y estadísticos, indicadores socioeconómicos de esta población, temas de salud y bienestar, servicios sociales disponibles para este colectivo, temas de actitudes hacias las personas mayores, nuevas tecnologías y la relación entre discapacidad y dependencia en este colectivo.

Momtaz, Ibrahim, Hamid y Yahaya (2011) realizan un estudio para estudiar los indicadores sociodemográficos que predicen el bienestar psicológico en PMs de Malasia. Para ello emplean una muestra de 1.415 PMs de entre 60 y 100 años, a quienes les aplican el Índice de bienestar psicológico WHO-five. Los resultados indican que la edad, el sexo, el estado civil y el nivel de ingresos económicos son predictores del bienestar psicológico en la muestra estudiada, mientras que el nivel educativo, la cualificación profesional y el lugar de residencia no se mostraron como predictores de dicho bienestar. Según este estudio, serían las mujeres de Malasia más mayores, solteras y con pobres niveles económicos las que tendrían mayor riesgo de un bajo nivel de bienestar psicológico. Por lo tanto, el estudio concluye que este colectivo necesita atención especial por parte de las familias, de las políticas de actuación y de los profesionales que trabajan con PMs.

Olesen y Berry (2011) realizan un estudio para observar si la participación comunitaria durante la edad adulta se relaciona más con la salud mental durante la jubila- 
ción que durante la etapa laboral. 633 personas mayores de 45 años fueron evaluadas mediante la escala de distrés psicológico de Kessler. Los resultados indicaron que los jubilados no participaban más en la comunidad que las personas activas en ese momento. La relación entre participación comunitaria y distrés psicológico no varió al considerar todas las edades de las personas participantes, sin embargo, se encontraron asociaciones fuertes entre varias actividades y menor distrés de las personas jubiladas con respecto a las activas de la cohorte de 45 a 54 años. Esta franja de edad en Australia coincide con la transición a la jubilación. Los autores concluyen que la participación comunitaria puede ayudar en la gestión adecuada de las implicaciones mentales sanitarias de la transición del trabajo a la jubilación.

Otero, Zunzunegui, Rodríguez-Laso, Aguilar y Lázaro (2004) hicieron un estudio en el que pretendían estimar la evolución de la dependencia en la población española de 65 y más años, debido al incremento del envejecimiento poblacional. Estos autores definen la dependencia como la necesidad de ayuda en al menos una de ocho tareas de Actividades Básicas de la Vida Diaria (ABVD). Emplearon para la estimación una muestra de 1560 personas de Leganés (Madrid). Entre los resultados encontrados observan una disminución de la dependencia tanto en hombres como en mujeres desde el año 1993 hasta 1999, así como que la prevalencia es mayor en mujeres y en personas con bajos niveles educativos. Así también, el número de personas dependientes aumentó del año 1991 al 2001, existiendo un envejecimiento de este colectivo. Estos autores concluyen que la dependencia cada vez aparece a edades más tardías, lo que implica una esperanza de vida libre de discapacidad así como una necesidad de cuidados más complejos para este colectivo dependiente, que estará formado mayoritariamente por mujeres mayores. 
Pin, Zin, Chiang y Heok (2011) investigan si las personas mayores que siguen una religión particular son más o menos propensas a solicitar atención sanitaria mental y si a su vez está relacionado con sus creencias sobre la salud. Emplean una encuesta nacional de salud mental para mayores de Singapur realizada en 2004. Las personas mayores afiliadas a alguna religión mostraron niveles más altos de prevalencia de trastornos mentales sin informar de recibir tratamiento profesional para ello. Algunas religiones diferían de otras en determinadas creencias negativas sobre la salud, pero no se pudo explicar por qué las personas que siguen alguna religión buscan tratamiento sanitario mental con menor probabilidad. Los autores concluyen que algunos estudios deben evaluar la menor probabilidad con que las personas mayores que siguen una religión solicitan tratamiento psiquiátrico.

Richardson, Simning y Conwell (2011) estos autores realizan un estudio para evaluar las características de la ansiedad en los usuarios de los servicios para personas mayores (personas mayores de 60 años). Para ello aplican la Escala de Ansiedad de Goldberg. Los resultados indican que de 378 personas entrevistadas, un 27\% tenía niveles significativos de síntomas de ansiedad, que a su vez correlacionaban con una mayor frecuencia de episodios de depresión mayor, determinadas condiciones médicas, dolor, una menor edad, bajo nivel de ingresos y eventos vitales negativos. Una menor edad correlacionaba significativamente con la presencia de síntomas ansiosos en esta población. Los autores concluyen con la necesidad de cuidados multidisciplinares.

Troutman, Nies y Bentley (2011) estos autores realizan un estudio para validad la prueba SAI, que tiene por objetivo medir el envejecimiento satisfactorio en personas mayores de raza negra. Para ello emplean una muestra de 100 personas negras de 65 años o mayores de Carolina del Norte. Para ello les aplican una forma demográfica del 
SAI; una prueba de propósitos vitales, el inventario A de satisfacción con la vida, una escala de dominio y una escala de depresión. Los autores concluyen que la validez interna, convergente y discriminante fueron aceptables, por lo que la prueba SAI es adecuada para medir el envejecimiento satisfactorio en esta población.

Turner, Spencer y Williams (2010) realizan un estudio para comprobar la percepción de la salud en 101 personas mayores de 60 años de varias zonas rurales (oeste de Virginia). Para ello realizan grupos focales que giran en torno a 4 temas; la salud como valor, las dimensiones de la vida, la naturaleza holística de la salud y el uso y la adherencia a los cuidados de salud. Los resultados indican que la salud es un constructo subjetivo, multidimensional basado en la experiencia diaria de los adultos. Los profesionales en muchas ocasiones no tienen en cuenta las percepciones de estas personas, por lo que los proveedores de cuidados sanitarios deben reconsiderar sus enfoques de actuación.

Urquijo, Monchietti y Krzemien (2008) estos autores realizan un estudio para investigar los factores que influyen en el afrontamiento de las personas mayores en situaciones críticas de esta edad, además de intentar relacionar los estilos de afrontamiento con la personalidad. Para ello emplearon una muestra de 212 mujeres de entre $60 \mathrm{y}$ 95 años. Los resultados indican que la mayor parte de la muestra consideraba las situaciones críticas del envejecimiento como pérdidas, hechos naturales de la vida y un mínimo control interno, y ante estas situaciones ponían en marcha un afrontamiento de tipo cognitivo. Por otro lado, los autores encuentran que los estilos de personalidad están significativamente asociados con los estilos y estrategias de afrontamiento, de manera que las mujeres solían emplear estrategias de afrontamiento típicas de su estilo de personalidad. 
Walker, Luszcz, Gerstorf y Hoppmann (2011) realizan un estudio para examinar si las relaciones diádicas entre las personas mayores influyen en el bienestar subjetivo. Para ello recogen los datos de un estudio longitudinal realizado en Australia con 316 parejas de personas mayores de media de 75 años para investigar si los niveles de bienestar subjetivo de un miembro de la pareja influyen en los niveles del otro. Los autores encontraron diferencias específicas de género, en el sentido de que el bienestar en las mujeres predice un cambio en los maridos, pero no a la inversa. Se sugiere que las mujeres juegan un importante rol en las relaciones afectivas de las parejas de personas mayores.

\subsubsection{Resumen}

Una parte de las investigaciones revisadas sobre el envejecimiento en la población general giran en torno a temas tales como el estudio de las características sociodemográficas de las PMs en distintos países y su asociación con diversas variables como la depresión, los cambios físicos, la participación comunitaria o la salud general principalmente.

Por otro lado, también aparecen estudios centrados en la búsqueda del perfil de las PMs y de la prevalencia en la sociedad nuevamente en diferentes países.

Otro de los temas recurrentes es acerca del uso de recursos comunitarios disponibles para las PMs, así como de su nivel de participación en la sociedad.

En la mayoría de las investigaciones se señala la necesidad de coordinación y adecuación de los servicios y recursos disponibles a las necesidades de las personas que envejecen. 


\subsubsection{Envejecimiento en personas con discapacidad}

En la tabla 5 se resumen las investigaciones revisadas acerca del envejecimiento en las personas con discapacidad.

Berlau, Corrada y Kawas (2009) estos autores estudian la prevalencia de discapacidad en la población de 90 años o más de EEUU. Los participantes fueron seleccionados de un programa longitudinal denominado estudio de 90 años o más y se les pasaba un cuestionario. Los autores se basan en las dificultades en las ABVD y en las AIVD que más dependencia generan, y obtienen que entre los 90 y 94 años un $71 \%$ de personas tenían dificultades en las ABVD, entre los 95 y 99 años las tenía un $87 \%$ y entre los participantes centenarios un 97\%. En cuanto a la dependencia en las AIVD, entre los 90 y 94 años un 44\% dependía de otras personas para realizar tales tareas, entre los 95 y 99 años un 66\% y entre los participantes centenarios un 92\%. La ABVD en las que se daban mayores dificultades era el caminar, mientras que la que mayor grado de dependencia generaba era el baño. Encontraron también que la edad, el género y la institucionalización se asociaron significativamente tanto con las dificultades como con la dependencia en las ABVD. Los autores concluyen que la prevalencia de discapacidad en esta muestra de la población se seguirá incrementando rápidamente y que esto tiene implicaciones para la salud pública. 


\begin{tabular}{|c|c|c|c|c|}
\hline Autor/es & Temática & Resumen & Estudio & Observaciones \\
\hline $\begin{array}{l}\text { Berlau et. al. } \\
(2009)\end{array}$ & $\begin{array}{l}\text { Prevalencia de } \\
\text { discapacidad en } \\
\text { P.de > } 90 \text { años }\end{array}$ & $\begin{array}{l}\text { La discapacidad se } \\
\text { seguirá incrementan- } \\
\text { do rápidamente }\end{array}$ & $\begin{array}{l}\text { Transver- } \\
\text { sal }\end{array}$ & \\
\hline $\begin{array}{l}\text { Bigby } \\
(2002)\end{array}$ & $\begin{array}{l}\text { Servicios de PMs } \\
\text { y PcD en Austra- } \\
\text { lia }\end{array}$ & $\begin{array}{l}\text { Propuestas para me- } \\
\text { jorar la atención }\end{array}$ & Revisión & $\begin{array}{l}\text { Estudio de servi- } \\
\text { cios en Australia }\end{array}$ \\
\hline $\begin{array}{l}\text { Bódalo } \\
\text { (2006) }\end{array}$ & $\begin{array}{l}\text { Envejecimiento y } \\
\text { discapacidad }\end{array}$ & $\begin{array}{l}\text { Población en proceso } \\
\text { de envejecimiento y } \\
\text { discapacidad }\end{array}$ & Revisión & \\
\hline $\begin{array}{l}\text { Daniels et. } \\
\text { al. (2011) }\end{array}$ & $\begin{array}{l}\text { Programa preven- } \\
\text { ción de discapaci- } \\
\text { dad en PMs frági- } \\
\text { les }\end{array}$ & $\begin{array}{l}\text { Presentación de pro- } \\
\text { grama para prevenir } \\
\text { la discapacidad en } \\
\text { PMs }\end{array}$ & Revisión & $\begin{array}{l}\text { Necesario un enfo- } \\
\text { que multidiscipli- } \\
\text { nar. }\end{array}$ \\
\hline $\begin{array}{l}\text { Dewhurst et. } \\
\text { al. (2012) }\end{array}$ & $\begin{array}{l}\text { Prevalencia de } \\
\text { discapacidad en } \\
\text { PMs de Taiwan }\end{array}$ & $\begin{array}{l}\text { Prevalencia discapa- } \\
\text { cidad severa del } \\
3,7 \% \text { y moderada del } \\
6,2 \%\end{array}$ & $\begin{array}{l}\text { Transver- } \\
\text { sal }\end{array}$ & $\begin{array}{l}\text { Mujeres, problemas } \\
\text { neurológicos pre- } \\
\text { dictores de disc. }\end{array}$ \\
\hline $\begin{array}{l}\text { Dunne et. al. } \\
(2011)\end{array}$ & $\begin{array}{l}\text { Discapacidad fun- } \\
\text { cional y síntomas } \\
\text { depresivos en } \\
\text { PMs }\end{array}$ & $\begin{array}{l}\text { Los síntomas depre- } \\
\text { sivos y la discapaci- } \\
\text { dad funcional au- } \\
\text { mentan con el tiempo }\end{array}$ & $\begin{array}{l}\text { Longitu- } \\
\text { dinal }\end{array}$ & $\begin{array}{l}\text { Retirar el esfuerzo } \\
\text { de metas inalcan- } \\
\text { zables protege de la } \\
\text { depresión }\end{array}$ \\
\hline $\begin{array}{l}\text { Fuller- } \\
\text { Thompson } \\
\text { et.al. (2011) }\end{array}$ & $\begin{array}{l}\text { Prevalencia de } \\
\text { discapacidad en } \\
\text { subpoblaciones } \\
\text { asiáticas }\end{array}$ & $\begin{array}{l}\text { Evalúa la tasa de } \\
\text { prevalencia de disca- } \\
\text { pacidad de distintas } \\
\text { subpoblaciones }\end{array}$ & $\begin{array}{l}\text { Transver- } \\
\text { sal }\end{array}$ & \\
\hline $\begin{array}{l}\text { Gispert et. } \\
\text { al. (2008) }\end{array}$ & $\begin{array}{l}\text { Perfiles de depen- } \\
\text { dencia en España }\end{array}$ & $\begin{array}{l}\text { Tipo y gravedad de } \\
\text { discapacidad asocia- } \\
\text { das: } 5 \text { tipos de } \\
\text { P.dependientes }\end{array}$ & $\begin{array}{l}\text { Transver- } \\
\text { sal }\end{array}$ & $\begin{array}{l}\text { Limitación de la } \\
\text { medida de discapa- } \\
\text { cidad y gravedad }\end{array}$ \\
\hline $\begin{array}{l}\text { Hart et. al. } \\
\text { (2011) }\end{array}$ & $\begin{array}{l}\text { Funciones ejecu- } \\
\text { tivas y AVD }\end{array}$ & $\begin{array}{l}\text { Funcionamiento ge- } \\
\text { neral y deterioro } \\
\text { cognitivo en AVD. }\end{array}$ & $\begin{array}{l}\text { Transver- } \\
\text { sal }\end{array}$ & $\begin{array}{l}\text { Limitaciones en la } \\
\text { elección de las } \\
\text { pruebas }\end{array}$ \\
\hline $\begin{array}{l}\text { Instituto } \\
\text { Normaliza- } \\
\text { ción (2004) }\end{array}$ & $\begin{array}{l}\text { Envejecimiento y } \\
\text { discapacidad }\end{array}$ & $\begin{array}{l}\text { Prevención de la } \\
\text { discapacidad en el } \\
\text { envejeci-miento }\end{array}$ & Revisión & $\begin{array}{l}\text { Determinadas } \\
\text { prácticas retrasan la } \\
\text { aparición de disca- } \\
\text { pacidad }\end{array}$ \\
\hline $\begin{array}{l}\text { Kahanet.al. } \\
(2006)\end{array}$ & $\begin{array}{l}\text { Tratamiento de } \\
\text { depresión en PMs } \\
\text { con discapacidad }\end{array}$ & $\begin{array}{l}\text { Es posible tratar } \\
\text { síntomas depresión } \\
\text { en PcD }\end{array}$ & $\begin{array}{l}\text { Longitu- } \\
\text { dinal }\end{array}$ & $\begin{array}{l}\text { No se compara con } \\
\text { personas sin disca- } \\
\text { pacidad }\end{array}$ \\
\hline $\begin{array}{l}\text { Lee et. al. } \\
(2012)\end{array}$ & $\begin{array}{l}\text { Visita al médico y } \\
\text { coste en EEUU }\end{array}$ & $\begin{array}{l}\text { Las PcD, mayores } \\
\text { problemas para acu- } \\
\text { dir al médico debido } \\
\text { al coste }\end{array}$ & $\begin{array}{l}\text { Transver- } \\
\text { sal }\end{array}$ & $\begin{array}{l}\text { Debe tenerse en } \\
\text { cuenta en las políti- } \\
\text { cas dirigidas a PcD }\end{array}$ \\
\hline
\end{tabular}

Tabla 5.1.: Literatura sobre envejecimiento en las personas con discapacidad. 


\begin{tabular}{|c|c|c|c|c|}
\hline Autor/es & Temática & Resumen & Estudio & Observaciones \\
\hline $\begin{array}{l}\text { Lorenz } \\
\text { (2009) }\end{array}$ & $\begin{array}{l}\text { Indicadores de la } \\
\text { discapacidad en } \\
\text { mujeres mayores }\end{array}$ & $\begin{array}{l}\text { Existen síntomas } \\
\text { preclínicos en las } \\
\text { mujeres }\end{array}$ & $\begin{array}{l}\text { Longitu- } \\
\text { dinal }\end{array}$ & $\begin{array}{l}\text { Sólo se realizó con } \\
\text { mujeres, }\end{array}$ \\
\hline $\begin{array}{l}\text { Mitchell, et. } \\
\text { al. (2006) }\end{array}$ & $\begin{array}{l}\text { Efectos de edad } \\
\text { en el empleo en } \\
\text { PcD y sin disca- } \\
\text { pacidad }\end{array}$ & $\begin{array}{l}\text { Edad, discapacidad, } \\
\text { predictoras de tasa de } \\
\text { empleo }\end{array}$ & $\begin{array}{l}\text { Transver- } \\
\text { sal }\end{array}$ & $\begin{array}{l}\text { No aborda el estu- } \\
\text { dio de otras varia- } \\
\text { bles predictoras }\end{array}$ \\
\hline $\begin{array}{l}\text { Verbrugge } \\
\text { et. al. }(2002)\end{array}$ & $\begin{array}{l}\text { Envejecimiento } \\
\text { con discapacidad, } \\
\text { Reino Unido }\end{array}$ & $\begin{array}{l}\text { Compara PcD adqui- } \\
\text { ridas en infancia con } \\
\text { posteriores }\end{array}$ & $\begin{array}{l}\text { Transver- } \\
\text { sal }\end{array}$ & $\begin{array}{l}\text { No estudian varia- } \\
\text { bles psicológicas }\end{array}$ \\
\hline $\begin{array}{l}\text { Virués- } \\
\text { Ortega et. al. } \\
(2011)\end{array}$ & $\begin{array}{l}\text { Prevalencia de } \\
\text { discapacidad en } \\
\text { personas mayores }\end{array}$ & $\begin{array}{l}\text { Alta prevalencia en } \\
\text { la población mayor } \\
\text { española }\end{array}$ & $\begin{array}{l}\text { Transver- } \\
\text { sal }\end{array}$ & \\
\hline $\begin{array}{l}\text { Yaffe et al. } \\
\text { (2010) }\end{array}$ & $\begin{array}{l}\text { El efecto de fun- } \\
\text { ciones cognitivas }\end{array}$ & $\begin{array}{l}\text { Deterioro cognitivo y } \\
\text { discapacidad }\end{array}$ & $\begin{array}{l}\text { Longitu- } \\
\text { dinal }\end{array}$ & $\begin{array}{l}\text { Limitaciones del } \\
\text { Minimental }\end{array}$ \\
\hline
\end{tabular}

Tabla 5.2.: Literatura sobre envejecimiento en las personas con discapacidad. (Continuación).

Bigby (2002) realiza una comparación y un contraste entre los servicios de cuidados de personas mayores y los servicios de discapacidad existentes en Australia, y propone las directrices de cambio necesarias para mejorar las políticas y los servicios disponibles para las PcD que envejecen. Hace referencia a que la edad de envejecimiento es diferente en la población general que en las $\mathrm{PcD}$, y que éstas suelen sin embargo residir o hacer uso de los servicios genéricos de atención a las personas mayores, aunque no puedan atender las necesidades específicas que tiene este colectivo.La autora analiza las similitudes y diferencias de los servicios de atención a las personas mayores y los servicios de discapacidad y también trata la accesibilidad, disponibilidad y adecuación de los servicios, todo ello para concluir con la propuesta de las directrices que deben seguirse desde las políticas y los servicios tanto del sector de la atención a personas mayores como desde el sector de la discapacidad, que serían el cubrir el vacío que existe en los servicios especializados, apoyar la inclusión de manera que las PcD mayores sean visibles en los sistemas de atención a mayores, adaptar y dotar de recursos el 
sector de la discapacidad para lograr un envejecimiento exitoso en este colectivo y desarrollar asociaciones para facilitar la accesibilidad a tales servicios.

Bódalo (2006) realiza una revisión de la encuesta EDDES de 1999. Alude a que el aumento de la esperanza de vida en la población general y los avances médicos y científicos han permitido que el número de $\mathrm{PcD}$ se haya incrementado. Basándose en los datos de la encuesta, esta autora cita que en España 32 de cada 100 personas mayores tienen alguna discapacidad, siendo las mujeres las que tienen tasas de prevalencia mayores y las que antes tienen problemas de dependencia. Las mayores tasas de discapacidad están relacionadas con el aspecto de la movilidad. Del mismo modo, un porcentaje considerable de personas mayores no pueden realizar las tareas del hogar, por lo que la ayuda domiciliaria se convierte en este aspecto en un factor fundamental. Asimismo, un $12,6 \%$ de personas mayores tienen problemas para levantarse, acostarse o moverse dentro del hogar. Por otro lado, el problema funcional más importante en las personas mayores son las deficienciasosteoarticulares, En cuanto a los cuidadores de este colectivo destacan en gran medida la mujer o esposa y las hijas. La autora incide en la necesidad de investigación en el ámbito de las PcD que envejecen para que alcancen un alto grado de autonomía e independencia.

Daniels, van Rossum, Metzelthin, Sipers et al. (2011) publican un programa para prevenir la discapacidad en PMs frágiles. El programa sería aplicado por un equipo interdisciplinar de profesionales y consistiría a grandes rasgos en 6 pasos establecidos, entre los que se incluyen el diagnóstico y la evaluación, la preparación inicial de un plan de acción, el establecimiento del acuerdo con dicho plan, la ejecución del plan y la evaluación final y seguimiento. Este programa de intervención serviría para identificar las 
necesidades de las PMs frágiles y cooperar en el esfuerzo porque puedan vivir de forma independiente y para señalar posibles factores de riesgo.

Dewhurst, Dewhurst, Gray, Howlett, et. al. (2012) realizan un estudio para examinar la prevalencia de discapacidad en PMs de Tanzania. Para ello emplean una muestra de 2.232 participantes de 70 y más años de Hai, Tanzania, a quienes aplican el BI. Los resultados indican que la prevalencia de discapacidad severa ajustada por edad fue del 3,7\%; mientras que de discapacidad moderada fue del 6,2\%. La edad avanzada, el sexo femenino, los problemas de memoria y la presencia de trastornos neurológicos fueron predictores independientes de la presencia de discapacidad. Los autores concluyen que la media de discapacidad observada en este país fue menor que la observada en otros países de mayor nivel económico. La discapacidad es probable que aumente en la población mayor de países de bajos ingresos económicos y que mejore la supervivencia a las enfermedades.

Dunne, Wrosch y Miller (2011) realizan un estudio para observar la relación entre la capacidad de ajuste de las PMs a los objetivos, la discapacidad funcional y los síntomas depresivos. Para ello emplean una muestra de 135 PMs mayores de 60 años, a quienes aplican una entrevista, el CES-D10 y el ADLs. Los resultados indican que los síntomas depresivos y la discapacidad funcional se incrementan con el tiempo. La capacidad de no poder retirar el esfuerzo de los objetivos que no son realistas y los altos niveles de discapacidad funcional incrementaron en 6 años los síntomas depresivos. Los autores concluyen que el poder retirar el esfuerzo de los objetivos que no son realistas produce un rol adaptativo en las PMs ante los síntomas depresivos. 
Fuller-Thompson, Brennenstuhl y Hurd (2011) evalúan la prevalencia y probabilidad de 4 tipos de discapacidad en distintas poblaciones asiático americanas de las islas del Pacífico, comparándolo con los datos de la población blanca no hispana. Los datos se tomaron de la Encuesta Americana sobre la Comunidad de 1996 y la edad de todos los participantes era de 55 años o más. Los tipos de discapacidad que se estudiaron para cada grupo fueron la limitación funcional, la limitación en actividades de la vida diaria, los problemas cognitivos y la sordera o ceguera. Los autores encuentran que las tasas de discapacidad más variadas se dan entre los adultos mayores de las subpoblaciones asiático americanas y a su vez, que los adultos mayores asiáticos tienen como promedio mejores resultados en discapacidad que los blancos no hispanos. Los investigadores concluyen que el estudio proporciona fuerte evidencia de que la exclusión de las personas mayores institucionalizadas minimiza las diferencias en discapacidad entre las subpoblaciones asiática y blanca.

Gispert, Clot-Razquin, Rivero, Freitas et al. (2008) realizan un estudio en el que revisan la EDDES de 1999. El objetivo era calcular el perfil de la dependencia en España a partir de la gravedad y los tipos de discapacidad de esta población. Los autores obtienen que los niveles de gravedad dependen del tipo de discapacidad, es decir, que hay niveles de gravedad más asociados a un tipo de discapacidad que a otro. El perfil de la dependencia que obtuvieron los autores para la población española se dividía en 5 grupos que estaban en consonancia con los niveles de gravedad; en el extremo más leve se incluían las personas jóvenes y de edades medias, varones y discapacidades sensoriales, mientras que el más dependiente estaba representado por las mujeres, los mayores de 80 años y las discapacidades de movilidad y en las actividades de la vida diaria. Encontraron asimismo que la mayoría de las PcD son más dependientes en las actividades 
de la vida diaria cuando coexisten otras discapacidades. Como conclusión, observan que el tipo y la gravedad de la discapacidad están asociadas y dan lugar a los cinco tipos de dependencia encontrados. A partir de estos tipos se podría estudiar su frecuencia en la población y así poder gestionar de una manera más eficaz los recursos socio-sanitarios existentes.

Hart y Bean (2011) realizan un estudio para comprender la relación que los cambios cognitivos tienen con las AVD en las personas mayores, y así poder realizar recomendaciones sobre la capacidad de funcionamiento independiente. Para ello examinan a 92 personas de 55 a 91 años con deterioro cognitivo. Se les aplican medidas de funcionamiento (pruebas de evaluación de la función ejecutiva), inteligencia general (Escala abreviada de Weschler) y AVD (SSSQ). Los resultados indican que la comprensión de la contribución de los dominios cognitivos al deterioro funcional en las personas mayores debe tener en cuenta el funcionamiento intelectual general, y que la persistencia de los procesos cognitivos autodirigidos puede ser importante para la adaptación en la vida diaria. Los resultados tienen implicaciones para realizar recomendaciones importantes en cuanto al funcionamiento autónomo de estas personas en su vida diaria.

Según el Instituto de Normalización Previsional (2004) es común que en aquellos casos en los que aparece la discapacidad en las personas en proceso de envejecimiento, sobre todo a edades muy avanzadas, ésta sea en la mayor parte de los casos física o psicológica, lo que conlleva la necesidad de determinados recursos económicos para hacer frente a los costes sanitarios. Una cuestión que podría reducir el riesgo de discapacidad en este período de la vida podría ser la detección temprana y tratamiento adecuado de cualquier enfermedad posible. Las enfermedades degenerativas suelen ser comunes en el colectivo de personas mayores, y ello requiere un cierto ajuste por parte 
tanto de familia como de la comunidad. En el plano de la salud, las personas mayores suelen sufrir trastornos del estado de ánimo, como la depresión, lo que también necesita esa detección y tratamiento adecuados. El trabajoconcluye que se busca el envejecimiento activo por medio de la participación social, la práctica regular de actividad física, etc. Se sabe que realizar actividad física incrementa el bienestar general y el poder conservar la capacidad funcional a largo plazo, así como reduce el riesgo de diversas enfermedades.

Kahan, Mitchell, Kemp y Adkins (2006) estudian la influencia de un tratamiento para la depresión mayor basado en la combinación de la psicoterapia y la medicación antidepresiva en los síntomas depresivos, la satisfacción con la vida y las actividades en la comunidad en personas que envejecen con una discapacidad. La muestra empleada fueron 55 personas que aceptaron someterse al tratamiento comparadas tras 6 meses de tratamiento con 22 que no lo aceptaron. Los resultados indican que los individuos que recibieron el tratamiento mejoraron significativamente en las 3 medidas, disminuyéndose significativamente los síntomas depresivos en un 50\%, frente a una disminución no significativa del $12 \%$ en las personas que no habían sido sometidas al mismo. La conclusión que extraen los autores es que la depresión se puede tratar en las personas que envejecen con una discapacidad.

Lee, Hasnain-Wynia y Lau (2012) realizan un estudio para investigar la disparidad en las visitas al médico entre PcD y personas sin discapacidad en EEUU. Para ello revisan una encuesta de supervisión realizada previamente. Los autores encuentran que las PcD tienen mayores problemas económicos para acudir al médico que las personas sin discapacidad, tras haber controlado los factores sociodemográficos, sanitarios y financieros. Aunque las variables de salud y financieras atenuaban tal disparidad, no la 
explicaban. Los autores concluyen que las PcD tienen mayores dificultades económicas para acudir al médico que sus iguales sin discapacidad. Esto debe tenerse en cuenta para el desarrollo de políticas eficaces en este colectivo.

Lorenz (2009) tiene el objetivo de conocer cómo experimentan sus cuerpos las mujeres mayores antes de la aparición de la discapacidad. Para ello la autora aplica entrevistas a 12 mujeres de entre 60 y 80 años, a las que se les realiza un seguimiento a lo largo de 18 meses. Los resultados indican que los síntomas percibidos por las mujeres se agrupan en 3 tipos de indicadores de una discapacidad incipiente, y que son la ausencia de sincronización del cuerpo, un cuerpo llamativo y un cuerpo vulnerable, aunque son percibidos por las mujeres de la muestra como síntomas normales de un cuerpo que envejece. La autora concluye que el estudio apoya la idea de que las personas mayores son conscientes del deterioro de su cuerpo, y que además, proporciona un elemento interesante para los clínicos a la hora de programar intervenciones tempranas con el objetivo de prevenir la discapacidad, cuando la persona aún tiene una gran cantidad de recursos para prevenirla.

Mitchell, Adkins y Kemp (2006) realizan un estudio con 262 PcD y 115 personas sin ella, de edades comprendidas entre los 25 y 65 años, para comparar la tasa de empleo en ambos colectivos. El estudio refiere que en EEUU hay cerca de 12 millones de personas con discapacidad física, y que por primera vez en la historia este colectivo está envejeciendo entre los 50 y 60 años. En cuanto a los resultados obtenidos por edad, en PcD las tasas de empleo más altas están entre los 20 y los 30 años, mientras que a partir de los 40 se produce una recaída de las mismas, mientras que en las personas sin discapacidad este decaimiento se produce en los 50 y 60 años. En lo referente al nivel educativo únicamente analizado en $\mathrm{PcD}$, el grupo de alto nivel educativo tenía una ele- 
vada tasa de empleo entre los 20 y los 30 años, que decae a los 40 años y aún más en los 60, mientras que en aquellos con un nivel educativo bajo la tasa de empleo era más elevada a los 30 años y decae a los 40 . Los autores concluyen que las variables edad, la discapacidad y la interacción entre ambas son variables predictoras de la tasa de empleabilidad, aunque en el estudio no se abordaron otras posibles variables explicativas.

Verbrugge y Yang (2002) comparan a las personas con discapacidad adquirida en la infancia (lo denominan "envejecimiento con discapacidad" e incluye a las personas que han adquirido la discapacidad antes de los 20 años), con aquellas personas que han adquirido la discapacidad en la edad adulta (denominado "discapacidad con envejecimiento" e incluye aquellas personas que han adquirido la discapacidad después de los 20 años), todas ellas pertenecientes al Reino Unido. Para ello emplean los datos del NHIS-D de los años 1994-1995. Investigan tres ámbitos, como son el dominio del cuidado personal por parte de ambos colectivos, la administración del hogar y las actividades físicas básicas. Los autores encuentran que los individuos del grupo "envejecimiento con discapacidad" constituyen entre el 7 y el $9 \%$ de todo el colectivo de PcD; además tienen mayores niveles de participación social que el grupo de "discapacidad con envejecimiento", así como aceptan más a menudo la etiqueta de PcD. Por otro lado, un nivel pobre de salud constituía una desventaja en ambos grupos, ya que reducía su participación social. Los autores concluyen que sería oportuno estudiar aspectos de tipo psicológico como la sensación de integración, la autoeficacia, la autoestima, etc., y que debe hacerse con escalas más amplias, ya que la empleada en el estudio sólo recoge aspectos meramente sociodemográficos.

Virués-Ortega, de Pedro-Cuesta, Seijo-Martínez, Saz, et. al. (2011) realizan un estudio para calcular la prevalencia de la discapacidad leve, moderada y severa entre 
población española de 75 años o más, siguiendo los criterios de la ICF. Se empleó para ello una muestra de 503 personas mayores. Los resultados indican que la prevalencia de discapacidad en las ABVD y en las actividades de movilidad era 3 veces mayor que la media de la población, y era a su vez mayor en las mujeres. Los autores concluyen que la prevalencia de discapacidad es alta en la población mayor española.

Yaffe, Lindquist, Vittinghoff, Barnes, et. al. (2010) intentan determinar si el mantenimiento a largo plazo de las funciones cognitivas se asocia con ventajas en la salud de las personas mayores, es decir, si reduce la incidencia de discapacidad y produce una menor tasa de mortalidad. Con 2733 participantes de una media de 74 años al inicio del estudio y 80 en el seguimiento, llevan a cabo 2 mediciones del test $3 \mathrm{MS}$ y dividen a los participantes en 3 grupos dependiendo del deterioro cognitivo (los que mantienen la cognición sin cambio con respecto a la primera medición, los que tienen un deterioro bajo y los que obtienen un grado de deterioro más alto). Los autores encuentran que aquellos participantes que se mantuvieron tuvieron una menor tasa de mortalidad y una menor incidencia de discapacidad que aquellos cuyo deterioro había sido bajo, y a su vez, los participantes del deterioro bajo habían tenido tasas menores tanto de mortalidad como de discapacidad que aquellos en los que el deterioro había sido grande, y estas diferencias se seguían manteniendo tras el control de otras variables intervinientes como la edad, el género, etc. Los autores concluyen que aquellas personas de entre 80-90 años que mantienen su función cognitiva muestran un menor riesgo de muerte y menor deterioro funcional que aquellos que tienen un declive en la función cognitiva por mínimo que sea, lo que apoya el concepto de "envejecimiento exitoso de la cognición". 


\subsubsection{Resumen}

En la revisión presentada sobre el envejecimiento en las $\mathrm{PcD}$, son numerosos los estudios que tratan el tema del envejecimiento y la discapacidad, en el sentido de explorar la prevalencia, la esperanza de vida, los predictores de discapacidad en PMs o la influencia de la discapacidad en las AVD. Las principales discapacidades que se analizan en estos estudios suelen ser las relativas al declive cognitivo y las limitaciones visuales y auditivas. Asimismo, también se han encontrado investigaciones sobre programas de mantenimiento o mejora de las funciones cognitivas o de prevención de la discapacidad.

Otros temas recurrentes en estas investigaciones son el estudio de la depresión en las PMs con discapacidad, la participación y el uso de los recursos comunitarios disponibles por parte de PMs con y sin discapacidad.

Referente a las PcD que envejecen, algunas investigaciones revisadas hacen alusión a la necesidad de especialización de los recursos a este colectivo.

\subsubsection{Envejecimiento en personas con discapacidades intelectuales y del desarrollo}

Seguidamente se presenta la tabla 6, que refleja un resumen de las investigaciones revisadas acerca del envejecimiento en las personas con discapacidad intelectual.

Aronow y Hahn (2005) muestran los resultados de la aplicación de un programa de salud preventivo en 201 PcDI mayores de 32 años. Ellos crearon una escala de evaluación propia y dos programas preventivos aplicados en el hogar de la PcDI. Uno de los programas se basaba en la visita de una enfermera al hogar que les aportaba información específica y les hacía visitas de seguimiento. El otro programa consistía en enviar a los hogares de las PcDI información impresa acerca de los factores de riesgo para 
la salud. Los resultados indican que es posible aplicar cualquiera de los dos programas a PcDI leve o moderada. Además los autores identificaron varios factores de riesgo para la salud que sugieren la necesidad de llevar a cabo intervenciones efectivas en este campo con este colectivo. Los dos grupos mostraron una reducción significativa en los factores de riesgo para la salud en el seguimiento a partir de la línea base. Los autores concluyen que son necesarias intervenciones preventivas comunitarias en este colectivo. 


\begin{tabular}{|c|c|c|c|c|c|c|}
\hline Autor/es & Temática & Muestra & Medidas & Resumen & Estudio & Observaciones \\
\hline $\begin{array}{l}\text { Aronow y } \\
\text { Hahn } \\
(2005)\end{array}$ & $\begin{array}{l}\text { Programa sanitario } \\
\text { preventivo en PcDI } \\
\text { mayores }\end{array}$ & $\begin{array}{l}201 \text { PcDI } \\
\text { mayores de } \\
32 \text { años }\end{array}$ & $\begin{array}{l}\text { Escala de eva- } \\
\text { luación y pro- } \\
\text { gramas de } \\
\text { tratamiento }\end{array}$ & $\begin{array}{l}\text { Programa preventivo } \\
\text { reduce factores de ries- } \\
\text { go para salud }\end{array}$ & Longitudinal & $\begin{array}{l}\text { No hubo un grupo de } \\
\text { comparación al que no se } \\
\text { asignó ningún tratamiento }\end{array}$ \\
\hline $\begin{array}{l}\text { Bigby } \\
(2008)\end{array}$ & $\begin{array}{l}\text { Revisión de la política } \\
\text { australiana para PcDI } \\
\text { mayores }\end{array}$ & & & $\begin{array}{l}\text { Obstáculos para que } \\
\text { PcDI puedan envejecer } \\
\text { en lugares apropiados }\end{array}$ & Revisión & \\
\hline $\begin{array}{l}\text { Bigby et. } \\
\text { al. (2011) }\end{array}$ & $\begin{array}{l}\text { Cambio de residencia } \\
\text { en PcDI mayores }\end{array}$ & $\begin{array}{l}13 \text { hogares } \\
\text { de grupo; } \\
\text { edad media } \\
\text { de } 60 \text { años }\end{array}$ & Entrevista & $\begin{array}{l}\text { Los traslados a una } \\
\text { residencia se hacían } \\
\text { rápidamente y tomaba } \\
\text { la elección la familia }\end{array}$ & Longitudinal & $\begin{array}{l}\text { El resto de miembros del } \\
\text { hogar desconocen sus } \\
\text { derechos y las decisiones } \\
\text { de los profesionales }\end{array}$ \\
\hline $\begin{array}{l}\text { Bigby et. } \\
\text { al. (2009) }\end{array}$ & $\begin{array}{l}\text { Experiencias del uso } \\
\text { de los servicios en } \\
\text { PcDI mayores }\end{array}$ & $\begin{array}{l}16 \text { PcDI de } \\
52 \text { a } 80 \text { años } \\
\text { de Australia }\end{array}$ & $\begin{array}{l}\text { Entrevista } \\
\text { propia }\end{array}$ & $\begin{array}{l}\text { Necesario que servicios } \\
\text { apoyen la construcción } \\
\text { de relaciones en PcDI } \\
\text { mayores }\end{array}$ & Transversal & $\begin{array}{l}\text { Los espacios sociales de } \\
\text { las PcDI se restringen a } \\
\text { dos esferas, la familiar y } \\
\text { la de los servicios }\end{array}$ \\
\hline $\begin{array}{l}\text { Bigby et al. } \\
(2008)\end{array}$ & $\begin{array}{l}\text { PcDI mayores que } \\
\text { viven en residencias } \\
\text { para P. mayores }\end{array}$ & $\begin{array}{l}826 \text { residen- } \\
\text { cias de PMs } \\
\text { de Victoria } \\
\end{array}$ & $\begin{array}{l}\text { Entrevista } \\
\text { propia }\end{array}$ & $\begin{array}{l}\text { Las PcDI que enveje- } \\
\text { cen necesitan servicios } \\
\text { especializados }\end{array}$ & Transversal & La muestra está limitada \\
\hline
\end{tabular}

Tabla 6.1.: Literatura sobre envejecimiento en personas con discapacidad intelectual. 


\begin{tabular}{|c|c|c|c|c|c|c|}
\hline Autor/es & Temática & Muestra & Medidas & Resumen & Estudio & Observaciones \\
\hline $\begin{array}{l}\text { Brehmer } \\
\text { et. al. } \\
(2010)\end{array}$ & $\begin{array}{l}\text { Distinción entre fragi- } \\
\text { lidad y DI en PcDI }\end{array}$ & $\begin{array}{l}190 \text { PcDI } \\
\text { con una } \\
\text { media de } 41 \\
\text { años }\end{array}$ & Entrevista; VFQ-ID & $\begin{array}{l}\text { La fragilidad suele ir } \\
\text { asociada al envejeci- } \\
\text { miento, no a la disca- } \\
\text { pacidad }\end{array}$ & Transversal & $\begin{array}{l}\text { Muestra no representa- } \\
\text { tiva. }\end{array}$ \\
\hline $\begin{array}{l}\text { Burt et al. } \\
(2005)\end{array}$ & $\begin{array}{l}\text { Envejecimiento pre- } \\
\text { coz en PcSD }\end{array}$ & $\begin{array}{l}55 \text { PcSD y } \\
75 \text { PcDI por } \\
\text { otras causas }\end{array}$ & $\begin{array}{l}\text { Evaluación neurop- } \\
\text { sicológica; examen } \\
\text { médico }\end{array}$ & $\begin{array}{l}\text { Hay cierta evidencia } \\
\text { de un envejecimiento } \\
\text { precoz en PcSD en su } \\
\text { rendimiento en una } \\
\text { prueba de fluidez ver- } \\
\text { bal }\end{array}$ & Transversal & $\begin{array}{l}\text { Algunos resultados ob- } \\
\text { tenidos no son coheren- } \\
\text { tes con los estudios lon- } \\
\text { gitudinales }\end{array}$ \\
\hline $\begin{array}{l}\text { Buys et. al. } \\
\text { (2008) }\end{array}$ & $\begin{array}{l}\text { Envejecimiento activo } \\
\text { en PcDI mayores }\end{array}$ & $\begin{array}{l}16 \text { PcDI de } \\
+50 \text { años y } \\
\text { varios }\end{array}$ & $\begin{array}{l}\text { Entrevista semies- } \\
\text { tructurada propia }\end{array}$ & $\begin{array}{l}\text { Las PcDI mayores } \\
\text { buscan tener un mayor } \\
\text { control sobre sus vidas }\end{array}$ & Transversal & \\
\hline $\begin{array}{l}\text { Carmeli et } \\
\text { al. (2008) }\end{array}$ & $\begin{array}{l}\text { Entrenamiento físico } \\
\text { y sensación de bienes- } \\
\text { tar en PcDI mayores }\end{array}$ & $\begin{array}{l}62 \text { PcDI } \\
\text { leve mayo- } \\
\text { res que vi- } \\
\text { ven en una } \\
\text { residencia }\end{array}$ & $\begin{array}{l}\text { BMI, Perfil de au- } \\
\text { topercepción de } \\
\text { bienestar, NHP }\end{array}$ & $\begin{array}{l}\text { Relación positiva entre } \\
\text { el entrenamiento físico } \\
\text { y el grado de bienestar } \\
\text { percibido en PcDI }\end{array}$ & Longitudinal & $\begin{array}{l}\text { Podrían investigarse los } \\
\text { beneficios concretos } \\
\text { que pueda tener un pro- } \\
\text { grama de ejercicio físi- } \\
\text { co }\end{array}$ \\
\hline $\begin{array}{l}\text { Carr et. al. } \\
(2014)\end{array}$ & SD y envejecimiento & $\begin{array}{l}\text { Muestra de } \\
\text { PcSD }\end{array}$ & $\begin{array}{l}\text { Test cognitivos y de } \\
\text { memoria }\end{array}$ & Declive en test & Longitudinal & $\begin{array}{l}\text { Aunque no haya dia- } \\
\text { gnóstico de demencia se } \\
\text { produce un declive cog- } \\
\text { nitivo }\end{array}$ \\
\hline
\end{tabular}

Tabla 6.2.: Literatura sobre envejecimiento en personas con discapacidad intelectual. (Continuación). 


\begin{tabular}{|c|c|c|c|c|c|c|}
\hline Autor/es & Temática & Muestra & Medidas & Resumen & Estudio & Observaciones \\
\hline $\begin{array}{l}\text { Chan et al. } \\
(2001)\end{array}$ & $\begin{array}{l}\text { PcDI y uso de los } \\
\text { servicios de respiro } \\
\text { temporal a largo } \\
\text { plazo }\end{array}$ & $\begin{array}{l}10 \text { PcDI de } 3 \\
\text { unidades de } \\
\text { respiro inter- } \\
\text { nos }\end{array}$ & $\begin{array}{l}\text { Historial y entre- } \\
\text { vista directa fami- } \\
\text { lia }\end{array}$ & $\begin{array}{l}\text { Factores personales y } \\
\text { familiares influyen en } \\
\text { el uso de un servicio } \\
\text { de respiro temporal }\end{array}$ & Transversal & $\begin{array}{l}\text { Muestra no representa- } \\
\text { tiva de otras poblacio- } \\
\text { nes, no hay grupo de } \\
\text { comparación o grupo } \\
\text { control }\end{array}$ \\
\hline $\begin{array}{l}\text { Cleaver et } \\
\text { al. }(2008)\end{array}$ & $\begin{array}{l}\text { Relación entre limi- } \\
\text { taciones de movili- } \\
\text { dad y lugares para } \\
\text { PcDI mayores }\end{array}$ & $\begin{array}{l}128 \text { PcDI de } \\
45 \text { años o más } \\
\text { del Sureste de } \\
\text { Ontario }\end{array}$ & $\begin{array}{l}\text { Entrevista telefóni- } \\
\text { ca; } \\
\text { RMI }\end{array}$ & $\begin{array}{l}\text { Limitaciones movili- } \\
\text { dad se relacionan con } \\
\text { los servicios residen- } \\
\text { ciales de alto apoyo }\end{array}$ & Transversal & \\
\hline $\begin{array}{l}\text { Cleaver et. } \\
\text { al. (2009) }\end{array}$ & $\begin{array}{l}\text { Prevalencia de limi- } \\
\text { taciones movilidad } \\
\text { de PcDI mayores }\end{array}$ & $\begin{array}{l}128 \text { PcDI de } \\
45 \text { años o más }\end{array}$ & RMI, PALS & $\begin{array}{l}\text { Las limitaciones de } \\
\text { movimiento son muy } \\
\text { comunes en las PcDI } \\
\text { mayores }\end{array}$ & Transversal & $\begin{array}{l}\text { Hay muy pocas investi- } \\
\text { gaciones dedicadas a la } \\
\text { movilidad en PcDI }\end{array}$ \\
\hline $\begin{array}{l}\text { Coppus } \\
(2013)\end{array}$ & $\begin{array}{l}\text { Esperanza de vida en } \\
\text { PcDID }\end{array}$ & & & $\begin{array}{l}\text { La esperanza de vida } \\
\text { depende de síntomas } \\
\text { y complicaciones de } \\
\text { cada caso }\end{array}$ & Revisión & $\begin{array}{l}\text { Aporta datos cuantitati- } \\
\text { vos }\end{array}$ \\
\hline $\begin{array}{l}\text { Coppus et. } \\
\text { al. (2008) }\end{array}$ & $\begin{array}{l}\text { Supervivencia en } \\
\text { PcSD }\end{array}$ & $\begin{array}{l}506 \text { PcSD de } \\
45 \text { o más años }\end{array}$ & $\begin{array}{l}\text { DMR; SRZ; exa- } \\
\text { men físico; entre- } \\
\text { vista familia, etc. }\end{array}$ & $\begin{array}{l}\text { Edad, demencia y } \\
\text { movilidad, factores } \\
\text { más importantes para } \\
\text { predecir superviven- } \\
\text { cia }\end{array}$ & Longitudinal & $\begin{array}{l}\text { La principal causa de } \\
\text { muerte en PcSD son las } \\
\text { afecciones respiratorias }\end{array}$ \\
\hline
\end{tabular}

Tabla 6.3.: Literatura sobre envejecimiento en personas con discapacidad intelectual. (Continuación). 


\begin{tabular}{|c|c|c|c|c|c|c|}
\hline Autor/es & Temática & Muestra & Medidas & Resumen & Estudio & Observaciones \\
\hline $\begin{array}{l}\text { Crossley et } \\
\text { al. (2009) }\end{array}$ & $\begin{array}{l}\text { Medicación antip- } \\
\text { sicótica en PcDI }\end{array}$ & $\begin{array}{l}8 \text { PcDI } 31 \text { y } \\
66 \text { años de } \\
\text { leve a mode- } \\
\text { rada DI }\end{array}$ & Entrevista & $\begin{array}{l}\text { PcDI tienen medica- } \\
\text { ción antipsicótica sin } \\
\text { diagnóstico }\end{array}$ & Transversal & $\begin{array}{l}\text { La muestra de PcDI es } \\
\text { muy pequeña y las eda- } \\
\text { des son muy dispersas }\end{array}$ \\
\hline $\begin{array}{l}\text { Davidson } \\
\text { et. al. } \\
(2003)\end{array}$ & $\begin{array}{l}\text { Asociación trastor- } \\
\text { nos de comporta- } \\
\text { miento y estado de } \\
\text { salud en PcDI mayo- } \\
\text { res. }\end{array}$ & $\begin{array}{l}60.752 \text { PcDI } \\
\text { de una base de } \\
\text { datos de Nue- } \\
\text { va York }\end{array}$ & & $\begin{array}{l}\text { Asociación estado de } \\
\text { salud y trastornos del } \\
\text { comportamiento }\end{array}$ & Transversal & $\begin{array}{l}\text { Dificultades para agru- } \\
\text { par a los sujetos en fun- } \\
\text { ción del tipo de enfer- } \\
\text { medad }\end{array}$ \\
\hline $\begin{array}{l}\text { De Winter } \\
\text { et. al. } \\
(2015)\end{array}$ & $\begin{array}{l}\text { Ansiedad, depresión, } \\
\text { diabetes y riesgo } \\
\text { cardiovascular }\end{array}$ & $\begin{array}{l}909 \text { PcDID de } \\
50 \text { o más años }\end{array}$ & $\begin{array}{l}\text { Cuestionario } \\
\text { Examen físico }\end{array}$ & $\begin{array}{l}\text { Relación entre sínto- } \\
\text { mas de ansiedad y } \\
\text { diabetes }\end{array}$ & Transversal & $\begin{array}{l}\text { Necesidad de más estu- } \\
\text { dios }\end{array}$ \\
\hline $\begin{array}{l}\text { Dodd et. } \\
\text { al. (2009) }\end{array}$ & $\begin{array}{l}\text { Evaluación y carac- } \\
\text { terísticas de PcDI } \\
\text { mayores }\end{array}$ & $\begin{array}{l}\text { Base de datos } \\
\text { NIDD }\end{array}$ & $\begin{array}{l}\text { Cuestionario pro- } \\
\text { pio }\end{array}$ & $\begin{array}{l}\text { Las PcDI no tienen } \\
\text { acceso a los servicios }\end{array}$ & Transversal & $\begin{array}{l}\text { La muestra se restringe } \\
\text { a una base de datos na- } \\
\text { cional, no representativa }\end{array}$ \\
\hline $\begin{array}{l}\text { Doody et. } \\
\text { al. }(2011)\end{array}$ & $\begin{array}{l}\text { Envejecimiento de } \\
\text { PcDID en Irlanda }\end{array}$ & & & $\begin{array}{l}\text { Necesidad de servi- } \\
\text { cios de apoyo espe- } \\
\text { cializados }\end{array}$ & Revisión & $\begin{array}{l}\text { Importancia de ajustar } \\
\text { los servicios a las nece- } \\
\text { sidades }\end{array}$ \\
\hline $\begin{array}{l}\text { Doody et. } \\
\text { al. (2013) }\end{array}$ & $\begin{array}{l}\text { Experiencias en el } \\
\text { cuidado de PcDID } \\
\text { mayores }\end{array}$ & 7 enfermeras & $\begin{array}{l}\text { Entrevista semies- } \\
\text { tructurada }\end{array}$ & $\begin{array}{l}\text { Importancia de la } \\
\text { atención médica indi- } \\
\text { vidualizada }\end{array}$ & Transversal & $\begin{array}{l}\text { Pequeño tamaño de } \\
\text { muestra }\end{array}$ \\
\hline
\end{tabular}

Tabla 6.4.: Literatura sobre envejecimiento en personas con discapacidad intelectual. (Continuación). 


\begin{tabular}{|c|c|c|c|c|c|c|}
\hline Autor/es & Temática & Muestra & Medidas & Resumen & Estudio & Observaciones \\
\hline $\begin{array}{l}\text { Dos San- } \\
\text { tos et. al. } \\
(2009)\end{array}$ & $\begin{array}{l}\text { Marcadores de auto- } \\
\text { nomía en PcDI. }\end{array}$ & $\begin{array}{l}47 \text { PcDI de } 28 \\
\text { a } 58 \text { años cen- } \\
\text { tro ocupacional } \\
\text { Brasil }\end{array}$ & $\begin{array}{l}\text { StanfordBinet; } \\
\text { WISC; Escala } \\
\text { propia de Auto- } \\
\text { nomía }\end{array}$ & $\begin{array}{l}\text { La autonomía en PcDI es } \\
\text { un fenómeno multifacto- } \\
\text { rial asociado al deterioro } \\
\text { cognitivo }\end{array}$ & Longitudinal & $\begin{array}{l}\text { Número de participan- } \\
\text { tes pequeño, baja repre- } \\
\text { sentatividad, }\end{array}$ \\
\hline $\begin{array}{l}\text { Dykens } \\
(2013)\end{array}$ & $\begin{array}{l}\text { Envejecimiento en } \\
\text { síndromes raros }\end{array}$ & & & $\begin{array}{l}\text { Estudio sobre los avances } \\
\text { en investigación en enve- } \\
\text { jecimiento }\end{array}$ & Revisión & \\
\hline $\begin{array}{l}\text { Esbensen } \\
(2016)\end{array}$ & $\begin{array}{l}\text { Problemas sueño } \\
\text { PcSD }\end{array}$ & 75 PcSD & Cuestionario & $\begin{array}{l}\text { Relación entre trastorno } \\
\text { mental y problemas sueño }\end{array}$ & Transversal & $\begin{array}{l}\text { Necesario tratar los } \\
\text { problemas de sueño } \\
\text { para prevenir trastor- } \\
\text { nos. }\end{array}$ \\
\hline $\begin{array}{l}\text { Evenhuis } \\
\text { et. al. } \\
\text { (2013) }\end{array}$ & Fragilidad en PcDID & & & $\begin{array}{l}\text { La fragilidad aparece antes } \\
\text { y de forma más severa en } \\
\text { PcDID mayores que en } \\
\text { población general }\end{array}$ & Revisión & $\begin{array}{l}\text { Necesario investigar } \\
\text { resultados de salud, } \\
\text { causas y prevención de } \\
\text { la fragilidad. }\end{array}$ \\
\hline $\begin{array}{l}\text { Glaesser } \\
\text { et. al. } \\
(2013)\end{array}$ & $\begin{array}{l}\text { Comportamiento au- } \\
\text { tolesivo }\end{array}$ & & & $\begin{array}{l}\text { Factores que influyen en el } \\
\text { comportamiento autolesi- } \\
\text { vo }\end{array}$ & Revisión & $\begin{array}{l}\text { Tiene implicaciones } \\
\text { para los profesionales }\end{array}$ \\
\hline $\begin{array}{l}\text { Hartley } \\
\text { et. al. } \\
\text { (2007) }\end{array}$ & $\begin{array}{l}\text { Comportamientos } \\
\text { desafiantes de PcDI } \\
\text { mayores hacia el per- } \\
\text { sonal }\end{array}$ & $\begin{array}{l}132 \mathrm{PcDI} \text { ma- } \\
\text { yores }\end{array}$ & ICAP & $\begin{array}{l}\text { Conocer comportamientos } \\
\text { desafiantes de las PcDI } \\
\text { mejora la calidad de los } \\
\text { servicios }\end{array}$ & Longitudinal & \\
\hline $\begin{array}{l}\text { Heller } \\
(2009)\end{array}$ & Modelos teóricos & & & $\begin{array}{l}\text { Modelo de apoyos- } \\
\text { resultados }\end{array}$ & Revisión & \\
\hline
\end{tabular}

Tabla 6.5.: Literatura sobre envejecimiento en personas con discapacidad intelectual. (Continuación). 


\begin{tabular}{|c|c|c|c|c|c|c|}
\hline Autor/es & Temática & Muestra & Medidas & Resumen & Estudio & Observaciones \\
\hline $\begin{array}{l}\text { Henderson } \\
\text { et. al. } \\
(2009)\end{array}$ & $\begin{array}{l}\text { Estado de salud y } \\
\text { AVD en PcDI }\end{array}$ & $\begin{array}{l}1.371 \text { adultos } \\
\text { mayores de } 40 \\
\text { años }\end{array}$ & RHSS & $\begin{array}{l}\text { El estado de salud es un } \\
\text { predictor del deterioro } \\
\text { funcional, pero no lo es la } \\
\text { edad avanzada }\end{array}$ & Transversal & \\
\hline $\begin{array}{l}\text { Hermans } \\
\text { et. al. } \\
(2013)\end{array}$ & $\begin{array}{l}\text { Síntomas de depre- } \\
\text { sión y ansiedad }\end{array}$ & $\begin{array}{l}990 \text { PcDID de } \\
50 \text { años o más }\end{array}$ & $\begin{array}{l}\text { Cuestionario } \\
\text { psiquiátrico }\end{array}$ & $\begin{array}{l}\text { Factores asociados a los } \\
\text { síntomas de depresión y } \\
\text { ansiedad. }\end{array}$ & Transversal & $\begin{array}{l}\text { Las AIVD, las redes } \\
\text { sociales son factores } \\
\text { protectores. }\end{array}$ \\
\hline $\begin{array}{l}\text { Iacono et. } \\
\text { al. (2014) }\end{array}$ & SD y Alzheimer & $\begin{array}{l}\text { Personal que } \\
\text { atiende a } 9 \\
\text { PcSD y Alz- } \\
\text { heimer }\end{array}$ & Entrevistas & $\begin{array}{l}\text { Limitaciones del personal } \\
\text { para entender la influencia } \\
\text { del Alzheimer }\end{array}$ & Longitudinal & $\begin{array}{l}\text { Necesidad de forma- } \\
\text { ción }\end{array}$ \\
\hline $\begin{array}{l}\text { Janicki et. } \\
\text { al. (2008) }\end{array}$ & $\begin{array}{l}\text { Características sani- } \\
\text { tarias y utilización de } \\
\text { servicios sanitarios } \\
\text { en PcDI mayores que } \\
\text { viven en residencias }\end{array}$ & $\begin{array}{l}1371 \text { PcDI de } \\
40 \text { años o más } \\
\text { de dos regio- } \\
\text { nes de EEUU }\end{array}$ & $\begin{array}{l}\text { Cuestionario; } \\
\text { Encuesta Nacio- } \\
\text { nal }\end{array}$ & $\begin{array}{l}\text { Los problemas de salud en } \\
\text { PcDI son relativos y se } \\
\text { incrementan con la edad }\end{array}$ & Transversal & $\begin{array}{l}\text { Los resultados son con- } \\
\text { tradictorios, parece que } \\
\text { determinados factores } \\
\text { de riesgo aun no estan- } \\
\text { do presentes incremen- } \\
\text { tan la morbilidad de las } \\
\text { PcDI }\end{array}$ \\
\hline $\begin{array}{l}\text { Jansen et. } \\
\text { al. (2013) }\end{array}$ & $\begin{array}{l}\text { Prevalencia de en- } \\
\text { fermedades cardio- } \\
\text { vasculares }\end{array}$ & $\begin{array}{l}510 \text { PcDID y } \\
823 \text { personas } \\
\text { sin discapaci- } \\
\text { dad de } 50 \text { o } \\
\text { más años }\end{array}$ & Historial médico & $\begin{array}{l}\text { No hay prevalencia distin- } \\
\text { ta de enfermedad cardi- } \\
\text { vascular en PcDID que en } \\
\text { población general }\end{array}$ & Transversal & $\begin{array}{l}\text { La población con SD } \\
\text { no estaba bien repre- } \\
\text { sentada. }\end{array}$ \\
\hline $\begin{array}{l}\text { Krinsky- } \\
\text { Mc-Hale } \\
\text { et. al. } \\
\text { (2013) }\end{array}$ & $\begin{array}{l}\text { Diagnóstico del dete- } \\
\text { rioro cognitivo leve }\end{array}$ & & & $\begin{array}{l}\text { Necesarios criterios e ins- } \\
\text { trumentos diagnósticos } \\
\text { específicos }\end{array}$ & Revisión & $\begin{array}{l}\text { No hay instrumentos } \\
\text { adaptados. }\end{array}$ \\
\hline
\end{tabular}

Tabla 6.6.: Literatura sobre envejecimiento en personas con discapacidad intelectual. (Continuación). 


\begin{tabular}{|c|c|c|c|c|c|c|}
\hline Autor/es & Temática & Muestra & Medidas & Resumen & Estudio & Observaciones \\
\hline $\begin{array}{l}\text { Lehman et. } \\
\text { al. (2013) }\end{array}$ & $\begin{array}{l}\text { Impacto de recursos } \\
\text { personales }\end{array}$ & $\begin{array}{l}669 \text { PcDI ma- } \\
\text { yores con DI } \\
\text { leve o mode- } \\
\text { rada }\end{array}$ & Entrevista & $\begin{array}{l}\text { Recursos personales in- } \\
\text { fluyen en la satisfacción } \\
\text { en el envejecimiento }\end{array}$ & Longitudinal & \\
\hline $\begin{array}{l}\text { Lifshitz } \\
(2002)\end{array}$ & $\begin{array}{l}\text { Actitudes hacia el } \\
\text { envejecimiento en } \\
\text { PcDI adultas y ma- } \\
\text { yores }\end{array}$ & $\begin{array}{l}32 \text { PcDI de } 20 \\
\text { y más años; } 32 \\
\text { personas sin } \\
\text { DI de } 20 \text { a } 59 \\
\text { años }\end{array}$ & $\begin{array}{l}\text { Cuestionario } \\
\text { propio. Prueba } \\
\text { de diferencial } \\
\text { semántico }\end{array}$ & $\begin{array}{l}\text { Necesarios programas } \\
\text { para preparar a las PcDI } \\
\text { para envejecimiento }\end{array}$ & Transversal & $\begin{array}{l}\text { La muestra por edades } \\
\text { es reducida. Material } \\
\text { no adaptado a PcDI }\end{array}$ \\
\hline $\begin{array}{l}\text { Maes et. al. } \\
(2008)\end{array}$ & $\begin{array}{l}\text { Adaptación de servi- } \\
\text { cios envejecimiento } \\
\text { PcDI }\end{array}$ & $\begin{array}{l}\text { Coordinadores } \\
\text { de servicios en } \\
\text { Flandes }\end{array}$ & $\begin{array}{l}\text { Cuestionario } \\
\text { propio }\end{array}$ & $\begin{array}{l}\text { Los servicios han empe- } \\
\text { zado a adaptarse para las } \\
\text { PcDI, pero aún faltan mu- } \\
\text { chas mejoras }\end{array}$ & Transversal & $\begin{array}{l}\text { Tamaño de muestra } \\
\text { reducido; la evaluación } \\
\text { de las opiniones del } \\
\text { personal puede no ser } \\
\text { objetiva }\end{array}$ \\
\hline $\begin{array}{l}\text { Marks et. } \\
\text { al. (2013) }\end{array}$ & $\begin{array}{l}\text { Programa de salud } \\
\text { en PcDID }\end{array}$ & $\begin{array}{l}67 \text { PcDID de } \\
30 \text { años o más }\end{array}$ & $\begin{array}{l}\text { Programa de } \\
\text { entrenamiento } \\
\text { específico sobre } \\
\text { salud }\end{array}$ & El programa es eficaz & Longitudinal & $\begin{array}{l}\text { Promoción de la edu- } \\
\text { cación para la salud }\end{array}$ \\
\hline $\begin{array}{l}\text { McCarron } \\
\text { et. al. } \\
(2003)\end{array}$ & $\begin{array}{l}\text { Respuesta a los retos } \\
\text { del envejecimiento y } \\
\text { la demencia en PcDI } \\
\text { en Irlanda }\end{array}$ & & & $\begin{array}{l}\text { La demencia en algunas } \\
\text { PcDI necesita un modelo } \\
\text { multidisciplinar. }\end{array}$ & Revisión & \\
\hline $\begin{array}{l}\text { McConkey } \\
\text { et. al. } \\
(2006)\end{array}$ & $\begin{array}{l}\text { Personas adultas con } \\
\text { DI en Irlanda }\end{array}$ & $\begin{array}{l}\text { Base de datos } \\
\text { de PcDI }\end{array}$ & Base de datos & $\begin{array}{l}\text { 25.134 personas. preva- } \\
\text { lencia de PcDI es de } \\
6,34 / 1000 \text { habitantes }\end{array}$ & Transversal & $\begin{array}{l}\text { Prevalencia varía a lo } \\
\text { largo de diferentes re- } \\
\text { giones }\end{array}$ \\
\hline
\end{tabular}

Tabla 6.7.: Literatura sobre envejecimiento en personas con discapacidad intelectual. (Continuación). 


\begin{tabular}{|c|c|c|c|c|c|c|}
\hline Autor/es & Temática & Muestra & Medidas & Resumen & Estudio & Observaciones \\
\hline $\begin{array}{l}\text { McGlinchey } \\
\text { ey. al. } \\
\text { (2013) }\end{array}$ & Empleo en PcDID & $\begin{array}{l}\text { Base de datos } \\
\text { ( } 753 \text { PcDID de } \\
40 \text { o más años) } \\
\end{array}$ & Base de datos & $\begin{array}{l}\text { El } 73,5 \% \text { de PcDID esta- } \\
\text { ban desempleadas }\end{array}$ & Transversal & $6,6 \%$ PcDID trabajan \\
\hline $\begin{array}{l}\text { Mercier et. } \\
\text { al. }(2011)\end{array}$ & Pobreza y DI & $\begin{array}{l}68 \text { PcDI sin } \\
\text { casa, edad de } \\
48 \text { años }\end{array}$ & $\begin{array}{l}\text { DSM-IV; Índice } \\
\text { Habilidad de } \\
\text { Hayes }\end{array}$ & $\begin{array}{l}\text { DI es un factor de riesgo } \\
\text { de la falta de vivienda }\end{array}$ & Transversal & $\begin{array}{l}\text { Necesidad de preven- } \\
\text { ción e intervención de } \\
\text { quedar sin hogar }\end{array}$ \\
\hline $\begin{array}{l}\text { Millán- } \\
\text { Calenti et. } \\
\text { al. (2008) }\end{array}$ & DI y envejecimiento & $\begin{array}{l}189 \text { PcDI ma- } \\
\text { yores de } 45 \\
\text { años de Gali- } \\
\text { cia }\end{array}$ & $\begin{array}{l}\text { Cuestionario } \\
\text { propio }\end{array}$ & $\begin{array}{l}\text { Casi la mitad de PcDI } \\
\text { viven con sus familias. y } \\
\text { tienen DI moderada }\end{array}$ & Transversal & $\begin{array}{l}\text { Es necesario mejorar la } \\
\text { calidad de la atención } \\
\text { de los servicios, }\end{array}$ \\
\hline $\begin{array}{l}\text { Murray et. } \\
\text { al. (2013) }\end{array}$ & Gravedad de la DI & $\begin{array}{l}215 \text { PcDID de } \\
\text { media } 34 \text { años }\end{array}$ & $\begin{array}{l}\text { Cuestionario de } \\
\text { screening de DI }\end{array}$ & $\begin{array}{l}\text { Aporta datos de gravedad } \\
\text { a la evaluación }\end{array}$ & Transversal & $\begin{array}{l}\text { Se adecúa a las propie- } \\
\text { dades de la escala } \\
\text { Mokken }\end{array}$ \\
\hline $\begin{array}{l}\text { Patja et. al. } \\
(2000)\end{array}$ & $\begin{array}{l}\text { Esperanza de vida en } \\
\text { PcDI }\end{array}$ & $\begin{array}{l}\text { 60.969 PcDI } \\
\text { de Finlandia }\end{array}$ & Base de datos & $\begin{array}{l}\text { PcDI leve esperanza de } \\
\text { vida similar a población } \\
\text { general }\end{array}$ & Longitudinal & $\begin{array}{l}\text { Las necesidades de } \\
\text { cada colectivo son di- } \\
\text { ferentes }\end{array}$ \\
\hline $\begin{array}{l}\text { Patti et. al. } \\
\text { (2010) }\end{array}$ & $\begin{array}{l}\text { Problemas de ubica- } \\
\text { ción y final de la } \\
\text { vida de personas con } \\
\text { y sin SD }\end{array}$ & $\begin{array}{l}61 \text { PcSD y } 79 \\
\text { P. sin SD }\end{array}$ & Base de datos & $\begin{array}{l}\text { SD más recolocaciónes en } \\
\text { hogares y edad media de } \\
\text { muerte más alta que sin } \\
\text { SD }\end{array}$ & Transversal & $\begin{array}{l}\text { Diferencias significati- } \\
\text { vas en estado de de- } \\
\text { mencia de ambos gru- } \\
\text { pos. }\end{array}$ \\
\hline $\begin{array}{l}\text { Ribes et. al. } \\
\text { (2000) }\end{array}$ & $\begin{array}{l}\text { Evaluación del enve- } \\
\text { jecimiento patológi- } \\
\text { co en PcDID }\end{array}$ & & & $\begin{array}{l}\text { La evaluación de DI en } \\
\text { áreas de salud, afectiva, } \\
\text { cognitiva, social y de la } \\
\text { vida diaria }\end{array}$ & Revisión & $\begin{array}{l}\text { Se centra básicamente } \\
\text { en tres áreas y en po- } \\
\text { blación con síndrome } \\
\text { de Down }\end{array}$ \\
\hline $\begin{array}{l}\text { Smulders et. } \\
\text { al. (2013) }\end{array}$ & $\begin{array}{l}\text { Caídas en PcDID } \\
\text { mayores }\end{array}$ & $\begin{array}{l}38 \text { PcDID de } \\
50 \text { años o más }\end{array}$ & Registro & $\begin{array}{l}\mathrm{N}^{\circ} \text { de caídas comparable a } \\
\text { población general }\end{array}$ & Longitudinal & $\begin{array}{l}\text { Consecuencias graves } \\
\text { de las caídas }\end{array}$ \\
\hline
\end{tabular}

Tabla 6.8.: Literatura sobre envejecimiento en personas con discapacidad intelectual. (Continuación). 


\begin{tabular}{|c|c|c|c|c|c|c|}
\hline Autor/es & Temática & Muestra & Medidas & Resumen & Estudio & Observaciones \\
\hline $\begin{array}{l}\text { Shaw et. al. } \\
\text { (2011) }\end{array}$ & $\begin{array}{l}\text { Vivienda en PcDI } \\
\text { mayores }\end{array}$ & $\begin{array}{l}15 \text { PcDI me- } \\
\text { dia } 46 \text { años; } \\
10 \text { familiares }\end{array}$ & Grupos focales & $\begin{array}{l}\text { Las PcDI quieren enveje- } \\
\text { cer en su entorno sin per- } \\
\text { der su red social }\end{array}$ & Transversal & $\begin{array}{l}\text { Importante a tener en } \\
\text { cuenta en las políticas } \\
\text { futuras }\end{array}$ \\
\hline $\begin{array}{l}\text { Schoufour } \\
\text { et. al. } \\
(2015)\end{array}$ & $\begin{array}{l}\text { Fragilidad y mortali- } \\
\text { dad en } 3 \text { años }\end{array}$ & $\begin{array}{l}982 \text { PcDID de } \\
50 \text { o más años }\end{array}$ & $\begin{array}{l}\text { Cuestionario } \\
\text { Índice de fragi- } \\
\text { lidad }\end{array}$ & $\begin{array}{l}\text { Relación entre mayor } \\
\text { fragilidad y supervivencia }\end{array}$ & Longitudinal & $\begin{array}{l}\text { Indep. de sexo, edad, } \\
\text { nivel de DI }\end{array}$ \\
\hline $\begin{array}{l}\text { Thompson } \\
\text { et. al. } \\
\text { (2004) }\end{array}$ & $\begin{array}{l}\text { PcDI que viven en } \\
\text { residencias de ancia- } \\
\text { nos }\end{array}$ & $\begin{array}{l}2.570 \text { residen- } \\
\text { cias y } 53 \\
\text { hogares }\end{array}$ & $\begin{array}{l}\text { Cuestionario } \\
\text { propio }\end{array}$ & $\begin{array}{l}\text { Las residencias no cubren } \\
\text { todas las necesidades }\end{array}$ & Transversal & $\begin{array}{l}\text { Cambiar la residencia } \\
\text { de ancianos por una } \\
\text { para PcDI, }\end{array}$ \\
\hline $\begin{array}{l}\text { Thorpe et. } \\
\text { al. }(2001)\end{array}$ & $\begin{array}{l}\text { Problemas de com- } \\
\text { portamiento }\end{array}$ & & & $\begin{array}{l}\text { Formación específica de } \\
\text { los profesionales }\end{array}$ & Revisión & $\begin{array}{l}\text { No se debe confundir } \\
\text { la DI con trastornos } \\
\text { psiquiátricos }\end{array}$ \\
\hline $\begin{array}{l}\text { Van De } \\
\text { Wouw et. } \\
\text { al. }(2013) \\
\end{array}$ & $\begin{array}{l}\text { Sueño en PcDID ma- } \\
\text { yores }\end{array}$ & $\begin{array}{l}10 \text { PcDID } \\
\text { mayores }\end{array}$ & Actiwatch & $\begin{array}{l}\text { El instrumento detecta los } \\
\text { problemas de sueño en } \\
\text { PcDID }\end{array}$ & Transversal & $\begin{array}{l}\text { Se recomienda para } \\
\text { evaluación clínica del } \\
\text { sueño. }\end{array}$ \\
\hline $\begin{array}{l}\text { Wart et. al. } \\
\text { (2014) }\end{array}$ & $\begin{array}{l}\text { Personal que atiende a } \\
\text { PcDID que envejecen }\end{array}$ & Base de datos & Método Delphi & $\begin{array}{l}\text { Importancia de } 5 \text { temas en } \\
\text { el personal }\end{array}$ & Transversal & Mejora en la formación \\
\hline $\begin{array}{l}\text { Whitehouse } \\
\text { et. al. } \\
(2006)\end{array}$ & $\begin{array}{l}\text { Terapias cognitivo- } \\
\text { conductuales y psi- } \\
\text { coanalíticas }\end{array}$ & & & Adaptación de las terapias & Revisión & $\begin{array}{l}\text { Podrían valorarse más } \\
\text { tipos de adaptaciones }\end{array}$ \\
\hline $\begin{array}{l}\text { Zigman } \\
(2013)\end{array}$ & Alzheimer y PcSD & & & $\begin{array}{l}\text { La esperanza de vida si- } \\
\text { gue siendo menor en } \\
\text { PcSD }\end{array}$ & Revisión & $\begin{array}{l}\text { Entre el } 20-30 \% \text { de } \\
\text { PcSD no debería mos- } \\
\text { trar signos de Alzhei- } \\
\text { mer por el fenotipo }\end{array}$ \\
\hline
\end{tabular}

Tabla 6.9.: Literatura sobre envejecimiento en personas con discapacidad intelectual. (Continuación). 
Bigby (2008) lleva a cabo una revisión para conocer por qué hay obstáculos a la hora de que las PcDI mayores puedan envejecer en lugares especializados. Normalmente las PcDI cuando alcanzan una edad media son derivadas a hogares de grupo, donde conviven con personas mayores, o a residencias de personas mayores. La autora revisa las políticas llevadas a cabo en Australia para apoyar que las PcDI puedan envejecer en el lugar apropiado, y las razones del desarrollo lento que parecen estar teniendo. Los resultados indican que no hay mecanismos para organizar la financiación de la discapacidad cuando cambian las necesidades del colectivo por causa de la edad, lo que obliga a los servicios de discapacidad a trabajar por su cuenta para favorecer el envejecimiento de este colectivo en un lugar especializado. La autora concluye que aunque se ha intentado compaginar la política de discapacidad con la de cuidado de personas mayores, determinadas características administrativas y de financiación de tales servicios siguen obstaculizando la implantación de estrategias que apoyen el envejecimiento en un lugar apropiado para PcDI.

Bigby, Bowers y Webber (2011) realizan un estudio para investigar las percepciones de los familiares, los profesionales y el personal de la organización sobre el futuro de los residentes con DI mayores y la decisión del traslado a una residencia si fuera necesario. Se realizaron entrevistas en un período de 18 meses. Los resultados indican que los planes de alojamiento para toda la vida en un hogar grupal y la sucesión de la persona que se va fueron efectivos; sin embargo, la decisión de un traslado a una residencia de ancianos se realizó de forma rápida y se ve como un hecho consumado por los miembros de la familia involucrados. Los autores concluyen que aunque los miembros del hogar grupal se tomen en serio el supervisar el bienestar de su compañero, tienen 
poco conocimiento acerca de sus derechos y de las decisiones inapropiadas que toman los profesionales.

Bigby y Knox (2009) realizan un estudio para investigar las experiencias que 16 PcDI de 52-80 años tienen de los servicios que utilizan. El objetivo del estudio era obtener información sobre el desarrollo de las prácticas y los servicios que se llevan a cabo para las PcDI mayores en Australia. Los resultados sugieren que los servicios, aun facilitando las relaciones sociales de sus usuarios con los usuarios y el personal de otros servicios, tienen la necesidad de seguir trabajando en la dirección de crear iniciativas para que las PcDI puedan acceder a más esferas de relación que no sean meramente la de la familia y la de los servicios, y que además esas relaciones puedan mantenerse en el tiempo con independencia de los cambios que se puedan producir en la vida de estas personas. Las autoras proponen asimismo que los servicios deben aplicar la filosofía de Reino Unido de una planificación centrada en la persona.

Bigby, Webber, Bowers y McKenzie-Green (2008) analizan la situación de PcDI que envejecen en residencias genéricas para personas mayores en Victoria. Para ello elaboraron un cuestionario que enviaron a 826 residencias para recoger información de los directores de las mismas acerca de sus residentes mayores con DI. Los resultados indican que los residentes con DI eran más jóvenes que el resto de residentes, así como que entraban más jóvenes en el servicio residencial. Los directores identificaban dos áreas principales en las que las PcDI tenían dificultades, una de ellas era la incapacidad para adaptarse a la comunidad residente, y la otra la falta de participación en las actividades y la falta de relaciones sociales significativas. Los autores concluyen que es necesaria más investigación en este ámbito, ya que las PcDI suelen ser internadas en servi- 
cios residenciales genéricos para personas mayores, mientras requieren una atención especializada.

Brehmer y Weber (2010) realizan un estudio con el fin de distinguir la DI y la fragilidad. Para ello emplean una muestra de 190 PcDI a las que someten a una entrevista y al cuestionario VFQ-ID, que recoge 4 dominios de fragilidad, que son social, cognitivo, físico y salud mental. Los resultados indican que todas las personas entrevistadas habían experimentado cambios en los dominios físico y psicológico, y que el deterioro en ambos dominios es frecuente en las personas frágiles. También se encontró que la percepción de una disminución del estado de salud general era el elemento más importante de la fragilidad. Este estudio demuestra que la discapacidad y la fragilidad son dos variables diferentes, y que las PcDI pueden desarrollar el llamado síndrome de fragilidad, sobre todo porque éste está frecuentemente asociado al proceso de envejecimiento; sin embargo, no se sabe si la fragilidad en las PcDI severa o profunda progresa de manera diferente a la que se puede dar en PcDI leve o moderada.

Burt, Primeaux-Hart, Loveland, Cleveland, et. al. (2005) realizan un estudio acerca del envejecimiento precoz en PcSD. Para ello emplearon una muestra de 55 PcSD y de 75 PcDI derivada de otras causas, a la que sometieron a un examen neuropsicológico y una evaluación médica. Los resultados indican que una evidencia acerca del envejecimiento precoz en las PcSD fue su bajo rendimiento en una prueba de fluidez verbal con respecto a las PcDI por otras causas, y que además, una prueba de habilidades de motricidad fina también constituye un apoyo, aunque más débil que el anterior. Los autores también encontraron una relación consistente entre el nivel intelectual general, el género y el estado psiquiátrico y el rendimiento en las pruebas, lo cual, como 
concluyen los autores, indica la necesidad de tener en cuenta tales variables mediadoras en los futuros estudios acerca del envejecimiento en esta población.

Buys, Boulton-Lewis, Tedman-Hones, Edwards et. al. (2008) realizan un estudio para conocer las experiencias de PcDI de 50 años o mayores, con el fin de investigar el significado del envejecimiento activo en este colectivo. Para ello pasaron entrevistas semiestructuradas a 16 PcDI, a 16 proveedores de servicios y a16 miembros de una red de cuidado informal de Queensland y Victoria. Los autores identificaron temas como el tener una participación activa, la sensación de seguridad, el mantenimiento de habilidades y aprendizaje, el buen estado de salud y estado físico, el tener relaciones sociales satisfactorias y apoyo, entre otros. Las conclusiones a las que llegan los autores es que las PcDI que utilizan los servicios especializados quieren continuar inmersos en las áreas de la vida en las que se sienten cómodos, sin tener que interrumpir su participación a causa de la edad. Del mismo modo, este colectivo busca tener el control de las cuestiones que afectan a sus vidas y tener un papel significativo en ello. Asimismo, las PcDI valoraron positivamente la simulación mental, el compañerismo, el tener un apoyo fiable y la sensación de seguridad.

Carmeli, Orbach, Zinger-Vaknin, Morad y Merrick (2008) tenían como objetivo conocer el efecto que tiene el entrenamiento físico en la percepción de bienestar en PcDI mayores que viven en residencias de Israel. Para ello llevaron a cabo un programa de entrenamiento físico 3 veces a la semana en un grupo considerado experimental, para compararlo con otro grupo que no recibía el entrenamiento. Se tomaban varias medidas, ya que el programa de entrenamiento tenía una duración de 10 meses. Los resultados mostraron una relación positiva entre el bienestar general percibido por la PcDI y el entrenamiento físico, entre el grupo experimental y el grupo control. Los autores con- 
cluyen que esta relación positiva destaca el papel tan importante que tiene el entrenamiento físico para mejorar la autopercepción de bienestar en las PcDI mayores.

Carr y Collins (2014) realizan una evaluación de una muestra de PcSD en la infancia y a los 47 años. Evalúan la inteligencia, las AVD y las habilidades de lenguaje, así como el deterioro en memoria y a nivel cognitivo. Los resultados indican que los resultados los test de inteligencia verbal no cambiaron mucho. Sí que hubo declive en las habilidades de autoayuda y en dos pruebas de memoria, incluso teniendo en cuenta a los que ya tenían demencia. Los autores concluyen que estos daton reflejan el proceso de envejecimiento normal en este colectivo, ya que a los 47 años, en casi todos los test aparecía un declive, aunque no estuvieran diagnosticados con demencia.

Chan, Sigafoos, Watego y Potter (2001) llevan a cabo un estudio para conocer los posibles indicadores del uso a largo plazo de un servicio de respiro, que debería ser temporal. Para ello emplean una muestra compuesta por 10 PcDI adultas que vivían en 3 unidades de respiro por un tiempo superior a 12 meses. Recogieron diversa información sobre el estado de salud, las características familiares, etc., a través de registros médicos y psicológicos. También se obtenía información por medio de una entrevista directa con los familiares. Los resultados indican que determinados factores influyen sobre el empleo de un medio de respiro a largo plazo, y que estos pueden ser o bien personales o bien familiares. Entre los factores personales eran consistentes a lo largo de la muestra los cambios de comportamiento de la PcDI y las nulas habilidades comunicativas. Entre los factores familiares destacan el estado civil del cuidador (padre/madre soltero/a), la edad avanzada y la salud de los padres o de uno de ellos y las familias que provienen de lugares donde el inglés no es la lengua habitual. Los autores concluyen que, aunque el estudio tiene limitaciones (falta de grupo control, falta de representativi- 
dad de la muestra), es importante llevar a cabo una planificación de los servicios de respiro, así como el uso de las técnicas de modificación del comportamiento y el empleo de estrategias eficaces de comunicación.

Cleaver, Ouellette-Kuntz y Hunter (2008) llevan a cabo un estudio para investigar la relación entre las limitaciones de movilidad y los lugares donde residen 128 PcDI de 45 años o más. Para ello llevan a cabo una entrevista telefónica además de la aplicación del RMI. Los lugares donde residen estas personas los dividen en dos grupos, servicios de alto apoyo (residencias para mayores, hogares de grupo) y de bajo apoyo (viven en sus domicilios familiares, etc.). Los resultados indican que las personas con problemas de movilidad presentaban mayor probabilidad de vivir en un servicio de alto apoyo. Los autores concluyen que las limitaciones de movilidad se relacionan con los servicios de alto apoyo y que es necesaria mayor investigación para conocer la dirección de la causalidad y poder crear servicios y programas que favorezcan la igualdad de oportunidades en el colectivo estudiado.

Cleaver, Ouellette-Kuntz y Hunter (2009) realizan un estudio para conocer la prevalencia y severidad de las limitaciones de movilidad de las PcDI mayores. Para ello emplean una muestra de 128 PcDI de 45 años o más a quienes se pasaron dos pruebas, el RMI y el PALS. Los resultados sugieren que las limitaciones de movimiento eran comunes en esta población, aunque la prevalencia era diferente dependiendo de la definición de limitación de movimiento. Asimismo, la prevalencia encontrada por los autores fue mayor en mujeres que en hombres, sin que influyera la edad. Los autores concluyen que la naturaleza común que tienen las limitaciones de movilidad en las PcDI mayores tiene implicaciones tanto para aquellos responsables de la provisión de servicios como para los responsables del desarrollo de políticas en este colectivo. 
Coppus (2013) realiza una revisión para investigar la esperanza de vida en personas con DID. Los resultados indican que la esperanza de vida, con la edad máxima en el síndrome de Angelman es 72, en la PC es 55, en la Cornelia de Lange es de 71, en el síndrome de Down de 82, en el X frágil de 87, en la fenilcetonuria es de 70, en Prader Willi de 72, en síndrome de Rett 55, el Sanfilippo es de 69 años, en la esclerosis tuberosa de 50 y el síndrome de Williams de 55, dependiendo de cómo envejece el individuo, así como los síntomas y las complicaciones que subyacen a cada caso.

Coppus, Evenhuis, Verberne, Visser, et al. (2008) realizan un estudio para investigar cuáles son los factores que predicen la supervivencia de las PcSD de 45 o más años. Para ello emplean una muestra de 506 PcSD a la que sometieron a diversas pruebas físicas, médicas y neurológicas. Los resultados indican que la edad, la presencia de demencia y las limitaciones en la movilidad son los predictores más importantes de la supervivencia en este colectivo. Otros factores que predicen la supervivencia en menor medida serían la severidad de la discapacidad, la presencia de epilepsia y deficiencia visual, pero no lo eran los factores de riesgo cardiovascular ni el sexo, al contrario de lo que ocurre en la población general. En este estudio se confirma también que la principal causa de muerte en PcSD son las afecciones del sistema respiratorio.

Crossley y Withers (2009) realizan un estudio para conocer lo que las PcDI mayores saben de la medicación que toman y sus experiencias con la misma, ya que se sabe que los antipsicóticos suelen ser prescritos para este colectivo para reducir o mejorar los cambios de comportamiento, pero muchas veces se hace sin un diagnóstico psiquiátrico previo. A través de una metodología cualitativa, realizan una entrevista a 8 PcDI leve y moderada de entre 31 a 66 años, y lo que observan es que las personas entrevistadas tienen poco conocimiento de su medicación, y que a pesar de que ésta tiene 
efectos secundarios marcados, las personas de la muestra los aceptaban. Lo que los autores concluyen es que la prescripción y la administración de medicación antipsicótica es un área donde las PcDI no tienen control, y que los servicios dirigidos a este colectivo deben llevar un control de la medicación de estas personas, además de aportarles información sobre la medicación a la que son sometidos.

Davidson, Janicki, Ladrigan, Houser, et al. (2003) realizan un estudio para investigar la relación entre los trastornos del comportamiento y el estado de salud en PcDI y personas con discapacidad del desarrollo mayores de 21 años o más. Para ello emplean la base de datos de la agencia del Gobierno neoyorquino. Los datos indican que existe relación entre el estado de salud y los trastornos del comportamiento en la población estudiada, de hecho, los trastornos de comportamiento que persisten en la vejez pueden ser factores que influyen en la morbilidad médica tal y como demuestra este estudio, si bien pueden ser sensibles a la intervención. Por otro lado, los autores encuentran que la frecuencia de los diagnósticos psiquiátricos (un porcentaje elevado de PcDI y con discapacidad del desarrollo del estudio tenían diagnóstico psiquiátrico), puede ser, entre otros factores, causa del deterioro funcional en el colectivo estudiado de mayor edad, si bien las PcDI o con discapacidad del desarrollo pueden presentar más trastornos de conducta en función de la edad que en función de la discapacidad.

De Winter, Hermans, Evenhuis y Echteld (2015) investigan la asociación entre depresión, ansiedad y diabetes y los factores de riesgo cardiovascular en PcDID mayores. Para ello aplican cuestionarios a 990 PcDID de 50 o más años, así como un examen físico. El 17\% tenía síntomas de depresión y el 16\% de ansiedad. El 1\% presentaba diabetes tipo I, y el $13 \%$ diabetes tipo II. El $45 \%$ presentaba síndrome metabólico, el $48 \%$ obesidad, un $23 \%$ colesterol elevado y un 53\% hipertensión. Sólo se 
encontró una asociación significativa entre el incremento de síntomas de ansiedad y la diabetes. Los autores concluyen que el incremento de síntomas de ansiedad y la diabetes están relacionadas en PcDID mayores, y que esta relación puede ser bidireccional. Se necesita mayor investigación.

Dodd, Guerin, Mulvany, Tyrrell y Hillery (2009) tenían el objetivo de conocer la evaluación y las características de las PcDI mayores que no tienen acceso a los servicios especializados para este colectivo. En la primera parte de su estudio, emplean los datos recogidos en la NIDD para conocer estos datos. En una segunda parte, elaboraron un cuestionario con el fin de examinar cuáles eran los procedimientos empleados para contactar y evaluar a las PcDI en los servicios. Los resultados indicaron que un 7,5\% de PcDI moderada, severa o profunda tras los 30 años y que residían con sus familias estaban en espera de un servicio, o al menos no recibían atención por parte de ninguno. Con el cuestionario se observó que estas personas sin acceso a los servicios especializados había malas prácticas de evaluación, que incluían el paso de períodos de tiempo significativos a la hora de contactar con la persona y una limitada planificación del servicio. Los autores obtienen la conclusión de que los servicios especializados necesitan ser más activos para que las personas mayores vulnerables accedan a los servicios, además de ser necesario un enfoque estandarizado en la evaluación y seguimiento de las PcDI y sus familiares que se niegan a acceder a tales servicios.

Doody, Markey y Doody (2011) revisan la literatura sobre el envejecimiento de PcDID en Irlanda. Los autores indican que se está incrementando el número de PcDID que envejecen y con ello, se incrementa la necesidad de servicios de apoyo especializados. Las enfermeras con conocimientos en discapacidad trabajan en residencias, y esto es contrario a la filosofía de los apoyos de que las PcDID vivan en sus casas con un sis- 
tema de cuidados familiar y un sistema de atención primaria. Las PcDID necesitan servicios que respondan a los cambios que experimentan con el envejecimiento y la coordinación entre los distintos servicios proveedores de apoyo.

Doody, Markey y Doody (2013) pretenden explorar las experiencias de las enfermeras al cuidado de PcDID que envejecen, ya que el aspecto médico influye en la CV de estas personas. Para ello, realizaron entrevistas semiestructuradas a 7 participantes. Los resultados indican que hay temas clave en el envejecimiento de las PcDID, como los cuidados, la inclusión y los cuidados individualizados. Así es importante el trabajo en equipo, la planificación, la inclusión, las actitudes, el cuidado individualizado, conocer a la persona y las buenas prácticas en la administración de los cuidados a personas mayores con DID.

Dos Santos, Groth y Machado (2009) llevan a cabo un estudio para investigar la relación existente entre los marcadores de autonomía y algunas variables como el CI, el envejecimiento precoz y la alfabetización en 47 PcDI brasileñas. Para ello emplean las pruebas de inteligencia Stanford-Binet y Weschler y elaboran una escala propia de $\mathrm{Au}$ tonomía. Las autoras separaban a los sujetos en dos grupos en función de la edad, por un lado jóvenes y por otro mayores. Los resultados indican que no hubo diferencias significativas entre ambos grupos en las variables de participación social, integración comunitaria y elección de alternativas, pero sí se observó que la puntuación en el nivel de inteligencia es determinante de la puntuación de autonomía. Los autores concluyen que la autonomía en PcDI es un fenómeno multifactorial asociado al deterioro cognitivo, cosa que los autores atribuyen a un envejecimiento precoz, aunque no encontraron diferencias entre el grupo de PcDI jóvenes y PcDI mayores. 
Dikens (2013) realiza una revisión de la bibliografía para dar a conocer los cambios metodológicos en la investigación sobre envejecimiento, salud y mortalidad en adultos con síndromes raros de DI. Los principales obstáculos de los estudios son la comprobación de los diagnósticos genéticos en oposición a los clínicos, la probabilidad de que los adultos no reciban un tratamiento de salud adecuado ni sean derivados a especialistas genéticos, la diferencia de cohortes en los tratamientos y el incremento de la mortalidad y la supervivencia. El envejecimiento de las personas con Síndrome de Prader-Willi y de Williams revela nuevas perspectivas sobre la expresión fenotípica y las opciones de tratamiento para los adultos que envejecen con estos síndromes.

Esbensen (2016) realiza un estudio para relacionar los problemas de sueño en PcSD con los trastornos mentales. Para ello emplea un cuestionario que rellenan las familias de 75 adultos con SD. Los resultados indicaron que la apnea del sueño se asoció con trastornos de tipo respiratorio, y más frecuentemente con la visita al psiquiatra, pero no con afecciones cardiacas. Los trastornos del sueño se asociaron con una baja salud y con las visitas a urgencias y al centro sanitario, con problemas cardiacos, con ansiedad, depresión y demencia y con trastornos mentales.

Evenhuis, Schoufour y Echteld (2013) realizan un estudio de revisión acerca de la conceptualización de la fragilidad en personas con DID. Comentan que los estudios revisados indican que la fragilidad se desarrolla considerablemente antes y es más severa en PcDID que en población general, y que por ello deberían ser investigados los resultados de salud, las causas y la prevención de la fragilidad.

Glaesser y Perkins (2013) realizan una revisión de artículos sobre el comportamiento autolesivo y encuentran que en PcDID mayores hay factores de riesgo asociados a la edad, como por ejemplo, el incremento y la no resolución de los problemas de sa- 
lud, los cambios físicos, el declive de habilidades físicas, el cambio de ambiente residencial y el experimentar la pérdida o el duelo. Esto tiene implicaciones prácticas para los trabajadores sociales que tratan con PcDID en proceso de envejecimiento y con comportamientos autolesivos.

Hartley y MacLean (2007) estos autores estudiaron la frecuencia y severidad de los comportamientos desafiantes de 132 PcDI mayores hacia el personal de los servicios de cuidado. Para evaluarlo emplearon el ICAP, y se hicieron dos evaluaciones, a los 8 y 10 años. Los resultados indican que hubo una disminución intraindividual en la frecuencia y severidad del comportamiento desafiante. Se observó una prevalencia baja pero una comorbilidad alta de un comportamiento desafiante severo. El nivel de DI y el comportamiento adaptativo se vio que estaban relacionados con la frecuencia y la severidad del comportamiento desafiante. Los autores concluyen que conocer estos comportamientos ayuda a incrementar el bienestar del personal de los sistemas de servicio de atención a este colectivo y ayuda a la optimización de su cuidado.

Heller (2009) realiza un estudio de revisión sobre el modelo de apoyos actualizado para afrontar el envejecimiento en PcDID. Trata temas como las barreras, los cuidados sanitarios y de la familia y la participación en la comunidad como pilares de un enfoque de atención a este colectivo.

Henderson, Acquilano, Meccarello, Davidson y Robinson (2009) llevan a cabo un estudio con el objetivo de describir la relación entre el estado de salud y el nivel de independencia en las AVD en adultos mayores con DI y con discapacidad del desarrollo. 1.371 adultos mayores de 40 años de Nueva York fueron encuestados mediante el RHSS, que recoge las categorías de los trastornos orgánicos y el nivel de independencia en las AVD. Los resultados indican que el incremento en el número de comorbilidades 
correlacionaba con las dificultades en las AVD y el caminar, y no dependía del incremento en la edad. Asimismo, la severidad de la DI o de la discapacidad del desarrollo correlacionaba con dificultades en algunas AVD sin tener en cuenta el número de trastornos orgánicos ni la edad. Los autores concluyen que es el estado de salud, y no la edad avanzada, lo que predice el deterioro funcional.

Hermans y Evenhuis (2013) realizan un estudio para conocer los factores asociados con la depresión y la ansiedad en adultos mayores con DID. Para ello, evalúan a través de entrevistas psiquiátricas a una muestra de 290 PcDID de 50 o más años. Los resultados indican que el incremento de los síntomas depresivos podían estar relacionados con un incremento en los síntomas de ansiedad, el número de eventos durante el año anterior y los trastornos crónicos (fallo cardíaco, diabetes, enfermedad pulmonar obstructiva crónica, enfermedad de la arteria coronaria, entre otros). A su vez, estarían negativamente relacionados con las actividades instrumentales de vida diaria. Por otro lado, los síntomas de ansiedad se asociaron positivamente con un DI medio o límite y con el incremento de los síntomas de depresión, y negativamente con el síndrome de Down, la epilepsia y las redes sociales. Los trastornos de ansiedad no mostraron asociaciones significativas.

Iacono, Bigby, Carling-Jenkins y Torr (2014) realizan un estudio sobre las experiencias del personal que atiende a PcSD con Alzheimer en relación a la comprensión que tienen sobre este colectivo, sus reacciones ante ello y cómo se sienten ante su rol de apoyo. Para ello, entrevistan dos veces en intervalos de 6-9 meses a personal que atiende a 9 PcSD y Alzheimer. Surgieron tres temas principales, la lucha para entender los cambios, el tomar el día a día según viene y el que ellos tienen una discapacidad y este es su trabajo. Los autores concluyen que el personal tiene limitaciones para entender el 
impacto que tiene la enfermedad de Alzheimer en las PcSD, sus reacciones a los cambios eran ad hoc, y utilizaban estrategias de prueba y error para proporcionar su apoyo. La necesidad de colaboración entre el cuidado a la discapacidad, el envejecimiento y la enfermedad era evidente para facilitar el envejecimiento en el lugar y la atención en la época de transición.

Janicki, Davidson, Henderson, McCallion, et al. (2002) pretendían conocer las características sanitarias y la utilización de los recursos sanitarios de PcDI de 40 años o más. Para ello elaboran un cuestionario que pasaron a 1.371 PcDI. Los resultados indican que la mayoría tenían un buen estado de salud, sin embargo, con el avance de la edad los autores observaron un incremento en la frecuencia de las condiciones cardiovasculares, musculoesqueléticas y respiratorias, mientras que otras condiciones no se incrementaban. Del mismo modo, los autores observaron que los trastornos psiquiátricos y del comportamiento se reducían a medida que las PcDI avanzaban en edad. La frecuencia de las condiciones anteriores variaba en función del sexo y la edad. Por otro lado, se evaluaba la morbilidad, de manera que determinados factores, por ejemplo, factores de riesgo cardiovascular que aparecían con baja frecuencia, posteriormente eran la causa de muerte de algunas de estas personas, junto al cáncer. Los autores concluyen que puede estar dándose un efecto de la cohorte, de manera que las poblaciones contemporáneas están más sanas que las poblaciones anteriores.

Jansen, Rozeboom, Penning y Evenhuis (2013) realizan un estudio para recopilar información epidemiológica sobre los trastornos cardiovasculares relacionados con el envejecimiento en PcDID. Compararon la incidencia y la prevalencia de los accidentes cerebrovasculares y los infartos de miocardio en una muestra de 510 PcDID y 823 personas de la población general. El estudio concluye que ninguno de los trastornos 
tiene una prevalencia e incidencia distinta en PcDID que en personas de la población general.

Krinsky-McHale y Silverman (2013) realizan una revisión sobre el riesgo y la dificultad para evaluar el deterioro cognitivo leve en personas con DID. Concluyen que los instrumentos para evaluar deterioro cognitivo leve no están adaptados a la población con DID, y que es necesario desarrollar métodos y criterios diagnósticos para ello.

Lehmann, Bos, Rijken, Cardol, et al. (2013) realizan un estudio para examinar cómo los recursos personales como la salud física, la salud mental y las redes sociales influyen en el bienestar de las PcDID. Para ello se basan en dos entrevistas realizadas a 667 PcDID con DI moderada o leve. Los resultados indican que la edad se relaciona positivamente con un descenso de la movilidad, con la discapacidad auditiva y negativamente con la vida independiente, la autonomía en cómo emplea su propio tiempo, y la autonomía en la toma de decisiones. Los análisis longitudinales demostraron que, a excepción de la salud que se deterioraba y de la satisfacción social, que se incrementaba, todas las demás variables eran estables durante los 4 años siguientes. Por lo tanto, la salud física en 2006, predijo felicidad en 2010. Concluyen que aunque las PcDID que envejecen tienen peor salud física y mental, y menos redes sociales, tienen relativamente niveles altos de bienestar.

Lifshitz (2002) investiga las actitudes de las PcDI y de las personas sin DI hacia el envejecimiento. Para ello emplea una muestra de 32 PcDI y 32 personas sin DI. Los resultados indican que las PcDI en el plano cognitivo se centran en las características físicas del envejecimiento, en el plano afectivo perciben a la gente mayor como amenazante, mientras que en el plano comportamental de las actitudes ven a las personas mayores como indefensas e incompetentes. Por otro lado, hay diferencias entre 
la conceptualización del envejecimiento dependiendo del nivel de discapacidad. Por último, la autora realiza una prueba de diferencial semántico a PcDI y personas sin DI, y aunque las puntuaciones de las personas sin DI fueron significativamente más altas que las de las PcDI, éstos últimos se centraban menos en los atributos físicos y en las expresiones faciales. La autora concluye que son necesarios programas educativos de intervención para preparar a las PcDI para las últimas etapas de la vida.

Maes y Van Puyenbroeck (2008) realizan un estudio para observar las adaptaciones que tienen lugar en los servicios en los que residen PcDI y PcSD mayores en Flandes. Pretenden analizar temas como la adaptación del servicio y el personal, los métodos de trabajo del personal y sus perspectivas y actitudes. Para ello elaboran un cuestionario propio que realizan 66 coordinadores del personal de los servicios. Los resultados indican que las adaptaciones tanto de la instalación como del personal eran evidentes en los centros, así como que los métodos de trabajo estaban centrados en la persona, aunque no se tenía en cuenta el factor edad. En general, los autores concluyen que la mayor parte de los servicios han empezado a modificar sus instalaciones y el personal a las necesidades de las personas residentes, y que los resultados sugieren que es necesario mejorar la capacitación del personal, la introducción de métodos de trabajo específicos y el cambio de los estereotipos del personal, para poder conseguir que el colectivo de PcDI y PcSD puedan envejecer en un lugar apropiado.

Marks, Sisirak y Chang (2013) comprueban la eficacia de un programa de mejora de la salud en adultos co DID. Para ello, realizan la intervención del programa a 67 adultos con DID de 30 años o más durante 12 semanas. Los resultados indican que el grupo intervenido mostró mejoras en el estado de salud, el conocimiento, la autoeficacia y las aptitudes. Los autores concluyen que el programa fue eficaz en esta población. 
McCarron y Lawlor (2003) investigan la respuesta que se da desde los servicios y las políticas de discapacidad de Irlanda a los retos a los que se enfrentan las PcDI que además sufren una demencia. Para ello los autores revisan las diferentes áreas que cubren o deberían cubrir los servicios, y que son el diagnóstico y la evaluación, el sistema de apoyo clínico y la multidisciplinariedad, los servicios centrados en la persona, las modificaciones ambientales y la educación y la formación. Los autores observan múltiples carencias en estos servicios y proponen llevar a cabo un modelo multidisciplinar, desde el que se incremente el conocimiento acerca de la progresión y la importancia de la demencia en las PcDI, tanto en familiares como en cuidadores, el desarrollo de estructuras de educación y formación para los cuidadores formales e informales, recoger información epidemiológica precisa para poder planificar intervenciones o el desarrollo de un modelo de gestión de las políticas, junto al establecimiento en los servicios de una filosofía centrada en la persona.

McConkey, Mulvany y Barron (2006) realizaron un estudio para conocer el número de PcDI a lo largo de la isla de Irlanda. Para ello emplearon una base de datos de las PcDI conocidas por los servicios existentes en el país para este colectivo desde 1995. En Irlanda del Norte emplearon una base de datos regional. Estos autores encontraron una tasa de prevalencia de PcDI en la república de Irlanda de 6,34 personas adultas con DI por cada 1.000 habitantes. Tanto en la república de Irlanda como en Irlanda del Norte encuentran que el número de PcDI de 55 años o más tiende a disminuir más rápidamente que en la población general, lo que refleja la menor esperanza de vida de este colectivo. También observaron que en Irlanda del Norte la mitad de las PcDI adultas vivían con sus familiares, mientras que en la república de Irlanda la proporción era mucho menor, de manera que en su mayoría vivían en centros residenciales. Otro aspecto en el que se fijan estos autores es la severidad de la discapacidad y encuentran una 
tasa de prevalencia en Irlanda del 4,14 PcDI severa por cada 1.000 habitantes; sin embargo, la tasa fue mayor en Irlanda del Norte, donde las PcDI severa también suelen residir en hospitales, mientras que en la república de Irlanda suelen vivir con más probabilidad en centros residenciales. Los autores emplean los datos anteriores para realizar predicciones acerca del crecimiento de la población, y calculan que en el año 2021 en Irlanda del Norte habrá 9.175 PcDI adultas, mientras que en la república de Irlanda calculan que habrá 19.900 PcDI adultas. Los autores concluyen que las tasas de prevalencia varían en función de las características de la población estudiada y de la disponibilidad de los servicios existentes para las PcDI.

McGlinchey, McCallion, Burke, Carroll y McCarron (2013) realizan un estudio para comprobar el problema del empleo en adultos con DID en Irlanda. Para ello emplean una base de datos de un estudio longitudinal con 753 PcDID de 40 o más años. Concluyen que el 6,6\% tenía un empleo remunerado, el 7,4\% un empleo no remunerado, el $12 \%$ empleo protegido y un $73,5 \%$ no tenían empleo. Asimismo, se observaron diferencias en estos grupos en cuanto a actividades sociales, niveles de depresión y de percepción de la propia salud.

Mercier y Picard (2011) realizan un estudio para investigar la situación de estar sin hogar en 68 PcDI de una media de 48 años. Para ello aplican el Índice de Screening de Habilidad de Hayes. Los resultados indican que algunas de las PcDI, en especial, mujeres, experimentaron cortos periodos de vivir sin hogar, y su situación se estabilizó una vez que fueron identificadas y se les realizó un seguimiento. Otras PcDI experimentan esta situación de forma paralela a la severidad de sus otros problemas. Los autores concluyen que es necesario prevenir e intervenir en estas situaciones. Tener un funcio- 
namiento intelectual por debajo de la media es un factor de riesgo para quedarse sin hogar y un factor predisponente de la vulnerabilidad entre las personas de la calle.

Millán-Calenti, Meleiro, Quintana, López-Rey, et al. (2008) realizan un estudio para conocer las características de las PcDI que tienen más de 45 años. Para ello emplean una muestra de 189 PcDI de Galicia y les pasan un cuestionario de elaboración propia. Los resultados indican que la mayoría de las PcDI vivían con sus familias y valoraban la relación positivamente. Además, los autores observaron que aproximadamente la mitad de los encuestados tenían una DI moderada; y en casi el mismo porcentaje tampoco era conocido el origen de dicha discapacidad. Los autores concluyen que es necesario intervenir sobre los recursos, equipamientos y sobre la especialización de los profesionales que trabajan con el colectivo de PcDI, teniendo en cuenta también a las familias, todo ello para ir en la línea de una mejora en el soporte asistencial.

Murray y McKenzie (2013) realizan un estudio para ver si el Cuestionario de Screening de Discapacidad Intelectual se adecúa a las propiedades de la escala de Mokken. Para ello emplean una muestra de 215 personas con DID con una media de edad de 34 años. Concluyen que el cuestionario, excepto un ítem se adecúa la escala de Mokken y es un instrumento válido para evaluar la severidad de la DI en un individuo sobre el cual no tenemos información completa de su funcionamiento intelectual y adaptativo.

Patja, Iivanainen, Vesala, Oksanen y Ruoppilla (2000) llevan a cabo un estudio para calcular la expectativa de vida en PcDI, llevando a cabo un seguimiento de la mortalidad durante 35 años a 60.969 PcDI. Los resultados indican que las PcDI leve no tenían una esperanza de vida menor que la de la población general, ni tenían una menor esperanza de vida en las tres primeras décadas de la vida. Por otro lado, las PcDI profunda tenían una esperanza de vida menor que la de la población general. Los autores 
encuentran también que la epilepsia y los problemas de audición aumentan el riesgo relativo de muerte para todos los niveles de DI. Los autores concluyen que las PcDI ahora tienen mayor esperanza de vida que en épocas anteriores, y que de hecho, el envejecimiento de las PcDI leve parece ser igual que el envejecimiento de la población general, por lo que se plantean nuevos desafíos a aquellos profesionales del campo de la salud.

Patti, Amble y Flory (2010) realizan un estudio retrospectivo para comprobar las colocaciones y recolocaciones en distintos hogares a las que son sometidas las PcSD, comparándolas con otro grupo de personas sin SD. Para ello emplean una muestra de 61 PcSD de entre 50 y 71 años y 79 personas sin SD mayores de entre 57 y 89 años y observan las colocaciones y recolocaciones que han sufrido en unos períodos de 5 y 10 años. Todos ellos habían sido remitidos a una clínica de diagnóstico e investigación. Los resultados indican que las PcSD mayores han sufrido significativamente un mayor número de recolocaciones que las personas sin $\mathrm{SD}$, y además la mortalidad en el grupo de PcSD ocurría a edades más tempranas significativamente que en el otro grupo.

Ribes y Sanuy (2000) comentan que existen determinados aspectos que diferencian el envejecimiento de la población normal del de las PcDI. En primer lugar, el incremento de variables personales y ambientales por causa de la discapacidad intelectual, es decir, de la etiología, el nivel de retraso y de los problemas de salud asociados. Hay que tener en cuenta que el nivel de retraso predice el tipo de deterioro posible en el envejecimiento, de manera que las PcDI ligera van a tener un deterioro en capacidades cognitivas, mientras que las PcDI media y severa tendrán un deterioro funcional antes que cognitivo. En segundo lugar, está establecido que el inicio del proceso de envejecimiento en la población general se sitúa en los 65 años, mientras que en las PcDI este 
límite cronológico se sitúa en los 45 años, de manera que sufren un envejecimiento precoz. También hay que contemplar según estos autores que variables ambientales como el lugar de residencia, etc., pueden hacer que la PcDI tenga menos oportunidades. Estos autores proponen una evaluación bio-psico-social de las PcDI que contemple al menos cinco áreas de funcionamiento, el área social, de la salud, cognitiva, afectiva y de la vida diaria. Proponen para ello una serie de pruebas específicas y la necesidad de una evaluación longitudinal para las áreas de función cognitiva, vida cotidiana y afectiva; mientras que para el resto de las áreas proponen el empleo de la entrevista estructurada tanto al propio sujeto como a su familia.

Schoufour, Mitnitski, Rockwood, Evenhuis y Echteld (2015) analizan la relación entre la fragilidad y la supervivencia en PcDID mayores. El estudio se realiza con 982 PcDID de niveles borderline a profundo de 50 o más años. Los resultados indican que un mayor índice de fragilidad se asoció con riesgo de muerte, independientemente del sexo, edad, nivel de DI y SD. El riesgo de mortalidad era 2 veces mayor en PcDID vulnerables y 19 veces mayor en individuos con un nivel moderado de fragilidad. Los autores concluyen que hay una fuerte asociación entre el índice de fragilidad y la mortalidad en 3 años, por lo que los profesionales deben realizar actuaciones preventivas en las PcDID frágiles.

Shaw, Cartwright y Craig (2011) llevan a cabo una investigación para explorar las percepciones de las PcDI y los miembros de la familia que los cuidan sobre los modelos de hogar y de apoyo más favorables para las PcDI que envejecen. Para ello se realizaron grupos focales con 15 PcDI de una media de 46 años y con 10 miembros de su familia de una media de 41 años. Los resultados indican que los temas que más emergían en los grupos eran la estructura de la vivienda, las preferencias de hogar, en- 
vejecer en su lugar y la transición de una casa informal a una formal y los servicios de apoyo. Los autores concluyen que tanto las PcDI como sus cuidadores quieren servicios de apoyo que permitan a la PcDI envejecer en su entorno, sin perder sus redes sociales, es decir, que cuando sea necesario ingresar en un servicio de apoyo formal, que sea cerca de sus compañeros, y además, que sea en grupos comunitarios.

Smulders, Enkelaar, Weerdesteyn, Geurts y van Schrojenstein Lantman-de Valk (2013) realizan un estudio sobre las caídas en PcDID que envejecen. En el estudio participaron 82 PcDID holandesas de 50 años o más y discapacidad leve o moderada, cuyas caídas fueron registradas durante un año. 37 de los 38 participantes informaban de al menos una caída al año, y no estaban relacionados ni el sexo ni la edad. La mayoría de las caídas ocurría caminando, fuera del servicio y en el ambiente familiar. El 11,5\% de las caídas producían consecuencias importantes, sobre todo fracturas. Los autores concluyen que las causas y las consecuencias de las caídas son comparables con las de la población mayor general, aunque la tasa es algo mayor, por lo que podrían tomarse estrategias de prevención de caídas.

Thompson, Ryrie y Wright (2004) investigan las circunstancias de aquellas PcDI que residen en servicios genéricos para personas mayores. Para ello pasaron un cuestionario en 2.570 residencias de ancianos y en 53 hogares residenciales de las autoridades locales del Reino Unido. Encontraron en 530 cuestionarios que 215 PcDI vivían actualmente en 150 residencias de ancianos. Observaron que las PcDI eran significativamente más jóvenes que el resto de residentes, y que habían sido instaurados en dicho servicio fundamentalmente por un cambio en la organización familiar o por el envejecimiento o fallecimiento de su familiar cuidador, y sin haber tenido en cuenta sus propias necesidades. Del mismo modo, la residencia inadecuada para este colectivo se ob- 
servó que limitaba las oportunidades de las PcDI, en el sentido de que reducían sus oportunidades para salir, sus oportunidades para tener contacto con familiares y amigos y para recibir atención de otros profesionales fuera del hogar residencial. Las conclusiones que los autores extraen de este trabajo es que hay que tener en cuenta que los servicios residenciales genéricos (para personas mayores) deberían considerar las necesidades de atención de las PcDI y que debe trabajarse en la prevención de la colocación de las PcDI en estos servicios.

Thorpe, Davidson y Janicki (2001) realizan una revisión desde la IASSID para distinguir la DI de los trastornos psiquiátricos, tomando una perspectiva de las políticas llevadas a cabo por los países en desarrollo. Los autores aluden a que las políticas sociales llevadas a cabo en muchos países destinan escasos recursos a este colectivo, y que además, no tienen una separación clara entre el concepto de DI y el de trastorno psiquiátrico, ya que a menudo las PcDI conviven con un trastorno de este tipo. Los recursos son limitados y en muchos casos los países deben elegir a qué tipo de servicios destinarlos. Los autores proponen que es importante que haya un núcleo de profesionales y clínicos con formación específica y especializada en la DI, y que a su vez, todos los profesionales y clínicos de Salud Mental, Psiquiatría o Psicogeriatría reciban formación en este campo, ya que una mejora en las prácticas de diagnóstico eficaces permitirían el tratamiento efectivo de estas personas. Además, los autores proponen que los centros de recursos especializados en esta población deberían estar disponibles tanto para médicos, como familias y otros cuidadores, ya que de esta forma podrían buscar información y/o referencia.

Van De Wouw, Evenhuis y Echteld (2013) comprueban la eficacia del Actiwatch para medir el sueño en personas con DID mayores. Indican que la sensibilidad 
del instrumento es válida para detectar los problemas de sueño en este colectivo, así como que es necesaria mayor investigación a través de este instrumento para realizar estudios epidemiológicos.

Wart, Hussain y Edwards (2014) realizan un estudio para examinar las necesidades de los profesionales que atienden a PcDID que envejecen. Los autores se basan en datos del proyecto Delphi. Entre los resultados, los autores identifican 26 cuestiones, que se agruparon en 5 temas: cuestiones de formación, temas de envejecimiento que requieren cambios en los apoyos, salud mental, temas médicos y calidad de vida. Los autores concluyen que estos temas deben ser prioritarios en el personal que atiende a las PcDID que envejecen, y que sería útil desarrollar programas de formación.

Whitehouse, Tudway, Look y Stenfert (2006) realizan un estudio de revisión para ver si se lleva a cabo la adaptación de las terapias, tanto en el campo de las terapias cognitivo-conductuales, así como en el psicoanalítico. Estos autores destacan que existe una sobreconfianza en los tratamientos cognitivo-conductuales y en la medicación, así como también destacan la posible inseguridad de los profesionales al adaptar una terapia. Se hace alusión a la importancia de la relación terapéutica y la terapia individualizada, a la adaptación del lenguaje al cliente, al empleo de las técnicas de sugestión, a la flexibilidad en la longitud de las sesiones, establecimiento de objetivos simples, al apoyo externo para facilitar el progreso, entre otros. A partir de esto, los autores revisan 25 artículos, 10 de ellos de la rama cognitivo-conductual y 5 de la psicoanalítica. Los resultados indican que en las terapias cognitivo-conductuales el método de adaptación más frecuente es la flexibilidad, mientras que en los psicodinámicos es la transferencia y sus variantes. Seis estudios de terapias cognitivo-conductuales destacan el uso de métodos directivos, mientras que en los psicodinámicos no aparece en ninguno. Sólo un estudio 
cognitivo-conductual considera la transferencia y sólo uno psicodinámico afirmó haber simplificado el proceso terapéutico. Por último, sólo 7 de 25 estudios adaptaron el lenguaje de la terapia a las PcDI. Todo ello puede tener importantes implicaciones para las futuras intervenciones de los profesionales que trabajan con PcDI.

Zigman (2013) realiza una revisión de la bibliografía para estudiar el envejecimiento en personas con SD. Este autor apunta que aunque la esperanza de vida de las PcSD se ha incrementado, sigue habiendo una distancia entre la edad de mortalidad media de otras personas con DID y con la población general. Sobre la enfermedad de Alzheimer y el deterioro cognitivo leve, indica que entre un 20 y un 30\% de PcSD no debería mostrar signos de él.

\subsubsection{Resumen}

En las investigaciones realizadas numerosos estudios investigan la prevalencia y la esperanza de vida de las PcDID mayores en diferentes países.

Además, es de señalar la importancia en las investigaciones acerca de las necesidades específicas del envejecimiento de este colectivo, en el sentido de la especialización de los servicios, por ejemplo, en el caso de la residencias especializadas en PMs, las cuales constituyen en muchas ocasiones el recurso más empleado por las PcDID y sus familias de cara al futuro.

Otro de los temas destacables es el de los apoyos, tanto su estudio a nivel conceptual y teórico, así como práctico cuando se trata de la necesidad de apoyos específicos a este colectivo. Las posibilidades de acceso a los recursos también es un tema recurrente en la literatura revisada. 
Por otro lado, numerosos estudios investigan la repercusión de distintas variables, como el deterioro cognitivo, las limitaciones de movilidad, la autonomía, la inteligencia, los problemas de sueño, la salud, los síntomas ansiosos y depresivos, en el envejecimiento de las PcDID.

No son menos los estudios que tratan los problemas de comportamiento, conductas desafiantes, comportamientos autolesivos, y las posibles vías de evaluación e intervención sobre los mismos.

\subsubsection{Resumen}

Las investigaciones revisadas acerca del envejecimiento manifiestan, en general, que las personas que envejecen, ya sean $\mathrm{PcD}$ o sin discapacidad, tienen necesidades específicas, a las que es necesario hacer frente desde perspectivas multidisciplinares a nivel profesional, y adecuando las políticas públicas y los servicios destinados a este colectivo a tales necesidades concretas.

Es importante destacar que numerosos estudios señalan la importancia de determinadas variables en el envejecimiento satisfactorio y el bienestar de las personas, ya sean con o sin discapacidad, tales como la salud, la participación social y las redes de apoyo social.

\subsection{LITERATURA SOBRE DISCAPACIDAD}

\subsubsection{Introducción}

En este apartado se exponen en un principio las investigaciones revisadas que tratan temas de discapacidad en general, para finalizar con los estudios específicamente realizados acerca de la discapacidad intelectual. 


\subsubsection{Discapacidad}

A continuación se presenta la tabla 7 que contiene un resumen de las investigaciones revisadas acerca de la discapacidad.

Cabra (2004) analiza la situación social de las PcD en 4 aspectos. Uno de los aspectos trata sobre las bases jurídicas en los servicios especializados, y en cuanto a ello el autor remarca dos principios, como son el de la no discriminación y el de la accesibilidad universal. Un segundo aspecto, sería la inclusión social de las PcD, donde el autor remarca la necesidad de una conjunción entre la no discriminación y la acción positiva. El tercer aspecto se centra en la legislación existente para las PcD y sus familias, donde el autor alude a varias leyes llevadas a cabo para mejorar la situación social de las PcD. Por último, el autor realiza diversas consideraciones acerca de la protección social que también incluye tanto a las PcD como a sus familias.

Cabrero (2007) tiene el objetivo de investigar los indicadores de discapacidad en las AVD. Para ello emplea la muestra de la encuesta EDDES de 1999. Los resultados indican que las variaciones entre las personas aparecen en las actividades de movilidad. Asimismo, el indicador discapacidad residual severa (PcD grave) aglutina más personas con limitaciones de movilidad que el indicador dependencia más incapacidad y además excluye a personas con dificultades en las actividades domésticas y de autocuidado. El autor encuentra que el indicador más efectivo de discapacidad es la dependencia más incapacidad, que son aquellas personas dependientes que tienen una mayor incapacidad frente al resto. 


\begin{tabular}{|c|c|c|c|c|}
\hline Autor/es & Temática & Resumen & Estudio & Observaciones \\
\hline $\begin{array}{l}\text { Cabra } \\
(2004)\end{array}$ & $\begin{array}{l}\text { Protección } \\
\text { social en dis- } \\
\text { capacidad }\end{array}$ & $\begin{array}{l}\text { Trata de las políticas so- } \\
\text { ciales desarrolladas para } \\
\text { la mejora de la situación } \\
\text { de las PcD }\end{array}$ & Revisión & $\begin{array}{l}\text { Escasez de políti- } \\
\text { cas sociales para } \\
\text { mejorar situación } \\
\text { de familias }\end{array}$ \\
\hline $\begin{array}{l}\text { Cabrero } \\
(2007)\end{array}$ & $\begin{array}{l}\text { Indicadores } \\
\text { de discapaci- } \\
\text { dad }\end{array}$ & $\begin{array}{l}\text { El indicador principal de } \\
\text { discapacidad es la depen- } \\
\text { dencia más incapacidad }\end{array}$ & $\begin{array}{l}\text { Transver- } \\
\text { sal }\end{array}$ & $\begin{array}{l}\text { No se puede gene- } \\
\text { ralizar a personas } \\
\text { mayores de } 64 \\
\text { años }\end{array}$ \\
\hline $\begin{array}{l}\text { Gispert } \\
\text { et. al. } \\
(2009)\end{array}$ & $\begin{array}{l}\text { Prevalencia } \\
\text { de discapaci- } \\
\text { dad }\end{array}$ & $\begin{array}{l}\text { Factores individuales y } \\
\text { geográficos en variabili- } \\
\text { dad de discapacidad en } \\
\text { CCAA }\end{array}$ & $\begin{array}{l}\text { Transver- } \\
\text { sal }\end{array}$ & $\begin{array}{l}\text { Necesidad de otro } \\
\text { tipo de diseño que } \\
\text { no transversal }\end{array}$ \\
\hline $\begin{array}{l}\text { Gispert } \\
\text { et. al. } \\
(2007)\end{array}$ & $\begin{array}{l}\text { Esperanza de } \\
\text { vida libre de } \\
\text { discapaci-dad }\end{array}$ & $\begin{array}{l}\text { Una mayor esperanza de } \\
\text { vida no es sinónimo de } \\
\text { mayor porcentaje de espe- } \\
\text { ranza de vida libre de dis- } \\
\text { capacidad }\end{array}$ & $\begin{array}{l}\text { Transver- } \\
\text { sal }\end{array}$ & \\
\hline $\begin{array}{l}\text { Observa- } \\
\text { torio } \\
\text { Estatal } \\
\text { de Dis- } \\
\text { capaci- } \\
\text { dad } \\
(2015)\end{array}$ & $\begin{array}{l}\text { Informe si- } \\
\text { tuación de } \\
\text { PcD en Es- } \\
\text { paña }\end{array}$ & $\begin{array}{l}\text { Recoge las políticas y el } \\
\text { marco legal en referencia } \\
\text { a las PcD en España y } \\
\text { compara con Europa }\end{array}$ & Revisión & \\
\hline $\begin{array}{l}\text { Olatunde } \\
\text { et. al. } \\
(2010)\end{array}$ & $\begin{array}{l}\text { Esperanza de } \\
\text { vida libre de } \\
\text { discapacidad }\end{array}$ & $\begin{array}{l}\text { La esperanza de vida libre } \\
\text { de discapacidad varía en } \\
\text { función de la población y } \\
\text { del género }\end{array}$ & $\begin{array}{l}\text { Transver- } \\
\text { sal }\end{array}$ & \\
\hline $\begin{array}{l}\text { OMS } \\
(2011)\end{array}$ & $\begin{array}{l}\text { Informe de la } \\
\text { discapacidad } \\
\text { a nivel mun- } \\
\text { dial }\end{array}$ & $\begin{array}{l}\text { Factores que influyen en } \\
\text { situación de las PcD y } \\
\text { soluciones para problemas }\end{array}$ & Informe & $\begin{array}{l}\text { Implicaciones ante } \\
\text { actuaciones pre- } \\
\text { ventivas }\end{array}$ \\
\hline $\begin{array}{l}\text { Üstün et } \\
\text { al. } \\
(2010)\end{array}$ & $\begin{array}{l}\text { Instrumento } \\
\text { de evaluación } \\
\text { de discapaci- } \\
\text { dad }\end{array}$ & $\begin{array}{l}\text { El cuestionario es apro- } \\
\text { piado para evaluar a PcD } \\
\text { y planificar intervencio- } \\
\text { nes }\end{array}$ & $\begin{array}{l}\text { Transver- } \\
\text { sal }\end{array}$ & $\begin{array}{l}\text { Cuestionario a } \\
\text { escala mundial por } \\
\text { lo que puede ser } \\
\text { extrapolado }\end{array}$ \\
\hline
\end{tabular}

Tabla 7: Literatura sobre discapacidad.

Gispert, Clot-Razquin, March, Freitas, et. al. (2009) realizan un estudio para calcular la tasa de prevalencia de discapacidad entre las distintas Comunidades Autónomas españolas. Para ello emplean la muestra de la encuesta EDDES de 1999. Los resultados indican que la tasa de prevalencia de discapacidad en España es de 8.99 por cada 100 
habitantes, siendo mayor en mujeres que en hombres. La Comunidad Autónoma con mayor tasa de discapacidad resultó ser Castilla y León, mientras que en La Rioja se encontró la tasa más baja. Los autores encuetran una gran variabilidad entre las tasas de prevalencia de discapacidad en las Comunidades Autónomas. Sin embargo, esa variabilidad no se explica ni por los factores geográficos del entorno, ni por factores personales, tal y como concluyen los autores.

Gispert, Ruíz-Ramos, Barés, Viciana y Clot-Razquin (2007) estos autores realizan un estudio para calcular la esperanza de vida libre de discapacidad en las distintas Comunidades Autónomas españolas, calculada por el procedimiento de Sullivan. Para ello los autores emplean como muestra la EDDES de 1999. Los resultados indican que en el nacimiento la esperanza de vida libre de discapacidad en 1999 fue de 68,5 años en hombres y de 72,2 en mujeres. Asimismo, el tiempo vivido sin discapacidad fue superior en hombres que en mujeres y la expectativa de discapacidad fue de 6,8 años para los hombres, y de 10,1 para las mujeres. Los autores también encuentran una alta variabilidad entre Comunidades Autónomas, si bien, en aquellas Comunidades donde la población tiene una alta esperanza de vida no coinciden con las que tienen una mayor proporción de años vividos sin discapacidad. Por tanto, los autores concluyen que la mayor esperanza de vida no es sinónimo de una mayor esperanza de vida libre de discapacidad.

El Observatorio Estatal de Discapacidad (2015) publica un informe sobre la situación legal de las personas con discapacidad en España, sobre las políticas públicas puestas en marcha, la gestión de la crisis, el acceso al empleo, etc. Ofrece una panorámica sobre la situación de las personas con discapacidad en España con respecto a Europa. 
Olatunde, White y Smith (2010) realizan un estudio en Inglaterra para determinar la esperanza de vida y la esperanza de vida libre de discapacidad en distintas poblaciones. Para ello emplearon los datos de defunciones y enfermedades de larga duración del censo de 2001. Los resultados indican que la mayor tasa de esperanza de vida libre de discapacidad, tanto en varones como en mujeres, se daban en Kensington y t en Chelsea (73,9 años en varones y 74,4 en mujeres). La esperanza de vida libre de discapacidad más baja se daba en Manchester en varones (44,1 años) y en mujeres en Liverpool (48,2 años). Además, al nacer los varones residentes en poblaciones más desarrolladas podían aumentar en 12,6 años su esperanza de vida libre de discapacidad, en comparación con los hombres de zonas más desfavorecidas. En mujeres esta diferencia era de 10,9 años. También se observó que a los 65 años tales desigualdades persistían, pero la diferencia era menor.

La OMS (2011) elabora un informe sobre la situación de la discapacidad a nivel mundial. En él se estima la prevalencia de personas con discapacidad en un $15 \%$ de la población mundial. El informe también señala que cada persona con discapacidad tiene su propia experiencia de la misma, e indica que no todos los tipos de discapacidad se enfrentan a las mismas "desventajas". Asimismo, se dice que existe un diferente grado de vulnerabilidad entre poblaciones, siendo los más vulnerables aquellos niños pertenecientes a grupos étnicos minoritarios y de mayor pobreza. Por último, se realiza un análisis acerca de los factores que influyen en la situación de las personas con discapacidad y los efectos que tienen sobre ellas y se proponen líneas para abordar todos los problemas a los que este colectivo se enfrenta.

Üstün, Chatterji, Kostanjsek, Rehm, et. al. (2010) realizan un estudio para elaborar el WHODAS 2.0, el instrumento de evaluación de la discapacidad de la OMS.Para 
ello aplican el cuestionario en sus dos versiones (larga y reducida) a 65.000 personas de la población general, tanto con discapacidad como sin ella. El instrumento mide 6 dominios, como la cognición, la movilidad, el autocuidado, las relaciones, las AVD y la participación. Los resultados indican que el WHODAS 2.0 es un instrumento válido para evaluar el impacto de las condiciones sanitarias, para valorar la eficacia de las intervenciones y para estimar el peso de los trastornos físicos y mentales en diferentes poblaciones.

\subsubsection{Resumen}

La literatura sobre discapacidad en general se centra de forma reseñable en las PMs que envejecen con una discapacidad, y no tanto en las PcD.

Entre los artículos revisados, nos encontramos que los temas más tratados son acerca de la prevalencia de discapacidad en distintos países, y en España, de la prevalencia de discapacidad en las distintas CCAA, los indicadores de discapacidad relativos a las ABVD y las AIVD o la esperanza de vida de determinadas poblaciones y la esperanza de vida libre de discapacidad.

Asimismo, también se han revisado artículos que tratan los principios de no discriminación y accesibilidad universal, así como la situación legal de las $\mathrm{PcD}$, las políticas públicas y el acceso al empleo, sobre todo en España con respecto a Europa.

\subsubsection{Discapacidades intelectuales y del desarrollo}

Seguidamente se presenta la tabla 8 que resume las investigaciones revisadas que versan sobre la discapacidad intelectual.

Alonso, Serrano y Miron (2005) investigan los problemas de salud que con más frecuencia se asocian a la DI. Para ello emplean una muestra de 265 PcDI a quienes les 
aplican un cuestionario. Los resultados indican que las enfermedades más frecuentes en la población estudiada son las afecciones cardiovasculares, enfermedades neurológicas y osteomusculares. Asimismo, los autores destacan que la obesidad y el sobrepeso son los factores de riesgo más señalados en este colectivo. El nivel socioeconómico de las familias de las PcDI se asoció con una mayor demanda de la consulta médica de atención primaria, y con una baja frecuencia de asistencia al dentista.

Arias, Irurtia y Gómez (2009) elaboran un estudio con el objetivo de elaborar un sistema de clasificación de conductas problemáticas en PcDI. Para ello emplean dos muestras de estudiantes con experiencia en el campo de la DI, a quienes se les aplicaban por un lado un conjunto de conductas que con mayor frecuencia se habían asociado con la DI en la investigación, y por otro lado 10 escalas bipolares para calificar cada conducta. Al someter los datos a un análisis multidimensional, los autores obtienen dos dimensiones, la primera de ellas referida a comportamientos biológicos o sociales, dependiendo de a quién va dirigida la conducta y de sus determinantes, de etiología biológica o social. La segunda dimensión se compuso de las conductas abiertas y encubiertas, dependiendo de si la persona la realiza sin presencia de otras personas o no. Los autores concluyen que este sistema facilita la interpretación de los comportamientos problemáticos.

Arnold, Riches y Stancliffe (2014) exploran la medida y la clasificación de las necesidades de apoyo. El estudio presenta la comparación de las puntuaciones entre la escala de la OMS dde 2001 y la evaluación I-CAN de evaluación y planificación de las necesidades de apoyo, que propone una clasificación propia. Los resultados indican que la consistencia interna del instrumento es buena y se encontró validez de criterio. Así, 
los autores comentan que la forma de entender y medir las necesidades de apoyo cambiarán la forma en que las evaluamos, describimos y clasificamos.

Beadle-Brown, Mansell, Ashman, Ockenden, et. al. (2014) estudian aspectos de los servicios residenciales para PcDID, tales como el liderazgo y la gestión. Para ello, administraron cuestionarios al personal de residencias para PcDID sobre el apoyo activo y la calidad de la gestión en actividades significativas. Los autores encuentran que la práctica del liderazgo tuvo un impacto significativo en el apoyo activo, pero estaba mediado por el efecto de la calidad de gestión. Pero una mayor calida de la gestión por sí misma no producía por sí misma un mejor apoyo activo. Los autores concluyen que el liderazgo puede ser un factor importante a la hora de que el personal proporcione un apoyo activo, como parte de una buena gestión general. Los autores indican que es importante la formación de los profesionales y el apoyo de líderes para la gestión.

Beail y Williams (2014) revisan la literatura en relación a los métodos cualitativos en la investigación sobre DI. Examinaron la frecuencia con la que los estudios cualitativos habían sido publicados en tres importantes revistas sobre el tema durante una década. Los autores concluyen que los métodos cualitativos son fundamentales en el estudio de la DI, pero que los estudios revisados tienen algunos problemas metodológicos que necesitan mejorarse en el futuro. También comentan que es importante desarrollar métodos que permitan la participación de las PcDID en los estudios.

Bertoli, Biasini, Calignano, Celani, et. al. (2011) realizan un estudio para investigar las necesidades y los cambios en la salud, en la integración social y en la vida diaria de las PcSD de Roma, Italia. Mediante una entrevista, y a través del censo de Roma, encuentran 884 PcSD en la ciudad. De ellas, 518 tienen edades comprendidas entre los 0 y los 64 años. El 88\% viven con sus familias, el 82,1\% tienen uno o más hermanos y el 
19,5\% ha perdido un padre o ambos. El 100\% de los niños con SD están escolarizados en colegios ordinarios. Un $42,2 \%$ de toda la muestra estudiada tienen entre 25 y 30 años y practican alguna actividad regular. Tras los 30 años, se observa un declive de la actividad funcional, a la vez que se reducen los apoyos relacionados con la discapacidad. En otras palabras, la vida de las PcSD de Roma gira mayoritariamente alrededor del hogar, con muy pocas actividades en la comunidad. Los autores concluyen que se desconocen por ahora las necesidades de este colectivo, y que es urgente la necesidad de detectarlas para conseguir la inclusión social.

Claes, Van Hove, Vandevelde, van Loon y Schalock (2010) realizan un estudio de revisión con 3 objetivos. El primero de ellos, revisar las publicaciones sobre la eficacia de la Planificación Centrada en la Persona (PCP), describir tal eficacia en términos de resultados u objetivos y realizar una discusión acerca de la eficacia en términos de las prácticas basadas en la evidencia. Los resultados indican que la PCP tiene un impacto positivo, pero moderado en los resultados personales de las PcDI.

Cocks y Boaden (2011) revisan las publicaciones sobre el programa de apoyos personalizado en residencias para PcDI. Para ello, también realizan un estudio con 6 PcDI de entre 20 y 50 años a quienes les aplican dicho programa. Los resultados indican que el PRS está conformado por 9 temas y 28 atributos. Entre los 9 temas estarían las Asunciones, el Liderazgo, Mi Hogar, una Persona al mismo Tiempo, Planificación, Control, Apoyo, Desarrollo e Inclusión Social. Los autores concluyen que el estudio muestra las características del PRS. Además, los temas expresados en el PRS son válidos para otros tipos de vivienda y varios grupos diferentes de personas. Sin embargo, es necesaria mayor investigación en este campo. 
Cooper, McConachie, Allan, Melville, Smiley y Morrison (2011) estudian la relación entre la privación social, las desigualdades en el estado de salud y el acceso a los servicios en 1.023 PcDI mayores de 18 años. Para ello les aplican un cuestionario propio. Los resultados indican que la privación social no influye en el acceso a los apoyos sociales, a los servicios de atención primaria u hospitales, sin embargo, las personas con más privación social emplean menos los cuidados sanitarios secundarios, y utilizan más los servicios de emergencia. Los autores concluyen que en las PcDI, de la misma forma que en la población general la deprivación no contribuye a una salud desigual, pero son necesarias iniciativas de promoción de la salud en aquellas zonas de mayor privación social.

De Ruiter, Dekker, Douma, Verhulst y Koot (2008) comparan la evaluación que realizan los padres y profesores de PcDI media y moderada acerca del cambio en los problemas de comportamiento. Para ello se emplearon dos muestras de PcDI por un lado moderada y por otro leve, de 6 a 18 años. Los resultados indican que los niveles de estabilidad y cambio de los problemas de comportamiento fue similar en los dos tipos de DI, si bien en las evaluaciones de los informantes se encontró que las PcDI moderada mostraban niveles más altos de estabilidad, persistencia e inicio de la psicopatología. Los autores concluyen que las PcDI de ambos niveles están en riesgo de una psicopatología persistente en un grado similar.

Finlay, Rohleder y Culfear (2014) comprueban dos métodos cualitativos sobre la educación sexual en PcDID. Realizaron el análisis cualitativo de las conversaciones en las intervenciones de los dos métodos y luego se analizaron entrevistas con los educadores. Los educadores anticipaban problemas de comprensión y cómo iban a responder cuando un alumno con discapacidad no entendiera el mensaje. Esto ocurría cuando se 
trataba de oraciones largas y conceptos abstractos.Esto producía un patrón característico, en el que el alumno y el profesor daban conjuntamente una respuesta correcta de forma superficial.

Garaigordobil y López (2007) comparan el autoconcepto, la autoestima y los síntomas psicopatológicos en PcDI y en personas sin DI, además de investigar si existen diferencias de género en los resultados de ambas muestras. Para ello emplean dos muestras, una de ellas de 148 personas sin DI y 42 PcDI de entre 19 y 40 años, a quienes se les aplicaron 3 instrumentos. Los resultados indican que las PcDI puntuaban más bajo en las escalas de autoconcepto y autoestima, pero tenían puntuaciones más altas en síntomas psicopatológicos, excepto en la somatización. Asimismo, los autores no encontraron diferencias en cuanto al género.

Hahn y Aronow (2011) comprueban la fiabilidad y la validez del programa SWH-HRA de evaluación de los riesgos para la salud en PcDI. Para ello emplean una muestra de 201 PcDI de 32 y más años a quienes se les aplicó el programa. Los resultados indican que dicho programa de intervención es fiable y válido para detectar los riesgos de la salud en el colectivo estudiado. Los autores concluyen que deberían realizarse futuros análisis psicométricos para poder adaptar el programa a otros tipos de discapacidad.

Hanna, Taggart y Cousins (2011) realizan un estudio para fomentar la prevención del cáncer y la prevención de la salud en residencias de PcDI. Para ello emplean una muestra de 40 profesionales de 15 residencias distintas. Los resultados indican que los profesionales afirmaban no recibir formación ni entrenamiento en la prevención del cáncer, así como informaron de que ellos desconocían la historia familiar de las PcDI de sus centros. Los resultados del estudio indican que las actividades de promoción de la 
salud y prevención del cáncer para PcDI está por debajo de lo que debería ser lo óptimo. Los autores concluyen que es importante educar tanto a los profesionales como a las propias PcDI sobre las señales y los síntomas tempranos del cáncer y de la importancia de un estilo de vida saludable como factor protector que puede ayudar a reducir el riesgo de cáncer y morbilidad.

Hayes, McGuire, O’Neill, Oliver y Morrison (2011) comprueban la relación entre el estado de ánimo y el cambio de comportamiento en 52 PcDI mayores de 18 años, con DI severa y profunda. Para ello aplican el cuestionario sobre Estado de Ánimo, Intereses y Placer. Los resultados indican que la presencia de medidas de estado de ánimo bajo predijo la frecuencia y la severidad del cambio de comportamiento. Los autores concluyen que las PcDI severa y profunda muestran signos más claros y medibles de estado de ánimo bajo, y en esta pequeña muestra de PcDI institucionalizadas, el estado de ánimo se asoció con el cambio en el comportamiento.

Hulbert-Williams, Hastings, Crowe y Pemberton (2011) estudian los eventos vitales auto-informados, el apoyo social y los problemas psicológicos en 38 PcDI de 18 a 59 años. Para ello, les aplican el Programa de Eventos Negativos Autoinformados para PcDI de Bangor, el Inventario Breve de Síntomas y el Mapa de Redes Sociales. Los resultados indican que la exposición a los eventos vitales se asoció positivamente con medidas de problemas psicológicos. El apoyo social no estaba asociado a tales problemas, aunque los mayores problemas psicológicos fueron informados por participantes que hablaban de críticas hacia ellos mismos por parte de otros. Los autores concluyen que las medidas auto-informadas pueden proveer de una mayor sensibilidad a la información. 
Jordán de Urríes (2010) realiza un estudio sobre el empleo con apoyo en las PcDI. Para ello presenta el origen y la definición del mismo, posteriormente expone sus características y los principios que sustentan esta modalidad de empleo, hace referencia a su evolución desde los años 80 cuando surgió en EEUU hasta nuestros días, menciona sus fases de desarrollo y sus elementos fundamentales, para concluir con una revisión crítica del momento actual en el que se encuentra el empleo con apoyo y donde el autor alude a la necesidad de adaptarlo a cada persona, es decir, que el empleo cumpla sus metas, mejore su autodeterminación, permitiéndole tomar sus propias decisiones y que le lleve a conseguir resultados que para ella son importantes. El autor también propone que se lleve a cabo el desarrollo de la calidad en este tipo de empleo.

Lloyd y Kennedy (2014) realizan una revisión sobre la evaluación y el tratamiento de los cambios de conducta en PcDID. Realizan un seguimiento de la historia de las intervenciones que se han llevado a cabo hasta llegar a los modelos actuales de intervención. Asimismo, tratan las funciones operantes que suelen tener los problemas de conducta en este colectivo, sobre las tecnologías de evaluación funcional del comportamiento y las intervenciones basadas en el reforzamiento. Los autores concluyen con una discusión sobre los modelos preventivos validados en los procedimientos de evaluación y del uso extendido de los programas integrales de apoyo conductual.

Lund y Hammond (2014) realizan un estudio para comprobar la eficacia de la intervención de una única sesión denominada "Stopping Abuse For Everyone" ante el abuso y la agresión sexual en PcDID. Comentan que la experiencia del programa ha sido positiva, pero no recabaron datos formales. Esta metodología es interesante para el futuo de los programas psicoeducativos para PcDID que vivan en zonas rurales, y en discapacidad intelectual leve y moderada. 
McClean y Grey (2012) realizan una investigación para estudiar los componentes y factores más importantes del PBC. Para ello emplean una muestra de 61 trabajadores con PcDI y cambios conductuales que completaron un entrenamiento de PBS longitudinal. Se hicieron un total de 1.272 intervenciones y se llevaron a cabo evaluaciones a los 6 y 26 meses. Los resultados indican que hubo una reducción significativa en la frecuencia, en la dificultad de aplicación y en la severidad de los episodios de cambio conductual durante el estudio. Las huidas fueron identificadas por los profesionales como la función más frecuente, dando cuenta del 77\% de los cambios conductuales. Los autores concluyen que sólo la aceptación del tratamiento estaba relacionada con la reducción de la frecuencia del comportamiento. Ningún componente independiente tuvo asociación significativa con las reducciones en los cambios conductuales.

Medeiros, Rojahn, Moore y van Ingen (2014) realizan un perfil de DID sobre el comportamiento para poder diseñar intervenciones conductuales eficaces, ya que los problemas de conducta son comunes en PcDID con DI severa. Para ello investigan la relación entre el nivel de DI y el perfil funcional de agresividad, estereotipias y conducta autolesiva a través del cuestionario de Preguntas sobre la Función del Comportamiento. Participan 115 PcDID, y se hace la evaluación antes y después de un entrenamiento. Los resultados indican que hay relación entre los problemas de comportamiento y el nivel de DI. Asimismo, mientras que las autolesiones aparecen con frecuencia para escapar de demandas sociales y para acceder a objetos tangibles, con el declive del nivel de DI, la agresión y la estereotipia se muestran para múltiples funciones a todos los niveles de DI.

Navarro, Torrico y López (2010) presentan los resultados de un programa de intervención psicosexual en PcDI. La muestra a la que se aplicó el programa estaba for- 
mada por 37 PcDI de 17 a 36 años. Para ello el programa se adaptó a la comprensión de los participantes. Los resultados indican que los programas de intervención en educación psicosexual son efectivos en PcDI si están adaptados a sus necesidades y características, aunque hay, según los autores, una escasez de literatura de investigación en este tipo de programas educativos. Los autores insisten en la necesidad de adaptar tales programas a los grupos de personas participantes.

O’Brien, McConkey y García Iriarte (2014) realizan un estudio en el que participan como investigadores 5 PcDID, 4 investigadores de universidad y 3 personas del servicio de apoyo. Otras 15 PcDID recogían datos, mientras 168 personas participaban en 23 grupos focales. Los autores indican que es una experiencia de aprendizaje para todos.

Paredes (2010) realiza un estudio para crear y validar la escala EBEAP para PcDI moderada o grave, debido a la ampliamente documentada incapacidad de expresión del bienestar personal de este colectivo. Para ello el autor emplea una muestra de 193 PcDI adultas, a quienes les aplica la escala. Los resultados indican que este instrumento es válido para evaluar el bienestar personal en PcDI, y que además tiene diversas ventajas entre las que se encuentran su brevedad de aplicación, su sencillez y corrección rápida.

Pikora, Bourke, Bathgate, Foley, et. al. (2014) realizan un estudio para comprobar la prevalencia de las condiciones médicas y el uso de los servicios de salud en adultos con SD. Para ello aplican un cuestionario a padres de adultos jóvenes con SD sobre las condiciones descritas anteriormente de sus hijos durante los últimos 12 meses. Encuentran una prevalencia del $73 \%$ de problemas de visión, $45 \%$ de problemas de oído y audición, afectación cardíaca en el 25\%, y problemas respiratorios en un 36\%. También 
se encontró en el $61 \%$ de los casos problemas musculoesqueléticos, con un 57\% problemas de peso, habilidad de salud (56\%) y salud mental (32\%) y entre mujeres jóvenes, en un $58 \%$ problemas con la menstruación. Los padres decían que estas condiciones no tenían impacto en la restricción de oportunidades de participación en actividades laborales y sociales para las personas con SD jóvenes.

Reid, Smiley y Cooper (2011) realizan un estudio para estimar la prevalencia de los trastornos de ansiedad en PcDI. Para ello aplican diversas pruebas, como el C2ist, PASS-ADD, DC-LD, ICD-10-CDR; DSM-IV-TR y PPSALD a una muestra de 1.023 PcDI mayores de 16 años. Los resultados indican que en la cohorte estudiada la prevalencia de los trastornos de ansiedad es del 3,8\%; de ellos, el trastorno de ansiedad generalizada es el más frecuente seguido de la agorafobia. Los factores asociados independientemente con el padecimiento de un trastorno de ansiedad fueron el no tener ningún empleo durante el día y tener una reciente historia de eventos vitales. Haber residido previamente en un hospital estaba independientemente asociado con no tener un trastorno de ansiedad. Los autores concluyen que los trastornos de ansiedad son comunes entre las PcDI, por lo que es necesario aportar los cuidados y apoyos necesarios, además de desarrollar intervenciones eficaces para este colectivo.

Robles (2007) realiza una revisión de los datos existentes sobre la incidencia y prevalencia del SD en población española. Para ello la autora se basa en los datos recogidos en la FEISD y ECEMC. La autora alude que la incidencia de nacimientos de niños con SD se está reduciendo, debido en parte al incremento de interrupciones de embarazo cuando a través de las pruebas se confirma que el feto padece la trisomía 21. Asimismo, cada vez son más las pruebas a las que se somete a las madres mayores de 35 años para prevenir el nacimiento de niños con este síndrome. Pero por otro lado, la 
autora también afirma que la esperanza de vida de las PcSD se está incrementando. La autora concluye que el SD está en vías de extinción en España.

Schalock (2004) realiza un análisis para explicar las implicaciones del nuevo paradigma de DI emergente y de su relación con las políticas y prácticas llevadas a cabo. El autor propone 4 características del modelo emergente, como son las limitaciones funcionales, el bienestar personal, los apoyos individualizados y la competencia personal y adaptación. El autor resume las implicaciones que tiene cada característica en las políticas y en las prácticas llevadas a cabo en el campo de la DI, para concluir con una serie de sugerencias de cambio tanto a nivel de individuo, como de los servicios de prestación y de los niveles de la sociedad.

Schalock y Luckasson (2004) realizan un trabajo para revisar la relación entre la concepción de la DI (definición, clasificación y sistema de apoyos) de 2002 de la AAMR y las tendencias llevadas a cabo a nivel internacional, junto con los problemas que se han dado en el campo de la DI. Las tendencias internacionales como la perspectiva ecológica de la DI, su multidimensionalidad, la evaluación con el fin de intervenir y la importancia del juicio clínico, junto a los problemas del campo de la DI, como la distinción entre la definición y la clasificación, la respuesta a qué es la discapacidad y cuáles son sus características, las relaciones entre la inteligencia y el comportamiento adaptativo, etc., no concuerdan con el modelo de la AAMR de 2002, de manera que los autores dejan entrever un necesario cambio de paradigma.

Schalock, Luckasson, Shogren, Borthwick-Duffy, et. al. (2007) revisan el cambio de terminología de la AAIDD sobre la DI. El cambio de paradigma de este campo conlleva el cambio del término retraso mental por el de DI por varias causas, en un principio porque así refleja el cambio de constructo propuesto tanto por la AAIDD co- 
mo por la OMS, también porque así va en la línea de las prácticas profesionales actuales, que se focalizan en el comportamiento funcional y los factores contextuales, porque produce una base para la provisión de los apoyos individualizados basados en un modelo social y ecológico, a su vez que el término DI es menos ofensivo que el de retraso mental, y por último, por ser más consistente con la terminología internacional.

Snell, Luckasson, Borthwick-Duffy, Bradley, et. al. (2009) investigan acerca de las características de las PcDI que tienen CI superiores, es decir, cuyo CI está ligeramente por debajo de 70. Los autores aluden a que a menudo a esta población se la suele confundir con aquellas personas que no tienen un diagnóstico de DI, pero cuyo CI es bajo en relación a la población general. Los autores también señalan que las PcDI con CI superiores, son un porcentaje muy elevado de las PcDI en general, y que además, no tienen ningún rasgo fenotípico de comportamiento, ni ningún rasgo físico que les diferencie del resto de la población. Los autores por último, concluyen con la importancia radical que tiene la creación de un apoyo accesible e individualizado para este colectivo.

Stainton, Brown, Crawford, Hole y Charles (2011) comparan los resultados entre 4 tipos de centros residenciales para PcDI. Para ello, emplean una encuesta previa realizada en Columbia, Canadá, sobre padres y profesionales de PcDI. Tras establecer comparaciones entre 6 dominios diferentes (información y planificación, acceso y establecimiento de apoyos, elección y control, conexiones comunitarias, satisfacción y percepción de resultados), los resultados indicaron que en todas las demás medidas que no fueron control y elección, grupos de hogar y modelo familiar, mostraron mejores resultados que en las viviendas independientes o en los hogares familiares. Los autores concluyen que el cambio a una vivienda más independiente no está siendo acompañado de los apoyos adecuados. 
Stmadová Cumming, Knox, Parmenter (2014) realizan un estudio junto a personas con discapacidad intelectual y del desarrollo como investigadores también. El grupo de investigadores con y sin DID llevó a cabo 15 sesiones de entrenamiento sobre la investigación del bienestar de mujeres mayores con DID. Para apoyar la adquisición de habilidades sociales se empleó tecnología móvil. Este estudio demuestra que todos los miembros del equipo, independientemente de la habilidad, necesitaron sus propias experiencias, así como el aprendizaje de habilidades básicas de investigación. Todo ello muestra la necesidad de construir equipos, de la formación de la investigación conjuntamente entre todos los miembros y el apoyo a los iguales dentro del mismo.

Tassé y Wehmeyer (2010) comparan la intensidad de las necesidades de apoyo individuales y la presencia del diagnóstico de trastorno psiquiátrico según el DSM-IV en una muestra de 272 PcDI adultas. Entre los resultados encuentran que las PcDI diagnosticadas con trastorno psiquiátrico tienen mayores necesidades de apoyo en cuanto a problemas de comportamiento, pero menores necesidades de apoyo en lo referente a las condiciones médicas que afectan a la salud física. Asimismo, no se encontraron diferencias significativas en cuanto a la intensidad de las necesidades de apoyo entre PcDI con diagnóstico psiquiátrico o sin él.

Thompson, Bradley, Buntinx, Schalock, et. al. (2009) realizan un estudio para conceptualizar los apoyos y las necesidades de apoyo en PcDI, desde la AAIDD. En primer lugar los autores expresan los conceptos de ambos términos, y conceptualizan los apoyos como un puente entre lo que la persona es, y lo que puede llegar a ser, en cuanto a desarrollo, intereses, bienestar personal, etc.; mientras que las necesidades de apoyo las conceptualizan dentro de un modelo multidimensional del funcionamiento humano, y hacen referencia a la intensidad de los apoyos. Por último, los autores tam- 
bién proponen recomendaciones para el desarrollo y planificación de los apoyos individualizados.

Tyrer, McGrother, Thorp, Taub, et. al. (2008) elaboran una medida de PcDI moderada y profunda mediante varias variables, como el nivel de DI, el funcionamiento adaptativo y el nivel de dependencia. Para ello emplean una muestra de 322 PcDI adultas a quienes se les aplicó previamente la escala de comportamiento adaptativo de Vineland. Posteriormente se elaboró el instrumento y se realizó la validación de la prueba. Los resultados sugieren que este instrumento desarrollado en el condado de Leicester puede ayudar en la identificación de PcDI adultas con DI de moderada a profunda, y a aquellas PcDI que necesitan algún tipo de cuidado especializado.

Van Loon, Claes, Vandevelde, Van Hove y Schalock (2010) exponen datos recientes sobre la evaluación de las necesidades de apoyo con el objetivo de la consecución de resultados personales en PcDI. Para ello interrelacionan los conceptos y modelos actuales sobre necesidades de apoyo, calidad de vida, sistemas de apoyo personalizados y resultados personales. Para ello emplean los indicadores de la Escala de Intensidad de los Apoyos (SIS) de necesidades de apoyo, basada en los 8 indicadores de CV. Por último, los autores señalan las principales implicaciones de este modelo para los educadores y para la habilitación de los profesionales que trabajan en este campo.

Verdugo, Arias, Ibáñez y Schalock (2010) adaptan y validan la escala SIS de evaluación de la intensidad de los apoyos en España. Para ello emplean una muestra española de 885 PcDI de 15 a 76 años. Los autores concluyen que la escala SIS tiene numerosas utilidades en el ámbito de las PcDI. 
Wehmeyer, Buntinx, Lachapelle, Luckasson, et. al. (2008) ofrecen una visión del reciente constructo de DI y su relación con el funcionamiento humano, desde la AAIDD. Estos autores remarcan la importancia de emplear una definición constitutiva de la DI ante una definición operacional, para promover la base de un modelo teórico sobre la planificación y el desarrollo de los apoyos individualizados. De esta manera los autores describen un modelo teórico sobre el funcionamiento humano de tipo multidimensional, que incluye la capacidad intelectual, el funcionamiento adaptativo, la salud, la participación y el contexto. 


\begin{tabular}{|c|c|c|c|c|}
\hline Autor/es & Temática & Resumen & Estudio & Observaciones \\
\hline $\begin{array}{l}\text { Alonso et. al. } \\
(2005)\end{array}$ & $\begin{array}{l}\text { Problemas } \\
\text { salud }\end{array}$ & $\begin{array}{l}\text { Comorbilidad de } \\
\text { DI }\end{array}$ & Transversal & \\
\hline $\begin{array}{l}\text { Arias et. al. } \\
(2009)\end{array}$ & $\begin{array}{l}\text { Clasif. conduc- } \\
\text { tas problema }\end{array}$ & Multidimensional & Transversal & $\begin{array}{l}\text { Evaluación sin ex- } \\
\text { pertos }\end{array}$ \\
\hline $\begin{array}{l}\text { Arnold et. al. } \\
\text { (2014) }\end{array}$ & $\begin{array}{l}\text { Clasificación y } \\
\text { medida de las } \\
\text { Necesidades } \\
\text { de Apoyo }\end{array}$ & $\begin{array}{l}\text { Instrumento } \\
\text { ICAN }\end{array}$ & Transversal & \\
\hline $\begin{array}{l}\text { Beadle-Brown } \\
\text { et. al. (2014) }\end{array}$ & $\begin{array}{l}\text { Profesionales } \\
\text { que atienden }\end{array}$ & $\begin{array}{l}\text { Liderazgo, for- } \\
\text { mación }\end{array}$ & Longitudinal & Limitaciones \\
\hline $\begin{array}{l}\text { Beail et. al. } \\
\text { (2014) }\end{array}$ & $\begin{array}{l}\text { Estudios cuali- } \\
\text { tativos en } \\
\text { PcDID }\end{array}$ & $\begin{array}{l}\text { Importancia de } \\
\text { participación de } \\
\text { las PcDI en los } \\
\text { estudios }\end{array}$ & Revisión & $\begin{array}{l}\text { Problemas meto- } \\
\text { dológicos }\end{array}$ \\
\hline $\begin{array}{l}\text { Bertoli et. al. } \\
(2011)\end{array}$ & $\begin{array}{l}\text { Necesidades } \\
\text { de apoyo en } \\
\text { PcSD }\end{array}$ & $\begin{array}{l}\text { Necesidades des- } \\
\text { conocidas }\end{array}$ & Transversal & $\begin{array}{l}\text { Necesidad de inclu- } \\
\text { sión social }\end{array}$ \\
\hline $\begin{array}{l}\text { Claes et. al. } \\
\text { (2010) }\end{array}$ & PCP en PcDI & PCP es eficaz & Revisión & \\
\hline $\begin{array}{l}\text { Cocks et. al. } \\
(2011)\end{array}$ & $\begin{array}{l}\text { Apoyos en } \\
\text { residencias }\end{array}$ & $\begin{array}{l}\text { Apoyos persona- } \\
\text { lizados }\end{array}$ & Transversal & $\begin{array}{l}\text { Necesita más inves- } \\
\text { tigación }\end{array}$ \\
\hline $\begin{array}{l}\text { Cooper et. al. } \\
(2011)\end{array}$ & $\begin{array}{l}\text { Privación so- } \\
\text { cial y servicios }\end{array}$ & $\begin{array}{l}\text { Privación social } \\
\text { no es desigualdad }\end{array}$ & Transversal & $\begin{array}{l}\text { Necesaria promo- } \\
\text { ción de la salud }\end{array}$ \\
\hline $\begin{array}{l}\text { De Ruiter et. al. } \\
(2008)\end{array}$ & TC en PcDI & Riesgo de TC & Longitudinal & No generalizable \\
\hline $\begin{array}{l}\text { Finley et. al. } \\
(2014)\end{array}$ & $\begin{array}{l}\text { Educación } \\
\text { sexual en } \\
\text { PcDID }\end{array}$ & $\begin{array}{l}\text { Relación entre } \\
\text { alumno-formador }\end{array}$ & Transversal & \\
\hline $\begin{array}{l}\text { Garaigordobil } \\
\text { et. al. (2007) }\end{array}$ & $\begin{array}{l}\text { Autoconcepto, } \\
\text { autoestima }\end{array}$ & $\begin{array}{l}\text { Puntuaciones más } \\
\text { bajas }\end{array}$ & Transversal & $\begin{array}{l}\text { La muestra peque- } \\
\text { ña }\end{array}$ \\
\hline $\begin{array}{l}\text { Hahn et. al. } \\
(2011)\end{array}$ & SWH-HRA & $\begin{array}{l}\text { Instrumento váli- } \\
\text { do }\end{array}$ & Transversal & $\begin{array}{l}\text { Adaptar a otras } \\
\text { discapacidades }\end{array}$ \\
\hline $\begin{array}{l}\text { Hanna et. al. } \\
(2011)\end{array}$ & $\begin{array}{l}\text { Prevención del } \\
\text { cáncer }\end{array}$ & $\begin{array}{l}\text { Necesaria educa- } \\
\text { ción expresar } \\
\text { síntomas }\end{array}$ & Transversal & $\begin{array}{l}\text { Falta de más pro- } \\
\text { gramas }\end{array}$ \\
\hline $\begin{array}{l}\text { Hayes et. al. } \\
(2011)\end{array}$ & Conducta & Ánimo bajo y TC & Transversal & $\begin{array}{l}\text { DI severa y pro- } \\
\text { funda }\end{array}$ \\
\hline $\begin{array}{l}\text { Hulbert- } \\
\text { Williams } \\
(2011)\end{array}$ & Autoinforme & $\begin{array}{l}\text { Problemas psi- } \\
\text { cológicos }\end{array}$ & Transversal & $\begin{array}{l}\text { Información valio- } \\
\text { sa }\end{array}$ \\
\hline $\begin{array}{l}\text { Jordán de Urr- } \\
\text { íes (2010) }\end{array}$ & $\begin{array}{l}\text { Empleo con } \\
\text { apoyo }\end{array}$ & $\begin{array}{l}\text { Necesidad adap- } \\
\text { tación }\end{array}$ & Revisión & $\begin{array}{l}\text { PcDI no consigue } \\
\text { realizar sus metas }\end{array}$ \\
\hline $\begin{array}{l}\text { Lloyd et. al. } \\
\text { (2014) }\end{array}$ & $\begin{array}{l}\text { Tratamiento } \\
\text { PC }\end{array}$ & $\begin{array}{l}\text { Apoyo conduc- } \\
\text { tual positivo }\end{array}$ & Revisión & $\begin{array}{l}\text { Evaluación funcio- } \\
\text { nal }\end{array}$ \\
\hline
\end{tabular}

Tabla 8.1.: Literatura sobre discapacidad intelectual. 


\begin{tabular}{|c|c|c|c|c|}
\hline Autor/es & Temática & Resumen & Estudio & Observaciones \\
\hline $\begin{array}{l}\text { Lund et. al. } \\
\text { (2014) }\end{array}$ & $\begin{array}{l}\text { Programa con- } \\
\text { tra el abuso }\end{array}$ & $\begin{array}{l}\text { Prevención del } \\
\text { abuso sexual }\end{array}$ & Revisión & $\begin{array}{l}\text { Faltan datos cuanti- } \\
\text { tativos }\end{array}$ \\
\hline $\begin{array}{l}\text { McClean et. al. } \\
\text { (2012) }\end{array}$ & $\begin{array}{l}\text { Apoyo conduc- } \\
\text { tual positivo }\end{array}$ & $\begin{array}{l}\text { Aceptación de } \\
\text { tratamiento }\end{array}$ & Longitudinal & $\begin{array}{l}\text { Reducir cambio } \\
\text { conductual }\end{array}$ \\
\hline $\begin{array}{l}\text { Medeiros et. al. } \\
(2014)\end{array}$ & $\begin{array}{l}\text { Problemas de } \\
\text { comportamiento }\end{array}$ & $\begin{array}{l}\text { Se asocian al } \\
\text { nivel de DI }\end{array}$ & Longitudinal & $\begin{array}{l}\text { Objetivo de las } \\
\text { conductas problema }\end{array}$ \\
\hline $\begin{array}{l}\text { Navarro et. al. } \\
(2010)\end{array}$ & $\begin{array}{l}\text { Programa de } \\
\text { educación } \\
\text { sexual }\end{array}$ & Son eficaces & Longitudinal & $\begin{array}{l}\text { Escasez de biblio- } \\
\text { grafía }\end{array}$ \\
\hline $\begin{array}{l}\text { O’Brien et. al. } \\
(2014)\end{array}$ & $\begin{array}{l}\text { Investigadores } \\
\text { con DID y sin } \\
\text { ella }\end{array}$ & $\begin{array}{l}\text { Experiencia de } \\
\text { aprendizaje }\end{array}$ & Transversal & $\begin{array}{l}\text { Utilizan grupos } \\
\text { focales }\end{array}$ \\
\hline Paredes (2010) & $\begin{array}{l}\text { E.de bienestar } \\
\text { personal }\end{array}$ & $\begin{array}{l}\text { Instrumento va- } \\
\text { lidado }\end{array}$ & Transversal & $\begin{array}{l}\text { Necesidad de más } \\
\text { pruebas metodoló- } \\
\text { gicas }\end{array}$ \\
\hline $\begin{array}{l}\text { Pikora et. al. } \\
(2014)\end{array}$ & $\begin{array}{l}\text { Condiciones de } \\
\text { salud en PcSD }\end{array}$ & $\begin{array}{l}\text { Las condiciones } \\
\text { según los padres } \\
\text { no impactan en } \\
\text { vida social y } \\
\text { laboral }\end{array}$ & Transversal & \\
\hline $\begin{array}{l}\text { Reid et. al. } \\
(2011)\end{array}$ & $\begin{array}{l}\text { Prevalencia } \\
\text { ansiedad }\end{array}$ & $\begin{array}{l}\text { Prevalencia de } \\
\text { ansiedad 3,8\% }\end{array}$ & Transversal & $\begin{array}{l}\text { Adaptación de apo- } \\
\text { yos }\end{array}$ \\
\hline Robles (2007) & $\begin{array}{l}\text { Incidencia del } \\
\text { SD }\end{array}$ & $\begin{array}{l}\text { SD está redu- } \\
\text { ciendo }\end{array}$ & Revisión & \\
\hline $\begin{array}{l}\text { Schalock } \\
(2004)\end{array}$ & $\begin{array}{l}\text { Nuevo para- } \\
\text { digma }\end{array}$ & $\begin{array}{l}\text { Nuevas implica- } \\
\text { ciones }\end{array}$ & Revisión & \\
\hline $\begin{array}{l}\text { Schalock et. al. } \\
(2004)\end{array}$ & Concepto & $\begin{array}{l}\text { Necesaria actua- } \\
\text { lización }\end{array}$ & Revisión & $\begin{array}{l}\text { Cambio de para- } \\
\text { digma }\end{array}$ \\
\hline $\begin{array}{l}\text { Schalock et. al. } \\
(2007)\end{array}$ & $\begin{array}{l}\text { Cambio término } \\
\text { DI }\end{array}$ & $\begin{array}{l}\text { Ventajas térmi- } \\
\text { nología }\end{array}$ & Revisión & $\begin{array}{l}\text { La nueva termino- } \\
\text { logía }\end{array}$ \\
\hline $\begin{array}{l}\text { Snell et. al. } \\
(2009)\end{array}$ & CI's altos & $\begin{array}{l}\text { PcDI con CI's } \\
\text { altos }\end{array}$ & Revisión & $\begin{array}{l}\text { Apoyo individuali- } \\
\text { zado }\end{array}$ \\
\hline $\begin{array}{l}\text { Stainton et. al. } \\
\text { (2011) }\end{array}$ & $\begin{array}{l}\text { Apoyo comuni- } \\
\text { tario }\end{array}$ & $\begin{array}{l}\text { Vivienda inde- } \\
\text { pendiente }\end{array}$ & Transversal & $\begin{array}{l}\text { Necesidad de apo- } \\
\text { yos adecuados }\end{array}$ \\
\hline $\begin{array}{l}\text { Stmadová et. } \\
\text { al. (2014) }\end{array}$ & $\begin{array}{l}\text { Investigación } \\
\text { con PcDID }\end{array}$ & $\begin{array}{l}\text { PcDID como } \\
\text { investigadores }\end{array}$ & Longitudinal & \\
\hline $\begin{array}{l}\text { Tassé et. al. } \\
(2010)\end{array}$ & N. de apoyo & $\begin{array}{l}\text { TC más N. de } \\
\text { apoyo }\end{array}$ & Transversal & $\begin{array}{l}\text { Diagnóstico por } \\
\text { DSM }\end{array}$ \\
\hline $\begin{array}{l}\text { Thompson et. } \\
\text { al. (2009) }\end{array}$ & N. de apoyo & Constructo eficaz & Revisión & \\
\hline $\begin{array}{l}\text { Tyrer et. al. } \\
\text { (2008) }\end{array}$ & $\begin{array}{l}\text { Evaluación de } \\
\text { PcDI }\end{array}$ & Instrumento útil & Transversal & No extrapolable \\
\hline $\begin{array}{l}\text { Van Loon et. } \\
\text { al. (2010) }\end{array}$ & Escala SIS & $\begin{array}{l}\text { Necesidades de } \\
\text { apoyo }\end{array}$ & Revisión & \\
\hline
\end{tabular}

Tabla 8.2.: Literatura sobre discapacidad intelectual. (Continuación). 


\begin{tabular}{|l|l|l|l|l|}
\hline \multicolumn{1}{|c|}{ Autor/es } & \multicolumn{1}{c|}{ Temática } & \multicolumn{1}{c|}{ Resumen } & \multicolumn{1}{c|}{ Estudio } & \multicolumn{1}{c|}{ Observaciones } \\
\hline $\begin{array}{l}\text { Verdugo et. al. } \\
\text { (2010) }\end{array}$ & $\begin{array}{l}\text { Validación de la } \\
\text { SIS }\end{array}$ & $\begin{array}{l}\text { Válida muestra } \\
\text { española }\end{array}$ & Transversal & Limitación muestra \\
\hline $\begin{array}{l}\text { Wehmeyer et. } \\
\text { al. (2008) }\end{array}$ & Constucto DI & $\begin{array}{l}\text { El constructo DI } \\
\text { eficaz }\end{array}$ & Revisión & \\
\hline $\begin{array}{l}\text { Zakrajsek et. } \\
\text { al. (2014) }\end{array}$ & $\begin{array}{l}\text { Apoyo en la } \\
\text { participación en } \\
\text { la comunidad }\end{array}$ & $\begin{array}{l}\text { Intervenir con el } \\
\text { personal respon- } \\
\text { sable de agencias } \\
\text { de planificación } \\
\text { de apoyos }\end{array}$ & Transversal & \\
\hline
\end{tabular}

\section{Tabla 8.3.: Literatura sobre discapacidad intelectual. (Continuación).}

Zakrajsek, Hammel y Scazzero (2014) tienen el objetivo de empoderar a las PcDID para la participación comunitaria colaborando con agencias de administradores de apoyo para producir un cambio estratégico y de la programación en el servicio de atención. Para ello, se desarrolló, implementó y evaluó una intervención piloto. Los resultados indicaron que el personal que participaba incrementó la confianza en las PcDID para participar en la comunidad. Esto tiene consecuencias para la actuación de las agencias proveedoras de apoyos a la hora de aportar oportunidades a este colectivo.

\subsubsection{Resumen}

Un numeroso cuerpo de la investigación revisada tiene que ver con los cambios recientes en la conceptualización de la DID y con sus implicaciones a diferentes niveles (social, político, público, etc.).

Por otro lado, los problemas de salud, las conductas problemáticas y los trastornos de conducta también son estudiados en gran medida, así como la prevalencia y la prevención de diferentes problemas y enfermedades de la salud, como el cáncer.

La validación de escalas de evaluación como la SIS, y las intervenciones realizadas en función de las necesidades de apoyo de las PcDID y de sus resultados persona- 
les, desde la perspectiva de la planificación centrada en la persona también cobran importancia en los estudios revisados.

También aparecen estudios acerca de diversos programas de intervención, como los de educación psicosexual, empleo con apoyo, agresiones sexuales, intervenciones conductuales, etc.

La necesidad de adecuación y acceso a los servicios residenciales, de diagnóstico psiquiátrico y psicológico conductual adecuado nuevamente forman parte de algunas de las publicaciones de este apartado.

\subsubsection{Resumen}

Las investigaciones recientes aluden a un cambio de paradigma en el ámbito de la discapacidad intelectual. Desde la AAIDD, se entendió que lo que era denominado como "retraso mental" era un término que hacía referencia más a las limitaciones de la persona, que a sus capacidades, mientras que las capacidades son importantes elementos a tener en cuenta en la evaluación y en la intervención con este colectivo, tanto o más que las limitaciones. En la actualidad, y tal y como muestran las investigaciones revisadas se da un papel mucho más importante a los puntos fuertes de las personas, basándose las evaluaciones e intervenciones en las necesidades de apoyo de las mismas, incluso preguntándoles a las propias PcDID y a sus familias acerca de tales necesidades. En general, las investigaciones hablan de personalizar los apoyos, lo que tiene que traducirse a su vez en una renovación y adaptación de los recursos y servicios a esta nueva orientación en la atención a las personas de este colectivo. 


\subsection{LITERATURA SOBRE CALIDAD DE VIDA}

\subsubsection{Introducción}

En este apartado se recogen las publicaciones revisadas sobre calidad de vida en la población general, en la población con discapacidad y en la población con discapacidades intelectuales y del desarrollo. Posteriormente se expone la bibliografía encontrada acerca de la calidad de vida en el envejecimiento de la población general y en el envejecimiento de las personas con discapacidades intelectuales y del desarrollo.

\subsubsection{Calidad de vida en la población general}

A continuación se presenta la tabla 9, que recoge el resumen de las investigaciones revisadas sobre calidad de vida en la población general.

Chen, Cohen, Kasen, Gordan, Dufur y Smailes (2004) realizan un estudio con el objetivo de construir y validar un cuestionario para evaluar la CV en adultos jóvenes de la población general. Para ello aplican el cuestionario YAQOL a una muestra de 751 personas de entre los 18 y 25 años. Dicho instrumento está formado por 14 escalas que evalúan la salud física y aspectos del bienestar psicológico, las relaciones sociales, el rol funcional y el contexto ambiental. 8 escalas discriminaron entre jóvenes con y sin condiciones físicas crónicas, mientras que 12 escalas discriminaron entre jóvenes con y sin trastornos de personalidad. También se observó una relación negativa entre las puntuaciones de la escala y los síntomas de trastornos psiquiátricos. Los autores concluyen que este instrumento es óptimo para la evaluación de la CV en adultos jóvenes.

García-Altés, Pinilla y Peiró (2006) realizan un estudio con el objetivo de calcular los pesos de CV en la población española en los años 1987, 1993 y 2001 empleando el estado de salud autopercibida recogido en la Encuesta Nacional de Salud. Los autores 
proponen un método para calcular los pesos de CV. Sus resultados indican que la CV varía dependiendo del tipo de enfermedad crónica, en el sentido de que determinadas dolencias que se han sufrido durante el último año reducen en mayor medida la CV que las enfermedades crónicas. Asimismo, los autores observan que la CV disminuye a medida que aumenta la enfermedad y se incrementa cuanto mayor es el nivel de estudios. Otro hallazgo del estudio fue que en una misma enfermedad, ajustando las variables demográficas, los pesos de CV en 1993 y 2001 fueron mayores que en 1987.

Gullberg y Hollman-Frisman (2010) tratan de establecer las dimensiones de CV en la población general sueca. Para ello aplican el QLI en 3 ocasiones (al inicio, a las 3 semanas y a las 6 semanas) a 1.680 personas de entre 18 y 80 años. Los resultados indican que las personas encuestadas dieron importancia a 4 dimensiones de $\mathrm{CV}$, como son familia y amigos, salud y funcionamiento, económica y social y por último la psicológica o espiritual. Las dimensiones fueron valoradas de mayor a menor importancia en el orden expuesto. Los autores concluyen que las medidas tomadas en la población general sobre la CV y sus dimensiones, pueden ser útiles para tenerlos en cuenta a la hora de considerar la ganancia que se puede dar en un estudio de $\mathrm{CV}$ realizado en un grupo específico de pacientes.

Hinz, Kohlmann, Stöbel-Richter, Zenger y Brähler (2014) realizan un estudio para conocer las propiedades psicométricas del EQ-5D-5L en población general alemana. Para ello, aplican el cuestionario a una muestra representativa de 2469 sujetos. Los resultados indican que los hombres puntuaban mejor su estado de salud que las mujeres, y tenían una tendencia lineal de edad. Casi la mitad de los entrevistados puntuaban estar en un estado de salud óptima, lo que demostró un efecto techo. Los investigadores indican que es un cuestionario con aplicabilidad limitada, sobre todo por la asimetría y que 
la suma de las puntuaciones es útil por su simplicidad, generalización y validez de constructo.

Jiang y Hesser (2006) examinan los indicadores demográficos y las conductas de riesgo que predicen una pobre $\mathrm{CV}$ en la población general. Por medio de una base de datos y una entrevista telefónica al azar, obtienen una muestra de 1.843 entrevistados. Los autores identifican varios indicadores que predicen una pobre CV en esta población, como la discapacidad, la incapacidad para trabajar, el desempleo, bajos ingresos, la ausencia de ejercicio físico, la enfermedad de asma y el tabaquismo, este último relacionado especialmente con la mala CV. Los autores concluyen que con el empleo de múltiples medidas de CV se pueden lograr progresos en la evaluación de los niveles de mala salud de la población, en la identificación de subgrupos con una pobre $\mathrm{CV}$, en la mejora de las intervenciones, etc. Por último proponen que son necesarios estudios longitudinales para verificar la relación causal entre los factores estudiados y la CV relativa a la salud.

McGrath, O’Malley y Hendrix (2011) comprueban la relación existente entre el tipo de ejercicio físico realizado y la CV relativa a la salud en 143 adultos sanos que practicaban o bien Pilates, o aeróbic o ejercicios para entrenar la fuerza. A través de la aplicación de la entrevista RAND en su versión abreviada los autores obtienen una asociación significativa entre el tipo de ejercicio y el tiempo durante el que los participantes lo habían practicado, de manera que la mayoría de las personas que habían practicado ejercicio durante 5 años pertenecían al grupo de aeróbic. Con un análisis cualitativo los autores también examinan el beneficio percibido por los participantes de su experiencia del ejercicio en grupo. Los autores concluyen que es necesario que los proveedores de 
servicios conozcan el tipo de ejercicio que realizan las personas y los beneficios que tiene en su CV.

Oliva-Moreno, López-Bastida, Worbes-Cerezo y Serrano-Aguilar (2010) describen la CV relativa a la salud de la población canaria. Para ello emplean una muestra de 5.549 personas junto a la información de 3 estudios observacionales previamente realizados con población con enfermedad de Alzheimer, accidente cerebrovascular o VIH. El instrumento empleado fue el cuestionario EQ-5-D. Los resultados indican que las personas con enfermedades crónicas tienen una peor autopercepción del estado de salud que la población general. Asimismo, las dimensiones depresión/ansiedad y angustia/malestar fueron en las que más problemas se percibían. La mayor pérdida de CV se observó en personas con Alzheimer y con accidente cerebrovascular. Los autores sugieren que estos datos se tomen en consideración para establecer las prioridades sanitarias y para evaluar el impacto de las políticas sanitarias.

Schalock (2004) investiga qué es lo que actualmente se conoce y lo que se desconoce del concepto de $\mathrm{CV}$. El autor encuentra en diversas investigaciones que la $\mathrm{CV}$ se conforma de 8 dominios, que son las relaciones interpersonales, la inclusión social, el desarrollo personal, el bienestar físico, la autodeterminación, el bienestar material, el bienestar emocional y los derechos. Asimismo, habla de que lo que sabemos es el contexto histórico del concepto de CV, su importancia y uso como principio de los servicios, su naturaleza multidimensional y sus indicadores. Por otro lado, lo que se está empezando a conocer sería la importancia del pluralismo metodológico para evaluar la CV, los usos de los indicadores, los predictores de la $\mathrm{CV}$, entre otras cosas. Por último, el autor defiende que aún faltan muchas cuestiones por saber acerca de la $\mathrm{CV}$, como por ejemplo la evaluación de los programas de cambio relacionados con este constructo. 


\begin{tabular}{|c|c|c|c|c|}
\hline Autor/es & Temática & Resumen & Estudio & Observaciones \\
\hline $\begin{array}{l}\text { Chen et. al. } \\
\text { (2004) }\end{array}$ & $\begin{array}{l}\mathrm{CV} \text { en adul- } \\
\text { tos jóvenes }\end{array}$ & $\begin{array}{l}\text { YAQOL, instru- } \\
\text { mento válido para } \\
\text { medir CV }\end{array}$ & $\begin{array}{l}\text { Longitudi- } \\
\text { nal }\end{array}$ & $\begin{array}{l}\text { Se necesita continuar la } \\
\text { evaluación }\end{array}$ \\
\hline $\begin{array}{l}\text { García- } \\
\text { Altés et. al. } \\
(2006)\end{array}$ & $\begin{array}{l}\text { Pesos de CV } \\
\text { y salud auto- } \\
\text { percibida }\end{array}$ & $\begin{array}{l}\text { Se estiman los } \\
\text { pesos de CV a } \\
\text { partir del estado de } \\
\text { salud autopercibi- } \\
\text { do }\end{array}$ & $\begin{array}{l}\text { Transver- } \\
\text { sal }\end{array}$ & $\begin{array}{l}\text { Se propone un modelo } \\
\text { para calcular los pesos } \\
\text { de } \mathrm{CV}\end{array}$ \\
\hline $\begin{array}{l}\text { Gullberg } \\
\text { et. al. } \\
(2010)\end{array}$ & $\begin{array}{l}\text { Dimensiones } \\
\text { de la CV en } \\
\text { población } \\
\text { general }\end{array}$ & $\begin{array}{l}\text { Las dimensiones } \\
\text { de CV encontradas } \\
\text { son la familia y } \\
\text { amigos, salud, } \\
\text { social y económica } \\
\text { y psicológica } \\
\end{array}$ & $\begin{array}{l}\text { Longitudi- } \\
\text { nal }\end{array}$ & $\begin{array}{l}\text { Las puntuaciones nor- } \\
\text { mativas pueden emple- } \\
\text { arse para comprobar los } \\
\text { resultados en algún } \\
\text { grupo específico de } \\
\text { pacientes }\end{array}$ \\
\hline $\begin{array}{l}\text { Hinz et. al. } \\
\text { (2014) }\end{array}$ & $\begin{array}{l}\text { EQ-5D-5L } \\
\text { en alemanes }\end{array}$ & $\begin{array}{l}\text { Aplicabilidad limi- } \\
\text { tada }\end{array}$ & $\begin{array}{l}\text { Transver- } \\
\text { sal }\end{array}$ & \\
\hline $\begin{array}{l}\text { Jiang et. al. } \\
\text { (2006) }\end{array}$ & $\begin{array}{l}\text { Asociación } \\
\text { entre CV } \\
\text { relativa a } \\
\text { salud y fac- } \\
\text { tores de- } \\
\text { mográfi-cos } \\
\text { y sanitarios }\end{array}$ & $\begin{array}{l}\text { Hay múltiples in- } \\
\text { dicadores que pre- } \\
\text { dicen una pobre } \\
\text { CV }\end{array}$ & $\begin{array}{l}\text { Transver- } \\
\text { sal }\end{array}$ & $\begin{array}{l}\text { Muestra no representa- } \\
\text { tiva. Las inferencias } \\
\text { sobre relaciones causa- } \\
\text { les deben tomarse con } \\
\text { cautela en estudios } \\
\text { transversales }\end{array}$ \\
\hline $\begin{array}{l}\text { McGrath } \\
\text { et. al. } \\
(2011)\end{array}$ & $\begin{array}{l}\text { Relación } \\
\text { entre el tipo } \\
\text { de ejercicio } \\
\text { y la CV rela- } \\
\text { tiva a la sa- } \\
\text { lud }\end{array}$ & $\begin{array}{l}\text { El tipo de ejercicio } \\
\text { físico influye en la } \\
\text { CV relativa a la } \\
\text { salud }\end{array}$ & $\begin{array}{l}\text { Transver- } \\
\text { sal }\end{array}$ & $\begin{array}{l}\text { No se recogen en el } \\
\text { estudio variables socio- } \\
\text { demográficas. El tipo de } \\
\text { ejercicios está limitado } \\
\text { a } 3\end{array}$ \\
\hline $\begin{array}{l}\text { Oliva- } \\
\text { Moreno et. } \\
\text { al. (2010) }\end{array}$ & $\begin{array}{l}\mathrm{CV} \text { en po- } \\
\text { blación ca- } \\
\text { naria }\end{array}$ & $\begin{array}{l}\text { La autopercep- } \\
\text { ción del estado de } \\
\text { salud más pobre } \\
\text { en las P.con en- } \\
\text { fermedad crónica }\end{array}$ & $\begin{array}{l}\text { Transver- } \\
\text { sal }\end{array}$ & $\begin{array}{l}\text { La CV debe integrarse } \\
\text { con diversos datos para } \\
\text { el desarrollar y planifi- } \\
\text { car prácticas de salud } \\
\text { efectivas. }\end{array}$ \\
\hline $\begin{array}{l}\text { Schalock } \\
(2004)\end{array}$ & $\begin{array}{l}\text { Concepto de } \\
\mathrm{CV}\end{array}$ & $\begin{array}{l}\text { Hay numerosas } \\
\text { cuestiones de la } \\
\text { CV que conoce- } \\
\text { mos }\end{array}$ & Revisión & $\begin{array}{l}\text { Necesidad de continuar } \\
\text { la investigación en el } \\
\text { campo de la CV }\end{array}$ \\
\hline $\begin{array}{l}\text { Wang et. } \\
\text { al. (2012) }\end{array}$ & $\begin{array}{l}\text { Validación } \\
\text { del EQ-5D } \\
\text { en China }\end{array}$ & $\begin{array}{l}\text { EQ-5D es válido } \\
\text { para evaluar CV } \\
\text { relativa a la salud } \\
\text { en población china }\end{array}$ & $\begin{array}{l}\text { Transver- } \\
\text { sal }\end{array}$ & $\begin{array}{l}\text { Debería validarse en } \\
\text { más poblaciones }\end{array}$ \\
\hline
\end{tabular}

Tabla 9: Literatura sobre calidad de vida en la población general. 
Wang, Patrick, Edwards, Skalicky, et. al. (2012) validan el EQ-5D en población general china. Para ello emplearon una muestra de 1.747 personas. Los resultados indican que las propiedades psicométricas del cuestionario son las apropiadas. Además, permite distinguir bien entre grupos, por ejemplo, entre aquellos que informaron de una pobre salud general y trastornos crónicos tenían peor CV relativa a la salud que los que no tenían tales características. La gente mayor, mujeres, personas viudas o divorciadas y aquellos con bajo nivel socio-económico reportaban pobre CV relativa a la salud. Los autores concluyen que el EQ-D5 tiene una adecuada validez de constructo y es fiable para evaluar la CV relativa a la salud en población general china.

\subsubsection{Resumen}

En la población general la CV se estudia relacionada con variables de salud, pasando a denominarse CV relativa a la salud. Las investigaciones revisadas toman muestras de adultos o jóvenes de la población general, y buscan indicadores o conductas que influyen en este tipo de CV, como por ejemplo, la práctica de ejercicio físico.

\subsubsection{Calidad de vida en personas con discapacidad}

Seguidamente se presenta la tabla 10 que resume las publicaciones revisadas acerca de la calidad de vida en las personas con discapacidad. 


\begin{tabular}{|c|c|c|c|c|}
\hline Autor/es & Temática & Resumen & Estudio & $\begin{array}{c}\text { Observacio- } \\
\text { nes }\end{array}$ \\
\hline $\begin{array}{l}\text { Hernández } \\
\text { (2004) }\end{array}$ & CV y PcD & $\begin{array}{l}\text { Existen numerosas } \\
\text { medidas para mejo- } \\
\text { rar la CV de las PcD }\end{array}$ & Revisión & \\
\hline $\begin{array}{l}\text { Petry et. al. } \\
\text { (2009) }\end{array}$ & $\begin{array}{l}\text { Instrumento de } \\
\text { evaluación de la } \\
\text { CV en PcDs } \\
\text { múltiples }\end{array}$ & $\begin{array}{l}\text { Puntuacio-nes aso- } \\
\text { ciadas con la condi- } \\
\text { ción médica de los } \\
\text { participantes }\end{array}$ & $\begin{array}{l}\text { Transver- } \\
\text { sal }\end{array}$ & \\
\hline $\begin{array}{l}\text { Rodríguez- } \\
\text { Porrero } \\
(2000)\end{array}$ & $\begin{array}{l}\text { CV y discapaci- } \\
\text { dad }\end{array}$ & $\begin{array}{l}\text { Las nuevas tecno- } \\
\text { logías cooperen en } \\
\text { el aumento de la CV } \\
\text { de las PcD }\end{array}$ & Revisión & $\begin{array}{l}\text { Mejoras en el } \\
\text { diseño de vi- } \\
\text { viendas, pro- } \\
\text { ductos y servi- } \\
\text { cios }\end{array}$ \\
\hline
\end{tabular}

Tabla 10: Literatura sobre calidad de vida en las personas con discapacidad.

Hernández (2004) realiza un análisis acerca de los conceptos de discapacidad y $\mathrm{CV}$, además de aportar las medidas que se han llevado a cabo tanto a nivel internacional como en Colombia. Ella propone un concepto de CV en las PcD basado en la autonomía, la autodeterminación, la participación y responsabilidad y la solidaridad. Para cada área propone diferentes medidas que es necesario llevar a cabo para mejorar la CV de las PcD, entre ellas destacaría la provisión de oportunidades, donde la PcD pueda llevar el control de su propia vida; así como la eliminación de barreras, tanto en los medios de comunicación como en la creación de instituciones y centros de apoyo a este colectivo; la adaptación de entornos inmediatos; la promulgación de leyes en favor de los mismos. Pero todo ello no puede ser viable si la PcD no acepta su situación, y es aquí donde entra en juego el papel de los profesionales que trabajan en el ámbito de la discapacidad, así como las organizaciones dirigidas a ellos.

Petry, Maes y Vlaskamp (2009) evalúan las diferentes dimensiones de la CV en personas con múltiples discapacidades, comparando las puntuaciones de CV en el cuestionario QOL-PMD con variables personales y del entorno en una muestra de 49 personas con discapacidades múltiples. Los resultados indican que la variable más fuertemen- 
te asociada a la puntuación en el cuestionario fue la condición médica del participante. Por otro lado, características como la edad, el género o las limitaciones sensoriales o motoras no tuvieron ningún efecto significativo en las puntuaciones del QOL-PMD. Por último, también observaron un efecto significativo de determinadas variables del entorno sobre los resultados en el cuestionario.

Rodríguez-Porrero (2000) realiza un análisis sobre la CV en las PcD en relación con las nuevas tecnologías. La tecnología para la autora debe cumplir funciones como la comunicación, movilidad, relaciones sociales, el cuidado y las AVD. Pero no siempre las empresas tecnológicas tienen en cuenta que las innovaciones deben ser útiles para todos los colectivos de la sociedad. Esta autora hace referencia a las líneas de investigación que propone el estudio ETAM para la población mayor, que incluye las técnicas de aprendizaje continuo, el diseño de productos tecnológicos universales, la mejora de las infraestructuras, la aplicación de las nuevas tecnologías a la vida doméstica, la prevención, las tecnologías de apoyo y las telecomunicaciones médicas para realizar un seguimiento médico a distancia, todo ello con el objetivo de mejorar la CV de las PcD, y de aquellos mayores que se enfrentan a una discapacidad.

\subsubsection{Resumen}

Los artículos revisados acerca de la CV en las PcD han sido escasos, debido a que suelen tratarse de investigaciones acerca de un tipo de discapacidad concreta. Aun así, los estudios giran en torno a establecer posibles dimensiones, indicadores y medidas de CV, y en un caso, a relacionar la mejora de la CV con el uso de nuevas tecnologías. 


\subsubsection{Calidad de vida en personas con discapacidades intelectuales y del desarrollo}

A continuación se presenta la tabla 11 que recoge las investigaciones revisadas acerca de la calidad de vida en las personas con discapacidad intelectual.

Badia, Orgaz, Verdugo, Ullán y Martínez (2013) realizan un estudio con 125 PcDID de entre 17 y 65 años, a quienes aplican la Escala Integral de CV y la Escala GENCAT. No se encontró relación entre la CV objetiva y la participación en actividades de ocio de las PcDID, pero sí que hubo una relación predictiva entre la participación en el ocio y el bienestar material, emocional y físico, aspectos de la CV subjetiva.

Beyer, Jordán de Urríes y Verdugo (2010) comparan la situación de las PcDI que trabajan en un empleo con apoyo en Europa. Para ello se sirven de informes de 184 agencias que ofertan este tipo de empleo en ciudades europeas como Finlandia, España y Reino Unido. Observan que la mayoría de las organizaciones cuentan con servicios adicionales al empleo con apoyo, por ejemplo la formación profesional o el trabajo protegido. Se encontraron diferencias en el apoyo en el lugar de trabajo, lo que puede ser una desventaja para las PcDI. En Finlandia y España las PcDI trabajan más de 24 horas semanales y sólo una minoría tiene contratos indefinidos. Las horas de apoyo son pocas. Los autores concluyen que la financiación del empleo con apoyo es muy baja y perjudica a las PcDI severa. Asimismo, el que las PcDI trabajen menos horas en el Reino Unido que en otros países de la Unión Europea sugiere que no hay armonía entre las legislaciones vigentes, lo que afecta a las PcDI. Los autores concluyen con la sugerencia de la necesidad de más estudios de seguimiento. 


\begin{tabular}{|c|c|c|c|c|}
\hline Autor/es & Temática & Resumen & Estudio & Observaciones \\
\hline $\begin{array}{l}\text { Badia et. } \\
\text { al. (2013) }\end{array}$ & $\begin{array}{l}\text { CV y participa- } \\
\text { ción }\end{array}$ & $\begin{array}{l}\text { Mayor bienestar } \\
\text { físico, material y } \\
\text { psíquico }\end{array}$ & Transversal & \\
\hline $\begin{array}{l}\text { Beyer et. } \\
\text { al. (2010) }\end{array}$ & Empleo con apoyo & $\begin{array}{l}\text { Falta de consenso } \\
\text { entre legislaciones }\end{array}$ & Transversal & $\begin{array}{l}\text { Faltan estudios de } \\
\text { seguimiento }\end{array}$ \\
\hline $\begin{array}{l}\text { Bramston } \\
\text { et. al. } \\
(2005)\end{array}$ & $\begin{array}{l}\text { Principios concep- } \\
\text { tuales de la CV }\end{array}$ & $\begin{array}{l}\text { El apoyo social es } \\
\text { el predictor más } \\
\text { fuerte }\end{array}$ & Transversal & $\begin{array}{l}\text { Escasos estudios } \\
\text { comparan la CV en } \\
\text { P con y sin discapa- } \\
\text { cidad }\end{array}$ \\
\hline $\begin{array}{l}\text { Chou et. } \\
\text { al. (2007) }\end{array}$ & $\mathrm{CV}$ en PcDI & $\begin{array}{l}\text { Factores predicen } \\
\text { indicadores de } \mathrm{CV}\end{array}$ & Transversal & $\begin{array}{l}\text { Sólo incluye PcDI } \\
\text { leve }\end{array}$ \\
\hline $\begin{array}{l}\text { Claes et. } \\
\text { al. (2012) }\end{array}$ & $\begin{array}{l}\text { CV relativa a re- } \\
\text { sultados persona- } \\
\text { les }\end{array}$ & $\begin{array}{l}\text { Apoyos, vivienda y } \\
\text { trabajo yCV en DI }\end{array}$ & Transversal & \\
\hline $\begin{array}{l}\text { Davies et. } \\
\text { al. (2010) }\end{array}$ & $\begin{array}{l}\text { Empleo PDA para } \\
\text { uso transporte }\end{array}$ & $\begin{array}{l}\text { La PDA es útil para } \\
\text { utilizar el autobús }\end{array}$ & Transversal & $\begin{array}{l}\text { PcDI acompañadas } \\
\text { por observador }\end{array}$ \\
\hline $\begin{array}{l}\text { Fahey et. } \\
\text { al. (2010) }\end{array}$ & $\begin{array}{l}\mathrm{CV} \text { de PcDI en } \\
\text { residencias }\end{array}$ & $\begin{array}{l}\text { Comunidades resi- } \\
\text { denciales }\end{array}$ & Transversal & $\begin{array}{l}\text { Resultados no pue- } \\
\text { den extrapolarse }\end{array}$ \\
\hline $\begin{array}{l}\text { Foley et. } \\
\text { al. (2014) }\end{array}$ & $\begin{array}{l}\text { CV familiar, AVD } \\
\text { y empleo }\end{array}$ & $\begin{array}{l}\text { Mayor CV familiar } \\
\text { en empleo abierto y } \\
\text { mejores AVD }\end{array}$ & Transversal & En PcSD \\
\hline $\begin{array}{l}\text { Giné et. } \\
\text { al. (2013) }\end{array}$ & $\begin{array}{l}\text { Escalas de CV } \\
\text { Familiar }\end{array}$ & $\begin{array}{l}\text { Útil para planes de } \\
\text { acción }\end{array}$ & Transversal & \\
\hline $\begin{array}{l}\text { Gómez et. } \\
\text { al. (2012) }\end{array}$ & $\begin{array}{l}\text { Modelo de Rasch } \\
\text { de la } \\
\text { E.INTEGRAL }\end{array}$ & $\begin{array}{l}\text { Es útil para evaluar } \\
\text { CV en PcDI }\end{array}$ & Transversal & $\begin{array}{l}\text { Algunos ítems son } \\
\text { demasiado fáciles }\end{array}$ \\
\hline $\begin{array}{l}\text { Holburn } \\
\text { et. al. } \\
(2007)\end{array}$ & $\mathrm{CV}$ en PcDI & $\begin{array}{l}\text { Iimportancia de } \\
\text { preguntar a las } \\
\text { PcDI }\end{array}$ & Transversal & $\begin{array}{l}\text { Hay pocos estudios } \\
\text { con metodología } \\
\text { cualitativa }\end{array}$ \\
\hline $\begin{array}{l}\text { Kober et. } \\
\text { al. (2005) }\end{array}$ & $\begin{array}{l}\text { Tipo de empleo y } \\
\text { CV }\end{array}$ & $\begin{array}{l}\text { Las PcDI con alta } \\
\text { habilidad funcional }\end{array}$ & Transversal & $\begin{array}{l}\text { No hay línea base } \\
\text { sobre efecto del } \\
\text { empleo }\end{array}$ \\
\hline $\begin{array}{l}\text { Lucas- } \\
\text { Carrasco } \\
(2012)\end{array}$ & $\begin{array}{l}\text { Satisfacción con } \\
\text { la vida }\end{array}$ & $\begin{array}{l}\text { El SWLS, prueba } \\
\text { válida para satis- } \\
\text { facción con la vida } \\
\text { en PcDI }\end{array}$ & Transversal & $\begin{array}{l}\text { La muestra de PcDI } \\
\text { estudiada está satis- } \\
\text { fecha con la vida }\end{array}$ \\
\hline $\begin{array}{l}\text { Mirón et. } \\
\text { al. (2008) }\end{array}$ & CV en PcDI & $\begin{array}{l}\text { PcDI valoran su } \\
\text { CV relativa a la } \\
\text { salud, }\end{array}$ & Transversal & $\begin{array}{l}\text { Es necesaria la rea- } \\
\text { lización estudios } \\
\text { CV }\end{array}$ \\
\hline $\begin{array}{l}\text { Neely- } \\
\text { Barnes et. } \\
\text { al. (2008) }\end{array}$ & $\begin{array}{l}\text { CV y posibilidad } \\
\text { de elección }\end{array}$ & $\begin{array}{l}\text { PcDI leve tienen } \\
\text { mayores puntua- } \\
\text { ciones en CV }\end{array}$ & Transversal & $\begin{array}{l}\text { Sólo incluye PcDI } \\
\text { leve }\end{array}$ \\
\hline $\begin{array}{l}\text { Noonan } \\
\text { et. al. } \\
(2010) \\
\end{array}$ & $\begin{array}{l}\mathrm{CV} \text { y modelo de } \\
\text { alojamiento }\end{array}$ & $\begin{array}{l}\text { Diferencias en los } \\
\text { modelos organiza- } \\
\text { cionales }\end{array}$ & Revisión & $\begin{array}{l}\text { No tiene en cuenta } \\
\text { ingresos, variables } \\
\text { geográficas }\end{array}$ \\
\hline
\end{tabular}

Tabla 11.1.: Literatura sobre calidad de vida en las PcDID. 


\begin{tabular}{|c|c|c|c|c|}
\hline Autor/es & Temática & Resumen & Estudio & Observaciones \\
\hline $\begin{array}{l}\text { Nota et. } \\
\text { al. (2007) }\end{array}$ & $\begin{array}{l}\text { PcDI y CV, auto- } \\
\text { deter-minación y } \\
\text { habilidades socia- } \\
\text { les }\end{array}$ & $\begin{array}{l}\text { La CV y la autode- } \\
\text { ter-minación de- } \\
\text { penden de factores } \\
\text { varios }\end{array}$ & Transversal & $\begin{array}{l}\text { Las evaluaciones } \\
\text { sólo las realizaban } \\
\text { los profesionales }\end{array}$ \\
\hline $\begin{array}{l}\text { Nota et. } \\
\text { al. (2006) }\end{array}$ & $\begin{array}{l}\text { Validación de una } \\
\text { escala de CV }\end{array}$ & $\begin{array}{l}\text { La escala EQLI es } \\
\text { efectiva }\end{array}$ & Transversal & $\begin{array}{l}\text { No es generalizable } \\
\text { a PcDI que viven } \\
\text { con sus familias }\end{array}$ \\
\hline $\begin{array}{l}\text { Perri et. } \\
\text { al. (2013) }\end{array}$ & $\begin{array}{l}\text { Calidad de servi- } \\
\text { cio dentro y fuera } \\
\text { de la localidad }\end{array}$ & $\begin{array}{l}\text { Más ventaja estar } \\
\text { en servicio dentro } \\
\text { de la comunidad, } \\
\text { pero menor coste } \\
\text { en servicios más } \\
\text { alejado }\end{array}$ & Transversal & No extrapolable \\
\hline $\begin{array}{l}\text { Samuel et. } \\
\text { al. (2012) }\end{array}$ & CV familiar & $\begin{array}{l}\text { Revisa la literatura } \\
\text { sobre la CV fami- } \\
\text { liar }\end{array}$ & Revisión & $\begin{array}{l}\text { Antes las interven- } \\
\text { ciones sólo se dirig- } \\
\text { ían a la PcDI }\end{array}$ \\
\hline $\begin{array}{l}\text { Schalock } \\
\text { et.al. } \\
\text { (2016) }\end{array}$ & CV individual & $\begin{array}{l}\text { Modelo teórico de } \\
\mathrm{CV}\end{array}$ & Revisión & \\
\hline $\begin{array}{l}\text { Simoes et. } \\
\text { al. (2016) }\end{array}$ & $\begin{array}{l}\text { CV en PcDID y } \\
\text { poblac. general }\end{array}$ & Mayor CV sin DID & Transversal & $\begin{array}{l}\text { Repercusiones polí- } \\
\text { ticas }\end{array}$ \\
\hline $\begin{array}{l}\text { Turk } \\
(2012)\end{array}$ & $\begin{array}{l}\text { Necesidades en } \\
\text { salud mental }\end{array}$ & $\begin{array}{l}\text { PcDI adolescentes } \\
\text { tienen problemas } \\
\text { de salud mental }\end{array}$ & Transversal & $\begin{array}{l}\text { Autismo, baja capa- } \\
\text { cidad adaptativa, } \\
\text { antecedentes }\end{array}$ \\
\hline $\begin{array}{l}\text { Verdugo } \\
\text { et. al. } \\
(2006) \\
\end{array}$ & $\begin{array}{l}\text { CV en PcDI que } \\
\text { trabajan en em- } \\
\text { pleo con apoyo }\end{array}$ & $\begin{array}{l}\text { No hay diferencias } \\
\text { en CV }\end{array}$ & Transversal & \\
\hline $\begin{array}{l}\text { Verdugo } \\
\text { et. al. } \\
(2012)\end{array}$ & $\begin{array}{l}\text { Validación escala } \\
\text { Integral }\end{array}$ & $\begin{array}{l}\text { Evidencia de la } \\
\text { validez de la Escala } \\
\text { INTEGRAL en } 8 \\
\text { países }\end{array}$ & Transversal & $\begin{array}{l}\text { Tiene un reducido } \\
\text { número de ítems }\end{array}$ \\
\hline $\begin{array}{l}\text { Wang et. } \\
\text { al. (2010) }\end{array}$ & $\begin{array}{l}\text { Factor estructura } \\
\text { del constructo de } \\
\text { CV }\end{array}$ & $\begin{array}{l}\text { Se encuentra un } \\
\text { único factor de } \\
\text { orden secundario } \\
\text { en la CV }\end{array}$ & Transversal & $\begin{array}{l}\text { El concepto subje- } \\
\text { tivo de CV es rela- } \\
\text { tivo a la cultura }\end{array}$ \\
\hline $\begin{array}{l}\text { Wong et. } \\
\text { al. (2011) }\end{array}$ & $\begin{array}{l}\text { Validación } \\
\text { CQOL-ID en Chi- } \\
\text { na }\end{array}$ & $\begin{array}{l}\text { Este instrumento es } \\
\text { válido para medir } \\
\text { CV en PcDI chinas }\end{array}$ & Transversal & $\begin{array}{l}\text { Problemas cultura- } \\
\text { les }\end{array}$ \\
\hline
\end{tabular}

Tabla 11.2.: Literatura sobre calidad de vida en las PcDID. (Continuación).

Bramston, Chipuer y Pretty (2005) realizan un estudio para investigar 3 principios conceptuales de la $\mathrm{CV}$, a nivel individual, el estrés; a nivel comunitario el barrio de pertenencia, y a nivel interaccional el apoyo social. Para ello emplearon una muestra de 
80 PcDI y 120 personas sin DI de 16 a 23 años. Los resultados indican que las tasas de satisfacción de las PcDI con la salud eran mayores que las de las personas sin discapacidad, mientras que eran menores en intimidad y participación social. El apoyo social fue el predictor más fuerte de la satisfacción con la vida en ambos grupos. Los autores concluyen que los principios conceptuales de la CV subjetiva proporcionan un marco útil para analizar los resultados y estimular la investigación adicional.

Chou, Schalock, Tzou, Lin, et. al. (2007) examinan las percepciones de las PcDI acerca de su CV. Para ello emplean una muestra de 233 PcDI de Taiwan mayores de 16 años que residen con sus familias, y comprueban en ellos los indicadores transculturales de CV y los datos sociodemográficos. Los resultados indican que la importancia y el uso de tales indicadores fueron valorados positivamente por las PcDI, además, las características individuales de los participantes, como las AIVD y el nivel educativo eran predictores de la importancia que le daban a los indicadores. Por otro lado, la percepción de los adultos sobre el uso de los indicadores de CV se vio influida por el lugar de residencia y el nivel educativo del padre de la PcDI. Los autores concluyen que este estudio tiene implicaciones importantes para mejorar los servicios destinados a este colectivo.

Claes, Van Hove, Vandevelde, van Loon y Schalock (2012) realizan un estudio para valorar la relación entre la CV relativa a los resultados personales y las estrategias de apoyo, los estilos de vivienda y el estado del empleo en 186 PcDI. Los resultados indican que hubo un impacto significativo de la disponibilidad de las estrategias de apoyo, el estilo de vivienda, el estado del trabajo y el nivel de DI sobre la CV relativa a los resultados personales. 
Davies, Stock, Holloway y Wehmeyer (2010) realizan un estudio para observar la utilidad del empleo de una PDA en PcDI adolescentes y adultas a la hora de acceder a un transporte público. Esta tecnología con GPS integrado permite navegar por la ruta que va a realizar el autobús. En el grupo control, las personas se servían de mapas e instrucciones verbales. Los resultados indican que el $73 \%$ de las PcDI que emplearon la PDA tocaban el timbre y abandonaban el autobús en la parada adecuada en mayor medida que las personas del grupo control. Esto se observó en personas que no conocían las paradas de autobús empleadas en el estudio.

Fahey, Walsh, Emerson y Guerin (2010) tratan de conocer las diferencias existentes entre un grupo de PcDI que viven en comunidades residenciales y un grupo que vive en un servicio de cuidado ordinario. Para ello emplean una muestra de 29 PcDI irlandesas. Los resultados que obtienen van en la dirección de que en las comunidades residenciales hay beneficios que no hay en los servicios ordinarios, ya que los residentes en este tipo de comunidades reportaban que había mayor tasa de personal, zonas de vida familiar, bajos niveles de prácticas institucionalizadoras como el distanciamiento social, relaciones recíprocas con los cuidadores, buen desarrollo de los procedimientos de administración. La conclusión obtenida por los autores es que es interesante aplicar los beneficios de las comunidades residenciales en los servicios comunes.

Foley, Girdler, Downs, Jacoby, et. al. (2014) estudian la relación entre la CV familiar, las ocupaciones y las actividades de vida diaria de personas jóvenes con SD. Para ello utilizan una base de datos de 150 familias con un familiar con SD de entre 16 y 30 años. Al comparar los resultados, los autores encuentran que las familias que tienen una PcSD en un empleo protegido tienen menor CV familiar, y que el apoyo de la familia reduce la relación. Por otro lado, las familias con una PcSD con un alto funcio- 
namiento en las AVD tienen una mayor CV familiar independientemente de factores personales y ambientales, y la inclusión de factores familiares como el apoyo a la familia reducen esta relación. Los autores concluyen que la participación de las PcSD en empleos abiertos puede tener una influencia positiva en la CV familiar. Y por otro lado, los servicios que facilitan las AVD y que promueven el acceso de las familias a los apoyos que necesitan pueden tener una influencia positiva en la CV familiar.

Giné, Vilaseca, Gràcia, Mora, et. al. (2013) tienen el objetivo de explorar la calidad de vida familiar de PcDID en España y aportar una escala de medida, para mayores y para menores de 18 años, útil para programas acciones en los servicios. Participaron 1205 familias de PcDID de cinco regiones españolas. Los resultados indican que las dos escalas (para mayores y menores de 18 años) son consistentes y tienen propiedades psicométricas válidas, y son útiles para elaborar planes de acción dirigidos a mejorar la CV de las familias.

Gómez, Arias, Verdugo y Navas (2012) realizan una investigación para validar la escala INTEGRAL de CV en PcDI. La muestra estaba conformada por 271 PcDI adultas españolas. Los resultados mostraron que los datos se ajustaban al modelo, las correlaciones biseriales eran adecuadas, los ítems mostraban precisión, la fiabilidad de los ítems y de las personas fue adecuada, y las categorías de respuesta fueron adecuadas. Sin embargo, un ítem no se ajustaba al modelo y algunos ítems eran muy fáciles para que los participantes los respondieran. Los autores concluyen que es necesario incluir más ítems de mayor dificultad y eliminar uno de ellos, pero que la escala INTEGRAL es un instrumento útil para evaluar CV en PcDI.

Holburn, Cea, Coull y Goode (2007)tratan de conocer lo que 119 participantes (PcDI, miembros de su familia y personal del servicio que trabaja con ellos) de Nueva 
York opinan sobre qué aspectos deben mejorarse de la CV en el colectivo de PcDI. Para ello llevan a cabo una serie de grupos focales. Los resultados indican que para las PcDI la mejora en la CV se centra más en los aspectos que tienen que ver con la vida en el hogar residencial, las relaciones sociales y la comunidad, mientras que en el resto de participantes (miembros de la familia, personal de apoyo directo y gerentes del hogar residencial) los aspectos más importantes que deben mejorarse giran principalmente en torno a la vida en el hogar. Estos resultados indican la importancia de preguntar a las PcDI a la hora de evaluar su CV.

Kober y Eggleton (2005) comparan la CV de PcDI que trabajan en un empleo abierto y en un empleo protegido. Para ello emplean una muestra de 117 PcDI, que son evaluadas mediante un cuestionario de CV y otro de habilidad funcional para el trabajo. Los resultados indican que las PcDI que trabajaban en un empleo abierto tenían puntuaciones significativamente más altas en CV que las del empleo protegido. Los autores también encuentran que en las PcDI con una habilidad funcional baja para el empleo, el tipo de empleo no tenía efectos sobre su CV, pero cuando las PcDI tenían una alta habilidad funcional para el empleo y estaban en un empleo de tipo abierto sí se producía un incremento significativo en la CV.

Lucas-Carrasco (2012) realiza un estudio para comprobar la validez del cuestionario de satisfacción con la vida (SWLS) en PcDI españolas. Para ello, aplica tanto el SWLS, como el WHOQOL-BREF. Los resultados indican que las PcDI están satisfechas con su vida, pero las PcDI que viven en instituciones residenciales tienen menor satisfacción con la vida que aquellas que residen en comunidades o en su hogar, aunque no hay diferencias significativas. Asimismo, las puntuaciones del SWLS distinguían entre sano/no sano, y entre quienes informaban de mayor satisfacción en sus relaciones, 
ambiente comunitario y trabajo que los que informaban de menor satisfacción. La autora concluye que este estudio es el primero que expone las propiedades psicométricas del SWLS en PcDI, y que es un instrumento útil.

Mirón, Alonso, Serrano y Sáenz (2008) investigan la CV relativa a la salud percibida por las PcDI de Salamanca. Para ello emplean una muestra de 265 PcDI con una edad media de 35 años, a quienes se les pasó el cuestionario SF-36. Se estudiaron las dimensiones de la CV salud general, función física, rol físico, rol emocional, función social, dolor corporal, vitalidad y salud mental. Los resultados indican que las PcDI estudiadas perciben positivamente su estado en las dimensiones rol físico y función física, y ocurre al contrario con las dimensiones de salud general y vitalidad. Los autores concluyen que en general, las PcDI percibieron su CV relativa a la salud como buena y que son necesarios estudios que exploren la relación entre la CV relativa a la salud y los grados de DI para mejorar la oferta de intervenciones y programas, tanto sanitarios como sociales.

Neely-Barnes, Marcenko y Weber (2008) relacionan la posibilidad de elección de las PcDI con 3 indicadores de la CV, la inclusión en la comunidad, los derechos y las oportunidades para relacionarse. Para ello emplean una muestra de 224 PcDI leve de un estudio realizado previamente en Washington, y a quienes les pasan cuestionarios acerca del lugar de residencia, la posibilidad de elección (elegir el horario, el tiempo dedicado al ocio, etc.), sobre la inclusión comunitaria, los derechos y las relaciones sociales. Los resultados indican que las PcDI que viven en la comunidad y por ello tienen más posibilidades de elección, tenían mayores puntuaciones en la inclusión comunitaria, los derechos y las oportunidades de relacionarse. Los autores concluyen que el estudio tiene 
implicaciones importantes para el desarrollo de políticas y prácticas en el ámbito de la discapacidad, así como para la investigación futura en esta línea.

Noonan, Emerson, Lobb, Hatton, et. al. (2010) realizan una revisión de los artículos publicados desde 1995 a 2005 sobre el alojamiento con apoyo en PcDI y su relación con la CV. Con ello pretenden revisar los estudios sobre la desinstitucionalización y los estudios de las postinstitucionalización, examinar los instrumentos de medida empleados para medir en ambos modelos los resultados personales de los participantes, que en este caso son PcDI y comparar los costes y beneficios asociados a cada modelo. Los resultados indican que en los estudios de desinstitucionalización se encontraban mejores resultados y mayor autodeterminación, participación en relaciones sociales y en actividades comunitarias, así como una mayor satisfacción personal en el ámbito comunitario. En los estudios de la postinstitucionalización, se encontraron en menor medida la mejora de resultados, autodeterminación y actividades comunitarias, pero no se observó evidencia de un mayor bienestar físico ni material. Los autores concluyen con la necesidad de más investigaciones para encontrar factores relacionados con la mejora del bienestar de las PcDI que residen en alojamientos basados en estos modelos, controlando las limitaciones presentes en el estudio actual basadas en los índices de ingresos y pobreza, la cultura organizacional y las variaciones geográficas.

Nota, Ferrari, Soresi y Wehmeyer (2007) tratan de conocer la relación entre la autodeterminación, la CV y las habilidades sociales en la población con DI. Para ello emplean una muestra de 141 PcDI de entre 16 y 65 años, a quienes les realizan una evaluación de las 3 dimensiones objetivo de la investigación. Los resultados indican que lasPcDI atendidas en centros de día tenían mayor autonomía y autodeterminación que las PcDI que residían en instituciones. También, lasPcDI severa tenían niveles más ba- 
jos de autodeterminación, de CV y de habilidades sociales que el resto de niveles de DI; asimismo, las puntuaciones en habilidades sociales y de CI predecían la inserción de la PcDI en el grupo de alta o baja CV, mientras que las puntuaciones de CI predecían la inserción en alta o baja autodeterminación. También observaron que las mujeres tenían puntuaciones más altas en autodeterminación que los hombres. Los autores concluyen que la investigación ayuda a la ampliación del conocimiento sobre cómo influyen los factores intraindividuales y ambientales a la autodeterminación y a la CV.

Nota, Soresi y Perry (2006) elaboran un estudio para validar la prueba EQLI de evaluación de la CV en PcDI. Esta prueba fue diseñada con el objetivo de conocer la satisfacción de los usuarios con DI de los servicios residenciales y centros de día, por parte del personal de servicios sanitarios y sociales. Los resultados indican que la prueba es una medida psicométricamente válida para obtener la satisfacción de las PcDID que utilizan tales servicios, en concreto los autores analizaron la validez convergente y discriminante, en una muestra de 248 PcDI. Los autores concluyen que esta prueba es un instrumento por medio del que realizar una evaluación multidimensional, que puede contribuir a la identificación de las áreas de insatisfacción de los usuarios con los servicios.

Perri, Allen, Pimm, Meek, et. al. (2013) analizan la incidencia en la calidad de los servicios que atienden a PcDID en Gales. Comentan que personas con problemas de comportamiento severo a veces se encuentran en servicios alejados de la vida local cotidiana. Para ello compararon dos grupos de PcDID que estaban en servicios cercanos y lejanos a los servicios locales. Los resultados indicaron que hubo un patrón mixto en cuanto a la calidad del cuidado y de la calidad de los resultados, aunque el servicio más cercano a los servicios locales tenía mayores ventajas, los servicios alejados tenían me- 
nores costes totales, de alojamiento y de actividades diarias. Los autores indican que no llegaron a ninguna conclusión respecto al coste/actividad de ambos servicios.

Samuel, Rillota y Brown (2012) realizan una revisión sobre los cambios en el estudio de la CV familiar. Describen los cambios ocurridos en el concepto de CV familiar, desde que al principio sólo se consideraba a la propia PcDID, hasta que se ha empezado a tener en cuenta también al ambiente familiar. Además, también hablan sobre los problemas de medida de la CV familiar y contrastan dos modelos de medida de EEUU.

Schalock, Verdugo, Gómez y Reinders (2016) hablan sobre una posible teoría de calidad de vida individual. Para ello proponen 3 pasos, a saber, desarrollar un modelo conceptual, integrar los componentes teóricos y aplicar y evaluar la teoría. Los autores finalizan con una discusión sobre las implicaciones que tendría en el ámbito de la DID el desarrollo de una teoría de la CV individual.

Simoes y Santos (2016) comparan la CV de PcDID y personas de la población general en Portugal. Para ello, emplean una muestra de 1929 adultos con DID y 665 personas sin DID, y les pasan la versión portuguesa de la Escala de Resultados Personales. Los resultados indicaron una mayor CV significativa en las personas sin DID. Además la CV estaba influenciada por variables ambientales y que el estado de salud era el mejor predictor de la $\mathrm{CV}$ en ambos grupos. Los autores concluyen con las implicaciones que estos resultados tienen para las políticas dirigidas a este colectivo.

Turk (2012) estudia las necesidades de salud mental en PcDID adolescentes. Para ello emplea una muestra de 75 PcDI adolescentes. Aplicaron el cuestionario de desarrollo del comportamiento. Los resultados indican que la prevalencia de necesidades de 
salud mental se incrementó de un $51 \%$ cuando informaban los padres a un $67 \%$ en las entrevistas clínicas. Los casos se asociaron al diagnóstico de autismo, a la baja capacidad adaptativa y a la presencia de antecedentes familiares de trastorno mental. Las puntuaciones de una mala salud mental dadas por los padres se correlacionaron negativamente con las puntuaciones del funcionamiento adaptativo. Casi todas las PcDI se beneficiaban de la asistencia social y de salud. La mitad de la muestra había buscado ayuda en lo referente a salud mental. Casi la mitad de los que tomaban medicación, era medicación psiquiátrica. El autor concluye que las PcDI adolescentes pueden tener problemas mentales sin identificar, por lo que destaca la necesidad de identificar a las personas con riesgo de padecer un trastorno mental y realizar evaluaciones exhaustivas para mejorar la CV de este colectivo.

Verdugo, Gómez, Arias y Navas (2012) aportan evidencias de validez del modelo de calidad de vida de 8 dimensiones y sobre su aplicación en España y en distintos países latinoamericanos. Para ello emplean una muestra de 861 PcDI españolas de 31 a 40 años y 681 PcDI latinoamericanos en su mayoría de entre 16 y 40 años. Los resultados indican que la escala tiene un bajo número de ítems para poder ajustarse al modelo de 8 dimensiones de CV. En cuanto a los resultados en muestra española, la escala muestra que la CV de esta población es alta y además permitió observar una relación significativa entre tener pareja y los niveles de discapacidad severo y ligero; así también se observó que el nivel de discapacidad el tipo de vivienda tenían una asociación significativa con respecto al número de personas con nivel límite que viven de forma independiente. En la muestra latinoamericana se vio que existían diferencias en el nivel de CV en función del país estudiado, y que tales diferencias se observan mayoritariamente en la parte objetiva de la escala. Los autores concluyen con la perspectiva futura de des- 
arrollar versiones adaptadas a otros países tras realizar la validación española de la escala INTEGRAL.

Verdugo, Jordán de Urríes, Jenaro, Caballo y Crespo (2006) llevan a cabo un estudio para conocer las características del empleo con apoyo que incrementan la $\mathrm{CV}$, además de comprobar si existen diferencias entre la CV de las PcDI trabajadoras de un empleo con apoyo o de las PcDI que trabajan en un centro de empleo protegido. Para ello emplean una muestra de 232 PcDI. Los resultados indican que no hay diferencias entre la CV de los trabajadores de ambos tipos de empleo. Por otro lado, los autores encuentran que cuanto mayor es la tipicidad en el empleo con apoyo, mayor es la CV de los trabajadores, y que ciertas características del apoyo y del trabajo, como las horas de apoyo externo directo, se relacionan con la mejora de la $\mathrm{CV}$, si bien, los autores concluyen que este apoyo debe ser el mínimo necesario para procurar el desarrollo.

Wang, Schalock, Verdugo y Jenaro (2010) realizan un estudio para evaluar el modelo estructural del constructo de CV basado en factores de primer y de segundo orden. Para ello emplean una muestra de 769 PcDI adultas con DI de media a moderada de 15 países diferentes, que respondieron a una entrevista basada en los 8 indicadores de CV propuestos por Schalock y Verdugo. Los autores demuestran empíricamente la existencia de un solo factor de segundo orden. Todo esto tiene implicaciones para la investigación posterior, la práctica y las políticas sociales futuras de los servicios de atención.

Wong, Wong, Schalock y Chou (2011) realizan un estudio para validar el CQOL-ID a PcDI de China. Para ello emplean una muestra de 359 PcDI leve y/o moderada de 15 años o más. Los resultados indican que este cuestionario es un instrumento útil y válido para medir CV en las PcDI de China, pero existen determinados problemas culturales. 


\subsubsection{Resumen}

En cuanto a la CV de las PcDID, aparece un compendio de artículos dedicados al estudio de los modelos, los principios conceptuales y los indicadores. También aparecen investigaciones validando escalas de CV, como la Escala de Calidad de Vida o la Escala Integral, así como de CV familiar.

En segundo lugar, los estudios destacan necesidades de las PcDID para la mejora de su CV tales como el empleo (con apoyo), la salud mental o la vivienda siempre acordes con las necesidades de apoyo individuales.

Es de destacar en este apartado que existen estudios que preguntan a las propias PcDID o a sus familias, por su CV (o CV familiar) reconociendo la parte subjetiva que tiene este constructo.

\subsubsection{Calidad de vida en el envejecimiento de la población general}

Seguidamente se presenta la tabla 12 que recoge el resumen de las investigaciones revisadas sobre la calidad de vida en el envejecimiento de la población general.

Atkins, Naismith, Luscombe y Hickie (2013) realizan un estudio para investigar los factores de riesgo asociados a la calidad de vida y el distrés psicológico de personas australianas de 60 o más años residentes en entornos residenciales y comunitarios. Los resultados indican que el $17 \%$ de personas de la muestra residencial sufría un importante distrés psicológico, frente al $7 \%$ de la muestra comunitaria, y este distrés era predecido por una mayor edad, mayores limitaciones funcionales, mayor tiempo empleado en el sueño y menores niveles de apoyo social. Por otro lado, las limitaciones funcionales y un mayor nivel de distrés psicológico predecían una menor CV (daban cuenta del 35\% de varianza explicada). Los autores indican que es necesario realizar programas en los 
servicios residenciales para prevenir los factores de riesgo modificables, y que sobre todo es necesario promocionar la salud y la movilidad, regular los ciclos del sueño e incrementar las redes de apoyo social.

Berjano (2005) concibe la CV de las personas dependientes en base a 3 elementos, que son el grado de discapacidad, entendida como la limitación en una actividad y la necesidad de ayuda para realizarla; las expectativas de cuidado, que en la población española la principal expectativa cuando aparece la situación de dependencia es poder permanecer en el propio domicilio, y entre las que se incluyen los servicios de proximidad institucionales, como la teleasistencia, las ayudas técnicas y la adaptación de la vivienda, para las que existen pocas ayudas por parte de los servicios sociales ; y por último, el apoyo a la ayuda informal, que incluye la formación del cuidador, la conciliación en el cuidador de la vida familiar y laboral y los apoyos de respiro familiar.

Choi, Prieto-Merino, Dale, Nüesch, et. al. (2013) investigan el efecto de los cambios en la actividad física moderada o fuerte en la CV relativa a la salud en 7 mujeres británicas durante 7 años. Participaron 1926 mujeres que se evaluaron con el EQ5D. A los 7 años, las mujeres inactivas tuvieron una disminución en sus puntuaciones de calidad de vida relativa a la salud; por otro lado, las mujeres que pasaron de un nivel de actividad bajo a uno moderado o alto era más probable que mantuvieran o mejoraran sus niveles de CV relativa a la salud. Los resultados indican que un nivel moderado o alto de actividad física puede ayudar a las mujeres a prevenir el declive de su CV relativa a la salud y a mejorar su satisfacción con la vida.

Corrales, Tardón y Cueto (2000) tienen el objetivo de describir las características de las personas mayores residentes en la comunidad en términos de estado funcional, CV y posibles situaciones de riesgo. Para ello emplean una muestra de 300 perso- 
nas mayores de un centro de Salud de Mieres, a los que se evaluó el nivel cognitivo, las AVBD, las AIVD, la CV y aspectos físicos (evaluados mediante las láminas COOPWONKA) y sociodemográficos. Lo que se obtuvo fue que la mayoría de estas personas eran independientes para las AVBD y tenían un aparente bienestar físico, pero tenían altos niveles de dependencia en las AIVD. Los autores concluyen que una evaluación de este tipo aporta información amplia sobre la capacidad funcional y la CV de las personas mayores y además es susceptible de ser realizada en los servicios de Atención Primaria, por lo que tiene implicaciones para el servicio.

Davies (2011) realiza un artículo de revisión acerca de la promoción del envejecimiento saludable y la importancia de los estilos de vida en el Reino Unido. El autor indica que la esperanza de vida de la población cada vez es más alta, por lo que muchas personas tienen que convivir con muchos tipos de condiciones de cronicidad. Comenta que modificando el estilo de vida en lo referente a una dieta saludable, a la práctica de ejercicio físico, se puede lograr un envejecimiento saludable y un incremento de la CV de las personas mayores. Davies señala a las enfermeras como las personas apropiadas para informar a las personas mayores de estas cuestiones y reducir así el riesgo de enfermedad asociada a la edad. Todo esto requiere nuevas formas de trabajo, que las enfermeras realicen actividades de promoción de la salud con las personas mayores interviniendo en la planificación de conductas de salud.

Fagerström y Hellström (2011) realizan un estudio con el objetivo de investigar la presencia de problemas de sueño y discutir su asociación con la morbilidad y la CV relativa a la salud en personas de 60 o más años. Participaron 1128 personas suecas. Los resultados indican que se produjo una divergencia en los problemas de sueño entre aquellas personas sin morbilidad y aquellas con un alto grado de comorbilidad. Los au- 
tores indican que las personas con alto grado de comorbilidad parecen personas con alto riesgo de tener tanto problemas de sueño como un bajo nivel de CV relativa a la salud. El estudio sugiere que incluso si los problemas de sueño parecen ser difíciles de identificar y tratar satisfactoriamente, es importante investigar si la CV relativa a la salud se mantiene en aquellas personas con un alto grado de comorbilidad.

Fernández-Ballesteros, Caprara, Iñiguez y García (2005) presentan los resultados de la aplicación de un programa de promoción del envejecimiento activo. Para ello emplean una muestra de 107 personas mayores de 60 años que fueron repartidas en 3 grupos. A dos grupos experimentales se le aplicó el programa, uno en versión presencial y otro en la multimedia; el tercer grupo no recibió tratamiento. Los resultados indican que los programas tuvieron efectos positivos y significativos en la frecuencia de la práctica de actividades y en las creencias sobre el envejecimiento y la vejez, aunque sólo el programa multimedia obtuvo mejoras en los hábitos alimenticios y el ejercicio físico y en la satisfacción con la vida. Por otro lado, los autores no encontraron una mejora significativa ni en las relaciones sociales ni en la salud de los participantes.

Fernández-Mayoralas, Rojo, Abellán y Rodríguez (2003) definen la CV relativa a la salud como la suma del funcionamiento físico, psicológico y social, el bienestar mental y social, las percepciones y la satisfacción con todos los aspectos mencionados, así como los recursos y las prácticas que se llevan a cabo desde los servicios sociales. Estos autores dan importancia a la perspectiva subjetiva de la CV, en el sentido de que es necesario adoptar la perspectiva del individuo para evaluar la $\mathrm{CV}$, como demuestran las investigaciones revisadas por estos autores, un factor personal que influye en la desigualdad en el estado de salud es el nivel de instrucción. Y un factor social que también incide es la enfermedad y sus consecuencias. El CSIC intenta elaborar un modelo que 
explique las diferencias entre la población mayor y la población general en el uso de los servicios y en las desigualdades de salud, y proponiendo medidas a tener en cuenta para mejorar la CV de las personas mayores desde los servicios.

Giraldez-Garcia, Forjaz, Prieto-Flores, Rojo-Perez, et. al. (2013) evalúan la relación entre la perspectiva individual del ambiente de la comunidad y la salud en personas mayores. Para ello, aplican el Índice de Bienestar en la Comunidad a 1106 personas de una media de edad de 72 años. Las variables consideradas eran además los problemas con los vecinos, el tiempo en el barrio y otras medidas sociodemográficas y sociales. Además se estudiaron cuatro condiciones de la salud, como el estado de salud percibido, la independencia funcional, la depresión y el número de condiciones médicas crónicas. Los resultados indicaron que la satisfacción con los servicios de la comunidad podía asociarse positivamente con la salud percibida y con la independencia funcional, y negativamente con la depresión y las condiciones médicas crónicas. Por tanto, los autores concluyen que la perspectiva que tienen las personas sobre el ambiente en la comunidad está asociada con los resultados de salud e adultos mayores.

Gurland, Teresi, Eimicke, Maurer y Reid (2014) realizan un estudio para ver la relación entre la mortalidad y algunas medidas de CV. Para ello, utilizan una muestra de 2130 personas de 65 o más años del norte de Manhattan y de distintas etnias y miden el estado de ánimo deprimido, el dolor, la percepción de salud y las relaciones sociales y funcionales. El estado de ánimo deprimido y el dolor generalizado predijeron menor mortalidad, y sentirse aislado también iba en esta dirección, sin embargo, las limitaciones en el funcionamiento diario, subir escaleras, la falta de red de apoyo y la desconexión con algunas redes sociales incrementaba la mortalidad. El incremento de la mor- 
talidad era predecido por los síntomas somáticos de la depresión. Un pobre estado de salud percibido también predecía la mortalidad.

Hawton, Green, Dickens, Richards, et. al. (2011) pretenden estudiar el aislamiento social en 393 personas mayores con riesgo de exclusión social, en función del estado de salud y la CV relativa a la salud; la relación entre el aislamiento social y el estado de salud; y la relación entre dos medidas alternativas del estado de salud. Para ello emplearon las pruebas EQ-5D y SF-6D (SF-12). Los resultados indicaron que el estado de salud y la CV relativa a la salud percibida fueron menores en las personas mayores de Reino Unido. El aislamiento social se asoció significativamente con las puntuaciones en las pruebas empleadas de forma significativa. Se identificó un efecto techo en esta población en el EQ-5D. Este estudio demuestra la carga que el aislamiento social tiene en la salud y el bienestar de las personas mayores. También concluyen que las ganancias potenciales en CV relativa a la salud pueden ser considerables, tanto en el grupo con riesgo de exclusión social como el que no.

Hsu, Alfermann, Lu y Lin (2013) realizan un estudio para investigar el efecto mediador del autoconcepto de salud y de la independencia física en una muestra de personas taiwanesas y alemanas. Los resultados pusieron de manifiesto que la relación entre el miedo a las caídas y la calidad de vida está mediada parcialmente por la participación en actividades físicas, el autoconcepto de salud y la independencia física en ambas muestras. Pero la percepción propia de salud y la independencia física era un efecto mediador más potente en la muestra taiwanesa. Los autores concluyen que exisiten diferencias entre culturas.

Källstrand-Eriksson, Baigi, Buer y Hildingh (2012) investigan la relación entre la visión de las personas mayores y el riesgo de caídas y la CV. En el estudio participa- 
ron 212 personas. Los resultados indican que los participantes consideraban una alteración de la visión al percibir su estado de salud. La salud general se asoció significativamente tanto en hombres como en mujeres con las caídas; pero en los hombres se relacionaban específicamente otras variables como la cercanía o lejanía de las actividades, el funcionamiento social y las dificultades de rol, la dependencia, el color y la visión periférica también se asociaban con las caídas. 


\begin{tabular}{|c|c|c|c|c|}
\hline Autor/es & Temática & Resumen & Estudio & Observaciones \\
\hline $\begin{array}{l}\text { Atkins et. } \\
\text { al. (2013) }\end{array}$ & $\begin{array}{l}\text { CV y distrés } \\
\text { psicológico }\end{array}$ & $\begin{array}{l}\text { Importancia red de } \\
\text { apoyo social, ci- } \\
\text { clos de sueño y la } \\
\text { salud y movilidad }\end{array}$ & Revisión & $\begin{array}{l}\text { Sobre todo en ser- } \\
\text { vicio residencial }\end{array}$ \\
\hline $\begin{array}{l}\text { Berjano } \\
(2005)\end{array}$ & $\begin{array}{l}\mathrm{CV} \text { en perso- } \\
\text { nas dependien- } \\
\text { tes }\end{array}$ & $\begin{array}{l}\text { Grado de discapa- } \\
\text { cidad, }\end{array}$ & Revisión & $\begin{array}{l}\text { Es necesario el } \\
\text { apoyo al cuidado } \\
\text { informal }\end{array}$ \\
\hline $\begin{array}{l}\text { Choi et. al. } \\
(2013)\end{array}$ & $\begin{array}{l}\text { CV relativa a } \\
\text { la salud y acti- } \\
\text { vidad física }\end{array}$ & $\begin{array}{l}\text { Nivel alto o mode- } \\
\text { rado de actividad } \\
\text { mejor CV relativa } \\
\text { a la salud }\end{array}$ & Longitudinal & $\begin{array}{l}\text { Realizado en muje- } \\
\text { res }\end{array}$ \\
\hline $\begin{array}{l}\text { Corrales et. } \\
\text { al. }(2000)\end{array}$ & $\begin{array}{l}\text { CV y capaci- } \\
\text { dad funcional }\end{array}$ & $\begin{array}{l}\text { Mayor indepen- } \\
\text { dencia en ABVD } \\
\text { que AIVD }\end{array}$ & Transversal & \\
\hline $\begin{array}{l}\text { Davies } \\
(2011)\end{array}$ & $\begin{array}{l}\text { Promoción } \\
\text { envejecimiento } \\
\text { saludable }\end{array}$ & $\begin{array}{l}\text { Cambios en nutri- } \\
\text { ción y actividad } \\
\text { física mejoran la }\end{array}$ & Revisión & $\begin{array}{l}\text { Las enfermeras } \\
\text { tienen un papel } \\
\text { importante }\end{array}$ \\
\hline $\begin{array}{l}\text { Fagerström } \\
\text { et. al. } \\
(2011)\end{array}$ & $\begin{array}{l}\text { Problemas de } \\
\text { sueño y CV } \\
\text { relativa a la } \\
\text { salud }\end{array}$ & $\begin{array}{l}\text { Problemas de sue- } \\
\text { no se relacionan } \\
\text { con alta comorbi- } \\
\text { lidad y baja CV } \\
\text { relativa a salud }\end{array}$ & Transversal & $\begin{array}{l}\text { En el futuro, ob- } \\
\text { servar PM's con } \\
\text { alta comorbilidad y } \\
\text { CV relativa a la } \\
\text { salud mantenida }\end{array}$ \\
\hline $\begin{array}{l}\text { Fernández- } \\
\text { Ballesteros } \\
\text { et. al. } \\
(2009)\end{array}$ & $\begin{array}{l}\text { Promoción del } \\
\text { envejecimiento } \\
\text { activo }\end{array}$ & $\begin{array}{l}\text { Los programas } \\
\text { aplicados mejoran }\end{array}$ & Longitudinal & $\begin{array}{l}\text { No hubo cambios } \\
\text { significativos }\end{array}$ \\
\hline $\begin{array}{l}\text { Fernández- } \\
\text { Mayoralas } \\
\text { et. al. } \\
(2003)\end{array}$ & $\begin{array}{l}\mathrm{CV} \text { y envejeci- } \\
\text { miento }\end{array}$ & $\begin{array}{l}\text { En la evaluación } \\
\text { de la CV en PMs } \\
\text { las percepciones } \\
\text { subjetivas de esta } \\
\text { población }\end{array}$ & Revisión & \\
\hline $\begin{array}{l}\text { Giraldez- } \\
\text { Garcia et. } \\
\text { al. (2013) }\end{array}$ & $\begin{array}{l}\text { Percepción } \\
\text { con la comu- } \\
\text { nidad y salud }\end{array}$ & $\begin{array}{l}\text { La percepción con } \\
\text { la comunidad se } \\
\text { asocia con la salud } \\
\text { positivamente }\end{array}$ & Transversal & $\begin{array}{l}\text { Negativamente } \\
\text { asociada con croni- } \\
\text { cidad y depresión }\end{array}$ \\
\hline $\begin{array}{l}\text { Gurland et. } \\
\text { al. (2014) }\end{array}$ & $\begin{array}{l}\text { Predicción } \\
\text { mortalidad y } \\
\text { CV }\end{array}$ & $\begin{array}{l}\text { Pérdida de redes } \\
\text { sociales, limita- } \\
\text { ciones en vida } \\
\text { diaria relacionadas } \\
\text { con mortalidad } \\
\end{array}$ & Longitudinal & \\
\hline $\begin{array}{l}\text { Hawton et. } \\
\text { al. }(2011)\end{array}$ & $\begin{array}{l}\text { CV relativa a } \\
\text { la salud y ais- } \\
\text { lamiento social }\end{array}$ & $\begin{array}{l}\text { El aislamiento } \\
\text { social influye en } \\
\text { la CV de salud }\end{array}$ & Transversal & $\begin{array}{l}\text { CV relativa a la } \\
\text { salud, en relación } \\
\text { con el aislamiento } \\
\text { social }\end{array}$ \\
\hline
\end{tabular}

Tabla 12.1.: Literatura sobre calidad de vida en el envejecimiento de la población general. 


\begin{tabular}{|c|c|c|c|c|}
\hline Autor/es & Temática & Resumen & Estudio & Observaciones \\
\hline $\begin{array}{l}\text { Hsu et. al. } \\
\text { (2013) }\end{array}$ & $\begin{array}{l}\text { Autoconcepto, } \\
\text { riesgo de caí- } \\
\text { das e inde- } \\
\text { pendencia } \\
\text { física }\end{array}$ & $\begin{array}{l}\text { Hay relación entre } \\
\text { ellas }\end{array}$ & Transversal & $\begin{array}{l}\text { Hay diferencias } \\
\text { culturales }\end{array}$ \\
\hline $\begin{array}{l}\text { Källstrand- } \\
\text { Eriksson et. } \\
\text { al. (2012) }\end{array}$ & Caídas y CV & $\begin{array}{l}\text { Estado de salud } \\
\text { percibido relacio- } \\
\text { nado con las caí- } \\
\text { das }\end{array}$ & Transversal & $\begin{array}{l}\text { En hombres influ- } \\
\text { yen otras variables }\end{array}$ \\
\hline $\begin{array}{l}\text { Levasseur } \\
\text { et. al. } \\
(2010)\end{array}$ & $\begin{array}{l}\text { Asociación de } \\
\text { la CV con } \\
\text { nivel y la sa- } \\
\text { tisfacción }\end{array}$ & $\begin{array}{l}\text { La CV está rela- } \\
\text { cionada con el } \\
\text { nivel y la satisfac- } \\
\text { ción con la parti- } \\
\text { cipación social } \\
\end{array}$ & Transversal & $\begin{array}{l}\text { La muestra no es } \\
\text { representativa }\end{array}$ \\
\hline $\begin{array}{l}\text { Makhija et. } \\
\text { al. (2011) }\end{array}$ & $\begin{array}{l}\text { CV relativa a } \\
\text { la salud subje- } \\
\text { tiva y movili- } \\
\text { dad espacial } \\
\text { en PMs }\end{array}$ & $\begin{array}{l}\text { Hay asociaciones } \\
\text { significativas entre } \\
\text { la CV relativa a la } \\
\text { salud y la mobili- } \\
\text { dad informada }\end{array}$ & Transversal & $\begin{array}{l}\text { La disminución de } \\
\text { la } \mathrm{CV} \text { relativa a la } \\
\text { salud informada se } \\
\text { relaciona con la } \\
\text { reducción en la } \\
\text { mobilidad }\end{array}$ \\
\hline $\begin{array}{l}\text { Marrugat } \\
(2005)\end{array}$ & $\begin{array}{l}\text { Influencia de } \\
\text { los cuidados } \\
\text { informales en } \\
\text { la CV }\end{array}$ & $\begin{array}{l}\text { Importancia de } \\
\text { normas, senti- } \\
\text { mientos y compe- } \\
\text { tencias de cuida- } \\
\text { dor }\end{array}$ & Revisión & No es extrapolable \\
\hline $\begin{array}{l}\text { Molzahn et. } \\
\text { al. (2010) }\end{array}$ & $\begin{array}{l}\text { Importancia } \\
\text { de las áreas de } \\
\text { CV en adultos } \\
\text { mayores }\end{array}$ & $\begin{array}{l}\text { Para PMs son im- } \\
\text { portantes compo- } \\
\text { nentes físicos de } \\
\text { CV }\end{array}$ & Transversal & $\begin{array}{l}\text { La muestra no es } \\
\text { representativa }\end{array}$ \\
\hline $\begin{array}{l}\text { Moreno } \\
(2004)\end{array}$ & $\begin{array}{l}\mathrm{CV} \text { en perso- } \\
\text { nas mayores }\end{array}$ & $\begin{array}{l}\text { Importancia de la } \\
\text { educación, activi- } \\
\text { dad y nuevas tec- } \\
\text { nologías }\end{array}$ & Revisión & $\begin{array}{l}\text { Sólo se trata el área } \\
\text { social de la CV }\end{array}$ \\
\hline $\begin{array}{l}\text { Phillips et. } \\
\text { al. (2013) }\end{array}$ & $\begin{array}{l}\text { CV y activi- } \\
\text { dad física }\end{array}$ & $\begin{array}{l}\text { Salud influye en } \\
\text { autoestima, auto- } \\
\text { eficacia }\end{array}$ & Longitudinal & $\begin{array}{l}\text { Variables modifi- } \\
\text { cables en la rela- } \\
\text { ción actividad y } \\
\text { CV }\end{array}$ \\
\hline $\begin{array}{l}\text { Stewart et. } \\
\text { al. (2013) }\end{array}$ & $\begin{array}{l}\text { CV y control } \\
\text { percibido }\end{array}$ & $\begin{array}{l}\text { Apoyo a la teoría } \\
\text { de Heckhaussen y } \\
\text { Schultz }\end{array}$ & Longitudinal & \\
\hline $\begin{array}{l}\text { Sullivan et. } \\
\text { al. (2000) }\end{array}$ & $\begin{array}{l}\text { Relación entre } \\
\text { los componen- } \\
\text { tes de la CV }\end{array}$ & $\begin{array}{l}\text { Evaluación de CV } \\
\text { debe incluir el } \\
\text { estado funcional }\end{array}$ & Transversal & \\
\hline
\end{tabular}

Tabla 12.2.: Literatura sobre calidad de vida en el envejecimiento de la población general. (Continuación). 


\begin{tabular}{|l|l|l|l|l|}
\hline \multicolumn{1}{|c|}{ Autor/es } & \multicolumn{1}{|c|}{ Temática } & \multicolumn{1}{c|}{ Resumen } & Estudio & \multicolumn{1}{c|}{ Observaciones } \\
\hline $\begin{array}{l}\text { Sun et. al. } \\
(2011)\end{array}$ & $\begin{array}{l}\text { CV relativa a } \\
\text { la salud y es- } \\
\text { tructura de la } \\
\text { vivienda }\end{array}$ & $\begin{array}{l}\text { Vivir solo es un } \\
\text { predictor significa- } \\
\text { tivo de la morbili- } \\
\text { dad, dolor y ansie- } \\
\text { dad y depresión }\end{array}$ & Transversal & $\begin{array}{l}\text { Vivir solo tiene un } \\
\text { efecto negativo en } \\
\text { la CV relativa a la } \\
\text { salud en PMs }\end{array}$ \\
\hline $\begin{array}{l}\text { Willman et } \\
\text { al. (2013) }\end{array}$ & $\begin{array}{l}\text { CV relativa a } \\
\text { la salud y do- } \\
\text { lor }\end{array}$ & $\begin{array}{l}\text { Más dolor menos } \\
\text { CV relaiva a la } \\
\text { salud, menor con- } \\
\text { trol de su vida }\end{array}$ & Transversal & $\begin{array}{l}\text { Personas de 80 o } \\
\text { más años }\end{array}$ \\
\hline
\end{tabular}

Tabla 12.3.: Literatura sobre calidad de vida en el envejecimiento de la población general. (Continuación).

Levasseur, Desrosiers y Whiteneck (2010) investigan la relación entre la CV y el nivel de participación social y de satisfacción con la participación social en personas mayores. La muestra estaba compuesta por 155 personas canadienses de 60 años o más, con varios niveles de limitación en la realización de actividades diarias. Estas personas recibieron una evaluación completa de aspectos relacionados con la participación social y la CV. Los resultados obtenidos por los autores giran en torno a que la relación entre la CV y el nivel de participación social es similar que la relación de la CV con la satisfacción que las personas tienen con su participación social.

Makhija, Gilbert, Clay, Matthews, et. al. (2011) realizan un estudio para comprobar la asociación entre CV informada y la reducción de la movilidad espacial en una muestra de 288 PMs de 65 y más años. Para ello, los participantes son entrevistados con dos cuestionarios elaborados específicamente para el estudio sobre CV relativa a la salud informada y movilidad espacial. Los resultados indican que hay asociaciones significativas entre la CV relativa a la salud informada y la movilidad en las limitaciones funcionales informadas oralmente por las PMs, así como en el dolor y el disconfort informados, la desventaja y la salud autoinformadas. Los autores concluyen que el decremento en la CV relativa a la salud de los participantes estaba asociado a una menor mo- 
vilidad, lo que sugiere que las percepciones del bienestar informado tengan un efecto significativo sobre la movilidad y la participación social de las PMs.

Marrugat (2005) realiza una reflexión acerca de las conductas que se dan en el cuidado familiar de las personas dependientes y que influyen en la CV tanto de cuidadores como de cuidados. La autora expone que hay 3 factores en el ámbito familiar que influyen en la $\mathrm{CV}$ de las personas cuidadas, como son las normas, los sentimientos y las competencias del cuidador. En cuanto a las normas, la autora alude a que en la investigación está ampliamente documentado que la principal cuidadora es la mujer. En cuanto a los sentimientos, explica que pueden aparecer sentimientos negativos cuando aparece la situación o la necesidad de cuidar al mayor. También son importantes las competencias personales del cuidado, atribuidas de forma natural a las mujeres en la sociedad española. Por último, la autora propone acciones que deben ser tenidas en cuenta por los servicios, sobre todo en lo referente al apoyo y formación de los cuidadores y a la creación de servicios para ayudar a las familias en las que se presenta esta circunstancia.

Moreno (2004) realiza una revisión de la literatura para hablar de la CV en las personas mayores. Para ello expone las diferentes definiciones tomadas por los investigadores acerca de la CV, los que la consideran como algo objetivo, los que la consideran como algo subjetivo, y por último quienes interrelacionan ambos aspectos para definirla. La autora habla de 3 aspectos mediante los cuales favorecer la CV de las personas mayores. En primer lugar, la educación, trabajando sobre los prejuicios de la sociedad pero también educando a las personas para envejecer, por ello se hace indispensable el acceso de la población mayor a los proyectos educativos que se les ofertan, además de la realización de programas intergeneracionales. Por otro lado, la actividad, que las personas mayores mantengan su actividad y continúen integrados en la sociedad; y por 
último, el uso de las nuevas tecnologías, que permitan la consecución de las aspiraciones y fomente las oportunidades de este colectivo, por ejemplo con el uso de ordenadores para favorecer el ocio, la información, la participación, así como las relaciones sociales.

Molzahn, Skevington, Kalfoss y Makaroff (2010) realizan un estudio con el objetivo de describir la importancia que tienen diversas áreas de la $\mathrm{CV}$ en personas mayores de 22 países. Para ello, 7.401 personas mayores de 60 años realizaron un cuestionario. Los autores encontraron que no había diferencias significativas en la importancia de varias facetas de la $\mathrm{CV}$ en cuanto a edad, género y estado de salud y que las áreas valoradas como más importantes eran tener energía, ser feliz, tener la sensación de un buen funcionamiento y la ausencia de dolor. De manera que parece que las áreas físicas de la CV son significativamente importantes para este colectivo, y por lo tanto, será imprescindible que los profesionales las tengan en cuenta.

Phillips, Wòjcicki y McAuley (2013) realizan un estudio para investigar los roles que la autoeficacia y el estado de salud median en la relación entre la actividad física y la calidad de vida. Para ello pasaron una batería de cuestionarios a u grupo de personas de una media de 68 años en un formato longitudinal de 18 meses. Los autores encuentran que los incrementos en actividad física se asociaban con incrementos en la autoeficaciam que a su vez se asociaba con mayor autoestima y con menores limitaciones de discapacidad, lo que se asocia con una mayor satisfacción con la vida. Los resultados indican que hay una relación entre la actividad física y la CV global in adultos mayores, que puede estar mediada por variables modificables, por lo que pueden ser útiles los programas de actividad física. 
Stewart, Chipperfield, Ruthig y Heckhausen (2013) estudian que el control percibido es un moderador de la relación protectora entre la comparación social descendente y el bienestar subjetivo en personas mayores. Entrevistan a 97 personas de edades entre 79-97 años tres veces durante un período de 9 años. Entrevistaban sobre el control percibido sobre las cosas de la vida diaria, el uso de la comparación social descendente en respuesta a la restricción de tareas y sobre el bienestar subjetivo. Los resultados indican que hay una interacción significativa entre la comparación social descendente y el control percibido en tres cuestiones del bienestar subjetivo: la satisfacción con la vida, el estrés percibido y los síntomas depresivos. En otros análisis también encontraron que la comparación social descendente se asociaba con un mayor bienesar percibido a bajos niveles de percepción de control, ero no estaba relacionada con el bienestar subjetivo en altos niveles de percepción de control. Todo esto corrobora la teoría de Heckhaussen y Schultz, además de tener implicaciones para las intervenciones en el campo de la CV.

Sullivan, Kempen, Van Sonderen y Ormel (2000) realizan un estudio para validar un modelo de CV que ponga en relación todos sus componentes. Para ello emplean una muestra de 5.279 personas mayores holandesas que viven en la comunidad. Los autores examinan 3 modelos, uno de ellos lineal y dos no lineales. Los resultados indicaron que el modelo lineal no explica la CV. La CV general según los autores parece estar ligada al estado funcional de la persona. Los autores también encuentran que los síntomas depresivos y de ansiedad median en la relación entre la CV general y la percepción de salud de la persona. Los autores concluyen que la medida de la CV debe incluir una evaluación de los síntomas físicos y psicológicos graves, pero también una evaluación del estado funcional. 
Sun, Lucas, Meng y Zhang (2011) llevan a cabo una investigación para estudiar la asociación entre la CV relativa a la salud y la estructura o formas de vivienda en 9.711 PMs de más de 60 años en China. Para ello emplean el cuestionario EQ-5D. Los resultados indican que vivir solo es un predictor significativo de la morbilidad, del dolor y de la ansiedad y depresión. Tras introducir los indicadores de interacción social, las personas que tenían contacto cercano con los vecinos todas las semanas, así como con amigos y con el grupo de iguales tenían niveles más bajos de morbilidad, dolor, ansiedad y depresión; y aquellos que participaban en actividades sociales todas las semanas tenían menores problemas en todas las dimensiones, excepto en depresión y ansiedad. Los autores concluyen que vivir solo tiene un efecto negativo en la CV relativa a la salud en las PMs, mientras que relacionarse y participar en actividades sociales mejora dicha $\mathrm{CV}$, lo que debe ser considerado a la hora de establecer futuras políticas dirigidas a este colectivo.

Willman, Petzäll, Östberg y Hall-Lord (2013) tienen por objetivo estudiar el dolor desde una perspectiva multidimensional y la calidad de vida relativa a la salud, para comparar los grupos en función del sexo y la edad en personas de 80 años o más. Los resultados indicaron que la duración media del dolor era de 9 años en el colectivo estudiado, así como que la duración del dolor era mayor significativamente en las mujeres que en los hombres, así como que los mayores de 80-85 años tenían una mayor intensidad del dolor. Los participantes con una menor puntuación en CV relativa a la salud experimentaban un dolor significativamente más grave, tenían mayores problemas con el mismo y un menor control de sus vidas. Como conclusión, se sugiere que el dolor prolongado disminuye la CV relativa a la salud, que interfiere en la vida de las personas y además disminuye el control de sus vidas. 


\subsubsection{Resumen}

Las investigaciones revisadas sobre la CV en el envejecimiento de la población general ponen de manifiesto la importancia de la CV relativa a la salud en relación a la actividad física, a los patrones de sueño, los estilos de vida, el ambiente, la independencia de otras personas, de las formas de vivienda, entre otras. También toman relevancia los servicios de cuidado y las personas cuidadoras de personas dependientes.

El envejecimiento activo y la participación comunitaria también son temas de relevancia en este apartado.

\subsubsection{Calidad de vida en el envejecimiento de las personas con discapacidad}

Por último, se presenta la tabla 13 en la que aparece el resumen de las investigaciones revisadas acerca de la $\mathrm{CV}$ en el envejecimiento de las personas con discapacidad.

Alcedo, Aguado, Arias, González y Rozada (2008) realizan una investigación con el objetivo de elaborar y validar una escala para la evaluación de la CV en las PcD que envejecen, de manera que refleje la concepción de la $\mathrm{CV}$ por parte de este colectivo. Para ello aplican la escala ECV a una muestra de 2.292 PcD de 45 años o más. La escala evalúa 6 dimensiones de CV, como son el bienestar físico, la inclusión social, el bienestar emocional, el desarrollo personal y la autodeterminación, las relaciones interpersonales y el bienestar material. Los resultados indican que la escala es un instrumento válido para evaluar la $\mathrm{CV}$, tal y como es percibida por el colectivo de PcD que envejecen. 


\begin{tabular}{|c|c|c|c|c|}
\hline Autor/es & Temática & Resumen & Estudio & Observaciones \\
\hline $\begin{array}{l}\text { Alcedo et. } \\
\text { al. (2008) }\end{array}$ & $\begin{array}{l}\text { Escala para } \\
\text { evaluar la CV } \\
\text { en PcD mayo- } \\
\text { res }\end{array}$ & $\begin{array}{l}\text { ECV, instrumento } \\
\text { multidimensional } \\
\text { de la } \mathrm{CV} \text { en } \mathrm{PcD} \\
\text { mayores }\end{array}$ & $\begin{array}{l}\text { Transver- } \\
\text { sal }\end{array}$ & $\begin{array}{l}\text { Necesidad de realizar } \\
\text { análisis diferenciales }\end{array}$ \\
\hline $\begin{array}{l}\text { Gómez et. } \\
\text { al. (2008) }\end{array}$ & $\begin{array}{l}\text { Validación } \\
\text { escala FU- } \\
\text { MAT de CV }\end{array}$ & $\begin{array}{l}\text { Escala FUMAT, } \\
\text { objetivo para CV }\end{array}$ & $\begin{array}{l}\text { Transver- } \\
\text { sal }\end{array}$ & \\
\hline $\begin{array}{l}\text { Gómez- } \\
\text { Vela et. al. } \\
\text { (2000) }\end{array}$ & $\begin{array}{l}\text { Evolución del } \\
\text { concepto de } \\
\text { CV y líneas de } \\
\text { investigación }\end{array}$ & $\begin{array}{l}\text { La investiga-ción } \\
\text { de CV en PcD gira } \\
\text { en torno a progra- } \\
\text { mas de desinstitu- } \\
\text { cionalización y el } \\
\text { acceso al empleo }\end{array}$ & Revisión & \\
\hline $\begin{array}{l}\text { Kostka et. } \\
\text { al. (2010) }\end{array}$ & $\begin{array}{l}\text { Relación entre } \\
\text { CV y distintos } \\
\text { ambientes }\end{array}$ & $\begin{array}{l}\text { CV desciende con } \\
\text { el grado de disca- } \\
\text { pacidad y la insti- } \\
\text { tucionalización }\end{array}$ & $\begin{array}{l}\text { Transver- } \\
\text { sal }\end{array}$ & $\begin{array}{l}\text { No se especifica el } \\
\text { tipo de discapacidad } \\
\text { estudiada }\end{array}$ \\
\hline $\begin{array}{l}\text { Lin et. al. } \\
(2011)\end{array}$ & $\begin{array}{l}\text { CV relativa a } \\
\text { la salud en } \\
\text { PMs frágiles }\end{array}$ & $\begin{array}{l}\text { La discapacidad en } \\
\text { PMs frágiles se } \\
\text { relaciona con la } \\
\text { CV relativa a la } \\
\text { salud }\end{array}$ & $\begin{array}{l}\text { Transver- } \\
\text { sal }\end{array}$ & $\begin{array}{l}\text { La asociación entre } \\
\text { medidas clínicas y } \\
\text { una medida genérica } \\
\text { de la CV relativa a la } \\
\text { salud ayudan a enten- } \\
\text { der la fragilidad en } \\
\text { PMs }\end{array}$ \\
\hline
\end{tabular}

Tabla 13: Literatura sobre calidad de vida en el envejecimiento de PcD.

Gómez, Verdugo, Arias y Navas (2008) tienen el objetivo de desarrollar y validar una escala objetiva para evaluar la CV de personas mayores y con discapacidad que acuden a algún tipo de servicio social. Primero realizan un estudio para la elaboración de la escala con varios profesionales, y posteriormente realizan la validación con 100 personas mayores y PcD de entre 24 y 99 años de 5 centros de servicios sociales distintos, sobre los que 9 profesionales realizaban el cuestionario. Los resultados indican que la escala FUMAT es válida y fiable para la realización de planificaciones individuales e intervenciones centradas en la persona, y para mejorar la calidad de los servicios.

Gómez-Vela y Sabet (2000) realizan un trabajo de revisión de la investigación acerca del concepto de CV. Entre las líneas de investigación en este campo, las autoras 
destacan el interés actual por el estudio de la CV relativa a la salud debido a los avances médicos, y que se basa en las percepciones de los pacientes de los efectos de una enfermedad y sus consecuencias en los ámbitos psicológico, físico y social. Por otro lado, desde la psicología se llevan a cabo investigaciones más centradas en la medición de los resultados de diversos tratamientos médicos, especialmente en la esquizofrenia y la depresión mayor. En el ámbito educativo también se están llevando a cabo estudios sobre $\mathrm{CV}$, sin embargo es la línea menos desarrollada por el momento. Por último, en el ámbito de la discapacidad, la CV se ha convertido en el fin de numerosos programas de desinstitucionalización y el acceso al empleo por parte de las $\mathrm{PcD}$, siguiendo la línea de la autodeterminación, el modelo de apoyos y las técnicas de mejora de la CV. Las autoras recogen las investigaciones que el INICO ha llevado a cabo en los últimos años.

Kostka y Jachimowicz (2010) investigan la relación entre la CV y la disposición al optimismo, el control de la salud y la autoeficacia en sujetos que difieren en el nivel de discapacidad y que residen en distintos ambientes. Para ello emplean 3 grupos de personas mayores, que viven en la comunidad, en hogares de grupo o que residen en un servicio institucional de larga estancia. Los autores los evalúan y observan que la CV disminuye a medida que crece el nivel de dependencia y de institucionalización. Los autores sugieren que las personas mayores que residen en hogares de grupo, al ser un grupo en transición entre la comunidad y la institución, deben ser el primer objetivo de la prevención, tanto psicológica como sanitaria en general, para lograr una mejora en la CV de este colectivo.

Lin, Li, Chang, Liu, et. al. (2011) comprueban la asociación entre la CV relativa a la salud y la fragilidad en PMs. Para ello emplean una muestra de 933 PMs de Taiwan de 65 y más años, a quienes les aplican el MCS y el SF-36. Los resultados indican que 
las PMs sin fragilidad puntúan significativamente mejor que las que tienen fragilidad en todas las escalas, excepto en las referentes a limitaciones físicas y emocionales. Los autores concluyen que la discapacidad inherente a la salud física en la fragilidad está relacionada con una reducción de la CV relativa a la salud, y que la asociación entre las medidas clínicas y una medida genérica de CV relativa a la salud ofrece a los clínicos nueva información para entender la fragilidad y conceptualizarla en el contexto de la discapacidad.

\subsubsection{Resumen}

En cuanto al envejecimiento de las personas con discapacidad, hay investigaciones dedicadas a las escalas de evaluación de la CV (como la Escala de Calidad de Vida o la Escala FUMAT), así como dirigidas al estudio del propio concepto de CV.

Cobra importancia también la CV relativa a la salud y el estudio de las formas de vivienda.

\subsubsection{Calidad de vida en el envejecimiento de las personas con discapacidades intelectuales y del desarrollo.}

A continuación se presenta la tabla 14, que resume las investigaciones revisadas sobre la $\mathrm{CV}$ en el envejecimiento de las PcDID.

Caballo, Crespo, Jenaro, Verdugo y Martínez (2005) validan la escala QOL-Q en población con discapacidad de habla hispana. Para ello emplean una muestra de 209 personas con discapacidad física de México y 424 PcDI españolas. Los resultados indican que la escala QOL-Q es un instrumento válido para medir la CV en PcDI de habla hispana. 
Herps, Buntinx, Schalock, van Breukelen y Curfs (2016) realizan un estudio para investigar las diferencias en los planes de apoyo de PcDID de distintas edades y grados de discapacidad. Los resultados indicaron que las PcDID de niveles medios y moderados de discapacidad tenían más objetivos en sus planes relacionados con la independencia y la participación social, con respecto a las PcDID severas. Las PcDID profundas tenían objetivos más relacionados con su bienestar. Las personas mayores de 50 años tenían significativamente más objetivos relacionados nuevamente con el bienestar que las PcDID menores a esa edad. En cuanto a los recursos, el mayor porcentaje de los recursos necesarios en los planes eran servicios especializados, en segundo lugar recursos naturales y por último, la combinación entre ambos tipos.

McCausland, McCallion, Cleary y McCarron (2016) realizan un estudio para examinar los contactos sociales de las PcDID mayores en Irlanda. Para ello emplean los datos de un estudio irlandés. Los autores observaron que la residencia, el nivel de discapacidad y la edad eran factores determinantes para el contacto social, ya que las personas que estaban en residencias, las personas mayores y las que tenían discapacidades intelectuales severas y profundas tenían los menores niveles de contacto social.

Millán-Calenti, Meleiro, Quintana, López-Rey, et. al. (2003) investigan las características de las PcDI que envejecen. Para ello emplean una muestra de 189 PcDI mayores de 45 años con certificado de discapacidad. Los resultados indican que el $60 \%$ vive con su familia, con la que afirman tener una buena relación el 49;7\% de los participantes. Un 48,7\% de las PcDI tienen una discapacidad intelectual de nivel moderado, mientras que el $36,5 \%$ tienen un nivel profundo. En el $42,85 \%$ no se conoce la causa de la discapacidad. Los autores concluyen que tras detectar necesidades en los servicios asistenciales es urgente actuar sobre los recursos, los equipamientos y el grado de profe- 
sionalización de los profesionales que trabajan con este colectivo, teniendo en cuenta también a las familias que son quienes aportan el verdadero apoyo asistencial.

O'Brien, Thesing, Tuck y Capie (2001) realizan un estudio para conocer los efectos de la desinstitucionalización en 54 PcDI de Nueva Zelanda, que tras llevar una media de 22 años residiendo en un hospital psiquiátrico fueron trasladados a un hogar residencial de la comunidad. Para ello los autores llevan a cabo entrevistas con los propios afectados, con familiares y con el personal del hogar residencial. Los resultados indican que todos los entrevistados tenían una percepción positiva del cambio de hogar, de hecho, reportaban mejoras tanto en las ABVD, las habilidades sociales y en la CV. Todo ello tiene implicaciones para la investigación futura y para ayudar en la comprensión del efecto de la desinstitucionalización.

\begin{tabular}{|l|l|l|l|l|}
\hline \multicolumn{1}{|c|}{ Autor/es } & \multicolumn{1}{|c|}{ Temática } & \multicolumn{1}{|c|}{ Resumen } & \multicolumn{1}{|c|}{ Estudio } & $\begin{array}{l}\text { Observacio- } \\
\text { nes }\end{array}$ \\
\hline $\begin{array}{l}\text { Caballo et. } \\
\text { al. (2005) }\end{array}$ & Validación QOL-Q & $\begin{array}{l}\text { QOL-Q es un ins- } \\
\text { trumento válido }\end{array}$ & $\begin{array}{l}\text { Transver- } \\
\text { sal }\end{array}$ & $\begin{array}{l}\text { No generali- } \\
\text { zable a otras } \\
\text { poblaciones }\end{array}$ \\
\hline $\begin{array}{l}\text { Herps et. } \\
\text { al. (2016) }\end{array}$ & Planes de apoyo & $\begin{array}{l}\text { Planes de apoyo de } \\
\text { las PMs más rela- } \\
\text { cioados con el bien- } \\
\text { estar }\end{array}$ & $\begin{array}{l}\text { Transver- } \\
\text { sal }\end{array}$ & $\begin{array}{l}\text { Comparación } \\
\text { edades y gra- } \\
\text { do de DID }\end{array}$ \\
\hline $\begin{array}{l}\text { McCaus- } \\
\text { land et. al. } \\
\text { (2016) }\end{array}$ & $\begin{array}{l}\text { Relaciones sociales } \\
\text { en PcDID mayores }\end{array}$ & $\begin{array}{l}\text { Residencia, edad y } \\
\text { grado de DID influ- } \\
\text { yen en las rr.sociales }\end{array}$ & $\begin{array}{l}\text { Transver- } \\
\text { sal }\end{array}$ & $\begin{array}{l}\text { Necesidad de } \\
\text { políticas que } \\
\text { favorezcan } \\
\text { las rr.sociales }\end{array}$ \\
\hline $\begin{array}{l}\text { Millán- } \\
\text { Calenti et. } \\
\text { al. (2003) }\end{array}$ & $\begin{array}{l}\text { CV en PcDI que en- } \\
\text { vejecen }\end{array}$ & $\begin{array}{l}\text { La mayoría viven } \\
\text { con familias y tienen } \\
\text { nivel moderado }\end{array}$ & $\begin{array}{l}\text { Transver- } \\
\text { sal }\end{array}$ & $\begin{array}{l}\text { Necesidad de } \\
\text { actuar sobre } \\
\text { los recursos }\end{array}$ \\
\hline $\begin{array}{l}\text { O'Brien et. } \\
\text { al. (2001) }\end{array}$ & $\begin{array}{l}\text { Desinstitucionaliza- } \\
\text { ción y CV }\end{array}$ & $\begin{array}{l}\text { Desinstitucionaliza- } \\
\text { ción mejora ABVD }\end{array}$ & $\begin{array}{l}\text { Transver- } \\
\text { sal }\end{array}$ & $\begin{array}{l}\text { Estudio re- } \\
\text { trospectivo }\end{array}$ \\
\hline
\end{tabular}

Tabla 14: Literatura sobre la calidad de vida en el proceso de envejecimiento de las personas con discapacidad intelectual y del desarrollo. 


\subsubsection{Resumen}

En cuanto a las investigaciones relacionadas con el envejecimiento de las PcDID, aparece sobre todo el tema de la desinstitucionalización, las redes de apoyo social, los planes de apoyo y de nuevo, las escalas para medir la $\mathrm{CV}$ en este colectivo.

\subsubsection{Resumen}

La calidad de vida es un concepto que nace a finales de los años 50 en el ámbito de las ciencias sociales, y que hoy día se expande a muchas otras áreas, ejemplo de ello es el reciente concepto de calidad de vida relativa a la salud, muy frecuente en la investigación del ámbito sanitario; así como la calidad de vida familiar, concepto que nace para marcar el bienestar de la familia de la personas con discapacidad intelectual. Con el aumento de la esperanza de vida y el consecuente envejecimiento de la población, así como el incremento de la prevalencia de personas con enfermedades crónicas y distintas discapacidades y la aparición del concepto de Estado de Bienestar, surge la necesidad de recursos sociales que cooperen en la mejora de la situación de vida de estas personas. De esta forma, hoy se estudia el efecto que diversos tipos de programas, ya sean preventivos, de ocio, laborales, etc., tienen sobre la calidad de vida de cualquier colectivo. Son comunes los estudios en pacientes con cualquier tipo de enfermedad crónica, como el cáncer, el asma, la esclerosis múltiple, o simplemente en personas mayores o en personas con determinada discapacidad. En el ámbito de la discapacidad intelectual el concepto de calidad de vida se emplea para la planificación y evaluación de programas de intervención. Tales programas también son de todo tipo (programas sanitarios de prevención, programas de educación psicosexual, programas de empleo con apoyo, etc.). Un aspecto relevante de la calidad de vida es que engloba tanto componentes objetivos como subjetivos. Entre dichos componentes destaca el poder tomar decisiones acerca de 
las cuestiones que afectan a nuestra vida y el tener el control de la misma, cuestión que en las personas con discapacidad probablemente necesita una mayor atención, aunque muchos de los estudios revisados analizan la autopercepción de las personas con discapacidad intelectual en distintas áreas de la calidad de vida. Otro tema recurrente de nuevo en el ámbito de la CV es el de la importancia de la participación social, las redes sociales de apoyo y los tipos de vivienda, que tienen una notable influencia, según los estudios en la CV de las personas que envejecen, ya sean con o sin discapacidad.

\subsection{LITERATURA SOBRE NECESIDADES PERCIBIDAS}

\subsubsection{Introducción}

En este bloque se presentan algunas de las escasas investigaciones llevadas a cabo en torno a las necesidades percibidas en las personas con discapacidad.

\subsubsection{Necesidades percibidas en personas con discapacidad}

A continuación se presenta la tabla 15, que resume las investigaciones revisadas que tratan acerca de las necesidades percibidas en las personas con discapacidad.

Karas, Costain, Chow y Bassett (2014) realizan un estudio para examinar la carga percibida en cuidadores de personas adultas con un subtipo de discapacidad intelectual. Para ello, administraron un cuestionario a 85 cuidadores y a 34 PcDID y se realizaron análisis cuantitativos y cualitativos. La carga percibida era mayor cuando existían enfermedades psiquiátricas y problemas de comportamiento. Asimismo, los cuidadores se mostraban insatisfechos con los servicios médicos y sociales para las PcDID, incluso en el momento de la transición desde la atención pediátrica. Los autores concluyen que un diagnóstico rápido, con el correspondiente tratamiento de las enfermedades psiquiátricas, así como un apoyo más extenso en los momentos de transición y una mayor es- 
pecialización de los profesionales pueden ayudar a mejorar los resultados personales de las personas con este tipo de discapacidad, y reducir a su vez la carga de los cuidadores.

Dubois, Dubuc, Râiche, Caron y Hèbert (2008) miden la prevalencia e identifican los correlatos de la NP de institucionalización en personas mayores que están en riesgo de deterioro cognitivo. Para ello emplean una muestra de 781 personas de 78 años o mayores que viven en la comunidad, a quienes se realizaban 3 preguntas. Los resultados indican que tanto las personas que tienen un régimen de vida individual, como los que residen en colectividad, piensan en la institucionalización en el mismo grado, sobre todo si en el último año han tenido limitaciones físicas, han solicitado ayuda para el mantenimiento del hogar, o han observado un mayor deterioro funcional. Los autores concluyen que los factores relacionados con la discapacidad física y las insuficiencias de recursos son correlatos importantes de la NP de institucionalización en personas mayores.

Meadows, Harvey, Fossey y Burguess (2000) llevan a cabo un estudio para elaborar y validar un instrumento de evaluación de las NP's del cuidado de salud mental en la población australiana que había participado en la Encuesta Australiana de Salud Mental y Bienestar. Para ello emplearon una muestra de 145 personas con ansiedad clínica y 51 pacientes de los servicios psiquiátricos. El cuestionario PNCQ es una prueba que evalúa las NP's mediante 5 categorías de NP en los servicios de salud mental, que son la medicación, la información, el consejo incluyendo psicoterapia, las habilidades de formación y las intervenciones sociales. Los resultados indican que el cuestionario PNCQ es una prueba válida y fiable para evaluar las NP's de salud mental de la población australiana. 
Meadows, Burguess, Bobevski, Fossey, et. al. (2002) realizan un estudio basado en la Encuesta Australiana de Salud Mental y Bienestar para investigar la influencia del diagnóstico, la demografía y la discapacidad en las NP's en el cuidado de la salud mental. Los resultados indican que la NP era mayor en mujeres, en personas adultas de mediana edad y en personas con trastornos afectivos o comorbilidad de trastornos. Los autores también observaron una NP en los servicios de intervención social; y la discapacidad, los trastornos afectivos y la comorbilidad se relacionaron positivamente con la NP. Los autores concluyen que los resultados tienen implicaciones para los servicios de salud mental, que deben atender y ser sensibles a las necesidades de los pacientes.

Meadows y Burguess (2009) tienen el objetivo de investigar la NP de cuidado de salud mental en población australiana y la sensibilidad de los servicios a sus necesidades. Para ello emplean una muestra de personas que participaron en la Encuesta Australiana de Salud Mental y Bienestar. Los resultados indican que el 14\% de la población percibía la NP del cuidado de salud mental, y entre el 7-8\% percibían como satisfecha la necesidad de asesoramiento o medicación por parte de los servicios. La NP se percibía menos en personas con abuso de sustancias que en personas con ansiedad y trastornos afectivos. La medicación era la necesidad que se percibía como más satisfecha por parte de los servicios.

Samuel, Hobden, LeRoy y Lacey (2012) investigan las necesidades de las familias de PcDI en USA. Para ello emplean una muestra de 149 familias que rellenaron el FQOLS (2006). Los resultados indican que más de la mitad de las familias informaron de la necesidad de más ayuda desde el sistema de servicios, y para eliminar las barreras de acceso a los mismos. Casi todas las familias veían los servicios de apoyo como muy importantes para la CV familiar, sin embargo, sólo la mitad de ellas estaban satisfechas 
con el apoyo formal que estaban recibiendo. Menos de la mitad de las familias informaron de tener alguna oportunidad de servicio de apoyo y alta obtención de servicios de apoyo, pero casi todos habían buscado algún tipo de apoyo formal. Los autores concluyen que es necesario dar poder a las familias y valorar sus necesidades con el FQOLS para adecuar los servicios de apoyo a sus necesidades.

Sutherland, van der Meer, Sigafoos, Mirfin-Veitch, et. al. (2014) realizan un estudio para detectar las necesidades de sistemas alternativos y aumentativos de comunicación en adultos con DID en Nueva Zelanda. Para ello proporcionaron un cuestionario a 100 organizaciones de atención a este colectivo. Los resultados indicaron que el $28,8 \%$ de los adultos eran posibles candidatos a una intervención en SAAC, sim embargo, la mayoría del personal de atención no conocía o no tenía experiencia en estos sistemas de comunicación, por lo que se hacía evidente la formación en esta área.

Aguado y Alcedo (2004) tratan de identificar las NP's relacionadas con la CV en las PcD. Para ello aplican una entrevista semiestructurada a 325 PcD. Los resultados obtenidos indican que los principales focos a los que se dirigen las necesidades de este colectivo son la salud, los recursos económicos, la eliminación de barreras arquitectónicas, la ayuda a domicilio, la calidad de los servicios y el incremento de los recursos asistenciales. Los autores concluyen con una serie de propuestas de mejora de los servicios de atención a este colectivo con el objetivo de incrementar la autonomía y la independencia de las PcD y mejorar su CV.

Aguado, Alcedo y Arias (2005) realizan un estudio para identificar las necesidades de las PcD que envejecen percibidas por sus familiares. Para ello los autores emplean una muestra de 770 familiares de PcD a quienes les aplican una entrevista semiestructurada. Los resultados indican que los campos que más preocupan a los familiares 
de las PcD son el de la salud, como el estado de salud funcional o las limitaciones funcionales personales; los recursos de servicios sociales y sanitarios, como la ayuda a domicilio; las barreras arquitectónicas y la incertidumbre sobre con quién vivirá la PcD en el futuro. Por otro lado, los autores encuentran que los familiares apoyan medidas como la subida de las pensiones, servicios de ocio y tiempo libre, un aumento de la ayuda familiar y de ayuda para el cuidado personal.

Aguado, Alcedo y Fontanil (2005) realizan un estudio con el objetivo de identificar las necesidades de las PcD que envejecen percibidas por los profesionales que trabajan con ellas. Para ello emplean una muestra de 403 profesionales a quienes se les aplicaba una entrevista semiestructurada. Los autores encuentran que las principales preocupaciones de los profesionales acerca de las necesidades de las PcD tienen que ver con la escasez y la baja calidad de los recursos de los servicios sociales, con la existencia de barreras sociales y arquitectónicas, con los recursos económicos limitados y las consecuencias negativas de los problemas de salud. Los profesionales demandan más actividades de ocio y tiempo libre y servicios residenciales especializados. Los autores también encuentran entre las soluciones principales que aportan los profesionales la especialización profesional y el incremento de las subvenciones.

Aguado, Alcedo, Arias y Rueda (2006) realizan un estudio en Bizkaia para conocer las NP's de las PcDI, de sus familias y de los profesionales que trabajan con ellas. Para ello aplican tres entrevistas semiestructuradas a 229 PcDI mayores de 45 años, 198 familiares y 70 profesionales. Los resultados indican que existe un cierto consenso, en especial, entre personas y familias, y que esta perspectiva es complementada por la percepción de los profesionales. Las PcDI y sus familias demandan como la solución principal la subida de las pensiones, mientras que los profesionales eligen la supresión de 
barreras arquitectónicas. Tanto las PcDI, familias y profesionales piden más servicios de apoyo de ocio y tiempo libre y el apoyo para los cuidados personales diarios. Los autores concluyen su estudio con la propuesta de diferentes vías de actuación por parte de las políticas y los servicios públicos. 


\begin{tabular}{|c|c|c|c|c|}
\hline Autor/es & Medidas & Resumen & Estudio & Observaciones \\
\hline $\begin{array}{l}\text { Karas et. } \\
\text { al. (2014) }\end{array}$ & $\begin{array}{l}\text { Cuestio- } \\
\text { nario } \\
\text { propio }\end{array}$ & $\begin{array}{l}\text { El apoyo en las transi- } \\
\text { ciones, y el rápido dia- } \\
\text { gnóstico y tratamiento de } \\
\text { las PCDID ayudan a re- } \\
\text { ducir la carga percibida } \\
\text { de los cuidadores y a } \\
\text { mejorar los resultados } \\
\text { personales de las perso- } \\
\text { nas. }\end{array}$ & $\begin{array}{l}\text { Transver- } \\
\text { sal. }\end{array}$ & $\begin{array}{l}\text { Se entrevista tanto a } \\
\text { cuidadores como a } \\
\text { PcDID sobre los servi- } \\
\text { cios socio-sanitarios } \\
\text { que atienden a este co- } \\
\text { lectivo. }\end{array}$ \\
\hline $\begin{array}{l}\text { Dubois et. } \\
\text { al. (2008) }\end{array}$ & $\begin{array}{l}\text { Cuestio- } \\
\text { nario } \\
\text { propio }\end{array}$ & $\begin{array}{l}\text { La discapacidad física y } \\
\text { la insuficiencia de recur- } \\
\text { sos hacen que las perso- } \\
\text { nas mayores perciban la } \\
\text { necesidad de } \\
\text { institucionalización }\end{array}$ & $\begin{array}{l}\text { Longitudi- } \\
\text { nal }\end{array}$ & $\begin{array}{l}\text { No se estudió el tipo de } \\
\text { recursos que han reci- } \\
\text { bido las personas de la } \\
\text { muestra previamente }\end{array}$ \\
\hline $\begin{array}{l}\text { Meadows } \\
\text { et. al. } \\
(2000)\end{array}$ & PNCQ & $\begin{array}{l}\text { El PNCQ es una prueba } \\
\text { fiable y válida para eva- } \\
\text { luar NP's de salud men- } \\
\text { tal }\end{array}$ & $\begin{array}{l}\text { Transver- } \\
\text { sal }\end{array}$ & $\begin{array}{l}\text { Los resultados no son } \\
\text { extrapolables a otras } \\
\text { poblaciones }\end{array}$ \\
\hline $\begin{array}{l}\text { Meadows } \\
\text { et. al. } \\
(2002)\end{array}$ & $\begin{array}{l}\text { Cuestio- } \\
\text { nario } \\
\text { propio }\end{array}$ & $\begin{array}{l}\text { La discapacidad, los tras- } \\
\text { tornos afectivos y la co- } \\
\text { morbilidad se asociaron } \\
\text { con la NP de salud men- } \\
\text { tal }\end{array}$ & $\begin{array}{l}\text { Transver- } \\
\text { sal }\end{array}$ & $\begin{array}{l}\text { Los servicios de salud } \\
\text { mental deben ser sensi- } \\
\text { bles a las NP de los } \\
\text { pacientes }\end{array}$ \\
\hline $\begin{array}{l}\text { Meadows } \\
\text { et. al. } \\
(2009)\end{array}$ & $\begin{array}{l}\text { Cuestio- } \\
\text { nario de } \\
\text { NP de } \\
\text { salud } \\
\text { mental } \\
\end{array}$ & $\begin{array}{l}\text { La necesidad percibida } \\
\text { como más satisfecha por } \\
\text { la población es la medi- } \\
\text { cación }\end{array}$ & $\begin{array}{l}\text { Transver- } \\
\text { sal }\end{array}$ & $\begin{array}{l}\text { Continúan existiendo } \\
\text { vacíos en los servicios } \\
\text { de salud mental en la } \\
\text { atención a las NP de los } \\
\text { pacientes }\end{array}$ \\
\hline $\begin{array}{l}\text { Samuel } \\
\text { et. al. } \\
(2012)\end{array}$ & FQOLS & $\begin{array}{l}\text { Se remarca la necesidad } \\
\text { de recursos para dar po- } \\
\text { der a las familias y la } \\
\text { utilidad del FQOLS para } \\
\text { identificar las necesida- } \\
\text { des y dar apoyos }\end{array}$ & $\begin{array}{l}\text { Transver- } \\
\text { sal }\end{array}$ & $\begin{array}{l}\text { Adecuar los servicios } \\
\text { de apoyo a las necesi- } \\
\text { dades de las familias }\end{array}$ \\
\hline $\begin{array}{l}\text { Suther- } \\
\text { land et. } \\
\text { al. (2014) }\end{array}$ & $\begin{array}{l}\text { Cuestio- } \\
\text { nario } \\
\text { propio }\end{array}$ & $\begin{array}{l}\text { Necesidad de las PcDID } \\
\text { de SAAC y necesidad de } \\
\text { formación de los profe- } \\
\text { sionales }\end{array}$ & $\begin{array}{l}\text { Transver- } \\
\text { sal }\end{array}$ & $\begin{array}{l}\text { Incremento de forma- } \\
\text { ción y aplicación de } \\
\text { SAAC }\end{array}$ \\
\hline
\end{tabular}

Tabla 15.1.: Literatura sobre necesidades percibidas. 


\begin{tabular}{|c|c|c|c|c|}
\hline Autor/es & Medidas & Resumen & Estudio & Observaciones \\
\hline $\begin{array}{l}\text { Aguado } \\
\text { et. al. } \\
(2004)\end{array}$ & $\begin{array}{l}\text { Entrevis- } \\
\text { ta semi- } \\
\text { estructu- } \\
\text { rada }\end{array}$ & $\begin{array}{l}\text { Las NP`s de las PcD gi- } \\
\text { ran en torno a salud, re- } \\
\text { cursos económicos, ba- } \\
\text { rreras, ayuda a domicilio, } \\
\text { calidad de servicios y } \\
\text { recursos asistenciales }\end{array}$ & $\begin{array}{l}\text { Transver- } \\
\text { sal }\end{array}$ & $\begin{array}{l}\text { Los servicios deben } \\
\text { atender a las necesida- } \\
\text { des que perciben las } \\
\text { propias PcD }\end{array}$ \\
\hline $\begin{array}{l}\text { Aguado } \\
\text { et. al. } \\
(2005)\end{array}$ & $\begin{array}{l}\text { Entrevis- } \\
\text { ta semi- } \\
\text { estructu- } \\
\text { rada }\end{array}$ & $\begin{array}{l}\text { La preocupación de los } \\
\text { familiares: salud, servi- } \\
\text { cios socio-sanitarios, } \\
\text { barreras y futuro }\end{array}$ & $\begin{array}{l}\text { Transver- } \\
\text { sal }\end{array}$ & $\begin{array}{l}\text { Es necesaria la adecua- } \\
\text { ción de los recursos } \\
\text { existentes a las NP's de } \\
\text { las familias de las PcD, } \\
\text { y la creación de nuevos } \\
\text { servicios con el mismo } \\
\text { objetivo }\end{array}$ \\
\hline $\begin{array}{l}\text { Aguado } \\
\text { et. al. } \\
(2005)\end{array}$ & $\begin{array}{l}\text { Entrevis- } \\
\text { ta semi- } \\
\text { estructu- } \\
\text { rada }\end{array}$ & $\begin{array}{l}\text { A los profesionales: es- } \\
\text { casez y baja calidad de } \\
\text { servicios sociales y sani- } \\
\text { tarios, barreras, recursos } \\
\text { económicos y salud }\end{array}$ & $\begin{array}{l}\text { Transver- } \\
\text { sal }\end{array}$ & $\begin{array}{l}\text { Existe un vacío en los } \\
\text { recursos destinados a } \\
\text { las PcD en lo referente } \\
\text { a sus necesidades per- } \\
\text { cibidas por los profe- } \\
\text { sionales que les atien- } \\
\text { den }\end{array}$ \\
\hline $\begin{array}{l}\text { Aguado } \\
\text { et. al. } \\
(2006)\end{array}$ & $\begin{array}{l}\text { Entrevis- } \\
\text { ta semie- } \\
\text { tructura- } \\
\text { da }\end{array}$ & $\begin{array}{l}\text { No hay diferencias signi- } \\
\text { ficativas entre las NP's } \\
\text { de las PcDI, sus familia- } \\
\text { res y profesionales. }\end{array}$ & $\begin{array}{l}\text { Transver- } \\
\text { sal }\end{array}$ & $\begin{array}{l}\text { Se aportan líneas de } \\
\text { actuación para los ser- } \\
\text { vicios de atención }\end{array}$ \\
\hline $\begin{array}{l}\text { Aguado } \\
\text { et. al. } \\
(2012)\end{array}$ & $\begin{array}{l}\text { Entrevis- } \\
\text { ta semi- } \\
\text { estructu- } \\
\text { rada }\end{array}$ & $\begin{array}{l}\text { No se encontraron dife- } \\
\text { rencias significativas en } \\
\text { las NP's por PcDI, fami- } \\
\text { lias y profesionales }\end{array}$ & $\begin{array}{l}\text { Transver- } \\
\text { sal }\end{array}$ & $\begin{array}{l}\text { Se proponen líneas fu- } \\
\text { turas para los servicios } \\
\text { y políticas de actuación }\end{array}$ \\
\hline
\end{tabular}

Tabla 15.2.: Literatura sobre necesidades percibidas. (Continuación).

Aguado, Alcedo y Fontanil (2012) realizan una investigación para detectar las NP's relativas a la CV de las PcDI que envejecen. Para ello, aplican paralelamente 3 entrevistas semi-estructuradas a 377 PcDI, 61 familiares y 198 profesionales de Castilla y León. Los resultados indican que no hay diferencias significativas entre las NP's percibidas por los tres grupos estudiados. El tema de la salud personal preocupa del mismo modo a personas con DI, familias y profesionales, seguido de los recursos económicos y los recursos asistenciales sanitarios. A los familiares les preocupa principalmente los indicadores relacionados con los servicios sociales, mientras que a las PcDI les preocu- 
pa su salud personal por encima del resto, y a los profesionales les preocupa el futuro de las PcDI y la escasez de relaciones personales. Los autores concluyen el estudio con las propuestas de vías de actuación futuras tanto en el campo de los servicios de apoyo, como en las políticas públicas dedicadas a este colectivo.

\subsubsection{Resumen}

Aunque cada vez existen más recursos y servicios dirigidos a mejorar la calidad de vida de las personas con discapacidad, apenas se ha investigado acerca de lo que las propias personas con discapacidad perciben como necesario y echan en falta en tales servicios. En las investigaciones revisadas, se ha estudiado la carga percibida por los cuidadores de personas con DID, la necesidad percibida de salud mental y la adecuación de los servicios a tal necesidad, las necesidades de las familias de PcDID acerca de los servicios de asistencia o la necesidad de SAAC por parte de PcDID.

Por otro lado, y más en relación con la investigación que se presenta, el equipo de Aguado y cols. $(2004 ; 2005 ; 2006 ; 2012)$ preguntaban por medio de un cuestionario a PcDID, familias y profesionales de distintas CCAA españolas acerca de las NPs en los servicios.

\subsection{DISCUSIÓN DE LOS RESULTADOS DE LA REVISIÓN}

\subsubsection{Introducción}

En este apartado realizaremos un análisis general de las publicaciones revisadas en este trabajo, que versa sobre las necesidades percibidas relacionadas con la calidad de vida en las personas con discapacidades intelectuales y del desarrollo que se encuentran en proceso de envejecimiento. 


\subsubsection{Resumen de los resultados de la revisión}

En la investigación presente se revisaron un total de 224 artículos, de entre los años 2000 y 2016, que en función de los criterios de temática propuestos se resumen en:

- Envejecimiento: 19 artículos empleaban muestras de personas de la población general; 17 artículos tenían muestras de PcD y 56 artículos empleaban muestras de PcDID.

- Discapacidad: se revisaron 8 artículos que versaban sobre la discapacidad en general y 40 artículos sobre la DID.

- Calidad de vida: 9 artículos versaban sobre la CV en la población general; 3 sobre la $\mathrm{CV}$ en PcD y 27 sobre la CV en PcDID. Por otro lado, 23 artículos versaban sobre la CV en el envejecimiento de la población general; 5 sobre la CV en el envejecimiento de las PcD y 5 sobre la CV en el envejecimiento de las PcDID.

\subsubsection{Conclusiones y discusión de los resultados de la revisión}

El objetivo de la revisión era conocer el estado de la investigación actual acerca de las necesidades percibidas por las PcDID en proceso de envejecimiento.

Las conclusiones extraídas de las investigaciones revisadas podrían resumirse en los siguientes puntos:

- El envejecimiento es un tema bastante estudiado, tanto en la población general como en las PcD y PcDID. Se hace referencia a la aparición de diversas limitaciones, tanto en la población general que envejece como en la población con discapacidad, y que tienen que ver con los cambios físicos, los problemas de salud, el deterioro cognitivo, la movilidad, la autonomía, la aparición de 
síntomas de ansiedad y depresión y la pérdida o disminución de relaciones sociales. En concreto en el envejecimiento de las PcDID, cobra relevancia también el estudio de los problemas de comportamiento. El envejecimiento activo o satisfactorio es un tema de relevancia en este campo. Por último, numerosos son los estudios que hablan de la importancia en esta etapa de la vida de mantener las relaciones sociales y el apoyo social, además de la participación comunitaria.

- El compendio de artículos revisados sobre la discapacidad en general hacen referencia mayoritariamente a las PMs que envejecen con una discapacidad, y estudian los déficits que aparecen en este colectivo en relación principalmente a la dependencia a la hora de realizar las AVD.

- En DID las investigaciones se centran en la conceptualización y en los nuevos modelos de comprensión de la DID y de evaluación (escalas como la SIS de necesidades de apoyo) y de intervención (como la PCP). Así también, se estudian los problemas de salud, las conductas problemáticas y los trastornos de conducta.

- En cuanto a la calidad de vida, hay un elevado número de artículos dedicados a estudiar la conceptualización, las dimensiones y los posibles indicadores de este constructo, tanto en la población general como en PcD y PcDID. Aparecen estudios sobre el empleo de escalas de medida de la CV en PcDID y acerca de la relación de diversas variables con el incremento de la CV en este colectivo, como por ejemplo el empleo, la vivienda, los estilos de vida, la salud mental o la dependencia de otras personas. El tema de la salud, traducida en forma de CV relativa a la salud ocupa un gran número de investigaciones. Nuevamente en los artículos revisados se destaca la importancia de las redes de apoyo social como parte de una buena $\mathrm{CV}$, entre otros factores. 
- En lo referente a las NPs de las PcD, se han estudiado necesidades concretas, como las relativas a la salud mental, sobre la percepción de los recursos disponibles o acerca de la necesidad de SAAC en PcDID, bien preguntando a las familias o a las propias $\mathrm{PcD}$.

Por otro lado, y más en relación con nuestro estudio, el equipo de Aguado y cols. $(2004 ; 2005 ; 2006 ; 2012)$ ha realizado estudios preguntando a las PcDID, las familias y los profesionales que les atienden sobre las necesidades que perciben en los servicios de atención. En las distintas investigaciones, se observa que la salud, la existencia de barreras sociales y arquitectónicas y los recursos de servicios sociales son temas que interesan tanto a las PcDID, como a sus familias y a los profesionales. En estos estudios, se remarca también que el dónde y con quién vivirá la PcDID en el futuro también es una preocupación latente en los tres colectivos estudiados.

Estas preocupaciones detectadas, concuerdan en cierta medida con datos que se han encontrado en la revisión de las investigaciones sobre las PcDID que envejecen, que es la muestra relevante para el presente estudio, ya que en algunas de ellas se remarcan determinadas necesidades como la adecuación de los servicios, la especialización de los mismos así como de los profesionales, las necesidades de diagnósticos y tratamientos psiquiátricos y/o psicológicos adecuados, la adaptación de las residencias, la necesidad de participación en la comunidad y mantenimiento o creación de redes de apoyo social, etc., con la finalidad de que este colectivo pueda recibir los apoyos adecuados durante su proceso de envejecimiento; y es de este punto, de donde parte el trabajo que se presentará a continuación. Por tanto, a partir de aquí, presentaremos el estudio de las NP's por las PcDID que envejecen, sus familias y los profesionales que les atienden, siguiendo el modelo de estas últimas investigaciones comentadas, con el fin de proveer infor- 
mación a los servicios destinados a la atención de las PcDID que envejecen, para que adecúen sus recursos a las necesidades reales de este colectivo. 
PARTE EMPÍRICA 


\section{INTRODUCCIÓN}

En este apartado se presenta la parte empírica de la tesis doctoral, que consistirá en exponer, en primer lugar, los objetivos e hipótesis de trabajo, seguidos de la metodología y los instrumentos empleados. Posteriormente se detallan las características sociodemográficas de las muestras de PcDID, familias e instituciones, los principales resultados en cuanto a las NPs de cada una de ellas y los análisis estadísticos realizados para determinar cuáles han sido las variables intervinientes en los resultados de NPs.

\section{OBJETIVOS E HIPÓTESIS}

\subsection{OBJETIVO GENERAL}

El objetivo general de este estudio es conocer las NPs que aparecen en el proceso de envejecimiento de las PcDID.

\subsection{OBJETIVOS ESPECÍFICOS}

El objetivo general se puede traducir en los siguientes objetivos específicos:

- Detectar las NPs relativas a la CV de las PcDID mayores de 35 años.

- Estudiar la prevalencia de las necesidades en las PcDID mayores y los factores de riesgo que llevan a explicar tales necesidades.

- Analizar las NPs para extraer la suficiente información para elaborar un "mapa de necesidades".

- Estudiar la posible relación entre las variables sociodemográficas, geográficas y ambientales y las NPs.

- Contrastar los resultados de este estudio con los de otras investigaciones previas. 
- Proponer líneas de actuación para que los servicios puedan adecuar sus recursos a las necesidades del colectivo de personas con discapacidad intelectual en proceso de envejecimiento y logren mejorar su calidad de vida.

- Generar estrategias que permitan a las PcDI prevenir los problemas a los que se enfrentan en el proceso de envejecimiento, a través de la mejora de la planificación de los recursos destinados a incrementar la CV en este colectivo.

\subsection{HIPÓTESIS DE TRABAJO}

Para conseguir los objetivos propuestos, establecemos las siguientes hipótesis de trabajo:

1) Las NPs por las PcDID, así como sus familiares y los profesionales que les atienden, que participan en la investigación estarán relacionadas fundamentalmente con la salud, la carencia de recursos económicos, la dependencia de otras personas en las actividades de la vida diaria, la ayuda a domicilio y las barreras arquitectónicas.

2) Las soluciones propuestas por las PcDID, las familias y los profesionales, estarán fundamentalmente relacionadas con la salud, la carencia de recursos económicos, la dependencia de otras personas en las actividades de la vida diaria, la ayuda a domicilio y las barreras arquitectónicas.

3) Los apoyos requeridos serán principalmente de tipo económico, institucional y asistencial.

4) Existirán diferencias estadísticamente significativas en las NPs en función de la edad de las PcDID. 
5) No existirán diferencias estadísticamente significativas en las NPs por familiares, profesionales y PcDID.

6) No existirán diferencias significativas en las soluciones propuestas a las necesidades por parte de profesionales, familias y PcDID.

\section{PROCEDIMIENTO}

\subsection{INTRODUCCIÓN}

En este apartado se presenta el método llevado a cabo durante la investigación así como los instrumentos empleados en la misma.

\subsection{MÉTODO}

En primer lugar se realizó un entrenamiento para los entrevistadores, que eran personas ya formadas en la investigación y que formaban parte del equipo del Dr. D. Antonio-León Aguado Díaz en la Facultad de Psicología de la Universidad de Oviedo.

Posteriormente, se contactó de forma telefónica con asociaciones de personas con discapacidades intelectuales y del desarrollo a nivel nacional, a través de Organizaciones en Favor de las Personas con Discapacidad Intelectual (FEAPS), hoy día denominada Plena Inclusión, así como a través del contacto por medio de colabores o estudiantes de la Universidad de Oviedo y con familiares de personas con discapacidad.

La participación de las personas era voluntaria. Una vez establecido el contacto, se procedió a firmar el consentimiento informado para el tratamiento de los datos. Para realizar el estudio se emplearon tres cuestionarios paralelos construidos ad hoc autoaplicados acerca de las NP's relativas a la CV de las PcDID. Dado que la mayoría de las PcDID participantes superaba un grado de discapacidad del $65 \%$, el cuestionario fue cubierto en algunos casos por otras personas que no eran la propia PcDID, o en otras 
situaciones, contaba con la ayuda de un entrevistador. Por tanto, el cuestionario de las PcDID podía ser respondido por él/ella mismo/a, por un familiar, un amigo, personal de la asociación, por un trabajador social o por otros profesionales que formaban parte de la vida de la persona y tuvieran una relación cercana a él/ella. Por otro lado, los dos cuestionarios restantes eran cumplimentados por familiares o profesionales con relación directa con PcDID.

A los participantes se les facilitaba un número de teléfono para facilitar la comunicación en caso de dudas o sugerencias. Una vez cumplimentado el cuestionario, era devuelto bien mediante correo ordinario (la dirección estaba impresa en el cuestionario), o bien nos lo entregaban directamente en el Departamento de la Facultad de Psicología de la Universidad de Oviedo. El cuestionario recogía diversos ítems relativos a las NP's y las preocupaciones que se consideraban importantes para la vida de las PcDID que envejecen, así como soluciones, apoyos institucionales que se echaban en falta, problemas señalados y pensamientos de futuro. La persona que cumplimentaba la entrevista podía elegir varios de los ítems propuestos, sin existir un número mínimo o máximo de respuestas, pudiendo señalarlos todos si consideraba que todos ellos eran preocupaciones actuales y realistas para la persona. Por otro lado, también existían preguntas abiertas para que los participantes pudieran expresar otras cuestiones que no recogía el cuestionario.

Tras la aplicación y recepción de las entrevistas se procedió a almacenar los datos en una base de datos, para su posterior tratamiento estadístico. 


\subsection{INSTRUMENTOS DE EVALUACIÓN}

Para evaluar las necesidades percibidas de las personas con discapacidad en proceso de envejecimiento se han construido ad hoc tres entrevistas semiestructuradas, para las personas con DID que envejecen, sus familias y los profesionales que les atienden. Para su construcción se tomó como referencia el concepto de calidad de vida de Schalock (Schalock y Verdugo, 2006).

La entrevista personal semiestructurada (Aguado y cols., 2003, 2004, 2005) combina 94 preguntas abiertas y cerradas y va dirigida a obtener información sobre distintos aspectos de la vida de las personas con discapacidad intelectual en proceso de envejecimiento. Recoge información sobre variables descriptivas relacionadas con la discapacidad y sobre variables sociodemográficas y ambientales. Esta entrevista tiene los siguientes componentes:

- Datos personales: género, edad, estado civil, lugar de nacimiento, lugar de residencia, procedencia, nivel cultural, nivel profesional, ocupación actual, ingresos.

- Datos acerca de la cumplimentación de la entrevista: lugar y persona que la cumplimenta.

- Datos clínicos: tipo y descripción de la discapacidad, etiología, edad de adquisición, grado de minusvalía reconocido.

- Datos sobre la convivencia: presencia de padres, hermanos e hijos y tipo de convivencia.

- Preocupaciones y necesidades generales y específicas sobre salud personal, recursos económicos, recursos asistenciales sanitarios, recursos de servicios sociales, existencia de barreras y otras preocupaciones y necesidades.

- Soluciones que considera necesarias.

- Medidas y apoyos institucionales que echan en falta. 
- Pensamientos sobre su futuro.

- Problemas señalados.

- La última pregunta es abierta, por si hubiera alguna consideración más que añadir.

La entrevista familiar se sitúa anexa al cuestionario personal y se dirige a comprobar las necesidades percibidas por las familias sobre sus familiares con discapacidades intelectuales y del desarrollo. Tiene los siguientes componentes:

- Datos sobre el grado de parentesco de la persona que responde a la entrevista.

- Preocupaciones y necesidades generales y específicas sobre salud personal, recursos económicos, recursos asistenciales sanitarios, recursos de servicios sociales, existencia de barreras y otras preocupaciones y necesidades.

- Soluciones que considera necesarias.

- Medidas y apoyos institucionales que echan en falta.

- Pensamientos sobre su futuro.

- La última pregunta es abierta, por si hubiera alguna consideración más que añadir.

La entrevista institucional también se dirige a comprobar las necesidades de las personas con discapacidades intelectuales y del desarrollo pero, en este caso, percibidas por los profesionales que les atienden. Consta de los siguientes apartados:

- Datos de la institución, en la que se recogen datos sociodemográficos de la misma, así como quién la cumplimenta, el tipo de usuarios y discapacidades a las que atienden, los servicios y profesionales con los que cuenta, etc.

- Preocupaciones y necesidades generales y específicas sobre salud personal, recursos económicos, recursos asistenciales sanitarios, recursos de servicios sociales, existencia de barreras y otras preocupaciones y necesidades. 
- Demandas de los asociados.

- Soluciones que considera necesarias.

- Medidas o apoyos institucionales que echan en falta.

- Pensamientos de futuro de sus asociados.

- Pensamientos de futuro de las personas con discapacidad mayores.

- La última pregunta es abierta, por si hubiera alguna consideración más que añadir.

\subsection{RESUMEN}

Tras un entrenamiento previo de los investigadores de campo, se contactó con Asociaciones, PcDID y familias para la aplicación de los instrumentos. Estos consistieron en 3 entrevistas paralelas semiestructuradas construidas ad hoc, que incluían datos sobre variables sociodemográficas, NP's, soluciones propuestas, apoyos institucionales requeridos, pensamientos de futuro, problemas señalados y un apartado abierto para otros tipos de consideraciones no recogidas entre las anteriores. El desarrollo de la investigación que se presenta tiene por objetivo conocer las NPs por las PcDID, sus familias y los profesionales que les atienden que surgen en el proceso de envejecimiento.

\section{ANÁLISIS DE LA ENTREVISTA PERSONAL}

\subsection{INTRODUCCIÓN}

En este apartado se describen las características sociodemográficas de la muestra de PcDID, así como las NP's generales y específicas (salud personal, recursos económicos, existencia de barreras, recursos sobre servicios sociales, recursos sanitarios, otras NP's), las soluciones que proponen, los apoyos institucionales que echan en falta, los pensamientos de futuro, los problemas señalados y las demás consideraciones que indi- 
caron. Posteriormente se exponen los análisis estadísticos que se han elaborado con el objetivo de investigar las variables que predicen las NP's señaladas previamente.

\subsection{DESCRIPCIÓN DE LA MUESTRA DE PERSONAS CON DISCAPACIDAD INTELECTUAL Y DEL DESARROLLO}

\subsubsection{Introducción}

A continuación se presentan las características de la muestra de PcDID en función de diversas variables tales como la edad, el género, el estado civil, el tipo de cumplimentación, el lugar de residencia, el tipo de convivencia, el grado de discapacidad, el reconocimiento de la discapacidad, la edad de adquisición de la discapacidad, el tipo de ingresos, entre otras.

\subsubsection{Descripción de la muestra de personas con discapacidad intelectual y del desarrollo}

En la tabla 16 se muestra el número total de PcDID participantes en el estudio, caracterizados por género. La muestra estuvo compuesta por 1173 PcDID, de los cuales 685 eran hombres $(58,4 \%)$ y 488 mujeres $(41,6 \%)$.

\begin{tabular}{lcc}
\hline \multicolumn{1}{c}{ Género } & Total & $\%$ \\
\hline Hombres & 685 & $58,4 \%$ \\
Mujeres & 488 & $41,6 \%$ \\
\hline \multicolumn{1}{c}{ Total } & 1173 & $100 \%$ \\
\hline
\end{tabular}

Tabla 16: Características descriptivas de la muestra por género

En cuanto a las características de la muestra por edad, como se presenta en la tabla 17, la media de edad total fue de 52,27 años, la mediana 51, la moda 45, la DT 7,54 y el mínimo y el máximo fueron de 35 y 80 respectivamente. En lo referente a la edad de los hombres, la media se situó en 52,6 años, mientras que en mujeres en 51,81. La mediana 
en hombres fue de 51 frente a 50 en mujeres. La moda en ambos casos se mantuvo en 45 años. La DT en los hombres era 7,63 y 7,38 en mujeres. El mínimo y el máximo fueron 35 y 80 respectivamente tanto para hombres como para mujeres.

\begin{tabular}{cccc}
\hline Edad & Hombres & Mujeres & Total \\
\hline Media & 52,6 & 51,81 & 52,27 \\
Mediana & 51,0 & 50,0 & 51,0 \\
Moda & 45 & 45 & 45 \\
DT & 7,63 & 7,38 & 7,54 \\
Mínimo & 35 & 35 & 35 \\
Máximo & 80 & 80 & 80 \\
\hline $\mathbf{N}$ & $\mathbf{6 8 5}$ & $\mathbf{4 8 8}$ & $\mathbf{1 1 7 3}$ \\
\hline
\end{tabular}

Tabla 17: Características de la muestra por edad y género.

En lo que se refiere al tipo de discapacidad (tabla 18), todas las personas de la muestra tenían discapacidades intelectuales y del desarrollo, en concreto, participaron 211 PcSD, de los cuales 128 eran varones y 83 mujeres. La media de edad de los varones con SD era 48,63 años, la mediana 47, la moda 45, la DT 7,1, el mínimo 35 y el máximo 70 años. La media de edad de las mujeres con SD era de 47,17, la mediana 47, la moda 46, la DT 7,22, el mínimo 35 y el máximo 66 años. Asimismo, participaron 126 PcPC, de las cuales 75 eran varones y 51 mujeres. Los varones con PC tenían una media de edad de 50,77 años, la mediana era 49, la moda 45, la DT 5,58, el mínimo 45y el máximo 72 años. En cuanto a las mujeres con PC, su media de edad era de 51,06 años, la mediana 49, la moda 45, la DT 5,58, el mínimo 45 y el máximo 66 años. Por último, participaron en el estudio personas con otros tipos de DID no recogidos anteriormente, de los cuales, 482 eran varones y 354 mujeres. Entre los varones con otras DID, la media se situaba en 53,94 años, la mediana en 52, la moda 49, la DT 7,58, el mínimo 41 y el máximo 80. Las mujeres con otras DID, tenían una media de edad de 53 años, una mediana de 51, la moda 45, la DT 7,22, el mínimo 37 y el máximo 72 años. 


\begin{tabular}{|c|c|c|c|c|c|c|c|}
\hline \multirow{3}{*}{ Edad } & \multicolumn{7}{|c|}{ DI } \\
\hline & \multicolumn{2}{|c|}{ Down } & \multicolumn{2}{|c|}{ Otras } & \multicolumn{2}{|c|}{$\mathbf{P C}$} & \multirow{2}{*}{ Total } \\
\hline & V & M & V & M & $\mathbf{V}$ & M & \\
\hline Media & 48,63 & 47,17 & 53,94 & 53,00 & 50,77 & $\overline{51,06}$ & 52,27 \\
\hline Mediana & 47,00 & 47,00 & 52,00 & 51,00 & 49,00 & 49,00 & 51,0 \\
\hline Moda & 45 & 46 & 49 & 45 & 45 & 45 & 45 \\
\hline DT & 7,10 & 7,22 & 7,58 & 7,22 & 5,99 & 5,58 & 7,54 \\
\hline Mínimo & 35 & 35 & 41 & 37 & 45 & 45 & 35 \\
\hline Máximo & 70 & 66 & 80 & 80 & 72 & 66 & 80 \\
\hline \multirow{2}{*}{ Total } & 128 & 83 & 482 & 354 & 75 & 51 & \multirow{2}{*}{1173} \\
\hline & \multicolumn{2}{|c|}{211} & \multicolumn{2}{|c|}{836} & \multicolumn{2}{|c|}{126} & \\
\hline
\end{tabular}

Tabla 18: Características de la muestra por la edad en función del tipo de discapacidad desglosado por tipo de discapacidad y por género.

Si agrupamos las personas participantes por grupos de edad (tabla 19), nos encontramos que 512 personas $(43,6 \%)$ tenían entre 35 y 49 años, de los cuales 295 eran varones y 217 mujeres; 569 personas (48,5\%) tenían entre 50 y 64 años, y de ellos 330 eran varones y 239 mujeres. Por último, 92 personas (7,8\%) tenían 65 y más años, como era el caso de 60 varones y 32 mujeres.

\begin{tabular}{ccccc}
\hline Edad & Varones & Mujeres & Total & \% \\
\hline 35-49 años & 295 & 217 & 512 & $43,6 \%$ \\
50-64 años & 330 & 239 & 569 & $48,5 \%$ \\
$\mathbf{6 5}$ y + años & 60 & 32 & 92 & $7,8 \%$ \\
\hline Total & $\mathbf{6 8 5}$ & $\mathbf{4 8 8}$ & $\mathbf{1 1 7 3}$ & $\mathbf{1 0 0 \%}$ \\
\hline
\end{tabular}

Tabla 19: Características de la muestra por edad agrupada por percentiles y género.

En lo que respecta al tipo de cumplimentación (tabla 20), podemos observar que el cuestionario fue cumplimentado en la mayoría de los casos por personal del centro (30,9\%), como en el caso de 221 hombres y 141 mujeres. En segundo lugar, un 28,7\% de los cuestionarios fue autoaplicado, en el caso de 184 varones y 153 mujeres. El 
19,1\% fue cumplimentado por personal de la asociación, en el caso de 129 varones y 95 mujeres. El 14,8\% fue cumplimentado por un familiar, en el caso de 107 varones y 67 mujeres. En menores porcentajes fue cumplimentado por un trabajador social $(2,6 \%)$, el tutor legal $(2,3 \%)$ o por un amigo $(1,5 \%)$.

\begin{tabular}{lcccc}
\hline Tipo de cumplimentación & Varones & Mujeres & $\mathbf{N}$ & $\boldsymbol{\%}$ \\
\hline Personal del centro & 221 & 141 & 362 & $30,9 \%$ \\
Autoaplicada & 184 & 153 & 337 & $28,7 \%$ \\
Personal de la asociación & 129 & 95 & 224 & $19,1 \%$ \\
Familiar & 107 & 67 & 174 & $14,8 \%$ \\
Trabajador social & 15 & 16 & 31 & $2,6 \%$ \\
Tutor legal & 18 & 9 & 27 & $2,3 \%$ \\
Amigo & 11 & 7 & 18 & $1,5 \%$ \\
\hline \multicolumn{1}{c}{ Total } & $\mathbf{6 8 5}$ & $\mathbf{4 8 8}$ & $\mathbf{1 1 7 3}$ & $\mathbf{1 0 0 \%}$ \\
\hline
\end{tabular}

Tabla 20: Características de la muestra por tipo de cumplimentación de la entrevista y género.

Si resumimos el tipo de cumplimentación (tabla 21), podemos ver que en el 52,6\% (617 PcDID) de la muestra fue un profesional quien cumplimentó el cuestionario, como es el caso de 365 varones y 252 mujeres; mientras que un 28,7\% (337 PcDID) de la muestra respondió el cuestionario de forma autoaplicada, un total de 184 varones y 153 mujeres. Por último, los familiares cumplimentaron el cuestionario en el 18,7\% (219 PcDID) de los casos, como ocurrió con 136 varones y 83 mujeres.

\begin{tabular}{ccccc}
\hline Cumplimentada por & Varones & Mujeres & N & $\%$ \\
\hline Profesional & 365 & 252 & 617 & $52,6 \%$ \\
Autoaplicada & 184 & 153 & 337 & $28,7 \%$ \\
Familiar & 136 & 83 & 219 & $18,7 \%$ \\
\hline Total & $\mathbf{6 8 5}$ & $\mathbf{4 8 8}$ & $\mathbf{1 1 7 3}$ & $\mathbf{1 0 0 \%}$ \\
\hline
\end{tabular}

Tabla 21: Síntesis de las características de la muestra por tipo de cumplimentación de la entrevista y género. 
Si dicotomizamos el tipo de cumplimentación (tabla 22), observamos que en el $71,3 \%$ de los casos fue un heteroinforme (836 PcDID), como es el caso de 501 varones y 335 mujeres; mientras que el 28,7\% (337 PcDID) fue autoinforme, como fue el caso de 184 varones y 153 mujeres.

\begin{tabular}{lcccc}
\hline Tipo de informe & Varones & Mujeres & N & \% \\
\hline Héteroinforme & 501 & 335 & 836 & $71,3 \%$ \\
Autoinforme & 184 & 153 & 337 & $28,7 \%$ \\
\hline \multicolumn{1}{c}{ Total } & $\mathbf{6 8 5}$ & $\mathbf{4 8 8}$ & $\mathbf{1 1 7 3}$ & $\mathbf{1 0 0 \%}$ \\
\hline
\end{tabular}

Tabla 22: Síntesis de las características de la muestra por tipo de informe dicotomizado de la entrevista y género.

Si nos centramos en el lugar de aplicación del cuestionario (tabla 23), podemos observar que en el 25,3\% de los casos (297; 176 varones y 121 mujeres), se realizó en residencia; el 15,3\% en centros de trabajo (180; 111 varones y 69 mujeres); un 12,1\% en centro de día (142; 85 varones y 57 mujeres); el 11,6\% en el domicilio particular (136; 68 varones y 68 mujeres); un 11,4\% en una asociación (134; 69 varones y 65 mujeres), y en menores porcentajes en un centro de terapia ocupacional (8\%), en el domicilio de otro familiar (2\%), en un centro social (1\%), etc.

\begin{tabular}{lcccc}
\hline \multicolumn{1}{c}{ Lugar de aplicación } & Varones & Mujeres & N & \% \\
\hline Residencia & 176 & 121 & 297 & $25,3 \%$ \\
Centro de trabajo & 111 & 69 & 180 & $15,3 \%$ \\
Centro de día & 85 & 57 & 142 & $12,1 \%$ \\
Domicilio particular & 68 & 68 & 136 & $11,6 \%$ \\
Asociación & 69 & 65 & 134 & $11,4 \%$ \\
Centro de terapia ocupacional & 71 & 23 & 94 & $8,0 \%$ \\
Domicilio de otro familiar & 12 & 12 & 24 & $2,0 \%$ \\
Centro social & 7 & 6 & 13 & $1,1 \%$ \\
CRMF/CRE & 1 & 0 & 1 & $0,1 \%$ \\
Otros & 85 & 67 & 152 & $13,0 \%$ \\
\hline \multicolumn{1}{c}{ Total } & $\mathbf{6 8 5}$ & $\mathbf{4 8 8}$ & $\mathbf{1 1 7 3}$ & $\mathbf{1 0 0 \%}$ \\
\hline
\end{tabular}

Tabla 23: Características de la muestra por lugar de aplicación y género. 
En cuanto al lugar de residencia de los participantes (tabla 24), 811 PcDID (449 varones y 362 mujeres), lo que supone un $69,1 \%$ de la muestra, residían en zonas superiores a los 10.000 habitantes, mientras que 362 PcDID (236 varones y 126 mujeres), que conforman el 30,9\% de la muestra, residían en zonas inferiores a los 10.000 habitantes.

\begin{tabular}{ccccc}
\hline Residencia & Varones & Mujeres & $\mathbf{N}$ & $\boldsymbol{\%}$ \\
\hline$>\mathbf{1 0 . 0 0 0}$ & 449 & 362 & 811 & $69,1 \%$ \\
\hline$<\mathbf{1 0 . 0 0 0}$ & 236 & 126 & 362 & $30,9 \%$ \\
\hline Total & $\mathbf{6 8 5}$ & $\mathbf{4 8 8}$ & $\mathbf{1 1 7 3}$ & $\mathbf{1 0 0 \%}$ \\
\hline
\end{tabular}

Tabla 24: Características de la muestra por residencia y género.

En la tabla 25 podemos observar los lugares de procedencia de las PcDID participantes en el estudio. 344 PcDID (29,3\%) procedían de Castilla León; 235 PcDID (20\%), de Euskadi; 175 PcDID (14,9\%) de Asturias; 122 PcDID (10,4\%) de Valencia. Y en menores proporciones las PcDID procedían de Andalucía $(0,9 \%)$, Extremadura (3,2\%), Madrid (2,4\%), Cantabria (2,1\%), Galicia (0,3\%), Aragón (0,3\%), Castilla la Mancha (0,9\%), Navarra (6,6\%), Murcia $(0,1 \%)$, Canarias $(3,1 \%)$ y Baleares $(2,4 \%)$. 


\begin{tabular}{lcc}
\hline \multicolumn{1}{c}{ Procedencia } & N & \% \\
\hline Asturias & 175 & $14,9 \%$ \\
Andalucía & 10 & $0,9 \%$ \\
Euskadi & 235 & $20,0 \%$ \\
Castilla León & 344 & $29,3 \%$ \\
Extremadura & 37 & $3,2 \%$ \\
Madrid & 28 & $2,4 \%$ \\
Cantabria & 25 & $2,1 \%$ \\
Galicia & 3 & $0,3 \%$ \\
Aragón & 3 & $0,3 \%$ \\
Valencia & 122 & $10,4 \%$ \\
Castilla La Mancha & 11 & $0,9 \%$ \\
Navarra & 77 & $6,6 \%$ \\
La Rioja & 38 & $3,2 \%$ \\
Murcia & 1 & $0,1 \%$ \\
Canarias & 36 & $3,1 \%$ \\
Baleares & 28 & $2,4 \%$ \\
\hline \multicolumn{1}{c}{ Total } & $\mathbf{1 1 7 3}$ & $\mathbf{1 0 0 \%}$ \\
\hline \multicolumn{1}{c}{} &
\end{tabular}

Tabla 25: Características de la muestra por Comunidad Autónoma de procedencia.

En cuanto al estado civil (tabla 26), el 98,3\% de las PcDID (1153) estaban solteras, como era el caso de 680 hombres y 473 mujeres; 10 PcDID (0,9\%) separados o divorciados, en el caso de 1 hombre y 9 mujeres; 6 PcDID (0,5\%) en pareja, 3 varones y 3 mujeres; 2 PcDID (0,2\%) estaban casados, como en el caso de un hombre y una mujer; y 2 PcDID $(0,2 \%)$ viudos, como era el caso de 2 mujeres.

\begin{tabular}{lcccc}
\hline \multicolumn{1}{c}{ Estado Civil } & Hombres & Mujeres & $\mathbf{N}$ & $\boldsymbol{\%}$ \\
\hline Soltero & 680 & 473 & 1153 & $98,3 \%$ \\
Separado/divorciado & 1 & 9 & 10 & $0,9 \%$ \\
En pareja & 3 & 3 & 6 & $0,5 \%$ \\
Casado & 1 & 1 & 2 & $0,2 \%$ \\
Viudo & 0 & 2 & 2 & $0,2 \%$ \\
\hline \multicolumn{1}{c}{ Total } & $\mathbf{6 8 5}$ & $\mathbf{4 8 8}$ & $\mathbf{1 1 7 3}$ & $\mathbf{1 0 0 \%}$ \\
\hline
\end{tabular}

Tabla 26: Características de la muestra por estado civil y género.

Si agrupamos el estado civil (tabla 27), podemos ver que la mayoría de las PcDID participantes, en concreto, 1153 (el 98,3\%) están solteras (680 hombres y 473 
mujeres); 2 personas están casadas (1 hombre y 1 mujer); 2 mujeres están viudas y 16 PcDID (1,4\%) tienen otros tipos de situaciones, como es el caso de 4 hombres y 12 mujeres.

\begin{tabular}{lcccc}
\hline \multicolumn{1}{c}{ Estado Civil } & Hombres & Mujeres & N & \% \\
\hline Soltero & 680 & 473 & 1153 & $98,3 \%$ \\
Casado & 1 & 1 & 2 & $0,2 \%$ \\
Viudo & 0 & 2 & 2 & $0,2 \%$ \\
Otras situaciones & 4 & 12 & 16 & $1,4 \%$ \\
\hline \multicolumn{1}{c}{ Total } & $\mathbf{6 8 5}$ & $\mathbf{4 8 8}$ & $\mathbf{1 1 7 3}$ & $\mathbf{1 0 0 \%}$ \\
\hline
\end{tabular}

Tabla 27: Características de la muestra por estado civil recodificado y género.

En cuanto al nivel cultural, como podemos ver en la tabla 28, 687 PcDID (424 hombres y 263 mujeres) eran analfabetos, 239 neolectores (129 hombres y 110 mujeres), 239 con un nivel primario (129 hombres y 110 mujeres) y por último, 8 PcDID tenían un nivel cultural medio (3 hombres y 5 mujeres).

\begin{tabular}{lcccc}
\hline \multicolumn{1}{c}{ Nivel Cultural } & Hombres & Mujeres & N & \% \\
\hline Analfabeto & 424 & 263 & 687 & $58,6 \%$ \\
Neolector & 129 & 110 & 239 & $20,4 \%$ \\
$\begin{array}{l}\text { Primario } \\
\text { Medio }\end{array}$ & 129 & 110 & 239 & $20,4 \%$ \\
\multicolumn{1}{c}{ Total } & 3 & 5 & 8 & $0,7 \%$ \\
\hline
\end{tabular}

Tabla 28: Características de la muestra por nivel cultural alcanzado y género.

En cuanto al nivel profesional de las PcDID participantes (tabla 29), la mayoría, en concreto 837 personas no habían trabajado nunca, como era el caso de 488 hombres y 349 mujeres. 262 personas tenían un bajo nivel profesional (163 hombres y 99 mujeres). 18 mujeres eran amas de casa, 4 hombres eran autónomos, artesanos o con profesiones similares, y dos personas (1 hombre y 1 mujer) tenían un nivel profesional eleva- 
do. En otras circunstancias no recogidas en el cuestionario se encontraban 33 personas (16 hombres y 17 mujeres).

\begin{tabular}{lcccc}
\hline \multicolumn{1}{c}{ Nivel profesional } & Hombres & Mujeres & N & \% \\
\hline No ha trabajado & 488 & 349 & 837 & $71,4 \%$ \\
Bajo & 163 & 99 & 262 & $22,3 \%$ \\
Ama de casa & 0 & 18 & 18 & $1,5 \%$ \\
Medio & 13 & 4 & 17 & $1,4 \%$ \\
Autónomo, artesano o similar & 4 & 0 & 4 & $0,3 \%$ \\
Alto & 1 & 1 & 2 & $0,2 \%$ \\
Otras & 16 & 17 & 33 & $2,8 \%$ \\
\hline \multicolumn{1}{c}{ Total } & $\mathbf{6 8 5}$ & $\mathbf{4 8 8}$ & $\mathbf{1 1 7 3}$ & $\mathbf{1 0 0 \%}$ \\
\hline
\end{tabular}

Tabla 29: Características de la muestra por el nivel o cualificación profesional y género.

En relación a la situación laboral de las personas de la muestra (tabla 30), la mayoría eran pensionistas (843), como era el caso de 503 hombres y 340 mujeres; 141 estaban en paro o desempleados (86 hombres y 55 mujeres); 131 estaban en activo (74 hombres y 57 mujeres); 19 mujeres eran amas de casa; 11 personas estaban jubiladas (8 hombres y 3 mujeres), y en otras circunstancias se encontraban 28 personas (14 hombres y 14 mujeres).

\begin{tabular}{lcccc}
\hline \multicolumn{1}{c}{ Situación Laboral } & Hombres & Mujeres & N & \% \\
\hline Pensionista & 503 & 340 & 843 & $71,9 \%$ \\
En paro y/o sin empleo & 86 & 55 & 141 & $12,0 \%$ \\
En activo & 74 & 57 & 131 & $11,2 \%$ \\
Ama de casa & 0 & 19 & 19 & $1,6 \%$ \\
Jubilado & 8 & 3 & 11 & $0,9 \%$ \\
Otras & 14 & 14 & 28 & $2,4 \%$ \\
\hline \multicolumn{1}{c}{$\quad$ Total } & $\mathbf{6 8 5}$ & $\mathbf{4 8 8}$ & $\mathbf{1 1 7 3}$ & $\mathbf{1 0 0 \%}$
\end{tabular}

Tabla 30: Características de la muestra por situación laboral actual y género.

En lo referente al nivel de ingresos (tabla 31), 827 personas recibían una pensión no contributiva (472 hombres y 355 mujeres); 172 recibían otro tipo de pensiones (103 
hombres y 69 mujeres); 98 tenían un salario laboral (61 hombres y 37 mujeres); 54 recibían una pensión contributiva (37 hombres y 17 mujeres); 12 personas no tenían ningún tipo de ingreso (7 hombres y 5 mujeres); 2 personas no tenían ingresos fijos (1 hombre y 1 mujer); 1 mujer recibía otro tipo de ingresos y 7 personas (4 hombres y 3 mujeres) se encontraban en otras situaciones.

\begin{tabular}{lcccc}
\hline \multicolumn{1}{c}{ Nivel de ingresos } & Hombres & Mujeres & N & \% \\
\hline Pensión no contributiva & 472 & 355 & 827 & $70,5 \%$ \\
Otras pensiones & 103 & 69 & 172 & $14,7 \%$ \\
Salario laboral & 61 & 37 & 98 & $8,4 \%$ \\
Pensión contributiva & 37 & 17 & 54 & $4,6 \%$ \\
Sin ingresos & 7 & 5 & 12 & $1,0 \%$ \\
Sin ingresos fijos & 1 & 1 & 2 & $0,2 \%$ \\
Otras situaciones & 4 & 3 & 7 & $0,6 \%$ \\
Otros ingresos & 0 & 1 & 1 & $0,1 \%$ \\
\hline \multicolumn{1}{c}{ Total } & $\mathbf{6 8 5}$ & $\mathbf{4 8 8}$ & $\mathbf{1 1 7 3}$ & $\mathbf{1 0 0 \%}$
\end{tabular}

Tabla 31: Características de la muestra por nivel de ingresos y género.

En cuanto a la presencia de los padres (tabla 32), 588 personas se encontraban en situación de orfandad de ambos progenitores (348 hombres y 240 mujeres); 309 personas tenían madre (186 hombres y 123 mujeres); 198 contaban con ambos progenitores (114 hombres y 84 mujeres), y 78 personas tenían padre (37 hombres y 41 mujeres).

\begin{tabular}{lcccc}
\hline \multicolumn{1}{c}{ Presencia de padres } & Hombres & Mujeres & N & \% \\
\hline No vive ninguno de los dos & 348 & 240 & 588 & $50,1 \%$ \\
Vive su madre & 186 & 123 & 309 & $26,3 \%$ \\
Viven los dos & 114 & 84 & 198 & $16,9 \%$ \\
Vive su padre & 37 & 41 & 78 & $6,6 \%$ \\
\hline \multicolumn{1}{c}{ Total } & $\mathbf{6 8 5}$ & $\mathbf{4 8 8}$ & $\mathbf{1 1 7 3}$ & $\mathbf{1 0 0 \%}$ \\
\hline
\end{tabular}

Tabla 32: Característica de la muestra por presencia de los padres y género.

Por lo que respecta al número de hermanos (tabla 33), 176 (104 hombres y 72 mujeres) no tenían hermanos; 284 (159 hombres y 125 mujeres) tenían uno; 255 perso- 
nas (170 hombres y 85 mujeres) tenían dos; 173 (100 hombres y 73 mujeres) tenían 3; 117 personas (69 hombres y 48 mujeres) tenían 4; 69 (34 hombres y 35 mujeres) tenían 5; 43 (21 hombres y 22 mujeres) tenían 6, y 56 personas (28 hombres y 28 mujeres) contaban con 7 o más hermanos.

\begin{tabular}{lcccc}
\hline No de hermanos & Hombres & Mujeres & $\mathbf{N}$ & $\boldsymbol{\%}$ \\
\hline No tiene & 104 & 72 & 176 & $15 \%$ \\
Vive 1 & 159 & 125 & 284 & $24,2 \%$ \\
Viven 2 & 170 & 85 & 255 & $21,7 \%$ \\
Viven 3 & 100 & 73 & 173 & $14,7 \%$ \\
Viven 4 & 69 & 48 & 117 & $10,0 \%$ \\
Viven 5 & 34 & 35 & 69 & $5,9 \%$ \\
Viven 6 & 21 & 22 & 43 & $3,7 \%$ \\
Viven 7 o más & 28 & 28 & 56 & $4,8 \%$ \\
\hline \multicolumn{1}{c}{ Total } & $\mathbf{6 8 5}$ & $\mathbf{4 8 8}$ & $\mathbf{1 1 7 3}$ & $\mathbf{1 0 0 \%}$ \\
\hline
\end{tabular}

Tabla 33: Características de la muestra por número de hermanos y género.

En cuanto al número de hijos (tabla 34), 1138 PcDID no tenían ninguno (678 hombres y 462 mujeres); 13 personas (4 hombres y 9 mujeres) tenían 1 hijo; 13 mujeres tenían 2 hijos; 6 personas (2 hombres y 4 mujeres) tenían 3, y sólo un hombre tenía 5 hijos.

\begin{tabular}{lcccc}
\hline $\mathbf{N}^{\mathbf{0}}$ de Hijos/as & Hombres & Mujeres & $\mathbf{N}$ & $\mathbf{\%}$ \\
\hline No tiene & 678 & 462 & 1138 & $97,2 \%$ \\
Tiene 1 & 4 & 9 & 13 & $1,1 \%$ \\
Tiene 2 & 0 & 13 & 13 & $1,1 \%$ \\
Tiene 3 & 2 & 4 & 6 & $0,5 \%$ \\
Tiene 5 & 1 & 0 & 1 & $0,1 \%$ \\
\hline \multicolumn{1}{c}{ Total } & $\mathbf{6 8 5}$ & $\mathbf{4 8 8}$ & $\mathbf{1 1 7 3}$ & $\mathbf{1 0 0 \%}$ \\
\hline
\end{tabular}

Tabla 34: Características de la muestra por la presencia de hijos/as y género.

En cuanto al tipo de discapacidad de la muestra de personas (tabla 35), todas ellas tenían discapacidades intelectuales y del desarrollo, pero 211 (128 hombres y 83 mujeres) tenían Síndrome de Down; 126 (75 hombres y 51 mujeres) tenían parálisis 
cerebral, mientras que 836 personas (482 hombres y 354 mujeres) tenían otros tipos de DID.

\begin{tabular}{|c|c|c|c|c|c|c|c|}
\hline & \multicolumn{7}{|c|}{ DI } \\
\hline & \multicolumn{2}{|c|}{ Down } & \multicolumn{2}{|c|}{ Otras } & \multicolumn{2}{|c|}{ PC } & \multirow{2}{*}{ Total } \\
\hline & $\mathbf{V}$ & $\mathbf{M}$ & $\mathbf{V}$ & M & $\mathbf{V}$ & $\mathbf{M}$ & \\
\hline \multirow{2}{*}{ Totales } & 128 & 83 & 482 & 354 & 75 & 51 & \multirow{2}{*}{1173} \\
\hline & \multicolumn{2}{|c|}{211} & \multicolumn{2}{|c|}{836} & \multicolumn{2}{|c|}{126} & \\
\hline
\end{tabular}

Nota: Todas las personas con PC presentan también DI.

Tabla 35: Características de la muestra por el tipo de discapacidad.

En lo referente a la etiología de la discapacidad (tabla 36), sólo en 6 casos (4 hombres y 2 mujeres) no era congénita o perinatal, siendo adquirida la discapacidad antes de los 5 años. En las 1167 personas restantes (681 hombres y 486 mujeres), la discapacidad era de tipo congénito.

\begin{tabular}{ccccc}
\hline \multicolumn{1}{c}{ Etiología } & Hombres & Mujeres & $\mathbf{N}$ & $\%$ \\
\hline $\begin{array}{l}\text { Congénita/perinatal } \\
\text { Enfermedad antes } \\
\text { de los 5 años }\end{array}$ & 681 & 486 & 1167 & $99,5 \%$ \\
\hline \multicolumn{1}{c}{ Total } & $\mathbf{6 8 5}$ & $\mathbf{4 8 8}$ & $\mathbf{1 1 7 3}$ & $\mathbf{1 0 0 \%}$ \\
\hline
\end{tabular}

Tabla 36: Características de la muestra por la etiología de la discapacidad.

Relacionado con lo anterior, 1169 personas (682 hombres y 487 mujeres) adquirieron la discapacidad a los 0 años, mientras que dos hombres la adquirieron a los 3 años y un hombre y una mujer a los 4 años, como se refleja en la tabla 37. 


\begin{tabular}{|c|c|c|c|c|}
\hline $\begin{array}{l}\text { Edad de adquisi- } \\
\text { ción }\end{array}$ & Hombres & Mujeres & $\mathbf{N}$ & $\%$ \\
\hline 0 años & 682 & 487 & 1169 & $99,7 \%$ \\
\hline 3 años & 2 & 0 & 2 & $0,2 \%$ \\
\hline 4 años & 1 & 1 & 2 & $0,2 \%$ \\
\hline Total & 685 & 488 & 1173 & $100 \%$ \\
\hline
\end{tabular}

Tabla 37: Características de la muestra por la edad de adquisición de la discapacidad.

En la tabla 38, podemos ver que la media de años con la discapacidad para las personas de la muestra con DID era de 52,15 (52,45 para los hombres y 51,74 para las mujeres); la mediana 51 (51 para los hombres y 50 para las mujeres); la moda de 45 para todos los casos; la desviación típica total era de 7,65 (7,81 para los hombres y 7,40 en mujeres). En el caso de los hombres, el mínimo de edad con la discapacidad era de 8 y el máximo de 80; mientras que para las mujeres el mínimo era de 35 y el máximo de 80.

\begin{tabular}{cccc}
\hline $\begin{array}{c}\text { Años con la } \\
\text { discapacidad }\end{array}$ & Hombres & Mujeres & Total \\
\hline Media & 52,45 & 51,74 & 52,15 \\
Mediana & 51,00 & 50,00 & 51,00 \\
Moda & 45 & 45 & 45 \\
DT & 7,81 & 7,40 & 7,65 \\
Mínimo & 8 & 35 & 8 \\
Máximo & 80 & 80 & 80 \\
\hline N & $\mathbf{6 8 5}$ & $\mathbf{4 8 8}$ & $\mathbf{1 1 7 3}$ \\
\hline
\end{tabular}

Tabla 38: Estadísticos descriptivos de los años con discapacidad en función del género de los participantes.

En lo referente al reconocimiento oficial de la discapacidad, 1172 PcDID tenían dicho reconocimiento (684 hombres y 488 mujeres), y tan sólo un hombre no tenía la discapacidad reconocida (tabla 39). 


\begin{tabular}{lccccc}
\hline $\begin{array}{c}\text { Reconocimiento } \\
\text { oficial }\end{array}$ & Hombres & Mujeres & N & \% \\
\hline SI & & 684 & 488 & 1172 & $99,9 \%$ \\
NO & 1 & 0 & 1 & $0,1 \%$ \\
\hline & Total & $\mathbf{6 8 5}$ & $\mathbf{4 8 8}$ & $\mathbf{1 1 7 3}$ & $\mathbf{1 0 0 \%}$ \\
\hline
\end{tabular}

Tabla 39: Características de la muestra en función del género y del reconocimiento oficial de la situación de discapacidad.

En lo que respecta a una segunda discapacidad (tabla 40), 442 personas tenían asociada una segunda discapacidad. Las personas con PC de la muestra tenían como segunda discapacidad la discapacidad intelectual, como era el caso de 75 hombres y 51 mujeres. Las personas con SD, tenían en mayor medida discapacidades visuales: 13 varones y 10 mujeres tenían otros tipos de discapacidad visual, 3 varones y 1 mujeres tenían ceguera parcial, 1 hombre tenía ceguera. 7 varones y 2 mujeres con SD tenían además Alzheimer. 13 personas con SD tenían discapacidades auditivas, 10 PcSD también tenían discapacidades físicas, y en menor medida, también había personas con SD que tenían como segunda discapacidad trastornos mentales, problemas de conducta o epilepsia. En el colectivo de personas con otros tipos de DID, 29 varones y 20 mujeres padecían epilepsia, 22 varones y 15 mujeres tenían discapacidades físicas sin afectación cerebral, 27 varones y 29 mujeres tenían también trastornos mentales, y en menor medida, aparecen otros tipos de segundas discapacidades como las auditivas o visuales. 


\begin{tabular}{|c|c|c|c|c|c|c|c|c|}
\hline \multirow{3}{*}{ Segunda discapacidad } & \multicolumn{8}{|c|}{ DI } \\
\hline & \multicolumn{2}{|c|}{ Down } & \multicolumn{2}{|c|}{ Otras } & \multicolumn{2}{|c|}{$\mathbf{P C}$} & \multirow{2}{*}{ Total } & \multirow{2}{*}{$\%$} \\
\hline & $\mathbf{V}$ & $\mathbf{M}$ & $\mathbf{V}$ & $\mathbf{M}$ & $\mathbf{V}$ & $\mathbf{M}$ & & \\
\hline DI Otras & & & & & 75 & 51 & 126 & $10,7 \%$ \\
\hline DF LM & & & 3 & & & & 3 & $0,3 \%$ \\
\hline DF Amputación & & & 1 & & & & 1 & $0,1 \%$ \\
\hline DF Secuelas Poliomielitis & & & 2 & 1 & & & 3 & $0,3 \%$ \\
\hline DF Otras sin afectación cerebral & 1 & & 22 & 15 & & & 38 & $3,2 \%$ \\
\hline DF Artrosis & 1 & 2 & & 5 & & & 8 & $0,7 \%$ \\
\hline DF Otras por enfermedad & 4 & 2 & 9 & 2 & & & 17 & $1,4 \%$ \\
\hline DF Otras con afectación cerebral & & & 1 & 2 & & & 3 & $0,3 \%$ \\
\hline DV Ceguera & 1 & & 2 & 3 & & & 6 & $0,5 \%$ \\
\hline DV Ceguera parcial & 3 & 1 & 8 & & & & 12 & $1,0 \%$ \\
\hline DV Diabetes & & & 1 & & & & 1 & $0,1 \%$ \\
\hline DV Retinosis Pigmentaria & & & & 2 & & & 2 & $0,2 \%$ \\
\hline DV Otras & 13 & 10 & 17 & 12 & & & 52 & $4,4 \%$ \\
\hline DA Sordera total & & & 3 & 2 & & & 5 & $0,4 \%$ \\
\hline DA Hipoacusia & 5 & 1 & 6 & 2 & & & 14 & $1,2 \%$ \\
\hline DA Otras & 4 & 3 & 8 & 4 & & & 19 & $1,6 \%$ \\
\hline TM Esquizofrenia & & & 12 & 4 & & & 16 & $1,4 \%$ \\
\hline TM Otras & & 2 & 15 & 25 & & & 42 & $3,6 \%$ \\
\hline Alzheimer & 7 & 2 & & & & & 9 & $0,8 \%$ \\
\hline Parkinson & & & 1 & & & & 1 & $0,1 \%$ \\
\hline Autismo & & 1 & 2 & & & & 3 & $0,3 \%$ \\
\hline Epilepsia & 1 & 1 & 29 & 20 & & & 51 & $4,3 \%$ \\
\hline Problemas de conducta & 1 & 1 & 4 & 4 & & & 10 & $0,9 \%$ \\
\hline Totales & 41 & 26 & 146 & 103 & 75 & 51 & 442 & $37,7 \%$ \\
\hline
\end{tabular}

Nota: 731 personas $(62,2 \%)$ no aducen una tercera discapacidad.

Tabla 40: Características de la muestra por la segunda discapacidad.

En lo que respecta a una tercera discapacidad (tabla 41), 111 personas de la muestra experimentaban esta situación, como era el caso de 11 hombres y 4 mujeres con SD, 33 hombres y 29 mujeres con otros tipos de DID, y 23 varones y 11 mujeres con PC. Entre las discapacidades con mayor número de aparición a nivel global, destacan la epilepsia, las discapacidades visuales y auditivas, y en menor medida las discapacidades físicas y los trastornos mentales. 


\begin{tabular}{|c|c|c|c|c|c|c|c|c|}
\hline \multirow{3}{*}{ Tercera discapacidad } & \multicolumn{8}{|c|}{ DI } \\
\hline & \multicolumn{2}{|c|}{ Down } & \multicolumn{2}{|c|}{ Otras } & \multicolumn{2}{|c|}{ PC } & \multirow{2}{*}{ Total } & \multirow{2}{*}{$\%$} \\
\hline & $\mathbf{V}$ & $\mathbf{M}$ & $\mathbf{V}$ & $\mathbf{M}$ & $\mathbf{V}$ & $\mathbf{M}$ & & \\
\hline DF Amputación & & & 2 & & & & 2 & $0,2 \%$ \\
\hline DF Otras sin afectación cerebral & 1 & & 4 & 1 & & & 6 & $0,5 \%$ \\
\hline DF Esclerosis múltiple & & & 1 & & & & 1 & $0,1 \%$ \\
\hline DF Artrosis & & & & 1 & & & 1 & $0,1 \%$ \\
\hline DF Otras por enfermedad & 2 & 1 & 3 & & 1 & & 7 & $0,6 \%$ \\
\hline DF ACV & & & & & 1 & & 1 & $0,1 \%$ \\
\hline DV Ceguera & & & & & 1 & & 1 & $0,1 \%$ \\
\hline DV Ceguera parcial & & & 1 & & 2 & 1 & 4 & $0,3 \%$ \\
\hline DV Otras & 3 & 1 & 2 & 7 & 1 & 2 & 16 & $1,4 \%$ \\
\hline DA Sordera total & & & & & 1 & & 1 & $0,1 \%$ \\
\hline DA Hipoacusia & 1 & 1 & 2 & 1 & 1 & & 6 & $0,5 \%$ \\
\hline DA Otras & 2 & & 3 & 3 & 5 & 1 & 14 & $1,2 \%$ \\
\hline TM Esquizofrenia & & & & & 1 & 1 & 2 & $0,2 \%$ \\
\hline TM Otras & & & 1 & & 1 & 1 & 3 & $0,3 \%$ \\
\hline Parkinson & & & 3 & & 1 & & 4 & $0,3 \%$ \\
\hline Autismo & & & & & 1 & & 1 & $0,1 \%$ \\
\hline Epilepsia & 2 & 1 & 9 & 8 & 4 & 5 & 29 & $2,5 \%$ \\
\hline Problemas de conducta & & & 2 & 8 & 2 & & 12 & $1,0 \%$ \\
\hline $\begin{array}{c}\text { Totales } \\
\end{array}$ & 11 & 4 & 33 & 29 & 23 & 11 & 111 & $9,5 \%$ \\
\hline
\end{tabular}

Nota: 1062 personas $(90,5 \%)$ no aducen una segunda discapacidad.

Tabla 41: Características de la muestra por la tercera discapacidad.

En lo referente al grado de discapacidad (tabla 42), la media de la muestra era de 74,06 (73,94 en hombres y 74,24 en mujeres), la mediana era de 75 en todos los casos, la moda de 65 en todos los casos y una desviación típica de 13,96 para la muestra general (14,76 en hombres y 12,77 en mujeres). El mínimo, tanto para los hombres como para las mujeres era de 33, y el máximo para ambos era de 100. 


\begin{tabular}{cccc}
\hline Grado & Hombres & Mujeres & Total \\
\hline Media & 73,94 & 74,24 & 74,06 \\
Mediana & 75,00 & 75,00 & 75,00 \\
Moda & 65 & 65 & 65 \\
DT & 14,76 & 12,77 & 13,96 \\
Mínimo & 33 & 33 & 33 \\
Máximo & 100 & 100 & 100 \\
\hline $\mathbf{N}$ & $\mathbf{5 6 9}$ & $\mathbf{4 0 5}$ & $\mathbf{9 7 4}$
\end{tabular}

Nota: 199 personas, el 17\% ( 116 varones y 83 mujeres) no saben o no contestan.

Tabla 42: Descripción de la muestra por el grado de discapacidad reconocido y género.

861 personas tenían un grado de discapacidad igual o superior al 65\%, como ocurría en el caso de 494 hombres y 367 mujeres, mientras que las 113 personas restantes tenían un grado inferior al 65\%, como era el caso de 75 hombres y 38 mujeres, como podemos observar en la tabla 43.

\begin{tabular}{rcccc}
\hline Grado & Varones & Mujeres & N & $\%$ \\
\hline $\mathbf{6 5 \%}$ & 75 & 38 & 113 & $9,6 \%$ \\
$\geq \mathbf{6 5 \%}$ & 494 & 367 & 861 & $73,4 \%$ \\
\hline Total & $\mathbf{5 6 9}$ & $\mathbf{4 0 5}$ & $\mathbf{9 7 4}$ & $\mathbf{8 3 \%}$ \\
\hline
\end{tabular}

Nota: 199 personas, el 17\% (116 varones y 83 mujeres), no saben o no contestan.

\section{Tabla 43: Descripción de la muestra por el grado de discapacidad reconocido dico-} tomizado y género.

Al recodificar el grado de discapacidad (tabla 44), podemos ver que la mayoría de las PcDID de la muestra, 571 PcDID, tenían un grado entre el 65 y el 80\% (317 hombres y 254 mujeres), mientras que 289 (177 hombres y 112 mujeres) tenían un grado igual o superior al 81\%, y 114 PcDID (75 hombres y 39 mujeres) tenían un grado inferior al $65 \%$. 


\begin{tabular}{lcccc}
\hline \multicolumn{1}{c}{ Grado } & Varones & Mujeres & N & \% \\
\hline$<\mathbf{6 5 \%}$ & 75 & 39 & 114 & $9,7 \%$ \\
$\mathbf{6 5 - 8 0 \%}$ & 317 & 254 & 571 & $48,7 \%$ \\
$\geq \mathbf{8 1 \%}$ & 177 & 112 & 289 & $24,6 \%$ \\
\hline \multicolumn{1}{c}{ Total } & $\mathbf{5 6 9}$ & $\mathbf{4 0 5}$ & $\mathbf{9 7 4}$ & $\mathbf{8 3 \%}$ \\
\hline
\end{tabular}

Nota: 199 personas, el 17\% (116 varones y 83 mujeres), no saben o no contestan.

Tabla 44: Descripción de la muestra por el grado de discapacidad reconocido agrupado por percentiles y género.

En el tipo de convivencia (tabla 45), 340 personas (186 hombres y 154 mujeres) residían en un servicio residencial público, 259 (148 hombres y 111 mujeres) vivían con sus padres, 193 (114 hombres y 79 mujeres) vivían con sus hermanos, y en menor medida, vivían en centros para $\mathrm{PcD}$, en instituciones tutelares, pisos asistidos o servicios residenciales privados, entre otras situaciones.

\begin{tabular}{lcccc}
\hline Tipo de convivencia & Varones & Mujeres & $\mathbf{N}$ & $\boldsymbol{\%}$ \\
\hline Sólo & 17 & 9 & 26 & $2,2 \%$ \\
Con su cónyuge o pareja & 2 & 2 & 4 & $0,3 \%$ \\
Con sus hijos & 0 & 1 & 1 & $0,1 \%$ \\
Con sus padres & 148 & 111 & 259 & $22,1 \%$ \\
Con sus padres y hermanos & 40 & 31 & 71 & $6,1 \%$ \\
Con sus hermanos & 114 & 79 & 193 & $16,5 \%$ \\
Con otros parientes & 12 & 6 & 18 & $1,5 \%$ \\
Con otras personas & 5 & 2 & 7 & $0,6 \%$ \\
Institución tutelar & 41 & 24 & 65 & $5,5 \%$ \\
Piso asistido & 36 & 23 & 59 & $5,0 \%$ \\
Servicio residencial público & 186 & 154 & 340 & $29,0 \%$ \\
Servicio residencial privado & 25 & 18 & 43 & $3,7 \%$ \\
Centro para PcD & 52 & 25 & 77 & $6,6 \%$ \\
En otra institución & 1 & 0 & 1 & $0,1 \%$ \\
En otra situación & 6 & 3 & 9 & $0,8 \%$ \\
\hline Total & $\mathbf{6 8 5}$ & $\mathbf{4 8 8}$ & $\mathbf{1 1 7 3}$ & $\mathbf{1 0 0 \%}$ \\
\hline
\end{tabular}

Tabla 45: Características de la muestra por tipo de convivencia y género.

Recodificando el tipo de convivencia (tabla 46), nos encontramos con que 540 PcDID (313 hombres y 227 mujeres) vivían con la familia de origen, 393 (216 hombres 
y 177 mujeres) en servicios residenciales, 209 (137 hombres y 72 mujeres) en otras fórmulas, 26 (17 hombres y 9 mujeres) vivían solos, y tan sólo 5 personas ( 2 hombres y 3 mujeres) residían con su familia propia.

\begin{tabular}{lcccc}
\hline \multicolumn{1}{c}{ Vive con } & Varones & Mujeres & $\mathbf{N}$ & $\%$ \\
\hline Sólo & 17 & 9 & 26 & $2,2 \%$ \\
Familia propia & 2 & 3 & 5 & $0,4 \%$ \\
Familia de origen & 313 & 227 & 540 & $46,0 \%$ \\
Otras fórmulas & 137 & 72 & 209 & $17,8 \%$ \\
En un servicio residencial & 216 & 177 & 393 & $33,5 \%$ \\
\hline Total & $\mathbf{6 8 5}$ & $\mathbf{4 8 8}$ & $\mathbf{1 1 7 3}$ & $\mathbf{1 0 0 \%}$ \\
\hline
\end{tabular}

Tabla 46: Características de la muestra por tipo de convivencia recodificado y género.

Si dicotomizamos el tipo de convivencia (tabla 47), vemos que 602 PcDID residían en residencias, como era el caso de 353 hombres y 249 mujeres, mientras que 571 lo hacían en el domicilio, como era la situación de 332 hombres y 239 mujeres.

\begin{tabular}{lcccc}
\hline Convivencia & Varones & Mujeres & $\mathbf{N}$ & $\boldsymbol{\%}$ \\
\hline Domicilio & 332 & 239 & 571 & $48,7 \%$ \\
Residencia & 353 & 249 & 602 & $51,3 \%$ \\
\hline \multicolumn{1}{c}{ Total } & $\mathbf{6 8 5}$ & $\mathbf{4 8 8}$ & $\mathbf{1 1 7 3}$ & $\mathbf{1 0 0 \%}$ \\
\hline
\end{tabular}

Tabla 47: Características de la muestra por la convivencia recodificada y dicotomizada en dos categorías y género.

En la tabla 48 se presentan relacionados el tipo de convivencia y el tipo de discapacidad de las personas de la muestra. Es de destacar, que sólo una persona con SD, en este caso mujer, vive sola, y que ninguna persona de este colectivo tiene familia propia. En las personas con PC, 5 personas (3 hombres y 2 mujeres) viven solas, y tan sólo una tiene familia propia, mientras que en el colectivo de personas con otros tipos de DID 14 hombres y 5 mujeres viven solos, mientras que 1 hombres y 3 mujeres tienen su propia familia. 


\begin{tabular}{|l|c|c|c|c|c|c|c|c|}
\hline \multirow{2}{*}{ Tipo de convivencia } & \multicolumn{7}{|c|}{ DI } \\
\cline { 2 - 10 } & \multicolumn{2}{|c|}{ Down } & \multicolumn{2}{|c|}{ Otras } & \multicolumn{2}{c|}{ PC } & \multirow{2}{*}{ Total } & \multirow{2}{*}{$\%$} \\
\cline { 2 - 10 } & $\mathbf{V}$ & $\mathbf{M}$ & $\mathbf{V}$ & $\mathbf{M}$ & $\mathbf{V}$ & $\mathbf{M}$ & & \\
\hline Sólo & & 2 & 14 & 5 & 3 & 2 & 26 & $2,2 \%$ \\
\hline Familia propia & & & 1 & 3 & 1 & & 5 & $0,4 \%$ \\
\hline Familia de origen & 72 & 50 & 204 & 154 & 37 & 23 & 540 & $46,0 \%$ \\
\hline Otras fórmulas & 40 & 14 & 85 & 53 & 12 & 5 & 209 & $17,8 \%$ \\
\hline En un servicio residencial & 16 & 17 & 178 & 139 & 22 & 21 & 393 & $33,5 \%$ \\
\hline \multirow{2}{*}{ Totales } & $\mathbf{1 2 8}$ & $\mathbf{8 3}$ & $\mathbf{4 8 2}$ & $\mathbf{3 5 4}$ & $\mathbf{7 5}$ & $\mathbf{5 1}$ & $\mathbf{1 1 7 3}$ & $\mathbf{1 0 0 \%}$ \\
\hline
\end{tabular}

Tabla 48: Características de la muestra por tipo de discapacidad y por tipo de convivencia recodificado.

\subsubsection{Resumen}

En resumen, la muestra de PcDID estaba compuesta por hombres y mujeres de entre 35 y 80 años, con una media de edad de 52 años aproximadamente, de los cuales la mayoría tenían otros tipos de DID. Más de la mitad viven en poblaciones de más de 10.000 habitantes, y pertecen a Comunidades Autonómas españolas diversas, mayoritariamente a Castilla León, Euskadi, Asturias y Valencia. El 98\% de ellas estaban solteras y tenían un nivel cultural muy bajo, ya que más de la mitad eran analfabetos. La mayoría nunca han trabajado y son pensionistas, recibiendo una pensión no contributiva; si bien es de señalar que 12 personas de la muestra no tienen ningún tipo de ingreso. En cuanto a las características familiares, alrededor de la mitad de la muestra no tiene padres pero sí algún hermano. Una gran cantidad de personas no tenían hijos. La mayor parte de las discapacidades de las PcDID de la muestra era congénita, y a excepción de una persona, tenían el grado de discapacidad reconocido; tal grado estaba habitualmente entre el 65 y el $80 \%$. En cuanto a segundas discapacidades, existe una gran heterogeneidad, pero las principales eran, sin distinguir entre los tipos de DID, discapacidades físicas sin afectación cerebral, discapacidades visuales, trastornos mentales y epilepsia. Casi la mitad de las personas de la muestra residían con su familia de origen, si bien 26 
personas vivían solas y 5 residían con su propia familia. Un gran porcentaje vivía en servicios residenciales.

\subsection{DESCRIPCIÓN DE LAS FRECUENCIAS DE LAS NECESIDADES PERCIBIDAS EN LA MUESTRA DE PCDID}

\subsubsection{Introducción}

En este apartado se exponen las NP's señaladas por las PcDID referidas a la salud personal, los recursos económicos, la existencia de barreras, los recursos sobre servicios sociales, los recursos sanitarios y otras necesidades, así como las soluciones que han propuesto, los apoyos institucionales que echan en falta, los pensamientos de futuro, los problemas señalados y otras consideraciones.

\subsubsection{Preocupaciones y necesidades percibidas en la muestra de personas con dis- capacidad intelectual y del desarrollo}

En la tabla 49 se exponen los estadísticos de las preocupaciones y necesidades que las PcDID señalaron en el cuestionario. El cuestionario hacía referencia a necesidades de salud personal, recursos económicos, recursos sanitarios, recursos de servicios sociales, existencia de barreras y otras preocupaciones y necesidades.

En cuanto a la media de las necesidades, la salud personal tiene una media de 1,71; seguida de la existencia de barreras, con 1,36, los recursos de servicios sociales, con 1,29; otras preocupaciones con 1,24; recursos sanitarios con 1,13 y finalmente, recursos económicos cuya media fue de 0,97 . La mediana fue 1 en todos los casos. La moda es 1 en las necesidades de salud personal, recursos económicos y otras preocupaciones, mientras que resultó ser 0 en recursos sanitarios, recursos de servicios sociales y existencia de barreras. Las desviaciones típicas fueron en salud personal 1,3978, en recursos económicos 0,963 , en recursos sanitarios 1,341 , en recursos de servicios sociales 
1,416, en existencia de barreras 1,4702 y en otras preocupaciones 1,348. La asimetría y curtosis fueron respectivamente 1,207 y 2,156 en salud personal; 1,786 y 5,304 en recursos económicos; 1,687 y 4,015 en recursos sanitarios; 1,792 y 4,759 en recursos de servicios sociales; 1,648 y 3,818 en existencia de barreras y 1,348 y 3,465 en otras preocupaciones. El mínimo en todas las preocupaciones fue de 0 , mientras que el máximo fue de 9 para los recursos sanitarios, los recursos de servicios sociales y la existencia de barreras; 8 para la salud personal; 7 para los recursos económicos y 20 para otras preocupaciones y necesidades.

\begin{tabular}{cccccccc}
\hline & $\begin{array}{c}\text { Salud } \\
\text { personal }\end{array}$ & $\begin{array}{c}\text { Recursos } \\
\text { económicos }\end{array}$ & $\begin{array}{c}\text { Recursos } \\
\text { sanitarios }\end{array}$ & $\begin{array}{c}\text { Recursos } \\
\text { servicios } \\
\text { sociales }\end{array}$ & $\begin{array}{c}\text { Existencia } \\
\text { barreras }\end{array}$ & Otras & Total \\
\hline $\mathrm{N}$ & 1173 & 1173 & 1173 & 1173 & 1173 & 1173 & 1173 \\
\hline Media & 1,71 & 0,97 & 1,13 & 1,29 & 1,36 & 1,24 & 7,63 \\
\hline Mediana & 1,00 & 1,00 & 1,00 & 1,00 & 1,00 & 1,00 & 7,00 \\
\hline Moda & 1 & 1 & 0 & 0 & 0 & 1 & 6 \\
\hline Desv. típ. & 1,397 & 0,963 & 1,341 & 1,416 & 1,470 & 1,348 & 6,052 \\
\hline Asimetría & 1,207 & 1,786 & 1,687 & 1,792 & 1,648 & 3,465 & 1,710 \\
\hline Curtosis & 2,156 & 5,304 & 4,015 & 4,759 & 3,818 & 33,977 & 5,320 \\
\hline Mínimo & 0 & 0 & 0 & 0 & 0 & 0 & 0 \\
\hline Máximo & 8 & 7 & 9 & 9 & 9 & 20 & 44 \\
\hline \hline
\end{tabular}

Tabla 49: Estadísticos de las preocupaciones y necesidades percibidas de la muestra de personas con discapacidad intelectual general.

En el gráfico 3 se puede observar la frecuencia de elección de las necesidades percibidas por parte de las PcDID de la muestra en general. Podemos observar que las PcDID han señalado en un total de 2007 ocasiones la salud personal como una necesidad importante, seguida de la preocupación por la existencia de barreras, en 1601 casos, las preocupaciones sobre los recursos de servicios sociales en 1511 ocasiones, otras preocupaciones y necesidades con 1452 elecciones, las preocupaciones sobre recursos sanitarios en 1322 ocasiones, y por último, las necesidades sobre recursos económicos en 1133 elecciones. 


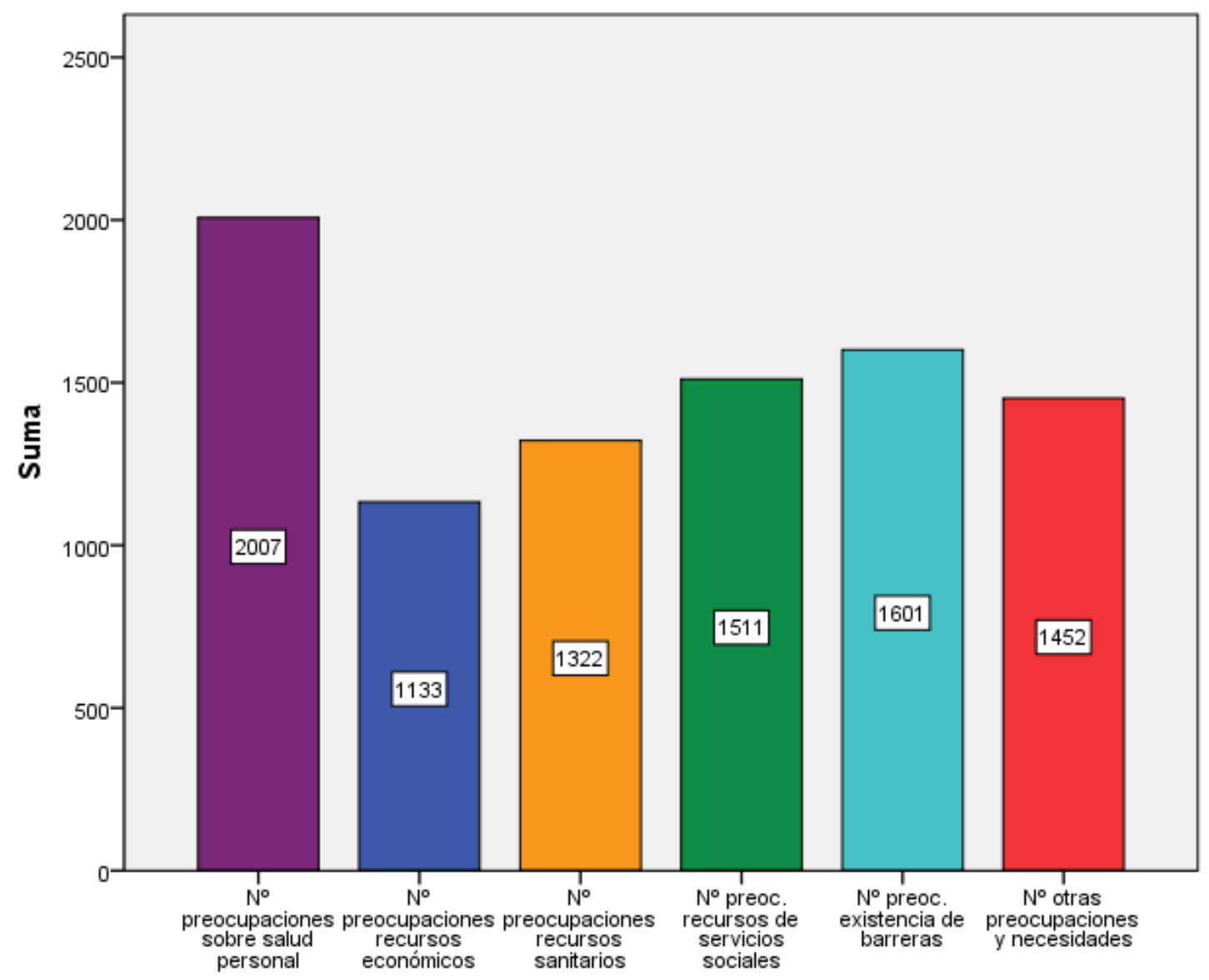

Gráfico 3: $\mathrm{N}^{\circ}$ Total de preocupaciones y necesidades percibidas de la muestra de PcDID general.

A continuación se presentan las distribuciones de las preocupaciones percibidas por los diferentes tipos de discapacidad intelectual de la muestra, es decir, de las personas con SD (tabla 50), con otros tipos de DID (tabla 51) y de las personas con PC (tabla $52)$. 


\begin{tabular}{lccccccc}
\hline & $\begin{array}{c}\text { Salud } \\
\text { personal }\end{array}$ & $\begin{array}{c}\text { Recursos } \\
\text { económicos }\end{array}$ & $\begin{array}{c}\text { Recursos } \\
\text { sanitarios }\end{array}$ & $\begin{array}{c}\text { Recursos } \\
\text { servicios } \\
\text { sociales }\end{array}$ & $\begin{array}{c}\text { Existencia } \\
\text { barreras }\end{array}$ & Otras & Total \\
\hline $\mathrm{N}$ & 211 & 211 & 211 & 211 & 211 & 211 & 211 \\
\hline Media & 1,66 & 0,88 & 0,80 & 1,07 & 1,11 & 1,05 & 6,56 \\
\hline Mediana & 1,00 & 1,00 & 1,00 & 1,00 & 1,00 & 1,00 & 6,00 \\
\hline Moda & 1 & 1 & 0 & 0 & 0 & 0 & 1 \\
\hline Desv. típ. & 1,365 & 0,805 & 0,955 & 1,085 & 1,127 & 1,160 & 4,715 \\
\hline Asimetría & 1,172 & 1,159 & 1,103 & 0,997 & 0,812 & 1,599 & 0,784 \\
\hline Curtosis & 1,563 & 2,083 & 0,566 & 0,791 & $-0,157$ & 3,854 & 0,545 \\
\hline Mínimo & 0 & 0 & 0 & 0 & 0 & 0 & 0 \\
\hline Máximo & 7 & 4 & 4 & 5 & 4 & 7 & 22 \\
\hline \hline
\end{tabular}

Tabla 50: Estadísticos de las preocupaciones y necesidades percibidas de la muestra de personas con síndrome de Down.

En las PcSD (tabla 50), es destacable la salud personal $(M=1,66)$, seguida de la existencia de barreras $(M=1,11)$, los recursos de servicios sociales $(M=1,07)$, otras preocupaciones $(\mathrm{M}=1,05)$, los recursos económicos $(\mathrm{M}=0,88)$ y por último los recursos sanitarios $(M=0,80)$. Las personas con otros tipos de DID (tabla 51) destacan la salud personal $(M=1,65)$, la existencia de barreras $(M=1,30)$, los recursos de servicios sociales $(M=1,29)$, otras preocupaciones $(M=1,22)$, los recursos sanitarios $(M=1,16)$ y los recursos económicos $(\mathrm{M}=0,98)$. Por último, las personas con PC (tabla 52) señalan la existencia de barreras $(M=2,20)$, la salud personal $(M=2,19)$, otras preocupaciones $(M=1,69)$, los recursos de servicios sociales $(M=1,64)$, los recursos sanitarios $(M=1,47)$ y los recursos económicos $(\mathrm{M}=1,04)$. Es de destacar, que mientras los grupos de personas con SD y otros tipos de DID señalan en mayor medida como preocupación importante la salud personal, las personas con PC ponen en primer lugar la existencia de barreras, lo que tiene sentido si consideramos que las personas con PC suelen tener, con frecuencia, mayores dificultades físicas. 


\begin{tabular}{lccccccc}
\hline & $\begin{array}{c}\text { Salud } \\
\text { personal }\end{array}$ & $\begin{array}{c}\text { Recursos } \\
\text { económicos }\end{array}$ & $\begin{array}{c}\text { Recursos } \\
\text { sanitarios }\end{array}$ & $\begin{array}{c}\text { Recursos } \\
\text { servicios } \\
\text { sociales }\end{array}$ & $\begin{array}{c}\text { Existencia } \\
\text { barreras }\end{array}$ & Otras & Total \\
\hline $\mathrm{N}$ & 836 & 836 & 836 & 836 & 836 & 836 & 836 \\
\hline Media & 1,65 & 0,98 & 1,16 & 1,29 & 1,30 & 1,22 & 7,53 \\
\hline Mediana & 1,00 & 1,00 & 1,00 & 1,00 & 1,00 & 1,00 & 7,00 \\
\hline Moda & 1 & 1 & 0 & 0 & 0 & 1 & 6 \\
\hline Desv. típ. & 1,338 & 0,979 & 1,355 & 1,451 & 1,414 & 1,204 & 5,973 \\
\hline Asimetría & 1,102 & 1,847 & 1,573 & 1,882 & 1,703 & 1,540 & 1,661 \\
\hline Curtosis & 1,830 & 5,608 & 3,377 & 5,046 & 4,364 & 4,058 & 0,085 \\
\hline Mínimo & 0 & 0 & 0 & 0 & 0 & 0 & 0 \\
\hline Máximo & 8 & 7 & 9 & 9 & 9 & 8 & 44 \\
\hline \hline
\end{tabular}

Tabla 51: Estadísticos de las preocupaciones y necesidades percibidas de la muestra de personas con otras DID.

\begin{tabular}{lccccccc}
\hline & $\begin{array}{c}\text { Salud } \\
\text { personal }\end{array}$ & $\begin{array}{c}\text { Recursos } \\
\text { económicos }\end{array}$ & $\begin{array}{c}\text { Recursos } \\
\text { sanitarios }\end{array}$ & $\begin{array}{c}\text { Recursos } \\
\text { servicios } \\
\text { sociales }\end{array}$ & $\begin{array}{c}\text { Existencia } \\
\text { barreras }\end{array}$ & Otras & Total \\
\hline $\mathrm{N}$ & 126 & 126 & 126 & 126 & 126 & 126 & 126 \\
\hline Media & 2,19 & 1,04 & 1,47 & 1,64 & 2,20 & 1,69 & 10,08 \\
\hline Mediana & 2,00 & 1,00 & 1,00 & 1,00 & 2,00 & 1,00 & 8,50 \\
\hline Moda & 2 & 1 & 0 & 0 & 1 & 1 & 11 \\
\hline Desv. típ. & 1,719 & 1,091 & 1,662 & 1,592 & 1,988 & 2,196 & 7,724 \\
\hline Asimetría & 1,302 & 1,723 & 1,761 & 1,414 & 1,123 & 5,044 & 0,216 \\
\hline Curtosis & 2,067 & 4,223 & 3,687 & 2,849 & 0,783 & 38,515 & 3,994 \\
\hline Mínimo & 0 & 0 & 0 & 0 & 0 & 0 & 0 \\
\hline Máximo & 8 & 6 & 8 & 8 & 8 & 20 & 42 \\
\hline \hline
\end{tabular}

Tabla 52: Estadísticos de las preocupaciones y necesidades percibidas de la muestra de personas con PC.

Cuando estudiamos la elección de las necesidades por parte de los tres colectivos de DID de la muestra, a saber, síndrome de Down, otros tipos de DID y parálisis cerebral, podemos observar que las personas con SD eligen en mayor medida la salud personal (351 elecciones), seguida de la existencia de barreras (234 elecciones), las preocupaciones sobre los recursos de servicios sociales (225 elecciones), otras necesidades (222), recursos económicos (186 elecciones) y recursos sanitarios (169 elecciones). 
Por otro lado, las personas con otros tipos de DID, eligen en 1380 ocasiones la salud personal, en 1090 la existencia de barreras, en 1079 las preocupaciones sobre los recursos de servicios sociales, en 1017 ocasiones otras necesidades, en 968 los recursos sanitarios y en 816 los recursos económicos.

Por su parte, las personas con PC, señalan en 277 ocasiones la existencia de barreras, junto a la salud personal, elegida en 276 ocasiones, seguidas de otras preocupaciones (213 elecciones), preocupación sobre los recursos de servicios sociales (207 elecciones), recursos sanitarios (185) y en último lugar los recursos económicos en 131 ocasiones.

En el gráfico 4, podemos observar las frecuencias de elección de las preocupaciones percibidas por cada uno de los tres tipos de PcDID, si bien debemos tener en cuenta el tamaño de cada una de las tres submuestras en este caso, y que las respuestas del cuestionario eran de tipo múltiple, pudiendo una sola persona marcar varias de las opciones dadas dentro de cada tipo de necesidad, sin existir un obligatorio número mínimo o máximo de casillas a marcar. 


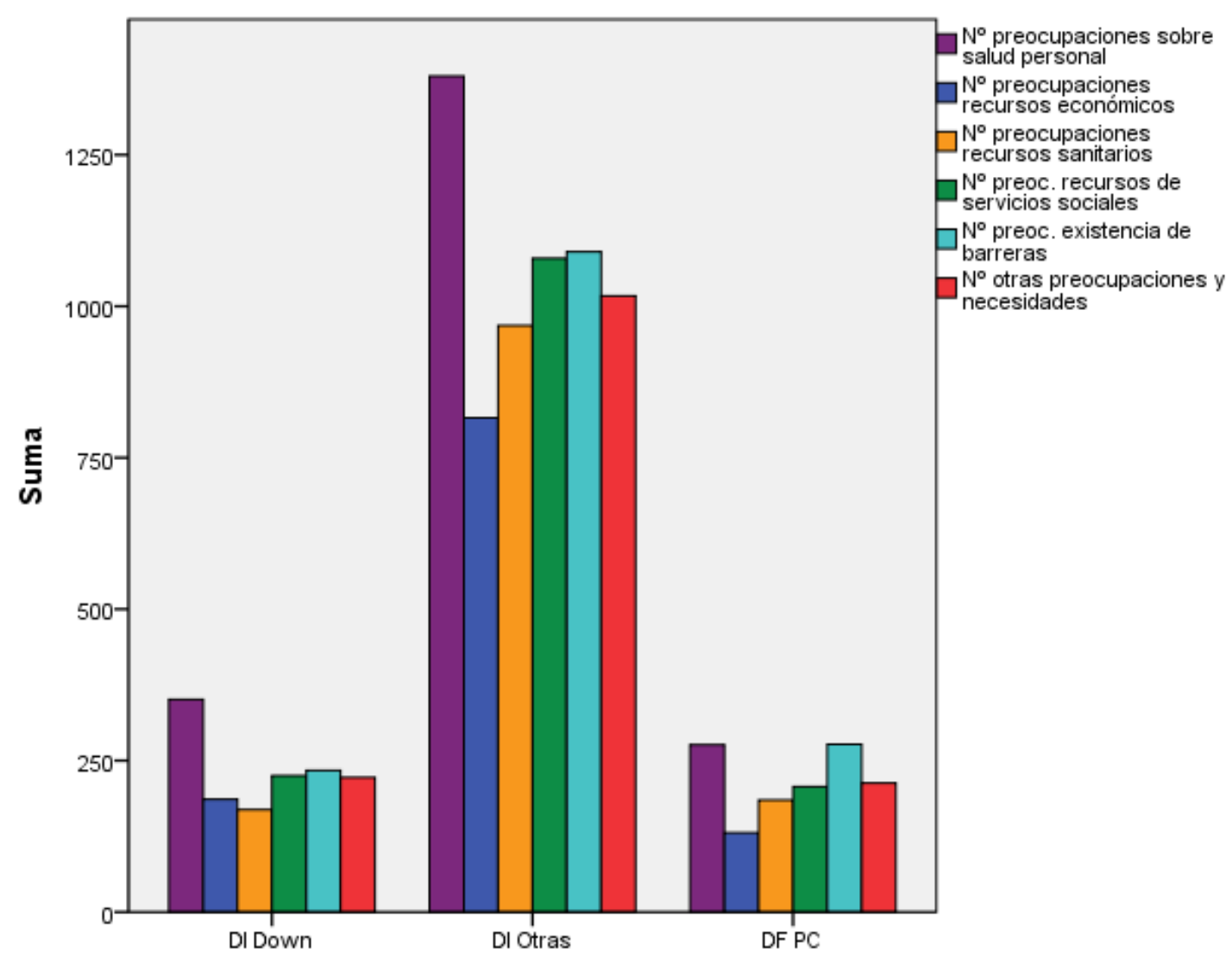

Gráfico 4: Comparación entre las necesidades específicas señaladas por las personas con SD, otros tipos de DID y SD.

\subsubsection{Necesidades de salud personal}

En cuanto a las necesidades de salud personal percibidas por la muestra de PcDID de la muestra (tabla 53), diríamos que en el 63\% de los casos se señaló el estado de salud general como una preocupación importante, seguida de los cuidados personales diarios (33,6\% de los casos), la dependencia (en el 30\% de los casos), las limitaciones funcionales personales $(27,9 \%$ de los casos) y los dolores (25,6\% de los casos). A estas preocupaciones les siguen en menor medida la aceptación de mi situación $(9,9 \%$ de los casos), las dificultades para tomar la medicación (8\%) o para acudir al tratamiento $(3,5 \%)$. En el 6,7\% de los casos, las PcDID señalaban como importantes otras necesidades no recogidas entre las anteriores. 


\begin{tabular}{lccc}
\hline \multicolumn{1}{c}{ Salud personal: } & N & \% resp & \% casos \\
\hline Estado de salud general & 605 & $30,3 \%$ & $63,0 \%$ \\
Cuidados personales diarios & 323 & $16,2 \%$ & $33,6 \%$ \\
Dependencia & 288 & $14,4 \%$ & $30,0 \%$ \\
Limitaciones funcionales personales & 268 & $13,4 \%$ & $27,9 \%$ \\
Dolores & 246 & $12,3 \%$ & $25,6 \%$ \\
Aceptación de mi situación & 95 & $4,8 \%$ & $9,9 \%$ \\
Dificultades para tomar la medicación & 77 & $3,9 \%$ & $8,0 \%$ \\
Dificultades para acudir al tratamiento & 34 & $1,7 \%$ & $3,5 \%$ \\
Otras & 64 & $3,2 \%$ & $6,7 \%$ \\
\hline \multicolumn{1}{c}{ Respuestas totales } & $\mathbf{2 0 0 0}$ & $\mathbf{1 0 0 \%}$ & $\mathbf{2 0 8 , 3 \%}$ \\
\hline
\end{tabular}

Nota: 213 casos perdidos; 960 casos válidos.

Tabla 53: Frecuencias y porcentajes (de respuestas y de casos) de preocupaciones sobre salud personal de las PcDID

\subsubsection{Necesidades sobre recursos económicos}

En la tabla 54 se observan las frecuencias y los porcentajes de respuestas y de casos sobre los recursos económicos. Las PcDID de la muestra señalaron en el $60,1 \%$ de los casos la pensión, en un 20,4\% la situación económica familiar, en un 20,1\% la independencia económica y en un 12,6\% las subvenciones, como principales preocupaciones.

En menor medida fueron señaladas el encontrar un puesto de trabajo $(10,8 \%)$, la incapacidad laboral $(8,5 \%)$ y otros tipos de necesidades sobre recursos económicos no recogidas en el cuestionario $(8,3 \%)$. 


\begin{tabular}{lccc}
\hline \multicolumn{1}{c}{ Recursos económicos: } & N & \% resp & \% casos \\
\hline Pensión & 483 & $42,7 \%$ & $60,1 \%$ \\
Situación económica familiar & 164 & $14,5 \%$ & $20,4 \%$ \\
Independencia económica & 162 & $14,3 \%$ & $20,1 \%$ \\
Subvenciones & 101 & $8,9 \%$ & $12,6 \%$ \\
Encontrar un puesto de trabajo & 87 & $7,7 \%$ & $10,8 \%$ \\
Incapacidad laboral & 68 & $6,0 \%$ & $8,5 \%$ \\
Otras & 67 & $5,9 \%$ & $8,3 \%$ \\
\hline \multicolumn{1}{c}{$\quad$ Respuestas totales } & $\mathbf{1 1 3 2}$ & $\mathbf{1 0 0 \%}$ & $\mathbf{1 4 0 , 8 \%}$ \\
\hline
\end{tabular}

Nota: 369 casos perdidos; 804 casos válidos.

Tabla 54: Frecuencias y porcentajes (de respuestas y de casos) de preocupaciones sobre recursos económicos de las PcDID.

\subsubsection{Necesidades sobre recursos sanitarios}

En lo referente a los recursos sanitarios (tabla 55), en el 32,7\% de los casos se señaló la calidad de la asistencia sanitaria, seguida de la asistencia sanitaria hospitalaria $(31,7 \%)$, la asistencia sanitaria domiciliaria $(26,2 \%)$, la asistencia en salud mental $(23,5 \%)$, más y mejores instalaciones sanitarias $(22,5 \%)$, los tratamientos de fisioterapia $(20,2 \%)$, seguidas de los dispositivos de apoyo y protésicos $(16,4 \%)$, la falta de información sobre este tipo de recursos $(12,8 \%)$ y otras necesidades $(7,0 \%)$. 


\begin{tabular}{lccc}
\hline \multicolumn{1}{c}{ Recursos sanitarios: } & N & \% resp \% casos \\
\hline Calidad de la asistencia sanitaria & 225 & $16,9 \%$ & $32,7 \%$ \\
Asistencia sanitaria hospitalaria & 218 & $16,4 \%$ & $31,7 \%$ \\
Asistencia sanitaria domiciliaria & 180 & $13,6 \%$ & $26,2 \%$ \\
Asistencia en salud mental & 162 & $12,2 \%$ & $23,5 \%$ \\
Más y mejores instalaciones sanitarias & 155 & $11,7 \%$ & $22,5 \%$ \\
Tratamiento de fisioterapia & 139 & $10,5 \%$ & $20,2 \%$ \\
Dispositivos de apoyo y protésicos & 113 & $8,5 \%$ & $16,4 \%$ \\
Falta de información sobre estos recursos & 88 & $6,6 \%$ & $12,8 \%$ \\
Otras & 48 & $3,6 \%$ & $7,0 \%$ \\
\hline \multicolumn{1}{c}{ Respuestas totales } & $\mathbf{1 3 2 8}$ & $\mathbf{1 0 0 \%}$ & $\mathbf{1 9 3 \%}$ \\
\hline
\end{tabular}

Nota: 485 casos perdidos; 688 casos válidos.

Tabla 55: Frecuencias y porcentajes (de respuestas y de casos) de preocupaciones sobre recursos sanitarios de las PcDID.

\subsubsection{Necesidades sobre recursos de servicios sociales}

En cuanto a los recursos de servicios sociales (tabla 56), las PcDID que completaron el cuestionario dan especial relevancia a los servicios de apoyo al ocio y tiempo libre, elegido en el 52,7\% de los casos. Con menor intensidad destacan la ayuda a domicilio (26\%), más y mejores instalaciones sociales $(23,5 \%)$, los servicios de alojamiento (23\%), la calidad de la asistencia social (20,8\%), el apoyo en las gestiones administrativas $(19,9 \%)$, la falta de información sobre estos recursos (15\%), el asesoramiento jurídico $(9,2 \%)$ y otras necesidades relacionadas con los servicios sociales $(4,4 \%)$. 


\begin{tabular}{|c|c|c|}
\hline Recursos servicios sociales: & $\mathbf{N}$ & $\%$ resp \% casos \\
\hline Servicios de apoyo al ocio y tiempo libre & 407 & $27,1 \%$ \\
\hline Ayuda a domicilio & 201 & $13,4 \%$ \\
\hline Más y mejores instalaciones sociales & 182 & $12,1 \%$ \\
\hline Servicios de alojamiento & 178 & $11,8 \%$ \\
\hline Calidad de la asistencia social & 161 & $10,7 \%$ \\
\hline Apoyo en las gestiones administrativas & 154 & $10,2 \%$ \\
\hline Falta de información sobre estos recursos & 116 & $15,0 \%$ \\
\hline Asesoramiento jurídico & 71 & $9,2 \%$ \\
\hline Otras & 34 & $2,3 \%$ \\
\hline Respuestas totales & 1504 & $100 \% 194,6 \%$ \\
\hline
\end{tabular}

Nota: 400 casos perdidos; 773 casos válidos.

Tabla 56: Frecuencias y porcentajes (de respuestas y de casos) de preocupaciones sobre recursos de servicios sociales de las PcDID.

\subsubsection{Necesidades sobre la existencia de barreras}

La existencia de barreras ha sido una de las necesidades más señaladas junto a la salud personal por la muestra de PcDID participantes. Si analizamos las principales elecciones (tabla 57), podemos ver que las barreras sociales fueron elegidas en el $42,7 \%$ de los casos, seguidas de la aceptación por parte de la sociedad (36,8\% de los casos), lo que viene a decir, que las PcDID se encuentran más fácilmente con barreras de tipo social, que arquitectónico. Las barreras arquitectónicas ocupan el tercer lugar con el $30,7 \%$ de las elecciones, seguidas de la facilidad de transporte $(28,6 \%)$, la escasez de voluntariado (19,9\%), la aceptación por parte de la familia $(19,1 \%)$, las ayudas técnicas (12,3\%), la accesibilidad a edificios públicos $(11,3 \%)$ y otras preocupaciones $(3,3 \%$ de los casos). 


\begin{tabular}{llll}
\hline \multicolumn{1}{c}{ Existencia de barreras: } & N & \% resp & \% casos \\
\hline Barreras sociales & 334 & $20,9 \%$ & $42,7 \%$ \\
Aceptación por parte de la sociedad & 288 & $18,0 \%$ & $36,8 \%$ \\
Barreras arquitectónicas & 240 & $15,0 \%$ & $30,7 \%$ \\
Facilidad de transporte & 224 & $14,0 \%$ & $28,6 \%$ \\
Escasez de voluntariado & 156 & $9,7 \%$ & $19,9 \%$ \\
Aceptación por parte de la familia & 149 & $9,3 \%$ & $19,1 \%$ \\
Ayudas técnicas & 96 & $6,0 \%$ & $12,3 \%$ \\
Accesibilidad a edificios públicos & 88 & $5,5 \%$ & $11,3 \%$ \\
Otras & 26 & $1,6 \%$ & $3,3 \%$ \\
\hline \multicolumn{1}{c}{$\quad$ Respuestas totales } & $\mathbf{1 6 0 1}$ & $\mathbf{1 0 0 \%}$ & $\mathbf{2 0 4 , 7 \%}$ \\
\hline \multicolumn{4}{c}{}
\end{tabular}

Nota: 391 casos perdidos; 782 casos válidos.

Tabla 57: Frecuencias y porcentajes (de respuestas y de casos) de preocupaciones sobre existencia de barreras de las PcDID.

\subsubsection{Otras necesidades y preocupaciones}

En cuanto a otros tipos de necesidades (tabla 58), preocupan especialmente el dónde y con quién vivir en el futuro (47,4\% de casos), seguida de la escasez de relaciones personales $(33,8 \%)$, el futuro de la familia $(32,5 \%)$, la salida del domicilio familiar $(23,8 \%)$, los problemas sociales $(11,2 \%)$, la protección jurídica $(8,1 \%)$, los avances tecnológicos $(6 \%)$, los problemas del movimiento asociativo $(5,1 \%)$ y otras preocupaciones no recogidas en el cuestionario $(10,6 \%)$. 


\begin{tabular}{lccc}
\hline \multicolumn{1}{c}{ Otras: } & N & \% resp \% casos \\
\hline Dónde y con quién vivir en el futuro & 381 & $26,6 \%$ & $47,4 \%$ \\
Escasez de relaciones personales & 272 & $19,0 \%$ & $33,8 \%$ \\
Futuro de la familia & 261 & $18,2 \%$ & $32,5 \%$ \\
Salida del domicilio familiar & 191 & $13,3 \%$ & $23,8 \%$ \\
Problemas sociales & 90 & $6,3 \%$ & $11,2 \%$ \\
Protección jurídica & 65 & $4,5 \%$ & $8,1 \%$ \\
Avances tecnológicos & 48 & $3,3 \%$ & $6,0 \%$ \\
Problemas del movimiento asociativo & 41 & $2,9 \%$ & $5,1 \%$ \\
Otras & 85 & $5,9 \%$ & $10,6 \%$ \\
\hline \multicolumn{1}{c}{$\quad$ Respuestas totales } & $\mathbf{1 4 3 4}$ & $\mathbf{1 0 0 \%}$ & $\mathbf{1 7 8 , 4 \%}$ \\
\hline
\end{tabular}

Nota: 369 casos perdidos; 804 casos válidos.

Tabla 58: Frecuencias y porcentajes (de respuestas y de casos) de preocupaciones sobre otras preocupaciones y necesidades de las PcDID.

\subsubsection{Soluciones propuestas por la muestra de personas con discapacidad intelec- tual y del desarrollo}

Entre las soluciones propuestas por las PcDID que envejecen de la muestra (tabla 59) destacan principalmente dos, a saber, la subida de las pensiones (elegida en el $48,1 \%$ de los casos) y la creación o mejora de los servicios de apoyo al ocio y tiempo libre (elegidas en el 41,8\% de los casos). A estas dos soluciones principales les siguen la ayuda para los cuidados personales diarios (33,9\% de los casos), el incremento de la ayuda familiar $(27,3 \%)$, las garantías de futuro $(22,4 \%)$, las facilidades de transporte $(22,2 \%)$, la especialización de los profesionales $(21,9 \%)$ de los casos, el incremento y la mejora de instalaciones sanitarias $(21,6 \%)$, la supresión de barreras arquitectónicas $(21,2 \%)$, la mejora de los servicios de alojamiento (20,8\%), el incremento de las subvenciones $(20,2 \%)$ y la mejora de la asistencia a domicilio (20\%), entre otras. 


\begin{tabular}{|c|c|c|c|}
\hline Soluciones: & $\mathbf{N}$ & $\begin{array}{c}\% \\
\text { resp }\end{array}$ & $\%$ casos \\
\hline Subida de las pensiones & 433 & $7,5 \%$ & $48,1 \%$ \\
\hline Servicios de apoyo al ocio y tiempo libre & 377 & $6,5 \%$ & $41,8 \%$ \\
\hline Ayuda para cuidados personales diarios & 305 & $5,3 \%$ & $33,9 \%$ \\
\hline Incremento de la ayuda familiar & 246 & $4,3 \%$ & $27,3 \%$ \\
\hline Garantías de futuro & 202 & $3,5 \%$ & $22,4 \%$ \\
\hline Facilidades de transporte & 200 & $3,5 \%$ & $22,2 \%$ \\
\hline Profesionales más especializados & 197 & $3,4 \%$ & $21,9 \%$ \\
\hline Más y mejores instalaciones sanitarias & 195 & $3,4 \%$ & $21,6 \%$ \\
\hline Supresión de barreras arquitectónicas & 191 & $3,3 \%$ & $21,2 \%$ \\
\hline Mejora de los servicios de alojamiento & 187 & $3,2 \%$ & $20,8 \%$ \\
\hline Incremento de las subvenciones & 182 & $3,2 \%$ & $20,2 \%$ \\
\hline Mejora de la asistencia a domicilio & 180 & $3,1 \%$ & $20,0 \%$ \\
\hline Centros de día & 178 & $3,1 \%$ & $19,8 \%$ \\
\hline Calidad de la asistencia sanitaria & 175 & $3,0 \%$ & $19,4 \%$ \\
\hline Aceptación por parte de la sociedad & 170 & $3,0 \%$ & $18,9 \%$ \\
\hline Asistencia psicológica & 166 & $2,9 \%$ & $18,4 \%$ \\
\hline Más y mejores instalaciones sociales & 157 & $2,7 \%$ & $17,4 \%$ \\
\hline Apoyo a los cuidadores informales & 149 & $2,6 \%$ & $16,5 \%$ \\
\hline Promoción del empleo protegido & 148 & $2,6 \%$ & $16,4 \%$ \\
\hline Promoción del voluntariado & 142 & $2,5 \%$ & $15,8 \%$ \\
\hline Calidad de la asistencia social & 136 & $2,4 \%$ & $15,1 \%$ \\
\hline Promoción de viviendas adaptadas & 136 & $2,4 \%$ & $15,1 \%$ \\
\hline Fisioterapia en la Seguridad Social & 135 & $2,3 \%$ & $15,0 \%$ \\
\hline Reserva de puestos de trabajo & 132 & $2,3 \%$ & $14,7 \%$ \\
\hline Programas de cambio de actitudes & 125 & $2,2 \%$ & $13,9 \%$ \\
\hline Más y mejor información & 112 & $1,9 \%$ & $12,4 \%$ \\
\hline Apoyo legal y administrativo & 111 & $1,9 \%$ & $12,3 \%$ \\
\hline Aceptación por parte de la familia & 111 & $1,9 \%$ & $12,3 \%$ \\
\hline Más información sobre recursos & 100 & $1,7 \%$ & $11,1 \%$ \\
\hline Adelantar la jubilación & 98 & $1,7 \%$ & $10,9 \%$ \\
\hline Mejora de apoyos y prótesis & 95 & $1,6 \%$ & $10,5 \%$ \\
\hline Más y mejores ayudas técnicas & 95 & $1,6 \%$ & $10,5 \%$ \\
\hline Incremento de la participación asociativa & 81 & $1,4 \%$ & $9,0 \%$ \\
\hline Campañas de imagen & 63 & $1,1 \%$ & $7,0 \%$ \\
\hline Otras & 52 & $0,9 \%$ & $5,8 \%$ \\
\hline Respuestas totales & \multicolumn{3}{|c|}{$5762100 \% 639,5 \%$} \\
\hline
\end{tabular}

Tabla 59: Frecuencias y porcentajes (de respuestas y de casos) de las soluciones propuestas por las PcDID.

Si observamos a qué bloque de necesidades corresponde cada solución (tabla 60), podemos decir que las dos grandes soluciones propuestas pertenecen a las áreas de 
recursos económicos y de recursos de servicios sociales, siendo éstas respectivamente la subida de las pensiones y la creación o mejora de los servicios de apoyo al ocio y tiempo libre. Dentro del área de salud personal destaca la ayuda para los cuidados personales diarios; dentro de los recursos asistenciales sanitarios destacan la especialización profesional y la mejora e incremento de las instalaciones sanitarias; en la existencia de barreras destacan la supresión de barreras arquitectónicas y la aceptación por parte de la sociedad, seguidas de la promoción de viviendas adaptadas, y en cuanto a las soluciones comunes, destacan las garantías de futuro y la asistencia psicológica. 


\begin{tabular}{|c|c|c|c|}
\hline Soluciones: & $\mathbf{N}$ & $\begin{array}{c}\% \\
\text { resp }\end{array}$ & $\%$ casos \\
\hline \multicolumn{4}{|l|}{ Salud personal } \\
\hline Ayuda para cuidados personales diarios & 305 & $5,3 \%$ & $33,9 \%$ \\
\hline $\begin{array}{c}\text { Apoyo a los cuidadores informales } \\
\text { Recursos económicos }\end{array}$ & 149 & $2,6 \%$ & $16,5 \%$ \\
\hline Subida de las pensiones & 433 & $7,5 \%$ & $48,1 \%$ \\
\hline Incremento de la ayuda familiar & 246 & $4,3 \%$ & $27,3 \%$ \\
\hline Incremento de las subvenciones & 182 & $3,2 \%$ & $20,2 \%$ \\
\hline Promoción del empleo protegido & 148 & $2,6 \%$ & $16,4 \%$ \\
\hline Reserva de puestos de trabajo & 132 & $2,3 \%$ & $14,7 \%$ \\
\hline \multicolumn{4}{|l|}{ Recursos asistenciales sanitarios } \\
\hline Profesionales más especializados & 197 & $3,4 \%$ & $21,9 \%$ \\
\hline Más y mejores instalaciones sanitarias & 195 & $3,4 \%$ & $21,6 \%$ \\
\hline Calidad de la asistencia sanitaria & 175 & $3,0 \%$ & $19,4 \%$ \\
\hline Fisioterapia en la Seguridad Social & 135 & $2,3 \%$ & $15,0 \%$ \\
\hline Mejora de apoyos y prótesis & 95 & $1,6 \%$ & $10,5 \%$ \\
\hline \multicolumn{4}{|l|}{ Recursos servicios sociales } \\
\hline Servicios de apoyo al ocio y tiempo libre & 377 & $6,5 \%$ & $41,8 \%$ \\
\hline Facilidades de transporte & 200 & $3,5 \%$ & $22,2 \%$ \\
\hline Mejora de los servicios de alojamiento & 187 & $3,2 \%$ & $20,8 \%$ \\
\hline Mejora de la asistencia a domicilio & 180 & $3,1 \%$ & $20,0 \%$ \\
\hline Centros de día & 178 & $3,1 \%$ & $19,8 \%$ \\
\hline Más y mejores instalaciones sociales & 157 & $2,7 \%$ & $17,4 \%$ \\
\hline Promoción del voluntariado & 142 & $2,5 \%$ & $15,8 \%$ \\
\hline Calidad de la asistencia social & 136 & $2,4 \%$ & $15,1 \%$ \\
\hline $\begin{array}{l}\text { Incremento de la participación asociativa } \\
\text { Existencia de barreras }\end{array}$ & 81 & $1,4 \%$ & $9,0 \%$ \\
\hline Supresión de barreras arquitectónicas & 191 & $3,3 \%$ & $21,2 \%$ \\
\hline Aceptación por parte de la sociedad & 170 & $3,0 \%$ & $18,9 \%$ \\
\hline Promoción de viviendas adaptadas & 136 & $2,4 \%$ & $15,1 \%$ \\
\hline Programas de cambio de actitudes & 125 & $2,2 \%$ & $13,9 \%$ \\
\hline Aceptación por parte de la familia & 111 & $1,9 \%$ & $12,3 \%$ \\
\hline Más y mejores ayudas técnicas & 95 & $1,6 \%$ & $10,5 \%$ \\
\hline Campañas de imagen & 63 & $1,1 \%$ & $7,0 \%$ \\
\hline \multicolumn{4}{|l|}{ Soluciones comunes } \\
\hline Garantías de futuro & 202 & $3,5 \%$ & $22,4 \%$ \\
\hline Asistencia psicológica & 166 & $2,9 \%$ & $18,4 \%$ \\
\hline Más y mejor información & 112 & $1,9 \%$ & $12,4 \%$ \\
\hline Apoyo legal y administrativo & 111 & $1,9 \%$ & $12,3 \%$ \\
\hline Más información sobre recursos & 100 & $1,7 \%$ & $11,1 \%$ \\
\hline Otras & 52 & $0,9 \%$ & $5,8 \%$ \\
\hline Respuestas totales & 5762 & $100 \%$ & $639,5 \%$ \\
\hline
\end{tabular}

Nota: 272 casos perdidos; 901 casos válidos.

Tabla 60: Frecuencias y porcentajes (de respuestas y de casos) de las soluciones propuestas por las PcDID en función de la temática. 
8.3.4. Medidas y apoyos institucionales requeridos por la muestra de personas con discapacidad intelectual y del desarrollo

En lo referente a las medidas y los apoyos institucionales requeridos (tabla 61), las PcDID señalan en el 42,1\% de los casos el incremento de los recursos de las asociaciones, seguido del apoyo de los Ayuntamientos (36\% de los casos), las actividades culturales $(32,1 \%)$, apoyos en el entorno $(31,1 \%)$, la coordinación entre las distintas administraciones $(29,1 \%)$, la igualdad de oportunidades $(27,3 \%)$, el apoyo de la comunidad (25,9\%), las actividades de formación $(20,4 \%)$ y otros apoyos $(3,4 \%)$.

\begin{tabular}{lccc}
\hline \multicolumn{1}{c}{ Apoyos requeridos: } & N & \% resp & \% casos \\
\hline Incrementar los recursos de las asociaciones & 306 & $17,0 \%$ & $42,1 \%$ \\
Apoyo de los Ayuntamientos & 261 & $14,5 \%$ & $36,0 \%$ \\
Actividades culturales & 233 & $13,0 \%$ & $32,1 \%$ \\
Apoyos en el entorno & 226 & $12,6 \%$ & $31,1 \%$ \\
Coordinación entre las distintas administraciones & 211 & $11,7 \%$ & $29,1 \%$ \\
Igualdad de oportunidades & 198 & $11,0 \%$ & $27,3 \%$ \\
Apoyo de la comunidad & 188 & $10,5 \%$ & $25,9 \%$ \\
Actividades de formación & 148 & $8,2 \%$ & $20,4 \%$ \\
Otros & 25 & $1,4 \%$ & $3,4 \%$ \\
\hline \multicolumn{1}{c}{ Respuestas totales } & $\mathbf{1 7 9 6}$ & $\mathbf{1 0 0 \%}$ & $\mathbf{2 4 7 , 4 \%}$ \\
\hline
\end{tabular}

Nota: 447 casos perdidos; 726 casos válidos.

Tabla 61: Frecuencias y porcentajes (de respuestas y de casos) de apoyos requeridos por las PcDID.

\subsubsection{Pensamientos sobre el futuro de las personas con discapacidad intelectual y del desarrollo}

En cuanto a los pensamientos de futuro de las PcDID que envejecen de la muestra (tabla 62), son destacables el no pensar en el futuro, elegido en el $28,4 \%$ de los casos; el vivir con calidad de vida, elegida en el $25,6 \%$ de los casos y seguir viviendo, elegida en el 22,9\% de los casos. A estas tres elecciones les siguen en frecuencia bien, 
sin problemas $(19,4 \%$ de los casos), vivir al día (17,5\%), con preocupación, futuro incierto $(15,2 \%)$ y la autonomía personal $(10,1 \%)$ entre otras.

\begin{tabular}{lccc}
\hline \multicolumn{1}{c}{ Pensamientos de futuro: } & N & $\begin{array}{c}\text { \% } \\
\text { resp }\end{array}$ & $\begin{array}{c}\text { \% } \\
\text { casos }\end{array}$ \\
\hline Nada, no pienso en el futuro & 301 & $14,6 \%$ & $28,4 \%$ \\
Vivir con calidad de vida & 271 & $13,1 \%$ & $25,6 \%$ \\
Seguir viviendo & 242 & $11,7 \%$ & $22,9 \%$ \\
Bien, sin problemas & 205 & $9,9 \%$ & $19,4 \%$ \\
Vivir al día & 185 & $9,0 \%$ & $17,5 \%$ \\
Con preocupación, futuro incierto & 161 & $7,8 \%$ & $15,2 \%$ \\
Autonomía personal & 107 & $5,2 \%$ & $10,1 \%$ \\
Soledad & 82 & $4,0 \%$ & $7,8 \%$ \\
Vida independiente & 76 & $3,7 \%$ & $7,2 \%$ \\
Resuelto & 74 & $3,6 \%$ & $7,0 \%$ \\
Triste & 73 & $3,5 \%$ & $6,9 \%$ \\
Aburrimiento & 61 & $3,0 \%$ & $5,8 \%$ \\
Dependerá del asociacionismo & 52 & $2,5 \%$ & $4,9 \%$ \\
Mal, negro & 43 & $2,1 \%$ & $4,1 \%$ \\
Pocas ganas de vivir & 29 & $1,4 \%$ & $2,7 \%$ \\
Preocupación por los hijos & 24 & $1,2 \%$ & $2,3 \%$ \\
Otros & 81 & $3,9 \%$ & $7,7 \%$ \\
\hline \multicolumn{1}{c}{ Respuestas totales } & $\mathbf{2 0 6 7}$ & $\mathbf{1 0 0 \%}$ & $\mathbf{1 9 5 , 4 \%}$ \\
\hline
\end{tabular}

Nota: 115 casos perdidos; 1058 casos válidos.

Tabla 62: Frecuencias y porcentajes (de respuestas y de casos) de pensamientos sobre el futuro de las PcDID.

Si analizamos detenidamente los pensamientos de futuro (tabla 63), podremos considerar que las principales respuestas dadas por las PcDID que envejecen son bien respuestas de evitación, bien respuestas de optimismo, aunque también destacan otras respuestas como vivir con calidad de vida, la autonomía personal, etc. Destacan las bajas elecciones en aquellas respuestas más vinculadas a la negatividad o pesimismo, que en ocasiones se suelen relacionar con la tenencia de una discapacidad o con el propio proceso de envejecimiento. 


\begin{tabular}{|c|c|c|c|}
\hline Pensamientos de futuro: & $\mathbf{N}$ & $\begin{array}{c}\% \\
\text { resp }\end{array}$ & $\begin{array}{c}\% \\
\text { casos }\end{array}$ \\
\hline \multicolumn{4}{|l|}{ Respuestas de evitación } \\
\hline Nada, no pienso en el futuro & 301 & $14,6 \%$ & $28,4 \%$ \\
\hline Seguir viviendo & 242 & $11,7 \%$ & $22,9 \%$ \\
\hline Vivir al día & 185 & $9,0 \%$ & $17,5 \%$ \\
\hline \multicolumn{4}{|l|}{ Preocupación } \\
\hline Con preocupación, futuro incierto & 161 & $7,8 \%$ & $15,2 \%$ \\
\hline \multicolumn{4}{|l|}{ Pesimismo } \\
\hline Soledad & 82 & $4,0 \%$ & $7,8 \%$ \\
\hline Triste & 73 & $3,5 \%$ & $6,9 \%$ \\
\hline Aburrimiento & 61 & $3,0 \%$ & $5,8 \%$ \\
\hline Mal, negro & 43 & $2,1 \%$ & $4,1 \%$ \\
\hline Pocas ganas de vivir & 29 & $1,4 \%$ & $2,7 \%$ \\
\hline \multicolumn{4}{|l|}{ Optimismo } \\
\hline Bien, sin problemas & 205 & $9,9 \%$ & $19,4 \%$ \\
\hline Resuelto & 74 & $3,6 \%$ & $7,0 \%$ \\
\hline \multicolumn{4}{|l|}{ Otras respuestas } \\
\hline Vivir con calidad de vida & 271 & $13,1 \%$ & $25,6 \%$ \\
\hline Autonomía personal & 107 & $5,2 \%$ & $10,1 \%$ \\
\hline Vida independiente & 76 & $3,7 \%$ & $7,2 \%$ \\
\hline Dependerá del asociacionismo & 52 & $2,5 \%$ & $4,9 \%$ \\
\hline Otros & 81 & $3,9 \%$ & $7,7 \%$ \\
\hline Respuestas totales & 2067 & $100 \%$ & $195,4 \%$ \\
\hline
\end{tabular}

Tabla 63: Frecuencias y porcentajes (de respuestas y de casos) de pensamientos sobre el futuro en función de la temática de las PcDID.

\subsubsection{Problemas señalados de las personas con discapacidad intelectual y del desa- rrollo}

Los problemas que las PcDID en proceso de envejecimiento señalan (tabla 64), tienen que ver principalmente con la salud. De hecho, los problemas de salud son señalados en el 45,6\% de los casos, muy por encima de la incapacidad de tomar decisiones (señalada en el 23,9\% de los casos), la inseguridad (21,5\%), la soledad (21,1\%), la ansiedad y el estrés $(20,1 \%)$ o los problemas de memoria $(16,7 \%)$. 
En menor medida las PcDID señalaron otros problemas como la timidez, el no poder divertirse o hacer amistades, el miedo a la muerte, la inferioridad, la depresión, el insomnio, los problemas sexuales, entre otros.

\begin{tabular}{|c|c|c|c|}
\hline Problemas señalados: & $\mathbf{N}$ & $\begin{array}{c}\% \\
\text { resp }\end{array}$ & $\begin{array}{c}\% \\
\text { casos }\end{array}$ \\
\hline Problemas de salud & 449 & $16,2 \%$ & $45,6 \%$ \\
\hline Incapaz de tomar decisiones & 235 & $8,5 \%$ & $23,9 \%$ \\
\hline Inseguridad & 212 & $7,6 \%$ & $21,5 \%$ \\
\hline Soledad & 208 & $7,5 \%$ & $21,1 \%$ \\
\hline Aburrimiento & 208 & $7,5 \%$ & $21,1 \%$ \\
\hline Ansiedad, tensión y estrés & 198 & $7,1 \%$ & $20,1 \%$ \\
\hline Problemas de memoria & 164 & $5,9 \%$ & $16,7 \%$ \\
\hline Timidez & 127 & $4,6 \%$ & $12,9 \%$ \\
\hline No poder divertirme & 119 & $4,3 \%$ & $12,1 \%$ \\
\hline No poder hacer amistades & 115 & $4,1 \%$ & $11,7 \%$ \\
\hline Miedo a la muerte & 98 & $3,5 \%$ & $10,0 \%$ \\
\hline Sentimientos de inferioridad & 90 & $3,2 \%$ & $9,1 \%$ \\
\hline Depresión & 89 & $3,2 \%$ & $9,0 \%$ \\
\hline Miedo a casi todo & 84 & $3,0 \%$ & $8,5 \%$ \\
\hline Insomnio & 82 & $3,0 \%$ & $8,3 \%$ \\
\hline Problemas sexuales & 64 & $2,3 \%$ & $6,5 \%$ \\
\hline No encontrar salida a mi situación & 49 & $1,8 \%$ & $5,0 \%$ \\
\hline Malas condiciones en el hogar & 36 & $1,3 \%$ & $3,7 \%$ \\
\hline Pocas ganas de vivir & 31 & $1,1 \%$ & $3,2 \%$ \\
\hline Ideas de suicidio & 24 & $0,9 \%$ & $2,4 \%$ \\
\hline Alcoholismo & 15 & $0,5 \%$ & $1,5 \%$ \\
\hline Drogas & 4 & $0,1 \%$ & $0,4 \%$ \\
\hline Otros & 73 & $2,6 \%$ & $7,4 \%$ \\
\hline Respuestas totales & 2774 & $100 \%$ & $\mathbf{2 8 1 , 9 \%}$ \\
\hline
\end{tabular}

Nota: 189 casos perdidos; 984 casos válidos.

Tabla 64: Frecuencias y porcentajes (de respuestas y de casos) de pensamientos sobre el futuro de las PcDID.

\subsubsection{Otras consideraciones}

En otras consideraciones, las PcDID señalaron como necesidades (tabla 65) la creación de centros especializados $(35,6 \%$ de los casos), las ayudas asistenciales $(28,9 \%$ de los casos), las ayudas económicas (20\%), la ayuda de la sociedad (15,6\%), la ayuda 
de las instituciones $(11,1 \%)$, la información adecuada $(6,7 \%)$ y la supresión de barreras arquitectónicas $(6,7 \%)$.

\begin{tabular}{lccc}
\hline \multicolumn{1}{c}{ Otras consideraciones: } & N & $\begin{array}{c}\text { \% } \\
\text { resp }\end{array}$ & $\begin{array}{c}\text { \% } \\
\text { casos }\end{array}$ \\
\hline Creación centros especializados & 16 & $28,6 \%$ & $35,6 \%$ \\
Ayudas asistenciales & 13 & $23,2 \%$ & $28,9 \%$ \\
Ayudas económicas & 9 & $16,1 \%$ & $20,0 \%$ \\
Ayuda de la sociedad & 7 & $12,5 \%$ & $15,6 \%$ \\
Ayuda de las instituciones & 5 & $8,9 \%$ & $11,1 \%$ \\
Información adecuada & 3 & $5,4 \%$ & $6,7 \%$ \\
Supresión de barreras arquitectónicas & 3 & $5,4 \%$ & $6,7 \%$ \\
\hline \multicolumn{1}{c}{ Respuestas totales } & $\mathbf{5 6}$ & $\mathbf{1 0 0 \%}$ & $\mathbf{1 2 4 , 4 \%}$ \\
\hline
\end{tabular}

Nota: 1128 casos perdidos; 45 casos válidos.

Tabla 65: Frecuencias y porcentajes (de respuestas y de casos) de otras consideraciones de las PcDID.

\subsubsection{Resumen}

A modo de resumen, diríamos que las PcDID que envejecen y que han participado en el estudio, tienen preocupaciones que giran principalmente en torno a la salud personal y a la existencia de barreras. Dentro de la salud personal preocupa en mayor medida el estado de salud general, mientras que dentro de la existencia de barreras es destacable los impedimentos o dificultades a nivel social, y no tanto arquitectónico. Otras preocupaciones señaladas en menor medida han sido la pensión, la creación y mejora de servicios de ocio y tiempo libre o el dónde y con quién vivir en el futuro. Para ello, las PcDID que envejecen señalan como principales soluciones la subida de las pensiones y la creación o mejora de servicio de apoyo al ocio y tiempo libre, seguidas con menores niveles de elección la ayuda para los cuidados personales diarios, el incremento de la ayuda familiar, las garantías de futuro, la especialización profesional, la supre- 
sión de barreras arquitectónicas, la mejora de los servicios de alojamiento, el incremento de las subvenciones, etc.

Por otro lado, las PcDID echan en falta determinados apoyos institucionales, como pueden ser el incremento de los recursos de las asociaciones, el apoyo de los Ayuntamientos, las actividades culturales y el contar con apoyos en el entorno.

Los pensamientos de futuro de las PcDID son principalmente respuestas de evitación, tales como "seguir viviendo" o no pensar en el futuro, o de optimismo, como "bien, sin problemas", aunque también encontramos otros tipos de pensamiento tales como "vivir con calidad de vida".

Entre los problemas que señalan, destacan los problemas de salud principalmente, y consideran relevante la creación de centros especializados, las ayudas asistenciales y económicas.

\subsection{ANÁLISIS DE LA RELACIÓN ENTRE PREOCUPACIONES Y NECESIDADES Y LAS VARIABLES PREDICTORAS: MUESTRA DE PCDID}

\subsubsection{Introducción}

Las necesidades estudiadas están influenciadas por variables denominadas predictoras, que en el caso que nos ocupa son el tipo de cumplimentación, el género, la edad, el grado de discapacidad, el tipo de convivencia, la población de residencia y el tipo de discapacidad (aunque todas las personas con discapacidad de la muestra tienen discapacidad intelectual, en ocasiones hemos dividido este grupo en personas con SD, otros tipos de DID y personas con PC). El estado civil podría formar parte de estas variables, pero en esta muestra carece de sentido analizar su influencia debido a que el 98\% de las PcDID estaban solteras. 
Lo que se realizará en este apartado es ver la influencia de estas variables en las necesidades a nivel general y específico (salud personal, recursos económicos, recursos de servicios sanitarios, recursos de servicios sociales, existencia de barreras y otras preocupaciones), soluciones, apoyos institucionales requeridos, pensamientos de futuro, problemas señalados y otras consideraciones.

\subsubsection{Prueba de normalidad de las distribuciones}

Como paso previo a los análisis, necesitamos conocer la normalidad de la distribución de las variables. Como reflejan las tablas 66 y 67, las variables estudiadas no siguen una distribución normal, ya que en todos los casos la prueba KolmogorovSmirnov para una muestra resultó estadísticamente significativa $(\mathrm{p}<0,01)$. De manera que todas las pruebas empleadas para el análisis de los resultados serán de tipo no paramétrico.

En los casos en los que la variable sea dicotómica, se empleará la prueba U de Mann-Whitney para establecer las diferencias significativas, mientras que en el caso de variables politómicas se empleará la prueba de Kruskal-Wallis. 


\begin{tabular}{|c|c|c|c|c|c|c|c|c|}
\hline & \multirow[b]{2}{*}{$\mathrm{N}$} & \multicolumn{2}{|c|}{$\begin{array}{c}\text { Parámetros } \\
\text { normales }\end{array}$} & \multicolumn{3}{|c|}{$\begin{array}{l}\text { Diferencias más ex- } \\
\text { tremas }\end{array}$} & \multirow[b]{2}{*}{$\begin{array}{l}\mathrm{Z} \text { de } \\
\mathrm{K}-\mathrm{S}\end{array}$} & \multirow[b]{2}{*}{ Sig. } \\
\hline & & Media & $\begin{array}{c}\text { Desviación } \\
\text { típica }\end{array}$ & Abs. & Pos. & Neg. & & \\
\hline $\mathrm{N}^{\mathrm{o}}$ preocupaciones & 1173 & 7,63 & 6,052 & 0,114 & 0,114 & $-0,104$ & 3,905 &, 000 \\
\hline $\mathrm{N}^{\mathrm{o}}$ soluciones & 1173 & 4,88 & 6,167 & 0,214 & 0,192 & $-0,214$ & 7,338 & ,000 \\
\hline $\begin{array}{l}\mathrm{N}^{\mathrm{o}} \text { apoyos institu- } \\
\text { cionales }\end{array}$ & 1173 & 1,52 & 1,803 & 0,218 & 0,218 & $-0,199$ & 7,460 & 000 \\
\hline $\begin{array}{l}\mathrm{N}^{\mathrm{o}} \text { pensamientos } \\
\text { futuro }\end{array}$ & 1173 & 1,76 & 1,586 & 0,269 & 0,269 & $-0,218$ & 9,204 & ,000 \\
\hline $\begin{array}{l}\mathrm{N}^{\mathrm{o}} \text { problemas se- } \\
\text { ñalados }\end{array}$ & 1173 & 2,36 & 2,035 & 0,176 & 0,176 & $-0,123$ & 6,043 &, 000 \\
\hline $\mathrm{N}^{\mathrm{o}}$ consideraciones & 1173 & 0,16 & 0,418 & 0,507 & 0,507 & $-0,354$ & 17,353 &, 000 \\
\hline
\end{tabular}

Tabla 66: Prueba de Kolmogorov-Smirnov para una muestra en función de las necesidades y soluciones generales. Muestra de PcDID.

\begin{tabular}{|c|c|c|c|c|c|c|c|c|}
\hline & \multirow[b]{2}{*}{$\mathrm{N}$} & \multicolumn{2}{|c|}{$\begin{array}{l}\text { Parámetros } \\
\text { normales }\end{array}$} & \multicolumn{3}{|c|}{$\begin{array}{l}\text { Diferencias más ex- } \\
\text { tremas }\end{array}$} & \multirow[b]{2}{*}{$\begin{array}{l}\mathrm{Z} \text { de } \\
\mathrm{K}-\mathrm{S}\end{array}$} & \multirow[b]{2}{*}{ Sig. } \\
\hline & & Media & $\begin{array}{c}\text { Desviación } \\
\text { típica }\end{array}$ & Abs. & Pos. & Neg. & & \\
\hline $\begin{array}{l}\mathrm{N}^{\mathrm{o}} \text { nec. salud per- } \\
\text { sonal }\end{array}$ & 1173 & 1,71 & 1,397 & 0,204 & 0,204 & $-0,126$ & 6,989 & ,000 \\
\hline $\begin{array}{l}\mathrm{N}^{\mathrm{o}} \text { nec. recursos } \\
\text { económicos }\end{array}$ & 1173 & ,97 & ,963 & 0,312 & 0,312 & $-0,200$ & 10,684 & ,000 \\
\hline $\begin{array}{l}\mathrm{N}^{\mathrm{o}} \text { nec. recursos } \\
\text { sanitarios }\end{array}$ & 1173 & 1,13 & 1,341 & 0,236 & 0,236 & $-0,200$ & 8,081 &, 000 \\
\hline $\begin{array}{l}\mathrm{N}^{\mathrm{o}} \text { nec. recursos } \\
\text { de servicios socia- } \\
\text { les }\end{array}$ & 1173 & 1,29 & 1,416 & 0,229 & 0,229 & $-0,181$ & 7,857 & ,000 \\
\hline $\begin{array}{l}\mathrm{N}^{\mathrm{o}} \text { nec. existencia } \\
\text { de barreras }\end{array}$ & 1173 & 1,36 & 1,470 & 0,224 & 0,224 & $-0,177$ & 7,663 &, 000 \\
\hline $\begin{array}{l}N^{o} \text { otras necesida- } \\
\text { des }\end{array}$ & 1173 & 1,24 & 1,348 & 0,244 & 0,244 & $-0,179$ & 8,341 & ,000 \\
\hline
\end{tabular}

Tabla 67: Prueba de Kolmogorov-Smirnov para una muestra en función de las necesidades específicas. Muestra de PcDID. 


\subsubsection{Variable persona que cumplimenta la entrevista}

\subsubsection{Introducción}

A la hora de entrevistar a las PcDID de la muestra, nos encontramos con que la mayoría de ellas tenía un grado de discapacidad superior al $65 \%$, incluso algunos de ellos sobrepasaban el 80\%. Con ello, aparecían problemas de comunicación y/o comprensión que eran significativos a la hora de cumplimentar los cuestionarios. Es por ello por lo que se decidió que personas muy cercanas a las PcDID pudieran rellenar dicho cuestionario con la condición de ponerse siempre en el lugar de la PcDID. La entrevista podía ser cumplimentada por un familiar, un amigo, un profesional, o cualquier persona con la suficiente cercanía a la PcDID, pero desde su punto de vista, ya que para el resto de puntos de vista contábamos con entrevistas paralelas para familias y profesionales.

Así, los datos se analizaron en función de dos tipos de informe:

- Autoaplicado: cuando la propia PcDID respondía al cuestionario con los apoyos necesarios.

- Heteroinforme: cuando otra persona respondía al cuestionario poniéndose en lugar o empatizando con la PcDID, ya fuera un familiar o profesional.

A tales efectos, se consideró necesario estudiar si hubo diferencias estadísticamente significativas en cuanto a las necesidades y soluciones generales y las necesidades específicas en función de la persona que hubiera respondido al cuestionario. Para ello llevamos a cabo la prueba U de Mann Whitney, en primer lugar, agrupando la muestra en autoinforme y heteroinfome. 


\subsubsection{Resultados sobre la variable persona que cumplimenta la entrevista}

Los resultados, teniendo en cuenta el error de medida tipo I $(\mathrm{p}<0,05)$ indican una tendencia estadísticamente significativa a una mayor puntuación del grupo de heteroinforme (tabla 69) en el número de preocupaciones y necesidades generales (tabla 68).

Por otro lado, también había diferencias estadísticamente significativas en cuanto a los pensamientos de futuro (tabla 69), ya que el grupo autoinforme obtuvo mayores puntuaciones en dicha variable (tabla 68). 


\begin{tabular}{|c|c|c|c|}
\hline & Tipo de informe & $\mathbf{N}$ & $\begin{array}{c}\text { Rango pro- } \\
\text { medio }\end{array}$ \\
\hline \multirow{3}{*}{$\begin{array}{l}\mathbf{N}^{0} \text { preocupaciones } \mathbf{y} \\
\text { necesidades }\end{array}$} & Autoinforme & 337 & 512,40 \\
\hline & Héteroinforme & 836 & 617,07 \\
\hline & Total & 1173 & \\
\hline \multirow{3}{*}{$\mathbf{N}^{0}$ soluciones } & Autoinforme & 337 & 616,64 \\
\hline & Héteroinforme & 836 & 575,05 \\
\hline & Total & 1173 & \\
\hline \multirow{3}{*}{$\begin{array}{l}\mathrm{N}^{0} \text { apoyos institucio- } \\
\text { nales requeridos }\end{array}$} & Autoinforme & 337 & 584,55 \\
\hline & Héteroinforme & 836 & 587,99 \\
\hline & Total & 1173 & \\
\hline \multirow{3}{*}{$\begin{array}{l}\mathrm{N}^{0} \text { pensamientos so- } \\
\text { bre futuro }\end{array}$} & Autoinforme & 337 & 631,71 \\
\hline & Héteroinforme & 836 & 568,98 \\
\hline & Total & 1173 & \\
\hline \multirow{3}{*}{$\begin{array}{l}N^{0} \text { problemas señala- } \\
\text { dos }\end{array}$} & Autoinforme & 337 & 609,72 \\
\hline & Héteroinforme & 836 & 577,84 \\
\hline & Total & 1173 & \\
\hline \multirow{3}{*}{$\mathrm{N}^{0}$ consideraciones } & Autoinforme & 337 & 578,78 \\
\hline & Héteroinforme & 836 & 590,31 \\
\hline & Total & 1173 & \\
\hline
\end{tabular}

Tabla 68: Rangos promedios en función del tipo de informe dicotomizado en número total de preocupaciones y necesidades generales. Muestra de PcDID.

\begin{tabular}{lccccc}
\hline & $\begin{array}{c}\text { U de Mann- } \\
\text { Whitney }\end{array}$ & W de Wilcoxon & $\mathbf{Z}$ & Sig. & $\boldsymbol{\eta}^{\mathbf{2}}$ \\
\hline $\mathbf{N}^{\mathbf{0}}$ preocupaciones & 115726,500 & 172679,500 & $-4,798$ &, 000 & $-0,14$ \\
$\mathbf{N}^{\mathbf{0}}$ soluciones & 130876,500 & 480742,500 & $-1,919$ &, 055 & $-0,05$ \\
$\mathbf{N}^{\mathbf{o}}$ apoyos institucionales & 140040,500 & 196993,500 & $-0,163$ &, 870 & $-0,05$ \\
$\mathbf{N}^{\mathbf{o}}$ pensamientos futuro & 125798,500 & 475664,500 & $-3,073$ &, 002 & $-0,09$ \\
$\mathbf{N}^{\mathbf{o}}$ problemas señalados & 133210,500 & 483076,500 & $-1,483$ &, 138 & $-0,04$ \\
$\mathbf{N}^{\mathbf{0}}$ consideraciones & 138097,500 & 195050,500 & $-0,879$ &, 379 & $-0,02$ \\
\hline
\end{tabular}

Nota: el valor del tamaño del efecto $\left(\eta^{2}\right)$ debe interpretarse en valor absoluto.

Tabla 69: Estadísticos de contraste en función del tipo de informe dicotomizado desglosado en número total de preocupaciones y soluciones generales. Muestra de PcDID.

En lo referente a las necesidades específicas, se obtuvieron diferencias estadísticamente significativas $(\mathrm{p}<0,05)$ en el número de preocupaciones señaladas sobre salud 
personal, recursos sanitarios, recursos de servicios sociales y existencia de barreras (tabla 71). En todas las preocupaciones el grupo que presentaba puntuaciones más altas era el de heteroinforme (tabla 70). En el gráfico 5 se presentan los rangos promedios de ambos grupos en cada una de las variables. En la tabla 72 se expone el resumen de la significatividad de los resultados comentados. 


\begin{tabular}{|c|c|c|c|}
\hline & Tipo de informe & $\mathbf{N}$ & $\begin{array}{l}\text { Rango prome- } \\
\text { dio }\end{array}$ \\
\hline \multirow{3}{*}{$\begin{array}{l}\mathrm{N}^{0} \text { preocupaciones sobre } \\
\text { salud personal }\end{array}$} & Autoinforme & 337 & 503,41 \\
\hline & Héteroinforme & 836 & 620,70 \\
\hline & Total & 1173 & \\
\hline \multirow{3}{*}{$\begin{array}{l}\mathbf{N}^{\circ} \text { preocupaciones recursos } \\
\text { económicos }\end{array}$} & Autoinforme & 337 & 586,54 \\
\hline & Héteroinforme & 836 & 587,18 \\
\hline & Total & 1173 & \\
\hline \multirow{3}{*}{$\begin{array}{l}\mathbf{N}^{o} \text { preocupaciones recursos } \\
\text { sanitarios }\end{array}$} & Autoinforme & 337 & 497,57 \\
\hline & Héteroinforme & 836 & 623,05 \\
\hline & Total & 1173 & \\
\hline \multirow{3}{*}{$\begin{array}{l}N^{o} \text { preoc. recursos de servi- } \\
\text { cios sociales }\end{array}$} & Autoinforme & 337 & 533,65 \\
\hline & Héteroinforme & 836 & 608,51 \\
\hline & Total & 1173 & \\
\hline \multirow{3}{*}{$\begin{array}{l}N^{0} \text { preoc. existencia de ba- } \\
\text { rreras }\end{array}$} & Autoinforme & 337 & 517,38 \\
\hline & Héteroinforme & 836 & 615,06 \\
\hline & Total & 1173 & \\
\hline \multirow{3}{*}{$\begin{array}{l}\mathrm{N}^{0} \text { otras preocupaciones } \mathrm{y} \\
\text { necesidades }\end{array}$} & Autoinforme & 337 & 565,08 \\
\hline & Héteroinforme & 836 & 595,84 \\
\hline & Total & 1173 & \\
\hline
\end{tabular}

Tabla 70: Rangos promedios en función del tipo de informe dicotomizado en número total de preocupaciones específicas. Muestra de PcDID.

\begin{tabular}{lccccc}
\hline & $\begin{array}{c}\text { U de Mann- } \\
\text { Whitney }\end{array}$ & $\begin{array}{c}\text { W de Wil- } \\
\text { coxon }\end{array}$ & $\mathbf{Z}$ & Sig. & $\boldsymbol{\eta}^{\mathbf{2}}$ \\
\hline Salud personal & 112695,500 & 169648,500 & $-5,546$ &, 000 & $-0,16$ \\
Recursos económicos & 140712,500 & 197665,500 & $-0,032$ &, 974 & $-0,00$ \\
Recursos sanitarios & 110728,500 & 167681,500 & $-6,047$ &, 000 & $-0,10$ \\
Recursos de servicios socia- & 122886,000 & 179839,000 & $-3,568$ &, 000 & $-0,13$ \\
les & & & & & \\
Existencia de barreras & 117405,000 & 174358,000 & $-4,638$ &, 000 & $-0,17$ \\
Otras necesidades & 133478,500 & 190431,500 & $-1,472$ &, 141 & $-0,04$ \\
\hline
\end{tabular}

Nota: el valor del tamaño del efecto $\left(\eta^{2}\right)$ debe interpretarse en valor absoluto.

Tabla 71: Estadísticos descriptivos en función del tipo de informe dicotomizado en número total de necesidades específicas. Muestra de PCDID. 


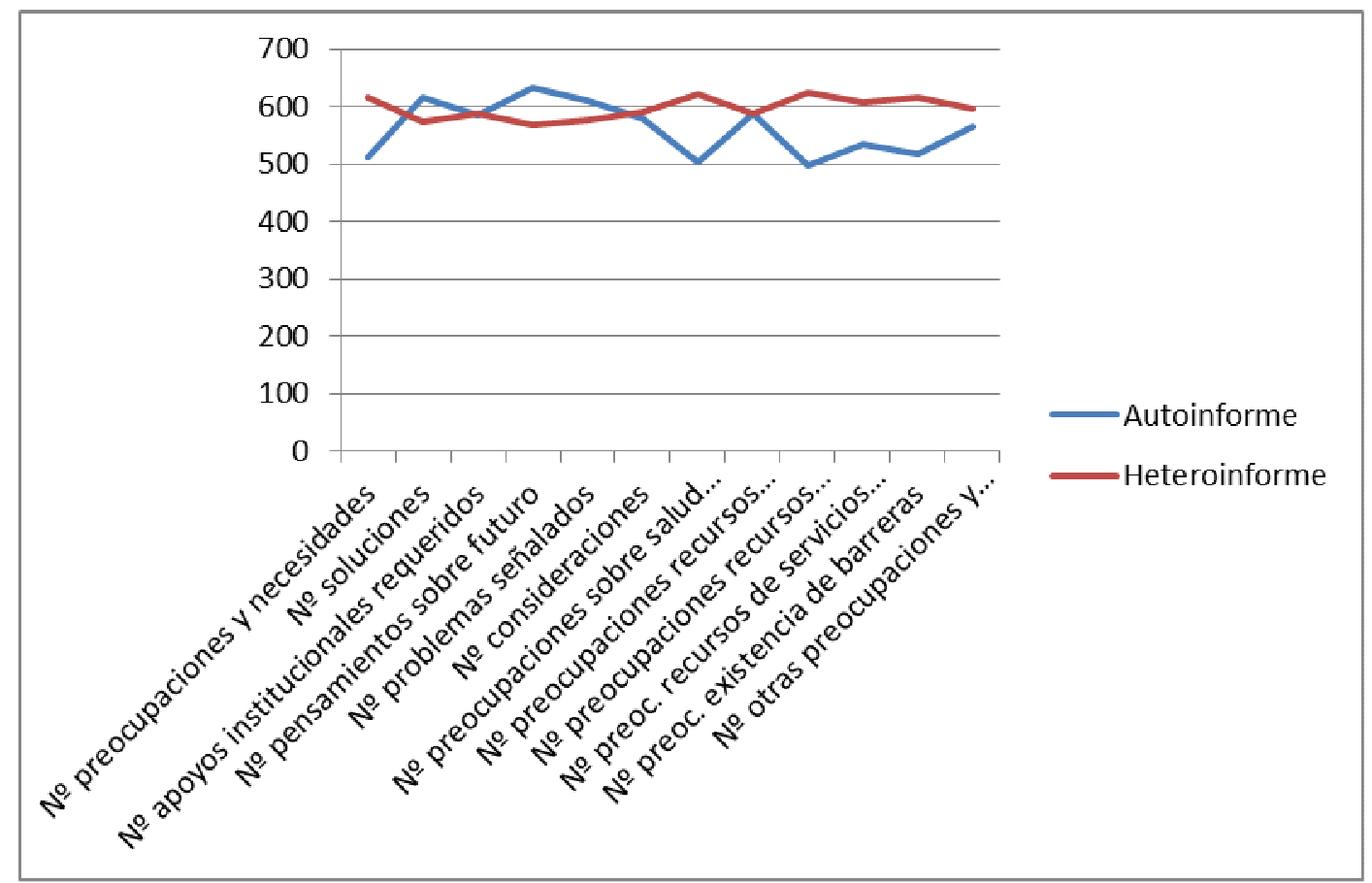

Gráfico 5: Rangos promedio en función del tipo de informe dicotomizado en número total de preocupaciones generales y específicas. Muestra de PcDID.

\begin{tabular}{|c|c|c|}
\hline PcDID & VARIABLES & $\begin{array}{c}\text { TIPO DE INFORME } \\
\text { Autoinforme } \\
\text { Heteroinforme }\end{array}$ \\
\hline \multirow{12}{*}{$\begin{array}{c}\text { TODOS } \\
\mathrm{N}=\mathbf{1 1 7 3} \\
\text { Autoinforme }=\mathbf{3 3 7} \\
\text { Heteroinforme }=\mathbf{8 3 6}\end{array}$} & $\mathrm{N}^{0}$ preoc y necesidades & SI:+Heteroinforme \\
\hline & $\mathrm{N}^{\circ}$ soluciones & $\mathrm{NO}$ \\
\hline & $\mathrm{N}^{\mathrm{o}}$ apoyos institucionales & $\mathrm{NO}$ \\
\hline & $\mathbf{N}^{0}$ pensam futuro & SI:+Autoinforme \\
\hline & $\mathrm{N}^{\mathrm{o}}$ problemas señalados & NO \\
\hline & $\mathrm{N}^{\circ}$ otras consideraciones & $\mathrm{NO}$ \\
\hline & $\begin{array}{l}N^{0} \text { necesidades salud per- } \\
\text { sonal }\end{array}$ & SI:+Heteroinforme \\
\hline & $\begin{array}{l}\mathrm{N}^{\mathrm{o}} \text { necesidades recursos } \\
\text { económicos }\end{array}$ & NO \\
\hline & $\begin{array}{l}\mathrm{N}^{\circ} \text { necesidades recursos } \\
\text { servicios sanitarios }\end{array}$ & SI:+Heteroinforme \\
\hline & $\begin{array}{l}\mathbf{N}^{0} \text { necesidades recursos } \\
\text { servicios sociales }\end{array}$ & SI:+Heteroinforme \\
\hline & $\begin{array}{l}N^{0} \text { necesidades existencia } \\
\text { de barreras }\end{array}$ & SI:+Heteroinforme \\
\hline & $\mathrm{N}^{\circ}$ otras necesidades & $\mathrm{NO}$ \\
\hline
\end{tabular}

Nota: $\mathrm{NO}=$ no hay diferencias estadísticamente significativas; SI: hay diferencias estadísticamente significativas; + seguido del grupo indica dónde se encuentran mayores rangos promedio.

Tabla 72: Resumen de diferencias en función del tipo de informe dicotomizado en número de necesidades y soluciones generales y necesidades específicas. Muestra de PcDID. 
Posteriormente se realizaron los mismos análisis agrupando la muestra en tres tipos de cumplimentación, en función de si el cuestionario había sido respondido por la propia PcDID, por un familiar o por un profesional. En este caso, al ser la variable politómica, se realizó la prueba Kruskal-Wallis (tablas 74 y 76).

Los resultados indican que hay diferencias estadísticamente significativas $(\mathrm{p}<0,05)$ en el número de preocupaciones, en el de soluciones y en el número de pensamientos de futuro (tabla 74), siendo mayor el número de puntuaciones del grupo de la entrevista autoaplicada en las soluciones y pensamientos de futuro, y mayor el número de puntuaciones de los profesionales en las preocupaciones señaladas (tabla 73). 


\begin{tabular}{|c|c|c|c|}
\hline & $\begin{array}{c}\text { Tipo de cumplimen- } \\
\text { tación }\end{array}$ & $\mathbf{N}$ & Rango promedio \\
\hline \multirow{4}{*}{$\begin{array}{l}\mathbf{N}^{0} \text { preocupaciones y necesi- } \\
\text { dades }\end{array}$} & Autoaplicada & 337 & 512,40 \\
\hline & Familiar & 219 & 593,14 \\
\hline & Profesional & 617 & 625,56 \\
\hline & Total & 1173 & \\
\hline \multirow{4}{*}{$\mathbf{N}^{0}$ soluciones } & Autoaplicada & 337 & 616,64 \\
\hline & Familiar & 219 & 610,13 \\
\hline & Profesional & 617 & 562,60 \\
\hline & Total & 1173 & \\
\hline \multirow{4}{*}{$\begin{array}{l}\mathbf{N}^{\circ} \text { apoyos institucionales re- } \\
\text { queridos }\end{array}$} & Autoaplicada & 337 & 584,55 \\
\hline & Familiar & 219 & 604,13 \\
\hline & Profesional & 617 & 582,26 \\
\hline & Total & 1173 & \\
\hline \multirow{4}{*}{$\mathrm{N}^{\mathbf{0}}$ pensamientos sobre futuro } & Autoaplicada & 337 & 631,71 \\
\hline & Familiar & 219 & 597,08 \\
\hline & Profesional & 617 & 559,00 \\
\hline & Total & 1173 & \\
\hline \multirow{4}{*}{$\mathbf{N}^{0}$ problemas señalados } & Autoaplicada & 337 & 609,72 \\
\hline & Familiar & 219 & 548,06 \\
\hline & Profesional & 617 & 588,41 \\
\hline & Total & 1173 & \\
\hline \multirow{4}{*}{$\mathrm{N}^{0}$ consideraciones } & Autoaplicada & 337 & 578,78 \\
\hline & Familiar & 219 & 584,37 \\
\hline & Profesional & 617 & 592,42 \\
\hline & Total & 1173 & \\
\hline
\end{tabular}

Tabla 73: Rangos promedios en función del tipo de informe recodificado en número total de preocupaciones y soluciones generales. Muestra de PcDID.

\begin{tabular}{lcccc}
\hline & Chi-cuadrado & gl & Sig. asintót. & $\boldsymbol{\eta}^{\mathbf{2}}$ \\
\hline $\mathbf{N}^{\mathbf{o}}$ preocupaciones & 24,511 & 2 &, 000 & $-0,09$ \\
$\mathbf{N}^{\mathbf{o}}$ soluciones & 6,922 & 2 &, 031 & $-0,04$ \\
$\mathbf{N}^{\mathbf{o}}$ apoyos institucionales & 0,753 & 2 &, 686 & $-0,01$ \\
$\mathbf{N}^{\mathbf{o}}$ pensamientos futuro & 11,788 & 2 &, 003 & $-0,06$ \\
$\mathbf{N}^{\mathbf{o}}$ problemas señalados & 4,571 & 2 &, 102 & $-0,04$ \\
$\mathbf{N}^{\mathbf{o}}$ consideraciones & 1,027 & 2 &, 598 & $-0,02$ \\
\hline \multicolumn{4}{c}{ Nota: el valor del tamaño del efecto $\left(\eta^{2}\right)$ debe interpretarse en valor absoluto. }
\end{tabular}

Tabla 74: Estadísticos descriptivos en función del tipo de informe recodificado en número total de preocupaciones y soluciones generales. Muestra de PcDID. 
Por otro lado, en cuanto a los resultados en las preocupaciones específicas, aparecen diferencias estadísticamente significativas $(p<0,05)$ en el número de opciones elegidas sobre la salud personal, los recursos de servicios sanitarios, los recursos de servicios sociales, la existencia de barreras y en otras necesidades (tabla 76). Las diferencias indican que las familias señalaron un número significativamente mayor de necesidades sobre salud personal y de otras necesidades; mientras que los profesionales señalaron mayor número de necesidades sobre recursos sanitarios, recursos sociales y existencia de barreras (tabla 75). En el gráfico 6 podemos observar la comparación de los rangos promedio en el número de respuestas de cada uno de los grupos en las distintas necesidades y soluciones estudiadas; mientras que la tabla 77 se muestra el resumen de las significaciones encontradas en esta parte del estudio. 


\begin{tabular}{|c|c|c|c|}
\hline & $\begin{array}{l}\text { Tipo de cumplimen- } \\
\text { tación }\end{array}$ & $\mathbf{N}$ & Rango promedio \\
\hline \multirow{4}{*}{$\begin{array}{l}\mathbf{N}^{0} \text { preocupaciones sobre sa- } \\
\text { lud personal }\end{array}$} & Autoaplicada & 337 & 503,41 \\
\hline & Familiar & 219 & 627,89 \\
\hline & Profesional & 617 & 618,14 \\
\hline & Total & 1173 & \\
\hline \multirow{4}{*}{$\begin{array}{l}N^{o} \text { preocupaciones recursos } \\
\text { económicos }\end{array}$} & Autoaplicada & 337 & 586,54 \\
\hline & Familiar & 219 & 574,86 \\
\hline & Profesional & 617 & 591,56 \\
\hline & Total & 1173 & \\
\hline \multirow{4}{*}{$\begin{array}{l}\mathbf{N}^{0} \text { preocupaciones recursos } \\
\text { sanitarios }\end{array}$} & Autoaplicada & 337 & 497,57 \\
\hline & Familiar & 219 & 560,94 \\
\hline & Profesional & 617 & 645,09 \\
\hline & Total & 1173 & \\
\hline \multirow{4}{*}{$\begin{array}{l}N^{o} \text { preoc. recursos de servi- } \\
\text { cios sociales }\end{array}$} & Autoaplicada & 337 & 533,65 \\
\hline & Familiar & 219 & 600,14 \\
\hline & Profesional & 617 & 611,48 \\
\hline & Total & 1173 & \\
\hline \multirow{4}{*}{$\begin{array}{l}N^{\circ} \text { preoc. existencia de barre- } \\
\text { ras }\end{array}$} & Autoaplicada & 337 & 517,38 \\
\hline & Familiar & 219 & 575,53 \\
\hline & Profesional & 617 & 629,09 \\
\hline & Total & 1173 & \\
\hline \multirow{4}{*}{$\begin{array}{l}N^{o} \text { otras preocupaciones y } \\
\text { necesidades }\end{array}$} & Autoaplicada & 337 & 565,08 \\
\hline & Familiar & 219 & 633,82 \\
\hline & Profesional & 617 & 582,36 \\
\hline & Total & 1173 & \\
\hline
\end{tabular}

Tabla 75: Rangos promedios en función del tipo de informe recodificado en número total de preocupaciones específicas. Muestra de PcDID. 


\begin{tabular}{lcccc}
\hline & Chi-cuadrado & gl & Sig. asintót. & $\boldsymbol{\eta}^{\mathbf{2}}$ \\
\hline Salud personal & 30,902 & 2 &, 000 & $-0,10$ \\
Recursos económicos & 0,472 & 2 &, 790 & $-0,01$ \\
Recursos sanitarios & 47,638 & 2 &, 000 & $-0,12$ \\
$\begin{array}{l}\text { Recursos de servicios so- } \\
\text { ciales }\end{array}$ & 12,924 & 2 &, 002 & $-0,03$ \\
$\begin{array}{l}\text { Existencia de barreras } \\
\text { Otras necesidades }\end{array}$ & 25,861 & 2 &, 000 & $-0,09$ \\
\multicolumn{2}{c}{ Nota: el valor del tamaño del efecto $\left(\eta^{2}\right)$ debe interpretarse en valor absoluto. }
\end{tabular}

Nota: el valor del tamaño del efecto $\left(\eta^{2}\right)$ debe interpretarse en valor absoluto.

Tabla 76: Estadísticos de contraste en función del tipo de informe recodificado en número total de preocupaciones específicas.

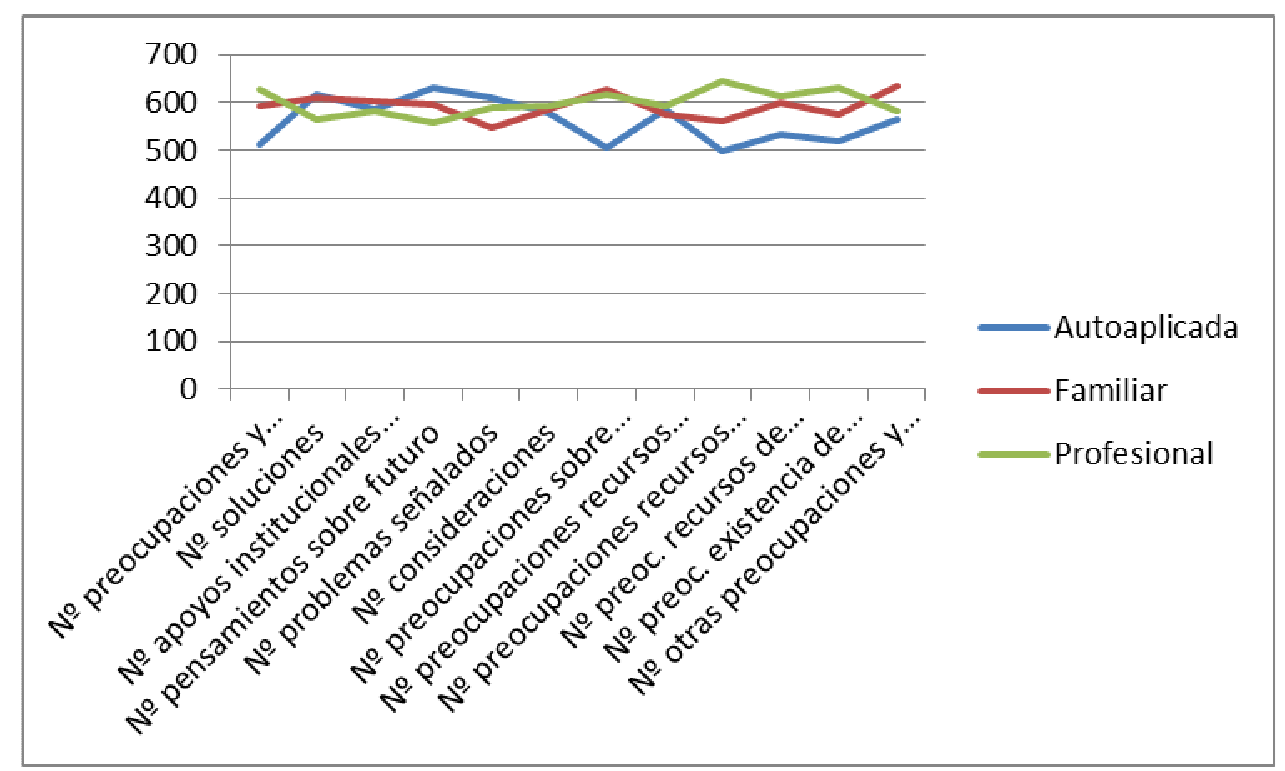

Gráfico 6: Rangos promedio en función del tipo de cumplimentación recodificado en número total de preocupaciones generales y específicas. Muestra de PcDID. 


\begin{tabular}{|c|c|c|}
\hline PcDID & VARIABLES & $\begin{array}{c}\text { Tipo de informe } \\
\text { Autoaplicada } \\
\text { Familiar } \\
\text { Profesional }\end{array}$ \\
\hline \multirow{12}{*}{$\begin{array}{c}\text { TODOS } \\
\text { N= 1173 } \\
\text { Autoaplicada }= \\
337 \\
\text { Familiar }=\mathbf{2 1 9} \\
\text { Profesional= } \\
617\end{array}$} & $\mathbf{N}^{0}$ preoc y necesidades & SI:+Profesional \\
\hline & $\mathbf{N}^{\circ}$ soluciones & SI:+Autoaplicada \\
\hline & $\mathrm{N}^{\circ}$ apoyos institucionales & NO \\
\hline & $\mathbf{N}^{0}$ pensam futuro & SI:+Autoaplicada \\
\hline & $\mathrm{N}^{\circ}$ problemas señalados & NO \\
\hline & $\mathrm{N}^{\circ}$ otras consideraciones & $\mathrm{NO}$ \\
\hline & $\begin{array}{l}\mathbf{N}^{\mathbf{0}} \text { necesidades salud per- } \\
\text { sonal }\end{array}$ & SI:+Familiar \\
\hline & $\begin{array}{l}\mathrm{N}^{\circ} \text { necesidades recursos } \\
\text { económicos }\end{array}$ & NO \\
\hline & $\begin{array}{l}\mathbf{N}^{0} \text { necesidades recursos } \\
\text { servicios sanitarios }\end{array}$ & SI:+Profesional \\
\hline & $\begin{array}{l}\mathbf{N}^{0} \text { necesidades recursos } \\
\text { servicios sociales }\end{array}$ & SI:+Profesional \\
\hline & $\begin{array}{l}\mathbf{N}^{0} \text { necesidades existencia } \\
\text { de barreras }\end{array}$ & SI:+Profesional \\
\hline & $\mathbf{N}^{0}$ otras necesidades & SI:+Familiar \\
\hline
\end{tabular}

Nota: $\mathrm{NO}=$ no hay diferencias estadísticamente significativas; SI: hay diferencias estadísticamente significativas; + seguido del grupo indica dónde se encuentran mayores rangos promedio.

Tabla 77: Resumen de diferencias en función del tipo de informe recodificado de la muestra de PcDID.

\subsubsection{Resumen}

Finalmente, ha resultado interesante agrupar la muestra en función del tipo de cumplimentación, ya que nos ha permitido observar que existen diferencias estadísticamente significativas en función de la persona que responde al cuestionario, y además, también hemos visto diferencias cuando la persona que cumplimenta el cuestionario era un familiar o un profesional. 


\subsubsection{Variable Género}

\subsubsection{Introducción}

La variable género también puede actuar como variable que interfiere en los resultados obtenidos, y es por ello por lo que también se ha estudiado su influencia.

\subsubsection{Resultados sobre la variable género}

Tras realizar los análisis correspondientes, a saber, la prueba U de MannWhitney, observamos que existen diferencias estadísticamente significativas $(p<0,05)$ en todas las variables criterio estudiadas excepto en el número de necesidades acerca de los recursos económicos, y esta significatividad tiene una tendencia clara: son las mujeres las que mayor número de preocupaciones generales y específicas (tabla 80), soluciones, apoyos institucionales, pensamientos de futuro, problemas señalados y otras consideraciones han señalado (tabla 78). En el gráfico 7 se puede observar claramente la tendencia comentada. En la tabla 82 aparece un resumen de la significatividad de estos resultados. 


\begin{tabular}{|c|c|c|c|}
\hline & Género & $\mathbf{N}$ & $\begin{array}{l}\text { Rango pro- } \\
\text { medio }\end{array}$ \\
\hline \multirow{3}{*}{$\begin{array}{l}\mathrm{N}^{0} \text { preocupaciones } \mathrm{y} \\
\text { necesidades }\end{array}$} & Varón & 685 & 555,28 \\
\hline & Mujer & 488 & 631,52 \\
\hline & Total & 1173 & \\
\hline \multirow{3}{*}{$\mathbf{N}^{0}$ soluciones } & Varón & 685 & 560,83 \\
\hline & Mujer & 488 & 623,73 \\
\hline & Total & 1173 & \\
\hline \multirow{3}{*}{$\begin{array}{l}\mathrm{N}^{\circ} \text { apoyos institucio- } \\
\text { nales requeridos }\end{array}$} & Varón & 685 & 565,35 \\
\hline & Mujer & 488 & 617,39 \\
\hline & Total & 1173 & \\
\hline \multirow{3}{*}{$\begin{array}{l}\mathbf{N}^{\circ} \text { pensamientos so- } \\
\text { bre futuro }\end{array}$} & Varón & 685 & 565,13 \\
\hline & Mujer & 488 & 617,70 \\
\hline & Total & 1173 & \\
\hline \multirow{3}{*}{$\begin{array}{l}N^{o} \text { problemas señala- } \\
\text { dos }\end{array}$} & Varón & 685 & 563,69 \\
\hline & Mujer & 488 & 619,72 \\
\hline & Total & 1173 & \\
\hline \multirow{3}{*}{$\mathrm{N}^{\mathbf{o}}$ consideraciones } & Varón & 685 & 570,63 \\
\hline & Mujer & 488 & 609,98 \\
\hline & Total & 1173 & \\
\hline
\end{tabular}

Tabla 78: Rangos promedios en función del género en número total de preocupaciones y soluciones generales. Muestra de PcDID. 


\begin{tabular}{|c|c|c|c|c|c|}
\hline & $\begin{array}{c}\text { U de Mann- } \\
\text { Whitney }\end{array}$ & $\begin{array}{l}\text { W de Wil- } \\
\text { coxon }\end{array}$ & $\mathbf{Z}$ & Sig. & $\eta^{2}$ \\
\hline $\mathbf{N}^{0}$ preocupaciones & 145415,000 & 380370,000 & $-3,807$ &, 000 & $-0,11$ \\
\hline $\mathbf{N}^{0}$ soluciones & 149213,500 & 384168,500 & $-3,162$ & ,002 & $-0,09$ \\
\hline $\mathbf{N}^{\circ}$ apoyos institucionales & 152307,500 & 387262,500 & $-2,693$ & ,007 & $-0,08$ \\
\hline $\mathbf{N}^{\mathbf{o}}$ pensamientos futuro & 152158,500 & 387113,500 & $-2,805$ &, 005 & $-0,08$ \\
\hline $\mathbf{N}^{0}$ problemas señalados & 151171,000 & 386126,000 & $-2,840$ & ,005 & $-0,08$ \\
\hline $\mathbf{N}^{0}$ consideraciones & 155926,000 & 390881,000 & $-3,270$ & ,001 & $-0,09$ \\
\hline
\end{tabular}

Tabla 79: Estadísticos de contraste en función del género en número total de preocupaciones y soluciones generales. Muestra de PcDID.

\begin{tabular}{|c|c|c|c|}
\hline & Género & $\mathbf{N}$ & $\begin{array}{l}\text { Rango pro- } \\
\text { medio }\end{array}$ \\
\hline \multirow{3}{*}{$\begin{array}{l}\mathrm{N}^{\circ} \text { preocupaciones } \\
\text { sobre salud personal }\end{array}$} & Varón & 685 & 564,92 \\
\hline & Mujer & 488 & 617,99 \\
\hline & Total & 1173 & \\
\hline \multirow{3}{*}{$\begin{array}{l}\mathrm{N}^{0} \text { preocupaciones } \\
\text { recursos económicos }\end{array}$} & Varón & 685 & 579,91 \\
\hline & Mujer & 488 & 596,95 \\
\hline & Total & 1173 & \\
\hline \multirow{3}{*}{$\begin{array}{l}\mathbf{N}^{0} \text { preocupaciones } \\
\text { recursos sanitarios }\end{array}$} & Varón & 685 & 562,20 \\
\hline & Mujer & 488 & 621,81 \\
\hline & Total & 1173 & \\
\hline \multirow{3}{*}{$\begin{array}{l}\mathbf{N}^{0} \text { preoc. recursos de } \\
\text { servicios sociales }\end{array}$} & Varón & 685 & 562,58 \\
\hline & Mujer & 488 & 621,28 \\
\hline & Total & 1173 & \\
\hline \multirow{3}{*}{$\begin{array}{l}N^{0} \text { preoc. existencia de } \\
\text { barreras }\end{array}$} & Varón & 685 & 555,78 \\
\hline & Mujer & 488 & 630,83 \\
\hline & Total & 1173 & \\
\hline \multirow{3}{*}{$\begin{array}{l}N^{0} \text { otras preocupacio- } \\
\text { nes y necesidades }\end{array}$} & Varón & 685 & 560,57 \\
\hline & Mujer & 488 & 624,09 \\
\hline & Total & 1173 & \\
\hline
\end{tabular}

Tabla 80: Rangos promedios en función del género en número total de preocupaciones y necesidades específicas. 


\begin{tabular}{lccccc}
\hline & $\begin{array}{c}\text { U de Mann- } \\
\text { Whitney }\end{array}$ & $\begin{array}{c}\text { W de Wil- } \\
\text { coxon }\end{array}$ & $\mathbf{Z}$ & Sig. & $\boldsymbol{\eta}^{\mathbf{2}}$ \\
\hline Salud personal & 152017,000 & 386972,000 & $-2,733$ &, 006 & $-0,08$ \\
Recursos económicos & 162284,000 & 397239,000 & $-0,930$ &, 352 & $-0,03$ \\
Recursos sanitarios & 150154,500 & 385109,500 & $-3,129$ &, 002 & $-0,09$ \\
Recursos de servicios sociales & 150411,000 & 385366,000 & $-3,047$ &, 002 & $-0,01$ \\
Existencia de barreras & 145751,000 & 380706,000 & $-3,882$ &, 000 & $-0,09$ \\
Otras necesidades & 149038,000 & 383993,000 & $-3,311$ &, 001 & $-0,09$ \\
\hline \multicolumn{4}{c}{ Nota: el valor del tamaño del efecto $\left(\eta^{2}\right)$ debe interpretarse en valor absoluto. } \\
\hline
\end{tabular}

Tabla 81: Estadísticos de contraste en función del género en número total de preocupaciones específicas. Muestra de PcDID.

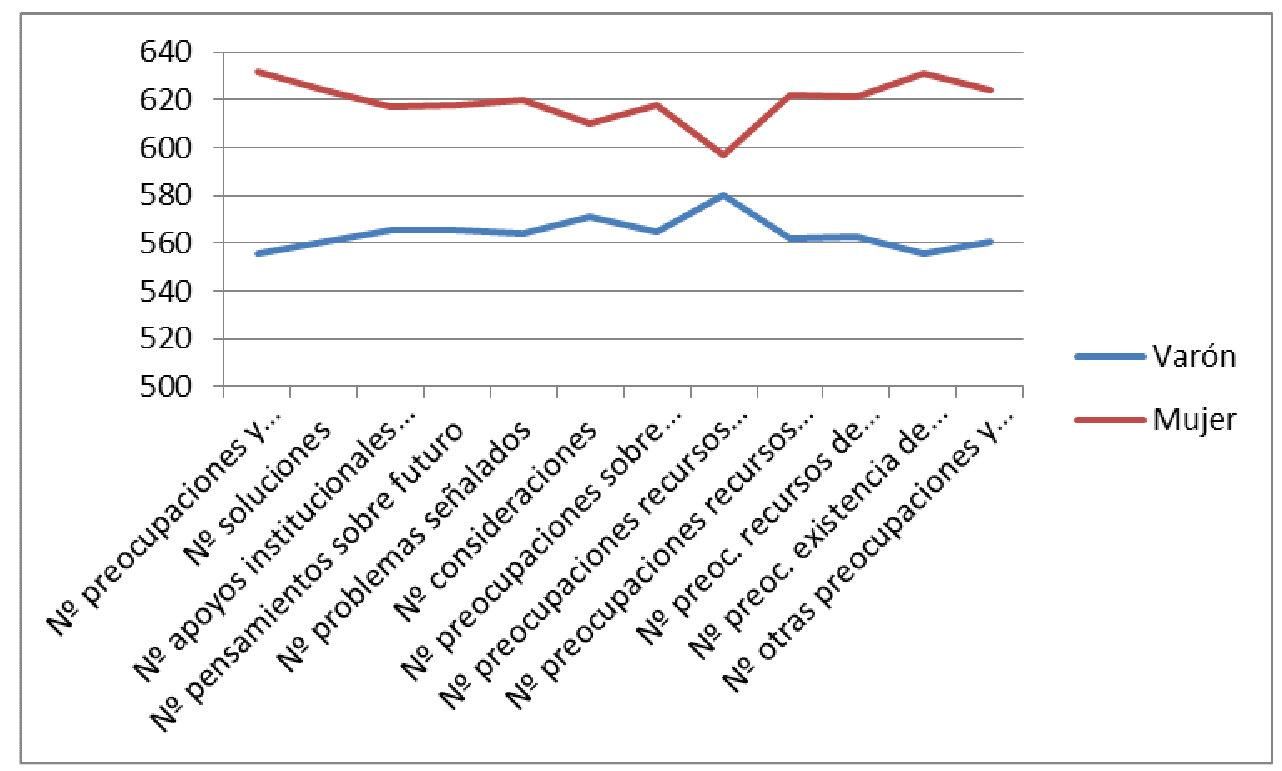

Gráfico 7: Rangos promedio en función del género en número total de preocupaciones generales y específicas. Muestra de PcDID. 


\begin{tabular}{|c|c|c|}
\hline PcDID & VARIABLES & $\begin{array}{c}\text { GÉNERO } \\
\text { Mujer } \\
\text { Hombre }\end{array}$ \\
\hline \multirow{12}{*}{$\begin{array}{c}\text { TODOS } \\
\text { N= 1173 } \\
\text { Mujer: } 488 \\
\text { Hombre: } 685\end{array}$} & $\mathrm{~N}^{\circ}$ preoc y necesidades & SI:+Mujer \\
\hline & $\mathrm{N}^{\circ}$ soluciones & SI:+Mujer \\
\hline & $\mathrm{N}^{\circ}$ apoyos institucionales & SI:+Mujer \\
\hline & $\mathrm{N}^{0}$ pensam futuro & SI:+Mujer \\
\hline & $\mathbf{N}^{0}$ problemas señalados & SI:+Mujer \\
\hline & $\mathbf{N}^{0}$ otras consideraciones & SI:+Mujer \\
\hline & $\mathbf{N}^{\mathbf{0}}$ necesidades salud personal & SI:+Mujer \\
\hline & $\mathrm{N}^{\mathrm{o}}$ necesidades recursos económicos & NO \\
\hline & $\mathrm{N}^{\circ}$ necesidades recursos servicios sanitarios & SI:+Mujer \\
\hline & $\mathbf{N}^{0}$ necesidades recursos servicios sociales & SI:+Mujer \\
\hline & $\mathbf{N}^{0}$ necesidades existencia de barreras & SI:+Mujer \\
\hline & $\mathbf{N}^{0}$ otras necesidades & SI:+Mujer \\
\hline
\end{tabular}

Nota: $\mathrm{NO}=$ no hay diferencias estadísticamente significativas; SI: hay diferencias estadísticamente significativas; + seguido del grupo indica dónde se encuentran mayores rangos promedio.

Tabla 82: Resumen de diferencias en función del género. Muestra de PcDID.

\subsubsection{Resumen}

Con estos resultados, podemos decir que la variable género influye significativamente en los resultados de la entrevista, cuestión que podría estudiarse más a fondo para comprender por qué se producen tales diferencias en cuanto a las necesidades percibidas por hombres y mujeres.

\subsubsection{Variable edad}

\subsubsection{Introducción}

Otra de las variables predictoras que hemos estudiado ha sido la edad. Como en investigaciones previas revisadas la edad que se ha marcado como inicio del envejecimiento en PcDID es 45 años, en las PcSD se marca alrededor de los 35 y en la población general sobre los 65 , se han establecido tres grupos de edad para el estudio de esta variable: 
- $\quad$ De 35 a 49 años

- $\quad$ De 40 a 64 años

- 65 y más años

\subsubsection{Resultados sobre la variable edad}

En este caso la prueba elegida fue la Kruskal-Wallis.

Los resultados indican que existen diferencias estadísticamente significativas $(p<0,05)$ en cuanto al número de soluciones, apoyos institucionales que se echan en falta, pensamientos de futuro y otras consideraciones (tabla 84), de manera que las personas con DID de entre 35 y 49 años han señalado un mayor número de soluciones, apoyos institucionales y pensamientos de futuro, mientras que las personas con DID de 65 o más años han señalado un mayor número de otras consideraciones (tabla 83). 


\begin{tabular}{|c|c|c|c|}
\hline & $\begin{array}{l}\text { Edad recodifi- } \\
\text { cada }\end{array}$ & $\mathbf{N}$ & $\begin{array}{c}\text { Rango pro- } \\
\text { medio }\end{array}$ \\
\hline \multirow{4}{*}{$\begin{array}{l}\mathrm{N}^{\mathbf{o}} \text { preocupaciones } \mathrm{y} \\
\text { necesidades }\end{array}$} & 35-49 años & 512 & 607,44 \\
\hline & 50-64 años & 569 & 571,96 \\
\hline & 65 o más años & 92 & 566,30 \\
\hline & Total & 1173 & \\
\hline \multirow[t]{4}{*}{$\mathbf{N}^{\mathbf{o}}$ soluciones } & 35-49 años & 512 & 635,11 \\
\hline & 50-64 años & 569 & 568,65 \\
\hline & 65 o más años & 92 & 432,72 \\
\hline & Total & 1173 & \\
\hline \multirow{4}{*}{$\begin{array}{l}\mathrm{N}^{\circ} \text { apoyos institucio- } \\
\text { nales requeridos }\end{array}$} & 35-49 años & 512 & 612,93 \\
\hline & 50-64 años & 569 & 583,21 \\
\hline & 65 o más años & 92 & 466,10 \\
\hline & Total & 1173 & \\
\hline \multirow{4}{*}{$\begin{array}{l}\mathrm{N}^{0} \text { pensamientos so- } \\
\text { bre futuro }\end{array}$} & 35-49 años & 512 & 608,58 \\
\hline & 50-64 años & 569 & 578,28 \\
\hline & 65 o más años & 92 & 520,83 \\
\hline & Total & 1173 & \\
\hline \multirow{4}{*}{$\begin{array}{l}\mathrm{N}^{0} \text { problemas señala- } \\
\text { dos }\end{array}$} & 35-49 años & 512 & 595,11 \\
\hline & 50-64 años & 569 & 580,47 \\
\hline & 65 o más años & 92 & 582,24 \\
\hline & Total & 1173 & \\
\hline \multirow[t]{4}{*}{$\mathrm{N}^{\circ}$ consideraciones } & 35-49 años & 512 & 582,76 \\
\hline & 50-64 años & 569 & 578,43 \\
\hline & 65 o más años & 92 & 663,57 \\
\hline & Total & 1173 & \\
\hline
\end{tabular}

Tabla 83: Rangos promedios en función de la edad recodificada en número total de preocupaciones y soluciones generales. Muestra de PcDID. 


\begin{tabular}{lcccc}
\hline & Chi-cuadrado & gl & Sig. & $\boldsymbol{\eta}^{\mathbf{2}}$ \\
\hline $\mathbf{N}^{\mathbf{0}}$ preocupaciones & 3,343 & 2 &, 188 & $-0,03$ \\
$\mathbf{N}^{\mathbf{o}}$ soluciones & 31,624 & 2 &, 000 & $-0,12$ \\
$\mathbf{N}^{\mathbf{o}}$ apoyos institucionales & 15,948 & 2 &, 000 & $-0,08$ \\
$\mathbf{N}^{\mathbf{o}}$ pensamientos futuro & 6,840 & 2 &, 033 & $-0,06$ \\
$\mathbf{N}^{\mathbf{o}}$ problemas señalados & 0,541 & 2 &, 763 & $-0,01$ \\
$\mathbf{N}^{\mathbf{o}}$ otras consideraciones & 14,304 & 2 &, 001 & $-0,07$ \\
\hline Nota: el valor del tamaño del efecto $\left(\eta^{2}\right)$ debe interpretarse en valor absoluto.
\end{tabular}

Tabla 84: Estadísticos de contraste en función de la edad recodificada en número total de preocupaciones y soluciones generales. Muestra de PcDID.

En lo referente a las necesidades específicas, observamos que existen diferencias estadísticamente significativas $(\mathrm{p}<0,05)$ en el número de necesidades sobre recursos económicos y en otras preocupaciones y necesidades (tabla 86), siendo mayor el número de respuestas en ambos tipos de necesidades por parte de las PcDID de entre 35 y 49 años (tabla 85).

En el gráfico 8 se reflejan los rangos promedios de las elecciones de los tres grupos de edad de la muestra en cada una de las variables criterio estudiadas. 


\begin{tabular}{|c|c|c|c|}
\hline & $\begin{array}{l}\text { Edad recodifica- } \\
\text { da }\end{array}$ & $\mathbf{N}$ & $\begin{array}{l}\text { Rango pro- } \\
\text { medio }\end{array}$ \\
\hline \multirow{4}{*}{$\begin{array}{l}\mathbf{N}^{\circ} \text { preocupaciones so- } \\
\text { bre salud personal }\end{array}$} & 35-49 años & 512 & 594,54 \\
\hline & 50-64 años & 569 & 573,08 \\
\hline & 65 o más años & 92 & 631,12 \\
\hline & Total & 1173 & \\
\hline \multirow{4}{*}{$\begin{array}{l}\mathrm{N}^{0} \text { preocupaciones re- } \\
\text { cursos económicos }\end{array}$} & $35-49$ años & 512 & 616,77 \\
\hline & 50-64 años & 569 & 568,06 \\
\hline & 65 o más años & 92 & 538,46 \\
\hline & Total & 1173 & \\
\hline \multirow{4}{*}{$\begin{array}{l}\mathbf{N}^{0} \text { preocupaciones re- } \\
\text { cursos sanitarios }\end{array}$} & 35-49 años & 512 & 573,38 \\
\hline & 50-64 años & 569 & 591,96 \\
\hline & 65 o más años & 92 & 632,12 \\
\hline & Total & 1173 & \\
\hline \multirow{4}{*}{$\begin{array}{l}\mathrm{N}^{\circ} \text { preoc. recursos de } \\
\text { servicios sociales }\end{array}$} & 35-49 años & 512 & 602,54 \\
\hline & 50-64 años & 569 & 581,78 \\
\hline & 65 o más años & 92 & 532,78 \\
\hline & Total & 1173 & \\
\hline \multirow{4}{*}{$\begin{array}{l}N^{0} \text { preoc. existencia de } \\
\text { barreras }\end{array}$} & 35-49 años & 512 & 602,26 \\
\hline & 50-64 años & 569 & 577,68 \\
\hline & 65 o más años & 92 & 559,71 \\
\hline & Total & 1173 & \\
\hline \multirow{4}{*}{$\begin{array}{l}\mathbf{N}^{\circ} \text { otras preocupacio- } \\
\text { nes y necesidades }\end{array}$} & 35-49 años & 512 & 627,10 \\
\hline & 50-64 años & 569 & 569,82 \\
\hline & 65 o más años & 92 & 470,11 \\
\hline & Total & 1173 & \\
\hline
\end{tabular}

Tabla 85: Rangos promedios en función de la edad recodificada en número total de preocupaciones específicas. Muestra de PcDID.

\begin{tabular}{lcccc}
\hline & Chi-cuadrado & gl & Sig asintót & $\boldsymbol{\eta}^{\mathbf{2}}$ \\
\hline Salud personal & 2,964 & 2 &, 227 & $-0,04$ \\
Recursos económicos & 9,145 & 2 &, 010 & $-0,05$ \\
Recursos sanitarios & 2,864 & 2 &, 239 & $-0,04$ \\
Recursos s.sociales & 3,873 & 2 &, 144 & $-0,04$ \\
Existencia barreras & 2,226 & 2 &, 329 & $-0,03$ \\
Otras preocupaciones & 21,440 & 2 &, 000 & $-0,10$ \\
\hline Nota: el valor del tamaño del efecto $\left(\eta^{2}\right)$ debe interpretarse en valor absoluto.
\end{tabular}

Tabla 86: Estadísticos de contraste en función de la edad recodificada en número total de preocupaciones específicas. Muestra de PcDID. 


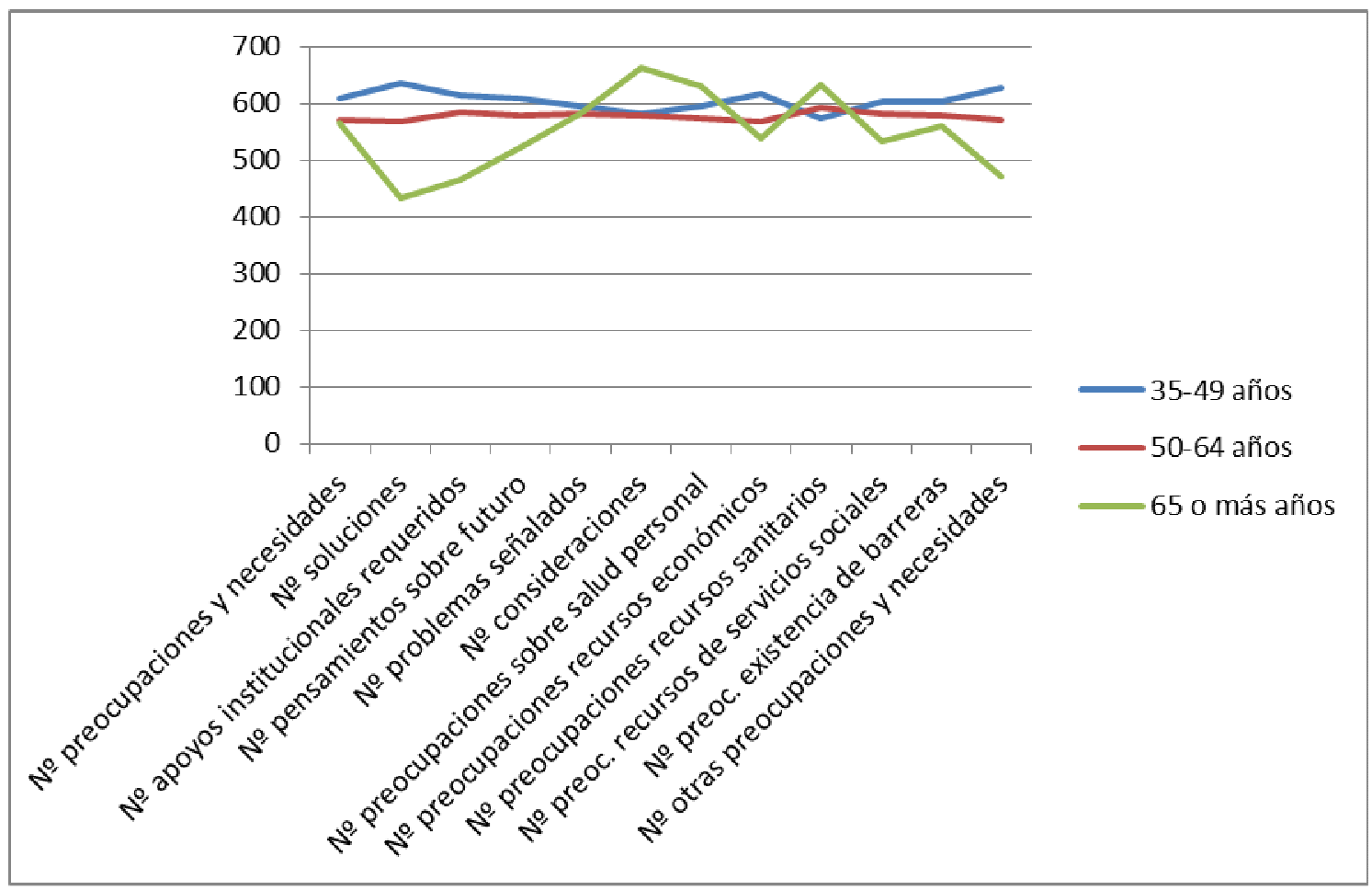

Gráfico 8: Rangos promedio en función del grupo de edad recodificada en número total de precupaciones generales y específicas. Muestra de PcDID.

En la tabla 87 aparece el resumen de la significatividad de los resultados estadísticos comentados previamente. 


\begin{tabular}{|c|c|c|}
\hline PcDID & VARIABLES & $\begin{array}{c}\text { EDAD } \\
\text { 35-49 años } \\
\text { 50-64 años } \\
65 \text { o más años }\end{array}$ \\
\hline \multirow{12}{*}{$\begin{array}{c}\text { TODOS } \\
\mathrm{N}=1173 \\
\text { 35-49 años }=512 \\
50-64 \text { años }=569 \\
65 \text { o más años }=92\end{array}$} & $\mathrm{~N}^{\mathrm{o}}$ preoc y necesidades & NO \\
\hline & $\mathrm{N}^{0}$ soluciones & SI:+35-49 años \\
\hline & $\mathrm{N}^{\mathbf{o}}$ apoyos institucionales & SI:+35-49 años \\
\hline & $\mathrm{N}^{\mathbf{o}}$ pensam futuro & SI:+35-49 años \\
\hline & $\mathrm{N}^{\circ}$ problemas señalados & $\mathrm{NO}$ \\
\hline & $\mathbf{N}^{0}$ otras consideraciones & SI:+65 o más años \\
\hline & $\mathrm{N}^{\mathrm{o}}$ necesidades salud personal & NO \\
\hline & $\mathrm{N}^{\circ}$ necesidades recursos económicos & SI:+35-49 años \\
\hline & $\mathrm{N}^{\circ}$ necesidades recursos servicios sanitarios & NO \\
\hline & $\mathrm{N}^{\mathrm{o}}$ necesidades recursos servicios sociales & NO \\
\hline & $\mathrm{N}^{\circ}$ necesidades existencia de barreras & NO \\
\hline & $\mathrm{N}^{\mathbf{0}}$ otras necesidades & SI:+35-49 años \\
\hline
\end{tabular}

Nota: $\mathrm{NO}=$ no hay diferencias estadísticamente significativas; SI: hay diferencias estadísticamente significativas; + seguido del grupo indica dónde se encuentran mayores rangos promedio.

Tabla 87: Resumen de diferencias en función de la edad recodificada. Muestra de PcDID.

\subsubsection{Resumen}

En este apartado hemos visto que la edad también influye en las variables estudiadas, de forma que las PcDID de entre 35 y 49 años han señalado un mayor número de necesidades en general que el resto de los grupos de edad, teniendo en cuenta que las personas de 65 o más años han marcado un mayor número de necesidades dentro del apartado otras consideraciones. Esto podría estudiarse más profundamente, ya que puede ser que el cuestionario no haya recogido explícitamente necesidades más ajustadas a las personas con DID de este rango de edad. 


\subsubsection{Variable grado de discapacidad}

\subsubsection{Introducción}

El grado de discapacidad es una variable de suma importancia en nuestros resultados, ya que a mayor grado de discapacidad se infiere que mayores necesidades de apoyo tendrá la persona. Además, puede ocurrir que las PcDID con grados más elevados de discapacidad tengan mayores dificultades a la hora de responder el cuestionario, aunque en algunos casos fue otra persona quien se puso en el lugar de la PcDID para responder.

\subsubsection{Resultados sobre la variable grado de discapacidad}

En primer lugar, hemos dividido la muestra en dos grupos en función de si el grado de discapacidad era menor o igual o mayor al $65 \%$, ya que es el porcentaje a partir del cual las PcDID acceden a recursos administrativos y los hemos analizado a través de la prueba U de Mann-Whitney.

Los resultados indican que hay diferencias estadísticamente significativas $(\mathrm{p}<0,05)$ en el número de soluciones, apoyos institucionales y pensamientos de futuro (tabla 89), de manera que las personas con un grado de discapacidad menor al $65 \%$ han elegido más necesidades en las áreas señaladas (tabla 88).

En cuanto a las necesidades específicas, se encontraron diferencias estadísticamente significativas $(\mathrm{p}<0,05)$ en recursos económicos y en recursos sobre servicios sociales (tabla 91), de forma que las personas con un grado de discapacidad menor al $65 \%$ también en este caso han puntuado un mayor número de ítems en estas variables (tabla 90). En la tabla 92 se recoge un resumen de la significatividad de los resultados obteni- 
dos, mientras que en el gráfico 9 se pueden observar las diferencias en los rangos promedio de ambos grupos en cuanto a la elección de respuestas.

\begin{tabular}{|c|c|c|c|}
\hline & $\begin{array}{l}\text { Grado de discapa- } \\
\text { cidad }\end{array}$ & $\mathbf{N}$ & $\begin{array}{l}\text { Rango pro- } \\
\text { medio }\end{array}$ \\
\hline \multirow{3}{*}{$\begin{array}{l}\mathbf{N}^{0} \text { preocupaciones } \mathbf{y} \\
\text { necesidades }\end{array}$} & Menor de 65 & 113 & 492,16 \\
\hline & $\begin{array}{l}\text { Igual o mayor que } \\
65\end{array}$ & 861 & 486,89 \\
\hline & Total & 974 & \\
\hline \multirow[t]{3}{*}{$\mathrm{N}^{\mathbf{o}}$ soluciones } & Menor de 65 & 113 & 572,85 \\
\hline & $\begin{array}{l}\text { Igual o mayor que } \\
65\end{array}$ & 861 & 476,30 \\
\hline & Total & 974 & \\
\hline \multirow{3}{*}{$\begin{array}{l}\mathrm{N}^{\circ} \text { apoyos institucio- } \\
\text { nales requeridos }\end{array}$} & Menor de 65 & 113 & 571,98 \\
\hline & $\begin{array}{l}\text { Igual o mayor que } \\
65\end{array}$ & 861 & 476,41 \\
\hline & Total & 974 & \\
\hline \multirow{3}{*}{$\begin{array}{l}N^{0} \text { pensamientos so- } \\
\text { bre futuro }\end{array}$} & Menor de 65 & 113 & 601,39 \\
\hline & $\begin{array}{l}\text { Igual o mayor que } \\
65\end{array}$ & 861 & 472,55 \\
\hline & Total & 974 & \\
\hline \multirow{3}{*}{$\begin{array}{l}N^{0} \text { problemas señala- } \\
\text { dos }\end{array}$} & Menor de 65 & 113 & 501,44 \\
\hline & $\begin{array}{l}\text { Igual o mayor que } \\
65\end{array}$ & 861 & 485,67 \\
\hline & Total & 974 & \\
\hline \multirow[t]{3}{*}{$\mathrm{N}^{0}$ consideraciones } & Menor de 65 & 113 & 459,62 \\
\hline & $\begin{array}{l}\text { Igual o mayor que } \\
65\end{array}$ & 861 & 491,16 \\
\hline & Total & 974 & \\
\hline
\end{tabular}

Tabla 88: Rangos promedios en función del grado de discapacidad dicotomizado en número total de preocupaciones y soluciones generales. Muestra de PcDID.

\begin{tabular}{lccccc}
\hline & $\begin{array}{c}\text { U de Mann- } \\
\text { Whitney }\end{array}$ & $\begin{array}{c}\text { W de Wil- } \\
\text { coxon }\end{array}$ & $\mathbf{Z}$ & Sig. & $\boldsymbol{\eta}^{\mathbf{2}}$ \\
\hline $\mathbf{N}^{\mathbf{0}}$ preocupaciones & 48120,000 & 419211,000 & $-0,188$ &, 851 & 0,00 \\
$\mathbf{N}^{\mathbf{o}}$ soluciones & 39002,500 & 410093,500 & $-3,462$ &, 001 & $-0,10$ \\
$\mathbf{N}^{\mathbf{0}}$ apoyos institucionales & 39100,500 & 410191,500 & $-3,530$ &, 000 & $-0,10$ \\
$\mathbf{N}^{\mathbf{o}}$ pensamientos futuro & 35777,000 & 406868,000 & $-4,876$ &, 000 & $-0,14$ \\
$\mathbf{N}^{\mathbf{0}}$ problemas señalados & 47071,500 & 418162,500 & $-0,570$ &, 569 & $-0,02$ \\
$\mathbf{N}^{\mathbf{o}}$ consideraciones & 45496,500 & 51937,500 & $-1,858$ &, 063 & $-0,05$ \\
\hline \multicolumn{2}{c}{ Nota: el valor del tamaño del efecto $\left(\eta^{2}\right)$ debe interpretarse en valor absoluto. } \\
\hline
\end{tabular}

Nota: el valor del tamaño del efecto $\left(\eta^{2}\right)$ debe interpretarse en valor absoluto.

Tabla 89: Estadísticos de contraste en función del grado de discapacidad recodificado en número total de preocupaciones específicas. Muestra de PcDID. 


\begin{tabular}{|c|c|c|c|}
\hline & $\begin{array}{l}\text { Grado de discapaci- } \\
\text { dad }\end{array}$ & $\mathbf{N}$ & $\begin{array}{l}\text { Rango pro- } \\
\text { medio }\end{array}$ \\
\hline \multirow{3}{*}{$\begin{array}{l}\mathbf{N}^{\circ} \text { preocupaciones } \\
\text { sobre salud personal }\end{array}$} & Menor de 65 & 113 & 443,08 \\
\hline & Igual o mayor que 65 & 861 & 493,33 \\
\hline & Total & 974 & \\
\hline \multirow{3}{*}{$\begin{array}{l}N^{0} \text { preocupaciones } \\
\text { recursos económicos }\end{array}$} & Menor de 65 & 113 & 534,87 \\
\hline & Igual o mayor que 65 & 861 & 481,28 \\
\hline & Total & 974 & \\
\hline \multirow{3}{*}{$\begin{array}{l}\mathrm{N}^{o} \text { preocupaciones } \\
\text { recursos sanitarios }\end{array}$} & Menor de 65 & 113 & 501,11 \\
\hline & Igual o mayor que 65 & 861 & 485,71 \\
\hline & Total & 974 & \\
\hline \multirow{3}{*}{$\begin{array}{l}\mathrm{N}^{\circ} \text { preoc. recursos de } \\
\text { servicios sociales }\end{array}$} & Menor de 65 & 113 & 539,06 \\
\hline & Igual o mayor que 65 & 861 & 480,73 \\
\hline & Total & 974 & \\
\hline \multirow{3}{*}{$\begin{array}{l}N^{0} \text { preoc. existencia } \\
\text { de barreras }\end{array}$} & Menor de 65 & 113 & 468,66 \\
\hline & Igual o mayor que 65 & 861 & 489,97 \\
\hline & Total & 974 & \\
\hline \multirow{3}{*}{$\begin{array}{l}N^{o} \text { otras preocupacio- } \\
\text { nes y necesidades }\end{array}$} & Menor de 65 & 113 & 507,33 \\
\hline & Igual o mayor que 65 & 861 & 484,90 \\
\hline & Total & 974 & \\
\hline
\end{tabular}

Tabla 90: Estadísticos de contraste en función del grado de discapacidad dicotomizado en número total de preocupaciones específicas. Muestra de PcDID. 


\begin{tabular}{lccccc}
\hline & $\begin{array}{c}\text { U de Mann- } \\
\text { Whitney }\end{array}$ & $\begin{array}{c}\text { W de Wil- } \\
\text { coxon }\end{array}$ & $\mathbf{Z}$ & Sig. & $\boldsymbol{\eta}^{\mathbf{2}}$ \\
\hline Salud personal & 43627,000 & 50068,000 & $-1,844$ &, 065 & $-0,00$ \\
Recursos económicos & 43294,000 & 414385,000 & $-2,076$ &, 038 & $-0,10$ \\
Recursos sanitarios & 47108,500 & 418199,500 & $-0,574$ &, 566 & $-0,10$ \\
Recursos s.sociales & 42820,500 & 413911,500 & $-2,158$ &, 031 & $-0,14$ \\
Existencia barreras & 46517,500 & 52958,500 & $-0,784$ &, 433 & $-0,02$ \\
Otras preocupaciones & 46406,000 & 417497,000 & $-0,833$ &, 405 & $-0,05$ \\
\hline
\end{tabular}

Nota: el valor del tamaño del efecto $\left(\eta^{2}\right)$ debe interpretarse en valor absoluto.

Tabla 91: Estadísticos de contraste en función del grado de discapacidad dicotomizado en número total de preocupaciones específicas. Muestra de PcDID.

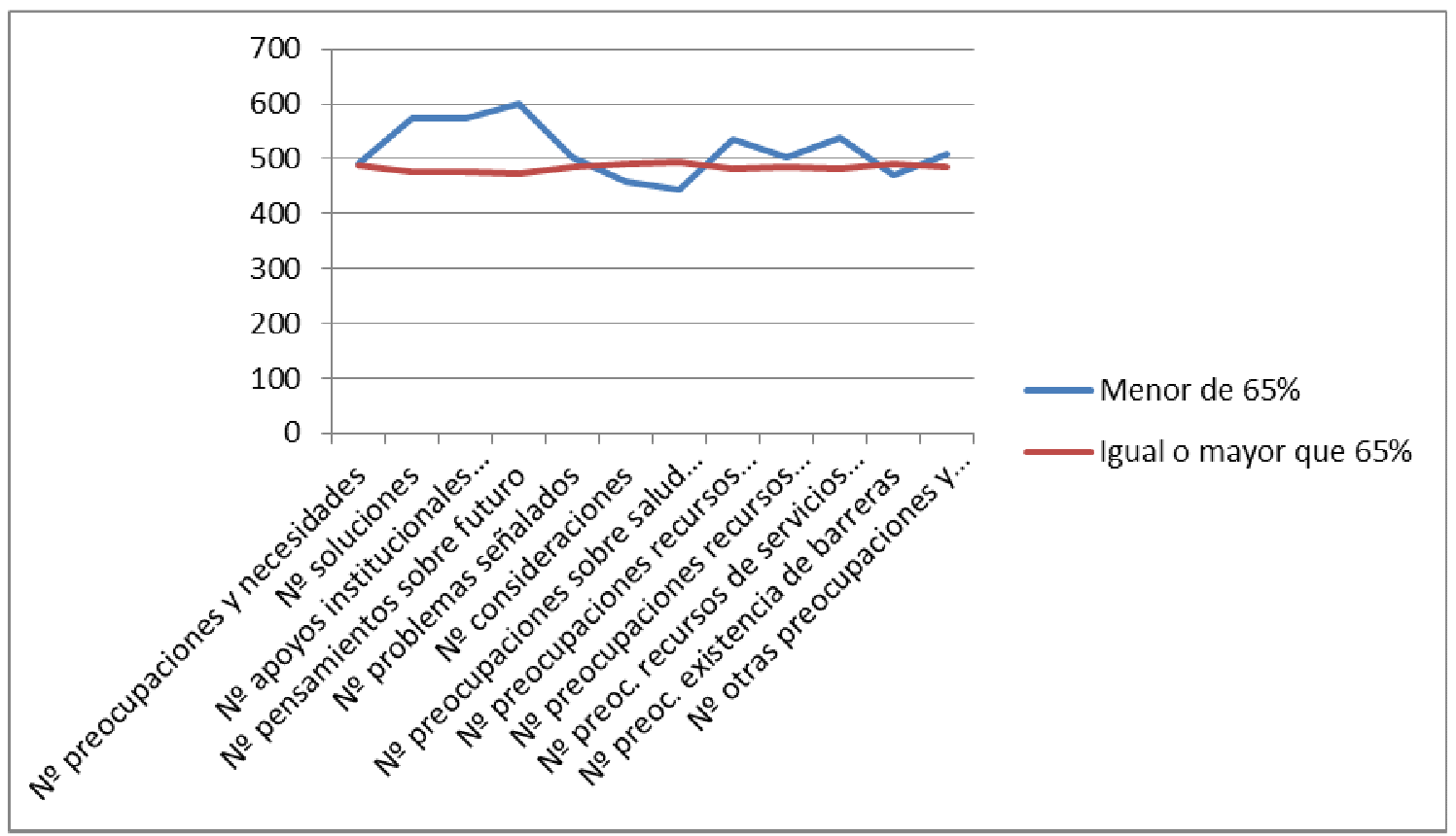

Gráfico 9: Rangos promedio en función del grado de discapacidad dicotomizado en número total de preocupaciones generales y específicas. Muestra de PcDID. 


\begin{tabular}{|c|c|c|}
\hline PcDID & VARIABLES & $\begin{array}{c}\text { GRADO DISCAPACIDAD } \\
\qquad 6 \mathbf{6 5} \\
\geq 65\end{array}$ \\
\hline \multirow{12}{*}{$\begin{array}{l}\text { TODOS } \\
\mathbf{N}=1173 \\
<65=113 \\
\geq 65=861\end{array}$} & $\mathrm{~N}^{\mathrm{o}}$ preoc y necesidades & NO \\
\hline & $\mathrm{N}^{\circ}$ soluciones & SI: $+<65$ \\
\hline & $\mathrm{N}^{\circ}$ apoyos institucionales & SI: $+<65$ \\
\hline & $\mathrm{N}^{0}$ pensam futuro & SI:+<65 \\
\hline & $\mathrm{N}^{\circ}$ problemas señalados & $\mathrm{NO}$ \\
\hline & $\mathrm{N}^{\mathrm{o}}$ otras consideraciones & NO \\
\hline & $\mathrm{N}^{\mathrm{o}}$ necesidades salud personal & $\mathrm{NO}$ \\
\hline & $\mathrm{N}^{\mathbf{o}}$ necesidades recursos económicos & SI: $+<65$ \\
\hline & $\mathrm{N}^{\circ}$ necesidades recursos servicios sanitarios & $\mathrm{NO}$ \\
\hline & $\mathrm{N}^{\circ}$ necesidades recursos servicios sociales & SI:+<65 \\
\hline & $\mathrm{N}^{\circ}$ necesidades existencia de barreras & $\mathrm{NO}$ \\
\hline & $\mathrm{N}^{\circ}$ otras necesidades & NO \\
\hline
\end{tabular}

Nota: $\mathrm{NO}=$ no hay diferencias estadísticamente significativas; SI: hay diferencias estadísticamente significativas; + seguido del grupo indica dónde se encuentran mayores rangos promedio.

\section{Tabla 92: Resumen de diferencias en función del grado de discapacidad dicotomi-} zado. Muestra de PcDID.

Posteriormente, dividimos la muestra de PcDID en tres grupos en función del grado de discapacidad:

- Hasta el 65\%

- $\quad$ Entre el 65 y el $80 \%$

- Igual o mayor que $81 \%$

En este caso, se realizó la prueba de Krukal-Wallis y los resultados indicaron que existen diferencias estadísticamente significativas $(\mathrm{p}<0,05)$ en el número de soluciones, apoyos institucionales requeridos y pensamientos de futuro (tabla 94), número que continúa siendo superior en el grupo de personas con un grado de discapacidad de hasta el $65 \%$ (tabla 93).

En cuanto a las necesidades específicas, se obtuvieron diferencias estadísticamente significativas $(\mathrm{p}<0,05)$ en el número de preocupaciones sobre recursos económicos, recursos sobre servicios sociales y en otras preocupaciones (tabla 96), y en todos los 
casos, la tendencia a una mayor puntuación se obtuvo en el grupo de personas con un grado de discapacidad inferior al 65\% (tabla 95). En el gráfico 10 podemos observar los rangos promedios de cada grupo en cuanto al número de elecciones en cada una de las variables estudiadas. Por último, en la tabla 97 aparece un resumen de la significatividad de los datos obtenidos.

\begin{tabular}{|c|c|c|c|}
\hline & $\begin{array}{l}\text { Grado de discapa- } \\
\text { cidad }\end{array}$ & $\mathbf{N}$ & $\begin{array}{l}\text { Rango pro- } \\
\text { medio }\end{array}$ \\
\hline \multirow{4}{*}{$\begin{array}{l}\mathrm{N}^{\circ} \text { preocupaciones } \mathrm{y} \\
\text { necesidades }\end{array}$} & Hasta 65 & 114 & 491,48 \\
\hline & De 65 a 80 & 571 & 485,65 \\
\hline & $\begin{array}{l}\text { Igual o mayor que } \\
81\end{array}$ & 289 & 489,58 \\
\hline & Total & 974 & \\
\hline \multirow{4}{*}{$\mathbf{N}^{o}$ soluciones } & Hasta 65 & 114 & 571,15 \\
\hline & De 65 a 80 & 571 & 493,10 \\
\hline & $\begin{array}{l}\text { Igual o mayor que } \\
81\end{array}$ & 289 & 443,44 \\
\hline & Total & 974 & \\
\hline \multirow{4}{*}{$\begin{array}{l}N^{0} \text { apoyos institucio- } \\
\text { nales requeridos }\end{array}$} & Hasta 65 & 114 & 571,21 \\
\hline & De 65 a 80 & 571 & 492,19 \\
\hline & $\begin{array}{l}\text { Igual o mayor que } \\
81\end{array}$ & 289 & 445,21 \\
\hline & Total & 974 & \\
\hline \multirow{4}{*}{$\begin{array}{l}N^{0} \text { pensamientos so- } \\
\text { bre futuro }\end{array}$} & Hasta 65 & 114 & 603,46 \\
\hline & De 65 a 80 & 571 & 488,86 \\
\hline & $\begin{array}{l}\text { Igual o mayor que } \\
81\end{array}$ & 289 & 439,08 \\
\hline & Total & 974 & \\
\hline \multirow{4}{*}{$\begin{array}{l}N^{0} \text { problemas señala- } \\
\text { dos }\end{array}$} & Hasta 65 & 114 & 499,27 \\
\hline & De 65 a 80 & 571 & 491,12 \\
\hline & $\begin{array}{l}\text { Igual o mayor que } \\
81\end{array}$ & 289 & 475,70 \\
\hline & Total & 974 & \\
\hline \multirow{4}{*}{$\mathrm{N}^{0}$ consideraciones } & Hasta 65 & 114 & 459,27 \\
\hline & De 65 a 80 & 571 & 487,74 \\
\hline & $\begin{array}{l}\text { Igual o mayor que } \\
81\end{array}$ & 289 & 498,17 \\
\hline & Total & 974 & \\
\hline
\end{tabular}

Tabla 93: Rangos promedios en función del grado de discapacidad recodificado en número total de preocupaciones y soluciones generales. Muestra de PcDID. 


\begin{tabular}{lcccc}
\hline & Chi-cuadrado & gl. & Sig. & \multicolumn{1}{c}{$\boldsymbol{\eta}^{\mathbf{2}}$} \\
\hline $\mathbf{N}^{\mathbf{0}}$ preocupaciones & 0,064 & 2 &, 969 & 0,00 \\
$\mathbf{N}^{\mathbf{0}}$ soluciones & 17,718 & 2 &, 000 & $-0,04$ \\
$\mathbf{N}^{\mathbf{0}}$ apoyos institucionales & 18,146 & 2 &, 000 & $-0,04$ \\
$\mathbf{N}^{\mathbf{a}}$ pensamientos futuro & 31,713 & 2 &, 000 & $-0,11$ \\
$\mathbf{N}^{\mathbf{0}}$ problemas señalados & 0,830 & 2 &, 660 & $-0,01$ \\
$\mathbf{N}^{\mathbf{0}}$ consideraciones & 4,304 & 2 &, 116 & $-0,04$ \\
\hline Nota: el valor del tamaño del efecto $\left(\eta^{2}\right)$ debe interpretarse en valor absoluto.
\end{tabular}

Tabla 94: Estadísticos de contraste en función del grado de discapacidad recodificado en número total de preocupaciones y soluciones generales. Muestra de PcDID.

\begin{tabular}{|c|c|c|c|}
\hline & $\begin{array}{l}\text { Grado de discapa- } \\
\text { cidad }\end{array}$ & $\mathbf{N}$ & $\begin{array}{l}\text { Rango pro- } \\
\text { medio }\end{array}$ \\
\hline \multirow{4}{*}{$\begin{array}{l}\mathbf{N}^{0} \text { preocupaciones so- } \\
\text { bre salud personal }\end{array}$} & Hasta 65 & 114 & 442,00 \\
\hline & De 65 a 80 & 571 & 485,61 \\
\hline & $\begin{array}{l}\text { Igual o mayor que } \\
81\end{array}$ & 289 & 509,18 \\
\hline & Total & 974 & \\
\hline \multirow{4}{*}{$\begin{array}{l}\mathrm{N}^{\circ} \text { preocupaciones re- } \\
\text { cursos económicos }\end{array}$} & Hasta 65 & 114 & 535,07 \\
\hline & De 65 a 80 & 571 & 490,24 \\
\hline & $\begin{array}{l}\text { Igual o mayor que } \\
81\end{array}$ & 289 & 463,32 \\
\hline & Total & 974 & \\
\hline \multirow{4}{*}{$\begin{array}{l}\mathbf{N}^{0} \text { preocupaciones re- } \\
\text { cursos sanitarios }\end{array}$} & Hasta 65 & 114 & 501,35 \\
\hline & De 65 a 80 & 571 & 473,49 \\
\hline & $\begin{array}{l}\text { Igual o mayor que } \\
81\end{array}$ & 289 & 509,73 \\
\hline & Total & 974 & \\
\hline \multirow{4}{*}{$\begin{array}{l}\mathbf{N}^{0} \text { preoc. recursos de } \\
\text { servicios sociales }\end{array}$} & Hasta 65 & 114 & 538,54 \\
\hline & De 65 a 80 & 571 & 488,79 \\
\hline & $\begin{array}{l}\text { Igual o mayor que } \\
81\end{array}$ & 289 & 464,81 \\
\hline & Total & 974 & \\
\hline \multirow{4}{*}{$\begin{array}{l}\mathrm{N}^{0} \text { preoc. existencia de } \\
\text { barreras }\end{array}$} & Hasta 65 & 114 & 468,52 \\
\hline & De 65 a 80 & 571 & 482,89 \\
\hline & $\begin{array}{l}\text { Igual o mayor que } \\
81\end{array}$ & 289 & 504,10 \\
\hline & Total & 974 & \\
\hline \multirow{4}{*}{$\begin{array}{l}\mathbf{N}^{\mathbf{}} \text { otras preocupacio- } \\
\text { nes y necesidades }\end{array}$} & Hasta 65 & 114 & 507,12 \\
\hline & De 65 a 80 & 571 & 503,97 \\
\hline & $\begin{array}{l}\text { Igual o mayor que } \\
81\end{array}$ & 289 & 447,22 \\
\hline & Total & 974 & \\
\hline
\end{tabular}

Tabla 95: Rangos promedios en función del grado de discapacidad recodificado en número total de preocupaciones específicas. Muestra de PcDID. 


\begin{tabular}{lcccc}
\hline & Chi-cuadrado & gl & Sig. asintót. & $\boldsymbol{\eta}^{\mathbf{2}}$ \\
\hline Salud personal & 5,042 & 2 &, 080 & $-0,05$ \\
Recursos económicos & 6,479 & 2 &, 039 & $-0,05$ \\
Recursos sanitarios & 3,855 & 2 &, 146 & $-0,03$ \\
Recursos s.sociales & 6,123 & 2 &, 047 & $-0,05$ \\
Existencia barreras & 1,802 & 2 &, 406 & $-0,02$ \\
Otras preocupaciones & 9,220 & 2 &, 010 & -0.05 \\
\hline
\end{tabular}

Nota: el valor del tamaño del efecto $\left(\eta^{2}\right)$ debe interpretarse en valor absoluto.

Tabla 96: Estadísticos de contraste en función del grado de discapacidad recodificado en el número total de preocupaciones específicas. Muestra de PcDID.

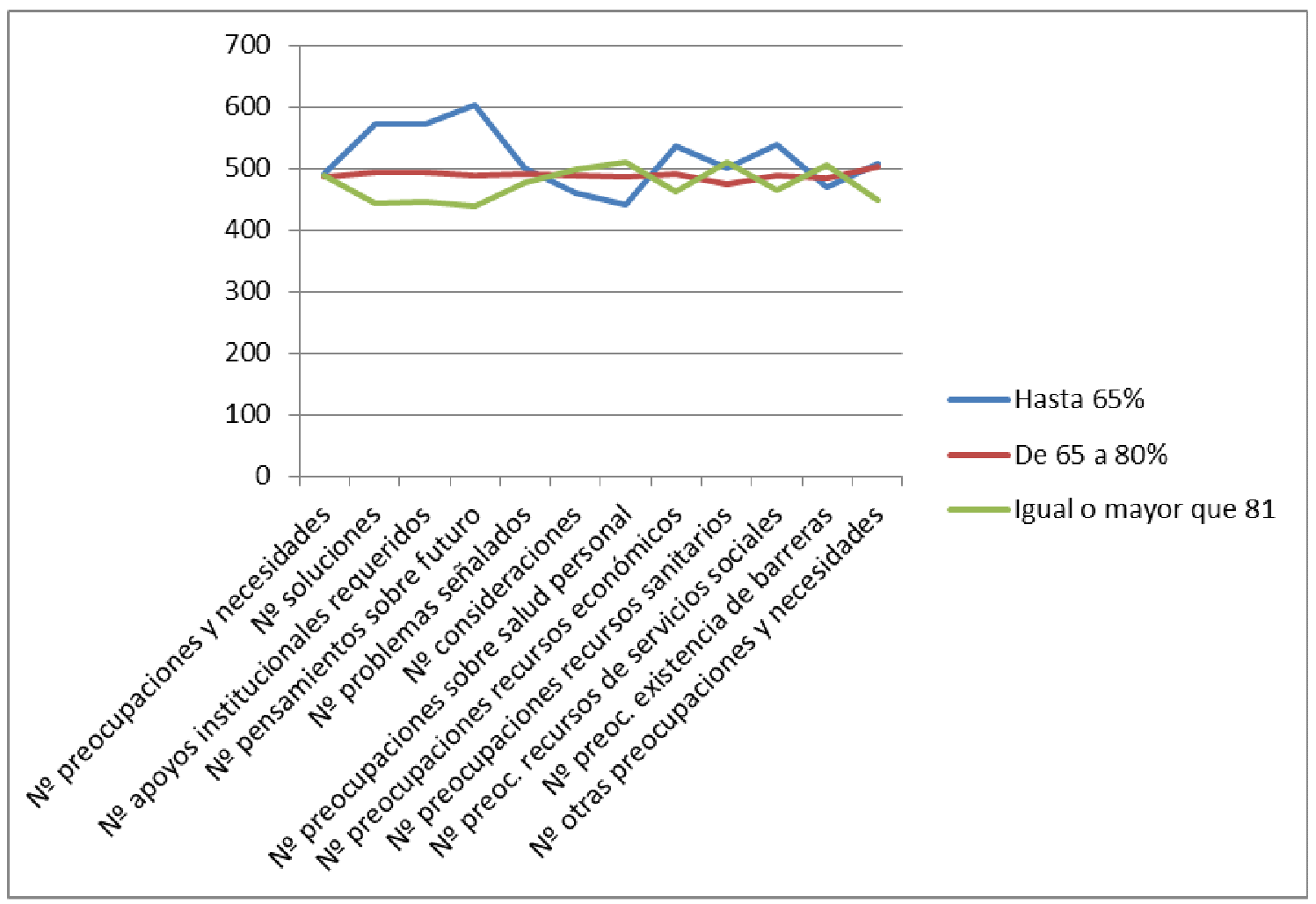

Gráfico 10: Rangos promedio en función del grado de discapacidad recodificado en número total de preocupaciones generales y específicas. Muestra de PcDID. 


\begin{tabular}{|c|c|c|}
\hline PcDID & VARIABLES & $\begin{array}{c}\text { GRADO DISCAPA- } \\
\text { CIDAD } \\
<65 \% \\
65-80 \% \\
\geq 81 \% \\
\end{array}$ \\
\hline \multirow{12}{*}{$\begin{array}{c}\text { TODOS } \\
N=1173 \\
<65 \%=114 \\
65-80 \%=571 \\
\geq 81 \%=289\end{array}$} & $\mathrm{~N}^{\circ}$ preoc y necesidades & $\mathrm{NO}$ \\
\hline & $\mathrm{N}^{\circ}$ soluciones & SI:+<65\% \\
\hline & $\mathrm{N}^{\circ}$ apoyos institucionales & SI:+<65\% \\
\hline & $\mathrm{N}^{\mathbf{o}}$ pensam futuro & SI:+<65\% \\
\hline & $\mathrm{N}^{\circ}$ problemas señalados & NO \\
\hline & $\mathrm{N}^{\mathrm{o}}$ otras consideraciones & NO \\
\hline & $\mathrm{N}^{\circ}$ necesidades salud personal & NO \\
\hline & $\mathbf{N}^{\circ}$ necesidades recursos económicos & SI:+<65\% \\
\hline & $\begin{array}{l}\mathrm{N}^{\circ} \text { necesidades recursos servicios sanita- } \\
\text { rios }\end{array}$ & NO \\
\hline & $\begin{array}{l}N^{0} \text { necesidades recursos servicios socia- } \\
\text { les }\end{array}$ & SI: $+<65 \%$ \\
\hline & $\mathrm{N}^{\circ}$ necesidades existencia de barreras & NO \\
\hline & $\mathbf{N}^{0}$ otras necesidades & SI: $+<65 \%$ \\
\hline
\end{tabular}

Nota: $\mathrm{NO}=$ no hay diferencias estadísticamente significativas; SI: hay diferencias estadísticamente significativas; + seguido del grupo indica dónde se encuentran mayores rangos promedio.

Tabla 97: Resumen de diferencias en función del grado de discapacidad recodificado. Muestra de PcDID.

\subsubsection{Resumen}

El grado de discapacidad ha influido en los resultados, de forma que las personas con un grado inferior al $65 \%$ han destacado significativamente en cuanto al número de ítems señalados. Esto podría ser debido a dificultades por parte de las personas con mayores grados de discapacidad para comprender y responder al cuestionario, o a diferencias en función de quién ha respondido la entrevista. Sea como fuere, no es posible determinar con estos datos cuál es la causa de los resultados, necesitando indagar en mayor medida en este aspecto. 


\subsubsection{Variable tipo de convivencia}

\subsubsection{Introducción}

Otra de las variables que hemos estudiado ha sido el tipo de convivencia, de manera que, dividimos la muestra en 5 grupos en función de si la persona con DID vivía:

- Sola

- Con la familia de origen

- Con la familia propia

- En otras fórmulas

- En un servicio residencial

\subsubsection{Resultados para la variable tipo de convivencia}

Al interpretar los datos, debemos tener en consideración que la muestra de personas que vivían solas o con la familia propia era bastante inferior al resto de grupos, de manera que los resultados deben tomarse con cierta cautela.

Como la agrupación que hemos hecho de la variable es de tipo politómica, la prueba elegida para los análisis fue la Kruskal-Wallis.

Los resultados indican que hay diferencias estadísticamente significativas $(\mathrm{p}<0,05)$ en el número de preocupaciones, soluciones, apoyos institucionales requeridos, pensamientos de futuro y número de consideraciones (tabla 99), de manera que las personas que vivían solas obtuvieron un número significativamente mayor de puntuaciones en el número de soluciones, apoyos institucionales requeridos y en otras consideraciones, mientras que las personas que vivían con la familia propia puntuaban significativamente más ítems en cuanto a las necesidades generales y los pensamientos de futuro (tabla 98). 


\begin{tabular}{|c|c|c|c|}
\hline & Tipo de convivencia & $\mathbf{N}$ & $\begin{array}{l}\text { Rango pro- } \\
\text { medio }\end{array}$ \\
\hline \multirow{6}{*}{$\begin{array}{l}\mathbf{N}^{0} \text { preocupaciones } \mathbf{y} \\
\text { necesidades }\end{array}$} & Sólo & 26 & 690,37 \\
\hline & Familia propia & 5 & 703,20 \\
\hline & Familia de origen & 540 & 607,69 \\
\hline & Otras fórmulas & 209 & 528,36 \\
\hline & $\begin{array}{l}\text { En un servicio residen- } \\
\text { cial }\end{array}$ & 393 & 581,43 \\
\hline & Total & 1173 & \\
\hline \multirow[t]{6}{*}{$\mathrm{N}^{\mathbf{0}}$ soluciones } & Sólo & 26 & 772,17 \\
\hline & Familia propia & 5 & 585,60 \\
\hline & Familia de origen & 540 & 667,24 \\
\hline & Otras fórmulas & 209 & 567,63 \\
\hline & $\begin{array}{l}\text { En un servicio residen- } \\
\text { cial }\end{array}$ & 393 & 474,82 \\
\hline & Total & 1173 & \\
\hline \multirow{6}{*}{$\begin{array}{l}\mathrm{N}^{0} \text { apoyos instituciona- } \\
\text { les requeridos }\end{array}$} & Sólo & 26 & 835,94 \\
\hline & Familia propia & 5 & 607,00 \\
\hline & Familia de origen & 540 & 639,26 \\
\hline & Otras fórmulas & 209 & 581,87 \\
\hline & $\begin{array}{l}\text { En un servicio residen- } \\
\text { cial }\end{array}$ & 393 & 501,19 \\
\hline & Total & 1173 & \\
\hline \multirow{6}{*}{$\begin{array}{l}\mathbf{N}^{0} \text { pensamientos sobre } \\
\text { futuro }\end{array}$} & Sólo & 26 & 762,60 \\
\hline & Familia propia & 5 & 906,10 \\
\hline & Familia de origen & 540 & 637,11 \\
\hline & Otras fórmulas & 209 & 626,19 \\
\hline & $\begin{array}{l}\text { En un servicio residen- } \\
\text { cial }\end{array}$ & 393 & 481,63 \\
\hline & Total & 1173 & \\
\hline \multirow{6}{*}{$\begin{array}{l}N^{0} \text { problemas señala- } \\
\text { dos }\end{array}$} & Sólo & 26 & 598,12 \\
\hline & Familia propia & 5 & 938,00 \\
\hline & Familia de origen & 540 & 591,76 \\
\hline & Otras fórmulas & 209 & 601,41 \\
\hline & $\begin{array}{l}\text { En un servicio residen- } \\
\text { cial }\end{array}$ & 393 & 567,59 \\
\hline & Total & 1173 & \\
\hline \multirow[t]{6}{*}{$\overline{\mathrm{N}^{0} \text { consideraciones }}$} & Sólo & 26 & 667,75 \\
\hline & Familia propia & 5 & 621,20 \\
\hline & Familia de origen & 540 & 572,36 \\
\hline & Otras fórmulas & 209 & 578,23 \\
\hline & $\begin{array}{l}\text { En un servicio residen- } \\
\text { cial }\end{array}$ & 393 & 606,00 \\
\hline & Total & 1173 & \\
\hline
\end{tabular}

Tabla 98: Rangos promedios en función del tipo de convivencia en número total de preocupaciones y soluciones específicas. Muestra de PcDID. 


\begin{tabular}{lcccc}
\hline & Chi-cuadrado & gl & Sig. & $\boldsymbol{\eta}^{\mathbf{2}}$ \\
\hline $\mathbf{N}^{\mathbf{0}}$ preocupaciones & 11,440 & 4 &, 022 & $-0,04$ \\
$\mathbf{N}^{\mathbf{0}}$ soluciones & 83,276 & 4 &, 000 & $-0,08$ \\
$\mathbf{N}^{\mathbf{0}}$ apoyos institucionales & 56,264 & 4 &, 000 & $-0,07$ \\
$\mathbf{N}^{\mathbf{0}}$ pensamientos futuro & 73,468 & 4 &, 000 & $-0,08$ \\
$\mathbf{N}^{\mathbf{o}}$ problemas señalados & 7,416 & 4 &, 115 & $-0,03$ \\
$\mathbf{N}^{\mathbf{0}}$ consideraciones & 10,882 & 4 &, 028 & $-0,03$ \\
\hline Nota: El valor del tamaño del efecto $\left(\eta^{2}\right)$ debe interpretarse en valor absoluto.
\end{tabular}

Tabla 99: Estadísticos de contraste en función del tipo de convivencia en número total de preocupaciones y soluciones generales. Muestra de PcDID.

En cuanto a las necesidades específicas (tabla 101), en todas ellas hay diferencias estadísticamente significativas $(\mathrm{p}<0,05)$, de manera que las personas que vivían con la familia propia puntuaban un mayor número de ítems de salud personal y recursos económicos, mientras que las personas que vivían solas lo hacían en ítems sobre recursos de servicios sanitarios, sociales, existencia de barreras y en otras preocupaciones (tabla 101). En el gráfico 11 podemos observar las diferencias en los rangos promedios de los grupos en función del tipo de convivencia en cada una de las variables criterio estudiadas. En la tabla 102 se recoge el resumen de la significatividad de los datos comentados. 


\begin{tabular}{|c|c|c|c|}
\hline & Tipo de convivencia & $\mathbf{N}$ & $\begin{array}{l}\text { Rango pro- } \\
\text { medio }\end{array}$ \\
\hline \multirow{6}{*}{$\begin{array}{l}\mathrm{N}^{\circ} \text { preocupaciones sobre } \\
\text { salud personal }\end{array}$} & Sólo & 26 & 590,69 \\
\hline & Familia propia & 5 & 738,30 \\
\hline & Familia de origen & 540 & 586,45 \\
\hline & Otras fórmulas & 209 & 523,32 \\
\hline & $\begin{array}{l}\text { En un servicio resi- } \\
\text { dencial }\end{array}$ & 393 & 619,46 \\
\hline & Total & 1173 & \\
\hline \multirow{6}{*}{$\begin{array}{l}N^{o} \text { preocupaciones recur- } \\
\text { sos económicos }\end{array}$} & Sólo & 26 & 726,44 \\
\hline & Familia propia & 5 & 838,50 \\
\hline & Familia de origen & 540 & 611,41 \\
\hline & Otras fórmulas & 209 & 579,14 \\
\hline & $\begin{array}{l}\text { En un servicio resi- } \\
\text { dencial }\end{array}$ & 393 & 545,21 \\
\hline & Total & 1173 & \\
\hline \multirow{6}{*}{$\begin{array}{l}\mathbf{N}^{0} \text { preocupaciones recur- } \\
\text { sos sanitarios }\end{array}$} & Sólo & 26 & 684,94 \\
\hline & Familia propia & 5 & 676,90 \\
\hline & Familia de origen & 540 & 563,45 \\
\hline & Otras fórmulas & 209 & 553,66 \\
\hline & $\begin{array}{l}\text { En un servicio resi- } \\
\text { dencial }\end{array}$ & 393 & 629,47 \\
\hline & Total & 1173 & \\
\hline \multirow{6}{*}{$\begin{array}{l}N^{0} \text { preoc. recursos de ser- } \\
\text { vicios sociales }\end{array}$} & Sólo & 26 & 741,62 \\
\hline & Familia propia & 5 & 641,60 \\
\hline & Familia de origen & 540 & 615,36 \\
\hline & Otras fórmulas & 209 & 546,96 \\
\hline & $\begin{array}{l}\text { En un servicio resi- } \\
\text { dencial }\end{array}$ & 393 & 558,40 \\
\hline & Total & 1173 & \\
\hline \multirow{6}{*}{$\begin{array}{l}N^{o} \text { preoc. existencia de } \\
\text { barreras }\end{array}$} & Sólo & 26 & 642,81 \\
\hline & Familia propia & 5 & 473,80 \\
\hline & Familia de origen & 540 & 596,10 \\
\hline & Otras fórmulas & 209 & 516,20 \\
\hline & $\begin{array}{l}\text { En un servicio resi- } \\
\text { dencial }\end{array}$ & 393 & 609,89 \\
\hline & Total & 1173 & \\
\hline \multirow{6}{*}{$\begin{array}{l}N^{0} \text { otras preocupaciones } y \\
\text { necesidades }\end{array}$} & Sólo & 26 & 683,13 \\
\hline & Familia propia & 5 & 664,50 \\
\hline & Familia de origen & 540 & 649,26 \\
\hline & Otras fórmulas & 209 & 574,51 \\
\hline & $\begin{array}{l}\text { En un servicio resi- } \\
\text { dencial }\end{array}$ & 393 & 500,75 \\
\hline & Total & 1173 & \\
\hline
\end{tabular}

Tabla 100: Rangos promedios en función del tipo de convivencia en número total de preocupaciones específicas. Muestra de PcDID. 


\begin{tabular}{lcccc}
\hline & Chi-cuadrado & gl & Sig. & $\boldsymbol{\eta}^{\mathbf{2}}$ \\
\hline Salud personal & 12,816 & 4 &, 012 & $-0,04$ \\
Recursos económicos & 19,274 & 4 &, 001 & $-0,05$ \\
Recursos sanitarios & 14,802 & 4 &, 005 & $-0,04$ \\
Recursos s.sociales & 16,335 & 4 &, 003 & $-0,05$ \\
Existencia barreras & 13,547 & 4 &, 009 & $-0,04$ \\
Otras preocupaciones & 50,723 & 4 &, 000 & $-0,06$ \\
\hline
\end{tabular}

Nota: El valor del tamaño del efecto $\left(\eta^{2}\right)$ debe interpretarse en valor absoluto.

Tabla 101: Estadísticos de contraste en función del tipo de convivencia en número total de preocupaciones específicas. Muestra de PcDID.

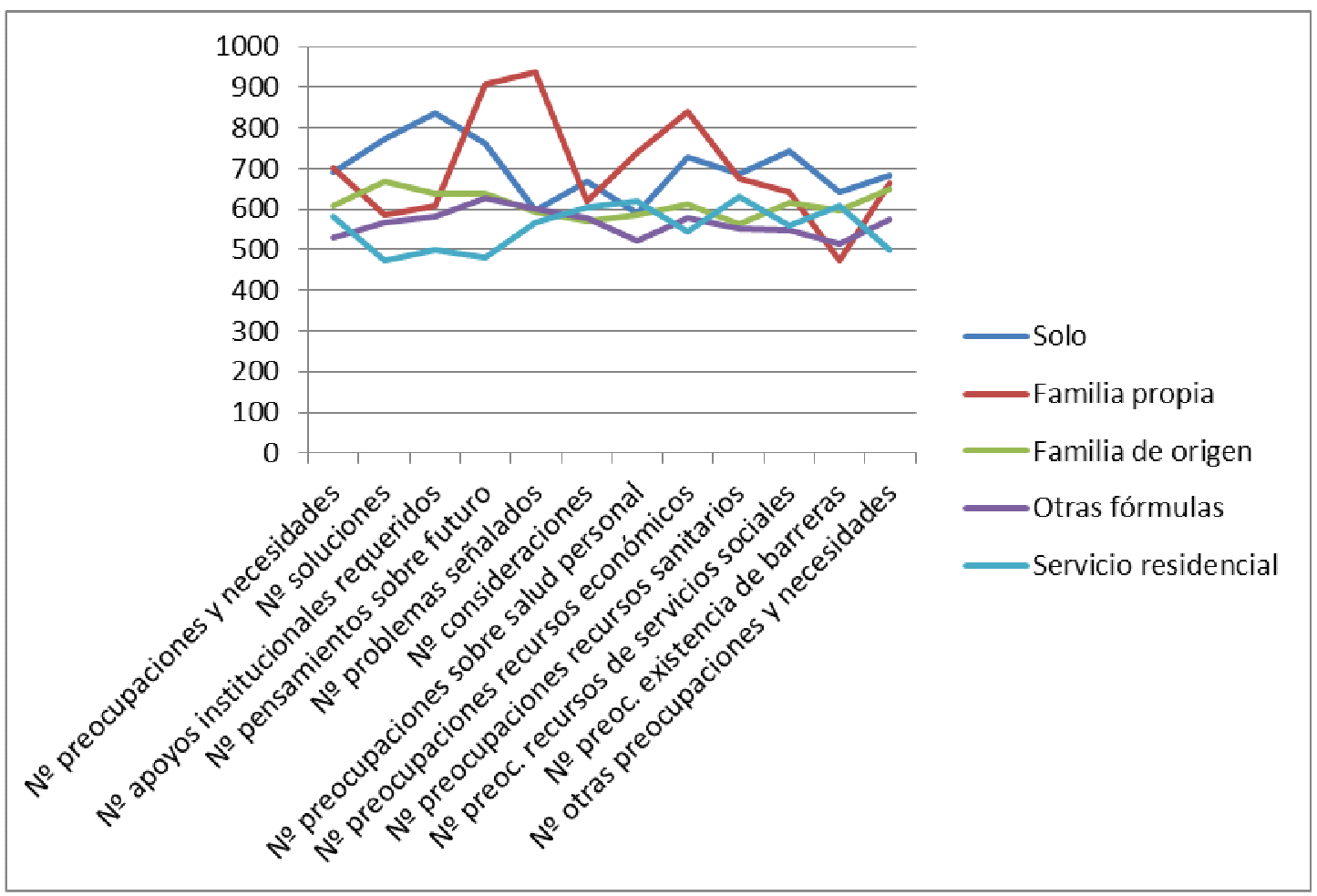

Gráfico 11: Rangos promedio en función del tipo de convivencia en número total de preocupaciones generales y específicas. Muestra de PcDID. 


\begin{tabular}{|c|c|c|}
\hline PcDID & VARIABLES & $\begin{array}{c}\text { TIPO DE CONVI- } \\
\text { VENCIA } \\
\text { Solo } \\
\text { Familia propia } \\
\text { Familia de origen } \\
\text { Otras fórmulas } \\
\text { Servicio residencial }\end{array}$ \\
\hline \multirow{4}{*}{$\begin{array}{l}\text { TODOS } \\
\mathrm{N}=1173\end{array}$} & $\mathrm{~N}^{0}$ preoc y necesidades & SI:+Familia propia \\
\hline & $\mathrm{N}^{\mathrm{o}}$ soluciones & SI:+Solo \\
\hline & $\mathrm{N}^{0}$ apoyos institucionales & SI:+Solo \\
\hline & $\mathrm{N}^{\mathbf{0}}$ pensam futuro & SI:+Familia propia \\
\hline \multirow{8}{*}{$\begin{array}{c}\text { Solo }=26 \\
\text { Familia propia }=5 \\
\text { Familia de origen= } \\
540 \\
\text { Otras fórmulas= } \\
209 \\
\text { Servicio residen- } \\
\text { cial }=393\end{array}$} & $\mathrm{~N}^{\mathrm{o}}$ problemas señalados & $\mathrm{NO}$ \\
\hline & $\mathbf{N}^{\circ}$ otras consideraciones & SI:+Solo \\
\hline & $\mathbf{N}^{\mathbf{o}}$ necesidades salud personal & SI:+Familia propia \\
\hline & $\begin{array}{l}N^{0} \text { necesidades recursos económi- } \\
\cos \end{array}$ & SI:+Familia propia \\
\hline & $\begin{array}{l}N^{0} \text { necesidades recursos servicios } \\
\text { sanitarios }\end{array}$ & SI:+Solo \\
\hline & $\begin{array}{l}\mathrm{N}^{0} \text { necesidades recursos servicios } \\
\text { sociales }\end{array}$ & SI:+Solo \\
\hline & $\begin{array}{l}\mathrm{N}^{0} \text { necesidades existencia de ba- } \\
\text { rreras }\end{array}$ & SI:+Solo \\
\hline & $\mathbf{N}^{0}$ otras necesidades & SI:+Solo \\
\hline
\end{tabular}

Nota: NO=no hay diferencias estadísticamente significativas; SI: hay diferencias estadísticamente significativas; + seguido del grupo indica dónde se encuentran mayores rangos promedio.

Tabla 102: Resumen de diferencias en función del tipo de convivencia recodificado. Muestra de PcDID.

\subsubsection{Resumen}

El dónde vive la PcDID tiene influencia a la hora de responder al cuestionario y señalar un mayor o menor número de ítems. En función del tipo de convivencia, las personas tienen necesidades diferentes.

\subsubsection{Variable residencia}

\subsubsection{Introducción}

La variable población o residencia es relevante también para nuestro estudio ya que en función de si la persona pertenece a una población con más o menos habitantes 
tendrá o no acceso a determinados servicios y en función de ello, tendrá diferentes necesidades.

\subsubsection{Resultados sobre la variable residencia}

En este caso, al ser una variable dicotómica, se empleó la prueba U de MannWhitney.

Los resultados indican que existen diferencias estadísticamente significativas $(p<0,05)$ en el número de preocupaciones, de soluciones y en el de otras preocupaciones (tabla 104). En el caso de las preocupaciones y soluciones, puntúan un mayor número de ítems las personas que viven en poblaciones de más de 10.000 habitantes, mientras que las personas que viven en poblaciones de menos de 10.000 habitantes obtienen mayores puntuaciones en otras preocupaciones no recogidas en el cuestionario (tabla 103).

En lo referente a las necesidades específicas, se han encontrado diferencias estadísticamente significativas ( $\mathrm{p}<0,05)$ en todas ellas (tabla 106), y en todos los casos, las personas que viven en localidades de más de 10.000 habitantes superan en número de elección de ítems al grupo de poblaciones de menor magnitud de habitantes (tabla 105). En el gráfico 12 se pueden observar las tendencias comentadas, mientras que en la tabla 107 se muestra el resumen de la significación de los resultados comentados. 


\begin{tabular}{|c|c|c|c|}
\hline & Residencia & $\mathbf{N}$ & $\begin{array}{c}\text { Rango pro- } \\
\text { medio }\end{array}$ \\
\hline \multirow{3}{*}{$\begin{array}{l}\mathrm{N}^{0} \text { preocupaciones } \mathrm{y} \\
\text { necesidades }\end{array}$} & $<10.000$ & 362 & 517,63 \\
\hline & $>10.000$ & 811 & 617,96 \\
\hline & Total & 1173 & \\
\hline \multirow{3}{*}{$\mathbf{N}^{0}$ soluciones } & $<10.000$ & 362 & 554,32 \\
\hline & $>10.000$ & 811 & 601,59 \\
\hline & Total & 1173 & \\
\hline \multirow{3}{*}{$\begin{array}{l}N^{0} \text { apoyos institucio- } \\
\text { nales requeridos }\end{array}$} & $<10.000$ & 362 & 559,17 \\
\hline & $>10.000$ & 811 & 599,42 \\
\hline & Total & 1173 & \\
\hline \multirow{3}{*}{$\begin{array}{l}\mathbf{N}^{0} \text { pensamientos so- } \\
\text { bre futuro }\end{array}$} & $<10.000$ & 362 & 568,09 \\
\hline & $>10.000$ & 811 & 595,44 \\
\hline & Total & 1173 & \\
\hline \multirow{3}{*}{$\begin{array}{l}N^{o} \text { problemas señala- } \\
\text { dos }\end{array}$} & $<10.000$ & 362 & 580,40 \\
\hline & $>10.000$ & 811 & 589,95 \\
\hline & Total & 1173 & \\
\hline \multirow{3}{*}{$N^{o}$ consideraciones } & $<10.000$ & 164 & 301,55 \\
\hline & $>10.000$ & 437 & 300,79 \\
\hline & Total & 601 & \\
\hline
\end{tabular}

Tabla 103: Rangos promedios en función de la residencia en número total de preocupaciones y soluciones generales. Muestra de PcDID.

\begin{tabular}{lccccc}
\hline & $\begin{array}{c}\text { U de Mann- } \\
\text { Whitney }\end{array}$ & $\begin{array}{c}\text { W de Wil- } \\
\text { coxon }\end{array}$ & $\mathbf{Z}$ & Sig. & $\boldsymbol{\eta}^{\mathbf{2}}$ \\
\hline $\mathbf{N}^{\mathbf{0}}$ preocupaciones $\mathbf{y}$ & 121679,500 & 187382,500 & $-4,695$ &, 000 & $-0,14$ \\
$\mathbf{N}^{\mathbf{0}}$ soluciones & 134960,000 & 200663,000 & $-2,227$ &, 026 & $-0,06$ \\
$\mathbf{N}^{\mathbf{0}}$ apoyos institucionales & 136715,000 & 202418,000 & $-1,952$ &, 051 & $-0,06$ \\
$\mathbf{N}^{\mathbf{o}}$ pensamientos futuro & 139945,000 & 205648,000 & $-1,368$ &, 171 & $-0,04$ \\
$\mathbf{N}^{\mathbf{o}}$ problemas señalados & 144401,000 & 210104,000 & $-0,453$ &, 650 & $-0,01$ \\
$\mathbf{N}^{\mathbf{o}}$ consideraciones & 136873,500 & 202576,500 & $-3,086$ &, 002 & $-0,09$ \\
\hline
\end{tabular}
Nota: El valor del tamaño del efecto $\left(\eta^{2}\right)$ debe interpretarse en valor absoluto.

Tabla 104: Estadísticos de contraste en función de la residencia en número total de preocupaciones y soluciones generales. Muestra de PcDID. 


\begin{tabular}{|c|c|c|c|}
\hline & Residencia & $\mathbf{N}$ & $\begin{array}{c}\text { Rango pro- } \\
\text { medio }\end{array}$ \\
\hline \multirow{3}{*}{$\begin{array}{l}\mathbf{N}^{0} \text { preocupaciones } \\
\text { sobre salud personal }\end{array}$} & $<10.000$ & 362 & 535,20 \\
\hline & $>10.000$ & 811 & 610,12 \\
\hline & Total & 1173 & \\
\hline \multirow{3}{*}{$\begin{array}{l}\mathrm{N}^{0} \text { preocupaciones } \\
\text { recursos económicos }\end{array}$} & $<10.000$ & 362 & 558,48 \\
\hline & $>10.000$ & 811 & 599,73 \\
\hline & Total & 1173 & \\
\hline \multirow{3}{*}{$\begin{array}{l}\mathrm{N}^{0} \text { preocupaciones } \\
\text { recursos sanitarios }\end{array}$} & $<10.000$ & 362 & 529,65 \\
\hline & $>10.000$ & 811 & 612,60 \\
\hline & Total & 1173 & \\
\hline \multirow{3}{*}{$\begin{array}{l}\mathbf{N}^{\circ} \text { preoc. recursos de } \\
\text { servicios sociales }\end{array}$} & $<10.000$ & 362 & 531,91 \\
\hline & $>10.000$ & 811 & 611,59 \\
\hline & Total & 1173 & \\
\hline \multirow{3}{*}{$\begin{array}{l}N^{0} \text { preoc. existencia de } \\
\text { barreras }\end{array}$} & $<10.000$ & 362 & 526,11 \\
\hline & $>10.000$ & 811 & 614,18 \\
\hline & Total & 1173 & \\
\hline \multirow{3}{*}{$\begin{array}{l}\mathbf{N}^{0} \text { otras preocupacio- } \\
\text { nes y necesidades }\end{array}$} & $<10.000$ & 362 & 546,23 \\
\hline & $>10.000$ & 811 & 605,20 \\
\hline & Total & 1173 & \\
\hline
\end{tabular}

Tabla 105: Rangos en función de la residencia en número total de preocupaciones específicas. Muestra de PcDID.

\begin{tabular}{lccccc}
\hline & $\begin{array}{c}\text { U de Mann- } \\
\text { Whitney }\end{array}$ & $\begin{array}{c}\text { W de Wil- } \\
\text { coxon }\end{array}$ & $\mathbf{Z}$ & Sig. & $\boldsymbol{\eta}^{\mathbf{2}}$ \\
\hline $\mathbf{N}^{\mathbf{0}}$ Salud personal & 128039,500 & 193742,500 & $-3,616$ &, 000 & $-0,10$ \\
$\mathbf{N}^{\mathbf{o}}$ Recursos económicos & 136468,500 & 202171,500 & $-2,110$ &, 035 & $-0,06$ \\
$\mathbf{N}^{\mathbf{o}}$ Recursos sanitarios & 126029,000 & 191732,000 & $-4,081$ &, 000 & $-0,12$ \\
$\mathbf{N}^{\mathbf{o}}$ Recursos de s.sociales & 126848,000 & 192551,000 & $-3,876$ &, 000 & $-0,11$ \\
$\mathbf{N}^{\mathbf{o}}$ Existencia de barreras & 124749,000 & 190452,000 & $-4,268$ &, 000 & $-0,12$ \\
$\mathbf{N}^{\mathbf{o}}$ Otras preocupaciones & 132030,500 & 197733,500 & $-2,881$ &, 004 & $-0,08$ \\
\hline \multicolumn{2}{c}{ Nota: El valor del tamaño del efecto $\left(\eta^{2}\right)$ debe interpretarse en valor absoluto. }
\end{tabular}

Tabla 106: Estadísticos de contraste en función de la residencia en número total de preocupaciones específicas. Muestra de PcDID. 


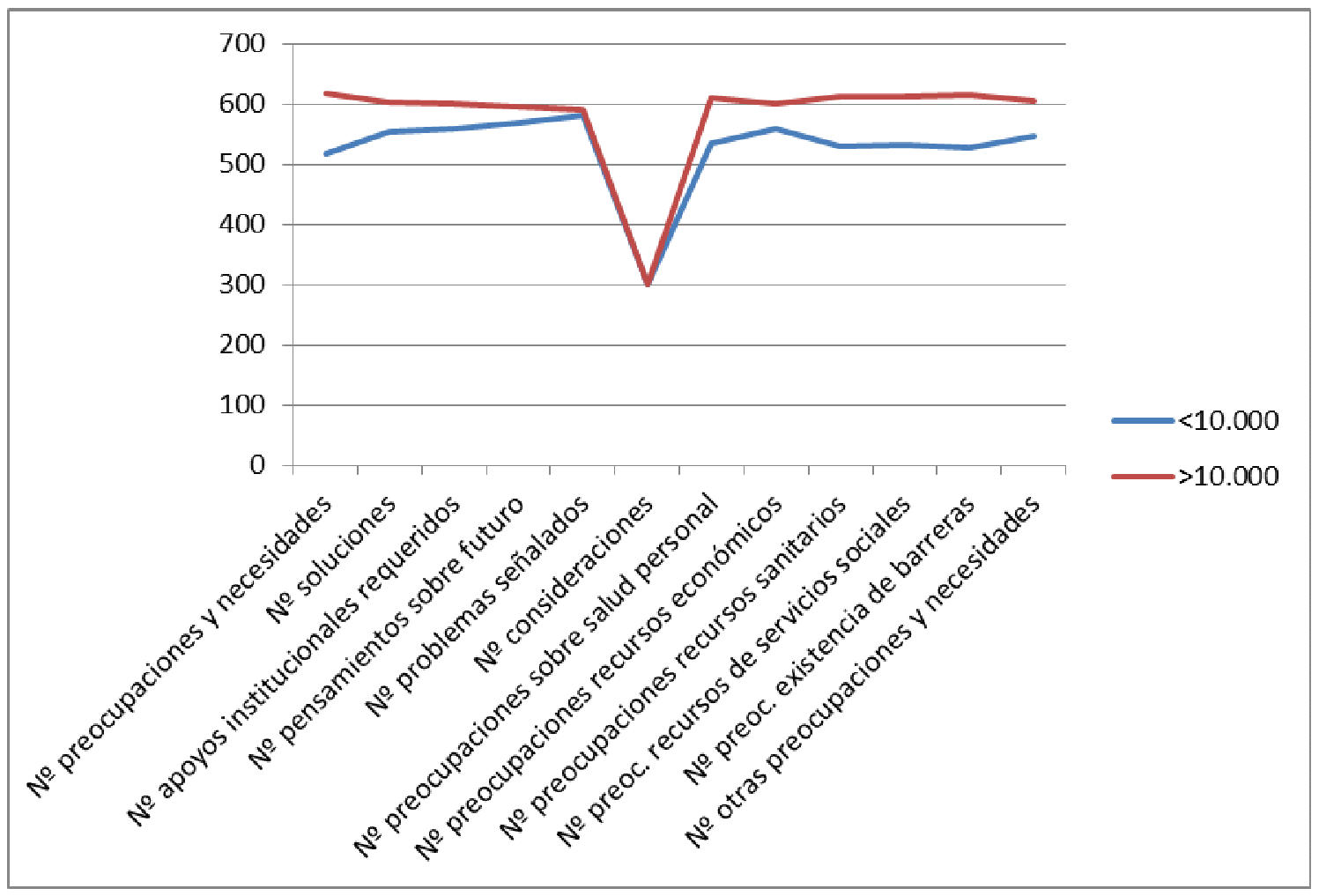

Gráfico 12: Rangos promedio en función de la residencia en número total de preocupaciones generales y específicas. Muestra de PcDID. 


\begin{tabular}{|c|c|c|}
\hline PcDID & VARIABLES & $\begin{array}{c}\text { RESIDENCIA } \\
<10.000 \\
\geq 10.000\end{array}$ \\
\hline \multirow{12}{*}{$\begin{array}{c}\text { TODOS } \\
\mathrm{N}=\mathbf{1 1 7 3} \\
<\mathbf{1 0 . 0 0 0}=\mathbf{3 6 2} \\
\geq \mathbf{1 0 . 0 0 0}=\mathbf{8 1 1}\end{array}$} & $\mathbf{N}^{0}$ preoc y necesidades & SI: $+\geq 10.000$ \\
\hline & $\mathbf{N}^{0}$ soluciones & SI: $+\geq 10.000$ \\
\hline & $\mathrm{N}^{\mathrm{o}}$ apoyos institucionales & NO \\
\hline & $\mathrm{N}^{\mathrm{o}}$ pensam futuro & $\mathrm{NO}$ \\
\hline & $\mathrm{N}^{\circ}$ problemas señalados & NO \\
\hline & $\mathrm{N}^{\circ}$ otras consideraciones & SI: $+<10.000$ \\
\hline & $\mathbf{N}^{\circ}$ necesidades salud personal & SI: $+\geq \mathbf{1 0 . 0 0 0}$ \\
\hline & $\mathrm{N}^{0}$ necesidades recursos económicos & SI: $+\geq 10.000$ \\
\hline & $\mathbf{N}^{0}$ necesidades recursos servicios sanitarios & SI: $+\geq \mathbf{1 0 . 0 0 0}$ \\
\hline & $\mathbf{N}^{0}$ necesidades recursos servicios sociales & SI: $+\geq \mathbf{1 0 . 0 0 0}$ \\
\hline & $\mathbf{N}^{0}$ necesidades existencia de barreras & SI: $+\geq 10.000$ \\
\hline & $\mathbf{N}^{0}$ otras necesidades & SI: $+\geq 10.000$ \\
\hline
\end{tabular}

Nota: $\mathrm{NO}=$ no hay diferencias estadísticamente significativas; SI: hay diferencias estadísticamente significativas; + seguido del grupo indica dónde se encuentran mayores rangos promedio.

Tabla 107: Resumen de diferencias en función de la residencia. Muestra de PcDID.

\subsubsection{Resumen}

En el caso de la población de residencia, es una variable que ha influido en nuestros resultados, de manera que las personas de lugares de más de 10.000 habitantes parecen tener un mayor número de necesidades que las personas de lugares con menor densidad de población. Esto podría ser debido a que el cuestionario no se adecúe a las características de las poblaciones con un bajo número de habitantes, pero es una cuestión que necesita de una investigación más amplia.

\subsubsection{Variable estado civil}

La variable estado civil, si bien se piensa que podría influir en nuestros resultados, hemos considerado no analizarla debido a que el 98\% de las PcDID de las muestra estaban solteras. 


\subsubsection{Variable tipo de discapacidad}

\subsubsection{Introducción}

El tipo de discapacidad también puede influir en el tipo de necesidades que tienen las personas de la muestra. Es por ello por lo que para este apartado la muestra se agrupó en personas con síndrome de Down, personas con otros tipos de DID y personas con parálisis cerebral. Aunque todas ellas tenían discapacidades intelectuales y del desarrollo, pueden existir diferencias en sus necesidades ya que las personas con parálisis cerebral pueden tener más necesidades acordes a sus dificultades motoras, mientras que las personas con síndrome de Down tienen mayores probabilidades de tener otras discapacidades, por ejemplo, de tipo visual.

\subsubsection{Resultados para la variable tipo de discapacidad}

Al agrupar la variable tipo de discapacidad en tres tipos, se empleó la prueba Kruskal-Wallis.

Analizando los resultados de esta variable, observamos que existían diferencias significativas $(\mathrm{p}<0,05)$ en cuanto al número de ítems señalados en preocupaciones, soluciones, pensamientos de futuro y problemas señalados (tabla 109). En todas ellas, el número de ítems señalados era superior en el grupo de personas con parálisis cerebral (tabla 108). 


\begin{tabular}{|c|c|c|c|}
\hline & $\begin{array}{l}\text { Tipo de discapaci- } \\
\text { dad }\end{array}$ & $\mathbf{N}$ & $\begin{array}{l}\text { Rango pro- } \\
\text { medio }\end{array}$ \\
\hline \multirow{4}{*}{$\begin{array}{l}\mathrm{N}^{o} \text { preocupaciones y } \\
\text { necesidades }\end{array}$} & DI Down & 211 & 536,98 \\
\hline & DI Otras & 836 & 582,34 \\
\hline & DF PC & 126 & 701,70 \\
\hline & Total & 1173 & \\
\hline \multirow{4}{*}{$\mathbf{N}^{0}$ soluciones } & DI Down & 211 & 569,22 \\
\hline & DI Otras & 836 & 575,37 \\
\hline & DF PC & 126 & 693,96 \\
\hline & Total & 1173 & \\
\hline \multirow{4}{*}{$\begin{array}{l}\mathrm{N}^{0} \text { apoyos institucio- } \\
\text { nales requeridos }\end{array}$} & DI Down & 211 & 578,54 \\
\hline & DI Otras & 836 & 580,07 \\
\hline & DF PC & 126 & 647,13 \\
\hline & Total & 1173 & \\
\hline \multirow{4}{*}{$\begin{array}{l}\mathrm{N}^{\mathrm{o}} \text { pensamientos so- } \\
\text { bre futuro }\end{array}$} & DI Down & 211 & 534,66 \\
\hline & DI Otras & 836 & 588,29 \\
\hline & DF PC & 126 & 666,11 \\
\hline & Total & 1173 & \\
\hline \multirow{4}{*}{$\begin{array}{l}N^{\circ} \text { problemas señala- } \\
\text { dos }\end{array}$} & DI Down & 211 & 519,88 \\
\hline & DI Otras & 836 & 599,48 \\
\hline & DF PC & 126 & 616,63 \\
\hline & Total & 1173 & \\
\hline \multirow{4}{*}{$\mathbf{N}^{o}$ consideraciones } & DI Down & 211 & 561,09 \\
\hline & DI Otras & 836 & 591,78 \\
\hline & DF PC & 126 & 598,67 \\
\hline & Total & 1173 & \\
\hline
\end{tabular}

Tabla 108: Rangos promedios en función del tipo de discapacidad intelectual y del desarrollo en número total de preocupaciones y soluciones generales. Muestra de PcDID. 


\begin{tabular}{lcccc}
\hline & Chi-cuadrado & gl & Sig. & $\boldsymbol{\eta}^{\mathbf{2}}$ \\
\hline $\mathbf{N}^{\mathbf{0}}$ preocupaciones & 19,283 & 2 &, 000 & $-0,10$ \\
$\mathbf{N}^{\mathbf{o}}$ soluciones & 14,376 & 2 &, 001 & $-0,07$ \\
$\mathbf{N}^{\mathbf{o}}$ apoyos institucionales & 4,799 & 2 &, 091 & -0.04 \\
$\mathbf{N}^{\mathbf{o}}$ pensamientos futuro & 13,670 & 2 &, 001 & $-0,08$ \\
$\mathbf{N}^{\mathbf{o}}$ problemas señalados & 10,735 & 2 &, 005 & $-0,06$ \\
$\mathbf{N}^{\mathbf{o}}$ consideraciones & 4,310 & 2 &, 116 & 0,04 \\
\hline Nota: El valor del tamaño del efecto $\left(\eta^{2}\right)$ debe interpretarse en valor absoluto.
\end{tabular}

Tabla 109: Estadísticos de contraste en función del tipo de discapacidad en número total de preocupaciones y soluciones generales. Muestra de PcDID.

En cuanto a las necesidades específicas, hay diferencias estadísticamente significativas $(p<0,05)$ en salud personal, recursos sanitarios, recursos de servicios sociales, existencia de barreras y otras preocupaciones (tabla 111). En todas ellas, también son las personas con parálisis cerebral las que obtienen un mayor número de puntuaciones (tabla 110).

En el gráfico 13 se pueden observar los rangos promedios de las puntuaciones de cada uno de los grupos en las variables estudiadas, mientras que en la tabla 112 aparece un resumen con la significatividad de los resultados obtenidos. 


\begin{tabular}{|c|c|c|c|}
\hline & $\begin{array}{l}\text { Tipo de discapaci- } \\
\text { dad }\end{array}$ & $\mathbf{N}$ & $\begin{array}{l}\text { Rango pro- } \\
\text { medio }\end{array}$ \\
\hline \multirow{4}{*}{$\begin{array}{l}\mathrm{N}^{0} \text { preocupaciones } \\
\text { sobre salud personal }\end{array}$} & DI Down & 211 & 573,10 \\
\hline & DI Otras & 836 & 576,41 \\
\hline & DF PC & 126 & 680,54 \\
\hline & Total & 1173 & \\
\hline \multirow{4}{*}{$\begin{array}{l}\mathrm{N}^{\circ} \text { preocupaciones } \\
\text { recursos económicos }\end{array}$} & DI Down & 211 & 570,09 \\
\hline & DI Otras & 836 & 589,53 \\
\hline & DF PC & 126 & 598,55 \\
\hline & Total & 1173 & \\
\hline \multirow{4}{*}{$\begin{array}{l}\mathbf{N}^{0} \text { preocupaciones } \\
\text { recursos sanitarios }\end{array}$} & DI Down & 211 & 519,25 \\
\hline & DI Otras & 836 & 594,02 \\
\hline & DF PC & 126 & 653,87 \\
\hline & Total & 1173 & \\
\hline \multirow{4}{*}{$\begin{array}{l}\mathbf{N}^{\circ} \text { preoc. recursos de } \\
\text { servicios sociales }\end{array}$} & DI Down & 211 & 549,71 \\
\hline & DI Otras & 836 & 584,32 \\
\hline & DF PC & 126 & 667,22 \\
\hline & Total & 1173 & \\
\hline \multirow{4}{*}{$\begin{array}{l}N^{0} \text { preoc. existencia de } \\
\text { barreras }\end{array}$} & DI Down & 211 & 542,98 \\
\hline & DI Otras & 836 & 575,76 \\
\hline & DF PC & 126 & 735,27 \\
\hline & Total & 1173 & \\
\hline \multirow{4}{*}{$\begin{array}{l}\mathbf{N}^{\circ} \text { otras preocupacio- } \\
\text { nes y necesidades }\end{array}$} & DI Down & 211 & 536,21 \\
\hline & DI Otras & 836 & 588,22 \\
\hline & DF PC & 126 & 663,97 \\
\hline & Total & 1173 & \\
\hline
\end{tabular}

Tabla 110: Rangos promedios en función del tipo de discapacidad intelectual y del desarrollo en número total de preocupaciones específicas. Muestra de PcDID.

\begin{tabular}{lcccc}
\hline & Chi-cuadrado & gl & Sig. & $\boldsymbol{\eta}^{\mathbf{2}}$ \\
\hline Salud personal & 11,514 & 2 &, 003 & $-0,06$ \\
Recursos económicos & 0,863 & 2 &, 650 & $-0,01$ \\
Recursos sanitarios & 15,213 & 2 &, 000 & $-0,09$ \\
Recursos s.Sociales & 10,500 & 2 &, 005 & $-0,07$ \\
Existencia barreras & 30,828 & 2 &, 000 & $-0,11$ \\
Otras preocupaciones & 12,320 & 2 &, 002 & $-0,08$ \\
\hline \multicolumn{2}{c}{ Nota: El valor del tamaño del efecto $\left(\eta^{2}\right)$ debe interpretarse en valor absoluto. }
\end{tabular}

Tabla 111: Estadísticos de contraste en función del tipo de discapacidad en número total de preocupaciones específicas. Muestra de PcDID. 


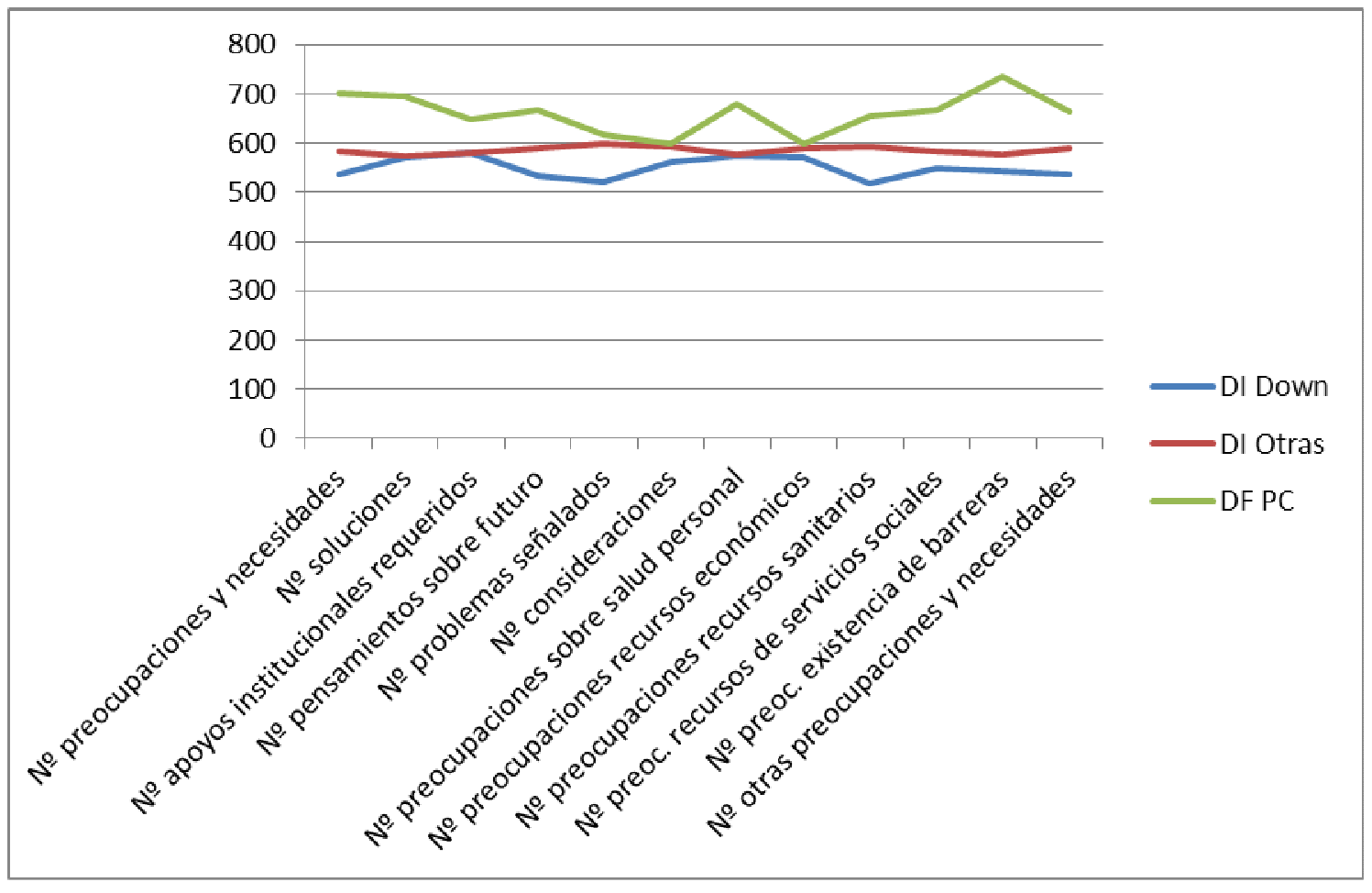

Gráfico 13: Rangos promedio en función del tipo de discapacidad en número total de preocupaciones generales y específicas. Muestra de PcDID. 


\begin{tabular}{|c|c|c|}
\hline PcDID & VARIABLES & $\begin{array}{c}\text { TIPO DISCAPACI- } \\
\text { DAD } \\
\text { Down } \\
\text { Otras DID } \\
\text { PC } \\
\end{array}$ \\
\hline \multirow{12}{*}{$\begin{array}{c}\text { TODOS } \\
\text { N= 1173 } \\
\text { DOWN= 211 } \\
\text { Otras DID= } \\
836 \\
\text { PC }=126\end{array}$} & $\mathrm{~N}^{0}$ preoc y necesidades & SI:+PC \\
\hline & $\mathbf{N}^{\mathbf{0}}$ soluciones & SI:+PC \\
\hline & $\mathrm{N}^{\mathrm{o}}$ apoyos institucionales & $\mathrm{NO}$ \\
\hline & $\mathrm{N}^{0}$ pensam futuro & SI:+PC \\
\hline & $\mathbf{N}^{\mathbf{0}}$ problemas señalados & SI:+PC \\
\hline & $\mathrm{N}^{\circ}$ otras consideraciones & $\mathrm{NO}$ \\
\hline & $\mathbf{N}^{\circ}$ necesidades salud personal & SI:+PC \\
\hline & $\mathrm{N}^{\circ}$ necesidades recursos económicos & $\mathrm{NO}$ \\
\hline & $\begin{array}{l}N^{\circ} \text { necesidades recursos servicios sani- } \\
\text { tarios }\end{array}$ & SI:+PC \\
\hline & $\begin{array}{l}N^{0} \text { necesidades recursos servicios socia- } \\
\text { les }\end{array}$ & SI:+PC \\
\hline & $\mathrm{N}^{0}$ necesidades existencia de barreras & SI:+PC \\
\hline & $\mathbf{N}^{0}$ otras necesidades & SI:+PC \\
\hline
\end{tabular}

Nota: $\mathrm{NO}=$ no hay diferencias estadísticamente significativas; SI: hay diferencias estadísticamente significativas; + seguido del grupo indica dónde se encuentran mayores rangos promedio.

Tabla 112: Resumen de diferencias en función del tipo de discapacidad. Muestra de PcDID.

\subsubsection{Resumen}

Parece ser, según los resultados obtenidos, que las personas con parálisis cerebral señalan un mayor número de necesidades que el resto de los grupos de PcDID, por tanto el tipo de discapacidad de los participantes también influye a la hora de responder el cuestionario presentado.

\subsection{RESUMEN}

El tipo de cumplimentación, el género, la edad, el grado de discapacidad, el tipo de convivencia, la residencia y el tipo de discapacidad han influido en cierta medida sobre los resultados obtenidos en el cuestionario de las PcDID que envejecen.

Un resumen conjunto de los resultados se puede observar en la tabla 113. 


\begin{tabular}{|c|c|c|c|c|c|c|c|c|c|}
\hline \multirow{2}{*}{ Variables } & \multicolumn{2}{|c|}{ Tipo cumplimentación } & \multirow{2}{*}{ Género } & \multirow{2}{*}{ Edad } & \multicolumn{2}{|c|}{$\begin{array}{l}\text { Grado discapaci- } \\
\text { dad }\end{array}$} & \multirow{2}{*}{$\begin{array}{l}\text { Tipo convi- } \\
\text { vencia }\end{array}$} & \multirow{2}{*}{ Residencia } & \multirow{2}{*}{$\begin{array}{l}\text { Tipo disca- } \\
\text { pacidad }\end{array}$} \\
\hline & Dicotomiz. & Recod. en tres & & & Dicotomiz. & $\begin{array}{l}\text { Recod. } \\
\text { en tres }\end{array}$ & & & \\
\hline $\mathbf{N}^{\circ}$ preoc y necesidades & Hetero & Profesional & Mujer & & & & Familia propia & $\geq 10.000$ & $\mathrm{PC}$ \\
\hline $\mathbf{N}^{0}$ soluciones & & Autoaplicada & Mujer & $35-49$ & $<65 \%$ & $<65 \%$ & Solo & $\geq 10.000$ & $\mathrm{PC}$ \\
\hline $\mathbf{N}^{\circ}$ apoyos institucionales & & & Mujer & $35-49$ & $<65 \%$ & $<65 \%$ & Solo & & \\
\hline $\mathrm{N}^{\mathbf{o}}$ p. futuro & Auto & Autoaplicada & Mujer & $35-49$ & $<65 \%$ & $<65 \%$ & Familia propia & & $\mathrm{PC}$ \\
\hline$N^{o}$ problemas señalados & & & Mujer & & & & & & $\mathrm{PC}$ \\
\hline $\mathbf{N}^{0}$ otras consideraciones & & & Mujer & $\begin{array}{l}65 \text { o } \\
\text { más }\end{array}$ & & & Solo & $<10.000$ & \\
\hline$N^{0}$ nec. salud personal & Hetero & Familiar & Mujer & & & & Familia propia & $\geq 10.000$ & $\mathrm{PC}$ \\
\hline $\mathbf{N}^{\circ}$ nec. recursos económicos & & & & $35-49$ & $<65 \%$ & $<65 \%$ & Familia propia & $\geq 10.000$ & \\
\hline $\mathbf{N}^{0}$ nec. recursos servicios sanitarios & Hetero & Profesional & Mujer & & & & Solo & $\geq 10.000$ & $\mathrm{PC}$ \\
\hline$N^{o}$ nec. recursos servicios sociales & Hetero & Profesional & Mujer & & $<65 \%$ & $<65 \%$ & Solo & $\geq 10.000$ & $\mathrm{PC}$ \\
\hline$N^{o}$ nec. existencia de barreras & Hetero & Profesional & Mujer & & & & Solo & $\geq 10.000$ & $\mathrm{PC}$ \\
\hline $\mathbf{N}^{0}$ otras nec. & & Familiar & Mujer & $35-49$ & & $<65 \%$ & Solo & $\geq 10.000$ & $\mathrm{PC}$ \\
\hline
\end{tabular}

Tabla 113: Resumen de los resultados significativos en cada una de las variables predictoras en la muestra de PcDID. 


\section{ANÁLISIS DE LA ENTREVISTA FAMILIAR}

\subsection{INTRODUCCIÓN}

En este apartado se describen las características sociodemográficas de la muestra de familias, así como las NP's generales y específicas (salud personal, recursos económicos, existencia de barreras, recursos sobre servicios sociales, recursos sanitarios, otras NP's), las soluciones que proponen, los apoyos institucionales que echan en falta, los pensamientos de futuro y las demás consideraciones que indicaron. Posteriormente se exponen los análisis estadísticos que se han elaborado con el objetivo de investigar las variables que predicen las NP's señaladas previamente.

\subsection{DESCRIPCIÓN DE LA MUESTRA FAMILIAR}

\subsubsection{Introducción}

En este apartado se presenta la muestra familiar en función del parentesco con la PcDID, y de otras características de la propia PcDID tales como la edad, la procedencia, el lugar de aplicación, la residencia y el estado civil.

\subsubsection{Descripción de la muestra de familias}

La muestra familiar estuvo compuesta por 606 familias, como podemos observar en la tabla 114. De manera que no respondieron al cuestionario el 48,3\% de familiares de las PcDID que sí lo habían rellenado, mientras que fue contestado por el $51,7 \%$ de las mismas. 


\begin{tabular}{|c|c|c|}
\hline Entrevista familiar & $\mathbf{N}$ & $\%$ \\
\hline $\mathbf{S i}$ & 606 & $51,7 \%$ \\
\hline NC & 567 & $48,3 \%$ \\
\hline Total & 1173 & $100 \%$ \\
\hline
\end{tabular}

Tabla 114: Total de personas de la muestra que han completado la entrevista familiar.

En cuanto al grado de parentesco de las familias respondientes (tabla 115), el $48,3 \%$ no indicaron dicho grado, el 25,3\% (297 personas) eran hermanos, el 13,7\% (161 personas) eran el padre o la madre de las PcDID, el 3,7\% (43 personas) eran tutores legales, y en menor medida el cuestionario fue respondido por sobrinos (1,3\%), amigos $(1,2 \%)$, hijos $(0,3 \%)$ u otros familiares $(6,2 \%)$.

\begin{tabular}{lcc}
\hline \multicolumn{1}{c}{ Parentesco } & N & \% \\
\hline NC & 567 & $48,3 \%$ \\
Hermano/a & 297 & $25,3 \%$ \\
Padre/madre & 161 & $13,7 \%$ \\
Tutor legal & 43 & $3,7 \%$ \\
Sobrino/a & 15 & $1,3 \%$ \\
Amigo & 14 & $1,2 \%$ \\
Hijo/a & 3 & $0,3 \%$ \\
Otro familiar & 73 & $6,2 \%$ \\
\hline \multicolumn{1}{c}{ Total } & $\mathbf{6 0 6}$ & $\mathbf{1 0 0 \%}$ \\
\hline
\end{tabular}

Tabla 115: Parentesco de las personas que han completado la entrevista familiar.

En cuanto a las características de la muestra familiar por género y edad de las PcDID (tabla 116), la media de edad de la muestra se situó aproximadamente en los 52 años, siendo la media de 52,16 para los hombres y 51,62 para las mujeres. La mediana fue, en todos los casos de 50 y la moda de 45. La desviación típica total era de 7,24, siendo para los hombres de 7,27 y de 7,20 para las mujeres. El mínimo de edad en total era de 35, siendo 36 para los hombres y 35 para las mujeres; mientras que el máximo total era de 80,76 en hombres y 80 en mujeres. 


\begin{tabular}{cccc}
\hline Edad & Hombres & Mujeres & Total \\
\hline Media & 52,16 & 51,62 & 51,92 \\
Mediana & 50,00 & 50,00 & 50,00 \\
Moda & 45 & 45 & 45 \\
DT & 7,27 & 7,20 & 7,24 \\
Mínimo & 36 & 35 & 35 \\
Máximo & 76 & 80 & 80 \\
\hline $\mathbf{N}$ & $\mathbf{3 3 6}$ & $\mathbf{2 7 0}$ & $\mathbf{6 0 6}$ \\
\hline
\end{tabular}

Tabla 116: Características de la muestra familiar por la edad y el género de las PcDID.

En lo referente al lugar de aplicación de la entrevista (tabla 117), el 19,8\% (120 casos) se realizó en el domicilio particular, el 18\% (109 casos) en una residencia, el 17,8\% (108 casos) en la Asociación, el 15,3\% (93 casos) en el centro de trabajo, el 9,2\% (56 casos) en un centro de día, y en menor medida, se realizó en el domicilio de otro familiar $(3,8 \%)$, en un centro social $(1,5 \%)$, en un centro ocupacional $(0,5 \%)$, en un CRMF (0,2\%), y en el 13,9\% de los casos se realizó en otros lugares diferentes.

\begin{tabular}{lcc}
\hline \multicolumn{1}{c}{ Lugar de aplicación } & N & \% \\
\hline Domicilio particular & 120 & $19,8 \%$ \\
Residencia & 109 & $18,0 \%$ \\
Asociación & 108 & $17,8 \%$ \\
Centro de trabajo & 93 & $15,3 \%$ \\
Centro de día & 56 & $9,2 \%$ \\
Domicilio de otro familiar & 23 & $3,8 \%$ \\
Centro social & 9 & $1,5 \%$ \\
Centro ocupacional & 3 & $0,5 \%$ \\
CRMF/CRE & 1 & $0,2 \%$ \\
Otros & 84 & $13,9 \%$ \\
\hline \multicolumn{1}{c}{ Total } & $\mathbf{6 0 6}$ & $\mathbf{1 0 0 \%}$ \\
\hline
\end{tabular}

Tabla 117: Lugar de aplicación de las entrevistas familiares.

En cuanto a la procedencia de las familias (tabla 118), el 32,8\% (199 personas) eran de Euskadi, el 16\% (97 personas) de Valencia, el 12,9\% (78 personas) de Asturias, el 10,2\% (62 personas) de Navarra, el 6,3\% (38 personas) de Castilla León, el 4,5\% (27 
personas) de Extremadura, el 4,1\% (25 personas) de Cantabria, el mismo porcentaje de la Rioja, y en menor medida, respondieron familias de Canarias $(2,8 \%)$, Baleares (2,5\%), Andalucía (1,3\%), Madrid (1,3\%), Galicia (0,5\%), Aragón (0,5\%) y Murcia $(0,2 \%)$

\begin{tabular}{lcc}
\hline Procedencia & N & \% \\
\hline Euskadi & 199 & $32,8 \%$ \\
Valencia & 97 & $16,0 \%$ \\
Asturias & 78 & $12,9 \%$ \\
Navarra & 62 & $10,2 \%$ \\
Castilla León & 38 & $6,3 \%$ \\
Extremadura & 27 & $4,5 \%$ \\
Cantabria & 25 & $4,1 \%$ \\
La Rioja & 25 & $4,1 \%$ \\
Canarias & 17 & $2,8 \%$ \\
Baleares & 15 & $2,5 \%$ \\
Andalucía & 8 & $1,3 \%$ \\
Madrid & 8 & $1,3 \%$ \\
Galicia & 3 & $0,5 \%$ \\
Aragón & 3 & $0,5 \%$ \\
Murcia & 1 & $0,2 \%$ \\
\hline \multicolumn{1}{c}{ Total } & $\mathbf{6 0 6}$ & $\mathbf{1 0 0 \%}$ \\
\hline
\end{tabular}

Tabla 118: Características de la muestra familiar en función de la procedencia de las PcDID.

En lo referente al tipo de población (tabla 119), el 72,8\% (441 familiares) pertenecían a poblaciones de 10.000 habitantes o más, mientras que el 27,2\% (165 familiares) residían en poblaciones de menos de 10.000 habitantes.

\begin{tabular}{ccc}
\hline Lugar de residencia & $\mathbf{N}$ & $\%$ \\
\hline $\mathbf{1 0 . 0 0 0}$ habitantes & 441 & $72,8 \%$ \\
\hline $\mathbf{1 0 . 0 0 0}$ habitantes & 165 & $27,2 \%$ \\
\hline Total & $\mathbf{6 0 6}$ & $\mathbf{1 0 0 \%}$ \\
\hline
\end{tabular}

Tabla 119: Características de la muestra familiar por lugar de residencia de las PcDI. 
En cuanto al estado civil de las PcDID cuyas familias respondieron al cuestionario (tabla 120), 597 estaban solteras (334 hombres y 263 mujeres); 4 mujeres estaban separadas o divorciadas; 2 personas (1 hombre y 1 mujer) estaban casadas; 2 personas (1 hombre y 1 mujer) en pareja y una mujer estaba viuda.

\begin{tabular}{lccc}
\hline \multicolumn{1}{c}{ Estado civil } & Hombres & Mujeres & Total \\
\hline Soltero & 334 & 263 & 597 \\
Separado/divorciado & - & 4 & 4 \\
Casado & 1 & 1 & 2 \\
En pareja & 1 & 1 & 2 \\
Viudo & - & 1 & 1 \\
\hline \multicolumn{1}{c}{ Total } & $\mathbf{3 3 6}$ & $\mathbf{2 7 0}$ & $\mathbf{6 0 6}$ \\
\hline
\end{tabular}

Tabla 120: Características de la muestra familiar en función del estado civil de las PcDID.

\subsubsection{Resumen}

En resumen, la muestra de familias estaba compuesta por personas con diferentes grados de parentesco, siendo importante el número de hermanos que han respondido a la entrevista; las PcDID de las que son familia tenían una media de 52 años aproximadamente, la mayoría estaban solteras y pertenecían a localidades de 10.000 o más habitantes, de Comunidades Autónomas como Euskadi, Valencia, Asturias o Navarra en mayor medida.

\subsection{DESCRIPCIÓN DE LAS FRECUENCIAS DE LAS NECESIDADES PERCIBIDAS EN LA MUESTRA DE FAMILIAS}

\subsubsection{Introducción}

Este epígrafe incluye una descripción de las necesidades percibidas por las familias de las PcDID que envejecen. Así, se recogen las necesidades sobre salud personal, recursos económicos, recursos sanitarios, recursos sobre servicios sociales, existencia de 
barreras y otras necesidades no recogidas entre las anteriores, las soluciones propuestas, los apoyos institucionales requeridos, los pensamientos de futura y otras consideraciones señaladas por las familias de la muestra.

\subsubsection{Preocupaciones y necesidades percibidas en la muestra de familias}

En la tabla 121 podemos observar los estadísticos de las necesidades percibidas por la muestra general de familias. Es importante señalar que las familias señalan en mayor medida necesidades de salud personal $(M=2,33)$, seguidas de necesidades sobre recursos de servicios sociales $(M=2,28)$, existencia de barreras $(M=1,88)$, otras preocupaciones $(M=1,82)$, preocupaciones sobre recursos sanitarios $(M=1,75)$ y finalmente, sobre recursos económicos $(\mathrm{M}=1,39)$.

En el gráfico 14, se presenta el número de ítems en cada uno de los grupos de necesidades que ha señalado la muestra general de familias. Las familias han señalado en mayor medida preocupaciones sobre salud personal y sobre recursos de servicios sociales, mientras que el grupo de necesidades en la que menores ítems han puntuado sería la de recursos económicos. 


\begin{tabular}{lccccccc}
\hline & $\begin{array}{c}\text { Salud } \\
\text { personal }\end{array}$ & $\begin{array}{c}\text { Recursos } \\
\text { económicos }\end{array}$ & $\begin{array}{c}\text { Recursos } \\
\text { sanitarios }\end{array}$ & $\begin{array}{c}\text { Recursos } \\
\text { servicios } \\
\text { sociales }\end{array}$ & $\begin{array}{c}\text { Existencia } \\
\text { barreras }\end{array}$ & Otras & Total \\
\hline $\mathrm{N}$ & 606 & 606 & 606 & 606 & 606 & 606 & 606 \\
\hline Media & 2,33 & 1,39 & 1,75 & 2,28 & 1,88 & 1,82 & 11,43 \\
\hline Mediana & 2,00 & 1,00 & 1,00 & 2,00 & 2,00 & 2,00 & 10,00 \\
\hline Moda & 1 & 1 & 1 & 2 & 1 & 1 & 8 \\
\hline Desv. típ. & 1,526 & 1,112 & 1,703 & 1,782 & 1,679 & 1,463 & 7,064 \\
\hline Asimetría & 0,850 & 1,436 & 1,450 & 1,284 & 1,332 & 1,318 & 1,405 \\
\hline Curtosis & 0,684 & 3,309 & 2,199 & 1,681 & 1,982 & 2,417 & 2,631 \\
\hline Mínimo & 0 & 0 & 0 & 0 & 0 & 0 & 0 \\
\hline Máximo & 8 & 7 & 8 & 9 & 9 & 8 & 41 \\
\hline \hline
\end{tabular}

Tabla 121: Estadísticos de las preocupaciones y necesidades percibidas de la muestra de familias en general.

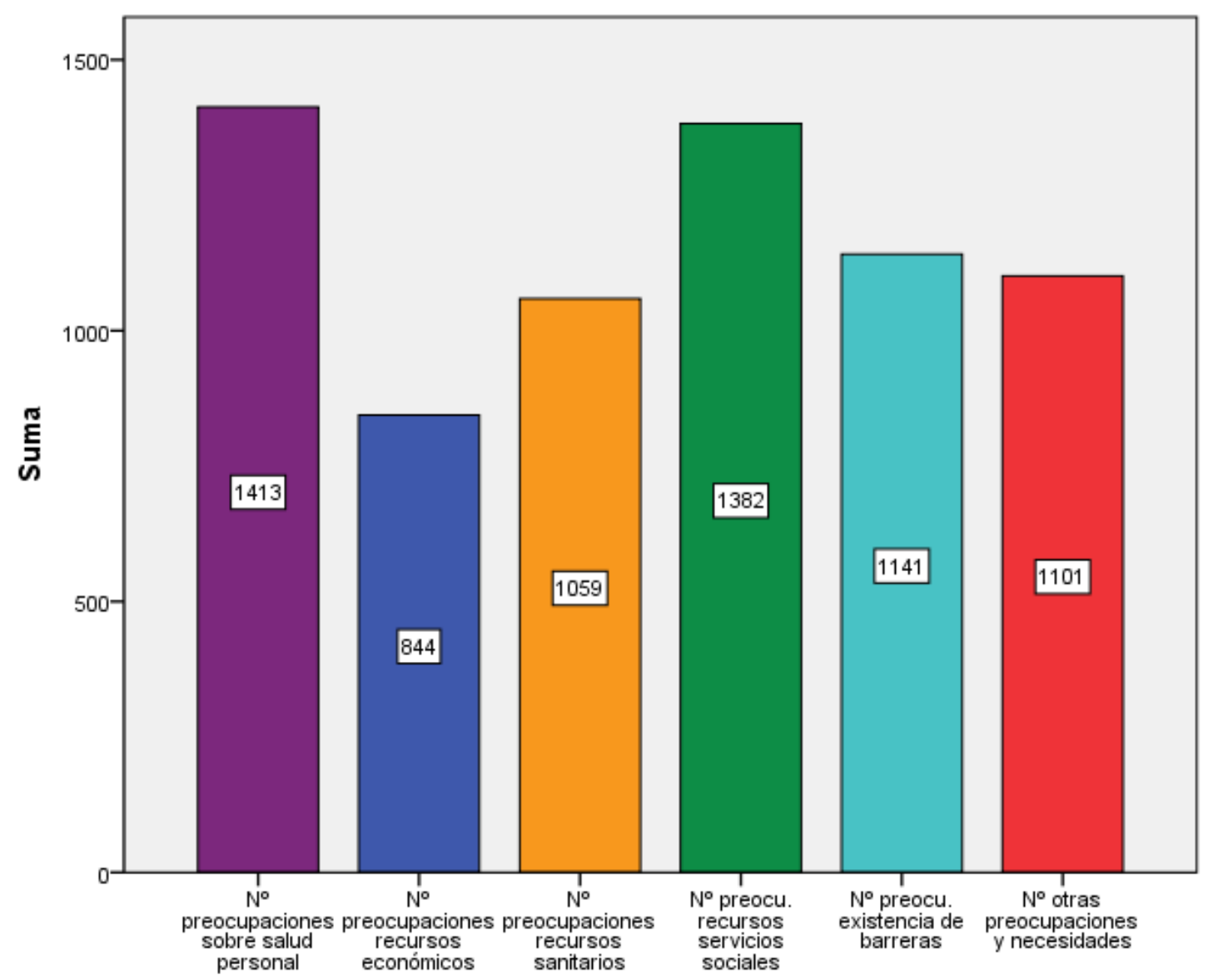

Gráfico 14: $\mathrm{N}^{\circ}$ Total de preocupaciones y necesidades percibidas de la muestra de familias en general. 
Si examinamos las preocupaciones de las familias en función de si eran familiares de personas con SD (tabla 122), otros tipos de DID (tabla 123) o PC (tabla 124), podemos observar que las familias de las PcSD (109 personas) eligen nuevamente en mayor medida necesidades de salud personal $(M=2,32)$, seguida de las necesidades sobre recursos de servicios sociales $(M=1,94)$, otras necesidades $(M=1,71)$, existencia de barreras $(M=1,43)$, recursos sanitarios $(M=1,32)$ y recursos económicos $(M=1,28)$, como se observa en la tabla 122.

En las familias de personas con otros tipos de DID (413 familias), destacan las necesidades de recursos de servicios sociales $(M=2,30)$, seguidas de las necesidades de salud personal $(M=2,25)$, existencia de barreras $(M=1,85)$, otras preocupaciones $(M=1,80)$, recursos sanitarios $(M=1,76)$ y recursos económicos $(M=1,38)$, como podemos ver en la tabla 123.

\begin{tabular}{lccccccc}
\hline & $\begin{array}{c}\text { Salud } \\
\text { personal }\end{array}$ & $\begin{array}{c}\text { Recursos } \\
\text { económicos }\end{array}$ & $\begin{array}{c}\text { Recursos } \\
\text { sanitarios }\end{array}$ & $\begin{array}{c}\text { Recursos } \\
\text { servicios } \\
\text { sociales }\end{array}$ & $\begin{array}{c}\text { Existencia } \\
\text { barreras }\end{array}$ & Otras & Total \\
\hline $\mathrm{N}$ & 109 & 109 & 109 & 109 & 109 & 109 & 109 \\
\hline Media & 2,32 & 1,28 & 1,32 & 1,94 & 1,43 & 1,71 & 9,93 \\
\hline Mediana & 2,00 & 1,00 & 1,00 & 2,00 & 1,00 & 1,00 & 8,00 \\
\hline Moda & 1 & 1 & 1 & 1 & 2 & 1 & 7 \\
\hline Desv. típ. & 1,446 & 1,010 & 1,276 & 1,496 & 1,294 & 1,300 & 5,600 \\
\hline Asimetría & 0,917 & 1,213 & 1,363 & 1,347 & 1,004 & 0,770 & 1,085 \\
\hline Curtosis & 1,231 & 2,314 & 2,916 & 2,230 & 1,088 & 0,351 & 1,299 \\
\hline Mínimo & 0 & 0 & 0 & 0 & 0 & 0 & 0 \\
\hline Máximo & 8 & 5 & 7 & 7 & 6 & 6 & 29 \\
\hline \hline
\end{tabular}

Tabla 122: Estadísticos de las preocupaciones y necesidades percibidas de la muestra de familias de las personas con SD. 


\begin{tabular}{lccccccc}
\hline & $\begin{array}{c}\text { Salud } \\
\text { personal }\end{array}$ & $\begin{array}{c}\text { Recursos } \\
\text { económicos }\end{array}$ & $\begin{array}{c}\text { Recursos } \\
\text { sanitarios }\end{array}$ & $\begin{array}{c}\text { Recursos } \\
\text { servicios } \\
\text { sociales }\end{array}$ & $\begin{array}{c}\text { Existencia } \\
\text { barreras }\end{array}$ & Otras & Total \\
\hline $\mathrm{N}$ & 413 & 413 & 413 & 413 & 413 & 413 & 413 \\
\hline Media & 2,25 & 1,38 & 1,76 & 2,30 & 1,85 & 1,80 & 11,36 \\
\hline Mediana & 2,00 & 1,00 & 1,00 & 2,00 & 1,00 & 2,00 & 10,00 \\
\hline Moda & 2 & 1 & 1 & 2 & 1 & 1 & 8 \\
\hline Desv. típ. & 1,480 & 1,117 & 1,715 & 1,733 & 1,644 & 1,430 & 6,947 \\
\hline Asimetría &, 865 & 1,552 & 1,393 & 1,270 & 1,436 & 1,417 & 1,439 \\
\hline Curtosis &, 667 & 3,922 & 1,798 & 1,763 & 2,542 & 3,053 & 2,853 \\
\hline Mínimo & 0 & 0 & 0 & 0 & 0 & 0 & 0 \\
\hline Máximo & 8 & 7 & 8 & 8 & 9 & 8 & 39 \\
\hline \hline
\end{tabular}

Tabla 123: Estadísticos de las preocupaciones y necesidades percibidas de la muestra de familias de las personas con otros tipos de DID.

En cuanto a las necesidades percibidas por las familias de personas con PC ( 84 familias), destacan las necesidades de salud personal $(M=2,73)$, seguidas de la existencia de barreras $(M=2,62)$, recursos de servicios sociales $(M=2,61)$, recursos sanitarios $(M=2,25)$, otras preocupaciones $(M=2,06)$ y recursos económicos $(M=1,57)$, como se observa en la tabla 124.

\begin{tabular}{lccccccc}
\hline & $\begin{array}{c}\text { Salud } \\
\text { personal }\end{array}$ & $\begin{array}{c}\text { Recursos } \\
\text { económicos }\end{array}$ & $\begin{array}{c}\text { Recursos } \\
\text { sanitarios }\end{array}$ & $\begin{array}{c}\text { Recursos } \\
\text { servicios } \\
\text { sociales }\end{array}$ & $\begin{array}{c}\text { Existencia } \\
\text { barreras }\end{array}$ & Otras & Total \\
\hline $\mathrm{N}$ & 84 & 84 & 84 & 84 & 84 & 84 & 84 \\
\hline Media & 2,73 & 1,57 & 2,25 & 2,61 & 2,62 & 2,06 & 13,71 \\
\hline Mediana & 3,00 & 1,00 & 2,00 & 2,00 & 2,00 & 2,00 & 11,00 \\
\hline Moda & 3 & 1 & 2 & 1 & 1 & 2 & 11 \\
\hline Desv. típ. & 1,786 & 1,205 & 1,981 & 2,250 & 2,029 & 1,779 & 8,662 \\
\hline Asimetría &, 594 & 1,097 & 1,320 & 1,020 &, 767 & 1,157 & 1,073 \\
\hline Curtosis &, 138 & 1,695 & 1,712 &, 346 &,- 138 &, 984 & 1,113 \\
\hline Mínimo & 0 & 0 & 0 & 0 & 0 & 0 & 0 \\
\hline Máximo & 8 & 6 & 8 & 9 & 8 & 7 & 41 \\
\hline \hline
\end{tabular}

Tabla 124: Estadísticos de las preocupaciones y necesidades percibidas de la muestra de familias de las personas con PC.

En el gráfico 15 se presenta el resumen del número total de preocupaciones específicas de las familias de personas con SD, con otros tipos de DID y con PC. En los tres casos todas las familias dan gran importancia a las necesidades sobre salud personal 
y recursos de servicios sociales. Además, las familias de las personas con PC también dan mucha importancia a la existencia de barreras.

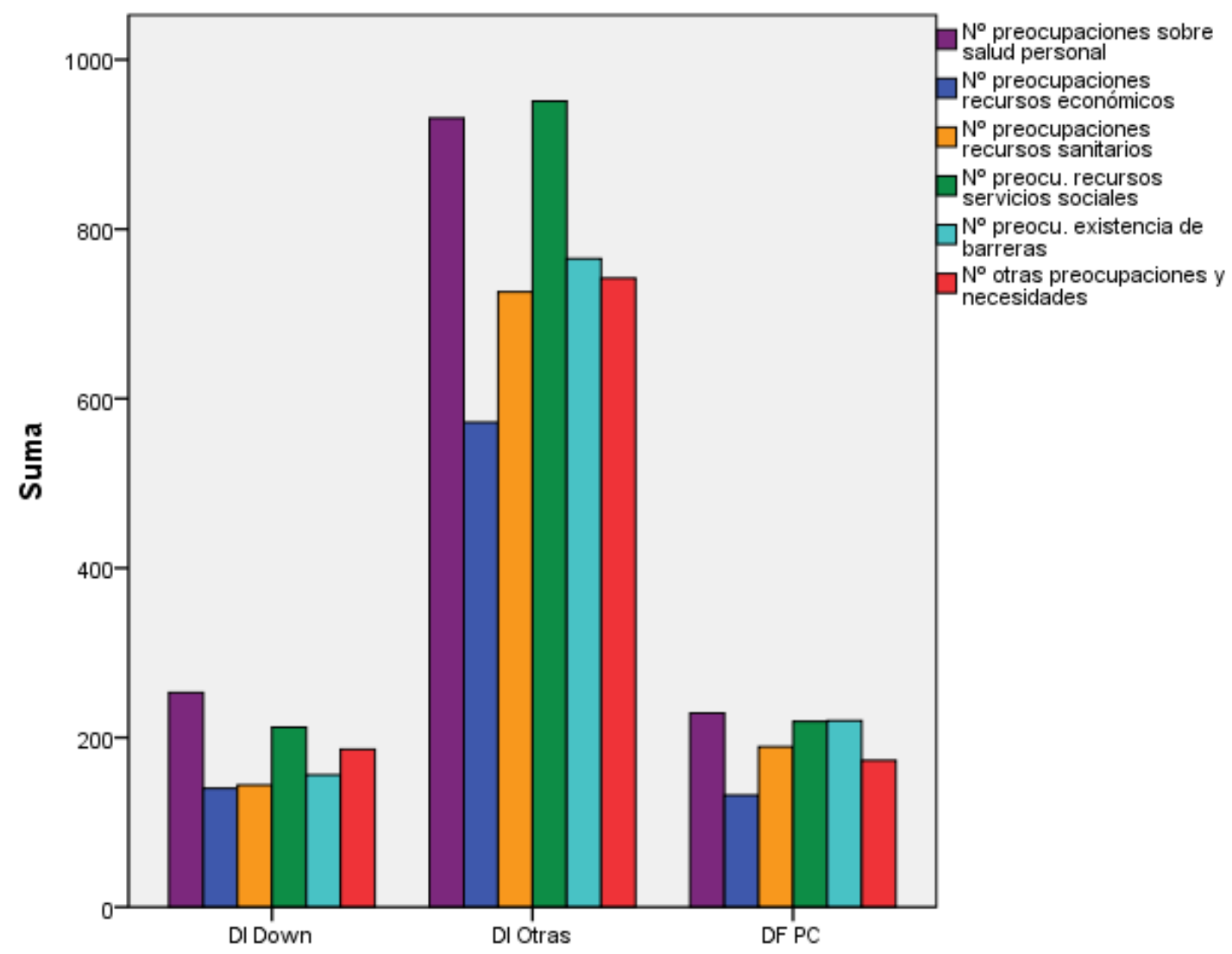

\section{Gráfico 15: Comparación de las necesidades específicas de las familias en función de las PcDID con SD, otros tipos de DID o PC.}

\subsubsection{Necesidades sobre salud personal}

En cuanto a las necesidades de salud personal (tabla 125), las familias eligen en el $64,8 \%$ de los casos el estado de salud general como una preocupación importante. En el 47,5\% de los casos han señalado la dependencia, en el 43,8\% los cuidados personales diarios y en el 40,6\% de los casos han señalado las limitaciones funcionales personales. En menor medida han elegido los dolores (19,4\% de los casos), las dificultades para tomar la medicación (10,9\%), la aceptación de la situación (9,3\%) o las dificultades para acudir al tratamiento (6\%). En el 10,7\% de los casos se ha señalado que había otro tipo de preocupaciones sobre salud personal. 


\begin{tabular}{lccc}
\hline \multicolumn{1}{c}{ Salud personal: } & N & \% resp & \% casos \\
\hline Estado de salud general & 364 & $25,6 \%$ & $64,8 \%$ \\
Dependencia & 267 & $18,8 \%$ & $47,5 \%$ \\
Cuidados personales diarios & 246 & $17,3 \%$ & $43,8 \%$ \\
Limitaciones funcionales personales & 228 & $16,0 \%$ & $40,6 \%$ \\
Dolores & 109 & $7,7 \%$ & $19,4 \%$ \\
Dificultades para tomar la medicación & 61 & $4,3 \%$ & $10,9 \%$ \\
Aceptación de mi situación & 52 & $3,7 \%$ & $9,3 \%$ \\
Dificultades para acudir al tratamiento & 34 & $2,4 \%$ & $6,0 \%$ \\
Otras & 60 & $4,2 \%$ & $10,7 \%$ \\
\hline \multicolumn{1}{c}{ Respuestas totales } & $\mathbf{1 4 2 1}$ & $\mathbf{1 0 0 \%}$ & $\mathbf{2 5 2 , 8 \%}$ \\
\hline
\end{tabular}

Nota: 44 casos perdidos; 562 casos válidos.

Tabla 125: Frecuencias y porcentajes (de respuestas y de casos) de preocupaciones sobre salud personal de las familias.

\subsubsection{Necesidades sobre recursos económicos}

En lo referente a las necesidades sobre recursos económicos que perciben las familias acerca de las PcDID (tabla 126), en el 63,4\% de los casos se señaló la pensión, seguida de la independencia económica (27,9\% de los casos), las subvenciones $(26,1 \%)$ o la situación económica familiar (25,9\%). En menor medida preocupaba la incapacidad laboral $(8,3 \%$ de los casos) o el encontrar un puesto de trabajo $(6,7 \%)$. El 8,3\% de los casos señaló otras preocupaciones diferentes sobre recursos económicos no recogidas entre las anteriores. 


\begin{tabular}{lccc}
\hline \multicolumn{1}{c}{ Recursos económicos: } & N & \% resp & \% casos \\
\hline Pensión & 320 & $38,0 \%$ & $63,4 \%$ \\
Independencia económica & 141 & $16,7 \%$ & $27,9 \%$ \\
Subvenciones & 132 & $15,7 \%$ & $26,1 \%$ \\
Situación económica familiar & 131 & $15,6 \%$ & $25,9 \%$ \\
Incapacidad laboral & 42 & $5,0 \%$ & $8,3 \%$ \\
Encontrar un puesto de trabajo & 34 & $4,0 \%$ & $6,7 \%$ \\
Otras & 42 & $5,0 \%$ & $8,3 \%$ \\
\hline \multicolumn{1}{c}{$\quad$ Respuestas totales } & $\mathbf{8 4 2}$ & $\mathbf{1 0 0 \%}$ & $\mathbf{1 6 6 , 7 \%}$ \\
\hline
\end{tabular}

Nota: 101 casos perdidos; 505 casos válidos.

Tabla 126: Frecuencias y porcentajes (de respuestas y de casos) de preocupaciones sobre recursos económicos de las familias.

\subsubsection{Preocupaciones sobre recursos sanitarios}

En cuanto a los recursos sanitarios (tabla 127), en el 38,3\% de los casos se señaló como necesidad la calidad de la asistencia sanitaria, seguida de la asistencia en salud mental (33,1\% de los casos), el incremento en número y calidad de las instalaciones sanitarias (31\%), la asistencia sanitaria hospitalaria $(30,3 \%)$, la asistencia sanitaria domiciliaria $(25,8 \%)$ y la falta de información sobre estos recursos $(24,1 \%)$. En menor cantidad se señalaron los tratamientos de fisioterapia (20,4\% de los casos) y los dispositivos de apoyo y protésicos $(18,7 \%)$. El 6,9\% de los casos señalaron otras necesidades sobre los recursos sanitarios no recogidas entre las anteriores. 


\begin{tabular}{lccc}
\hline \multicolumn{1}{c}{ Recursos sanitarios: } & N & \% resp \% casos \\
\hline Calidad de la asistencia sanitaria & 178 & $16,7 \%$ & $38,3 \%$ \\
Asistencia en salud mental & 154 & $14,5 \%$ & $33,1 \%$ \\
Más y mejores instalaciones sanitarias & 144 & $13,5 \%$ & $31,0 \%$ \\
Asistencia sanitaria hospitalaria & 141 & $13,3 \%$ & $30,3 \%$ \\
Asistencia sanitaria domiciliaria & 120 & $11,3 \%$ & $25,8 \%$ \\
Falta de información sobre estos recursos & 112 & $10,5 \%$ & $24,1 \%$ \\
Tratamiento de fisioterapia & 95 & $8,9 \%$ & $20,4 \%$ \\
Dispositivos de apoyo y protésicos & 87 & $8,2 \%$ & $18,7 \%$ \\
Otras & 32 & $3,0 \%$ & $6,9 \%$ \\
\hline \multicolumn{1}{c}{ Respuestas totales } & $\mathbf{1 0 6 3}$ & $\mathbf{1 0 0 \%}$ & $\mathbf{2 2 8 , 6 \%}$ \\
\hline
\end{tabular}

Nota: 141 casos perdidos; 465 casos válidos.

Tabla 127: Frecuencias y porcentajes (de respuestas y de casos) de preocupaciones sobre recursos sanitarios de las familias.

\subsubsection{Preocupaciones sobre recursos de servicios sociales}

Entre las preocupaciones acerca de los recursos de los servicios sociales (tabla 128), destacan la creación o mejora de servicios de apoyo al ocio y tiempo libre (47\% de los casos), los servicios de alojamiento (40,3\% de los casos), la ayuda a domicilio $(38,3 \%)$, el incremento y la mejora de instalaciones sociales $(31,6 \%)$ y la calidad de la asistencia social $(26,8 \%)$. En menor medida se ha elegido la falta de información sobre estos recursos (23,5\% de los casos), el asesoramiento jurídico (22,6\% de los casos) o el apoyo en las gestiones administrativas (20,5\%). En el 5,2\% de los casos se señalaron otras necesidades sobre los recursos de los servicios sociales no recogidas entre las anteriores. 


\begin{tabular}{lccc}
\hline \multicolumn{1}{c}{ Recursos servicios sociales: } & N & \% resp \% casos \\
\hline Servicios de apoyo al ocio y tiempo libre & 254 & $18,4 \%$ & $47,0 \%$ \\
Servicios de alojamiento & 218 & $15,8 \%$ & $40,3 \%$ \\
Ayuda a domicilio & 207 & $15,0 \%$ & $38,3 \%$ \\
Más y mejores instalaciones sociales & 171 & $12,4 \%$ & $31,6 \%$ \\
Calidad de la asistencia social & 145 & $10,5 \%$ & $26,8 \%$ \\
Falta de información sobre estos recursos & 127 & $9,2 \%$ & $23,5 \%$ \\
Asesoramiento jurídico & 122 & $8,8 \%$ & $22,6 \%$ \\
Apoyo en las gestiones administrativas & 111 & $8,0 \%$ & $20,5 \%$ \\
Otras & 28 & $2,0 \%$ & $5,2 \%$ \\
\hline \multicolumn{1}{c}{ Respuestas totales } & $\mathbf{1 3 8 3}$ & $\mathbf{1 0 0 \%}$ & $\mathbf{2 5 5 , 6 \%}$ \\
\hline
\end{tabular}

Nota: 65 casos perdidos; 541 casos válidos.

Tabla 128: Frecuencias y porcentajes (de respuestas y de casos) de preocupaciones sobre recursos de servicios sociales de las familias.

\subsubsection{Preocupaciones sobre la existencia de barreras}

En cuanto a las preocupaciones sobre la existencia de barreras (tabla 129), nos encontramos con que en el 43,2\% de los casos las familias señalaron la aceptación por parte de la sociedad, seguida de las barreras sociales $(42,4 \%$ de los casos), las barreras arquitectónicas $(38,1 \%$ de los casos), la facilidad de transporte $(34,2 \%)$ y la escasez de voluntariado $(25,9 \%)$. En menor porcentaje de casos se señalaron la aceptación por parte de la familia $(15,5 \%)$, las ayudas técnicas $(14,9 \%)$ y la accesibilidad a edificios públi$\cos (14,7 \%)$. En el 3,7\% de los casos se señalaron otras necesidades relativas a la existencia de barreras que no estaban recogidas entre las anteriores. 


\begin{tabular}{lccc}
\hline \multicolumn{1}{c}{ Existencia de barreras: } & N & \% resp & \% casos \\
\hline Aceptación por parte de la sociedad & 212 & $18,6 \%$ & $43,2 \%$ \\
Barreras sociales & 208 & $18,2 \%$ & $42,4 \%$ \\
Barreras arquitectónicas & 187 & $16,4 \%$ & $38,1 \%$ \\
Facilidad de transporte & 168 & $14,7 \%$ & $34,2 \%$ \\
Escasez de voluntariado & 127 & $11,1 \%$ & $25,9 \%$ \\
Aceptación por parte de la familia & 76 & $6,7 \%$ & $15,5 \%$ \\
Ayudas técnicas & 73 & $6,4 \%$ & $14,9 \%$ \\
Accesibilidad a edificios públicos & 72 & $6,3 \%$ & $14,7 \%$ \\
Otras & 18 & $1,6 \%$ & $3,7 \%$ \\
\hline \multicolumn{1}{c}{$\quad$ Respuestas totales } & $\mathbf{1 1 4 1}$ & $\mathbf{1 0 0 \%}$ & $\mathbf{2 3 2 , 4 \%}$ \\
\hline
\end{tabular}

Nota: 115 casos perdidos; 491 casos válidos.

Tabla 129: Frecuencias y porcentajes (de respuestas y de casos) de preocupaciones sobre existencia de barreras de las familias.

\subsubsection{Otras preocupaciones y necesidades}

En cuanto a otras preocupaciones (tabla 130), en el 63\% de los casos las familias señalaron el dónde y con quién vivir en el futuro, seguida del futuro de la familia (34,1\% de los casos), la salida del domicilio familiar (28,3\% de los casos), la escasez de relaciones personales $(27,1 \%$ de los casos) o la protección jurídica $(24,4 \%)$. En un menor porcentaje de casos se señalaron los problemas del movimiento asociativo $(11,9 \%)$, los problemas sociales $(11,1 \%)$ o los avances tecnológicos $(7,4 \%)$. En el 6,8\% de los casos se señalaron otras preocupaciones no recogidas entre las anteriores. 


\begin{tabular}{lccc}
\hline \multicolumn{1}{c}{ Otras: } & N & \% resp \% casos \\
\hline Dónde y con quién vivir en el futuro & 323 & $29,4 \%$ & $63,0 \%$ \\
Futuro de la familia & 175 & $15,9 \%$ & $34,1 \%$ \\
Salida del domicilio familiar & 145 & $13,2 \%$ & $28,3 \%$ \\
Escasez de relaciones personales & 139 & $12,7 \%$ & $27,1 \%$ \\
Protección jurídica & 125 & $11,4 \%$ & $24,4 \%$ \\
Problemas del movimiento asociativo & 61 & $5,6 \%$ & $11,9 \%$ \\
Problemas sociales & 57 & $5,2 \%$ & $11,1 \%$ \\
Avances tecnológicos & 38 & $3,5 \%$ & $7,4 \%$ \\
Otras & 35 & $3,2 \%$ & $6,8 \%$ \\
\hline \multicolumn{1}{c}{ Respuestas totales } & $\mathbf{1 0 9 8}$ & $\mathbf{1 0 0 \%}$ & $\mathbf{2 1 4 \%}$ \\
\hline
\end{tabular}

Nota: 93 casos perdidos; 513 casos válidos.

Tabla 130: Frecuencias y porcentajes (de respuestas y de casos) de preocupaciones sobre otras preocupaciones y necesidades de las familias.

\subsubsection{Soluciones propuestas}

Entre las soluciones propuestas por las familias de las PcDID de la muestra (tabla 131), en el $63,5 \%$ de los casos se señaló la subida de las pensiones, seguida de los servicios de apoyo al ocio y tiempo libre ( $44 \%$ de los casos), la ayuda para los cuidados personales diarios $(39,6 \%$ de los casos), el incremento de la ayuda familiar $(38,4 \%$ de los casos), las garantías de futuro $(36,8 \%)$, la mejora de los servicios de alojamiento $(32,5 \%)$, el incremento de las subvenciones $(31,3 \%)$ y el incremento del número y la calidad de las instalaciones sociales $(30,1 \%)$.

Con menor porcentaje de casos se eligieron la promoción del voluntariado (29,5\% de los casos), los centros de día $(28,4 \%)$, el apoyo a los cuidadores informales $(27,1 \%)$, más información sobre los recursos $(27,1 \%)$, el incremento en número y calidad de las instalaciones sanitarias $(26,4 \%)$, la aceptación por parte de la sociedad $(26,2 \%)$ o la calidad de la asistencia sanitaria (26\%), entre otras. 


\begin{tabular}{|c|c|c|c|}
\hline Soluciones: & $\mathbf{N}$ & $\%$ resp & $\%$ casos \\
\hline Subida de las pensiones & 371 & $7,2 \%$ & $63,5 \%$ \\
\hline Servicios de apoyo al ocio y tiempo libre & 257 & $5,0 \%$ & $44,0 \%$ \\
\hline Ayuda para cuidados personales diarios & 231 & $4,5 \%$ & $39,6 \%$ \\
\hline Incremento de la ayuda familiar & 224 & $4,4 \%$ & $38,4 \%$ \\
\hline Garantías de futuro & 215 & $4,2 \%$ & $36,8 \%$ \\
\hline Mejora de los servicios de alojamiento & 190 & $3,7 \%$ & $32,5 \%$ \\
\hline Incremento de las subvenciones & 183 & $3,6 \%$ & $31,3 \%$ \\
\hline Más y mejores instalaciones sociales & 176 & $3,4 \%$ & $30,1 \%$ \\
\hline Promoción del voluntariado & 172 & $3,4 \%$ & $29,5 \%$ \\
\hline Centros de día & 166 & $3,2 \%$ & $28,4 \%$ \\
\hline Apoyo a los cuidadores informales & 158 & $3,1 \%$ & $27,1 \%$ \\
\hline Más información sobre recursos & 158 & $3,1 \%$ & $27,1 \%$ \\
\hline Más y mejores instalaciones sanitarias & 154 & $3,0 \%$ & $26,4 \%$ \\
\hline Aceptación por parte de la sociedad & 153 & $3,0 \%$ & $26,2 \%$ \\
\hline Calidad de la asistencia sanitaria & 152 & $3,0 \%$ & $26,0 \%$ \\
\hline Facilidades de transporte & 151 & $2,9 \%$ & $25,9 \%$ \\
\hline Profesionales más especializados & 151 & $2,9 \%$ & $25,9 \%$ \\
\hline Supresión de barreras arquitectónicas & 150 & $2,9 \%$ & $25,7 \%$ \\
\hline Mejora de la asistencia a domicilio & 147 & $2,9 \%$ & $25,2 \%$ \\
\hline Apoyo legal y administrativo & 139 & $2,7 \%$ & $23,8 \%$ \\
\hline Más y mejor información & 132 & $2,6 \%$ & $22,6 \%$ \\
\hline Asistencia psicológica & 130 & $2,5 \%$ & $22,3 \%$ \\
\hline Fisioterapia en la Seguridad Social & 126 & $2,5 \%$ & $21,6 \%$ \\
\hline Promoción de viviendas adaptadas & 123 & $2,4 \%$ & $21,1 \%$ \\
\hline Promoción del empleo protegido & 117 & $2,3 \%$ & $20,0 \%$ \\
\hline Calidad de la asistencia social & 115 & $2,2 \%$ & $19,7 \%$ \\
\hline Programas de cambio de actitudes & 106 & $2,1 \%$ & $18,2 \%$ \\
\hline Más y mejores ayudas técnicas & 90 & $1,8 \%$ & $15,4 \%$ \\
\hline Reserva de puestos de trabajo & 82 & $1,6 \%$ & $14,0 \%$ \\
\hline Mejora de apoyos y prótesis & 81 & $1,6 \%$ & $13,9 \%$ \\
\hline Incremento de la participación asociativa & 79 & $1,5 \%$ & $13,5 \%$ \\
\hline Aceptación por parte de la familia & 75 & $1,5 \%$ & $12,8 \%$ \\
\hline Adelantar la jubilación & 67 & $1,3 \%$ & $11,5 \%$ \\
\hline Campañas de imagen & 67 & $1,3 \%$ & $11,5 \%$ \\
\hline Otras & 37 & $0,7 \%$ & $6,3 \%$ \\
\hline Respuestas totales & 5125 & $100 \%$ & $877,6 \%$ \\
\hline
\end{tabular}

Nota: 22 casos perdidos; 584 casos válidos.

Tabla 131: Frecuencias y porcentajes (de respuestas y de casos) de las soluciones propuestas por las familias. 


\begin{tabular}{|c|c|c|c|}
\hline Soluciones: & $\mathbf{N}$ & $\%$ resp & $\%$ casos \\
\hline \multicolumn{4}{|l|}{ Salud personal } \\
\hline Ayuda para cuidados personales diarios & 231 & $4,5 \%$ & $39,6 \%$ \\
\hline \multicolumn{4}{|l|}{ Recursos económicos } \\
\hline Subida de las pensiones & 371 & $7,2 \%$ & $63,5 \%$ \\
\hline Incremento de la ayuda familiar & 224 & $4,4 \%$ & $38,4 \%$ \\
\hline Incremento de las subvenciones & 183 & $3,6 \%$ & $31,3 \%$ \\
\hline Promoción del empleo protegido & 117 & $2,3 \%$ & $20,0 \%$ \\
\hline Reserva de puestos de trabajo & 82 & $1,6 \%$ & $14,0 \%$ \\
\hline \multicolumn{4}{|l|}{ Recursos asistenciales sanitarios } \\
\hline Más y mejores instalaciones sanitarias & 154 & $3,0 \%$ & $26,4 \%$ \\
\hline Calidad de la asistencia sanitaria & 152 & 3,0 & $26,0 \%$ \\
\hline Profesionales más especializados & 151 & $2,9 \%$ & $25,9 \%$ \\
\hline Fisioterapia en la Seguridad Social & 126 & $2,5 \%$ & $21,6 \%$ \\
\hline \multicolumn{4}{|l|}{ Recursos servicios sociales } \\
\hline Servicios de apoyo al ocio y tiempo libre & 257 & $5,0 \%$ & $44,0 \%$ \\
\hline Mejora de los servicios de alojamiento & 190 & $3,7 \%$ & $32,5 \%$ \\
\hline Más y mejores instalaciones sociales & 176 & $3,4 \%$ & $30,1 \%$ \\
\hline Promoción del voluntariado & 172 & $3,4 \%$ & $29,5 \%$ \\
\hline Centros de día & 166 & $3,2 \%$ & $28,4 \%$ \\
\hline Facilidades de transporte & 151 & $2,9 \%$ & $25,9 \%$ \\
\hline Mejora de la asistencia a domicilio & 147 & $2,9 \%$ & $25,2 \%$ \\
\hline Calidad de la asistencia social & 115 & $2,2 \%$ & $19,7 \%$ \\
\hline \multicolumn{4}{|l|}{ Existencia de barreras } \\
\hline Aceptación por parte de la sociedad & 153 & $3,0 \%$ & $26,2 \%$ \\
\hline Supresión de barreras arquitectónicas & 150 & $2,9 \%$ & $25,7 \%$ \\
\hline Promoción de viviendas adaptadas & 123 & $2,4 \%$ & $21,1 \%$ \\
\hline Programas de cambio de actitudes & 106 & $2,1 \%$ & $18,2 \%$ \\
\hline Más y mejores ayudas técnicas & 90 & $1,8 \%$ & $15,4 \%$ \\
\hline Aceptación por parte de la familia & 75 & $1,5 \%$ & $12,8 \%$ \\
\hline Campañas de imagen & 67 & $1,3 \%$ & $11,5 \%$ \\
\hline \multicolumn{4}{|l|}{ Soluciones comunes } \\
\hline Garantías de futuro & 215 & $4,2 \%$ & $36,8 \%$ \\
\hline Más información sobre recursos & 158 & $3,1 \%$ & $27,1 \%$ \\
\hline Apoyo legal y administrativo & 139 & $2,7 \%$ & $23,8 \%$ \\
\hline Más y mejor información & 132 & $2,6 \%$ & $22,6 \%$ \\
\hline Asistencia psicológica & 130 & $2,5 \%$ & $22,3 \%$ \\
\hline Otras & 37 & $0,7 \%$ & $6,3 \%$ \\
\hline Respuestas totales & 5125 & $100 \%$ & $877,6 \%$ \\
\hline
\end{tabular}

Nota: 22 casos perdidos; 584 casos válidos.

Tabla 132: Frecuencias y porcentajes (de respuestas y de casos) de las soluciones propuestas por las familias en función de la temática. 
Si observamos las soluciones en función del tipo de necesidades (tabla 132), observamos que en cuanto a la salud personal, las familias eligen en mayor medida la ayuda para los cuidados personales diarios (39,6\% de los casos). En cuanto a las soluciones relativas a los recursos económicos, eligen de forma destacable la subida de las pensiones $(63,5 \%$ de los casos), seguida del incremento de la ayuda familiar (38,4\% de los casos) y de las subvenciones (31,3\% de los casos). En cuanto a las soluciones sobre los recursos sanitarios, eligen más y mejores instalaciones sanitarias (26,4\% de los casos), la calidad de la asistencia sanitaria (26\% de los casos) y la especialización profesional (25,9\% de los casos). En lo referente a soluciones sobre los recursos de servicios sociales, señalan los servicios de apoyo al ocio y tiempo libre (44\% de los casos), la mejora de los servicios de alojamiento (32,5\% de los casos), más y mejores instalaciones sociales $(30,1 \%)$ o la promoción del voluntariado $(29,5 \%)$ o los centros de día $(28,4 \%)$. En cuanto a las soluciones sobre la existencia de barreras, las familias señalan la aceptación por parte de la sociedad (26,2\% de los casos) o la supresión de barreras arquitectónicas (25,7\% de los casos). Por último, las familias señalan entre las soluciones comunes las garantías de futuro $(36,8 \%)$ o el incremento de información sobre los recursos $(27,1 \%)$.

\subsubsection{Apoyos institucionales requeridos}

Entre los apoyos institucionales requeridos por las familias (tabla 133), existen tres necesidades claramente señaladas por este colectivo, el incremento de las ayudas de las asociaciones (47,7\% de los casos), el apoyo de los Ayuntamientos (46,6\% de los casos) y la coordinación entre distintas administraciones (44,2\% de los casos). A estas necesidades les siguen, con un menor porcentaje de casos de elección, el apoyo de la comunidad (38,8\% de los casos), los apoyos en el entorno (28,7\% de los casos), la igualdad de oportunidades $(27,6 \%)$ y las actividades culturales $(25,4 \%)$ y de formación (23\%). El 5,5\% de los casos señalaron otros apoyos no recogidos entre los anteriores. 


\begin{tabular}{|c|c|c|}
\hline Apoyos requeridos: & $\mathbf{N}$ & $\%$ resp \% casos \\
\hline Incrementar los recursos de las asociaciones & 261 & $16,6 \%$ \\
\hline Apoyo de los Ayuntamientos & 255 & $16,2 \%$ \\
\hline Coordinación entre las distintas administraciones & 242 & $44,2 \%$ \\
\hline Apoyo de la comunidad & 212 & $38,8 \%$ \\
\hline Apoyos en el entorno & 157 & $28,7 \%$ \\
\hline Igualdad de oportunidades & 151 & $27,6 \%$ \\
\hline Actividades culturales & 139 & $25,4 \%$ \\
\hline Actividades de formación & 126 & $23,0 \%$ \\
\hline Otros & 30 & $5,5 \%$ \\
\hline Respuestas totales & 1573 & $100 \% 287,6 \%$ \\
\hline
\end{tabular}

Tabla 133: Frecuencias y porcentajes (de respuestas y de casos) de apoyos requeridos por las familias.

\subsubsection{Pensamientos de futuro}

En cuanto a pensamientos de futuro (tabla 134) las familias señalan que las PcDID quieren vivir con calidad de vida (40,9\% de los casos) y que afrontan el futuro con preocupación, a la vez que éste es incierto (40,2\% de los casos). En menor medida las familias atribuyen a las PcDID pensamientos como el de seguir viviendo (15,7\%), que el futuro dependerá del asociacionismo $(12,1 \%)$, futuro resuelto $(11,8 \%)$, vivir al día $(11,6 \%)$, autonomía personal $(11,6 \%)$, preocupación por los hijos $(11,6 \%)$, bien sin problemas $(11,3 \%)$.

En el $1 \%$ de los casos las familias señalaron que las PcDID no tenían ganas de vivir. 


\begin{tabular}{lccc}
\hline \multicolumn{1}{c}{ Pensamientos de futuro: } & N & $\begin{array}{c}\text { \% } \\
\text { resp }\end{array}$ & $\begin{array}{c}\text { casos } \\
\text { Vivir con calidad de vida }\end{array}$ \\
Con preocupación, futuro incierto & 243 & $19,0 \%$ & $40,9 \%$ \\
Seguir viviendo & 93 & $18,6 \%$ & $40,2 \%$ \\
Dependerá del asociacionismo & 72 & $7,3 \%$ & $15,7 \%$ \\
Resuelto & 70 & $5,6 \%$ & $12,1 \%$ \\
Vivir al día & 69 & $5,4 \%$ & $11,8 \%$ \\
Autonomía personal & 69 & $5,4 \%$ & $11,6 \%$ \\
Preocupación por los hijos & 69 & $5,4 \%$ & $11,6 \%$ \\
Bien, sin problemas & 67 & $5,2 \%$ & $11,3 \%$ \\
Soledad & 60 & $4,7 \%$ & $10,1 \%$ \\
Triste & 46 & $3,6 \%$ & $7,7 \%$ \\
Mal, negro & 44 & $3,4 \%$ & $7,4 \%$ \\
Vida independiente & 33 & $2,6 \%$ & $5,6 \%$ \\
Aburrimiento & 27 & $2,1 \%$ & $4,5 \%$ \\
Nada, no pienso en el futuro & 20 & $1,6 \%$ & $3,4 \%$ \\
Pocas ganas de vivir & 6 & $0,5 \%$ & $1,0 \%$ \\
Otros & 55 & $4,3 \%$ & $9,3 \%$ \\
\hline \multicolumn{1}{c}{ Respuestas totales } & $\mathbf{1 2 8 2}$ & $\mathbf{1 0 0 \%}$ & $\mathbf{2 1 5 , 8 \%}$ \\
\hline
\end{tabular}

Nota: 12 casos perdidos; 594 casos válidos.

Tabla 134: Frecuencias y porcentajes (de respuestas y de casos) de pensamientos sobre el futuro de las familias.

Si clasificamos los pensamientos de futuro en función del tipo de respuesta (tabla 135), observamos que las familias atribuyen a las PcDID pensamientos relativos a la preocupación, como afrontar un futuro incierto (40,2\% de los casos), y de otro tipo de respuestas como es vivir con calidad de vida (40,9\% de los casos).

Es destacable que un bajo porcentaje de familias selecciona como pensamientos de futuro de las PcDID respuestas de tipo pesimista. 


\begin{tabular}{|c|c|c|c|}
\hline Pensamientos de futuro: & $\mathbf{N}$ & $\begin{array}{c}\% \\
\text { resp }\end{array}$ & $\begin{array}{c}\% \\
\text { casos }\end{array}$ \\
\hline \multicolumn{4}{|l|}{ Respuestas de evitación } \\
\hline Seguir viviendo & 93 & $7,3 \%$ & $15,7 \%$ \\
\hline Vivir al día & 69 & $5,4 \%$ & $11,6 \%$ \\
\hline Nada, no pienso en el futuro & 20 & $1,6 \%$ & $3,4 \%$ \\
\hline \multicolumn{4}{|l|}{ Preocupación } \\
\hline Con preocupación, futuro incierto & 239 & $18,6 \%$ & $40,2 \%$ \\
\hline Preocupación por los hijos & 69 & $5,4 \%$ & $11,6 \%$ \\
\hline \multicolumn{4}{|l|}{ Pesimismo } \\
\hline Soledad & 60 & $4,7 \%$ & $10,1 \%$ \\
\hline Triste & 46 & $3,6 \%$ & $7,7 \%$ \\
\hline Mal, negro & 44 & $3,4 \%$ & $7,4 \%$ \\
\hline Aburrimiento & 27 & $2,1 \%$ & $4,5 \%$ \\
\hline Pocas ganas de vivir & 6 & $0,5 \%$ & $1,0 \%$ \\
\hline \multicolumn{4}{|l|}{ Optimismo } \\
\hline Resuelto & 70 & $5,5 \%$ & $11,8 \%$ \\
\hline Bien, sin problemas & 67 & $5,2 \%$ & $11,3 \%$ \\
\hline \multicolumn{4}{|l|}{ Otras respuestas } \\
\hline Vivir con calidad de vida & 243 & $19,0 \%$ & $40,9 \%$ \\
\hline Dependerá del asociacionismo & 72 & $5,6 \%$ & $12,1 \%$ \\
\hline Autonomía personal & 69 & $5,4 \%$ & $11,6 \%$ \\
\hline Vida independiente & 33 & $2,6 \%$ & $5,6 \%$ \\
\hline Otros & 55 & $4,3 \%$ & $9,3 \%$ \\
\hline Respuestas totales & 1282 & $100 \%$ & $215,8 \%$ \\
\hline
\end{tabular}

Nota: 12 casos perdidos; 594 casos válidos.

Tabla 135: Frecuencias y porcentajes (de respuestas y de casos) de pensamientos sobre el futuro en función de la temática de las familias.

\subsubsection{Otras consideraciones}

En lo que respecta a otro tipo de consideraciones (tabla 136), las familias destacan como necesidades la creación de centros especializados $(27,2 \%$ de los casos), seguida de las ayudas asistenciales (13,2\% de los casos), la ayuda de las instituciones $(13,2 \%)$, las ayudas económicas $(10,6 \%)$ y la ayuda de la sociedad $(8,6 \%)$, entre otras. 


\begin{tabular}{lccc}
\hline \multicolumn{1}{c}{ Otras consideraciones: } & N & $\begin{array}{c}\text { \% } \\
\text { resp }\end{array}$ & $\begin{array}{c}\text { \% } \\
\text { casos }\end{array}$ \\
\hline Creación centros especializados & 41 & $21,1 \%$ & $27,2 \%$ \\
Ayudas asistenciales & 20 & $10,3 \%$ & $13,2 \%$ \\
Ayuda de las instituciones & 20 & $10,3 \%$ & $13,2 \%$ \\
Ayudas económicas & 16 & $8,2 \%$ & $10,6 \%$ \\
Ayuda de la sociedad & 13 & $6,7 \%$ & $8,6 \%$ \\
Información adecuada & 6 & $3,1 \%$ & $4,0 \%$ \\
Supresión de barreras arquitectónicas & 2 & $1,0 \%$ & $1,3 \%$ \\
Otras & 76 & $39,2 \%$ & $50,3 \%$ \\
\hline \multicolumn{1}{c}{ Respuestas totales } & $\mathbf{1 9 4}$ & $\mathbf{1 0 0 \%}$ & $\mathbf{1 2 8 , 5 \%}$ \\
\hline
\end{tabular}

Nota: 455 casos perdidos; 151 casos válidos.

Tabla 136: Frecuencias y porcentajes (de respuestas y de casos) de otras consideraciones de las familias.

\subsubsection{Resumen}

A modo de resumen, diríamos que la muestra de familias destaca como necesidades importantes para las PcDID las relativas a la salud personal, los recursos de servicios sociales y la existencia de barreras principalmente.

En cuanto a la salud personal, preocupan el estado de salud general, la dependencia, los cuidados personales diarios y las limitaciones funcionales personales fundamentalmente, para lo que las familias proponen como solución principal el incremento de los cuidados personales diarios.

En lo referente a los recursos económicos, las familias destacan como necesidad principal la pensión, y proponen la subida de las mismas.

En cuanto a los recursos sanitarios, las familias están preocupadas por la calidad de este tipo de asistencia y por los servicios de salud mental, proponiendo para ello el incremento en número y calidad de las instalaciones sanitarias. 
Por otro lado, en cuanto a los recursos sobre los servicios sociales, las familias están preocupadas por los servicios de apoyo al ocio y tiempo libre, los servicios de alojamiento y la ayuda a domicilio. Como soluciones en esta área, proponen la creación de servicios de apoyo al ocio y tiempo libre.

En la existencia de barreras, las familias destacan como preocupantes la aceptación por parte de la sociedad, las barreras sociales y en menor medida, las barreras arquitectónicas. Como soluciones, proponen la aceptación social y la eliminación de barreras arquitectónicas.

Por último, las familias están especialmente preocupadas por el dónde y con quién vivirá la PcDID en el futuro, para lo que señalan como solución las garantías de futuro.

Como apoyos institucionales importantes, las familias señalan el incremento de las ayudas a las asociaciones, el apoyo de los Ayuntamientos y una mayor coordinación entre las distintas administraciones.

En cuanto a los pensamientos de futuro sobre las PcDID, las familias comentan vivir con calidad de vida, y afrontar el futuro con preocupación, ya que tiene un carácter incierto. Sólo unas pocas familias señalan como pensamientos de futuro respuestas pesimistas.

\subsection{ANÁLISIS DE LA RELACIÓN ENTRE PREOCUPACIONES Y NECESIDADES Y LAS VARIABLES PREDICTORAS. MUESTRA FAMILIAR}

\subsubsection{Introducción}

En este apartado vamos a analizar la influencia de determinadas variables sociodemográficas de las PcDID en el número de necesidades percibidas (generales y especí- 
ficas), soluciones, apoyos institucionales requeridos, pensamientos de futuro y otras consideraciones por parte de las familias.

\subsubsection{Prueba de normalidad de las distribuciones}

En primer lugar, se realiza la prueba Kolmogorov-Smirnov para una muestra para comprobar la normalidad de las distribuciones de las variables criterio, a saber, preocupaciones, soluciones, apoyos institucionales, pensamientos de futuro y otras consideraciones (tabla 137) y de las necesidades específicas (tabla 138). En ambos casos, las variables no siguen una distribución normal $(\mathrm{p}<0,01)$, por lo que se emplean técnicas de análisis no paramétricas.

\begin{tabular}{|c|c|c|c|c|c|c|c|c|}
\hline & \multirow[b]{2}{*}{$\mathrm{N}$} & \multicolumn{2}{|c|}{$\begin{array}{c}\text { Parámetros norma- } \\
\text { les }\end{array}$} & \multicolumn{3}{|c|}{$\begin{array}{l}\text { Diferencias más ex- } \\
\text { tremas }\end{array}$} & \multirow{2}{*}{$\begin{array}{l}\mathrm{Z} \text { de } \\
\mathrm{K}-\mathrm{S}\end{array}$} & \multirow[b]{2}{*}{ Sig. } \\
\hline & & Media & DT & Abs. & Pos. & Neg. & & \\
\hline $\begin{array}{l}\mathrm{N}^{\circ} \text { preocupacio- } \\
\text { nes }\end{array}$ & 606 & 11,43 & 7,064 & 0,128 & 0,128 & $-0,078$ & 3,143 &, 000 \\
\hline $\mathrm{N}^{\mathrm{o}}$ soluciones & 606 & 8,45 & 7,317 & 0,175 & 0,175 & $-0,124$ & 4,303 & ,000 \\
\hline $\begin{array}{l}\mathrm{N}^{\circ} \text { apoyos insti- } \\
\text { tucionales }\end{array}$ & 606 & 2,60 & 2,028 & 0,211 & 0,211 & $-0,119$ & 5,183 &, 000 \\
\hline $\begin{array}{l}\mathrm{N}^{\circ} \text { pensamientos } \\
\text { futuro }\end{array}$ & 606 & 2,09 & 1,426 & 0,250 & 0,250 & $-0,203$ & 6,156 &, 000 \\
\hline $\begin{array}{l}N^{o} \text { consideracio- } \\
\text { nes }\end{array}$ & 600 & ,33 & 0,678 & 0,431 & 0,431 & $-0,312$ & 10,559 &, 000 \\
\hline
\end{tabular}

Tabla 137: Prueba de Kolmogorov-Smirnov para una muestra en número total de preocupaciones, soluciones, apoyos requeridos, pensamientos de futuro y otras consideraciones. 


\begin{tabular}{|c|c|c|c|c|c|c|c|c|}
\hline & \multirow[b]{2}{*}{$\mathrm{N}$} & \multicolumn{2}{|c|}{$\begin{array}{l}\text { Parámetros nor- } \\
\text { males }\end{array}$} & \multicolumn{3}{|c|}{$\begin{array}{l}\text { Diferencias más extre- } \\
\text { mas }\end{array}$} & \multirow{2}{*}{$\begin{array}{l}\mathrm{Z} \text { de } \\
\mathrm{K}-\mathrm{S}\end{array}$} & \multirow[b]{2}{*}{ Sig. } \\
\hline & & Media & DT & Abs. & Pos. & Neg. & & \\
\hline $\mathrm{N}^{\mathrm{o}}$ salud personal & 606 & 2,33 & 1,526 & 0,195 & 0,195 & $-0,124$ & 4,799 &, 000 \\
\hline $\begin{array}{l}\mathrm{N}^{\mathrm{o}} \text { recursos económi- } \\
\cos \end{array}$ & 606 & 1,39 & 1,112 & 0,291 & 0,291 & $-0,197$ & 7,175 &, 000 \\
\hline $\mathrm{N}^{\circ}$ recursos sanitarios & 606 & 1,75 & 1,703 & 0,224 & 0,224 & $-0,152$ & 5,517 &, 000 \\
\hline $\begin{array}{l}N^{o} \text { recursos s. socia- } \\
\text { les }\end{array}$ & 606 & 2,28 & 1,782 & 0,229 & 0,229 & $-0,131$ & 5,643 &, 000 \\
\hline $\begin{array}{l}N^{o} \text { existencia de ba- } \\
\text { rreras }\end{array}$ & 606 & 1,88 & 1,679 & 0,200 & 0,200 & $-0,131$ & 4,921 &, 000 \\
\hline $\begin{array}{l}\mathrm{N}^{\circ} \text { otras preocupa- } \\
\text { ciones }\end{array}$ & 606 & 1,82 & 1,463 & 0,209 & 0,209 & $-0,136$ & 5,151 & 000 \\
\hline
\end{tabular}

Tabla 138: Prueba de Kolmogorov-Smirnov para una muestra en número total de preocupaciones sobre salud personal, recursos económicos, recursos sanitarios, recursos de servicios sociales, existencia de barreras y otras preocupaciones.

\subsubsection{Variable género}

\subsubsection{Introducción}

En este apartado se analiza si han existido diferencias estadísticamente significativas en los resultados obtenidos en función del género de las PcDID.

\subsubsection{Resultados sobre la variable género}

La prueba U de Mann-Whitney revela que no existen diferencias significativas en el número de preocupaciones y soluciones generales en la muestra familiar (tabla 140), aunque se aprecia una tendencia a señalar un mayor número de estos ítems por parte de las mujeres (tabla 139), aunque no es estadísticamente significativa. 


\begin{tabular}{|c|c|c|c|}
\hline & Género & $\mathbf{N}$ & $\begin{array}{l}\text { Rango pro- } \\
\text { medio }\end{array}$ \\
\hline \multirow{3}{*}{$\begin{array}{l}\mathrm{N}^{0} \text { preocupaciones } \mathbf{y} \\
\text { necesidades }\end{array}$} & Varón & 336 & 299,59 \\
\hline & Mujer & 270 & 308,36 \\
\hline & Total & 606 & \\
\hline \multirow{3}{*}{$\mathbf{N}^{\mathbf{o}}$ soluciones } & Varón & 336 & 300,84 \\
\hline & Mujer & 270 & 306,81 \\
\hline & Total & 606 & \\
\hline \multirow{3}{*}{$\begin{array}{l}\mathbf{N}^{0} \text { apoyos institucio- } \\
\text { nales requeridos }\end{array}$} & Varón & 336 & 298,24 \\
\hline & Mujer & 270 & 310,04 \\
\hline & Total & 606 & \\
\hline \multirow{3}{*}{$\begin{array}{l}N^{0} \text { pensamientos so- } \\
\text { bre futuro }\end{array}$} & Varón & 336 & 302,19 \\
\hline & Mujer & 270 & 305,13 \\
\hline & Total & 606 & \\
\hline \multirow{3}{*}{$\mathrm{N}^{0}$ consideraciones } & Varón & 334 & 292,11 \\
\hline & Mujer & 266 & 311,04 \\
\hline & Total & 600 & \\
\hline
\end{tabular}

Tabla 139: Rangos promedio en función del género en número total de preocupaciones y soluciones generales. Muestra de familias.

\begin{tabular}{lccccc}
\hline & $\begin{array}{c}\text { U de Mann- } \\
\text { Whitney }\end{array}$ & $\begin{array}{c}\text { W de Wil- } \\
\text { coxon }\end{array}$ & $\mathbf{Z}$ & Sig. & $\boldsymbol{\eta}^{\mathbf{2}}$ \\
\hline $\mathbf{N}^{\mathbf{0}}$ preocupaciones & 44046,500 & 100662,500 & $-0,614$ &, 539 & $-0,018$ \\
$\mathbf{N}^{\mathbf{0}}$ soluciones & 44467,500 & 101083,500 & $-0,418$ &, 676 & $-0,012$ \\
$\mathbf{N}^{\mathbf{0}}$ apoyos institucionales & 43593,000 & 100209,000 & $-0,840$ &, 401 & $-0,024$ \\
$\mathbf{N}^{\mathbf{0}}$ pensamientos futuro & 44920,000 & 101536,000 & $-0,216$ &, 829 & $-0,000$ \\
$\mathbf{N}^{\mathbf{0}}$ consideraciones & 41619,500 & 97564,500 & $-1,745$ &, 081 & $-0,051$ \\
& & & & &
\end{tabular}

Nota: el tamaño del efecto $\left(\eta^{2}\right)$ debe interpretarse en valor absoluto.

Tabla 140: Estadísticos de contraste en función del género en número total de necesidades generales. Muestra de familias.

En cuanto a las necesidades específicas, los resultados indican que tampoco hay diferencias significativas en ellas en función del género de las PcDID (tabla 142). Si observamos los rangos promedio de las respuestas (tabla 141), observamos que no se produce una tendencia de respuesta destacable de un grupo sobre el otro, cuestión que también puede observarse en el gráfico 16. En la tabla 143 se presenta el resumen de la significatividad de los datos. 


\begin{tabular}{|c|c|c|c|}
\hline & Género & $\mathbf{N}$ & $\begin{array}{l}\text { Rango pro- } \\
\text { medio }\end{array}$ \\
\hline \multirow{3}{*}{$\begin{array}{l}\mathbf{N}^{0} \text { preocupaciones } \\
\text { sobre salud personal }\end{array}$} & Varón & 336 & 306,72 \\
\hline & Mujer & 270 & 299,50 \\
\hline & Total & 606 & \\
\hline \multirow{3}{*}{$\begin{array}{l}\mathbf{N}^{0} \text { preocupaciones } \\
\text { recursos económicos }\end{array}$} & Varón & 336 & 303,37 \\
\hline & Mujer & 270 & 303,67 \\
\hline & Total & 606 & \\
\hline \multirow{3}{*}{$\begin{array}{l}\mathrm{N}^{\circ} \text { preocupaciones } \\
\text { recursos sanitarios }\end{array}$} & Varón & 336 & 303,25 \\
\hline & Mujer & 270 & 303,81 \\
\hline & Total & 606 & \\
\hline \multirow{3}{*}{$\begin{array}{l}N^{0} \text { preocu. recursos } \\
\text { servicios sociales }\end{array}$} & Varón & 336 & 303,47 \\
\hline & Mujer & 270 & 303,54 \\
\hline & Total & 606 & \\
\hline \multirow{3}{*}{$\begin{array}{l}N^{o} \text { preocu. existencia } \\
\text { de barreras }\end{array}$} & Varón & 336 & 299,98 \\
\hline & Mujer & 270 & 307,88 \\
\hline & Total & 606 & \\
\hline \multirow{3}{*}{$\begin{array}{l}\mathbf{N}^{\circ} \text { otras preocupacio- } \\
\text { nes y necesidades }\end{array}$} & Varón & 336 & 293,74 \\
\hline & Mujer & 270 & 315,64 \\
\hline & Total & 606 & \\
\hline
\end{tabular}

Tabla 141: Rangos promedio en función del género en número total de necesidades específicas. Muestra de familias.

\begin{tabular}{lccccc}
\hline & U de Mann-WhitneyW de Wilcoxon & $\mathbf{Z}$ & Sig. & $\boldsymbol{\eta}^{\mathbf{2}}$ \\
\hline $\mathbf{N}^{\mathbf{o}}$ salud personal & 44279,500 & 80864,500 &,- 517 &, 605 &,- 015 \\
$\mathbf{N}^{\mathbf{o}}$ recursos económicos & 45315,000 & 101931,000 &,- 023 &, 982 &,- 000 \\
$\mathbf{N}^{\mathbf{o}}$ recursos sanitarios & 45275,000 & 101891,000 &,- 041 &, 967 &,- 000 \\
$\mathbf{N}^{\mathbf{o}}$ recursos servicios sociales & 45350,500 & 101966,500 &,- 005 &, 996 &,- 000 \\
$\mathbf{N}^{\mathbf{o}}$ existencia de barreras & 44177,500 & 100793,500 &,- 567 &, 571 &,- 016 \\
$\mathbf{N}^{\mathbf{o}}$ otras preocupaciones & 42082,000 & 98698,000 & $-1,581$ &, 114 &,- 046 \\
\hline
\end{tabular}

Nota: el tamaño del efecto $\left(\eta^{2}\right)$ debe interpretarse en valor absoluto.

Tabla 142: Estadísticos de contraste en función del género en número total de preocupaciones específicas. Muestra de familias. 


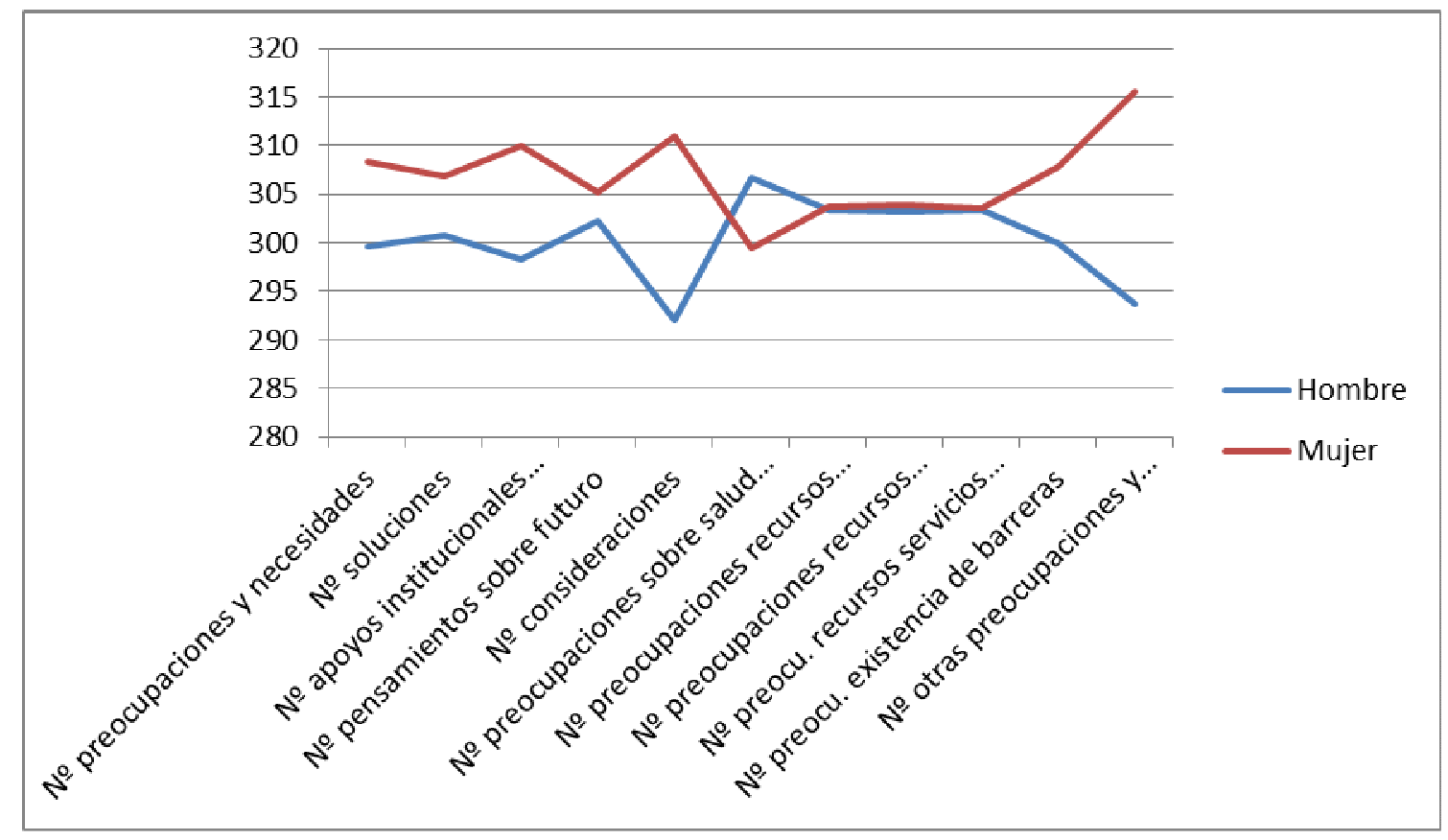

Gráfico 16: Rangos promedio en función del género en número total de preocupaciones generales y específicas. Muestra de familias.

\begin{tabular}{|c|c|c|}
\hline PcDID & VARIABLES & $\begin{array}{c}\text { GÉNERO } \\
\text { Mujer } \\
\text { Hombre }\end{array}$ \\
\hline \multirow{11}{*}{$\begin{array}{c}\text { TODOS } \\
\text { N=606 } \\
\text { Mujer: } 270 \\
\text { Varón: } 336\end{array}$} & $\mathrm{~N}^{\circ}$ preoc y necesidades & NO \\
\hline & $\mathrm{N}^{\mathrm{o}}$ soluciones & $\mathrm{NO}$ \\
\hline & $\mathrm{N}^{\circ}$ apoyos institucionales & $\mathrm{NO}$ \\
\hline & $\mathrm{N}^{\mathrm{o}}$ pensam futuro & NO \\
\hline & $\mathrm{N}^{\mathrm{o}}$ otras consideraciones & NO \\
\hline & $\mathrm{N}^{\circ}$ necesidades salud personal & $\mathrm{NO}$ \\
\hline & $\mathrm{N}^{\circ}$ necesidades recursos económicos & NO \\
\hline & $\mathrm{N}^{\circ}$ necesidades recursos servicios sanitarios & NO \\
\hline & $\mathrm{N}^{\circ}$ necesidades recursos servicios sociales & $\mathrm{NO}$ \\
\hline & $\mathrm{N}^{\circ}$ necesidades existencia de barreras & $\mathrm{NO}$ \\
\hline & $\mathrm{N}^{\mathrm{o}}$ otras necesidades & $\mathrm{NO}$ \\
\hline
\end{tabular}

Nota: $\mathrm{NO}=$ no hay diferencias estadísticamente significativas; SI: hay diferencias estadísticamente significativas; + seguido del grupo indica dónde se encuentran mayores rangos promedio.

Tabla 143: Resumen de diferencias en función del género. Muestra de familias.

\subsubsection{Resumen}

La variable género no ha influido en el número de preocupaciones generales y específicas señaladas por las familias de las PcDID. 


\subsubsection{Variable edad}

\subsubsection{Introducción}

En este apartado se analiza la influencia de la variable edad de las PcDID sobre el número de respuestas sobre las NP's de las familias. Para ello, la edad de las PcDID se recodificó en tres grupos:

- 35-49 años

- 50-64 años

- 65 o más años

\subsubsection{Resultados sobre la variable edad}

La prueba Kruskal-Wallis indica que hay diferencias estadísticamente significativas $(\mathrm{p}<0,05)$ en cuanto al número de preocupaciones generales (tabla 145), siendo mayor el número de necesidades señaladas en el grupo de 35-49 años (tabla 144). 


\begin{tabular}{|c|c|c|c|}
\hline & $\begin{array}{l}\text { Edad recodifi- } \\
\text { cada }\end{array}$ & $\mathbf{N}$ & $\begin{array}{l}\text { Rango pro- } \\
\text { medio }\end{array}$ \\
\hline \multirow{4}{*}{$\begin{array}{l}\mathrm{N}^{0} \text { preocupaciones } \mathrm{y} \\
\text { necesidades }\end{array}$} & 35-49 años & 287 & 320,42 \\
\hline & 50-64 años & 274 & 298,43 \\
\hline & +65 años & 45 & 226,43 \\
\hline & Total & 606 & \\
\hline \multirow{4}{*}{$\mathbf{N}^{\circ}$ soluciones } & 35-49 años & 287 & 306,49 \\
\hline & 50-64 años & 274 & 302,71 \\
\hline & +65 años & 45 & 289,24 \\
\hline & Total & 606 & \\
\hline \multirow{4}{*}{$\begin{array}{l}\mathrm{N}^{0} \text { apoyos institucio- } \\
\text { nales requeridos }\end{array}$} & 35-49 años & 287 & 315,86 \\
\hline & 50-64 años & 274 & 298,29 \\
\hline & +65 años & 45 & 256,39 \\
\hline & Total & 606 & \\
\hline \multirow{4}{*}{$\begin{array}{l}\mathrm{N}^{0} \text { pensamientos so- } \\
\text { bre futuro }\end{array}$} & 35-49 años & 287 & 319,66 \\
\hline & 50-64 años & 274 & 290,03 \\
\hline & +65 años & 45 & 282,44 \\
\hline & Total & 606 & \\
\hline \multirow{4}{*}{$\mathbf{N}^{0}$ consideraciones } & $35-49$ años & 283 & 312,05 \\
\hline & 50-64 años & 272 & 293,86 \\
\hline & +65 años & 45 & 267,99 \\
\hline & Total & 600 & \\
\hline
\end{tabular}

Tabla 144: Rangos promedio en función de la edad recodificada en número total de preocupaciones y soluciones generales. Muestra de familias.

\begin{tabular}{lcccc}
\hline & $\begin{array}{c}\text { Chi- } \\
\text { cuadrado }\end{array}$ & gl & Sig. & $\boldsymbol{\eta}^{\mathbf{2}}$ \\
\hline $\mathbf{N}^{\mathbf{0}}$ preocupaciones & 11,674 & 2 &, 003 & $-0,07$ \\
$\mathbf{N}^{\mathbf{0}}$ soluciones & 0,390 & 2 &, 823 & $-0,01$ \\
$\mathbf{N}^{\mathbf{0}}$ apoyos institucionales & 5,117 & 2 &, 077 & $-0,05$ \\
$\mathbf{N}^{\mathbf{0}}$ pensamientos futuro & 5,233 & 2 &, 073 & $-0,03$ \\
$\mathbf{N}^{\mathbf{0}}$ consideraciones & 5,582 & 2 &, 061 & $-0,05$ \\
\hline
\end{tabular}

Nota: el tamaño del efecto $\left(\eta^{2}\right)$ debe interpretarse en valor absoluto.

Tabla 145: Estadísticos de contraste en función de la edad recodificada en número total de preocupaciones y soluciones generales. Muestra de familias.

Por otro lado, en cuanto a las necesidades específicas (tabla 147), se observa que existen diferencias estadísticamente significativas $(p<0,05)$ en el número de recursos económicos, existencia de barreras y otras preocupaciones. Tanto en el número de recursos económicos, como de otras preocupaciones son superiores las puntuaciones del 
grupo de entre 35 y 49 años, mientras que en cuanto a la existencia de barreras, el grupo de entre 50 y 64 años obtiene mayores puntuaciones (tabla 146). En el gráfico 17 aparecen los rangos promedio de cada uno de los grupos de edad en las variables criterio estudiadas. 


\begin{tabular}{|c|c|c|c|}
\hline & $\begin{array}{l}\text { Edad recodifi- } \\
\text { cada }\end{array}$ & $\mathbf{N}$ & $\begin{array}{l}\text { Rango pro- } \\
\text { medio }\end{array}$ \\
\hline \multirow{4}{*}{$\begin{array}{l}\mathbf{N}^{0} \text { preoc. salud per- } \\
\text { sonal }\end{array}$} & 35-49 años & 287 & 310,43 \\
\hline & 50-64 años & 274 & 300,34 \\
\hline & +65 años & 45 & 278,57 \\
\hline & Total & 606 & \\
\hline \multirow{4}{*}{$\begin{array}{l}\mathrm{N}^{\circ} \text { preoc. recursos } \\
\text { económicos }\end{array}$} & 35-49 años & 287 & 324,26 \\
\hline & 50-64 años & 274 & 291,51 \\
\hline & +65 años & 45 & 244,06 \\
\hline & Total & 606 & \\
\hline \multirow{4}{*}{$\begin{array}{l}N^{o} \text { preoc. recursos sa- } \\
\text { nitarios }\end{array}$} & 35-49 años & 287 & 317,26 \\
\hline & 50-64 años & 274 & 296,77 \\
\hline & +65 años & 45 & 256,70 \\
\hline & Total & 606 & \\
\hline \multirow{4}{*}{$\begin{array}{l}\mathrm{N}^{\circ} \text { preoc. recursos } \\
\text { s.sociales }\end{array}$} & 35-49 años & 287 & 318,60 \\
\hline & 50-64 años & 274 & 292,38 \\
\hline & +65 años & 45 & 274,86 \\
\hline & Total & 606 & \\
\hline \multirow{4}{*}{$\begin{array}{l}\mathrm{N}^{0} \text { preoc. existencia } \\
\text { barreras }\end{array}$} & 35-49 años & 287 & 305,01 \\
\hline & 50-64 años & 274 & 314,01 \\
\hline & +65 años & 45 & 229,87 \\
\hline & Total & 606 & \\
\hline \multirow{4}{*}{$\begin{array}{l}N^{\circ} \text { Otras preocupacio- } \\
\text { nes }\end{array}$} & 35-49 años & 287 & 322,45 \\
\hline & 50-64 años & 274 & 297,25 \\
\hline & +65 años & 45 & 220,74 \\
\hline & Total & 606 & \\
\hline
\end{tabular}

Tabla 146: Rangos promedio en función de la edad recodificada en número total de preocupaciones específicas. Muestra de familias. 


\begin{tabular}{lcccc}
\hline & $\begin{array}{c}\text { Chi- } \\
\text { cuadrado }\end{array}$ & gl & Sig. & $\boldsymbol{\eta}^{\mathbf{2}}$ \\
\hline $\mathbf{N}^{\mathbf{0}}$ salud personal & 1,525 & 2 &, 467 & $-0,03$ \\
$\mathbf{N}^{\mathbf{0}}$ recursos económicos & 12,099 & 2 &, 002 & $-0,07$ \\
$\mathbf{N}^{\mathbf{0}}$ recursos sanitarios & 5,718 & 2 &, 057 & $-0,05$ \\
$\mathbf{N}^{\mathbf{0}}$ recursos s. sociales & 4,677 & 2 &, 096 & $-0,04$ \\
$\mathbf{N}^{\mathbf{o}}$ existencia barreras & 9,450 & 2 &, 009 & $-0,06$ \\
$\mathbf{N}^{\mathbf{o}}$ otras preocupaciones & 14,697 & 2 &, 001 & $-0,08$ \\
\hline
\end{tabular}

Nota: el tamaño del efecto $\left(\eta^{2}\right)$ debe interpretarse en valor absoluto.

Tabla 147: Estadísticos de contraste en función de la edad recodificada en número total de preocupaciones específicas. Muestra de familias.

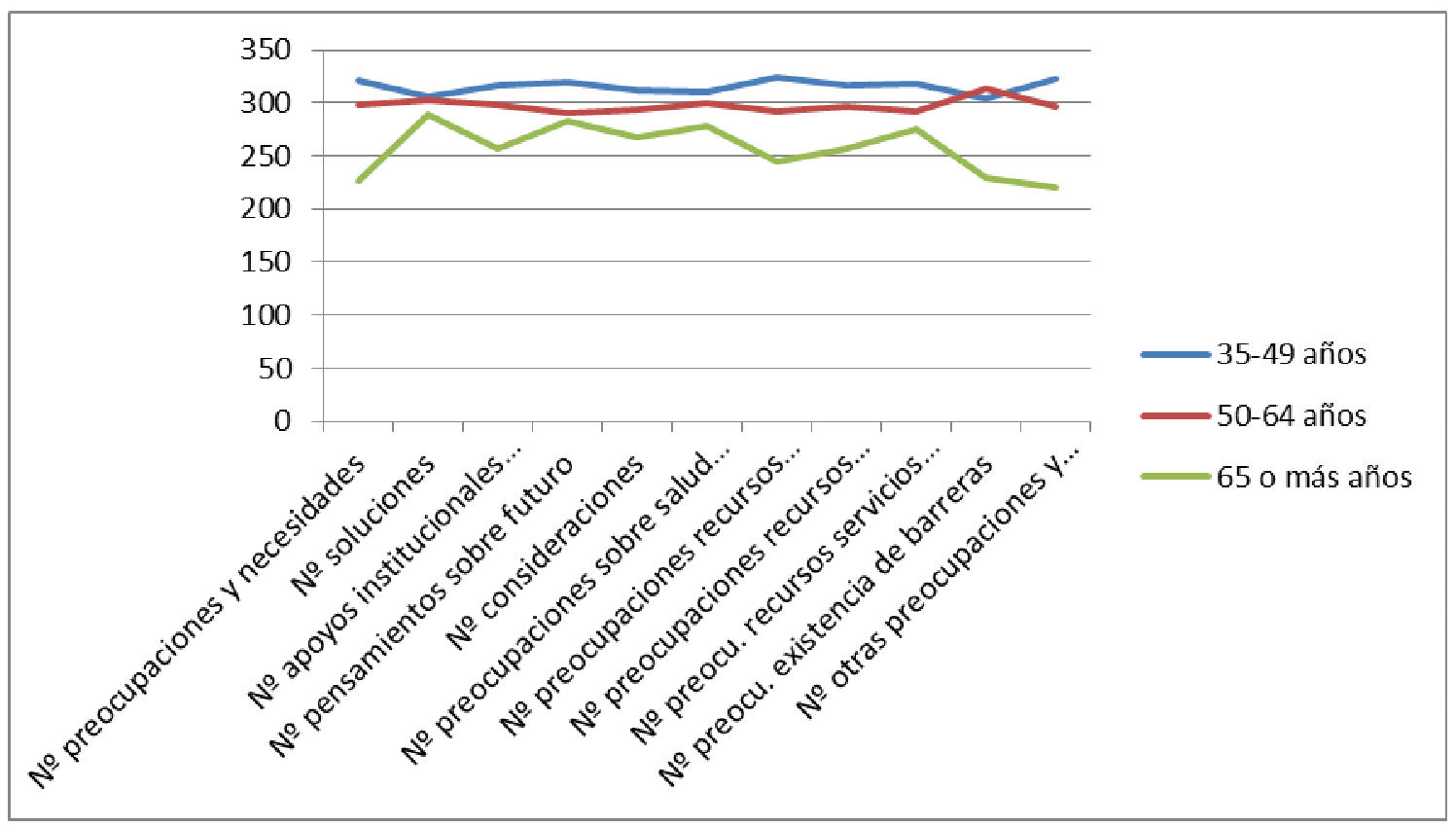

Gráfico 17: Rangos promedio en función de la edad en número total de preocupaciones generales y específicas. Muestra de familias.

La tabla 148 recoge un resumen de la significatividad de los datos. 


\begin{tabular}{|c|c|c|}
\hline PcDID & VARIABLES & $\begin{array}{c}\text { EDAD } \\
\text { 35-49 años } \\
\text { 50-64 años } \\
65 \text { o más años }\end{array}$ \\
\hline \multirow{11}{*}{$\begin{array}{c}\text { TODOS } \\
\text { N= 606 } \\
\text { 35-49 años }=287 \\
\text { 50-64 años }=274 \\
\text { 65 o más años }=45\end{array}$} & $\mathrm{~N}^{\circ}$ preoc y necesidades & SI:+35-49 años \\
\hline & $\mathrm{N}^{\circ}$ soluciones & $\mathrm{NO}$ \\
\hline & $\mathrm{N}^{\mathrm{o}}$ apoyos institucionales & NO \\
\hline & $\mathrm{N}^{\circ}$ pensam futuro & $\mathrm{NO}$ \\
\hline & $\mathrm{N}^{\mathrm{o}}$ otras consideraciones & NO \\
\hline & $\mathrm{N}^{\mathrm{o}}$ necesidades salud personal & NO \\
\hline & $\mathrm{N}^{0}$ necesidades recursos económicos & SI:+35-49 años \\
\hline & $\mathrm{N}^{\circ}$ necesidades recursos servicios sanitarios & $\mathrm{NO}$ \\
\hline & $\mathrm{N}^{\circ}$ necesidades recursos servicios sociales & $\mathrm{NO}$ \\
\hline & $\mathbf{N}^{0}$ necesidades existencia de barreras & SI:+50-64 años \\
\hline & $\mathbf{N}^{0}$ otras necesidades & SI:+35-49 años \\
\hline
\end{tabular}

Nota: $\mathrm{NO}=$ no hay diferencias estadísticamente significativas; SI: hay diferencias estadísticamente significativas; + seguido del grupo indica dónde se encuentran mayores rangos promedio.

Tabla 148: Resumen de diferencias en función de la edad recodificada. Muestra de familias.

\subsubsection{Resumen}

En lo que respecta a la edad de las PcDID, ha tenido una pequeña influencia sobre el número de ítems señalados por las familias, como se ha podido observar en este apartado.

\subsubsection{Variable grado de discapacidad}

\subsubsection{Introducción}

En este epígrafe se exponen los resultados relativos a la influencia del grado de discapacidad de las PcDID en el número de respuestas señaladas por sus familias en las variables del estudio. Para ello se ha dicotomizado la variable tipo de discapacidad:

- Menor del 65\%

- Igual o mayor del 65\% 


\subsubsection{Resultados sobre la variable grado de discapacidad}

En cuanto al grado de discapacidad, hemos realizado la prueba U de MannWhitney, y los resultados indican que no existen diferencias significativas en el número de preocupaciones y soluciones generales (tabla 150). Sí que se observa una tendencia a señalar un mayor número de preocupaciones y soluciones generales en el grupo de familias de personas de 65 o más años, exceptuando en la variable otras consideraciones en la que ocurre lo contrario, si bien estos resultados no son estadísticamente significativos (tabla 149). 


\begin{tabular}{|c|c|c|c|}
\hline & Grado discapacidad & $\mathbf{N}$ & $\begin{array}{l}\text { Rango prome- } \\
\text { dio }\end{array}$ \\
\hline \multirow{3}{*}{$\begin{array}{l}\mathbf{N}^{0} \text { preocupaciones y ne- } \\
\text { cesidades }\end{array}$} & Menor de 65 & 61 & 241,33 \\
\hline & Igual o mayor que 65 & 474 & 271,43 \\
\hline & Total & 535 & \\
\hline \multirow{3}{*}{$\mathrm{N}^{\mathrm{o}}$ soluciones } & Menor de 65 & 61 & 235,59 \\
\hline & Igual o mayor que 65 & 474 & 272,17 \\
\hline & Total & 535 & \\
\hline \multirow{3}{*}{$\begin{array}{l}\mathrm{N}^{\circ} \text { apoyos institucionales } \\
\text { requeridos }\end{array}$} & Menor de 65 & 61 & 247,43 \\
\hline & Igual o mayor que 65 & 474 & 270,65 \\
\hline & Total & 535 & \\
\hline \multirow{3}{*}{$\begin{array}{l}N^{o} \text { pensamientos de futu- } \\
\text { ro }\end{array}$} & Menor de 65 & 61 & 254,12 \\
\hline & Igual o mayor que 65 & 474 & 269,79 \\
\hline & Total & 535 & \\
\hline \multirow{3}{*}{$N^{o}$ consideraciones } & Menor de 65 & 61 & 280,56 \\
\hline & Igual o mayor que 65 & 470 & 264,11 \\
\hline & Total & 531 & \\
\hline
\end{tabular}

Tabla 149: Rangos promedio en función del grado de discapacidad dicotomizado en número total de preocupaciones y soluciones generales. Muestra de familias.

\begin{tabular}{lccccc}
\hline & $\begin{array}{c}\text { U de Mann- } \\
\text { Whitney }\end{array}$ & $\begin{array}{c}\text { W de Wil- } \\
\text { coxon }\end{array}$ & $\mathbf{Z}$ & Sig. & $\boldsymbol{\eta}^{\mathbf{2}}$ \\
\hline $\mathbf{N}^{\mathbf{0}}$ preocupaciones & 12830,000 & 14721,000 & $-1,435$ &, 151 & $-0,04$ \\
$\mathbf{N}^{\mathbf{0}}$ soluciones & 12480,000 & 14371,000 & $-1,744$ &, 081 & $-0,05$ \\
$\mathbf{N}^{\mathbf{0}}$ apoyos institucionales & 13202,500 & 15093,500 & $-1,125$ &, 261 & $-0,03$ \\
$\mathbf{N}^{\mathbf{0}}$ pensamientos futuro & 13610,500 & 15501,500 & $-0,785$ &, 432 & $-0,02$ \\
$\mathbf{N}^{\mathbf{0}}$ consideraciones & 13447,000 & 124132,000 & $-1,036$ &, 300 & $-0,03$ \\
\hline
\end{tabular}

Nota: el tamaño del efecto $\left(\eta^{2}\right)$ debe interpretarse en valor absoluto.

Tabla 150: Estadísticos de contraste en función del grado de discapacidad dicotomizado en número total de necesidades generales. Muestra de familias.

En cuanto a las necesidades específicas, la prueba U de Mann-Whitney muestra que hay diferencias estadísticamente significativas $(\mathrm{p}<0,05)$ en salud personal, recursos sanitarios y existencia de barreras (tabla 152). En los tres casos, son las familias de las PcDID de 65 o más años las que responden un mayor número de ítems relativos a estas variables (tabla 151). 
En el gráfico 18 se muestran los rangos promedio de los grupos de edad en las distintas variables criterio, mientras que en la tabla 153 se muestra la significatividad de los resultados obtenidos.

\begin{tabular}{|c|c|c|c|}
\hline & Grado discapacidad & $\mathbf{N}$ & $\begin{array}{c}\text { Rango } \\
\text { promedio }\end{array}$ \\
\hline \multirow{3}{*}{$\begin{array}{l}\mathbf{N}^{\circ} \text { preocupaciones sobre salud } \\
\text { personal }\end{array}$} & Menor de 65 & 61 & 219,05 \\
\hline & Igual o mayor que 65 & 474 & 274,30 \\
\hline & Total & 535 & \\
\hline \multirow{3}{*}{$\begin{array}{l}\mathrm{N}^{0} \text { preocupaciones recursos } \\
\text { económicos }\end{array}$} & Menor de 65 & 61 & 259,82 \\
\hline & Igual o mayor que 65 & 474 & 269,05 \\
\hline & Total & 535 & \\
\hline \multirow{3}{*}{$\begin{array}{l}N^{0} \text { preocupaciones recursos sani- } \\
\text { tarios }\end{array}$} & Menor de 65 & 61 & 229,10 \\
\hline & Igual o mayor que 65 & 474 & 273,01 \\
\hline & Total & 535 & \\
\hline \multirow{3}{*}{$\begin{array}{l}\mathbf{N}^{0} \text { preocu. recursos servicios so- } \\
\text { ciales }\end{array}$} & Menor de 65 & 61 & 267,27 \\
\hline & Igual o mayor que 65 & 474 & 268,09 \\
\hline & Total & 535 & \\
\hline \multirow{3}{*}{$\mathbf{N}^{\circ}$ preocu. existencia de barreras } & Menor de 65 & 61 & 221,66 \\
\hline & Igual o mayor que 65 & 474 & 273,96 \\
\hline & Total & 535 & \\
\hline \multirow{3}{*}{$\begin{array}{l}\mathbf{N}^{0} \text { otras preocupaciones y nece- } \\
\text { sidades }\end{array}$} & Menor de 65 & 61 & 273,84 \\
\hline & Igual o mayor que 65 & 474 & 267,25 \\
\hline & Total & 535 & \\
\hline
\end{tabular}

Tabla 151: Rangos promedio en función del grado de discapacidad dicotomizado en función del número total de preocupaciones específicas. Muestra de familias. 


\begin{tabular}{lccccc}
\hline & $\begin{array}{c}\text { U de Mann- } \\
\text { Whitney }\end{array}$ & $\begin{array}{c}\text { W de Wil- } \\
\text { coxon }\end{array}$ & $\mathbf{Z}$ & Sig. & $\boldsymbol{\eta}^{\mathbf{2}}$ \\
\hline $\mathbf{N}^{\mathbf{0}}$ salud personal & 11471,000 & 13362,000 & $-2,691$ &, 007 & $-0,08$ \\
$\mathbf{N}^{\mathbf{0}}$ recursos económicos & 13958,000 & 15849,000 & $-0,471$ &, 637 & $-0,01$ \\
$\mathbf{N}^{\mathbf{0}}$ recursos sanitarios & 12084,000 & 13975,000 & $-2,153$ &, 031 & $-0,06$ \\
$\mathbf{N}^{\mathbf{0}}$ recursos servicios socia- & 14412,500 & 16303,500 & $-0,040$ &, 968 & 0,00 \\
les & & & & \\
$\mathbf{N}^{\mathbf{0}}$ existencia de barreras & 11630,000 & 13521,000 & $-2,554$ &, 011 & $-0,07$ \\
$\mathbf{N}^{\mathbf{0}}$ otras preocupaciones & 14100,500 & 126675,500 & $-0,324$ &, 746 & 0,00 \\
\hline \multicolumn{4}{c}{ Nota: el tamaño del efecto $\left(\eta^{2}\right)$ debe interpretarse en valor absoluto. }
\end{tabular}

Tabla 152: Estadísticos de contraste en función del grado de discapacidad dicotomizado en número total de preocupaciones específicas. Muestra de familias.

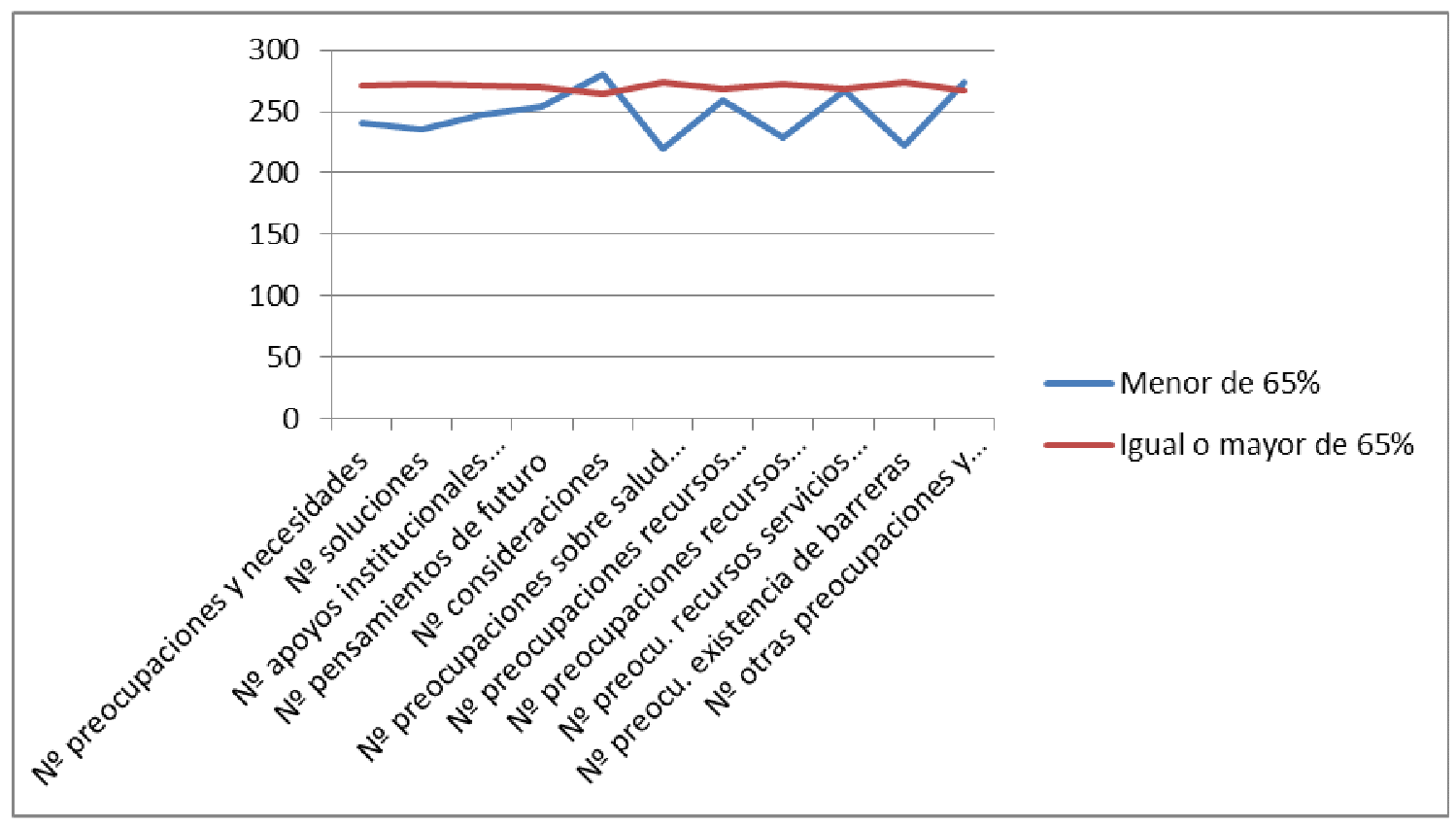

Gráfico 18: Rangos promedio en función del grado de discapacidad dicotomizado en número total de preocupaciones generales y específicas. Muestra de familias. 


\begin{tabular}{|c|c|c|}
\hline PcDID & VARIABLES & $\begin{array}{c}\text { GRADO DISCA- } \\
\text { PACIDAD } \\
<65 \% \\
\geq 65 \% \\
\end{array}$ \\
\hline \multirow{11}{*}{$\begin{array}{c}\text { TODOS } \\
N=606 \\
<65 \%=61 \\
\geq 65 \%=474\end{array}$} & $\mathrm{~N}^{\mathrm{o}}$ preoc y necesidades & $\mathrm{NO}$ \\
\hline & $\mathrm{N}^{\circ}$ soluciones & NO \\
\hline & $\mathrm{N}^{\mathrm{o}}$ apoyos institucionales & NO \\
\hline & $\mathrm{N}^{\mathrm{o}}$ pensam futuro & $\mathrm{NO}$ \\
\hline & $\mathrm{N}^{\circ}$ otras consideraciones & NO \\
\hline & $\mathbf{N}^{\circ}$ necesidades salud personal & SI:+ $\geq 65 \%$ \\
\hline & $\mathrm{N}^{\mathrm{o}}$ necesidades recursos económicos & NO \\
\hline & $\begin{array}{l}\mathrm{N}^{0} \text { necesidades recursos servicios sa- } \\
\text { nitarios }\end{array}$ & SI: $+\geq \mathbf{6 5 \%}$ \\
\hline & $\begin{array}{l}\mathrm{N}^{\circ} \text { necesidades recursos servicios socia- } \\
\text { les }\end{array}$ & NO \\
\hline & $\mathrm{N}^{0}$ necesidades existencia de barreras & SI: $+\geq 65 \%$ \\
\hline & $\mathrm{N}^{\circ}$ otras necesidades & $\mathrm{NO}$ \\
\hline
\end{tabular}

Nota: $\mathrm{NO}=$ no hay diferencias estadísticamente significativas; SI: hay diferencias estadísticamente significativas; + seguido del grupo indica dónde se encuentran mayores rangos promedio.

Tabla 153: Resumen de diferencias en función del tipo de informe dicotomizado de la muestra de PcDID.

\subsubsection{Resumen}

El grado de discapacidad de la PcDID ha influido ligeramente en la elección de los familiares, en concreto en el número de necesidades sobre salud personal, recursos sanitarios y recursos de servicios sociales.

\subsubsection{Variable tipo de convivencia}

\subsubsection{Introducción}

El tipo de convivencia de las PcDID también se ha analizado para comprobar su influencia sobre los resultados de las familias. Para estudiar esta variable se ha recodificado en 5 grupos en función de si la PcDID vivía: 
- Con la familia propia

- Con la familia de origen

- En otras fórmulas

- En un servicio residencial

\subsubsection{Resultados sobre la variable tipo de convivencia}

La prueba Kruskal-Wallis muestra que existen diferencias estadísticamente significativas $(\mathrm{p}<0,05)$ en el número de preocupaciones generales, el número de soluciones, de apoyos institucionales, de pensamientos de futuro y de otras consideraciones (tabla 155). Las familias de las PcDID que vivían en otras fórmulas señalaron un mayor número de preocupaciones generales y de soluciones; mientras que las familias de las PcDID que vivían solas puntuaron en mayor medida en los apoyos institucionales requeridos, en los pensamientos de futuro y en otras consideraciones (tabla 154). 


\begin{tabular}{|c|c|c|c|}
\hline & Recode Vive con & $\mathbf{N}$ & $\begin{array}{l}\text { Rango pro- } \\
\text { medio }\end{array}$ \\
\hline \multirow{6}{*}{$\begin{array}{l}\mathrm{N}^{0} \text { preocupaciones } \mathrm{y} \\
\text { necesidades }\end{array}$} & Sólo & 14 & 291,75 \\
\hline & Familia propia & 2 & 208,00 \\
\hline & Familia de origen & 368 & 319,22 \\
\hline & Otras fórmulas & 48 & 341,65 \\
\hline & $\begin{array}{l}\text { En un servicio residen- } \\
\text { cial }\end{array}$ & 174 & 261,76 \\
\hline & Total & 606 & \\
\hline \multirow{6}{*}{$\mathbf{N}^{0}$ soluciones } & Sólo & 14 & 275,29 \\
\hline & Familia propia & 2 & 317,75 \\
\hline & Familia de origen & 368 & 306,35 \\
\hline & Otras fórmulas & 48 & 373,09 \\
\hline & $\begin{array}{l}\text { En un servicio residen- } \\
\text { cial }\end{array}$ & 174 & 280,39 \\
\hline & Total & 606 & \\
\hline \multirow{6}{*}{$\begin{array}{l}\mathrm{N}^{\circ} \text { apoyos institucio- } \\
\text { nales requeridos }\end{array}$} & Sólo & 14 & 393,82 \\
\hline & Familia propia & 2 & 83,25 \\
\hline & Familia de origen & 368 & 313,27 \\
\hline & Otras fórmulas & 48 & 358,79 \\
\hline & $\begin{array}{l}\text { En un servicio residen- } \\
\text { cial }\end{array}$ & 174 & 262,85 \\
\hline & Total & 606 & \\
\hline \multirow{6}{*}{$\begin{array}{l}\mathrm{N}^{\circ} \text { pensamientos so- } \\
\text { bre futuro }\end{array}$} & Sólo & 14 & 382,79 \\
\hline & Familia propia & 2 & 138,00 \\
\hline & Familia de origen & 368 & 319,76 \\
\hline & Otras fórmulas & 48 & 377,74 \\
\hline & $\begin{array}{l}\text { En un servicio residen- } \\
\text { cial }\end{array}$ & 174 & 244,16 \\
\hline & Total & 606 & \\
\hline \multirow{6}{*}{$\mathbf{N}^{0}$ consideraciones } & Sólo & 14 & 398,50 \\
\hline & Familia propia & 2 & 366,50 \\
\hline & Familia de origen & 366 & 308,48 \\
\hline & Otras fórmulas & 48 & 270,65 \\
\hline & $\begin{array}{l}\text { En un servicio residen- } \\
\text { cial }\end{array}$ & 170 & 282,91 \\
\hline & Total & 600 & \\
\hline
\end{tabular}

Tabla 154: Rangos promedio en función del tipo de convivencia en número total de preocupaciones y soluciones generales. Muestra de familias. 


\begin{tabular}{lcccc}
\hline & $\begin{array}{c}\text { Chi- } \\
\text { cuadrado }\end{array}$ & gl & Sig. & $\boldsymbol{\eta}^{\mathbf{2}}$ \\
\hline $\mathbf{N}^{\mathbf{0}}$ preocupaciones & 15,854 & 4 &, 003 & $-0,03$ \\
$\mathbf{N}^{\mathbf{0}}$ soluciones & 11,150 & 4 &, 025 & $-0,03$ \\
$\mathbf{N}^{\mathbf{o}}$ apoyos institucionales & 23,031 & 4 &, 000 & $-0,06$ \\
$\mathbf{N}^{\mathbf{0}}$ pensamientos futuro & 40,448 & 4 &, 000 & $-0,07$ \\
$\mathbf{N}^{\mathbf{0}}$ consideraciones & 15,024 & 4 &, 005 & $-0,05$ \\
\hline
\end{tabular}

Nota: el tamaño del efecto $\left(\eta^{2}\right)$ debe interpretarse en valor absoluto.

Tabla 155: Estadísticos de contraste en función del tipo de convivencia en número total de preocupaciones y soluciones generales. Muestra de familias.

En cuanto a las necesidades específicas, existen diferencias estadísticamente significativas $(p<0,05)$ en el número de preocupaciones de salud personal, recursos económicos, recursos de servicios sociales y en otras necesidades (tabla 157). Las familias de las PcDID que vivían con la familia propia puntuaron más alto en las necesidades de salud personal y recursos económicos; mientras que las familas de PcDID que vivían en otras fórmulas puntuaban más alto en los recursos de servicios sociales y las familias de las PcDID que vivían solas puntuaban en mayor medida en otros tipos de necesidades (tabla 156).

El gráfico 19 muestra los rangos promedio de cada grupo en función del tipo de convivencia en cada una de las variables criterio. 


\begin{tabular}{|c|c|c|c|}
\hline & Recode Vive con & $\mathbf{N}$ & $\begin{array}{l}\text { Rango pro- } \\
\text { medio }\end{array}$ \\
\hline \multirow{6}{*}{$\begin{array}{l}\mathrm{N}^{0} \text { preocupaciones } \\
\text { sobre salud personal }\end{array}$} & Sólo & 14 & 232,36 \\
\hline & Familia propia & 2 & 357,50 \\
\hline & Familia de origen & 368 & 321,10 \\
\hline & Otras fórmulas & 48 & 328,54 \\
\hline & $\begin{array}{l}\text { En un servicio residen- } \\
\text { cial }\end{array}$ & 174 & 264,47 \\
\hline & Total & 606 & \\
\hline \multirow{6}{*}{$\begin{array}{l}\mathrm{N}^{0} \text { preocupaciones } \\
\text { recursos económicos }\end{array}$} & Sólo & 14 & 301,43 \\
\hline & Familia propia & 2 & 355,00 \\
\hline & Familia de origen & 368 & 315,04 \\
\hline & Otras fórmulas & 48 & 345,88 \\
\hline & $\begin{array}{l}\text { En un servicio residen- } \\
\text { cial }\end{array}$ & 174 & 266,98 \\
\hline & Total & 606 & \\
\hline \multirow{6}{*}{$\begin{array}{l}N^{\circ} \text { preocupaciones } \\
\text { recursos sanitarios }\end{array}$} & Sólo & 14 & 273,82 \\
\hline & Familia propia & 2 & 238,00 \\
\hline & Familia de origen & 368 & 298,20 \\
\hline & Otras fórmulas & 48 & 344,91 \\
\hline & $\begin{array}{l}\text { En un servicio residen- } \\
\text { cial }\end{array}$ & 174 & 306,42 \\
\hline & Total & 606 & \\
\hline \multirow{6}{*}{$\begin{array}{l}\mathbf{N}^{\circ} \text { preocu. recursos } \\
\text { servicios sociales }\end{array}$} & Sólo & 14 & 306,32 \\
\hline & Familia propia & 2 & 89,25 \\
\hline & Familia de origen & 368 & 321,69 \\
\hline & Otras fórmulas & 48 & 344,06 \\
\hline & $\begin{array}{l}\text { En un servicio residen- } \\
\text { cial }\end{array}$ & 174 & 256,08 \\
\hline & Total & 606 & \\
\hline \multirow{6}{*}{$\begin{array}{l}N^{0} \text { preocu. existencia } \\
\text { de barreras }\end{array}$} & Sólo & 14 & 279,32 \\
\hline & Familia propia & 2 & 271,00 \\
\hline & Familia de origen & 368 & 298,07 \\
\hline & Otras fórmulas & 48 & 317,81 \\
\hline & $\begin{array}{l}\text { En un servicio residen- } \\
\text { cial }\end{array}$ & 174 & 313,36 \\
\hline & Total & 606 & \\
\hline \multirow{6}{*}{$\begin{array}{l}N^{0} \text { otras preocupacio- } \\
\text { nes y necesidades }\end{array}$} & Sólo & 14 & 379,93 \\
\hline & Familia propia & 2 & 211,75 \\
\hline & Familia de origen & 368 & 334,57 \\
\hline & Otras fórmulas & 48 & 318,71 \\
\hline & $\begin{array}{l}\text { En un servicio residen- } \\
\text { cial }\end{array}$ & 174 & 228,51 \\
\hline & Total & 606 & \\
\hline
\end{tabular}

Tabla 156: Rangos promedio en función del tipo de convivencia en número total de preocupaciones específicas. Muestra de familias. 


\begin{tabular}{lcccc}
\hline & $\begin{array}{c}\text { Chi- } \\
\text { cuadrado }\end{array}$ & gl & Sig. & $\boldsymbol{\eta}^{\mathbf{2}}$ \\
\hline $\mathbf{N}^{\mathbf{0}}$ salud personal & 16,653 & 4 &, 002 & $-0,04$ \\
$\mathbf{N}^{\mathbf{0}}$ recursos económicos & 13,995 & 4 &, 007 & $-0,03$ \\
$\mathbf{N}^{\mathbf{0}}$ recursos sanitarios & 3,978 & 4 &, 409 & $-0,02$ \\
$\mathbf{N}^{\mathbf{0}}$ recursos s. sociales & 23,474 & 4 &, 000 & $-0,05$ \\
$\mathbf{N}^{\mathbf{0}}$ existencia barreras & 1,647 & 4 &, 800 & $-0,01$ \\
$\mathbf{N}^{\mathbf{0}}$ otras preocupaciones & 50,282 & 4 &, 000 & $-0,06$ \\
\hline
\end{tabular}

Nota: el tamaño del efecto $\left(\eta^{2}\right)$ debe interpretarse en valor absoluto.

Tabla 157: Estadísticos de contraste en función del tipo de convivencia en número total de preocupaciones específicas. Muestra de familias.

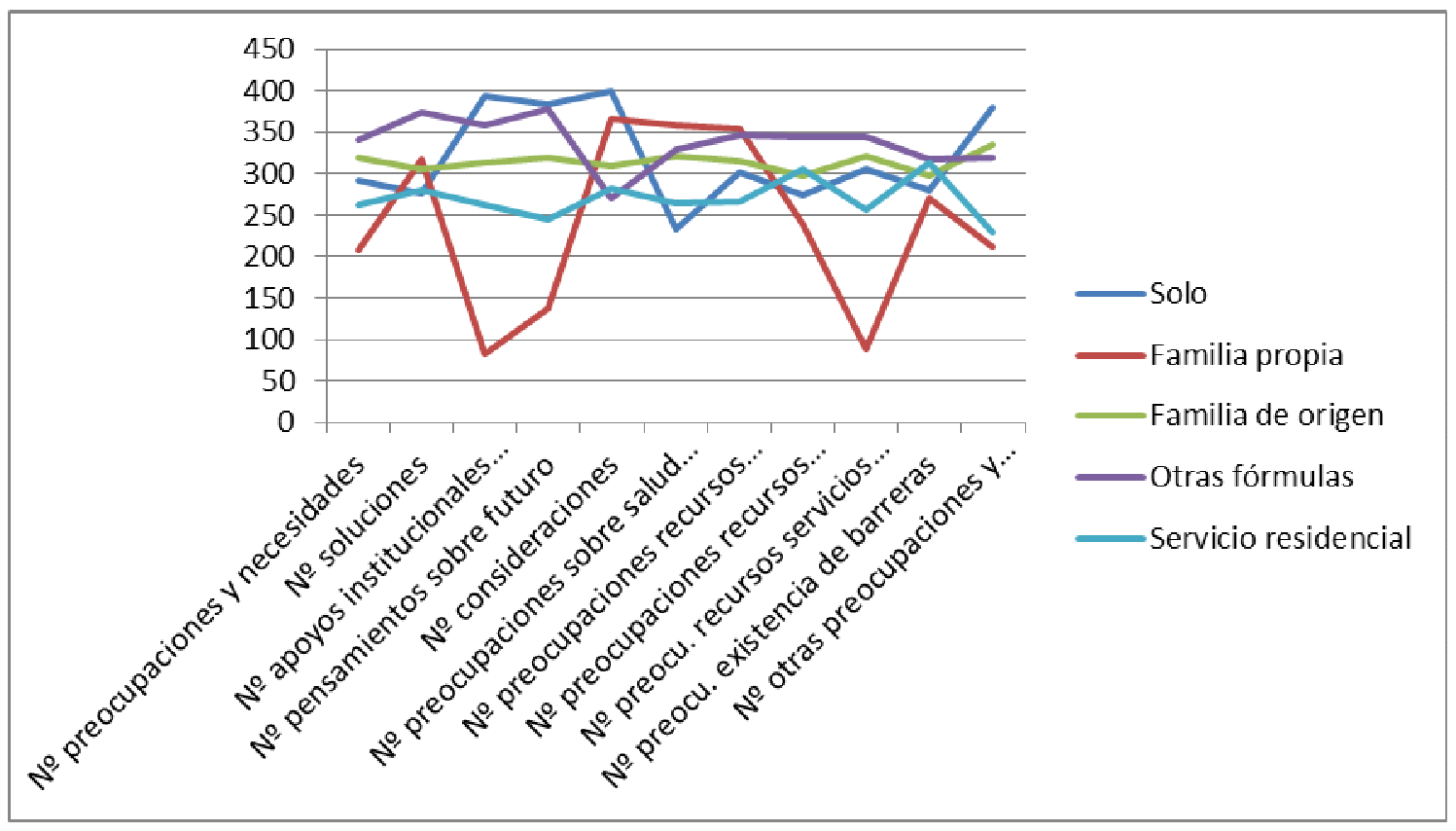

Gráfico 19: Rangos promedio en función del tipo de convivencia en número total de preocupaciones generales y específicas. Muestra de familias.

La tabla 158 muestra un resumen con la significatividad de los datos. 


\begin{tabular}{|c|c|c|}
\hline PCDID & VARIABLES & $\begin{array}{c}\text { TIPO DE CONVI- } \\
\text { VENCIA } \\
\text { Solo } \\
\text { Familia propia } \\
\text { Familia de origen } \\
\text { Otras fórmulas } \\
\text { Servicio residencial }\end{array}$ \\
\hline \multirow{11}{*}{$\begin{array}{c}\text { TODOS } \\
\text { N=606 } \\
\text { Solo= } 14 \\
\text { Familia propia= } 2 \\
\text { Familia de origen= } \\
368 \\
\text { Otras fórmulas= } 48 \\
\text { Servicio residencial= } \\
174\end{array}$} & $\mathrm{~N}^{0}$ preoc y necesidades & SI:+Otras fórmulas \\
\hline & $\mathbf{N}^{\circ}$ soluciones & SI:+Otras fórmulas \\
\hline & $\mathbf{N}^{0}$ apoyos institucionales & SI:+Solo \\
\hline & $\mathrm{N}^{\circ}$ pensam futuro & SI:+Solo \\
\hline & $\mathbf{N}^{\circ}$ otras consideraciones & SI:+Solo \\
\hline & $\mathrm{N}^{0}$ necesidades salud personal & SI:+Familia propia \\
\hline & $\mathrm{N}^{0}$ necesidades recursos económicos & SI:+Familia propia \\
\hline & $\begin{array}{l}\mathrm{N}^{\circ} \text { necesidades recursos servicios sani- } \\
\text { tarios }\end{array}$ & NO \\
\hline & $\begin{array}{l}\mathbf{N}^{0} \text { necesidades recursos servicios so- } \\
\text { ciales }\end{array}$ & SI:+Otras fórmulas \\
\hline & $\mathrm{N}^{\circ}$ necesidades existencia de barreras & NO \\
\hline & $\mathrm{N}^{\circ}$ otras necesidades & SI:+Solo \\
\hline
\end{tabular}

Nota: $\mathrm{NO}=$ no hay diferencias estadísticamente significativas; SI: hay diferencias estadísticamente significativas; + seguido del grupo indica dónde se encuentran mayores rangos promedio.

Tabla 158: Resumen de diferencias en función del tipo de convivencia. Muestra de familias.

\subsubsection{Resumen}

El tipo de convivencia de las PcDID influye sobre el número total de preocupaciones y necesidades generales, de soluciones, el número de apoyos institucionales, de pensamientos de futuro, de otras consideraciones, de las necesidades sobre la salud personal, los recursos económicos, los recursos de servicios sociales y otras necesidades señaladas por las familias. 


\subsubsection{Variable residencia}

\subsubsection{Introducción}

Otra de las variables estudiadas ha sido la población de la PcDID, en función de si residían en lugares de menos de 10.000 habitantes o de 10.000 o más.

\subsubsection{Resultados sobre la variable residencia}

La prueba U de Mann-Whitney revela que no hubo diferencias significativas $(p<0,05)$ en las preocupaciones y soluciones generales en función de si la población era mayor o menor de 10.000 habitantes (tabla 160). Los rangos promedio de las puntuaciones de ambos grupos aparecen en la tabla 159.

En cuanto a las necesidades específicas, tampoco aparecieron diferencias estadísticamente significativas (tabla 162). Los rangos promedio de estas puntuaciones aparecen en la tabla 161, mientras que su representación gráfica aparece en el gráfico 20. 


\begin{tabular}{llcc}
\hline & Residencia & N & $\begin{array}{c}\text { Rango pro- } \\
\text { medio }\end{array}$ \\
\hline $\mathbf{N}^{\mathbf{0}}$ preocupaciones $\mathbf{y}$ & $<10.000$ & 165 & 311,31 \\
necesidades & $>10.000$ & 441 & 300,58 \\
& Total & 606 & \\
\hline \multirow{2}{*}{$\mathbf{N}^{\mathbf{o}}$ soluciones } & $<10.000$ & 165 & 295,77 \\
& $>10.000$ & 441 & 306,39 \\
\hline $\mathbf{N}^{\mathbf{o}}$ apoyos institucio- & Total & 606 & \\
nales requeridos & $<10.000$ & 165 & 302,32 \\
\hline $\mathbf{N}^{\mathbf{0}}$ pensamientos so- & $>10.000$ & 441 & 303,94 \\
bre futuro & Total & 606 & \\
\hline \multirow{2}{*}{$\mathbf{N}^{\mathbf{o}}$ consideraciones } & $>10.000$ & 165 & 309,81 \\
& $>10.000$ & 441 & 301,14 \\
& Total & 606 & \\
\hline
\end{tabular}

Tabla 159: Rangos promedio en función de la residencia en número total de preocupaciones y soluciones específicas. Muestra de familias.

\begin{tabular}{lccccc}
\hline & $\begin{array}{c}\text { U de Mann- } \\
\text { Whitney }\end{array}$ & $\begin{array}{c}\text { W de Wil- } \\
\text { coxon }\end{array}$ & $\mathbf{Z}$ & Sig. & $\boldsymbol{\eta}^{\mathbf{2}}$ \\
\hline $\mathbf{N}^{\mathbf{0}}$ preocupaciones & 35093,500 & 132554,500 & $-0,673$ & 0,501 & $-0,02$ \\
$\mathbf{N}^{\mathbf{0}}$ soluciones & 35107,500 & 48802,500 & $-0,666$ & 0,505 & $-0,02$ \\
$\mathbf{N}^{\mathbf{0}}$ apoyos institucionales & 36187,500 & 49882,500 & $-0,104$ & 0,918 & 0,00 \\
$\mathbf{N}^{\mathbf{a}}$ pensamientos futuro & 35341,500 & 132802,500 & $-0,572$ & 0,568 & $-0,02$ \\
$\mathbf{N}^{\mathbf{0}}$ consideraciones & 35683,500 & 130949,500 & $-0,048$ & 0,962 & 0,00 \\
\hline
\end{tabular}

Nota: el tamaño del efecto $\left(\eta^{2}\right)$ debe interpretarse en valor absoluto.

Tabla 160: Estadísticos de contraste en función de la residencia en número total de necesidades generales. Muestra de familias. 


\begin{tabular}{|c|c|c|c|}
\hline & Residencia & $\mathbf{N}$ & $\begin{array}{l}\text { Rango pro- } \\
\text { medio }\end{array}$ \\
\hline \multirow{3}{*}{$\begin{array}{l}\mathbf{N}^{0} \text { preocupaciones } \\
\text { sobre salud personal }\end{array}$} & $<10.000$ & 165 & 323,07 \\
\hline & $>10.000$ & 441 & 296,18 \\
\hline & Total & 606 & \\
\hline \multirow{3}{*}{$\begin{array}{l}\mathrm{N}^{0} \text { preocupaciones } \\
\text { recursos económicos }\end{array}$} & $<10.000$ & 165 & 302,21 \\
\hline & $>10.000$ & 441 & 303,98 \\
\hline & Total & 606 & \\
\hline \multirow{3}{*}{$\begin{array}{l}\mathrm{N}^{0} \text { preocupaciones } \\
\text { recursos sanitarios }\end{array}$} & $<10.000$ & 165 & 293,68 \\
\hline & $>10.000$ & 441 & 307,17 \\
\hline & Total & 606 & \\
\hline \multirow{3}{*}{$\begin{array}{l}\mathbf{N}^{o} \text { preocu. recursos } \\
\text { servicios sociales }\end{array}$} & $<10.000$ & 165 & 290,18 \\
\hline & $>10.000$ & 441 & 308,49 \\
\hline & Total & 606 & \\
\hline \multirow{3}{*}{$\begin{array}{l}N^{o} \text { preocu. existencia } \\
\text { de barreras }\end{array}$} & $<10.000$ & 165 & 302,44 \\
\hline & $>10.000$ & 441 & 303,90 \\
\hline & Total & 606 & \\
\hline \multirow{3}{*}{$\begin{array}{l}N^{o} \text { otras preocupacio- } \\
\text { nes y necesidades }\end{array}$} & $<10.000$ & 165 & 305,54 \\
\hline & $>10.000$ & 441 & 302,74 \\
\hline & Total & 606 & \\
\hline
\end{tabular}

Tabla 161: Rangos promedio en función de la residencia en número total de preocupaciones específicas. Muestra de familias.

\begin{tabular}{lccccc}
\hline & $\begin{array}{c}\text { U de } \\
\text { Mann-Whitney }\end{array}$ & $\begin{array}{c}\text { W de } \\
\text { Wilcoxon }\end{array}$ & $\mathbf{Z}$ & Sig. & $\boldsymbol{\eta}^{\mathbf{2}}$ \\
\hline $\mathbf{N}^{\mathbf{0}}$ salud personal & 33153,500 & 130614,500 & $-1,725$ & 0,085 & $-0,05$ \\
$\mathbf{N}^{\mathbf{0}}$ recursos económicos & 36169,500 & 49864,500 & $-0,119$ & 0,905 & 0,00 \\
$\mathbf{N}^{\mathbf{0}}$ recursos sanitarios & 34763,000 & 48458,000 & $-0,869$ & 0,385 & $-0,02$ \\
$\mathbf{N}^{\mathbf{o}}$ recursos s. sociales & 34184,000 & 47879,000 & $-1,175$ & 0,240 & 0,00 \\
$\mathbf{N}^{\mathbf{o}}$ existencia barreras & 36208,000 & 49903,000 & $-0,093$ & 0,926 & 0,00 \\
\hline
\end{tabular}

Nota: el tamaño del efecto $\left(\eta^{2}\right)$ debe interpretarse en valor absoluto.

Tabla 162: Estadísticos de contraste en función de la residencia en número total de necesidades específicas. Muestra de familias.

En la tabla 163 se puede observar el resumen de los datos comentados. 


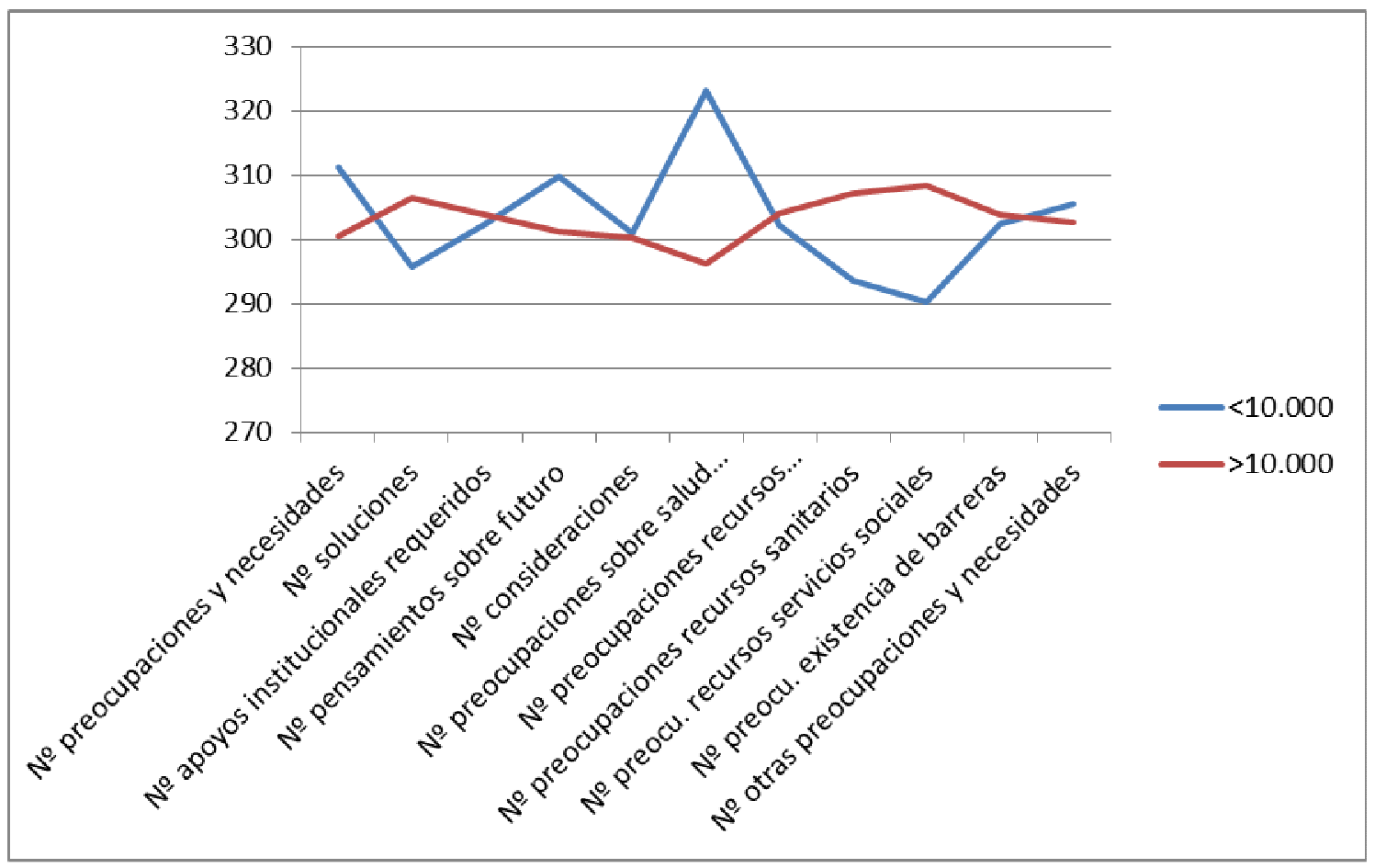

Gráfico 20: Rangos promedio en función de la residencia en número total de preocupaciones generales y específicas. Muestra familiar.

\begin{tabular}{|c|c|c|}
\hline PcDID & VARIABLES & $\begin{array}{c}\text { RESIDENCIA } \\
<10.000 \\
\geq 10.000 \\
\end{array}$ \\
\hline \multirow{11}{*}{$\begin{array}{c}\text { TODOS } \\
N=606 \\
<10.000=165 \\
\geq 10.000=441\end{array}$} & $\mathrm{~N}^{\mathrm{o}}$ preoc y necesidades & $\mathrm{NO}$ \\
\hline & $\mathrm{N}^{\mathrm{o}}$ soluciones & NO \\
\hline & $\mathrm{N}^{\mathbf{o}}$ apoyos institucionales & $\mathrm{NO}$ \\
\hline & $\mathrm{N}^{\circ}$ pensam futuro & NO \\
\hline & $\mathrm{N}^{\circ}$ otras consideraciones & $\mathrm{NO}$ \\
\hline & $\mathrm{N}^{\mathrm{o}}$ necesidades salud personal & NO \\
\hline & $\mathrm{N}^{\mathrm{o}}$ necesidades recursos económicos & NO \\
\hline & $\begin{array}{l}\mathrm{N}^{\circ} \text { necesidades recursos servicios sani- } \\
\text { tarios }\end{array}$ & NO \\
\hline & $\begin{array}{l}\mathrm{N}^{\circ} \text { necesidades recursos servicios socia- } \\
\text { les }\end{array}$ & $\mathrm{NO}$ \\
\hline & $\mathrm{N}^{\mathrm{o}}$ necesidades existencia de barreras & NO \\
\hline & $\mathrm{N}^{\mathrm{o}}$ otras necesidades & $\mathrm{NO}$ \\
\hline
\end{tabular}

Nota: $\mathrm{NO}=$ no hay diferencias estadísticamente significativas; SI: hay diferencias estadísticamente significativas; + seguido del grupo indica dónde se encuentran mayores rangos promedio.

Tabla 163: Resumen de diferencias en función de la residencia. Muestra de familias.

\subsubsection{Resumen}


La variable residencia no ha influido en el número de preocupaciones y soluciones señaladas por las familias.

\subsubsection{Variable estado civil}

No tiene sentido analizar el estado civil ya que el 98\% de las PcDID de la muestra estaban solteras.

\subsubsection{Variable tipo de discapacidad}

\subsubsection{Introducción}

En este epígrafe se exponen los análisis relativos a la influencia del tipo de discapacidad de la PcDID que envejece en las respuestas dadas por sus familias.

\subsubsection{Resultados sobre la variable tipo de discapacidad}

La prueba Kruskal-Wallis indica que hay diferencias estadísticamente significativas en el número de preocupaciones generales y en el número de soluciones (tabla 165). Fueron las familias de las PcPC quienes mayor número de preocupaciones y soluciones señalaron (tabla 164). 


\begin{tabular}{|c|c|c|c|}
\hline & $\begin{array}{l}\text { Tipo de discapaci- } \\
\text { dad }\end{array}$ & $\mathbf{N}$ & $\begin{array}{l}\text { Rango pro- } \\
\text { medio }\end{array}$ \\
\hline \multirow{4}{*}{$\begin{array}{l}\mathbf{N}^{0} \text { preocupaciones } \mathbf{y} \\
\text { necesidades }\end{array}$} & DI Down & 109 & 266,85 \\
\hline & DI Otras & 413 & 303,88 \\
\hline & DF PC & 84 & 349,19 \\
\hline & Total & 606 & \\
\hline \multirow{4}{*}{$\mathbf{N}^{0}$ soluciones } & DI Down & 109 & 288,10 \\
\hline & DI Otras & 413 & 298,45 \\
\hline & DF PC & 84 & 348,32 \\
\hline & Total & 606 & \\
\hline \multirow{4}{*}{$\begin{array}{l}\mathrm{N}^{0} \text { apoyos institucio- } \\
\text { nales requeridos }\end{array}$} & DI Down & 109 & 280,97 \\
\hline & DI Otras & 413 & 305,85 \\
\hline & DF PC & 84 & 321,17 \\
\hline & Total & 606 & \\
\hline \multirow{4}{*}{$\begin{array}{l}\mathbf{N}^{0} \text { pensamientos so- } \\
\text { bre futuro }\end{array}$} & DI Down & 109 & 319,08 \\
\hline & DI Otras & 413 & 295,61 \\
\hline & DF PC & 84 & 322,07 \\
\hline & Total & 606 & \\
\hline \multirow{4}{*}{$\mathrm{N}^{0}$ consideraciones } & DI Down & 108 & 295,27 \\
\hline & DI Otras & 409 & 300,84 \\
\hline & DF PC & 83 & 305,63 \\
\hline & Total & 600 & \\
\hline
\end{tabular}

Tabla 164: Rangos promedio en función del tipo de discapacidad en número total de preocupaciones y soluciones generales. Muestra de familias.

\begin{tabular}{lcccc}
\hline & $\begin{array}{c}\text { Chi- } \\
\text { cuadrado }\end{array}$ & gl & Sig. & $\boldsymbol{\eta}^{\mathbf{2}}$ \\
\hline $\mathbf{N}^{\mathbf{0}}$ preocupaciones & 10,540 & 2 &, 005 & $-0,07$ \\
$\mathbf{N}^{\mathbf{0}}$ soluciones & 6,727 & 2 &, 035 & $-0,05$ \\
$\mathbf{N}^{\mathbf{0}}$ apoyos institucionales & 2,837 & 2 &, 242 & $-0,03$ \\
$\mathbf{N}^{\mathbf{0}}$ pensamientos futuro & 2,936 & 2 &, 230 & $-0,02$ \\
$\mathbf{N}^{\mathbf{0}}$ consideraciones &, 298 & 2 &, 862 & $-0,01$ \\
\hline
\end{tabular}

Nota: el tamaño del efecto $\left(\eta^{2}\right)$ debe interpretarse en valor absoluto.

Tabla 165: Estadísticos de contraste en función del tipo de discapacidad en número total de preocupaciones y soluciones generales. Muestra de familias.

En cuanto a las necesidades específicas, se hallaron diferencias estadísticamente significativas en el número de preocupaciones sobre recursos sanitarios y existencia de barreras (tabla 166). En este caso, las familias de las personas con PC fueron nuevamente quienes más preocupaciones señalaron (tabla 165). 
El gráfico 21 muestra los rangos promedio de las puntuaciones de los grupos de familiares en función del tipo de discapacidad de las PcDID en cada una de las variables criterio estudiadas.

La tabla 168 muestra el resumen de la significatividad de los resultados. 


\begin{tabular}{|c|c|c|c|}
\hline & $\begin{array}{l}\text { Tipo de discapaci- } \\
\text { dad }\end{array}$ & $\mathbf{N}$ & $\begin{array}{l}\text { Rango pro- } \\
\text { medio }\end{array}$ \\
\hline \multirow{4}{*}{$\begin{array}{l}\mathbf{N}^{0} \text { preocupaciones } \\
\text { sobre salud personal }\end{array}$} & DI Down & 109 & 304,69 \\
\hline & DI Otras & 413 & 295,27 \\
\hline & DF PC & 84 & 342,41 \\
\hline & Total & 606 & \\
\hline \multirow{4}{*}{$\begin{array}{l}\mathrm{N}^{0} \text { preocupaciones } \\
\text { recursos económicos }\end{array}$} & DI Down & 109 & 289,69 \\
\hline & DI Otras & 413 & 301,64 \\
\hline & DF PC & 84 & 330,55 \\
\hline & Total & 606 & \\
\hline \multirow{4}{*}{$\begin{array}{l}\mathrm{N}^{\circ} \text { preocupaciones } \\
\text { recursos sanitarios }\end{array}$} & DI Down & 109 & 265,64 \\
\hline & DI Otras & 413 & 303,52 \\
\hline & DF PC & 84 & 352,53 \\
\hline & Total & 606 & \\
\hline \multirow{4}{*}{$\begin{array}{l}\mathbf{N}^{0} \text { preocu. recursos } \\
\text { servicios sociales }\end{array}$} & DI Down & 109 & 272,49 \\
\hline & DI Otras & 413 & 309,20 \\
\hline & DF PC & 84 & 315,72 \\
\hline & Total & 606 & \\
\hline \multirow{4}{*}{$\begin{array}{l}N^{0} \text { preocu. existencia } \\
\text { de barreras }\end{array}$} & DI Down & 109 & 261,04 \\
\hline & DI Otras & 413 & 301,36 \\
\hline & DF PC & 84 & 369,13 \\
\hline & Total & 606 & \\
\hline \multirow{4}{*}{$\begin{array}{l}N^{o} \text { otras preocupacio- } \\
\text { nes y necesidades }\end{array}$} & DI Down & 109 & 295,47 \\
\hline & DI Otras & 413 & 302,27 \\
\hline & DF PC & 84 & 319,99 \\
\hline & Total & 606 & \\
\hline
\end{tabular}

Tabla 166: Rangos promedio en función del tipo de discapacidad en número de preocupaciones específicas. Muestra de familias. 


\begin{tabular}{lcccc}
\hline & $\begin{array}{c}\text { Chi- } \\
\text { cuadrado }\end{array}$ & gl & Sig. & $\boldsymbol{\eta}^{\mathbf{2}}$ \\
\hline $\mathbf{N}^{\mathbf{0}}$ salud personal & 5,323 & 2 &, 070 & $-0,04$ \\
$\mathbf{N}^{\mathbf{0}}$ recursos económicos & 3,142 & 2 &, 208 & $-0,04$ \\
$\mathbf{N}^{\mathbf{0}}$ recursos sanitarios & 12,388 & 2 &, 002 & $-0,08$ \\
$\mathbf{N}^{\mathbf{0}}$ recursos s. sociales & 4,488 & 2 &, 106 & $-0,04$ \\
$\mathbf{N}^{\mathbf{o}}$ existencia barreras & 19,258 & 2 &, 000 & $-0,09$ \\
$\mathbf{N}^{\mathbf{0}}$ otras preocupaciones & 1,062 & 2 &, 588 & $-0,02$ \\
\hline
\end{tabular}

Nota: el tamaño del efecto $\left(\eta^{2}\right)$ debe interpretarse en valor absoluto.

Tabla 167: Estadísticos de contraste en función del tipo de discapacidad en número total de preocupaciones específicas. Muestra de familias.

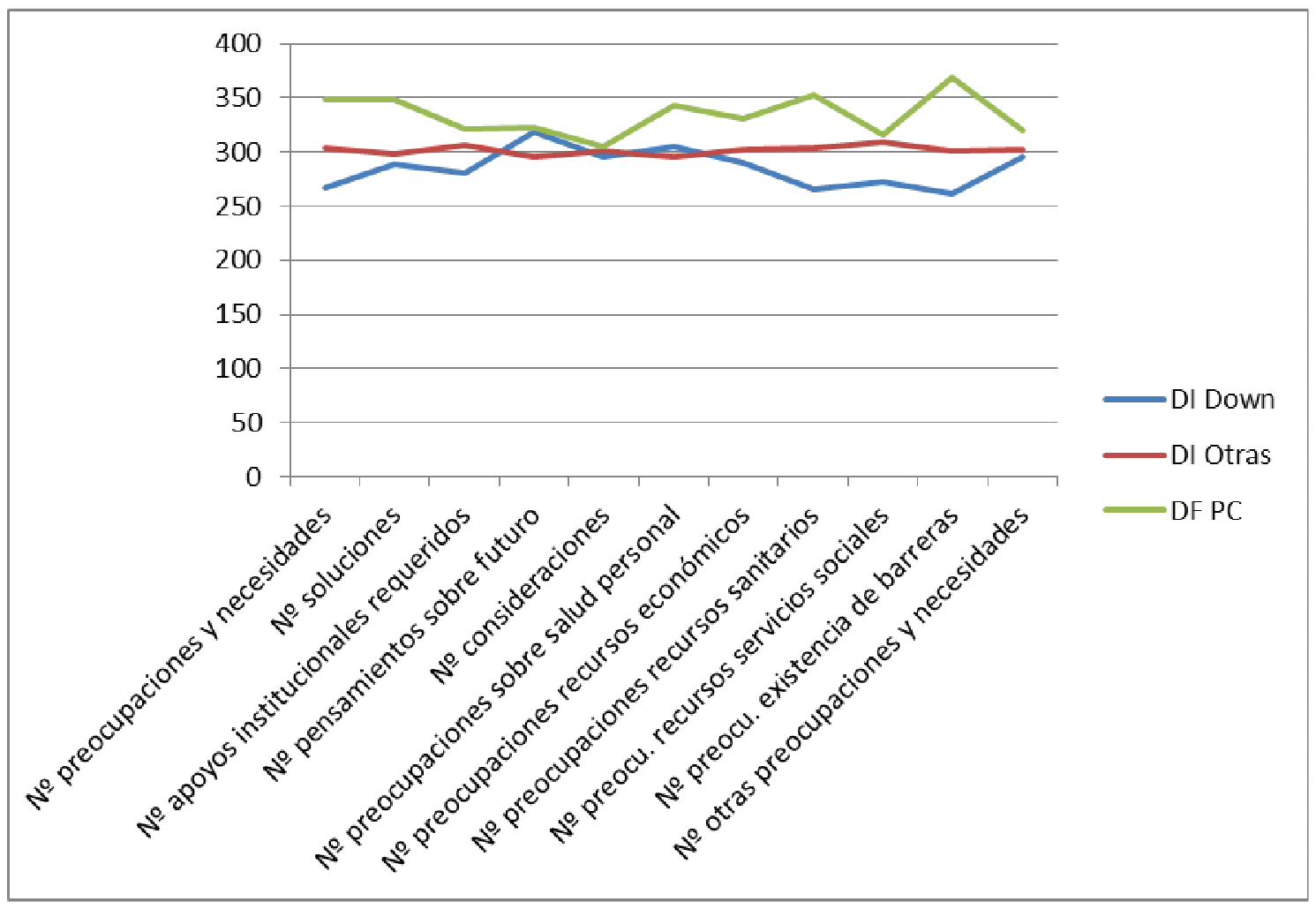

Gráfico 21: Rangos promedio en función del tipo de discapacidad en número total de preocupaciones generales y específicas. Muestra de familias. 


\begin{tabular}{|c|c|c|}
\hline PcDID & VARIABLES & $\begin{array}{c}\text { TIPO DISCAPA- } \\
\text { CIDAD } \\
\text { SD } \\
\text { DID Otras } \\
\text { PC }\end{array}$ \\
\hline \multirow{11}{*}{$\begin{array}{c}\text { TODOS } \\
\text { N=606 } \\
\text { SD }=109 \\
\text { DID Otras }=413 \\
\text { PC }=84\end{array}$} & $\mathrm{~N}^{\mathbf{o}}$ preoc y necesidades & SI:+PC \\
\hline & $\mathbf{N}^{\circ}$ soluciones & SI:+PC \\
\hline & $\mathrm{N}^{\circ}$ apoyos institucionales & NO \\
\hline & $\mathrm{N}^{\mathrm{o}}$ pensam futuro & $\mathrm{NO}$ \\
\hline & $\mathrm{N}^{\circ}$ otras consideraciones & NO \\
\hline & $\mathrm{N}^{\mathrm{o}}$ necesidades salud personal & $\mathrm{NO}$ \\
\hline & $\mathrm{N}^{\mathrm{o}}$ necesidades recursos económicos & NO \\
\hline & $\begin{array}{l}\mathbf{N}^{\mathbf{0}} \text { necesidades recursos servicios sa- } \\
\text { nitarios }\end{array}$ & SI:+PC \\
\hline & $\begin{array}{l}\mathrm{N}^{\circ} \text { necesidades recursos servicios socia- } \\
\text { les }\end{array}$ & NO \\
\hline & $\mathrm{N}^{\mathbf{o}}$ necesidades existencia de barreras & SI:+PC \\
\hline & $\mathrm{N}^{\mathrm{o}}$ otras necesidades & $\mathrm{NO}$ \\
\hline
\end{tabular}

Nota: $\mathrm{NO}=$ no hay diferencias estadísticamente significativas; SI: hay diferencias estadísticamente significativas; + seguido del grupo indica dónde se encuentran mayores rangos promedio.

Tabla 168: Resumen de diferencias en función del tipo de discapacidad. Muestra familiar.

\subsubsection{Resumen}

El tipo de discapacidad de la PcDID ha influido sobre el número de preocupaciones generales, el número de soluciones, el número de necesidades sobre los servicios sanitarios y sobre las preocupaciones sobre existencia de barreras señaladas por las familias. La tabla 169 presenta el resumen de los datos significativos en la muestra de familias. 


\begin{tabular}{|c|c|c|c|c|c|c|}
\hline Variables & Género & Edad & $\begin{array}{c}\text { Grado de } \\
\text { discapacidad }\end{array}$ & $\begin{array}{c}\text { Tipo de } \\
\text { convivencia }\end{array}$ & Residencia & $\begin{array}{l}\text { Tipo de dis- } \\
\text { capacidad }\end{array}$ \\
\hline $\begin{array}{l}\mathbf{N}^{0} \text { preoc y necesi- } \\
\text { dades }\end{array}$ & & $\begin{array}{r}35- \\
49\end{array}$ & & $\begin{array}{l}\text { Otras fórmu- } \\
\text { las }\end{array}$ & & $\mathrm{PC}$ \\
\hline $\mathbf{N}^{0}$ soluciones & & & & $\begin{array}{c}\text { Otras fórmu- } \\
\text { las }\end{array}$ & & $\mathrm{PC}$ \\
\hline $\begin{array}{l}\mathrm{N}^{0} \text { apoyos institu- } \\
\text { cionales }\end{array}$ & & & & Solo & & \\
\hline$N^{0}$ p. futuro & & & & Solo & & \\
\hline \multicolumn{7}{|l|}{$\begin{array}{l}\mathbf{N}^{0} \text { problemas } \\
\text { señalados }\end{array}$} \\
\hline $\begin{array}{l}\mathbf{N}^{0} \text { otras conside- } \\
\text { raciones }\end{array}$ & & & & Solo & & \\
\hline $\begin{array}{l}\mathrm{N}^{0} \text { nec. salud per- } \\
\text { sonal }\end{array}$ & & & $\geq 65 \%$ & $\begin{array}{c}\text { Familia pro- } \\
\text { pia }\end{array}$ & & \\
\hline $\begin{array}{l}\mathrm{N}^{0} \text { nec. recursos } \\
\text { económicos }\end{array}$ & & $\begin{array}{l}35- \\
49\end{array}$ & & $\begin{array}{l}\text { Familia pro- } \\
\text { pia }\end{array}$ & & \\
\hline $\begin{array}{l}N^{0} \text { nec. recursos } \\
\text { servicios sanita- } \\
\text { rios }\end{array}$ & & & $\geq 65 \%$ & & & $\mathrm{PC}$ \\
\hline $\begin{array}{l}\mathbf{N}^{0} \text { nec. recursos } \\
\text { servicios sociales }\end{array}$ & & & & $\begin{array}{l}\text { Otras fórmu- } \\
\text { las }\end{array}$ & & \\
\hline $\begin{array}{l}N^{0} \text { nec. existencia } \\
\text { de barreras }\end{array}$ & & $\begin{array}{c}50- \\
64 \\
\end{array}$ & $\geq 65 \%$ & & & $\mathrm{PC}$ \\
\hline $\mathbf{N}^{\circ}$ otras nec. & & $\begin{array}{l}35- \\
49\end{array}$ & & Solo & & \\
\hline
\end{tabular}

Tabla 169: Resumen de los resultados significativos en función de las variables predictoras en la muestra de familias. 


\section{ANÁLISIS DE LA ENTREVISTA INSTITUCIONAL}

\subsection{INTRODUCCIÓN}

En este apartado se presenta la descripción de la muestra institucional, seguida de las preocupaciones generales y específicas señaladas por los profesionales, así como las soluciones propuestas, las demandas de los asociados, los apoyos institucionales requeridos, los pensamientos de futuro de los asociados, los pensamientos de futuro de las PcD mayores y otras consideraciones no incluidas entre las anteriores.

Posteriormente se realiza el análisis estadístico de los resultados en función de las variables predictoras.

\subsection{DESCRIPCIÓN DE LA MUESTRA INSTITUCIONAL}

\subsubsection{Introducción}

A continuación se exponen las características de la muestra institucional en función del lugar de aplicación, de quién responde al cuestionario, de la sede y procedencia de la institución, del tipo de institución, del tipo de discapacidad atendida, de los profesionales y servicios que dispone y del tipo de alojamiento.

\subsubsection{Descripción de la muestra de instituciones}

La entrevista institucional fue respondida por 587 profesionales. En cuanto al lugar de aplicación (tabla 170), el 48,7\% se realizó en el centro de trabajo, el 16,9\% en una residencia, el 13,6\% en la sede de la asociación, el 6,1\% en un centro de día, el $1,7 \%$ en un centro social, el $1,5 \%$ en el domicilio particular y el $11,4 \%$ se realizó en otros lugares no recogidos entre los anteriores. 


\begin{tabular}{lcc}
\hline \multicolumn{1}{c}{ Lugar de aplicación } & N & \% \\
\hline Centro de trabajo & 286 & $48,7 \%$ \\
Residencia & 99 & $16,9 \%$ \\
Sede de la asociación & 80 & $13,6 \%$ \\
Otros & 67 & $11,4 \%$ \\
Centro de día & 36 & $6,1 \%$ \\
Centro social & 10 & $1,7 \%$ \\
Domicilio particular & 9 & $1,5 \%$ \\
\hline Total & $\mathbf{5 8 7}$ & $\mathbf{1 0 0 \%}$ \\
\hline
\end{tabular}

Tabla 170: Características de la muestra institucional por lugar de aplicación del cuestionario.

En lo que respecta a la cumplimentación (tabla 171) hubo un 46,5\% de profesionales, el 16,9\% eran cuidadores, el 9\% directores, el 5,8\% eran estudiantes, el 4,8\% eran personal de la asociación, el 4,6\% eran trabajadores sociales, el 3,7\% eran directivos, el $1 \%$ presidentes y el $7,7 \%$ tenían otros cargos.

\begin{tabular}{lcc}
\hline \multicolumn{1}{c}{ Cumplimentado por } & N & \% \\
\hline Profesional & 273 & $46,5 \%$ \\
Cuidador & 99 & $16,9 \%$ \\
Director & 53 & $9,0 \%$ \\
Estudiantes & 34 & $5,8 \%$ \\
Personal de la asociación & 28 & $4,8 \%$ \\
Trabajador social & 27 & $4,6 \%$ \\
Directivo & 22 & $3,7 \%$ \\
Presidente & 6 & $1,0 \%$ \\
Otros & 45 & $7,7 \%$ \\
\hline Total & $\mathbf{5 8 7}$ & $\mathbf{1 0 0 \%}$ \\
\hline
\end{tabular}

Tabla 171: Características de la muestra institucional por persona que cumplimenta el cuestionario.

En cuanto a la población en la que estaba ubicada la sede de la asociación (tabla 172), el $86,5 \%$ estaba en poblaciones de 10.000 o más habitantes, mientras que el 13,5\% restante estaba en poblaciones con menos de 10.000 . 


\begin{tabular}{lcc}
\hline \multicolumn{1}{c}{ Sede de la institución } & $\mathbf{N}$ & $\boldsymbol{\%}$ \\
\hline $\mathbf{1 0 . 0 0 0}$ & 508 & $86,5 \%$ \\
$<\mathbf{1 0 . 0 0 0}$ & 79 & $13,5 \%$ \\
\hline Total & $\mathbf{5 8 7}$ & $\mathbf{1 0 0 \%}$ \\
\hline
\end{tabular}

Tabla 172: Características de la muestra institucional por sede de la institución.

En lo que respecta a la procedencia de los profesionales de las entidades (tabla 173), el 24,9\% era de Castilla León, el 18,7\% de Asturias, el 18,7\% de Valencia, el 10,6\% de La Rioja, el 9\% de Euskadi, el 3,7\% de Navarra, y en menor medida de Andalucía (2,6\%), Madrid (2,4\%), Canarias (2,2\%), Extremadura (2\%), Castilla La Mancha $(1,4 \%)$, Baleares (1,4\%), Cantabria (0,7\%), Cataluña (0,5\%), Aragón (0,5\%), Galicia $(0,3 \%)$ y Murcia $(0,3 \%)$.

\begin{tabular}{lcc}
\hline \multicolumn{1}{c}{ Procedencia } & N & \% \\
\hline Castilla León & 146 & $24,9 \%$ \\
Asturias & 110 & $18,7 \%$ \\
Valencia & 110 & $18,7 \%$ \\
La Rioja & 62 & $10,6 \%$ \\
Euskadi & 53 & $9,0 \%$ \\
Navarra & 22 & $3,7 \%$ \\
Andalucía & 15 & $2,6 \%$ \\
Madrid & 14 & $2,4 \%$ \\
Canarias & 13 & $2,2 \%$ \\
Extremadura & 12 & $2,0 \%$ \\
Castilla La Mancha & 8 & $1,4 \%$ \\
Baleares & 8 & $1,4 \%$ \\
Cantabria & 4 & $0,7 \%$ \\
Cataluña & 3 & $0,5 \%$ \\
Aragón & 3 & $0,5 \%$ \\
Galicia & 2 & $0,3 \%$ \\
Murcia & 2 & $0,3 \%$ \\
\hline Total & $\mathbf{5 8 7}$ & $\mathbf{1 0 0 \%}$ \\
\hline
\end{tabular}

Tabla 173: Características de la muestra institucional por procedencia.

En cuanto al tipo de institución (tabla 174), el 51,3\% eran centros, el 30,7\% Asociaciones, el 11,8\% residencias y el 6,3\% eran de otros tipos. 


\begin{tabular}{lcc}
\hline \multicolumn{1}{c}{ Tipo de institución } & N & \% \\
\hline Centro & 301 & $51,3 \%$ \\
Asociación & 180 & $30,7 \%$ \\
Residencia & 69 & $11,8 \%$ \\
Otros & 37 & $6,3 \%$ \\
\hline Total & $\mathbf{5 8 7}$ & $\mathbf{1 0 0 \%}$ \\
\hline
\end{tabular}

Tabla 174: Características de la muestra institucional por tipo de institución.

En cuanto a los tipos de discapacidad atendida (tabla 175), todos los centros atendían a personas con discapacidades intelectuales y del desarrollo, pero además, atendían otros tipos de discapacidades como física (59,3\% de los casos), trastornos mentales (59,1\% de los casos), discapacidad visual (48\% de los casos), auditiva (45,3\% de los casos), tercera edad (26,6\% de los casos), parálisis cerebral (23,3\% de los casos), y en menores porcentajes de casos Alzheimer (17,7\%), Parkinson (15,5\%), autismo $(15,2 \%)$, lesión medular $(6,8 \%)$ y otras $(4,4 \%)$.

\begin{tabular}{lccc}
\hline Tipo de discapacidad atendida & $\mathbf{N}$ & \% de resp. & \% de casos \\
\hline Discapacidad intelectual & 587 & $23,7 \%$ & $100 \%$ \\
Discapacidad física & 348 & $14,1 \%$ & $59,3 \%$ \\
Trastorno mental & 347 & $14,0 \%$ & $59,1 \%$ \\
Discapacidad visual & 282 & $11,4 \%$ & $48,0 \%$ \\
Discapacidad auditiva & 266 & $10,8 \%$ & $45,3 \%$ \\
Tercera edad & 156 & $6,3 \%$ & $26,6 \%$ \\
Parálisis cerebral & 137 & $5,5 \%$ & $23,3 \%$ \\
Alzheimer & 104 & $4,2 \%$ & $17,7 \%$ \\
Parkinson & 91 & $3,7 \%$ & $15,5 \%$ \\
Autismo & 89 & $3,6 \%$ & $15,2 \%$ \\
Lesión medular & 40 & $1,6 \%$ & $6,8 \%$ \\
Otras & 26 & $1,1 \%$ & $4,4 \%$ \\
\hline Total & $\mathbf{2 4 7 3}$ & $\mathbf{1 0 0 \%}$ & $\mathbf{4 2 1 , 3 \%}$ \\
\hline
\end{tabular}

Tabla 175: Características de la muestra institucional por tipo de discapacidad atendida.

En lo que respecta a la especialización profesional (tabla 176), en el 86,1\% de los casos había psicólogos, en el 82,7\% de los casos personal de limpieza, en el 70,3\% 
de los casos administrativos, cuidadores en el 67,6\% de los casos, trabajadores sociales en el 66,3\%, fisioterapeutas en el 65\%, terapeutas o monitores en el 51,9\% de los casos, personal auxiliar en el 47,6\%, y en menor porcentaje de casos enfermeras $(39,3 \%)$, personal de cocina $(37,3 \%)$, médicos $(37,1 \%)$, personal de mantenimiento $(35,1 \%)$, monitores de tiempo libre $(33 \%)$, logopedas $(30,5 \%)$, conductores $(25,2 \%)$, educadores sociales $(23,6 \%)$, profesores $(22 \%)$, técnicos de apoyo al empleo (20,7\%), pedagogos $(18,7 \%)$, técnicos rehabilitadores $(14,6 \%)$, profesores de apoyo $(8,8 \%)$, abogados $(8,5 \%)$ y otras especializaciones $(18,7 \%$ de los casos).

\begin{tabular}{lccc}
\hline \multicolumn{1}{c}{ Especialización del personal } & N & \% de resp. & \% de casos \\
\hline Psicólogo & 478 & $9,5 \%$ & $86,1 \%$ \\
Personal de limpieza & 459 & $9,1 \%$ & $82,7 \%$ \\
Personal administrativo & 390 & $7,7 \%$ & $70,3 \%$ \\
Cuidador & 375 & $7,4 \%$ & $67,6 \%$ \\
Trabajador social & 368 & $7,3 \%$ & $66,3 \%$ \\
Fisioterapeuta & 361 & $7,1 \%$ & $65,0 \%$ \\
Terapeuta, monitor ocupacional, de taller & 288 & $5,7 \%$ & $51,9 \%$ \\
Personal auxiliar & 264 & $5,2 \%$ & $47,6 \%$ \\
Enfermera/ATS & 218 & $4,3 \%$ & $39,3 \%$ \\
Personal de cocina & 207 & $4,1 \%$ & $37,3 \%$ \\
Médico & 206 & $4,1 \%$ & $37,1 \%$ \\
Personal de mantenimiento & 195 & $3,9 \%$ & $35,1 \%$ \\
Monitor tiempo libre & 183 & $3,6 \%$ & $33,0 \%$ \\
Logopeda & 169 & $3,3 \%$ & $30,5 \%$ \\
Conductor & 140 & $2,8 \%$ & $25,2 \%$ \\
Educador social & 131 & $2,6 \%$ & $23,6 \%$ \\
Profesor & 122 & $2,4 \%$ & $22,0 \%$ \\
Técnico de apoyo al empleo & 115 & $2,3 \%$ & $20,7 \%$ \\
Pedagogo & 104 & $2,1 \%$ & $18,7 \%$ \\
Profesor de apoyo & 81 & $1,6 \%$ & $14,6 \%$ \\
Abogado & 49 & $1,0 \%$ & $8,8 \%$ \\
Otros & 47 & $0,9 \%$ & $8,5 \%$ \\
Total & 104 & $2,1 \%$ & $18,7 \%$ \\
\hline
\end{tabular}

Nota: 555 (94,5\%) casos válidos; 32 casos perdidos $(5,5 \%)$.

Tabla 176: Características de la muestra institucional por especialización del personal. 
En lo referente al tipo de servicios (tabla 177), en el 85,7\% de los casos existía servicio de comida; en el 81,3\% los usuarios recibían atención psicológica; en el 73,1\% de los casos había servicio de limpieza; en el 72,8\% de los casos servicio de ocio y tiempo libre; en el 66,1\% se ofrecía información y orientación; en el 64,1\% existía un servicio de fisioterapia; en el $56,8 \%$ de los casos había un departamento de trabajo social; en el 56,6\% de los casos se daban ayudas asistenciales; en el 54,6\% de los casos también se ofertaba un servicio de alojamiento; y en menor porcentaje de casos había gimnasio $(48,3 \%)$, lavandería $(47,9 \%)$, terapia ocupacional $(47,2 \%)$, asistencia médica (41,7\%), rehabilitación (40,3\%), enseñanza de adultos (28,9\%), servicio de logopedia $(27,8 \%)$, actividad laboral (26,3\%), biblioteca (24,5\%), alfabetización (22,7\%), podólogo $(21,8 \%)$, hidroterapia $(17,8 \%)$, asesoría jurídica $(14,2 \%)$ y otros servicios $(13,6 \%)$. 


\begin{tabular}{lccc}
\hline \multicolumn{1}{c}{ Tipo de servicio } & N & \% de resp. & \% de casos \\
\hline Servicio de comidas & 472 & $8,3 \%$ & $85,7 \%$ \\
Atención psicológica & 448 & $7,9 \%$ & $81,3 \%$ \\
Servicio de limpieza & 403 & $7,1 \%$ & $73,1 \%$ \\
Ocio y tiempo libre & 401 & $7,0 \%$ & $72,8 \%$ \\
Información y orientación & 364 & $6,4 \%$ & $66,1 \%$ \\
Fisioterapia & 353 & $6,2 \%$ & $64,1 \%$ \\
Dpto. Trabajo Social & 313 & $5,5 \%$ & $56,8 \%$ \\
Ayudas asistenciales & 312 & $5,5 \%$ & $56,6 \%$ \\
Alojamiento & 301 & $5,3 \%$ & $54,6 \%$ \\
Gimnasio & 266 & $4,7 \%$ & $48,3 \%$ \\
Lavandería & 264 & $4,6 \%$ & $47,9 \%$ \\
Terapia ocupacional & 260 & $4,6 \%$ & $47,2 \%$ \\
Asistencia médica & 230 & $4,0 \%$ & $41,7 \%$ \\
Rehabilitación & 222 & $3,9 \%$ & $40,3 \%$ \\
Enseñanza de adultos & 159 & $2,8 \%$ & $28,9 \%$ \\
Atención logopédica & 153 & $2,7 \%$ & $27,8 \%$ \\
Empleo, actividad laboral & 145 & $2,5 \%$ & $26,3 \%$ \\
Biblioteca & 135 & $2,4 \%$ & $24,5 \%$ \\
Alfabetización & 125 & $2,2 \%$ & $22,7 \%$ \\
Podólogo & 120 & $2,1 \%$ & $21,8 \%$ \\
Hidroterapia & 98 & $1,7 \%$ & $17,8 \%$ \\
Asesoría jurídica & 78 & $1,4 \%$ & $14,2 \%$ \\
Otros & 75 & $1,3 \%$ & $13,6 \%$ \\
\hline Total & $\mathbf{5 6 9 7}$ & $\mathbf{1 0 0 \%}$ & $\mathbf{1 0 3 3 , 9 \%}$ \\
\hline
\end{tabular}

Nota: $551(93,9 \%)$ casos válidos; 36 casos perdidos $(6,1 \%)$.

Tabla 177: Características de la muestra institucional por tipo de servicios.

En cuanto al tipo de alojamiento de los usuarios con los que contaban las entidades (tabla 178), en el 55,6\% de los casos tenían residencia para la $3^{\text {a }}$ edad pública; en el $32,6 \%$ de los casos domicilio propio; en el $22 \%$ de los casos tenían pisos tutelados; en el $15,6 \%$ de los casos tenían residencia para la $3^{\mathrm{a}}$ edad privada y centros de día en el $11,2 \%$ de los casos.

En menor porcentaje de casos, tenían alojamiento temporal $(8,7 \%)$, media pensión $(8,2 \%)$, centros ocupacionales $(7 \%)$, programas respiro $(3,4 \%)$, casa hogar $(3,2 \%)$, CAMP $(1,1 \%)$, CRMF $(1,1 \%)$, centro hospitalario $(0,6 \%)$, centro educativo $(0,6 \%)$, 
domicilio alquilado $(0,4 \%)$, CAMF $(0,2 \%)$, centros de trabajo protegidos $(0,2 \%)$ y otros tipos de alojamiento $(3,8 \%)$.

\begin{tabular}{lccc}
\hline \multicolumn{1}{c}{ Tipo de alojamiento } & $\mathbf{N}$ & \% de resp. & \% de casos \\
\hline Residencia $\mathbf{3}^{\text {a }}$ edad pública & 263 & $31,7 \%$ & $55,6 \%$ \\
Domicilio propio & 154 & $18,6 \%$ & $32,6 \%$ \\
Piso tutelado & 104 & $12,5 \%$ & $22,0 \%$ \\
Residencia 3 $\mathbf{3}^{\text {e edad privada }}$ & 74 & $8,9 \%$ & $15,6 \%$ \\
Centro de día & 53 & $6,4 \%$ & $11,2 \%$ \\
Alojamiento temporal & 41 & $4,9 \%$ & $8,7 \%$ \\
Media pensión & 39 & $4,7 \%$ & $8,2 \%$ \\
Centro ocupacional & 33 & $4,0 \%$ & $7,0 \%$ \\
Programa respiro & 16 & $1,9 \%$ & $3,4 \%$ \\
Casa hogar & 15 & $1,8 \%$ & $3,2 \%$ \\
CAMP & 5 & $0,6 \%$ & $1,1 \%$ \\
CRMF & 5 & $0,6 \%$ & $1,1 \%$ \\
Hospitalario & 3 & $0,4 \%$ & $0,6 \%$ \\
Centro educativo & 3 & $0,4 \%$ & $0,6 \%$ \\
Domicilio alquilado & 2 & $0,2 \%$ & $0,4 \%$ \\
CAMF & 1 & $0,1 \%$ & $0,2 \%$ \\
Centro de trabajo protegido & 1 & $0,1 \%$ & $0,2 \%$ \\
Otros & 18 & $2,2 \%$ & $3,8 \%$ \\
\hline Total & $\mathbf{8 3 0}$ & $\mathbf{1 0 0 \%}$ & $\mathbf{1 7 5 , 5 \%}$ \\
\hline
\end{tabular}

Nota: 473 (80,6\%) casos válidos; 114 casos perdidos $(19,4 \%)$.

Tabla 178: Características de la muestra institucional por el tipo de alojamiento de los usuarios.

\subsubsection{Resumen}

En resumen, la muestra institucional estaba compuesta principalmente por profesionales. La mayoría de las instituciones tenían su sede en poblaciones de 10.000 o más habitantes, y pertenecían a Comunidades Autónomas diversas, entre las que destacan Castilla León, Asturias y Valencia. En mayor medida eran centros y Asociaciones, con atención a personas con DID principalmente, aunque también a otros tipos de discapacidades (asociadas), como la discapacidad física, visual y auditiva, así como los trastornos mentales. Los profesionales tenían varias especializaciones, aunque principalmente había psicólogos, personal de limpieza, cuidadores, administrativos, trabajadores socia- 
les, fisioterapeutas y monitores; que prestaban servicios como los de comida, atención psicológica, limpieza, ocio y tiempo libre, información y orientación, fisioterapia, trabajo social, ayudas asistenciales, alojamiento y terapia ocupacional principalmente. En cuanto a los tipos de alojamiento, en mayor medida las instituciones contaban con residencia de $3^{\mathrm{a}}$ edad pública o privada, pisos tutelados, domicilio propio y centros de día, entre otros.

\subsection{ANÁLISIS DE LAS NECESIDADES DE LAS INSTITUCIONES}

\subsubsection{Introducción}

A continuación se presenta el análisis de las necesidades generales y específicas, las soluciones, los apoyos institucionales requeridos, las demandas de los asociados, los pensamientos de futuro de los asociados y de las personas mayores, así como otras consideraciones percibidas por los profesionales.

\subsubsection{Análisis de las necesidades percibidas. Muestra institucional.}

En cuanto a las necesidades percibidas por los profesionales que respondieron al cuestionario institucional, en la tabla 179 podemos observar los estadísticos de los distintos grupos de necesidades. Podemos destacar que los profesionales señalan como

preocupaciones importantes para las PcDID otras preocupaciones $(M=3,12)$, seguidas de las preocupaciones sobre salud personal $(M=2,50)$, la existencia de barreras $(M=2,26)$, los recursos de servicios sociales $(M=2,10)$, los recursos sanitarios $(M=2,01)$ y en último lugar, los recursos económicos $(\mathrm{M}=1,59)$. 


\begin{tabular}{lccccccc}
\hline & $\begin{array}{c}\text { Salud } \\
\text { personal }\end{array}$ & $\begin{array}{c}\text { Recursos } \\
\text { económicos }\end{array}$ & $\begin{array}{c}\text { Recursos } \\
\text { sanitarios }\end{array}$ & $\begin{array}{c}\text { Recursos } \\
\text { servicios } \\
\text { sociales }\end{array}$ & $\begin{array}{c}\text { Existencia } \\
\text { barreras }\end{array}$ & Otras & Total \\
\hline $\mathrm{N}$ & 587 & 587 & 587 & 587 & 587 & 587 & 587 \\
\hline Media & 2,50 & 1,59 & 2,01 & 2,10 & 2,26 & 3,12 & 13,54 \\
\hline Mediana & 2,00 & 1,00 & 1,00 & 1,00 & 1,00 & 2,00 & 7,00 \\
\hline Moda & 0 & 0 & 0 & 1 & 0 & 1 & 3 \\
\hline Desv. típ. & 2,656 & 1,784 & 2,093 & 2,020 & 2,523 & 3,209 & 12,572 \\
\hline Asimetría & 0,786 & 1,156 & 1,086 & 1,100 & 0,911 & 0,962 & 0,887 \\
\hline Curtosis & $-0,565$ & 0,474 & 0,513 & 0,643 & $-0,455$ & $-0,142$ & $-0,336$ \\
\hline Mínimo & 0 & 0 & 0 & 0 & 0 & 0 & 0 \\
\hline Máximo & 9 & 7 & 9 & 9 & 9 & 12 & 53 \\
\hline \hline
\end{tabular}

Tabla 179: Estadísticos descriptivos de las necesidades específicas señaladas por la muestra institucional.

En el gráfico 22 se muestra el número de preocupaciones señaladas en cada uno de los grupos de necesidades. En primer lugar, los profesionales eligen otras necesidades, seguidas de las necesidades de salud personal, la existencia de barreras, los recursos de servicios sociales, los recursos sanitarios y por último, los recursos económicos. 


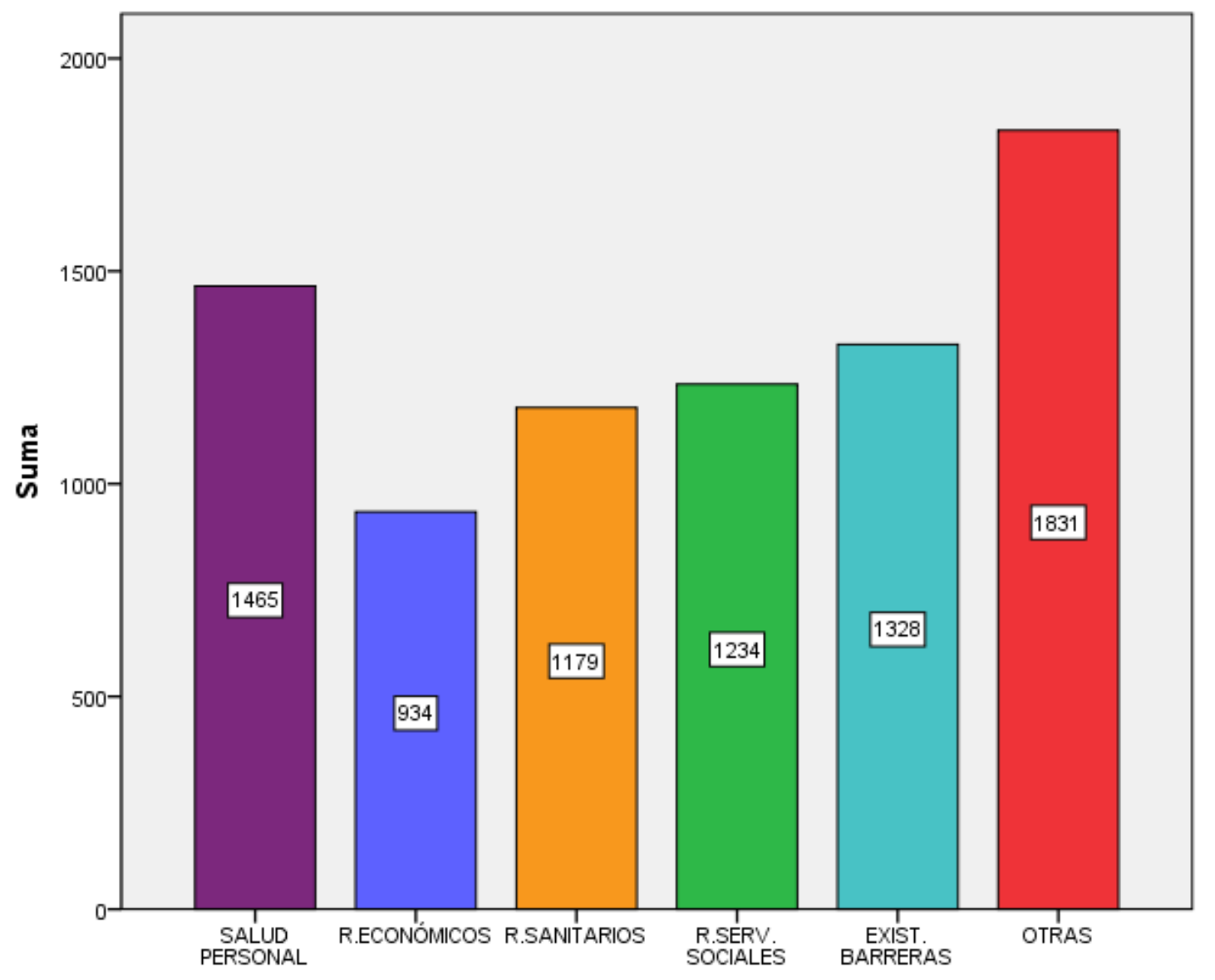

Gráfico 22: Frecuencia de necesidades específicas percibidas por la muestra institucional.

\subsubsection{Necesidades de salud personal}

En cuanto a las necesidades de salud personal (tabla 180), los profesionales señalan en el 74,2\% de los casos el estado de salud general, seguido por los cuidados personales diarios $(68,8 \%$ de los casos), las limitaciones funcionales personales $(63,8 \%$ de los casos) y la dependencia (63\% de los casos). En menores porcentajes de casos eligen las dificultades para tomar la medicación (35,3\%), la aceptación de la situación (32,6\%), los dolores $(31 \%)$ y las dificultades para acudir al tratamiento $(21,4 \%)$. En el $10,4 \%$ de los casos señalaron otras preocupaciones sobre salud personal no recogidas entre las anteriores. 


\begin{tabular}{lccc}
\hline \multicolumn{1}{c}{ Salud personal: } & N & \% resp & \% casos \\
\hline Estado de salud general & 271 & $18,5 \%$ & $74,2 \%$ \\
Cuidados personales diarios & 251 & $17,2 \%$ & $68,8 \%$ \\
Limitaciones funcionales personales & 233 & $15,9 \%$ & $63,8 \%$ \\
Dependencia & 230 & $15,7 \%$ & $63,0 \%$ \\
Dificultades para tomar la medicación & 129 & $8,8 \%$ & $35,3 \%$ \\
Aceptación de mi situación & 119 & $8,1 \%$ & $32,6 \%$ \\
Dolores & 113 & $7,7 \%$ & $31,0 \%$ \\
Dificultades para acudir al tratamiento & 78 & $5,3 \%$ & $21,4 \%$ \\
Otras & 38 & $2,6 \%$ & $10,4 \%$ \\
\hline \multicolumn{1}{c}{ Respuestas totales } & $\mathbf{1 4 6 2}$ & $\mathbf{1 0 0 \%}$ & $\mathbf{4 0 0 , 5 \%}$ \\
\hline
\end{tabular}

Nota: 222 casos perdidos; 365 casos válidos.

Tabla 180: Frecuencias y porcentajes (de respuestas y de casos) de preocupaciones sobre salud personal de la muestra institucional.

\subsubsection{Preocupaciones sobre recursos económicos}

En cuanto a las preocupaciones de los profesionales sobre los recursos económicos (tabla 181), en el 59,7\% de los casos han señalado las subvenciones, seguidas de la situación económica familiar (45,3\% de los casos), la independencia económica (42,1\% de los casos), el encontrar un puesto de trabajo (40,3\% de los casos), la pensión (36,5\% de los casos), la incapacidad laboral (19,7\% de los casos) y otras preocupaciones $(5,3 \%$ de los casos).

\begin{tabular}{lccc}
\hline \multicolumn{1}{c}{ Recursos económicos: } & N & \% resp & \% casos \\
\hline Subvenciones & 224 & $24,0 \%$ & $59,7 \%$ \\
Situación económica familiar & 170 & $18,2 \%$ & $45,3 \%$ \\
Independencia económica & 158 & $16,9 \%$ & $42,1 \%$ \\
Encontrar un puesto de trabajo & 151 & $16,2 \%$ & $40,3 \%$ \\
Pensión & 137 & $14,7 \%$ & $36,5 \%$ \\
Incapacidad laboral & 74 & $7,9 \%$ & $19,7 \%$ \\
Otras & 20 & $2,1 \%$ & $5,3 \%$ \\
\hline \multicolumn{1}{c}{ Respuestas totales } & $\mathbf{9 3 4}$ & $\mathbf{1 0 0 \%}$ & $\mathbf{2 4 9 , 1 \%}$ \\
\hline
\end{tabular}

Nota: 212 casos perdidos; 375 casos válidos.

Tabla 181: Frecuencias y porcentajes (de respuestas y de casos) de preocupaciones sobre recursos económicos de la muestra institucional. 


\subsubsection{Preocupaciones sobre recursos sanitarios}

En lo referente a las preocupaciones sobre los recursos sanitarios (tabla 182), los profesionales señalaron en el 59,6\% de los casos la calidad de la asistencia sanitaria, en el $51,2 \%$ la asistencia en salud mental; y con porcentajes de casos menores los tratamientos de fisioterapia $(37,9 \%)$, la asistencia sanitaria hospitalaria $(32,5 \%)$, los dispositivos de apoyo y protésicos $(28,8 \%)$, el incremento y la mejora de las instalaciones sanitarias $(26,6 \%)$, la asistencia sanitaria domiciliaria $(23,2 \%)$, la falta de información sobre estos recursos $(20,7 \%)$ y otras necesidades no recogidas entre las anteriores $(10,3 \%)$.

\begin{tabular}{lccc}
\hline \multicolumn{1}{c}{ Recursos sanitarios: } & N & \% resp & \% casos \\
\hline Calidad de la asistencia sanitaria & 242 & $20,5 \%$ & $59,6 \%$ \\
Asistencia en salud mental & 208 & $17,6 \%$ & $51,2 \%$ \\
Tratamiento de fisioterapia & 154 & $13,0 \%$ & $37,9 \%$ \\
Asistencia sanitaria hospitalaria & 132 & $11,2 \%$ & $32,5 \%$ \\
Dispositivos de apoyo y protésicos & 117 & $9,9 \%$ & $28,8 \%$ \\
Más y mejores instalaciones sanitarias & 108 & $9,1 \%$ & $26,6 \%$ \\
Asistencia sanitaria domiciliaria & 94 & $8,0 \%$ & $23,2 \%$ \\
Falta de información sobre estos recursos & 84 & $7,1 \%$ & $20,7 \%$ \\
Otras & 42 & $3,6 \%$ & $10,3 \%$ \\
\hline \multicolumn{1}{c}{ Respuestas totales } & $\mathbf{1 1 8 1}$ & $\mathbf{1 0 0 \%}$ & $\mathbf{2 9 0 , 9 \%}$ \\
\hline
\end{tabular}

Nota: 181 casos perdidos; 406 casos válidos.

Tabla 182: Frecuencias y porcentajes (de respuestas y de casos) de preocupaciones sobre recursos sanitarios de la muestra institucional.

\subsubsection{Necesidades sobre recursos de servicios sociales}

En cuanto a las necesidades sobre los recursos de los servicios sociales (tabla 183), los profesionales señalaron los servicios de apoyo al ocio y tiempo libre $(50,4 \%$ de los casos), la calidad de la asistencia social (49,3\% de los casos), el incremento y la mejora de las instalaciones sociales (42,5\% de los casos), los servicios de alojamiento (40,3\% de los casos); y en menores porcentajes de casos la ayuda a domicilio $(25,2 \%)$, el apoyo en las gestiones administrativas $(24,3 \%)$, la falta de información sobre estos 
recursos $(19 \%)$, el asesoramiento jurídico (17\%) y otras necesidades relacionadas con los recursos de servicios sociales no recogidas entre las anteriores $(6,2 \%)$.

\begin{tabular}{lccc}
\hline \multicolumn{1}{c}{ Recursos servicios sociales: } & N & \% resp & \% casos \\
\hline Servicios de apoyo al ocio y tiempo libre & 228 & $18,4 \%$ & $50,4 \%$ \\
Calidad de la asistencia social & 223 & $18,0 \%$ & $49,3 \%$ \\
Más y mejores instalaciones sociales & 192 & $15,5 \%$ & $42,5 \%$ \\
Servicios de alojamiento & 182 & $14,7 \%$ & $40,3 \%$ \\
Ayuda a domicilio & 114 & $9,2 \%$ & $25,2 \%$ \\
Apoyo en las gestiones administrativas & 110 & $8,9 \%$ & $24,3 \%$ \\
Falta de información sobre estos recursos & 86 & $6,9 \%$ & $19,0 \%$ \\
Asesoramiento jurídico & 77 & $6,2 \%$ & $17,0 \%$ \\
Otras & 28 & $2,3 \%$ & $6,2 \%$ \\
\hline \multicolumn{1}{c}{ Respuestas totales } & $\mathbf{1 2 4 0}$ & $\mathbf{1 0 0 \%}$ & $\mathbf{2 7 4 , 3 \%}$ \\
\hline
\end{tabular}

Nota: 135 casos perdidos; 452 casos válidos.

Tabla 183: Frecuencias y porcentajes (de respuestas y de casos) de preocupaciones sobre recursos de servicios sociales de la muestra institucional.

\subsubsection{Necesidades sobre existencia de barreras}

En cuanto a la existencia de barreras (tabla 184), los profesionales señalaron en el 58,5\% de los casos las barreras sociales, seguidas de las barreras arquitectónicas en el 4,5\% de los casos, la aceptación por parte de la sociedad (49,2\% de los casos), la facilidad de transporte $(47,9 \%$ de los casos), la aceptación por parte de la familia $(43,1 \%$ de los casos), las ayudas técnicas (38,3\% de los casos), la accesibilidad a edificios públicos (33,2\% de los casos), la escasez de voluntariado (31,1\% de los casos) y otras necesidades $(2,4 \%$ de los casos). 


\begin{tabular}{lccc}
\hline \multicolumn{1}{c}{ Existencia de barreras: } & N & \% resp & \% casos \\
\hline Barreras sociales & 220 & $16,6 \%$ & $58,5 \%$ \\
Barreras arquitectónicas & 186 & $14,0 \%$ & $49,5 \%$ \\
Aceptación por parte de la sociedad & 185 & $13,9 \%$ & $49,2 \%$ \\
Facilidad de transporte & 180 & $13,6 \%$ & $47,9 \%$ \\
Aceptación por parte de la familia & 162 & $12,2 \%$ & $43,1 \%$ \\
Ayudas técnicas & 144 & $10,8 \%$ & $38,3 \%$ \\
Accesibilidad a edificios públicos & 125 & $9,4 \%$ & $33,2 \%$ \\
Escasez de voluntariado & 117 & $8,8 \%$ & $31,1 \%$ \\
Otras & 9 & $0,7 \%$ & $2,4 \%$ \\
\hline \multicolumn{1}{c}{ Respuestas totales } & $\mathbf{1 3 2 8}$ & $\mathbf{1 0 0 \%}$ & $\mathbf{3 5 3 , 2 \%}$ \\
\hline
\end{tabular}

Nota: 211 casos perdidos; 376 casos válidos.

Tabla 184: Frecuencias y porcentajes (de respuestas y de casos) de preocupaciones sobre existencia de barreras de la muestra institucional.

\subsubsection{Otras necesidades}

En lo referente a otras necesidades y preocupaciones (tabla 185), los profesionales señalaron en el 47,2\% de los casos el dónde y con quién vivir en el futuro, seguida de la atención integral e individualizada (47\% de los casos), la necesidad de más profesionales $(43,3 \%$ de los casos), la necesidad de formación y reciclaje profesional (40\% de los casos), la escasez de relaciones personales (39,3\% de los casos), la coordinación entre instituciones $(35,1 \%$ de los casos), el futuro de la familia $(28,7 \%$ de los casos), la salida del domicilio familiar (27,6\% de los casos), los problemas sociales (27,2\% de los casos), la protección jurídica (19,6\% de los casos), los problemas del movimiento asociativo (17,7\% de los casos), los avances tecnológicos (17,2\% de los casos) y otras necesidades (14,8\% de los casos). 


\begin{tabular}{lccc}
\hline \multicolumn{1}{c}{ Otras: } & N & \% resp & \% casos \\
\hline Dónde y con quién vivir en el futuro & 214 & $11,7 \%$ & $47,2 \%$ \\
Atención integral e individualizada & 213 & $11,6 \%$ & $47,0 \%$ \\
Necesidad de más profesionales & 196 & $10,7 \%$ & $43,3 \%$ \\
Formación y reciclaje del personal & 181 & $9,9 \%$ & $40,0 \%$ \\
Escasez de relaciones personales & 178 & $9,7 \%$ & $39,3 \%$ \\
Coordinación entre instituciones & 159 & $8,7 \%$ & $35,1 \%$ \\
Futuro de la familia & 130 & $7,1 \%$ & $28,7 \%$ \\
Salida del domicilio familiar & 125 & $6,8 \%$ & $27,6 \%$ \\
Problemas sociales & 123 & $6,7 \%$ & $27,2 \%$ \\
Protección jurídica & 89 & $4,9 \%$ & $19,6 \%$ \\
Problemas del movimiento asociativo & 80 & $4,4 \%$ & $17,7 \%$ \\
Avances tecnológicos & 78 & $4,3 \%$ & $17,2 \%$ \\
Otras & 67 & $3,7 \%$ & $14,8 \%$ \\
\hline \multicolumn{1}{c}{ Respuestas totales } & $\mathbf{1 8 3 3}$ & $\mathbf{1 0 0 \%}$ & $\mathbf{4 0 4 , 7 \%}$ \\
\hline
\end{tabular}

Nota: 134 casos perdidos; 453 casos válidos.

Tabla 185: Frecuencias y porcentajes (de respuestas y de casos) de preocupaciones sobre otras preocupaciones y necesidades de la muestra institucional.

\subsubsection{Demandas de los asociados}

En cuanto a las demandas que los profesionales de las instituciones atribuyen a las personas asociadas a su entidad (tabla 186), destacan con un alto porcentaje de casos los servicios de apoyo al ocio y tiempo libre (55,5\% de los casos). En menores porcentajes de casos, señalan los servicios residenciales $(34,6 \%)$, las ayudas económicas $(34,5 \%)$, favorecer la vida independiente $(31,3 \%)$, la participación $(30,2 \%)$, la inserción laboral $(29,3 \%)$, el fomento de la calidad de vida $(28,4 \%)$, la ayuda a las familias (26,7\%), el apoyo afectivo a las PcDID (25,6\%), las relaciones afectivas y de amistad $(25,4 \%)$, las ayudas médicas $(25,3 \%)$, el incremento y la mejora de instalaciones $(24,7 \%)$, los programas de respiro $(24,4 \%)$, la supresión de barreras sociales $(23,7 \%)$, entre otras. 


\begin{tabular}{lccc}
\hline \multicolumn{1}{c}{ Demandas de los asociados: } & N & \% resp & \% casos \\
\hline Actividades de ocio y tiempo libre & 314 & $7,6 \%$ & $55,5 \%$ \\
Servicios residenciales & 196 & $4,7 \%$ & $34,6 \%$ \\
Ayudas económicas & 195 & $4,7 \%$ & $34,5 \%$ \\
Favorecer la vida independiente & 177 & $4,3 \%$ & $31,3 \%$ \\
Participación, que se les escuche & 171 & $4,1 \%$ & $30,2 \%$ \\
Inserción laboral & 166 & $4,0 \%$ & $29,3 \%$ \\
Fomento de la calidad de vida & 161 & $3,9 \%$ & $28,4 \%$ \\
Ayuda a las familias & 151 & $3,6 \%$ & $26,7 \%$ \\
Apoyo afectivo a la PcD & 145 & $3,5 \%$ & $25,6 \%$ \\
Relaciones afectivas, de amistad & 144 & $3,5 \%$ & $25,4 \%$ \\
Ayudas médicas & 143 & $3,5 \%$ & $25,3 \%$ \\
Más y mejores instalaciones & 140 & $3,4 \%$ & $24,7 \%$ \\
Programas de respiro & 138 & $3,3 \%$ & $24,4 \%$ \\
Supresión de barreras sociales & 134 & $3,2 \%$ & $23,7 \%$ \\
Más personal y mejores servicios & 130 & $3,1 \%$ & $23,0 \%$ \\
Tratamientos psicológicos & 128 & $3,1 \%$ & $22,6 \%$ \\
Apoyo e implicación familiar & 126 & $3,0 \%$ & $22,3 \%$ \\
Alternativas ocupacionales & 123 & $3,0 \%$ & $21,7 \%$ \\
Más recursos técnicos, materiales y persona- & 121 & $2,9 \%$ & $21,4 \%$ \\
les & & & \\
Rehabilitación & 110 & $2,7 \%$ & $19,4 \%$ \\
Supresión de barreras arquitectónicas & 110 & $2,7 \%$ & $19,4 \%$ \\
Ayuda a domicilio & 97 & $2,3 \%$ & $17,1 \%$ \\
Apoyo a cuidadores & 93 & $2,2 \%$ & $16,4 \%$ \\
Apoyo institucional & 86 & $2,1 \%$ & $15,2 \%$ \\
Formación & 86 & $2,1 \%$ & $15,2 \%$ \\
Más información & 80 & $1,9 \%$ & $14,1 \%$ \\
Centros de día & 74 & $1,8 \%$ & $13,1 \%$ \\
Apoyo distintas administraciones & 72 & $1,7 \%$ & $12,7 \%$ \\
Tutorización & 66 & $1,6 \%$ & $11,7 \%$ \\
Disminución ratio PcD/Profesional & 65 & $1,6 \%$ & $11,5 \%$ \\
Profesionales más especializados & 59 & $1,4 \%$ & $10,4 \%$ \\
Trato más humano & 57 & $1,4 \%$ & $10,1 \%$ \\
Otras demandas & 83 & $2,0 \%$ & $14,7 \%$ \\
\hline \multicolumn{1}{c}{ Respus totales } & $\mathbf{1 0 0 \%}$ & $\mathbf{7 1 6 , 4 \%}$ \\
\hline
\end{tabular}

Nota: 21 casos perdidos; 566 casos válidos.

Tabla 186: Frecuencias y porcentajes (de respuestas y de casos) de demandas de los asociados de la muestra institucional.

10.3.4. Soluciones propuestas

En cuanto a las soluciones propuestas por los profesionales (tabla 187), destaca la creación o mejora de servicios de apoyo al ocio y tiempo libre (37,1\% de los casos), 
el incremento de las subvenciones (34,9\% de los casos), la promoción de viviendas adaptadas $(32,8 \%$ de los casos), la atención individualizada (32,4\% de los casos), la coordinación entre instituciones (31,9\% de los casos), la mayor especialización profesional (31,2\% de los casos) y la adecuación de los programas de intervención (30,3\% de los casos).

En menor medida destacan la supresión de barreras arquitectónicas $(29,1 \%$ de los casos), la asistencia psicológica (28\% de los casos), las garantías de futuro $(27,3 \%$ de los casos), la calidad de la asistencia sanitaria (27,3\% de los casos), la aceptación por parte de la sociedad $(27,1 \%$ de los casos), la ayuda para los cuidados personales diarios (26,2\% de los casos), la mejora de los servicios de alojamiento (25,2\% de los casos), la calidad de la asistencia social $(24,1 \%$ de los casos), los programas de cambio de actitudes (24,1\% de los casos), las facilidades de transporte (23,2\% de los casos), entre otras. 


\begin{tabular}{|c|c|c|c|}
\hline Soluciones: & $\mathbf{N}$ & $\%$ resp & $\%$ casos \\
\hline Servicios de apoyo al ocio y tiempo libre & 209 & $4,0 \%$ & $37,1 \%$ \\
\hline Incremento de las subvenciones & 197 & $3,7 \%$ & $34,9 \%$ \\
\hline Promoción de viviendas adaptadas & 185 & $3,5 \%$ & $32,8 \%$ \\
\hline Atención individualizada & 183 & $3,5 \%$ & $32,4 \%$ \\
\hline Coordinación entre instituciones & 180 & $3,4 \%$ & $31,9 \%$ \\
\hline Profesionales más especializados & 176 & $3,3 \%$ & $31,2 \%$ \\
\hline Programas adecuados de intervención & 171 & $3,2 \%$ & $30,3 \%$ \\
\hline Supresión de barreras arquitectónicas & 164 & $3,1 \%$ & $29,1 \%$ \\
\hline Asistencia psicológica & 158 & $3,0 \%$ & $28,0 \%$ \\
\hline Garantías de futuro & 154 & $2,9 \%$ & $27,3 \%$ \\
\hline Calidad de la asistencia sanitaria & 154 & $2,9 \%$ & $27,3 \%$ \\
\hline Aceptación por parte de la sociedad & 153 & $2,9 \%$ & $27,1 \%$ \\
\hline Ayuda para cuidados personales diarios & 148 & $2,8 \%$ & $26,2 \%$ \\
\hline Mejora de los servicios de alojamiento & 142 & $2,7 \%$ & $25,2 \%$ \\
\hline Calidad de la asistencia social & 136 & $2,6 \%$ & $24,1 \%$ \\
\hline Programas de cambio de actitudes & 136 & $2,6 \%$ & $24,1 \%$ \\
\hline Facilidades de transporte & 131 & $2,5 \%$ & $23,2 \%$ \\
\hline Más y mejores instalaciones sanitarias & 131 & $2,5 \%$ & $23,2 \%$ \\
\hline Más y mejores instalaciones sociales & 131 & $2,5 \%$ & $23,2 \%$ \\
\hline Aceptación por parte de la familia & 133 & $2,5 \%$ & $23,6 \%$ \\
\hline Subida de las pensiones & 125 & $2,4 \%$ & $22,2 \%$ \\
\hline Promoción del empleo protegido & 129 & $2,4 \%$ & $22,9 \%$ \\
\hline $\begin{array}{l}\text { Más actividades ocupacionales, más y mejores } \\
\text { recursos comunitarios }\end{array}$ & 127 & $2,4 \%$ & $22,5 \%$ \\
\hline Incremento de la ayuda familiar & 123 & $2,3 \%$ & $21,8 \%$ \\
\hline Fisioterapia en la Seguridad Social & 114 & $2,2 \%$ & $20,2 \%$ \\
\hline Mejora de la asistencia a domicilio & 113 & $2,1 \%$ & $20,0 \%$ \\
\hline Centros de día & 109 & $2,1 \%$ & $19,3 \%$ \\
\hline Apoyo a los cuidadores informales & 110 & $2,1 \%$ & $19,5 \%$ \\
\hline Promoción del voluntariado & 106 & $2,0 \%$ & $18,8 \%$ \\
\hline Más información sobre recursos & 107 & $2,0 \%$ & $19,0 \%$ \\
\hline Incremento de la participación asociativa & 108 & $2,0 \%$ & $19,1 \%$ \\
\hline Reserva de puestos de trabajo & 99 & $1,9 \%$ & $17,6 \%$ \\
\hline Más y mejor información & 103 & $1,9 \%$ & $18,3 \%$ \\
\hline Apoyo legal y administrativo & 97 & $1,8 \%$ & $17,2 \%$ \\
\hline Más y mejores ayudas técnicas & 92 & $1,7 \%$ & $16,3 \%$ \\
\hline Incremento de la atención sanitaria & 90 & $1,7 \%$ & $16,0 \%$ \\
\hline Adelantar la jubilación & 79 & $1,5 \%$ & $14,0 \%$ \\
\hline Mejora de apoyos y prótesis & 77 & $1,5 \%$ & $13,7 \%$ \\
\hline Campañas de imagen & 70 & $1,3 \%$ & $12,4 \%$ \\
\hline Disminución de la relación profesional/usuario & 55 & $1,0 \%$ & $9,8 \%$ \\
\hline Otras & 84 & $1,6 \%$ & $14,9 \%$ \\
\hline Respuestas totales & 5289 & $100 \%$ & $\mathbf{9 3 7 , 8 \%}$ \\
\hline
\end{tabular}

Nota: 23 casos perdidos; 564 casos válidos.

Tabla 187: Frecuencias y porcentajes (de respuestas y de casos) de las soluciones propuestas por la muestra institucional. 
Si agrupamos las soluciones en función de los grupos de necesidades (tabla 188), podemos ver que en cuanto a soluciones de salud personal, destaca la ayuda para los cuidados personales diarios (26,2\% de los casos). En cuanto a los recursos económicos, los profesionales han señalado en el 34,9\% de los casos el incremento de las subvenciones. En lo referente a las necesidades sobre recursos sanitarios, los profesionales han señalado en el 31,2\% de los casos la especialización profesional. En cuanto a los recursos de servicios sociales, han destacado los servicios de apoyo al ocio y tiempo libre (37,1\% de los casos) y la atención individualizada (32,4\% de los casos). Por otro lado, en lo que respecta a la existencia de barreras, han señalado en el 32,8\% de los casos la promoción de viviendas adaptadas. Por último, en lo referente a las soluciones comunes, los profesionales han elegido en el 31,9\% de los casos la coordinación entre instituciones, y en el 30,3\% de los casos la adecuación de los programas de intervención. 


\begin{tabular}{|c|c|c|c|}
\hline Soluciones: & $\mathbf{N}$ & $\begin{array}{c}\% \\
\text { resp }\end{array}$ & $\begin{array}{c}\% \\
\text { casos }\end{array}$ \\
\hline \multicolumn{4}{|l|}{ Salud personal } \\
\hline Ayuda para cuidados personales diarios & 148 & $2,8 \%$ & $26,2 \%$ \\
\hline Apoyo a los cuidadores informales & 110 & $2,1 \%$ & $19,5 \%$ \\
\hline \multicolumn{4}{|l|}{ Recursos económicos } \\
\hline Incremento de las subvenciones & 197 & $3,7 \%$ & $34,9 \%$ \\
\hline Subida de las pensiones & 125 & $2,4 \%$ & $22,2 \%$ \\
\hline Promoción del empleo protegido & 129 & $2,4 \%$ & $22,9 \%$ \\
\hline Incremento de la ayuda familiar & 123 & $2,3 \%$ & $21,8 \%$ \\
\hline Reserva de puestos de trabajo & 99 & $1,9 \%$ & $17,6 \%$ \\
\hline Adelantar la jubilación & 79 & $1,5 \%$ & $14,0 \%$ \\
\hline \multicolumn{4}{|l|}{ Recursos asistenciales sanitarios } \\
\hline Profesionales más especializados & 176 & $3,3 \%$ & $31,2 \%$ \\
\hline Calidad de la asistencia sanitaria & 154 & $2,9 \%$ & $27,3 \%$ \\
\hline Más y mejores instalaciones sanitarias & 131 & $2,5 \%$ & $23,2 \%$ \\
\hline Fisioterapia en la Seguridad Social & 114 & $2,2 \%$ & $20,2 \%$ \\
\hline Incremento de la atención sanitaria & 90 & $1,7 \%$ & $16,0 \%$ \\
\hline Mejora de apoyos y prótesis & 77 & $1,5 \%$ & $13,7 \%$ \\
\hline \multicolumn{4}{|l|}{ Recursos servicios sociales } \\
\hline Servicios de apoyo al ocio y tiempo libre & 209 & $4,0 \%$ & $37,1 \%$ \\
\hline Atención individualizada & 183 & $3,5 \%$ & $32,4 \%$ \\
\hline Mejora de los servicios de alojamiento & 142 & $2,7 \%$ & $25,2 \%$ \\
\hline Calidad de la asistencia social & 136 & $2,6 \%$ & $24,1 \%$ \\
\hline Facilidades de transporte & 131 & $2,5 \%$ & $23,2 \%$ \\
\hline Más y mejores instalaciones sociales & 131 & $2,5 \%$ & $23,2 \%$ \\
\hline $\begin{array}{l}\text { Más actividades ocupacionales, más y mejores recursos comuni- } \\
\text { tarios }\end{array}$ & 127 & $2,4 \%$ & $22,5 \%$ \\
\hline Mejora de la asistencia a domicilio & 113 & $2,1 \%$ & $20,0 \%$ \\
\hline Centros de día & 109 & $2,1 \%$ & $19,3 \%$ \\
\hline Promoción del voluntariado & 106 & $2,0 \%$ & $18,8 \%$ \\
\hline Incremento de la participación asociativa & 108 & $2,0 \%$ & $19,1 \%$ \\
\hline \multicolumn{4}{|l|}{ Existencia de barreras } \\
\hline Promoción de viviendas adaptadas & 185 & $3,5 \%$ & $32,8 \%$ \\
\hline Supresión de barreras arquitectónicas & 164 & $3,1 \%$ & $29,1 \%$ \\
\hline Aceptación por parte de la sociedad & 153 & $2,9 \%$ & $27,1 \%$ \\
\hline Programas de cambio de actitudes & 136 & $2,6 \%$ & $24,1 \%$ \\
\hline Aceptación por parte de la familia & 133 & $2,5 \%$ & $23,6 \%$ \\
\hline Más y mejores ayudas técnicas & 92 & $1,7 \%$ & $16,3 \%$ \\
\hline Campañas de imagen & 70 & $1,3 \%$ & $12,4 \%$ \\
\hline
\end{tabular}

Tabla 188.1.: Frecuencias y porcentajes (de respuestas y de casos) de las soluciones propuestas por la muestra institucional en función de la temática. 


\begin{tabular}{lrrr}
\hline \multicolumn{1}{c}{ Soluciones: } & N & $\begin{array}{c}\text { \% } \\
\text { resp }\end{array}$ & $\begin{array}{c}\text { \% } \\
\text { casos }\end{array}$ \\
\hline \multicolumn{1}{c}{$\begin{array}{l}\text { Soluciones comunes } \\
\text { Coordinación entre instituciones }\end{array}$} & 180 & $3,4 \%$ & $31,9 \%$ \\
Programas adecuados de intervención & 171 & $3,2 \%$ & $30,3 \%$ \\
Asistencia psicológica & 158 & $3,0 \%$ & $28,0 \%$ \\
Garantías de futuro & 154 & $2,9 \%$ & $27,3 \%$ \\
Más información sobre recursos & 107 & $2,0 \%$ & $19,0 \%$ \\
Más y mejor información & 103 & $1,9 \%$ & $18,3 \%$ \\
Apoyo legal y administrativo & 97 & $1,8 \%$ & $17,2 \%$ \\
Disminución de la relación profesional/usuario & 55 & $1,0 \%$ & $9,8 \%$ \\
Otras & 84 & $1,6 \%$ & $14,9 \%$ \\
\hline \multicolumn{1}{c}{ Respuestas totales } & $\mathbf{5 2 8 9}$ & $\mathbf{1 0 0 \%}$ & $\mathbf{9 3 7 , 8 \%}$ \\
\hline
\end{tabular}

Nota: 23 casos perdidos; 564 casos válidos.

Tabla 188.2.: Frecuencias y porcentajes (de respuestas y de casos) de las soluciones propuestas por la muestra institucional en función de la temática (Continuación).

\subsubsection{Medidas y apoyos institucionales requeridos}

En cuanto a los apoyos institucionales requeridos (tabla 189), los profesionales han señalado en el 50,8\% de los casos el incremento de los recursos de las asociaciones, seguido de la coordinación entre distintas administraciones $(48,8 \%$ de los casos). En menor medida han señalado la creación de centros y recursos necesarios $(37,5 \%$ de los casos), la mayor implicación de la administración (34,5\% de los casos), las actividades de formación (31,5\% de los casos), tener en cuenta la opinión de los profesionales (28,8\% de los casos), la igualdad de oportunidades (26,7\% de los casos), los apoyos en el entorno (23,9\% de los casos), así como de los Ayuntamientos $(21,8 \%)$ y de la comunidad $(21,3 \%)$, la reorganización de los servicios sociales $(18,1 \%$ de los casos), las actividades culturales $(13,9 \%$ de los casos) y otros apoyos (15,3\% de los casos). 


\begin{tabular}{lccc}
\hline \multicolumn{1}{c}{ Apoyos requeridos: } & N & \% resp & \% casos \\
\hline Incrementar los recursos de las asociaciones & 270 & $13,6 \%$ & $50,8 \%$ \\
Coordinación entre las distintas administraciones & 259 & $13,1 \%$ & $48,8 \%$ \\
Creación de centros y recursos necesarios & 199 & $10,1 \%$ & $37,5 \%$ \\
Mayor implicación de la administración & 183 & $9,2 \%$ & $34,5 \%$ \\
Actividades de formación & 167 & $8,4 \%$ & $31,5 \%$ \\
Tener en cuenta la opinión de los profesionales & 153 & $7,7 \%$ & $28,8 \%$ \\
Igualdad de oportunidades & 142 & $7,2 \%$ & $26,7 \%$ \\
Apoyos en el entorno & 127 & $6,4 \%$ & $23,9 \%$ \\
Apoyo de los Ayuntamientos & 116 & $5,9 \%$ & $21,8 \%$ \\
Apoyo de la comunidad & 113 & $5,7 \%$ & $21,3 \%$ \\
Reorganización de los servicios sociales & 96 & $4,8 \%$ & $18,1 \%$ \\
Actividades culturales & 74 & $3,7 \%$ & $13,9 \%$ \\
Otros & 81 & $4,1 \%$ & $15,3 \%$ \\
\hline \multicolumn{1}{c}{ Respuestas totales } & $\mathbf{1 9 8 0}$ & $\mathbf{1 0 0 \%}$ & $\mathbf{3 7 2 , 9 \%}$ \\
\hline
\end{tabular}

Nota: 56 casos perdidos; 531 casos válidos.

Tabla 189: Frecuencias y porcentajes (de respuestas y de casos) de apoyos requeridos por la muestra institucional.

10.3.6. Pensamientos sobre el futuro de los asociados

En cuanto a los pensamientos sobre el futuro de los asociados (tabla 190), en el $52,2 \%$ de los casos los profesionales señalaron vivir con calidad de vida, seguido, con menores porcentajes de casos de elección, de la atención personalizada (29,4\% de los casos), el afrontamiento del futuro con preocupación (29\%), la necesidad de apoyos especiales $(26,3 \%)$, la mayor especialización y personalización del servicio $(25,9 \%)$, la mayor implicación de la administración (23,9\%), los servicios específicos (23,3\%), la autonomía personal $(21,1 \%)$, la mayor preparación de los profesionales $(19,1 \%)$ o la vida independiente (16\%), entre otros. 


\begin{tabular}{|c|c|c|c|}
\hline Pensamientos de futuro de sus asociados: & $\mathbf{N}$ & $\begin{array}{c}\% \\
\text { resp }\end{array}$ & $\begin{array}{c}\% \\
\text { casos }\end{array}$ \\
\hline Vivir con calidad de vida & 284 & $15,8 \%$ & $52,2 \%$ \\
\hline Atención personalizada & 160 & $8,9 \%$ & $29,4 \%$ \\
\hline Con preocupación, futuro incierto & 158 & $8,8 \%$ & $29,0 \%$ \\
\hline Necesidad de apoyos especiales & 143 & $8,0 \%$ & $26,3 \%$ \\
\hline $\begin{array}{l}\text { Mayor especialización y personalización en el ser- } \\
\text { vicio }\end{array}$ & 139 & $7,8 \%$ & $25,6 \%$ \\
\hline Más implicación de la administración & 130 & $7,3 \%$ & $23,9 \%$ \\
\hline Servicios específicos & 127 & $7,1 \%$ & $23,3 \%$ \\
\hline Autonomía personal & 115 & $6,4 \%$ & $21,1 \%$ \\
\hline Más y mejor preparación de los profesionales & 104 & $5,8 \%$ & $19,1 \%$ \\
\hline Vida independiente & 87 & $4,9 \%$ & $16,0 \%$ \\
\hline Preocupación por los hijos & 63 & $3,5 \%$ & $11,6 \%$ \\
\hline Dependerá del asociacionismo & 59 & $3,3 \%$ & $10,8 \%$ \\
\hline Bien, sin problemas & 52 & $2,9 \%$ & $9,6 \%$ \\
\hline Seguir viviendo & 34 & $1,9 \%$ & $6,3 \%$ \\
\hline Vivir al día & 22 & $1,2 \%$ & $4,0 \%$ \\
\hline Soledad & 22 & $1,2 \%$ & $4,0 \%$ \\
\hline Resuelto & 20 & $1,1 \%$ & $3,7 \%$ \\
\hline Triste & 11 & $0,6 \%$ & $2,0 \%$ \\
\hline Aburrimiento & 11 & $0,6 \%$ & $2,0 \%$ \\
\hline Mal, negro & 9 & $0,5 \%$ & $1,7 \%$ \\
\hline Nada, no pienso en el futuro & 5 & $0,3 \%$ & $0,9 \%$ \\
\hline Pocas ganas de vivir & 3 & $0,2 \%$ & $0,6 \%$ \\
\hline Otros & 34 & $1,9 \%$ & $6,3 \%$ \\
\hline Respuestas totales & 1792 & $100 \%$ & $329,4 \%$ \\
\hline
\end{tabular}

Nota: 43 casos perdidos; 544 casos válidos.

Tabla 190: Frecuencias y porcentajes (de respuestas y de casos) de pensamientos sobre el futuro de la muestra institucional.

Si analizamos los pensamientos de futuro en función del tipo de respuesta (tabla 191), destaca el vivir con calidad de vida $(52,2 \%$ de los casos) y la atención personalizada (29,4\% de los casos) seguidas de respuestas de preocupación, como el afrontar el futuro con preocupación, por ser aún incierto (29\% de los casos).

Es de destacar que las respuestas pesimistas y de evitación son las menos elegidas por los profesionales. 


\begin{tabular}{|c|c|c|c|}
\hline $\begin{array}{l}\text { Pensamientos de futuro de sus } \\
\text { asociados: }\end{array}$ & $\mathbf{N}$ & $\begin{array}{c}\% \\
\text { resp }\end{array}$ & $\begin{array}{c}\% \\
\text { casos }\end{array}$ \\
\hline \multicolumn{4}{|l|}{ Respuestas de evitación } \\
\hline Seguir viviendo & 34 & $1,9 \%$ & $6,3 \%$ \\
\hline Vivir al día & 22 & $1,2 \%$ & $4,0 \%$ \\
\hline Nada, no pienso en el futuro & 5 & $0,3 \%$ & $0,9 \%$ \\
\hline \multicolumn{4}{|l|}{ Preocupación } \\
\hline Con preocupación, futuro incierto & 158 & $8,8 \%$ & $29,0 \%$ \\
\hline Preocupación por los hijos & 63 & $3,5 \%$ & $11,6 \%$ \\
\hline \multicolumn{4}{|l|}{ Pesimismo } \\
\hline Soledad & 22 & $1,2 \%$ & $4,0 \%$ \\
\hline Triste & 11 & $0,6 \%$ & $2,0 \%$ \\
\hline Aburrimiento & 11 & $0,6 \%$ & $2,0 \%$ \\
\hline Mal, negro & 9 & $0,5 \%$ & $1,7 \%$ \\
\hline Pocas ganas de vivir & 3 & $0,2 \%$ & $0,6 \%$ \\
\hline \multicolumn{4}{|l|}{ Optimismo } \\
\hline Bien, sin problemas & 52 & $2,9 \%$ & $9,6 \%$ \\
\hline Resuelto & 20 & $1,1 \%$ & $3,7 \%$ \\
\hline \multicolumn{4}{|l|}{ Otras respuestas } \\
\hline Vivir con calidad de vida & 284 & $15,8 \%$ & $52,2 \%$ \\
\hline Atención personalizada & 160 & $8,9 \%$ & $29,4 \%$ \\
\hline Necesidad de apoyos especiales & 143 & $8,0 \%$ & $26,3 \%$ \\
\hline $\begin{array}{l}\text { Mayor especialización y personali- } \\
\text { zación en el servicio }\end{array}$ & 139 & $7,8 \%$ & $25,6 \%$ \\
\hline $\begin{array}{l}\text { Más implicación de la administra- } \\
\text { ción }\end{array}$ & 130 & $7,3 \%$ & $23,9 \%$ \\
\hline Servicios específicos & 127 & $7,1 \%$ & $23,3 \%$ \\
\hline Autonomía personal & 115 & $6,4 \%$ & $21,1 \%$ \\
\hline $\begin{array}{l}\text { Más y mejor preparación de los pro- } \\
\text { fesionales }\end{array}$ & 104 & $5,8 \%$ & $19,1 \%$ \\
\hline Vida independiente & 87 & $4,9 \%$ & $16,0 \%$ \\
\hline Dependerá del asociacionismo & 59 & $3,3 \%$ & $10,8 \%$ \\
\hline Otros & 34 & $1,9 \%$ & $6,3 \%$ \\
\hline Respuestas totales & 1792 & $100 \%$ & $329,4 \%$ \\
\hline
\end{tabular}

Nota: 43 casos perdidos; 544 casos válidos.

Tabla 191: Frecuencias y porcentajes (de respuestas y de casos) de pensamientos sobre el futuro en función de la temática de la muestra institucional.

\subsubsection{Pensamientos de futuro de las personas con discapacidad mayores}

Cuando los profesionales han respondido acerca de los pensamientos de futuro de las personas con discapacidad que se encuentran en proceso de envejecimiento (tabla 
192), destacan el vivir con calidad de vida (43,3\% de los casos), seguida de afrontar el futuro con preocupación (36,8\% de los casos), la atención personalizada (35,7\% de los casos), la necesidad de apoyos especiales (33,8\% de los casos), los servicios específicos (28,3\% de los casos), la mayor especialización y personalización en el servicio (26\% de los casos) y la mayor implicación de la administración (21,8\% de los casos), entre otros.

\begin{tabular}{|c|c|c|c|}
\hline Pensamientos de futuro de las PcD mayores: & $\mathbf{N}$ & $\begin{array}{c}\% \\
\text { resp }\end{array}$ & $\begin{array}{c}\% \\
\text { casos }\end{array}$ \\
\hline Vivir con calidad de vida & 240 & $13,1 \%$ & $43,3 \%$ \\
\hline Con preocupación, futuro incierto & 204 & $11,2 \%$ & $36,8 \%$ \\
\hline Atención personalizada & 198 & $10,8 \%$ & $35,7 \%$ \\
\hline Necesidad de apoyos especiales & 187 & $10,2 \%$ & $33,8 \%$ \\
\hline Servicios específicos & 157 & $8,6 \%$ & $28,3 \%$ \\
\hline $\begin{array}{l}\text { Mayor especialización y personalización en el ser- } \\
\text { vicio }\end{array}$ & 144 & $7,9 \%$ & $26,0 \%$ \\
\hline Más implicación de la administración & 121 & $6,6 \%$ & $21,8 \%$ \\
\hline Más y mejor preparación de los profesionales & 100 & $5,5 \%$ & $18,1 \%$ \\
\hline Autonomía personal & 87 & $4,8 \%$ & $15,7 \%$ \\
\hline Vida independiente & 60 & $3,3 \%$ & $10,8 \%$ \\
\hline Dependerá del asociacionismo & 59 & $3,2 \%$ & $10,6 \%$ \\
\hline Preocupación por los hijos & 48 & $2,6 \%$ & $8,7 \%$ \\
\hline Seguir viviendo & 39 & $2,1 \%$ & $7,0 \%$ \\
\hline Soledad & 33 & $1,8 \%$ & $6,0 \%$ \\
\hline Bien, sin problemas & 30 & $1,6 \%$ & $5,4 \%$ \\
\hline Vivir al día & 24 & $1,3 \%$ & $4,3 \%$ \\
\hline Mal, negro & 16 & $0,9 \%$ & $2,9 \%$ \\
\hline Triste & 15 & $0,8 \%$ & $2,7 \%$ \\
\hline Resuelto & 10 & $0,5 \%$ & $1,8 \%$ \\
\hline Pocas ganas de vivir & 7 & $0,4 \%$ & $1,3 \%$ \\
\hline Aburrimiento & 4 & $0,2 \%$ & $0,7 \%$ \\
\hline Nada, no pienso en el futuro & 1 & $0,1 \%$ & $0,2 \%$ \\
\hline Otros & 42 & $2,3 \%$ & $7,6 \%$ \\
\hline Respuestas totales & 1826 & $100 \%$ & $329,6 \%$ \\
\hline
\end{tabular}

Nota: 33 casos perdidos; 554 casos válidos.

Tabla 192: Frecuencias y porcentajes (de respuestas y de casos) de pensamientos sobre el futuro de la muestra institucional.

Cuando analizamos los pensamientos de futuro en relación al tipo de respuestas (tabla 193), en el 43,4\% de los casos señalan el vivir con calidad de vida, afrontar el 
futuro con preocupación $(36,8 \%$ de los casos) y la atención personalizada $(35,7 \%$ de los casos). En este caso los profesionales han antepuesto la preocupación en un puesto con respecto a los pensamientos de futuro de los asociados, lo que viene a decir que hay mayor preocupación con respecto al futuro de las personas con DID que envejecen.

Además, en este caso las respuestas de pesimismo y evitación, superan ligeramente los porcentajes señalados en las respuestas de optimismo por parte de los profesionales, en relación a las puntuaciones encontradas en los pensamientos de futuro de los asociados. 


\begin{tabular}{|c|c|c|c|}
\hline $\begin{array}{c}\text { Pensamientos de futuro de las PcD } \\
\text { mayores: }\end{array}$ & $\mathbf{N}$ & $\begin{array}{c}\% \\
\text { resp }\end{array}$ & $\begin{array}{c}\% \\
\text { casos }\end{array}$ \\
\hline \multicolumn{4}{|l|}{ Respuestas de evitación } \\
\hline Seguir viviendo & 39 & $2,1 \%$ & $7,0 \%$ \\
\hline Vivir al día & 24 & $1,3 \%$ & $4,3 \%$ \\
\hline Nada, no pienso en el futuro & 1 & $0,1 \%$ & $0,2 \%$ \\
\hline \multicolumn{4}{|l|}{ Preocupación } \\
\hline Con preocupación, futuro incierto & 204 & $11,2 \%$ & $36,8 \%$ \\
\hline Preocupación por los hijos & 48 & $2,6 \%$ & $8,7 \%$ \\
\hline \multicolumn{4}{|l|}{ Pesimismo } \\
\hline Soledad & 33 & $1,8 \%$ & $6,0 \%$ \\
\hline Mal, negro & 16 & $0,9 \%$ & $2,9 \%$ \\
\hline Triste & 15 & $0,8 \%$ & $2,7 \%$ \\
\hline Pocas ganas de vivir & 7 & $0,4 \%$ & $1,3 \%$ \\
\hline Aburrimiento & 4 & $0,2 \%$ & $0,7 \%$ \\
\hline \multicolumn{4}{|l|}{ Optimismo } \\
\hline Bien, sin problemas & 30 & $1,6 \%$ & $5,4 \%$ \\
\hline Resuelto & 10 & $0,5 \%$ & $1,8 \%$ \\
\hline \multicolumn{4}{|l|}{ Otras respuestas } \\
\hline Vivir con calidad de vida & 240 & $13,1 \%$ & $43,3 \%$ \\
\hline Atención personalizada & 198 & $10,8 \%$ & $35,7 \%$ \\
\hline Necesidad de apoyos especiales & 187 & $10,2 \%$ & $33,8 \%$ \\
\hline Servicios específicos & 157 & $8,6 \%$ & $28,3 \%$ \\
\hline $\begin{array}{l}\text { Mayor especialización y personali- } \\
\text { zación en el servicio }\end{array}$ & 144 & $7,9 \%$ & $26,0 \%$ \\
\hline $\begin{array}{l}\text { Más implicación de la administra- } \\
\text { ción }\end{array}$ & 121 & $6,6 \%$ & $21,8 \%$ \\
\hline $\begin{array}{l}\text { Más y mejor preparación de los pro- } \\
\text { fesionales }\end{array}$ & 100 & $5,5 \%$ & $18,1 \%$ \\
\hline Autonomía personal & 87 & $4,8 \%$ & $15,7 \%$ \\
\hline Vida independiente & 60 & $3,3 \%$ & $10,8 \%$ \\
\hline Dependerá del asociacionismo & 59 & $3,2 \%$ & $10,6 \%$ \\
\hline Otros & 42 & $2,3 \%$ & $7,6 \%$ \\
\hline Respuestas totales & 1826 & $100 \%$ & $329,6 \%$ \\
\hline
\end{tabular}

Nota: 33 casos perdidos; 554 casos válidos.

Tabla 193: Frecuencias y porcentajes (de respuestas y de casos) de pensamientos sobre el futuro en función de la temática de la muestra institucional. 


\subsubsection{Otras consideraciones}

En lo que respecta a otras consideraciones (tabla 194), los profesionales señalaron en el $23,5 \%$ de los casos la creación de centros especializados, seguido de una mayor formación de los profesionales (14\% de los casos), la ayuda de la sociedad (13,2\% de los casos), de las instituciones (12,5\% de los casos), las ayudas asistenciales $(8,8 \%$ de los casos), la mayor investigación académica ( $8,1 \%$ de los casos), las ayudas económicas (5,1\% de los casos), la información adecuada (5,1\% de los casos), la supresión de barreras arquitectónicas $(1,5 \%$ de los casos) y otras consideraciones $(44,9 \%$ de los casos).

\begin{tabular}{|c|c|c|c|}
\hline Otras consideraciones: & $\mathbf{N}$ & $\begin{array}{c}\% \\
\text { resp }\end{array}$ & $\begin{array}{c}\% \\
\text { casos }\end{array}$ \\
\hline Creación centros especializados & 32 & $17,2 \%$ & $23,5 \%$ \\
\hline $\begin{array}{l}\text { Más formación por parte de los profesio- } \\
\text { nales }\end{array}$ & 19 & $10,2 \%$ & $14,0 \%$ \\
\hline Ayuda de la sociedad & 18 & $9,7 \%$ & $13,2 \%$ \\
\hline Ayuda de las instituciones & 17 & $9,1 \%$ & $12,5 \%$ \\
\hline Ayudas asistenciales & 12 & $6,5 \%$ & $8,8 \%$ \\
\hline Más investigación a nivel académico & 11 & $5,9 \%$ & $8,1 \%$ \\
\hline Ayudas económicas & 7 & $3,8 \%$ & $5,1 \%$ \\
\hline Información adecuada & 7 & $3,8 \%$ & $5,1 \%$ \\
\hline Supresión de barreras arquitectónicas & 2 & $1,1 \%$ & $1,5 \%$ \\
\hline Otras & 61 & $32,8 \%$ & $44,9 \%$ \\
\hline Respuestas totales & 186 & $100 \%$ & $136,8 \%$ \\
\hline
\end{tabular}

Nota: 451 casos perdidos; 136 casos válidos.

Tabla 194: Frecuencias y porcentajes (de respuestas y de casos) de otras consideraciones de la muestra institucional.

\subsubsection{Resumen}

En resumen, a la muestra institucional le preocupan otras necesidades como dónde y con quién vivir en el futuro, la atención integral e individual, el incremento de profesionales y la formación y el reciclaje profesional. En segundo lugar, señalan las preocupaciones sobre salud personal, tales como el estado de salud general, los cuidados 
personales diarios, las limitaciones funcionales personales y la dependencia. A estas preocupaciones les siguen aquellas relacionadas con la existencia de barreras, tales como las barreras sociales y arquitectónicas, la aceptación de la sociedad, las facilidades de transporte y la aceptación por parte de la familia. Seguidamente, sobre las preocupaciones acerca de los servicios sociales, les preocupan los servicios de apoyo al ocio y tiempo libre, la calidad de la asistencia social, el incremento y la mejora de las instalaciones sociales, y los servicios de alojamiento. Sobre los recursos sanitarios les preocupan la calidad de la asistencia sanitaria y la asistencia en salud mental. Por último, en lo referente a los recursos económicos les preocupan las subvenciones, la situación económica familiar, la independencia económica y el encontrar un puesto de trabajo.

Los profesionales destacan como principal demanda de sus asociados las actividades de ocio y tiempo libre.

Para estas necesidades proponen soluciones como la ayuda para los cuidados personales diarios, el incremento de las subvenciones, la mayor especialización profesional, la creación y mejora de servicios de apoyo al ocio y tiempo libre, la atención individualizada, la promoción de viviendas adaptadas, la supresión de barreras arquitectónicas, la aceptación por parte de la sociedad, la coordinación entre instituciones, los programas adecuados de intervención, la asistencia psicológica y las garantías de futuro.

Entre las medidas y apoyos institucionales requeridos, los profesionales abogan por el incremento de los recursos de las asociaciones y una mayor coordinación entre las administraciones.

Entre los pensamientos de futuro de los asociados, los profesionales señalan el vivir con calidad de vida, la atención personalizada y el afrontar el futuro con preocupación; lo mismo ocurre en el caso de los pensamientos de futuro que atribuyen a las PcD 
mayores, aunque en este caso priman en mayor medida las respuestas de preocupación, y las pesimistas y de evitación superan en porcentajes pequeños a las respuestas optimistas, que en los pensamientos de los asociados se puntúan levemente por encima.

Como otras consideraciones, los profesionales proponen la creación de centros especializados y la mayor formación de los profesionales.

\subsection{ANÁLISIS DE LA RELACIÓN ENTRE PREOCUPACIONES Y NECESIDADES Y LAS VARIABLES PREDICTORAS. MUESTRA INSTITUCIONAL}

\subsubsection{Introducción}

En el caso de la muestra institucional, las variables que hemos considerado como predictoras han sido la residencia y el tipo de institución. En este apartado analizaremos en qué medida influyen sobre las variables criterio que hemos mantenido durante todo el estudio, a saber, las necesidades y soluciones generales y las necesidades específicas; incluyendo en el caso de los profesionales las demandas de los asociados, así como los pensamientos de futuro de los asociados y de las personas con discapacidad mayores.

\subsubsection{Prueba de normalidad de las distribuciones}

En primer lugar, comprobamos la normalidad de las distribuciones de las variables criterio (tablas 195 y 196). En ambos casos, se demuestra que las variables no siguen una distribución normal $(\mathrm{p}<0,01)$, por lo que se emplearán pruebas no paramétricas. 


\begin{tabular}{|c|c|c|c|c|c|c|c|c|}
\hline & \multirow[b]{2}{*}{$\mathrm{N}$} & \multicolumn{2}{|c|}{$\begin{array}{l}\text { Parámetros } \\
\text { normales }\end{array}$} & \multicolumn{3}{|c|}{$\begin{array}{l}\text { Diferencias más ex- } \\
\text { tremas }\end{array}$} & \multirow{2}{*}{$\begin{array}{l}\mathrm{Z} \text { de } \\
\mathrm{K}-\mathrm{S}\end{array}$} & \multirow[b]{2}{*}{ Sig. } \\
\hline & & Media & DT & Abs. & Pos. & Neg. & & \\
\hline $\mathrm{N}^{\circ}$ preocupaciones & 587 & 13,54 & 12,572 & 0,220 & 0,220 & $-0,141$ & 5,328 &, 000 \\
\hline $\begin{array}{l}\mathrm{N}^{\mathrm{o}} \text { demandas de los aso- } \\
\text { ciados }\end{array}$ & 587 & 7,05 & 6,584 & 0,212 & 0,212 & $-0,143$ & 5,133 &, 000 \\
\hline $\mathrm{N}^{\mathrm{o}}$ soluciones & 587 & 9,05 & 9,033 & 0,213 & 0,213 & $-0,158$ & 5,153 &, 000 \\
\hline $\begin{array}{l}\mathrm{N}^{\circ} \text { apoyos instituciona- } \\
\text { les requeridos }\end{array}$ & 587 & 3,41 & 2,864 & 0,178 & 0,178 & $-0,117$ & 4,315 &, 000 \\
\hline $\begin{array}{l}\mathrm{N}^{\circ} \text { pensamientos futuro } \\
\text { de sus asociados }\end{array}$ & 587 & 3,05 & 2,765 & 0,220 & 0,220 & $-0,158$ & 5,340 & ,000 \\
\hline $\begin{array}{l}\mathrm{N}^{\circ} \text { pensamientos futuro } \\
\mathrm{PcD} \text { mayores }\end{array}$ & 587 & 3,11 & 2,810 & 0,227 & 0,227 & $-0,169$ & 5,508 &, 000 \\
\hline $\mathrm{N}^{\mathrm{o}}$ Consideraciones & 587 & 0,32 & 0,679 & 0,448 & 0,448 & $-0,318$ & 10,858 & 000 \\
\hline
\end{tabular}

Tabla 195: Prueba de Kolmogorov-Smirnov para una muestra en número de preocupaciones y soluciones generales. Muestra de profesionales.

\begin{tabular}{|l|c|c|c|c|c|c|c|c|}
\hline & & \multicolumn{2}{|c|}{$\begin{array}{r}\text { Parámetros norma- } \\
\text { les }\end{array}$} & \multicolumn{3}{|c|}{ Diferencias más extre- } & \multirow{2}{*}{ mas } & \\
\cline { 3 - 8 } & $\mathrm{N}$ & Media & DT & Abs. & Pos. & Neg. & S & Sig. \\
\hline Salud personal & 587 & 2,50 & 2,656 & 0,199 & 0,199 & $-0,174$ & 4,832 &, 000 \\
Recursos económi- & 587 & 1,59 & 1,784 & 0,241 & 0,241 & $-0,186$ & 5,848 &, 000 \\
cos & & & & & & & & \\
Recursos sanitarios & 587 & 2,01 & 2,093 & 0,203 & 0,203 & $-0,169$ & 4,917 &, 000 \\
Recursos s.sociales & 587 & 2,10 & 2,020 & 0,212 & 0,212 & $-0,149$ & 5,126 &, 000 \\
Existencia barreras & 587 & 2,26 & 2,523 & 0,235 & 0,235 & $-0,185$ & 5,693 &, 000 \\
Otras & 587 & 3,12 & 3,209 & 0,217 & 0,217 & $-0,166$ & 5,267 &, 000 \\
\hline
\end{tabular}

Tabla 196: Prueba de Kolmogorov-Smirnov para una muestra en número de preocupaciones específicas. Muestra de profesionales.

\subsubsection{Variable tipo de residencia}

\subsubsection{Introducción}

La variable tipo de residencia de la sede de la institución se analizó como posible variable predictora de los resultados obtenidos acerca de las NP's por los profesionales que cumplimentaron el cuestionario. 


\subsubsection{Resultados sobre la variable tipo de residencia}

En cuanto al tipo de residencia, la prueba U de Mann-Whitney indica que hay diferencias estadísticamente significativas $(\mathrm{p}<0,05)$ en el número de demandas de los asociados, apoyos institucionales y consideraciones (tabla 198). En todos los casos, los profesionales de las instituciones cuyas sedes estaban situadas en poblaciones de 10.000 o más habitantes puntuaron de forma superior al otro grupo (tabla 197).

En cuanto a las necesidades específicas, sólo se observaron diferencias estadísticamente significativas $(\mathrm{p}<0,05)$ en el número de necesidades sobre recursos sanitarios (tabla 200). En este caso, el grupo de profesionales de instituciones cuya institución tenía la sede en poblaciones de 10.000 o más habitantes puntuaron en mayor medida en esta variable (tabla 199).

El gráfico 23 muestra los rangos promedio de cada uno de los grupos en función de la residencia en cada una de las variables criterio.

La tabla 201 muestra el resumen de la significatividad de los datos. 


\begin{tabular}{|c|c|c|c|}
\hline & Residencia & $\mathbf{N}$ & Rango promedio \\
\hline \multirow{3}{*}{$\begin{array}{l}\mathbf{N}^{\circ} \text { Preocupaciones } \mathbf{y} \\
\text { necesidades }\end{array}$} & $<10.000$ & 79 & 261,13 \\
\hline & $>10.000$ & 508 & 299,11 \\
\hline & Total & 587 & \\
\hline \multirow{3}{*}{$\begin{array}{l}\mathrm{N}^{0} \text { demandas de los } \\
\text { asociados }\end{array}$} & $<10.000$ & 79 & 256,52 \\
\hline & $>10.000$ & 508 & 299,83 \\
\hline & Total & 587 & \\
\hline \multirow{3}{*}{$\mathrm{N}^{\mathbf{o}}$ soluciones } & $<10.000$ & 79 & 275,87 \\
\hline & $>10.000$ & 508 & 296,82 \\
\hline & Total & 587 & \\
\hline \multirow{3}{*}{$\begin{array}{l}\mathrm{N}^{\circ} \text { Apoyos institucio- } \\
\text { nales requeridos }\end{array}$} & $<10.000$ & 79 & 245,35 \\
\hline & $>10.000$ & 508 & 301,56 \\
\hline & Total & 587 & \\
\hline \multirow{3}{*}{$\begin{array}{l}\mathrm{N}^{\circ} \text { Pensamientos so- } \\
\text { bre futuro de sus aso- } \\
\text { ciados }\end{array}$} & $<10.000$ & 79 & 290,27 \\
\hline & $>10.000$ & 508 & 294,58 \\
\hline & Total & 587 & \\
\hline \multirow{3}{*}{$\begin{array}{l}\mathrm{N}^{\circ} \text { Pensamientos so- } \\
\text { bre futuro discapaci- } \\
\text { tados mayores }\end{array}$} & $<10.000$ & 79 & 276,34 \\
\hline & $>10.000$ & 508 & 296,75 \\
\hline & Total & 587 & \\
\hline \multirow{3}{*}{$\mathbf{N}^{0}$ Consideraciones } & $<10.000$ & 79 & 261,97 \\
\hline & $>10.000$ & 508 & 298,98 \\
\hline & Total & 587 & \\
\hline
\end{tabular}

Tabla 197: Rangos promedio en función del tipo de residencia en número total de preocupaciones y soluciones generales. 


\begin{tabular}{lccccc}
\hline & $\begin{array}{c}\text { U de Mann- } \\
\text { Whitney }\end{array}$ & $\begin{array}{c}\text { W de Wil- } \\
\text { coxon }\end{array}$ & $\mathbf{Z}$ & Sig. & $\boldsymbol{\eta}^{\mathbf{2}}$ \\
\hline $\mathbf{N}^{\mathbf{0}}$ preocupaciones & 17469,000 & 20629,000 & $-1,857$ &, 063 & $-0,08$ \\
$\mathbf{N}^{\mathbf{0}}$ demandas de asociados & 17105,000 & 20265,000 & $-2,121$ &, 034 & $-0,09$ \\
$\mathbf{N}^{\mathbf{o}}$ soluciones & 18633,500 & 21793,500 & $-1,026$ &, 305 & $-0,04$ \\
$\mathbf{N}^{\mathbf{o}}$ apoyos institucionales & 16223,000 & 19383,000 & $-2,769$ &, 006 & $-0,11$ \\
$\mathbf{N}^{\mathbf{0}}$ pensamientos futuro asociados & 19771,000 & 22931,000 & $-0,217$ &, 828 & 0,00 \\
$\mathbf{N}^{\mathbf{0}}$ pensamientos futuro PcD mayo- & 18670,500 & 21830,500 & $-1,029$ &, 304 & $-0,04$ \\
res & 17535,500 & 20695,500 & $-2,446$ &, 014 & $-0,10$ \\
$\mathbf{N}^{\mathbf{0}}$ consideraciones & \multicolumn{7}{c}{ Nota: el tamaño del efecto $\left(\eta^{2}\right)$ debe interpretarse en valor absoluto. } & &
\end{tabular}

Tabla 198: Estadísticos de contraste en función de la residencia en número total de necesidades generales. Muestra de profesionales.

\begin{tabular}{|c|c|c|c|}
\hline & Residencia & $\mathbf{N}$ & Rango promedio \\
\hline \multirow{3}{*}{ Salud personal } & $<10.000$ & 79 & 268,97 \\
\hline & $>10.000$ & 508 & 297,89 \\
\hline & Total & 587 & \\
\hline \multirow{3}{*}{ Recursos económicos } & $<10.000$ & 79 & 294,36 \\
\hline & $>10.000$ & 508 & 293,94 \\
\hline & Total & 587 & \\
\hline \multirow{3}{*}{ Recursos sanitarios } & $<10.000$ & 79 & 259,25 \\
\hline & $>10.000$ & 508 & 299,40 \\
\hline & Total & 587 & \\
\hline \multirow{3}{*}{$\begin{array}{l}\text { Recursos servicios so- } \\
\text { ciales }\end{array}$} & $<10.000$ & 79 & 264,03 \\
\hline & $>10.000$ & 508 & 298,66 \\
\hline & Total & 587 & \\
\hline \multirow{3}{*}{ Existencia de barreras } & $<10.000$ & 79 & 282,82 \\
\hline & $>10.000$ & 508 & 295,74 \\
\hline & Total & 587 & \\
\hline \multirow{3}{*}{ Otras } & $<10.000$ & 79 & 270,03 \\
\hline & $>10.000$ & 508 & 297,73 \\
\hline & Total & 587 & \\
\hline
\end{tabular}

Tabla 199: Rangos promedio en función del tipo de residencia en número total de preocupaciones y soluciones generales. Muestra de los profesionales. 


\begin{tabular}{lccccc}
\hline & $\begin{array}{c}\text { U de Mann- } \\
\text { Whitney }\end{array}$ & $\begin{array}{c}\text { W de Wil- } \\
\text { coxon }\end{array}$ & $\mathbf{Z}$ & Sig. & $\boldsymbol{\eta}^{2}$ \\
\hline $\mathbf{N}^{\mathbf{0}}$ salud personal & 18088,500 & 21248,500 & $-1,452$ &, 146 & $-0,06$ \\
$\mathbf{N}^{\mathbf{0}}$ recursos económicos & 20037,500 & 149323,500 & $-0,021$ &, 983 & 0,00 \\
$\mathbf{N}^{\mathbf{0}}$ recursos sanitarios & 17320,500 & 20480,500 & $-2,003$ &, 045 & $-0,08$ \\
$\mathbf{N}^{\mathbf{0}}$ recursos servicios sociales & 17698,000 & 20858,000 & $-1,723$ &, 085 & $-0,07$ \\
$\mathbf{N}^{\mathbf{0}}$ existencia de barreras & 19182,500 & 22342,500 & $-0,648$ &, 517 & $-0,03$ \\
$\mathbf{N}^{\mathbf{0}}$ otras preocupaciones & 18172,000 & 21332,000 & $-1,371$ &, 171 & $-0,06$ \\
\hline
\end{tabular}

Nota: el tamaño del efecto $\left(\eta^{2}\right)$ debe interpretarse en valor absoluto.

Tabla 200: Estadísticos de contraste en función de la residencia en número total de preocupaciones específicas. Muestra de profesionales.

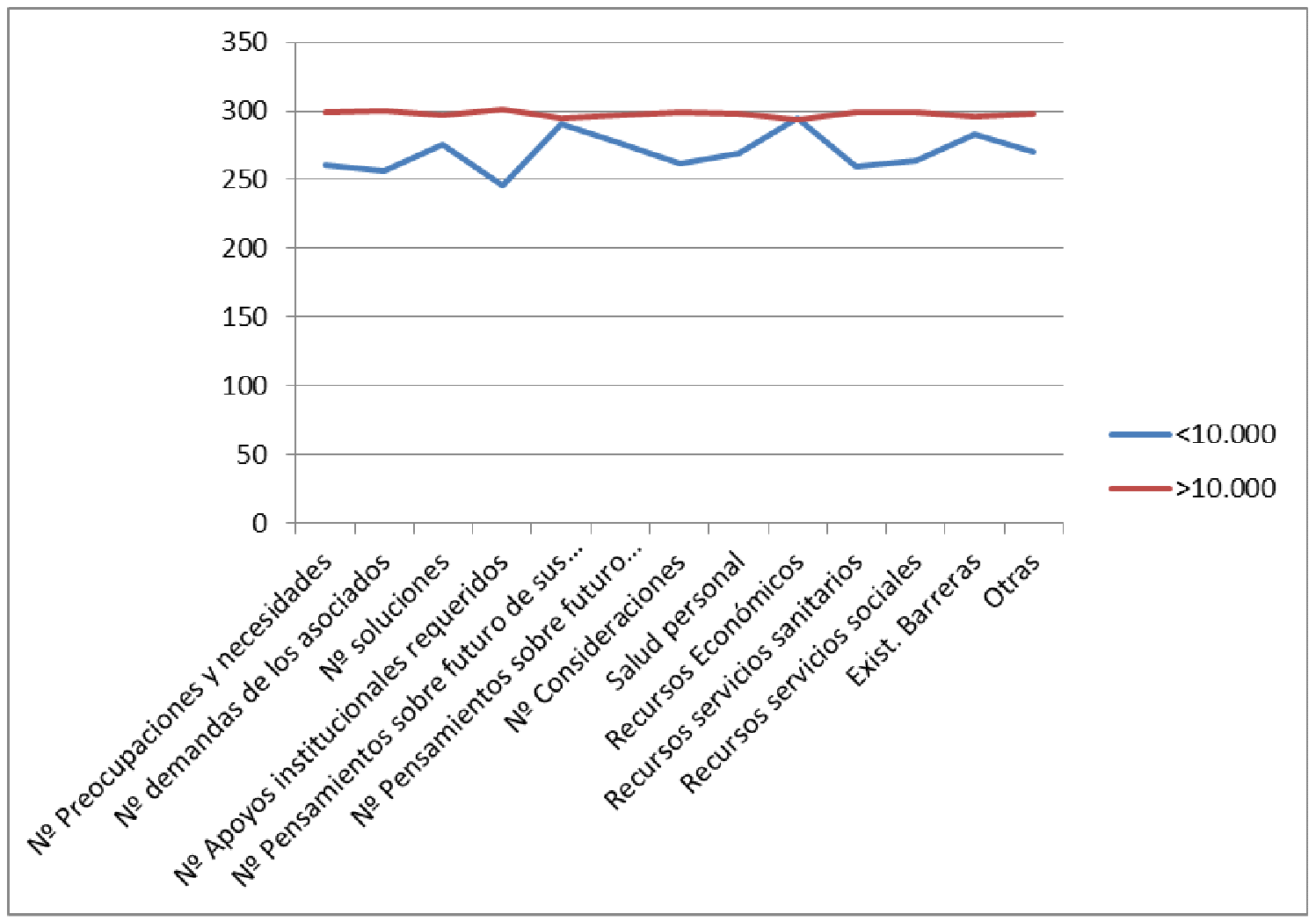

Gráfico 23: Rangos promedio en función de la residencia en número total de preocupaciones y necesidades específicas. Muestra de profesionales. 


\begin{tabular}{|c|c|c|}
\hline PcDID & VARIABLES & $\begin{array}{c}\text { Residencia } \\
<\mathbf{1 0 . 0 0 0} \text { habitantes } \\
>\mathbf{1 0 . 0 0 0} \text { habitantes }\end{array}$ \\
\hline \multirow{13}{*}{$\begin{array}{l}\text { TODOS } \\
\mathbf{N}=587\end{array}$} & $\mathrm{~N}^{\mathrm{o}}$ preoc y necesidades & $\mathrm{NO}$ \\
\hline & $\mathrm{N}^{\circ}$ demandas asociados & $\mathrm{SI}+>10.000$ \\
\hline & $\mathrm{N}^{\circ}$ apoyos institucionales & SI +>10.000 \\
\hline & $\mathrm{N}^{\mathrm{o}}$ soluciones & $\mathrm{NO}$ \\
\hline & $\mathrm{N}^{\circ}$ pensam futuro asociados & NO \\
\hline & $\mathrm{N}^{\circ}$ pensam futuro PcD mayores & NO \\
\hline & $\mathbf{N}^{\mathbf{o}}$ otras consideraciones & SI: +>10.000 \\
\hline & $\mathrm{N}^{\circ}$ necesidades salud personal & $\mathrm{NO}$ \\
\hline & $\mathrm{N}^{\circ}$ necesidades recursos económicos & $\mathrm{NO}$ \\
\hline & $\begin{array}{l}N^{o} \text { necesidades recursos servicios sanita- } \\
\text { rios }\end{array}$ & $\mathrm{SI}+>10.000$ \\
\hline & $\mathrm{N}^{\circ}$ necesidades recursos servicios sociales & $\mathrm{NO}$ \\
\hline & $\mathrm{N}^{\circ}$ necesidades existencia de barreras & $\mathrm{NO}$ \\
\hline & $\mathrm{N}^{\mathrm{o}}$ otras necesidades & $\mathrm{NO}$ \\
\hline
\end{tabular}

Nota: $\mathrm{NO}=$ no hay diferencias estadísticamente significativas; SI: hay diferencias estadísticamente significativas; + seguido del grupo indica dónde se encuentran mayores rangos promedio.

Tabla 201: Resumen de diferencias en función de la residencia. Muestra de profesionales.

\subsubsection{Resumen}

El lugar de residencia tiene influencia sobre el número de demandas de los asociados, el número de apoyos institucionales requeridos, el número de consideraciones y sobre el número de necesidades sobre los recursos de servicios sanitarios señalados por los profesionales.

\subsubsection{Variable tipo de institución}

\subsubsection{Introducción}

En lo referente al tipo de institución, la muestra se agrupó en función de si se trataba de una asociación, una residencia, un centro u otro tipo. 


\subsubsection{Resultados sobre la variable tipo de institución}

La prueba Kruskal-Wallis indica que existen diferencias significativas $(\mathrm{p}<0,05)$ en el número de preocupaciones, demandas de los asociados, soluciones, apoyos institucionales requeridos y de pensamientos de futuro, tanto de los asociados como de las PcD mayores (tabla 203). Los profesionales del grupo de otras instituciones tuvieron mayores puntuaciones en el número de preocupaciones, soluciones, demandas de los asociados, apoyos institucionales requeridos y en los pensamientos de futuro sobre las PcD mayores; mientras que los profesionales del grupo de asociación puntuaron un mayor número de pensamientos de futuro de las PcD mayores (tabla 202). 


\begin{tabular}{|c|c|c|c|}
\hline & Tipo de institución & $\mathbf{N}$ & Rango promedio \\
\hline \multirow{5}{*}{$\begin{array}{l}\mathrm{N}^{\circ} \text { Preocupaciones y } \\
\text { necesidades }\end{array}$} & Asociación & 180 & 331,23 \\
\hline & Residencia & 69 & 313,31 \\
\hline & Centro & 301 & 252,13 \\
\hline & Otros & 37 & 417,46 \\
\hline & Total & 587 & \\
\hline \multirow{5}{*}{$\begin{array}{l}\mathrm{N}^{0} \text { demandas de los } \\
\text { asociados }\end{array}$} & Asociación & 180 & 338,13 \\
\hline & Residencia & 69 & 254,67 \\
\hline & Centro & 301 & 262,69 \\
\hline & Otros & 37 & 407,41 \\
\hline & Total & 587 & \\
\hline \multirow{5}{*}{$\mathbf{N}^{0}$ soluciones } & Asociación & 180 & 331,16 \\
\hline & Residencia & 69 & 278,62 \\
\hline & Centro & 301 & 260,32 \\
\hline & Otros & 37 & 415,93 \\
\hline & Total & 587 & \\
\hline \multirow{5}{*}{$\begin{array}{l}\mathrm{N}^{\circ} \text { Apoyos institucio- } \\
\text { nales requeridos }\end{array}$} & Asociación & 180 & 334,08 \\
\hline & Residencia & 69 & 268,26 \\
\hline & Centro & 301 & 263,31 \\
\hline & Otros & 37 & 396,72 \\
\hline & Total & 587 & \\
\hline \multirow{5}{*}{$\begin{array}{l}N^{\circ} \text { Pensamientos so- } \\
\text { bre futuro de sus aso- } \\
\text { ciados }\end{array}$} & Asociación & 180 & 348,63 \\
\hline & Residencia & 69 & 304,03 \\
\hline & Centro & 301 & 254,80 \\
\hline & Otros & 37 & 328,39 \\
\hline & Total & 587 & \\
\hline \multirow{5}{*}{$\begin{array}{l}N^{\circ} \text { Pensamientos so- } \\
\text { bre futuro discapaci- } \\
\text { tados mayores }\end{array}$} & Asociación & 180 & 352,21 \\
\hline & Residencia & 69 & 273,64 \\
\hline & Centro & 301 & 253,77 \\
\hline & Otros & 37 & 376,07 \\
\hline & Total & 587 & \\
\hline \multirow{5}{*}{$\mathbf{N}^{\circ}$ Consideraciones } & Asociación & 180 & 287,24 \\
\hline & Residencia & 69 & 290,20 \\
\hline & Centro & 301 & 294,07 \\
\hline & Otros & 37 & 333,41 \\
\hline & Total & 587 & \\
\hline
\end{tabular}

Tabla 202: Rangos promedios en función del tipo de institución en número de preocupaciones y soluciones generales. Muestra de profesionales. 


\begin{tabular}{lcccc}
\hline & Chi-cuadrado & gl & Sig. & $\boldsymbol{\eta}^{\mathbf{2}}$ \\
\hline $\mathbf{N}^{\mathbf{0}}$ preocupaciones & 47,797 & 3 &, 000 & $-0,12$ \\
$\mathbf{N}^{\mathbf{0}}$ demandas de asociados & 43,098 & 3 &, 000 & $-0,14$ \\
$\mathbf{N}^{\mathbf{0}}$ soluciones & 40,543 & 3 &, 000 & $-0,09$ \\
$\mathbf{N}^{\mathbf{0}}$ apoyos institucionales & 35,813 & 3 &, 000 & $-0,13$ \\
$\mathbf{N}^{\mathbf{0}}$ pensamientos futuro aso- & 38,773 & 3 &, 000 & $-0,09$ \\
ciados & 51,067 & 3 &, 000 & $-0,13$ \\
$\mathbf{N}^{\mathbf{0}}$ pensamientos futuro PcD & & & & \\
mayores & 4,259 & 3 &, 235 & $-0,04$ \\
$\mathbf{N}^{\mathbf{0}}$ consideraciones &
\end{tabular}

Nota: el tamaño del efecto $\left(\eta^{2}\right)$ debe interpretarse en valor absoluto.

Tabla 203: Estadísticos de contraste en función del tipo de institución en número total de preocupaciones y soluciones generales. Muestra de profesionales.

En cuanto a las necesidades específicas (tabla 205), en todas ellas hubo diferencias estadísticamente significativas $(\mathrm{p}<0,05)$. En todas ellas, el grupo de profesionales de otros tipos de instituciones señalaron un mayor número de preocupaciones (tabla 204).

En el gráfico 24 aparecen los rangos promedio de los distintos grupos de instituciones en cada una de las variables criterio estudiadas.

En la tabla 206 se resume la significatividad de las puntuaciones comentadas. 


\begin{tabular}{|c|c|c|c|}
\hline & $\begin{array}{l}\text { Tipo de institu- } \\
\text { ción }\end{array}$ & $\mathbf{N}$ & $\begin{array}{c}\text { Rango pro- } \\
\text { medio }\end{array}$ \\
\hline \multirow{5}{*}{ Salud personal } & Asociación & 180 & 330,58 \\
\hline & Residencia & 69 & 330,61 \\
\hline & Centro & 301 & 251,75 \\
\hline & Otros & 37 & 391,54 \\
\hline & Total & 587 & \\
\hline \multirow{5}{*}{$\begin{array}{l}\text { Recursos econó- } \\
\text { micos }\end{array}$} & Asociación & 180 & 341,83 \\
\hline & Residencia & 69 & 271,70 \\
\hline & Centro & 301 & 255,22 \\
\hline & Otros & 37 & 418,41 \\
\hline & Total & 587 & \\
\hline \multirow{5}{*}{$\begin{array}{l}\text { Recursos sanita- } \\
\text { rios }\end{array}$} & Asociación & 180 & 315,48 \\
\hline & Residencia & 69 & 299,17 \\
\hline & Centro & 301 & 265,22 \\
\hline & Otros & 37 & 414,03 \\
\hline & Total & 587 & \\
\hline \multirow{5}{*}{$\begin{array}{l}\text { Recursos servi- } \\
\text { cios sociales }\end{array}$} & Asociación & 180 & 323,20 \\
\hline & Residencia & 69 & 284,63 \\
\hline & Centro & 301 & 261,36 \\
\hline & Otros & 37 & 435,00 \\
\hline & Total & 587 & \\
\hline \multirow{5}{*}{$\begin{array}{l}\text { Existencia de ba- } \\
\text { rreras }\end{array}$} & Asociación & 180 & 315,31 \\
\hline & Residencia & 69 & 340,11 \\
\hline & Centro & 301 & 254,27 \\
\hline & Otros & 37 & 427,55 \\
\hline & Total & 587 & \\
\hline \multirow{5}{*}{ Otras } & Asociación & 180 & 343,79 \\
\hline & Residencia & 69 & 269,07 \\
\hline & Centro & 301 & 257,18 \\
\hline & Otros & 37 & 397,82 \\
\hline & Total & 587 & \\
\hline
\end{tabular}

Tabla 204: Rangos promedio en función del tipo de institución en tipo de necesidades específicas. Muestra de profesionales. 


\begin{tabular}{|c|c|c|c|c|}
\hline & $\begin{array}{c}\text { Chi- } \\
\text { cuadrado }\end{array}$ & gl & Sig. & $\eta^{2}$ \\
\hline $\mathbf{N}^{\circ}$ salud personal & 45,070 & 3 & 000, & $-0,12$ \\
\hline$N^{0}$ recursos económicos & 54,819 & 3 &, 000 & $-0,16$ \\
\hline $\mathrm{N}^{0}$ recursos sanitarios & 31,551 & 3 &, 000 & $-0,12$ \\
\hline $\mathrm{N}^{0}$ recursos s. sociales & 44,003 & 3 &, 000 & $-0,15$ \\
\hline $\mathbf{N}^{0}$ existencia barreras & 50,166 & 3 &, 000 & $-0,15$ \\
\hline $\mathbf{N}^{\circ}$ otras preocupaciones & 46,393 & 3 &, 000 & $-0,13$ \\
\hline
\end{tabular}

Nota: el tamaño del efecto $\left(\eta^{2}\right)$ debe interpretarse en valor absoluto.

Tabla 205: Estadísticos de contraste en función del tipo de institución en número total de preocupaciones específicas. Muestra de profesionales.

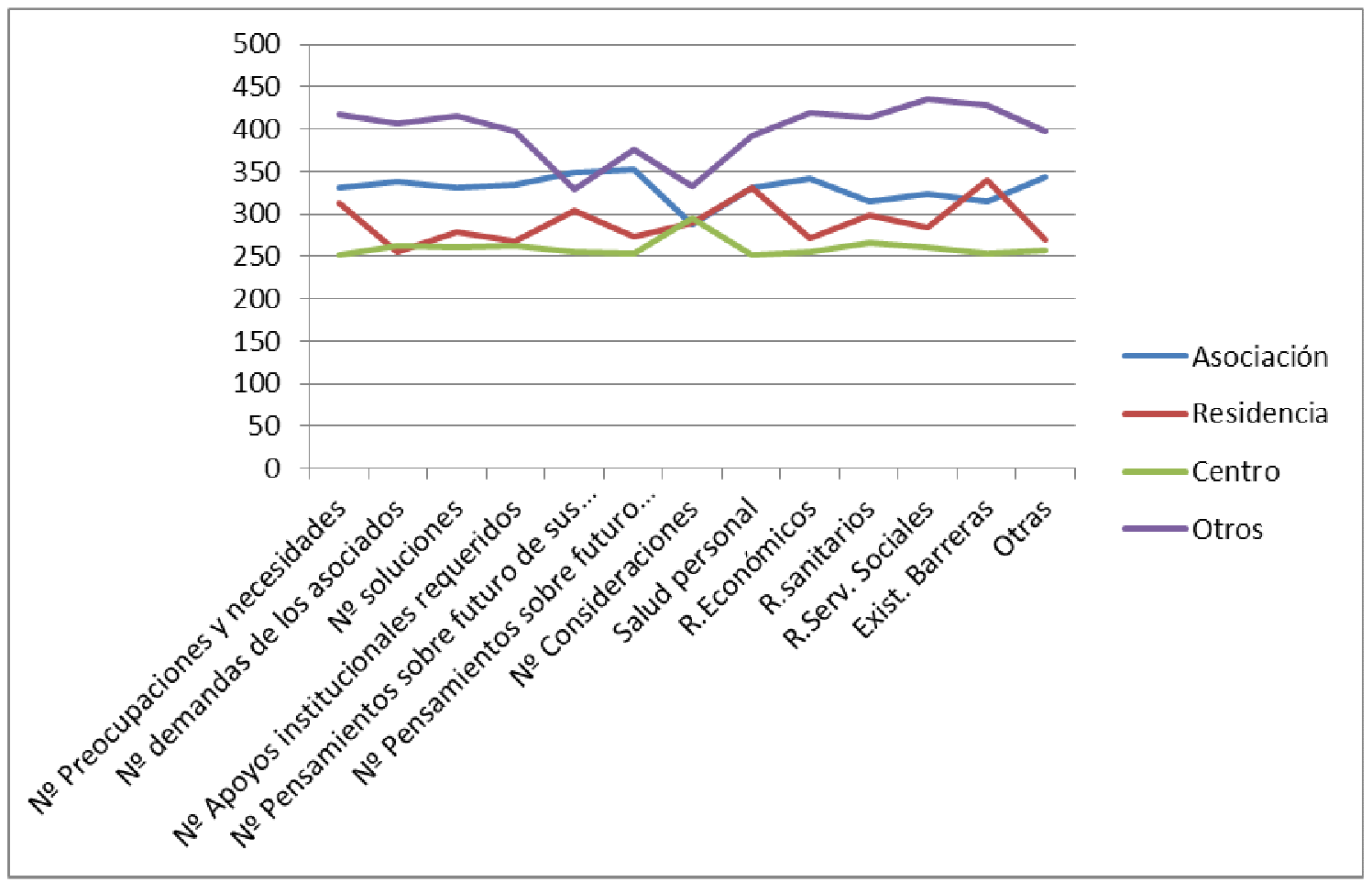

Gráfico 24: Rangos promedio en función del tipo de institución en número total de preocupaciones y necesidades específicas. Muestra de profesionales. 


\begin{tabular}{|c|c|c|}
\hline PcDID & VARIABLES & $\begin{array}{c}\text { TIPO INSTITUCIÓN } \\
\text { Asociación } \\
\text { Residencia } \\
\text { Centro } \\
\text { Otros }\end{array}$ \\
\hline \multirow{13}{*}{$\begin{array}{c}\text { TODOS } \\
\text { N=587 } \\
\text { Asociación }= \\
180 \\
\text { Residencia }=\mathbf{6 9} \\
\text { Centro }=\mathbf{3 0 1} \\
\text { Otros }=\mathbf{3 7}\end{array}$} & $\mathrm{N}^{0}$ preoc y necesidades & SI:+Otros \\
\hline & $\mathbf{N}^{0}$ demandas asociados & SI:+Otros \\
\hline & $\mathrm{N}^{0}$ apoyos institucionales & SI:+Otros \\
\hline & $\mathbf{N}^{0}$ soluciones & SI:+Otros \\
\hline & $\mathbf{N}^{0}$ pensam futuro asociados & SI:+Asociación \\
\hline & $\mathrm{N}^{0}$ pensam futuro PcD mayores & SI:+Otros \\
\hline & $\mathrm{N}^{\circ}$ otras consideraciones & NO \\
\hline & $\mathbf{N}^{0}$ necesidades salud personal & SI:+Otros \\
\hline & $\mathrm{N}^{0}$ necesidades recursos económicos & SI:+Otros \\
\hline & $\begin{array}{l}N^{0} \text { necesidades recursos servicios sanita- } \\
\text { rios }\end{array}$ & SI:+Otros \\
\hline & $N^{0}$ necesidades recursos servicios sociales & SI:+Otros \\
\hline & $\mathbf{N}^{0}$ necesidades existencia de barreras & SI:+Otros \\
\hline & $\mathbf{N}^{0}$ otras necesidades & SI:+Otros \\
\hline
\end{tabular}

Nota: $\mathrm{NO}=$ no hay diferencias estadísticamente significativas; SI: hay diferencias estadísticamente significativas; + seguido del grupo indica dónde se encuentran mayores rangos promedio.

Tabla 206: Resumen de diferencias en función del tipo de institución. Muestra de profesionales.

\subsubsection{Resumen}

La variable tipo de institución ha influido en todas las variables excepto en el número de otras consideraciones señaladas por los profesionales. En la tabla 207 se presenta el resumen de los resultados significativos en este apartado. 


\begin{tabular}{|l|l|l|}
\hline \multicolumn{1}{|c|}{ VARIABLES } & \multicolumn{1}{|c|}{ RESIDENCIA } & \multicolumn{1}{c|}{ TIPO INSTITU- } \\
CIÓN
\end{tabular}

Tabla 207: Resumen de los resultados significativos en la muestra institucional.

\section{PERSONAS, FAMILIAS Y PROFESIONALES: CONVERGENCIAS Y \\ DIVERGENCIAS}

\subsection{INTRODUCCIÓN}

En este apartado se trata de analizar en qué puntos han coincidido o no lo han hecho las tres muestras del estudio, es decir, las PcDID, sus familias y los profesionales que les atienden. En primer lugar se exponen las necesidades percibidas por los tres grupos de la muestra, seguidas de las soluciones, los apoyos institucionales requeridos y los pensamientos de futuro. Finalmente se trata un epígrafe sobre las respuestas que han superado el $40 \%$ de elección.

\subsection{NECESIDADES}

En primer lugar, en lo referente a las preocupaciones y necesidades percibidas (tabla 208), las PcDID señalaron un mayor número de preocupaciones sobre salud per- 
sonal, seguidas de preocupaciones sobre la existencia de barreras, los recursos de servicios sociales, otras necesidades, recursos sanitarios y recursos económicos.

Las familias por su parte, señalaron en su mayoría necesidades de salud personal, seguidas de las de recursos de servicios sociales, existencia de barreras, otras necesidades, recursos de servicios sanitarios y por último los recursos económicos.

Los profesionales han mostrado preocupación en primer lugar por otras necesidades, seguidas de las de salud personal, existencia de barreras, recursos de servicios sociales, recursos de servicios sanitarios y recursos de servicios sociales.

Básicamente, las tres muestras coinciden en señalar la importancia de las necesidades de salud personal, existencia de barreras y necesidades sobre los recursos de los servicios sociales fundamentalmente; mientras que las tres muestras han señalado menor número de preocupaciones sobre recursos económicos.

En el gráfico 24 podemos observar estas tendencias gráficamente.

\begin{tabular}{lccc}
\hline $\begin{array}{l}\text { Preocupaciones y necesidades } \\
\text { percibidas }\end{array}$ & Personas & Familias & Profesionales \\
\hline Salud personal & 2007 & 1413 & 1462 \\
Recursos económicos & 1133 & 844 & 934 \\
Recursos servicios sanitarios & 1322 & 1059 & 1181 \\
Recursos servicios sociales & 1511 & 1382 & 1240 \\
Existencia de barreras & 1601 & 1141 & 1328 \\
Otras necesidades & 1452 & 1101 & 1833 \\
\hline \multicolumn{1}{c}{ Respuestas totales } & $\mathbf{9 0 2 6}$ & $\mathbf{6 9 4 0}$ & $\mathbf{7 9 7 8}$ \\
\hline \multicolumn{1}{c}{$\mathbf{N}$} & $\mathbf{1 1 7 3}$ & $\mathbf{6 0 6}$ & $\mathbf{5 8 7}$ \\
\hline
\end{tabular}

Tabla 208: Frecuencias de las necesidades específicas señaladas por la muestra de PcDID, familias y profesionales. 


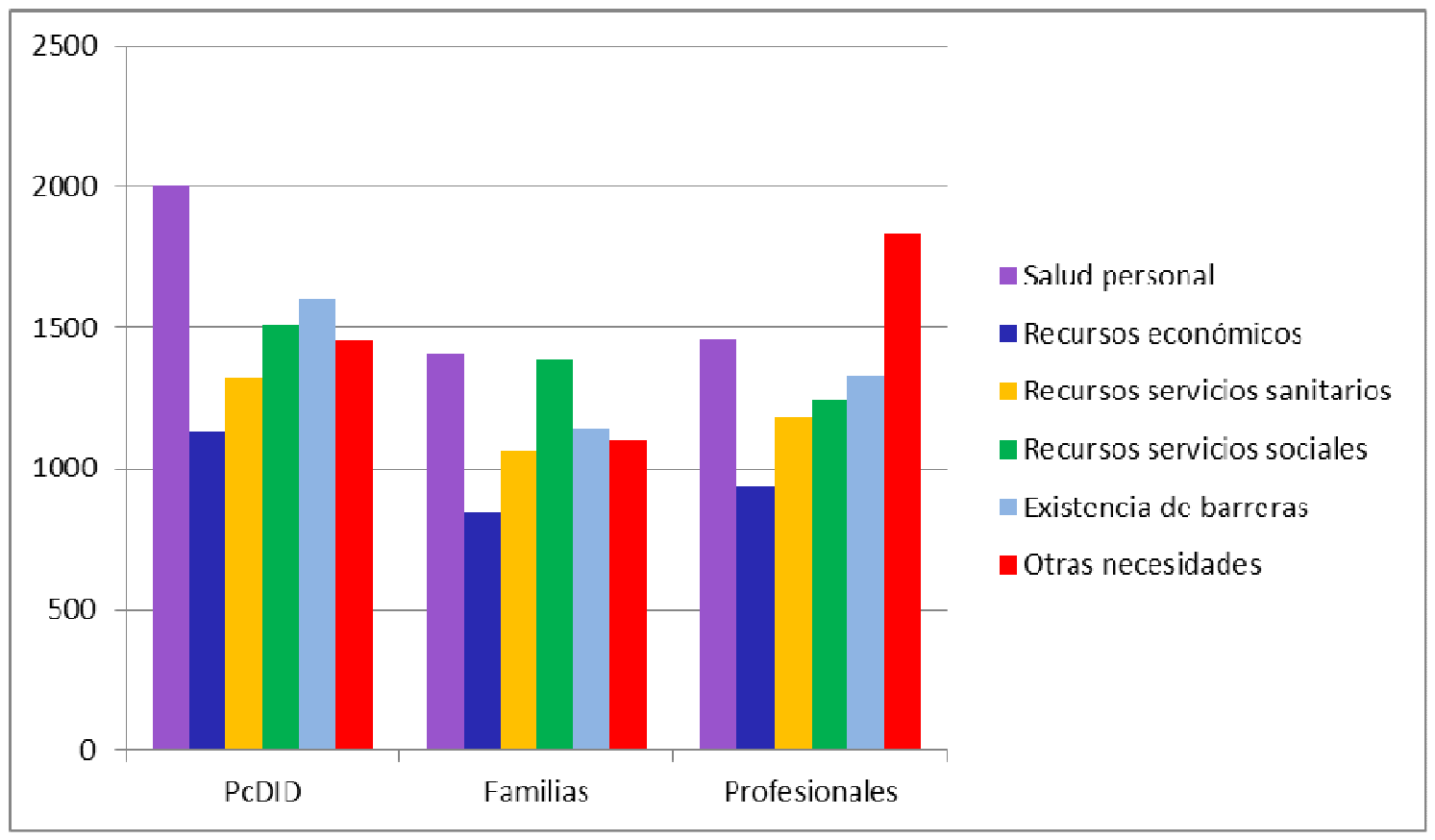

Gráfico 24: Frecuencia de las necesidades específicas señaladas por la muestra de PcDID, familias y profesionales.

\subsubsection{Necesidades de salud personal}

En cuanto a las necesidades sobre salud personal (tabla 209), parecen ser de gran relevancia para los tres grupos el estado de salud general, los cuidados personales diarios, las limitaciones funcionales personales y la dependencia, no existiendo enormes diferencias entre los porcentajes de casos entre los tres grupos. 


\begin{tabular}{|c|c|c|c|}
\hline Salud personal & Personas & Familias & Profesionales \\
\hline Estado de salud general & $63,0 \%$ & $64,8 \%$ & $74,2 \%$ \\
\hline Cuidados personales diarios & $33,6 \%$ & $43,8 \%$ & $68,8 \%$ \\
\hline Limitaciones funcionales personales & $30,0 \%$ & $40,6 \%$ & $63,8 \%$ \\
\hline Dependencia & $27,9 \%$ & $47,5 \%$ & $63,0 \%$ \\
\hline Dificultades para tomar la medicación & $25,6 \%$ & $10,9 \%$ & $35,3 \%$ \\
\hline Dificultades para acudir al tratamiento & $9,9 \%$ & $6,0 \%$ & $21,4 \%$ \\
\hline Dolores & $8,0 \%$ & $19,4 \%$ & $31,0 \%$ \\
\hline Aceptación de mi situación & $3,5 \%$ & $9,3 \%$ & $32,6 \%$ \\
\hline Otras & $6,7 \%$ & $10,7 \%$ & $10,4 \%$ \\
\hline Casos perdidos & 213 & 44 & 222 \\
\hline Casos válidos & 960 & 562 & 365 \\
\hline Respuestas totales & 2000 & 1421 & 1462 \\
\hline Porcentaje de casos & $208,03 \%$ & $252,8 \%$ & $400,5 \%$ \\
\hline
\end{tabular}

Tabla 209: Porcentajes de casos de preocupaciones sobre salud personal de las tres muestras.

\subsubsection{Necesidades sobre recursos económicos}

En cuanto a las preocupaciones sobre recursos económicos (tabla 210), las familias y las PcDID señalan mayoritariamente la pensión, mientras que los profesionales señalan las subvenciones. Los profesionales asimismo, dan mayor relevancia que las PcDID y las familias al encontrar un puesto de trabajo. En las tres muestras se da relevancia, aunque en distintos grados, a la situación económica familiar y a la independencia económica. 


\begin{tabular}{|c|c|c|c|}
\hline Recursos económicos & Personas & Familias & Profesionales \\
\hline Pensión & $60,1 \%$ & $63,4 \%$ & $36,5 \%$ \\
\hline Situación económica familiar & $20,4 \%$ & $25,9 \%$ & $45,3 \%$ \\
\hline Independencia económica & $20,1 \%$ & $27,9 \%$ & $42,1 \%$ \\
\hline Subvenciones & $12,6 \%$ & $26,1 \%$ & $59,7 \%$ \\
\hline Encontrar un puesto de trabajo & $10,8 \%$ & $6,7 \%$ & $40,3 \%$ \\
\hline Incapacidad laboral & $8,5 \%$ & $8,3 \%$ & $19,7 \%$ \\
\hline Otras & $8,3 \%$ & $8,3 \%$ & $5,3 \%$ \\
\hline Casos perdidos & 369 & 101 & 212 \\
\hline Casos válidos & 804 & 505 & 375 \\
\hline Respuestas totales & 1132 & 842 & 934 \\
\hline Porcentaje de casos & $140,8 \%$ & $166,7 \%$ & $249,1 \%$ \\
\hline
\end{tabular}

Tabla 210: Porcentajes de casos de preocupaciones sobre recursos económicos de las tres muestras.

\subsubsection{Necesidades sobre recursos de los servicios sanitarios}

En lo que respecta a las necesidades sobre los recursos de servicios sanitarios (tabla 211), los profesionales dan especial relevancia a la calidad de la asistencia sanitaria, si bien también es puntuada en buena medida por las PcDID y sus familias. Las tres muestras nuevamente coinciden en señalar de forma similar la asistencia sanitaria hospitalaria, así como la domiciliaria. Los profesionales a su vez, señalan de forma llamativamente superior la asistencia en salud mental como otra de las necesidades importantes, en mayor medida que las PcDID y sus familias. 


\begin{tabular}{|c|c|c|c|}
\hline Recursos servicios sanitarios & Personas & Familias & Profesionales \\
\hline Calidad de la asistencia sanitaria & $32,7 \%$ & $38,3 \%$ & $59,6 \%$ \\
\hline Asistencia sanitaria hospitalaria & $31,7 \%$ & $30,3 \%$ & $32,5 \%$ \\
\hline Asistencia sanitaria domiciliaria & $26,2 \%$ & $25,8 \%$ & $23,2 \%$ \\
\hline Asistencia en salud mental & $23,5 \%$ & $33,1 \%$ & $51,2 \%$ \\
\hline Más y mejores instalaciones sanitarias & $22,5 \%$ & $31,0 \%$ & $26,6 \%$ \\
\hline Tratamiento de fisioterapia & $20,2 \%$ & $20,4 \%$ & $37,9 \%$ \\
\hline Dispositivos de apoyo y protésicos & $16,4 \%$ & $18,7 \%$ & $28,8 \%$ \\
\hline Falta de información sobre estos recursos & $12,8 \%$ & $24,1 \%$ & $20,7 \%$ \\
\hline Otras & $7,0 \%$ & $6,9 \%$ & $10,3 \%$ \\
\hline Casos perdidos & 485 & 141 & 181 \\
\hline Casos válidos & 688 & 465 & 406 \\
\hline Respuestas totales & 1328 & 1063 & 1181 \\
\hline Porcentaje de casos & $193 \%$ & $228,6 \%$ & $290,9 \%$ \\
\hline
\end{tabular}

Tabla 211: Porcentajes de casos de preocupaciones sobre recursos de servicios sanitarios de las tres muestras.

\subsubsection{Necesidades sobre recursos de servicios sociales}

En cuanto a las necesidades sobre recursos de servicios sociales (tabla 212), las tres muestras coinciden en señalar llamativamente los servicios de apoyo al ocio y tiempo libre. Los profesionales destacan por encima del resto de muestras al señalar el incremento del número y la calidad de instalaciones sociales y la calidad de la asistencia social; pero coinciden con las familias a la hora de señalar los servicios de alojamiento y la ayuda a domicilio. 


\begin{tabular}{|c|c|c|c|}
\hline Recursos servicios sociales & Personas & Familias & Profesionales \\
\hline Servicios de apoyo al ocio y tiempo libre & $52,7 \%$ & $47,0 \%$ & $50,4 \%$ \\
\hline Ayuda a domicilio & $26,0 \%$ & $38,3 \%$ & $25,2 \%$ \\
\hline Más y mejores instalaciones sociales & $23,5 \%$ & $31,6 \%$ & $42,5 \%$ \\
\hline Servicios de alojamiento & $23,0 \%$ & $40,3 \%$ & $40,3 \%$ \\
\hline Calidad de la asistencia social & $20,8 \%$ & $26,8 \%$ & $49,3 \%$ \\
\hline Apoyo en las gestiones administrativas & $19,9 \%$ & $20,5 \%$ & $24,3 \%$ \\
\hline Falta de información sobre estos recursos & $15,0 \%$ & $23,5 \%$ & $19,0 \%$ \\
\hline Asesoramiento jurídico & $9,2 \%$ & $22,6 \%$ & $17,0 \%$ \\
\hline Otras & $4,4 \%$ & $5,2 \%$ & $6,2 \%$ \\
\hline Casos perdidos & 400 & 65 & 135 \\
\hline Casos válidos & 773 & 541 & 452 \\
\hline Respuestas totales & 1504 & 1383 & 1240 \\
\hline Porcentaje de casos & $194,6 \%$ & $255,6 \%$ & $274,3 \%$ \\
\hline
\end{tabular}

Tabla 212: Porcentajes de casos de preocupaciones sobre recursos de servicios sociales de las tres muestras.

\subsubsection{Necesidades sobre la existencia de barreras}

En lo referente a las necesidades sobre la existencia de barreras (tabla 213), todas las muestras dan especial importancia a las barreras sociales, así como a la aceptación por parte de la sociedad. Los profesionales también señalan las barreras arquitectónicas, la facilidad de transporte y la aceptación por parte de la familia en mayor medida que las PcDID y sus familias. 


\begin{tabular}{|c|c|c|c|}
\hline Existencia de barreras & Personas & Familias & Profesionales \\
\hline Barreras sociales & $42,7 \%$ & $42,4 \%$ & $58,5 \%$ \\
\hline Aceptación por parte de la sociedad & $36,8 \%$ & $43,2 \%$ & $49,2 \%$ \\
\hline Barreras arquitectónicas & $30,7 \%$ & $38,1 \%$ & $49,5 \%$ \\
\hline Facilidad de transporte & $28,6 \%$ & $34,2 \%$ & $47,9 \%$ \\
\hline Escasez de voluntariado & $19,9 \%$ & $25,9 \%$ & $31,1 \%$ \\
\hline Aceptación por parte de la familia & $19,1 \%$ & $15,5 \%$ & $43,1 \%$ \\
\hline Ayudas técnicas & $12,3 \%$ & $14,9 \%$ & $38,3 \%$ \\
\hline Accesibilidad a edificios públicos & $11,3 \%$ & $14,7 \%$ & $33,2 \%$ \\
\hline Otras & $3,3 \%$ & $3,7 \%$ & $2,4 \%$ \\
\hline Casos perdidos & 391 & 115 & 211 \\
\hline Casos válidos & 782 & 491 & 376 \\
\hline Respuestas totales & 1601 & 1141 & 1328 \\
\hline Porcentaje de casos & $204,7 \%$ & $232,4 \%$ & $353,2 \%$ \\
\hline
\end{tabular}

Tabla 213: Porcentajes de casos de preocupaciones sobre existencia de barreras de las tres muestras.

\subsubsection{Otras necesidades}

En cuanto a otras necesidades (tabla 214), todos coinciden en señalar el dónde y con quién vivir en el futuro como una preocupación importante.

\begin{tabular}{|c|c|c|c|}
\hline Otras necesidades & Personas & Familias & Profesionales \\
\hline Dónde y con quién vivir en el futuro & $47,4 \%$ & $63,0 \%$ & $47,2 \%$ \\
\hline Escasez de relaciones personales & $33,8 \%$ & $27,1 \%$ & $39,3 \%$ \\
\hline Futuro de la familia & $32,5 \%$ & $34,1 \%$ & $28,7 \%$ \\
\hline Salida del domicilio familiar & $23,8 \%$ & $28,3 \%$ & $27,6 \%$ \\
\hline Problemas sociales & $11,2 \%$ & $11,1 \%$ & $27,2 \%$ \\
\hline Protección jurídica & $8,1 \%$ & $24,4 \%$ & $19,6 \%$ \\
\hline Avances tecnológicos & $6,0 \%$ & $7,4 \%$ & $17,2 \%$ \\
\hline Problemas del movimiento asociativo & $5,1 \%$ & $11,9 \%$ & $17,7 \%$ \\
\hline Otras & $10,6 \%$ & $6,8 \%$ & $14,8 \%$ \\
\hline Casos perdidos & 369 & 93 & 134 \\
\hline Casos válidos & 804 & 513 & 453 \\
\hline Respuestas totales & 1434 & 1098 & 1833 \\
\hline Porcentaje de casos & $178,4 \%$ & $214 \%$ & $404,7 \%$ \\
\hline
\end{tabular}

Tabla 214: Porcentajes de casos de preocupaciones sobre otras necesidades de las tres muestras. 


\subsection{SOLUCIONES}

En las soluciones (tabla 215), las familias en mayor medida, y las PcDID, dan especial importancia a la subida de las pensiones, mientras que las tres muestras se observa que señalan en una medida considerable los servicios de apoyo al ocio y tiempo libre. También coinciden, si bien en menor medida, en señalar la ayuda para los cuidados personales diarios. 


\section{Soluciones}

Salud personal

Ayuda para cuidados personales diarios

Apoyo a los cuidadores informales

\section{Recursos económicos}

Subida de las pensiones

Incremento de la ayuda familiar

Incremento de las subvenciones

Promoción del empleo protegido

Reserva de puestos de trabajo

Adelantar la jubilación

\section{Recursos asistenciales sanitarios}

Profesionales más especializados

Más y mejores instalaciones sanitarias

Calidad de la asistencia sanitaria

Fisioterapia en la Seguridad Social

Mejora de apoyos y prótesis

\section{Recursos servicios sociales}

Servicios de apoyo al ocio y tiempo libre

Facilidades de transporte

Mejora de los servicios de alojamiento

Mejora de la asistencia a domicilio

Centros de día

Más y mejores instalaciones sociales

Promoción del voluntariado

Calidad de la asistencia social

Incremento de la participación asociativa

\section{Existencia de barreras}

Supresión de barreras arquitectónicas

Aceptación por parte de la sociedad

Promoción de viviendas adaptadas

Programas de cambio de actitudes

Aceptación por parte de la familia

Más y mejores ayudas técnicas

Campañas de imagen

\section{Soluciones comunes}

Garantías de futuro

Asistencia psicológica

Más y mejor información

Apoyo legal y administrativo

Más información sobre recursos

Otras

\begin{tabular}{rccc} 
& $22,4 \%$ & $36,8 \%$ & $27,3 \%$ \\
& $18,4 \%$ & $22,3 \%$ & $28,0 \%$ \\
& $12,4 \%$ & $22,6 \%$ & $18,3 \%$ \\
& $12,3 \%$ & $23,8 \%$ & $17,2 \%$ \\
& $11,1 \%$ & $27,1 \%$ & $19,0 \%$ \\
& $5,8 \%$ & $6,3 \%$ & $14,9 \%$ \\
\hline Casos perdidos & 272 & 22 & 23 \\
Casos válidos & 901 & 584 & 564 \\
Respuestas totales & 5762 & 5125 & 5289 \\
\hline & $639,5 \%$ & $877,6 \%$ & $937,8 \%$
\end{tabular}

\footnotetext{
Porcentaje de casos

$639,5 \%$

Nota: los profesionales eligen también coordinación entre instituciones (31,9\%), programas adecuados de
}

$48,1 \%$

$63,5 \%$

$22,2 \%$

$27,3 \%$

$38,4 \%$

$21,8 \%$

$20,2 \%$

$31,3 \%$

$34,9 \%$

$16,4 \%$

$20,0 \%$

$22,9 \%$

$14,7 \%$

$14,0 \%$

$17,6 \%$

$10,9 \%$

$11,5 \%$

$14,0 \%$

\section{$21,9 \%$}

$25,9 \%$

$31,2 \%$

$21,6 \%$

$26,4 \%$

$23,2 \%$

$19,4 \%$

$26,0 \%$

$27,3 \%$

$15,0 \%$

$21,6 \%$

$20,2 \%$

$10,5 \%$

$13,9 \%$

$13,7 \%$

$41,8 \%$

$44,0 \%$

$37,1 \%$

$22,2 \%$

$25,9 \%$

$23,2 \%$

$20,8 \%$

$32,5 \%$

$25,2 \%$

$20,0 \%$

$25,2 \%$

$20,0 \%$

$19,8 \%$

$28,4 \%$

$19,3 \%$

$17,4 \%$

$30,1 \%$

$23,2 \%$

$15,8 \%$

$29,5 \%$

$18,8 \%$

$15,1 \%$

$19,7 \%$

$24,1 \%$

$9,0 \%$

$13,5 \%$

$19,1 \%$

$21,2 \%$

$25,7 \%$

$29,1 \%$

$18,9 \%$

$26,2 \%$

$27,1 \%$

$15,1 \%$

$21,1 \%$

$32,8 \%$

$13,9 \%$

$18,2 \%$

$24,1 \%$

$12,3 \%$

$12,8 \%$

$23,6 \%$

$10,5 \%$

$15,4 \%$

$16,3 \%$

$7,0 \%$

$11,5 \%$

$12,4 \%$ intervención $(30,3 \%)$ y disminución de la relación profesional/usuario $(9,8 \%)$.

Tabla 215: Porcentajes de casos de soluciones de las tres muestras. 


\subsection{APOYOS INSTITUCIONALES REQUERIDOS}

En lo que respecta a los apoyos institucionales requeridos (tabla 216), los tres grupos señalan el incrementar los recursos de las asociaciones, si bien las familias, y en menor medida las PcDID, también dan relevancia al apoyo de los Ayuntamientos. Los profesionales señalan de forma destacable la necesidad de una mayor coordinación entre las distintas administraciones.

Todos puntúan en porcentajes similares otros apoyos como los apoyos en el entorno, el apoyo de la comunidad, la igualdad de oportunidades o las actividades de formación.

\begin{tabular}{|c|c|c|c|}
\hline Apoyos institucionales requeridos & Personas & Familias & Profesionales \\
\hline $\begin{array}{l}\text { Incrementar los recursos de las asociacio- } \\
\text { nes }\end{array}$ & $42,1 \%$ & $47,7 \%$ & $50,8 \%$ \\
\hline Apoyo de los Ayuntamientos & $36,0 \%$ & $46,6 \%$ & $21,8 \%$ \\
\hline Actividades culturales & $32,1 \%$ & $25,4 \%$ & $13,9 \%$ \\
\hline Apoyos en el entorno & $31,1 \%$ & $28,7 \%$ & $23,9 \%$ \\
\hline $\begin{array}{l}\text { Coordinación entre las distintas adminis- } \\
\text { traciones }\end{array}$ & $29,1 \%$ & $44,2 \%$ & $48,8 \%$ \\
\hline Igualdad de oportunidades & $27,3 \%$ & $27,6 \%$ & $26,7 \%$ \\
\hline Apoyo de la comunidad & $25,9 \%$ & $38,8 \%$ & $21,3 \%$ \\
\hline Actividades de formación & $20,4 \%$ & $23,0 \%$ & $31,5 \%$ \\
\hline Otros & $3,4 \%$ & $5,5 \%$ & $15,3 \%$ \\
\hline Casos perdidos & 447 & 59 & 56 \\
\hline Casos válidos & 726 & 547 & 531 \\
\hline Respuestas totales & 1796 & 1573 & 1980 \\
\hline Porcentaje de casos & $247,4 \%$ & $287,6 \%$ & $372,9 \%$ \\
\hline
\end{tabular}

Tabla 216: Porcentajes de casos de apoyos institucionales requeridos de las tres muestras.

\subsection{PENSAMIENTOS DE FUTURO}

En lo referente a los pensamientos de futuro (tabla 217), las PcDID señalan en mayor medida que el resto respuestas de evitación, como no pensar en el futuro, res- 
puestas de otro tipo como vivir con calidad de vida o seguir viviendo, o respuestas optimistas, como bien, sin problema. Las familias por su parte, y los profesionales, señalan en mayor medida pensamientos como vivir con calidad de vida, coincidiendo con las PcDID, y respuestas de preocupación, como afrontar el futuro con preocupación, ya que es incierto.

\begin{tabular}{|c|c|c|c|c|}
\hline \multirow[t]{2}{*}{ Pensamientos de futuro } & \multirow[t]{2}{*}{ Personas } & \multirow[t]{2}{*}{ Familias } & \multicolumn{2}{|c|}{ Profesionales } \\
\hline & & & Asociados & $\begin{array}{c}\text { Mayores con } \\
\text { Disc. }\end{array}$ \\
\hline \multicolumn{5}{|l|}{ Respuestas de evitación } \\
\hline Nada, no pienso en el futuro & $28,4 \%$ & $3,4 \%$ & $0,9 \%$ & $0,2 \%$ \\
\hline Seguir viviendo & $22,9 \%$ & $15,7 \%$ & $6,3 \%$ & $7,0 \%$ \\
\hline Vivir al día & $17,5 \%$ & $11,6 \%$ & $4,0 \%$ & $4,3 \%$ \\
\hline \multicolumn{5}{|l|}{ Preocupación } \\
\hline Con preocupación, futuro incierto & $15,2 \%$ & $40,2 \%$ & $29,0 \%$ & $36,8 \%$ \\
\hline Preocupación por los hijos & $2,3 \%$ & $11,6 \%$ & $11,6 \%$ & $8,7 \%$ \\
\hline \multicolumn{5}{|l|}{ Pesimismo } \\
\hline Soledad & $7,8 \%$ & $10,1 \%$ & $4,0 \%$ & $6,0 \%$ \\
\hline Triste & $6,9 \%$ & $7,7 \%$ & $2,0 \%$ & $2,7 \%$ \\
\hline Aburrimiento & $5,8 \%$ & $4,5 \%$ & $2,0 \%$ & $0,7 \%$ \\
\hline Mal, negro & $4,1 \%$ & $7,4 \%$ & $1,7 \%$ & $2,9 \%$ \\
\hline Pocas ganas de vivir & $2,7 \%$ & $1,0 \%$ & $0,6 \%$ & $1,3 \%$ \\
\hline \multicolumn{5}{|l|}{ Optimismo } \\
\hline Bien, sin problemas & $19,4 \%$ & $11,3 \%$ & $9,6 \%$ & $5,4 \%$ \\
\hline Resuelto & $7,0 \%$ & $11,8 \%$ & $3,7 \%$ & $1,8 \%$ \\
\hline \multicolumn{5}{|l|}{ Otras respuestas } \\
\hline Vivir con calidad de vida & $25,6 \%$ & $40,9 \%$ & $52,2 \%$ & $43,3 \%$ \\
\hline Autonomía personal & $10,1 \%$ & $11,6 \%$ & $21,1 \%$ & $15,7 \%$ \\
\hline Vida independiente & $7,2 \%$ & $5,6 \%$ & $16,0 \%$ & $10,8 \%$ \\
\hline Dependerá del asociacionismo & $4,9 \%$ & $12,1 \%$ & $10,8 \%$ & $10,6 \%$ \\
\hline Otros & $7,7 \%$ & $9,3 \%$ & $6,3 \%$ & $7,6 \%$ \\
\hline Casos perdidos & 115 & 12 & 43 & 33 \\
\hline Casos válidos & 1058 & 594 & 544 & 554 \\
\hline Respuestas totales & 2067 & 1282 & 1792 & 1826 \\
\hline Porcentaje de casos & $195,4 \%$ & $215,8 \%$ & $329,4 \%$ & $329,6 \%$ \\
\hline
\end{tabular}

Nota: los profesionales eligen en asociados/personas mayores con disc.: atención personalizada $(29,4 \% / 35,7 \%)$, necesidad de apoyos especiales $(26,3 \% / 33,8 \%)$, mayor especialización y personalización en el servicio $(25,6 \% / 26,0 \%)$, más implicación de la administración (23,9\%/21,8\%), servicios específicos $(23,3 \% / 28,3 \%)$ y más y mejor preparación de los profesionales $(19,1 \% / 18,1 \%)$.

Tabla 217: Porcentajes de casos de pensamientos de futuro de las tres muestras. 


\subsection{RESPUESTAS SUPERIORES AL 40\% DE ELECCIÓN}

En la tabla 218 podemos ver las respuestas que obtuvieron más de un $40 \%$ de casos de elecciones en la muestra de PcDID, familias y profesionales. Las tres muestras coinciden a la hora de señalar la importancia del estado de salud general, de la necesidad de servicios de apoyo al ocio y tiempo libre, de eliminar barreras sociales e incrementar los recursos de las asociaciones. Asimismo, todas señalan la preocupación latente sobre dónde y con quién vivirá la PcDID en el futuro, cuando sus padres ya no puedan hacerse cargo de ellas.

Entre las respuestas que han tenido mayores porcentajes de elección en dos de las tres muestras, podemos señalar los cuidados personales diarios y las limitaciones funcionales personales (coincidentes en profesionales y familias, aunque en menor medida por las PcDID); la dependencia de otra persona (coincidente en familias y profesionales), las pensiones (en PcDID y familias), los servicios de alojamiento y la aceptación de la sociedad (en familias y profesionales), los servicios de apoyo al ocio y tiempo libre (PcDID y familias) y la coordinación entre administraciones y el pensamiento de vivir con calidad de vida (coincide en familias y profesionales).

Por último, entre las respuestas que han obtenido porcentajes de casos superiores al $40 \%$ en una de las muestras, aparecen la situación económica familiar, la independencia económica, las subvenciones, el encontrar un puesto de trabajo, la calidad de la asistencia sanitaria, la asistencia en salud mental, el incremento y mejora de instalaciones sociales, así como la calidad de la asistencia social, las barreras arquitectónicas y las facilidades de transporte, todas ellas puntuadas en mayor medida por los profesionales. Las familias, por su parte, han señalado en mayor medida el apoyo de los Ayuntamientos. 


\section{Personas Familias Profesionales}

\begin{tabular}{|c|c|c|c|}
\hline \multicolumn{4}{|l|}{ Respuestas $>40 \%$ en las 3 muestras } \\
\hline Estado de salud general & $63,0 \%$ & $64,8 \%$ & $74,2 \%$ \\
\hline Servicios de apoyo al ocio y tiempo libre & $52,7 \%$ & $47,0 \%$ & $50,4 \%$ \\
\hline Barreras sociales & $42,7 \%$ & $42,4 \%$ & $58,5 \%$ \\
\hline Dónde y con quién vivir en el futuro & $47,4 \%$ & $63,0 \%$ & $47,2 \%$ \\
\hline Incrementar los recursos de las asociaciones & $42,1 \%$ & $47,7 \%$ & $50,8 \%$ \\
\hline \multicolumn{4}{|l|}{ Respuestas $>40 \%$ en 2 muestras } \\
\hline Cuidados personales diarios & $33,6 \%$ & $43,8 \%$ & $68,8 \%$ \\
\hline Limitaciones funcionales personales & $30,0 \%$ & $40,6 \%$ & $63,8 \%$ \\
\hline Dependencia & $27,9 \%$ & $47,5 \%$ & $63,0 \%$ \\
\hline Pensión & $60,1 \%$ & $63,4 \%$ & $36,5 \%$ \\
\hline Servicios de alojamiento & $23,0 \%$ & $40,3 \%$ & $40,3 \%$ \\
\hline Aceptación por parte de la sociedad & $36,8 \%$ & $43,2 \%$ & $49,2 \%$ \\
\hline Subida de las pensiones & $48,1 \%$ & $63,5 \%$ & $22,2 \%$ \\
\hline Servicios de apoyo al ocio y tiempo libre & $41,8 \%$ & $44,0 \%$ & $37,1 \%$ \\
\hline $\begin{array}{l}\text { Coordinación entre las distintas administra- } \\
\text { ciones }\end{array}$ & $29,1 \%$ & $44,2 \%$ & $48,8 \%$ \\
\hline Vivir con calidad de vida & $25,6 \%$ & $40,9 \%$ & $52,2 \% / 43,3 \%$ \\
\hline \multicolumn{4}{|l|}{ Respuestas $>40 \%$ en una muestra } \\
\hline Situación económica familiar & $20,4 \%$ & $25,9 \%$ & $45,3 \%$ \\
\hline Independencia económica & $20,1 \%$ & $27,9 \%$ & $42,1 \%$ \\
\hline Subvenciones & $12,6 \%$ & $26,1 \%$ & $59,7 \%$ \\
\hline Encontrar un puesto de trabajo & $10,8 \%$ & $6,7 \%$ & $40,3 \%$ \\
\hline Calidad de la asistencia sanitaria & $32,7 \%$ & $38,3 \%$ & $59,6 \%$ \\
\hline Asistencia en salud mental & $23,5 \%$ & $33,1 \%$ & $51,2 \%$ \\
\hline Más y mejores instalaciones sociales & $23,5 \%$ & $31,6 \%$ & $42,5 \%$ \\
\hline Calidad de la asistencia social & $20,8 \%$ & $26,8 \%$ & $49,3 \%$ \\
\hline Barreras arquitectónicas & $30,7 \%$ & $38,1 \%$ & $49,5 \%$ \\
\hline Facilidad de transporte & $28,6 \%$ & $34,2 \%$ & $47,9 \%$ \\
\hline Apoyo de los Ayuntamientos & $36,0 \%$ & $46,6 \%$ & $21,8 \%$ \\
\hline
\end{tabular}

Tabla 218: Porcentaje de respuestas superiores al $40 \%$ en las tres muestras.

\subsection{RESUMEN}

Se observan grandes coincidencias entre las tres muestras. La salud es un tema que preocupa a familias, PcDID y profesionales, así como la existencia de barreras y los recursos de servicios sociales. Dentro de la salud, preocupan el estado de salud personal, 
los cuidados personales diarios, las limitaciones funcionales personales y la dependencia.

Por otro lado, otras preocupaciones destacadas en las tres muestras son la pensión, la calidad de la asistencia sanitaria y domiliciaria, la asistencia en salud mental o los servicios de apoyo al ocio y tiempo libre. Las barreras sociales y el dónde y con quién vivirá la PcDID en el futuro también han sido señaladas en gran medida por las tres muestras.

Como soluciones, coinciden en los tres grupos la creación y mejora de servicios de apoyo al ocio y tiempo libre así como la ayuda para los cuidados personales diarios. El apoyo institucional más elegido por familias, profesionales y PcDID ha sido el incremento de las ayudas a las Asociaciones. Los pensamientos de futuro de las tres muestras giraban en torno a respuestas de evitación, optimismo y calidad de vida.

\section{DISCUSIÓN DE RESULTADOS}

\subsection{INTRODUCCIÓN}

El objetivo de esta tesis doctoral era conocer las necesidades percibidas relativas a la calidad de vida de las PcDID, de sus familias y de los profesionales que les atienden, y conocer posibles variables predictoras que influyan sobre las mismas. En los próximos apartados, se presenta la discusión de los resultados de la muestra de PcDID, familias e instituciones.

\subsection{DISCUSIÓN DE RESULTADOS DE LA ENTREVISTA PERSONAL}

La entrevista personal fue respondida por 1173 PcDID, con un número similar de hombres y mujeres (hubo ligeramente un mayor número de hombres), de entre $35 \mathrm{y}$ 80 años con una media de edad de 52. Todas las personas tenían discapacidades intelectuales y del desarrollo, si bien en el grupo había personas con SD, PC y con lo que 
hemos denominado otros tipos de DID; la causa de la discapacidad era en su gran mayoría de tipo congénito o perinatal. Muchas de estas personas tenían segundas discapacidades, tales como discapacidades físicas sin afectación cerebral, discapacidades visuales, trastorno mental o epilepsia. Todas las personas de la muestra, excepto una, tenían el grado de discapacidad reconocido. En la mayor parte de ellas dicho grado estaba entre el 65 y el $81 \%$.

Más de la mitad de estas personas residían en poblaciones de 10.000 o más habitantes y la mayor parte de ellas vivían con su familia de origen o en un servicio residencial, si bien es interesante destacar que 26 PcDID vivían solas y 5 de ellas con su familia propia. Alrededor de la mitad de la muestra carecía ya de padre o madre, pero contaba como mínimo, con algún hermano. Un 98\% de PcDID estaban solteras.

Existía en nuestra muestra un elevado número de pensionistas que nunca habían trabajado, y percibían una pensión no contributiva, teniendo un nivel educativo muy bajo, ya que la mitad de las PcDID de la muestra no sabían leer ni escribir. Hemos de destacar que 12 personas de la muestra no recibían ningún tipo de ingreso económico.

En cuanto a los resultados obtenidos en cuanto a las necesidades percibidas por este colectivo, en primer lugar se sitúan las relativas a la salud personal, seguidas de las relacionadas con la existencia de barreras, los recursos de servicios sociales, otros tipos de necesidades, necesidades sobre recursos sanitarios y por último los recursos económicos. Resultados muy similares se han encontrado en estudios previos sobre las necesidades percibidas en PcDID, como la tesis de Solís (2014), o los estudios de Aguado y cols. (2006; 2012) en Bizkaia y Castilla y León, si bien en estas dos últimas aun con ligeras variaciones, debidas a que en estos casos primaban preocupaciones de otro tipo como dónde y con quién vivirá la persona en el futuro antes que los recursos de tipo 
social, continúa apareciendo la importancia de la salud personal, la existencia de barreras y de los recursos de los servicios sociales en este colectivo.

Cuando en el estudio presente valoramos el número de necesidades de cada tipo en función del tipo de discapacidad, nos encontramos que las PcDID y las PcSD tenían preocupaciones similares, mientras que las PC primaban levemente la existencia de barreras ante la salud personal, cuestión que cobra sentido si consideramos que la PC también conlleva dificultades físicas asociadas.

Dentro de las necesidades sobre salud personal, a las PcDID les preocupa especialmente el estado de salud general, los cuidados personales diarios, la dependencia de terceras personas, las limitaciones funcionales personales y los dolores. En cuanto a la existencia de barreras, preocupan las barreras sociales, como la aceptación por parte de la sociedad, pero también las barreras arquitectónicas.

Por lo que respecta a las necesidades sobre los recursos de servicios sociales, a las PcDID de nuestra muestra les preocupan de forma llamativa los servicios de apoyo al ocio y tiempo libre, y en menor medida, la ayuda a domicilio, la mejora de instalaciones sociales, los servicios de alojamiento y la calidad de la asistencia social.

Las PcDID participantes mostraron también otras preocupaciones y necesidades tales como el dónde y con quién vivir en el futuro y la escasez de relaciones personales; así como la calidad de la asistencia sanitaria y domiciliaria o la asistencia en salud mental dentro de las necesidades acerca de los recursos sanitarios.

Llama la atención que las PcDID hayan señalado un menor número de preocupaciones relativas a los recursos económicos, dentro de los cuales, indicaron la pensión, 
la situación económica familiar y la independencia económica como preocupaciones principales.

En estudios previos se han obtenido resultados muy similares (Solís, 2014); Aguado y cols. (2006); si bien el equipo de Aguado y cols., señaló que a las PcDID de Bizkaia les preocupaban también las subvenciones, dentro de necesidades relativas a recursos económicos, y la asistencia en salud mental en cuanto a necesidades de los recursos sanitarios.

Entre las soluciones que las PcDID han propuesto en nuestra investigación destaca el incremento de las pensiones, la creación y mejora de los servicios de apoyo al ocio y tiempo libre, la ayuda para los cuidados personales diarios, el incremento de la ayuda familiar, el tener garantías de futuro, una mayor especialización profesional, la supresión de barreras arquitectónicas, la mejora de los servicios de alojamiento y el incremento de las subvenciones. Aguado y cols. (2012), indican que las PcDID también proponían la asistencia psicológica entre sus soluciones.

Cuando preguntamos a las PcDID sobre los apoyos institucionales que echan en falta, han señalado el incremento de los recursos de las asociaciones, contar con el apoyo de los Ayuntamientos, más actividades culturales y más apoyos en el entorno. En estudios previos se han encontrado resultados similares (Solís, 2014; Aguado y cols. 2006; 2012), si bien, las PcDID de Castilla y León señalaron también la coordinación entre administraciones como otro de los apoyos requeridos.

Como pensamientos de futuro de las PcDID destacaron respuestas de tipo evitativo, como "no pensar en el futuro"; optimistas, como "bien, sin problemas"; "vivir con calidad de vida" o "seguir viviendo", al igual que en las investigaciones previas (Solís, 2014; Aguado y cols. (2006; 2012). 
En cuanto a los problemas señalados, las PcDID de nuestra muestra indicaron mayoritariamente los problemas de salud, seguidos de la incapacidad para tomar decisiones, la inseguridad, la soledad, el aburrimiento o la ansiedad, tensión y estrés en menor medida. Del mismo modo estos problemas han aparecido en las investigaciones precedentes ya comentadas.

Por último, en cuanto a otras consideraciones aportadas por las PcDID, aparecen la creación de centros especializados y las ayudas asistenciales y económicas.

Por otro lado, otro de los objetivos de nuestro estudio estaba relacionado con estudiar las variables sociodemográficas que influían en las NP's de las PcDID. En lo referente a este tema, estudiamos variables como el tipo de informe, el género, la edad, el grado de discapacidad, el tipo de convivencia, la población y el tipo de discapacidad.

En lo referente al tipo de informe, cuando lo analizamos de forma dicotómica (autoinforme/heteroinforme), los resultados dieron lugar a diferencias estadísticamente significativas, ya que el grupo "heteroinforme" tenía un mayor número de preocupaciones generales y específicas, en concreto, sobre la salud personal, los servicios sanitarios, los recursos de servicios sociales y la existencia de barreras; mientras que el grupo "autoinforme" presentaba un mayor número de pensamientos de futuro. Posteriormente, al agrupar la muestra en tres tipos de informe (autoaplicado, familiar y profesional), los resultados también arrojaron diferencias estadísticamente significativas, ya que las PcDID del grupo autoinformado tuvieron un mayor número de soluciones y de pensamientos de futuro, mientras que en el grupo de profesionales obtuvieron mayores números de preocupaciones generales, preocupaciones sobre recursos sanitarios, recursos de servicios sociales y existencia de barreras. A su vez, también las familias tenían un mayor número de preocupaciones sobre salud personal y otros tipos de necesidades. En 
investigaciones previas, Solís (2014) encontró diferencias significativas cuando consideraba la variable tipo de informe de forma dicotómica tan sólo en el número de pensamientos de futuro y en el número de preocupaciones generales, de forma que eran las PcDID del grupo "heteroinforme" quienes mayor puntuación obtenían. Esta misma autora, cuando recodificó la variable en autoaplicada, familiar y profesional, obtuvo resultados similares a los nuestros, tales como el mayor número de preocupaciones generales, recursos sanitarios, existencia de barreras y recursos de servicios sociales por parte de los profesionales, así como el mayor número de pensamientos de futuro dados por las PcDID del grupo "autoaplicado", y la preocupación de las familias por la salud personal; pero también obtuvo resultados diferentes, ya que ella no encontró diferencias significativas en función del tipo de informe acerca del número de soluciones, que en nuestro caso sí fue significativo para las PcDID del grupo "autoaplicado"; así como el mayor número de otras consideraciones señaladas por el grupo "familias". En otro estudio similar previo (Aguado y cols., 2006) se dieron diferencias significativas en el número de pensamientos de futuro para el caso del autoinforme, cuando el tipo de informe era dicotomizado; y en el número de preocupaciones sobre recursos sanitarios y existencia de barreras para el caso de los profesionales, cuando la variable tipo de informe era recodificada en los tres tipos ya comentados previamente. Con todo, nuestros resultados señalan que la variable tipo de informe sí que influye en las necesidades generales y soluciones percibidas por las PcDID.

Otras de las variables estudiadas en el estudio presente ha sido el género. En este caso, los resultados fueron estadísticamente significativos en el caso de las mujeres en el número de necesidades generales, soluciones, pensamientos de futuro, apoyos institucionales que se echan en falta, problemas señalados, en las consideraciones y en necesidades específicas como las relativas a la salud personal, recursos sanitarios, recursos de 
servicios sociales, existencia de barreras y otros tipos. La única variable en la que no hubo ningún resultado significativo fue en las necesidades sobre los recursos económicos. En el estudio de Solís (2014) se obtuvieron los mismos resultados; mientras que en el estudio de Aguado y cols. (2006) con las PcDID de Bizkaia sólo se encontraron diferencias significativas por parte de las mujeres en dos variables, el número de preocupaciones sobre los recursos sanitarios y en el número de preocupaciones sobre la existencia de barreras. Estos resultados nos indican la influencia del género a la hora de que las PcDID señalen las necesidades, soluciones, etc., que les preocupan.

En cuanto a la variable edad, agrupamos la muestra en PcDID de 35-49 años; de 50 a 64 y de 65 o más años. Los resultados arrojaron diferencias significativas en el número de soluciones, de apoyos institucionales requeridos, pensamientos de futuro, necesidades sobre recursos económicos y otras necesidades, de manera que el grupo de PcDID de entre 35 y 49 años obtuvo mayores puntuaciones. Por su parte, también hubo diferencias significativas en cuanto al número de otras consideraciones por parte del grupo de PcDID de 65 o más años. Resultados similares se obtuvieron en el trabajo de Solís (2014), con la diferencia de que ella agrupaba la muestra por edad en función de los percentiles. En nuestro caso particular, la edad no pareció predecir con claridad la elección de necesidades específicas.

Por otro lado estudiamos el grado de discapacidad como otra posible predictora, y lo hicimos agrupando la muestra en un primer momento en grado de discapacidad menor al $65 \%$ o del $65 \%$ o más. En este caso, observamos diferencias estadísticamente significativas en el número de soluciones, de apoyos institucionales requeridos, pensamientos de futuro, necesidades sobre los recursos económicos y sobre los recursos de servicios sociales; en todos los casos los rangos eran mayores en el grupo de PcDID con 
un grado de discapacidad inferior al 65\%. Posteriormente agrupamos la muestra en tres categorías; si el grado era menor al $65 \%$, si estaba entre el 65 y el $80 \%$ o si era del $80 \%$ o superior. En este caso, encontramos diferencias significativas en el número de soluciones, de apoyos institucionales requeridos, en los pensamientos de futuro, en las necesidades sobre los recursos económicos, recursos de servicios sociales y en otras necesidades. Nuevamente en todas ellas, el rango era superior para las PcDID con grados de discapacidad inferiores al $65 \%$.

En cuanto al tipo de convivencia, encontramos diferencias estadísticamente significativas en todas las variables estudiadas, excepto en el número de problemas señalados. Las PcDID que vivían solas tenían mayores puntuaciones en el número de necesidades generales, soluciones, de apoyos requeridos, en el número de consideraciones, así como en el número de preocupaciones sobre los recursos sanitarios, sociales, existencia de barreras y otras necesidades; mientras que las PcDID que vivían con la familia propia obtenían mayores rangos en el número de preocupaciones generales, pensamientos de futuro y en las necesidades sobre salud personal y los recursos económicos. Resultados muy similares fueron encontrados por Solís (2014); mientras que en otros estudios no se encontraron tales diferencias (Aguado y cols., 2006).

En lo que respecta a la población de las PcDID, se encontraron diferencias significativas en el número de preocupaciones generales, de soluciones, en el número de necesidades sobre salud personal, recursos económicos, recursos de servicios sociales, servicios sanitarios, existencia de barreras y otras preocupaciones para el caso de las PcDID que vivían en poblaciones de 10.000 o más habitantes; mientras que se observaron diferencias significativas también en el número de consideraciones con mayor rango en el grupo de PcDID que vivían en poblaciones inferiores a los 10.000 habitantes. 
La última variable estudiada fue el tipo de discapacidad, ya que en la muestra participante, si bien todas las personas tenían DID, algunas tenían también SD o PC. En este caso, se encontraron diferencias significativas en el número de preocupaciones generales, de soluciones, de pensamientos de futuro, de problemas señalados, de necesidades sobre salud personal, servicios sanitarios, recursos de servicios sociales, existencia de barreras y otras necesidades. En todas ellas las personas con PC tuvieron mayores puntuaciones.

Por tanto, parece ser que todas las variables en nuestro estudio tuvieron cierta influencia a la hora de señalar las preocupaciones y soluciones generales por parte de las PcDID, con distintas variaciones que ya hemos comentado en los párrafos anteriores.

\subsection{DISCUSIÓN DE RESULTADOS DE LA ENTREVISTA FAMILIAR}

La muestra de familias estaba compuesta por 606 personas con diferentes grados de parentesco, entre los que había hermanos, padres, madres, tutores legales, sobrinos, amigos, hijos y otras personas con relaciones cercanas a las PcDID. Tales familiares tenían en sus círculos una PcDID de una media de 52 años, la mayoría solteras y residentes en localidades de 10.000 o más habitantes.

En cuanto a las necesidades señaladas por las familias, en mayor medida estaban relacionadas con la salud personal, los recursos de servicios sociales, la existencia de barreras, otras necesidades como el futuro de las PcDID, los recursos sanitarios y por último, los recursos económicos. Las familias de las personas con SD primaban la salud personal, al igual que las familias de las PcPC; mientras que las familias de personas con otros tipos de DID primaban las necesidades relacionadas con los recursos de servicios sociales. Asimismo, las familias de las personas con PC destacaban en mayor medida que el resto de familias la existencia de barreras. Destaca el que todas las familias 
dejen en último lugar las preocupaciones y necesidades relacionadas con los recursos económicos, cuestión que también apareción en investigaciones previas cuando a las familias se les preguntaba acerca de las necesidades de las PcDID (Aguado y cols., 2006; 2012; Solís, 2014).

Si nos centramos en las necesidades de salud personal percibidas por la muestra familiar, cobran importancia el estado de salud general, la dependencia, los cuidados personales diarios y las limitaciones funcionales personales. Las familias señalan también en gran medida los servicios de apoyo al ocio y tiempo libre, los servicios de alojamiento, la ayuda a domicilio, la mejora de instalaciones sociales, la calidad de la asistencia social, la falta de información sobre los recursos, el asesoramiento jurídico y el apoyo a las gestiones administrativas, dentro de las necesidades sobre los recursos de servicios sociales. En cuanto a la existencia de barreras, destacan la aceptación por parte de la sociedad, las barreras sociales y arquitectónicas, las facilidades de transporte y la escasez de voluntariado. También preocupan el dónde y con quién vivir en el futuro, el futuro de la familia, la salida del domicilio familiar por parte de la PcDID, la escasez de relaciones personales y la protección jurídica. Otras preocupaciones giran en torno a los recursos sanitarios, como la calidad de la asistencia sanitaria, la asistencia es salud mental, la mejora e incremento de instalaciones sanitarias, la asistencia sanitaria hospitalaria y domiciliaria, la falta de información sobre estos recursos, así como el tratamiento de fisioterapia. Por último, las familias señalaron preocupaciones acerca de los recursos económicos tales como la pensión, la independencia económica de la PcDID, las subvenciones o la situación económica familiar. Resultados muy similares también fueron hallados en estudios previos realizados con otras PcDID (Solís, 2014), con personas con DID de Bizkaia (Aguado y cols., 2006) o con PcDID de Castilla y León (Aguado y cols., 2012). 
Las familias de nuestro estudio proponían soluciones como la subida de las pensiones, la creación de servicios de ocio y tiempo libre, la ayuda para los cuidados personales diarios, el incremento de la ayuda familiar, las garantías de futuro, la mejora de los servicios de alojamiento, el incremento de las subvenciones, el incremento en número y calidad de las instalaciones sociales, la promoción del voluntariado, la creación de centros de día y una mayor información sobre los recursos disponibles. También proponen apoyos como el incremento de los recursos de las asociaciones, el apoyo de los Ayuntamientos, la coordinación entre administraciones, el apoyo de la comunidad y los apoyos en el entorno. En otros estudios previos (Verdugo, Rodríguez y Sánchez, 2009), las familias de personas con DID demandaban necesidades como la formación acerca de la información sobre los recursos disponibles y derechos legales, las ayudas para el mantenimiento de la casa y el pago de facturas, así como apoyos en el domicilio, ayudas económicas para el transporte, y el apoyo para aliviar el estrés en las personas cuidadoras, períodos de respiro y, en general, el apoyo a las familias.

La muestra de familias participantes en el estudio presente tenía pensamientos de futuro tales como que las PcDID vivan con calidad de vida, aunque denotaban preocupación, ante un futuro incierto. Una de las consideraciones más solicitadas por las familias fue también la creación de centros especializados. Todo esto, junto a la especial preocupación mencionada anteriormente sobre el futuro de las PcDID, acerca de dónde y con quién van a vivir, nos enlazan con la investigación de Verdugo y cols. (2009) en la que las familias solicitaban un mayor número de plazas en residencias para atender a sus hijos cuando ellas ya no puedan hacerse cargo o sistemas alternativos, incluso la creación de residencias conjuntas para familias e hijos con discapacidades. 
Por otro lado, en lo referente a las variables que pueden influir en las respuestas de las familias acerca de las necesidades de las PcDID, no encontramos en nuestro estudio diferencias en cuanto al género, ni en cuanto al tipo de residencia. En cuanto a la edad, se encontraron diferencias significativas en el número de preocupaciones generales, necesidades sobre recursos económicos y otras necesidades, con mayores puntuaciones entre las familias de las PcDID de entre 35 y 49 años; mientras que también hubo diferencias significativas en el grupo de familias de PcDID de entre 50 y 64 años acerca de la existencia de barreras. La edad de las PCDID en este caso, no fue especialmente relevante a la hora de responder al cuestionario.

Por otro lado se analizó el grado de discapacidad, y aparecieron diferencias estadísticamente significativas en el número de preocupaciones sobre salud personal, recursos sanitarios y existencia de barreras; en todos los casos las familias con una PcDID de un grado de discapacidad igual o superior al $65 \%$ eran las que mayor número de estas preocupaciones señalaban.

El tipo de convivencia fue otra de las variables analizadas, y en este caso, también se observaron diferencias significativas en el número de apoyos requeridos, pensamientos de futuro, otras consideraciones y otras necesidades en el caso de las familias de PcDID que vivían solas; en las necesidades de salud personal y recursos económicos en el caso de las familias de las PcDID que vivían con la familia propia; y en el número de preocupaciones generales, soluciones y necesidades sobre recursos de servicios sociales para el caso de las familias de las PcDID que vivían en otras fórmulas.

Por último, estudiamos la variable tipo de discapacidad. En este caso, hubo diferencias significativas en el número de preocupaciones generales, soluciones, recursos 
sanitarios y existencia de barreras con mayores rangos en las familias de las personas con PC de la muestra.

En su investigación, Solís (2014), encontró diferencias significativas en relación con la edad en el número de otras preocupaciones, así como en el número de soluciones y de apoyos requeridos, siendo los rangos mayores en todos los casos en las familias de PcDID menores de 48 años. En relación al grado de discapacidad, tan sólo observó diferencias significativas en el número de soluciones por parte de las familias de PcDID con un grado de discapacidad menor al $73 \%$. Y en lo referente al tipo de convivencia, encuentra diferencias estadísticamente significativas en el número de preocupaciones sobre recursos sanitarios (familias de PcDID de residencias), otras necesidades y apoyos requeridos (familias de PcDID que vivían solas) y en el número de soluciones y pensamientos de futuro (familias de PcDID que vivían con su familia propia).

En otro estudio, Aguado y cols. (2006) encontraron diferencias estadísticamente significativas en relación con la edad en el número de recursos económicos y el número de preocupaciones generales, con rangos mayores en las familias de PcDID mayores de 53 años. Por otro lado, teniendo en cuenta el grado de discapacidad, encontraron diferencias estadísticamente significativas en las preocupaciones de salud personal y la existencia de barreras, con rangos mayores por parte de las familias de las PcDID con grados superiores al $66 \%$. Por último, relativo al tipo de convivencia, estos autores encontraron diferencias significativas en en número de consideraciones, mayor en este caso, en las familias de las PcDID que residían en el domicilio familiar.

En nuestro estudio en particular, podríamos decir que las variables sociodemográficas han influido en las respuestas de las familias al cuestionario en menor medida que en las propias PcDID a la hora de respoder al suyo. 


\subsection{DISCUSIÓN DE RESULTADOS DE LA ENTREVISTA INSTITUCIONAL}

La muestra institucional estaba compuesta por 587 profesionales de diversa índole, tales como profesionales, cuidadores, directores, estudiantes, personas de las asociaciones, trabajadores sociales, directivos, presidentes, terapeutas ocupacionales, etc. En la mayoría de los casos la entrevista se aplicó en el propio lugar de trabajo, aunque también se llevó a cabo en residencias o sedes de las asociaciones. La mayor parte de las instituciones estaban situadas en poblaciones de 10.000 o más habitantes y más de la mitad de las mismas eran centros. En todos los casos se atendía a personas con DID, aunque también otros tipos de discapacidades secundarias como discapacidades físicas, trastornos mentales, discapacidades visuales y auditivas, personas mayores y personas con PC. La especialización de los profesionales era de diferentes tipos, como psicólogos, personal de limpieza, administrativos, cuidadores, trabajadores sociales, fisioterapeutas, monitores, terapeutas ocupacionales, etc. Por otro lado, los servicios de los cuales disponían las instituciones abarcaban servicio de comidas, atención psicológica, servicio de limpieza, de ocio, de información y orientación, servicio de fisioterapia, departamento de trabajo social, ayudas asistenciales, alojamiento, gimnasio, terapia ocupacional, entre otros. Los tipos de alojamiento disponibles mayoritariamente consistían en residencias de tercera edad, ya fuesen públicas o privadas, domicilio propio, piso tutelado o centro de día.

En cuanto a las necesidades percibidas por los profesionales entrevistados, destacaron en primer lugar las relativas al futuro de la PcDID, seguidas de las necesidades de salud personal, existencia de barreras, recursos sobre servicios sociales, recursos sanitarios y en último lugar, las necesidades relacionadas con los recursos económicos. En el estudio de Aguado y cols. (2006), los profesionales señalaban en mayor medida nece- 
sidades sobre existencia de barreras, seguidas de las necesidades relacionadas con la salud personal y de aquéllas relativas a los recursos sociales y económicos.

En lo referente al grupo de necesidades con mayores puntuaciones recibidas por parte de los profesionales, destacan el dónde y con quién vivir en el futuro, la atención integral e individual, el incremento del número de profesionales, la formación y el reciclaje de los mismos, la escasez de relaciones personales de las PcDID y la coordinación entre instituciones. En cuanto a la salud personal, los profesionales indicaron preocupantes el estado de salud general, los cuidados personales diarios, las limitaciones funcionales personales, la dependencia, la dificultad a la hora de tomar la medicación, la aceptación de la situación y los dolores. Por lo que respecta a las preocupaciones sobre la existencia de barreras, los profesionales señalaron las barreras tanto sociales como arquitectónicas, la aceptación de la sociedad, las facilidades de transporte, la aceptación de las familias, las ayudas técnicas y la accesibilidad. Otras preocupaciones de los profesionales fueron los servicios de apoyo al ocio y tiempo libre, la calidad de la asistencia social, así como el incremento en número y calidad de las instalaciones sociales y los servicios de alojamiento, dentro de las necesidades relacionadas con los servicios sociales. Por otro lado, en cuanto a los recursos sanitarios los profesionales refieren preocupantes la calidad de la asistencia sanitaria, la asistencia en salud mental, los servicios de fisioterapia y la asistencia sanitaria hospitalaria. Por último, entre las preocupaciones acerca de los recursos económicos los profesionales indicaron las subvenciones, la situación económica familiar, la independencia económica, el encontrar un puesto de trabajo y la pensión. Necesidades similares se encontraron en estudios previos como los realizados por Aguado y cols. (2006) y Solís (2014). 
Entre las demandas percibidas por los profesionales acerca de sus asociados, destacan las actividades de ocio y tiempo libre, los servicios residenciales, las ayudas económicas, el favorecer la vida independiente, la participación y la inserción laboral de las PcDID, así como el fomento de la calidad de vida.

Los profesionales proponen soluciones como la creación de servicios de apoyo al ocio y tiempo libre, el incremento de las subvenciones, la promoción de viviendas adaptadas, la atención individualizada, la coordinación entre instituciones, la mayor especialización profesional, programas de intervención adecuados, la supresión de barreras arquitectónicas y la asistencia psicológica. También proponen apoyos como el incremento de los recursos de las asociaciones, la coordinación entre las distintas administraciones, la creación de centros y recursos necesarios, la mayor implicación de la administración, actividades de formación y contar con la opinión de los propios profesionales.

Como pensamientos de futuro de sus asociados, la muestra institucional señalaba el vivir con calidad de vida, la atención personalizada, afrontar el futuro con preocupación por ser incierto, la necesidad de apoyos especiales y una mayor especialización y personalización en los servicios. Cuando se preguntaba a los profesionales acerca de los pensamientos de futuro de las PcDID mayores, indicaban los mismos que para sus asociados, con la diferencia de que señalaban en más ocasiones la preocupación ante el futuro y las respuestas pesimistas que en el caso de los pensamientos de futuro de sus asociados, señalando a su vez la necesidad de la creación de centros específicos para este colectivo. 
Otras consideraciones que aportaban los profesionales era la mayor formación de los profesionales, la ayuda de la sociedad y de las instituciones y, nuevamente, la creación de recursos y centros especializados.

Resultados similares a los comentados se encontraron en las investigaciones de Solís (2014) y Aguado y cols. (2006).

Cuando analizamos la influencia de las variables sociodemográficas sobre las necesidades percibidas por la muestra institucional, nos encontramos que en la variable residencia hubo diferencias estadísticamente significativas en el número de demandas de los asociados, en el número de apoyos requeridos, en los pensamientos de futuro de los asociados y en las necesidades sobre los recursos sanitarios. En todos los casos, los rangos eran mayores en el grupo de población de 10.000 o más habitantes.

Por otro lado, cuando estudiamos la variable tipo de institución, encontramos diferencias estadísticamente significativas en el número de preocupaciones, de demandas de sus asociados, de apoyos requeridos, de soluciones, de pensamientos de futuro de las PcD mayores y en las necesidades sobre la salud personal, recursos económicos, recursos sobre servicios sociales, existencia de barreras y otras necesidades, siendo el rango superior para el grupo de otros tipos de institución; así como también se hallaron diferencias estadísticamente significativas en el número de pensamientos de futuro sobre las PcD mayores con un rango superior cuando la institución era una Asociación.

\subsection{COINCIDENCIAS Y DIVERGENCIAS ENTRE LAS TRES MUESTRAS}

Tanto las PcDID, como las familias y los profesionales han aportado mayor relevancia a las necesidades sobre salud personal, existencia de barreras y los recursos de servicios sociales. Y a su vez, en las tres entrevistas, la necesidad que menores elecciones conllevó fue la de los recursos económicos, lo que es bastante llamativo. 
En cuanto a las necesidades sobre la salud personal, las tres muestras de nuestro estudio giraban en torno a la importancia del estado de salud general, los cuidados personales diarios, las limitaciones funcionales personales y la dependencia, con ligeras variaciones.

Por lo referente a las necesidades sobre la existencia de barreras, todos destacaban las barreras sociales y a la aceptación por parte de la sociedad; aportando los profesionales la importancia de las facilidades de transporte y la aceptación por parte de las familias, y no sólo de la sociedad.

En cuanto a los recursos de los servicios sociales, las tres muestras destacaban necesidades como la creación de servicios de apoyo al ocio y tiempo libre; dando importancia los profesionales a su vez al incremento en número y calidad de las instalaciones sociales y a la calidad de la asistencia social; y, en el caso de las familias, a los servicios de alojamiento y la ayuda a domicilio.

Por lo que respecta a las necesidades sobre los recursos sanitarios las tres muestras coincidían en la necesidad de aumentar la calidad de la asistencia sanitaria (señalada en mayor frecuencia por los profesionales) y la asistencia sanitaria hospitalaria y domiciliaria. Los profesionales también otorgaban relevancia a la necesidad de asistencia en los servicios de salud mental.

Por último, en cuanto a los recursos económicos, las familias y las PcDID señalaban en mayor medida la pensión, mientras que los profesionales se centraban más en las subvenciones y en que las PcDID encontraran un puesto de trabajo. A su vez, en las tres muestras se consideraba importante la situación económica familiar y la independencia económica. 
Otra preocupación destacada en todas las muestras fue el dónde y con quién vivirá la PcDID en el futuro.

Ante estas necesidades, las tres muestras coincidían en dar soluciones tales como la subida de las pensiones (en el caso de las PcDID y las familias en mayor medida), así como la creación de servicios de apoyo al ocio y tiempo libre o la ayuda para los cuidados personales diarios (señaladas en todas las muestras).

Como apoyos requeridos, las tres muestras solicitaban el incremento de los recursos de las asociaciones, los apoyos en el entorno, la igualdad de oportunidades o las actividades de formación. Las familias y las PcDID señalaban en mayor medida que los profesionales el apoyo de los Ayuntamientos, mientras que los profesionales señalaron en más ocasiones la mayor coordinación entre las administraciones, la creación de centros y recursos necesarios y la mayor implicación por parte de la administración.

Las PcDID empleaban respuestas de evitación al pensar en su futuro, como "no pensar", "seguir viviendo", o respuestas como "vivir con calidad de vida". Ésta última también fue señalada por familias y profesionales, unidas a la preocupación por un futuro que aún consideran incierto.

Entre todas las respuestas, hubo algunas que superaban el porcentaje del $40 \%$ de casos de elección, ya fuera en las tres muestras, en dos de ellas, o en una. En este caso, las tres muestras señalaron con un alto porcentaje el estado de salud general, los servicios de apoyo al ocio y tiempo libre, las barreras sociales, la preocupación sobre dónde y con quién vivirá la PcDID en el futuro y la necesidad de incrementar los recursos de las asociaciones. 
Las PcDID y sus familias estaban más preocupadas que los profesionales en la pensión y la subida de las mismas y en la creación de servicios de apoyo al ocio y tiempo libre; mientras que los profesionales y las familias daban especial relevancia a los cuidados personales diarios, las limitaciones funcionales personales, la dependencia, los servicios de alojamiento, la aceptación por parte de la sociedad, la coordinación entre las distintas administraciones y a vivir con $\mathrm{CV}$.

Los profesionales también señalaron de forma llamativa la situación económica familiar, la independencia económica, las subvenciones, el encontrar un puesto de trabajo, la calidad de la asistencia social y sanitaria, la asistencia en salud mental, al incremento en número y calidad de las instalaciones sociales, la calidad de la asistencia social, las barreras arquitectónicas y las facilidades de transporte; mientras que las familias destacaban el apoyo de los Ayuntamientos.

Estos resultados son similares a los encontrados por Aguado y cols. (2012) con PcDID, familias y profesionales de Castilla y León. En su caso, las tres muestras coincidían en señalar necesidades de salud y existencia de barreras principalmente, de forma que dentro de las necesidades sobre salud personal destacaban la dependencia, las limitaciones funcionales personales y la ayuda para los cuidados personales diarios; mientras que en cuanto a las barreras destacaban las barreras arquitectónicas y sociales, así como el transporte adaptado y la eliminación de las barreras mencionadas como una solución. Las PcDID mencionaban en mayor medida necesidades relacionadas con la salud personal, mientras que sus familias demandaban servicios sociales como el ocio, la ayuda a domicilio y más y mejores instalaciones sociales. Los profesionales por su parte indicaban la importancia del futuro de las PcDID, acerca de dónde y con quién vivirán, así como la escasez de relaciones personales. 
La sintonía de los resultados, también se ha observado en otro estudio realizado por el mismo equipo investigador (Aguado y cols., 2006) con PcDID, familias y profesionales en Bizkaia.

Podemos concluir este apartado comentando la semejanza habida entre las preocupaciones y necesidades que perciben las PcDID, sus familias y los profesionales que les atienden, si bien, los profesionales parecen complementar, en cierta medida, las necesidades expuestas por las PcDID y sus familias.

\section{CONCLUSIONES Y POSIBLES LÍNEAS DE ACTUACIÓN}

Según datos del Proyecto ELES del IMSERSO (2011), en el año 2025 en España casi 1 de cada 4 ciudadanos tendrá más de 65 años y la mitad serán mayores de 50, es decir, se está produciendo un envejecimiento demográfico que supone nuevos retos y desafíos tanto en la vida de las personas, en sus familias, en la economía de los países y en la reorganización de los sistemas social y sanitario.

Si recurrimos a datos del IMSERSO (2015) sobre las PcDID con reconocimiento oficial del grado de discapacidad en España, observamos que hay un total de 122.967 PcDID de entre 35 y 64 años, 246.073 mayores de 65 años, 17.223 PcDID de entre 65 y 79 años y 4.781 de 80 o más años; lo que quiere decir, que en esta población también se está produciendo un aumento de la esperanza de vida, ya que cada vez viven más años gracias a todos los avances médicos, tecnológicos y sociales que se han ido produciendo en las últimas décadas. Todo ello supone también, al igual que en la población general, que la PcDID que envejece, sus familias y los profesionales nos enfrentemos a nuevos desafíos que se producen con la llegada de una nueva vulnerabilidad producida por el envejecimiento a la discapacidad que previamente ya tenía la persona. 
El envejecimiento produce también en las PcDID cambios en la salud, apareciendo nuevos problemas y enfermedades que previamente no existían, pero que se unen con la edad a las dificultades que ya le podía ocasionar a la persona y a su entorno la propia discapacidad. Ante esta situación, los recursos sanitarios deben adecuarse a las nuevas necesidades que se plantean. Si previamente, en la delimitación conceptual de esta tesis, hemos hablado del envejecimiento prematuro de las PcDID, ahora debemos comentar que se suele dar la circunstancia de que las PcDID y sus familias envejezcan más o menos a la par, lo que hace que los principales cuidadores de las PcDID se conviertan también en personas susceptibles de ser cuidadas, y aparezca la preocupación de las familias sobre el futuro de la PcDID. Los recursos también deben hacer frente a estas situaciones, ya sea con servicios de alojamiento especializados o recursos compartidos, para familias y PcDID. Si aparecen recursos, las PcDID es posible que tengan que cambiar su residencia, y por tanto, cambiar todo su entorno por completo, sus lugares y sus relaciones, cuando ya sabemos que de por sí, suelen ser escasas, al menos en las personas participantes en el estudio presente. Esto conlleva que la persona reduzca en muchos casos sus redes sociales. Según el INE (2008), se sabe que las personas con discapacidad consideran difícil relacionarse fuera de su entorno; de hecho 7 de cada 10 declaraban poca o ninguna posibilidad de establecer nuevas amistades, y 2 de cada 3 consideraban imposible o casi imposible dirigirse a personas fuera de su entorno. Asimismo, en el informe Olivenza (2014) aparece que la población con relaciones de amistad precarias en la población general es del 12,67\%, mientras que en las PcD es del 21,54\%, lo que señala la dificultad para establecer relaciones por parte de este colectivo. Cabe hablar aquí de las barreras sociales y arquitectónicas. Las barreras sociales pueden ocurrir por diversas circunstancias, ya sean personales de la PcDID, como por una falta de aceptación de las PcDID por parte de la sociedad; sin embargo, cuando las personas 
envejecen, también pueden aparecer problemas de movilidad que junto a las barreras arquitectónicas impiden el acceso a los lugares donde se producen las relaciones sociales. Asimismo, este tipo de barreras también influyen en el acceso de la PcDID a actividades de ocio y tiempo libre comunitarias, o al propio acceso a los servicios comunitarios básicos. De hecho, hay datos que indican que si en la población general el porcentaje de personas que no tienen influencia cívica, que no participan en las elecciones o que no son miembros de organizaciones ciudadanas es del $14,37 \%$, en las personas con discapacidad en general es del $17,80 \%$. Por tanto, este es otro de los frentes a gestionar por parte de los servicios y recursos destinados a la población con DID.

Por otro lado, en nuestra investigación había un pequeño porcentaje de personas con DID que no recibía ningún tipo de ingreso económico, aunque en otros casos se cobraba algún tipo de pensión o la pensión no contributiva. Si a esto le añadimos algún problema físico o cognitivo que requiera de apoyos técnicos, protésicos o simplemente de ayuda para los cuidados, dificulta enormemente su coste, y además empobrece la calidad de vida de estas personas que pueden tener incluso pocos recursos para las cosas básicas necesarias para la alimentación, la higiene, y, en general, la vida.

Por lo tanto, queda constatado que con el envejecimiento de las PcDID y los nuevos retos que ello conlleva, los servicios de atención y los recursos destinados a mejorar la calidad de vida de estas personas deben adecuarse a las necesidades que les surgen a lo largo de este proceso, que ya no sólo afecta a las propias PcDID, si no también a sus familias. He aquí donde surge la necesidad de realizar estudios que reflejen y expongan cuáles son tales necesidades y realicen propuestas con el fin de incrementar el bienestar y la calidad de vida de este colectivo. 
El objetivo de esta investigación era conocer las necesidades percibidas relativas a la CV de las PcDID que se encuentran en proceso de envejecimiento, y además conocer las variables sociodemográficas que les caracterizan e investigar si estas variables influyen en las necesidades. Además, y como este tema ya se ha tratado en los puntos anteriores detalladamente, otro de los objetivos era realizar propuestas para la mejora de los servicios de atención a estas personas. Para ello, analizamos las entrevistas aplicadas tanto a las PcDID, como a sus familias y a los profesionales que les atienden, y de ahí, podemos señalar las siguientes líneas posibles de actuación:

Como primera línea, conociendo la importancia que tanto las PcDID, sus familias y los profesionales que les atienden han dado a la salud personal, creemos necesario el apoyo a los cuidados personales diarios, que a su vez reduzcan las posibles limitaciones funcionales personales y una posible dependencia de terceras personas. Para ello, los servicios de ayuda a domicilio, la figura del asistente personal o los centros especializados, junto a una mayor formación de personal dedicado a estas tareas incrementarían la calidad de vida de estas personas. No podemos olvidar el apoyo a los cuidadores informales, que suelen ser los principales soportes de las PcDID, y este apoyo puede producirse a través de servicios de respiro, apoyo psicológico e información sobre los recursos existentes.

En lo referente a la existencia de barreras, es necesaria la participación de las PcDID en los recursos y servicios comunitarios, que aumenten la visibilidad y el trato de la sociedad con este colectivo para que llegue a ser una relación normalizada. Los servicios de atención a las PcDID deben fomentar este tipo de actividades, no restringiéndose exclusivamente al 
uso de los centros disponibles. Por otro lado, en cuanto a las barreras arquitectónicas, son necesarias ayudas para que las personas que lo requieran puedan contar con dispositivos técnicos y de accesibilidad cognitiva que les permita el uso y el acceso a cualquier servicio.

$\checkmark$ En cuanto a los recursos de los servicios sociales, es de vital importancia contar con servicios de apoyo al ocio y tiempo libre, y además, es un servicio demandado en gran medida tanto por PcDID, como por familias y profesionales. Estos servicios deben facilitar un ocio inclusivo, comunitario, de personas con y sin discapacidad, donde se fomente también el establecimiento y mantenimiento de relaciones personales. Los servicios de alojamiento también son necesarios y demandados por las personas participantes en nuestro estudio. Pero tales servicios deben adecuarse a cada persona y a cada familia, siempre intentando promover la permanencia de la PcDID en su entorno comunitario, con el fin de no perder las redes de apoyo social que ya tenía previamente.

El dónde y con quién vivir en el futuro es una preocupación recurrente de las familias y los profesionales a lo largo de diversas investigaciones. esto va íntimamente relacionado con los servicios de alojamiento, que en cierta medida, deben fomentar que la persona no se aleje de su familia y su entorno cercano. Incluso pueden plantearse servicios de alojamiento conjunto para familias y PcDID. Los pisos tutelados también podrían ser una opción.

En cuanto a los recursos sanitarios, es importante la especialización y formación continua de los profesionales, ya que estamos en un campo en 
el que siempre se presentan nuevos desafíos, pero a la vez, nuevos métodos y modelos de evaluación e intervención. Es importante que los equipos de investigadores cuenten con recursos para poder seguir avanzando en la investigación. Por otro lado, también es necesaria la especialización en el campo de la psiquiatría, por las dificultades que entraña el diagnóstico de síntomas y trastornos mentales en PcDID, así como por la dificultad del ajuste de los tratamientos farmacológicos en este colectivo, en muchos casos producido por las dificultades de comunicación de las personas con DID.

$\checkmark$ En cuanto a los recursos económicos, es necesario que las PcDID puedan vivir de forma digna y tengan asegurada la calidad de vida, por lo que es necesario que las pensiones que reciban cubran al menos las necesidades básicas. Además, se hacen necesarias otros tipos de ayudas económicas, ya que con el envejecimiento pueden aparecer necesidades en la persona de dispositivos técnicos o de otros tipos de apoyo, que una sola pensión no podría suministrar. Por otro lado, en nuestro estudio las personas, familias y profesionales también sugieren que se incrementen los recursos de los que disponen las asociaciones que se dedican a la atención de las PcDID para poder incrementar su CV.

En cuanto a la atención a las PcDID en las instituciones, se debe cuidar siempre su calidad de vida, a través de modelos centrados en las personas y en las familias; empleando métodos que sitúen a las personas en el centro de todos los procesos, tanto evaluaciones, como intervenciones. Asimismo, estos centros deben potenciar las relaciones interpersonales y el 
uso de servicios y práctica de actividades comunitarias, no permaneciendo ajenas al entorno que las rodea, y tratando de buscar apoyos naturales en tal entono para que la persona pueda desarrollar los resultados personales que puedan ser de su interés.

Como líneas futuras de investigación, sería interesante realizar trabajos que comparen las NP's por las PcDID, sus familias y los profesionales que les atienden en las diferentes Comunidades Autónomas, ya que en general, la atención al Tercer Sector depende de cada una de ellas. Así se podría comparar las políticas, los servicios y recursos en diferentes lugares españoles, y poder igualar los mismos en todo el territorio para asegurar una adecuada $\mathrm{CV}$ en el envejecimiento de este colectivo.

Asimismo, otra línea futura de investigación podría girar en torno a la ampliación de la muestra, el estudio de las necesidades en zonas rurales, ya que en la investigación presente la mayoría de las PcDID residían en zonas de más de 10.000 habitantes, y con una alta probabilidad las necesidades no serán las mismas en ambas zonas.

Por último, sería interesante también continuar estudiando las variables sociodemográficas que influyen en las PcDID que envejecen a la hora de señalar las NP's, debido a la enorme heterogeneidad de este colectivo.

Como conclusión final, se trata de que la PcDID sea considerada primero por ser persona que por tener una discapacidad, que siempre se tenga en consideración su plan de vida, sus metas o resultados personales, desde perspectivas centradas en la propia persona, a través de la participación, de que puedan tener roles sociales valorados, de conocer sus derechos, de tener un empleo e independencia económica, de incluirse en la sociedad, etc. En conclusión, la clave está en empoderar a la persona para sea quien guíe, con los apoyos que sean necesarios, su propia vida, y por ello, en este estudio 
hemos tratado de conocer qué piensan las PcDID, sus familias y los profesionales que les atienden acerca de lo que es necesario cambiar en los servicios y recursos para que estas personas puedan alcanzar las metas que se propongan y vivir como todos queremos, con calidad de vida durante su envejecimiento. 


\section{REFERENCIAS BIBLIOGRÁFICAS}

Adams, K.B.; Roberts, A.R.; Cole, M.B. (2011): Changes in activity and interest in the third and fourth age: associations with health, functioning and depressive symptoms. Occup. Ther. Int., 18, pp. 4-17.

Aguado, A.L. (1995). Historia de las deficiencias. Madrid: Escuela Libre Editorial, Fundación ONCE, (p. 55-122).

Aguado, A.L. y Alcedo, M.A. (2003). Análisis comparativo de las necesidades percibidas por las personas discapacitadas de edad en función del tipo de discapacidad. Análisis y Modificación de Conducta, 29 (126), 523-560.

Aguado, A.L. y Alcedo, M.A. (2003). Envejecimiento y discapacidad, el gran reto. Revista ENLACE, 6, 23-26.

Aguado, A.L.; Alcedo, M.A. (2004): Necesidades percibidas en el proceso de envejecimiento de las personas con discapacidad. Psicothema, Vol. 16, $N^{o} 2$, pp. 261-269.

Aguado, A.L.; Alcedo, M.A.; Arias, B. (2005): Las necesidades de las personas con discapacidad que envejecen percibidas por sus familiares. Intervención Psicosocial, Vol. 14, No3, pp. 309-325.

Aguado, A.L.; Alcedo, M.A.; Arias, B.; Rueda, B. (2006): Necesidades de las personas con discapacidad intelectual en proceso de envejecimiento. Diputación Foral de Bizkaia.

Aguado, A.L.; Alcedo, M.A.; Fontanil, Y. (2005): Las necesidades de las personas con discapacidad que envejecen percibidas por los profesionales que les atienden. Psicothema, Vol. 17, $N^{o} 4$, pp. 657-662. 
Aguado, A.L.; Alcedo, M.A.; Fontanil, Y. (2012): Proceso de envejecimiento en personas con discapacidad intelectual de Castilla y León: calidad de vida y necesidades percibidas. En Verdugo, M.A.; Canal, R.; Jenaro, C.; Badia, M.; Aguado, A.L. (coords): Aplicación del paradigma de calidad de vida a la intervención con personas con discapacidad desde una perspectiva integral. Publicaciones del INICO, pp. 95121.

Aguado, A.L., Alcedo, M.A., Fontanil, Y., Arias, B. y Verdugo, M.A. (2001). Discapacidad y envejecimiento: Necesidades percibidas por las personas discapacitadas mayores de 45 años y propuesta de líneas de actuación. Informe de proyecto de investigación, IMSERSO y Departamento de Psicología, Universidad de Oviedo. (Inédito).

Aguado, A.L.; Alcedo, M.A.; Rozada, C.; González, M.; Real, S.; Fontanil, Y. (2010): Calidad de vida y necesidades percibidas de las personas con discapacidad intelectual en proceso de envejecimiento en Castilla y León: avance de resultados. En Verdugo, M.A.; Crespo, M.; Nieto, T. (coords): Aplicación del paradigma de calidad de vida. VII Seminario de Actualización Metodológica en Investigación sobre Discapacidad, SAID. Publicaciones del INICO, pp. 117-135.

Alcedo, M.A.; Aguado, A.L.; Arias, B.; González, M.; Rozada, C. (2008): Escala de calidad de vida (ECV) para personas con discapacidad que envejecen: estudio preliminar. Intervención Psicosocial, Vol. 17, N², pp. 153-167.

Alonso, P.; Sansó, F.J.; Díaz-Canel, A.M.; Carrasco, M.; Oliva, T. (2007): Envejecimiento poblacional y fragilidad en el adulto mayor. Revista Cubana Salud Pública, 33 (1), pp.1-17. 
Alonso, M.; Serrano, A.; Miron, J.A. (2005): Problemas y necesidades relacionados con la salud en personas con discapacidad intelectual. Siglo Cero, Vol. 36, $N^{o} 215$, pp. 25-37.

Arias, B.; Irurtia, M.J.; Gómez, L.E. (2009): Conductas problemáticas en personas con discapacidad intelectual: un estudio preliminar sobre dimensionalidad y propuesta de clasificación. Behavioral Psychology, Vol. 17, N², pp. 257-275.

Arnold, S.R.C.; Riches, V.C.; Stancliffe, R.J. (2014): I-CAN: The classification and prediction of support needs. JARID, 27, pp. 97-111.

Aronow, H.; Hahn, J.E. (2005): Stay well and healthy! Pilot study findings from an inhome preventive healthcare programme for persons ageing with intellectual and/or developmental disabilities. Journal of Applied Research in Intellectual Disabilities, 18, pp. 163-173.

Asociación Americana de Discapacidades Intelectuales y del Desarrollo - AAIDD (2011): Discapacidad intelectual. Definición, clasificación y sistemas de apoyo. Madrid, Alianza.

Atkins, J.; Naismith, S.L.; Luscombe, G.M.; Hickie, I.B. (2013): Psychological distress and quality of life in older persons: relative contributions of fixed and modifiable risk factors. BMC Psychiatry, 13, pp. 249. doi:10.1186/1471-244X-13-249

Badia, M.; Orgaz, M.B.; Verdugo, M.A.; Ullán, A.M.; Martínez, M. (2013): Relationships between Leisure Participation and quality of life of people with developmental disabilities. JARID, 26, pp. 533-545. 
Beadle-Brown, J.; Mansell, J.; Ashman, B.; Ockenden, J.; Iles, R.; Whelton, B. (2014): Practice leadership and active support in residential services for people with intellectual disabilities: an exploratory study. JIDR, Vol. 58, Part 9, pp. 838-850.

Beail, N.; Williams, K. (2014): Using qualitative methods in research with people who have intellectual disabilities. JARID, 27, pp. 85-96.

Bergland, A.; Engedal, K. (2011): Living arrangements, social networks, health, mobility, and balance of older women. Physical \& Occupational Therapy in Geriatrics, 29 (2), pp. 90-101.

Berjano, E. (2005): Dependencia y calidad de vida en las personas mayores. Rev. Mult. Gerontol., 15 (3), pp. 144-154.

Berlau, D.; Corrada, M.; Kawas, C. (2009): The prevalence of disability in the oldestold is high and continues to increase with age: findings from the $90+$ study. Int $J$ Geriatr Psychiatry, 24, pp. 1217-1225.

Bertoli, M.; Biasini, G.; Calignano, M.T.; Celani, G.; De Grossi, G.; Digilio, M.C.; Fermariello, C.C.; Loffredo, G.; Luchino, F.; Marchese, A.; Mazotti, S.; Menghi, B.; Razzano, C.; Tiano, C.; Hobart, A.Z.; Zampino, G.; Zuccalà, G. (2011): Needs and challenges of daily life for people with Down syndrome residing in the city of Rome, Italy. JIDR, Vol. 55, part 8, pp. 801-820.

Beyer, S.; Jordán de Urríes, F.B.; Verdugo, M.A. (2010): A comparative study of the situation of supported employment in Europe. Journal of Policy and Practice in Intellectual Disabilities, Vol. 7, $N^{o} 2$, pp. 130-136. 
Bigby, C. (2002): Ageing people with a lifelong disability: challenges for the aged care and disability sectors. Journal of Intellectual \& Developmental Disability.Vol. 27, $N^{o} 4$, pp. 231-241.

Bigby, C. (2008): Beset by obstacles: a review of Australian policy development to support ageing in place for people with intellectual disability.Journal of Intellectual\&DevelopmentalDisability, Vol. 33, $N^{o} 1$, pp. 76-86.

Bigby, C.; Bowers, B.; Webber, R. (2011): Planning and decision making about the future care of older group home residents and transition to residential aged care. JIDR, Vol. 55, part 8, pp. 777-789.

Bigby, C.; Knox, M. (2009): “I want to see the Queen”: experiences of service use by ageing people with intellectual disability. Australian Social Work, Vol. 62, $N^{\circ} 2$, pp. 216-231.

Bigby, C.; Webber, R.; Bowers, B.; McKenzie-Green, B. (2008): A survey of people with intellectual disabilities living in residential aged care facilities in Victoria. Journal of IntellectualDisabilityResearch, Vol. 52, Part. 5, pp. 404-414.

Bódalo, E. (2010): Envejecimiento y discapacidad: una aproximación al caso español desde la perspectiva del bienestar social. Portularia, Vol. 4, $N^{o} 1$, pp. 67-78.

Bramston, P.; Chipuer, H.; Pretty, G. (2005): Conceptual principles of quality of life: an empirical exploration. Journal of Intellectual Disability Research, Vol. 49, Part. 10, pp. $728-733$.

Brehmer, B.; Weber, G. (2010): Frailty vs. disability distinctions in people with intellectual disabilities. Journal of Policy and Practice in Intellectual Disabilities, Vol. 7, $N^{o} 1$, pp. $49-58$. 
Burt, D.; Primeaux-Hart, S.; Loveland, K.; Cleveland, L.; Lewis, K.; Lesser, J.; Pearson, P. (2005): Aging in adults with intellectual disabilities. American Journal on Mental Retardation. Vol. 110, $N^{o} 4$, pp. 268-284.

Buys, L.; Boulton-Lewis, G.; Tedman-Jones, J.; Edwards, H.; Knox, M.; Bigby, C. (2008): Issues of active ageing: perceptions of older people with lifelong intellectual disability. Australasian Journal on Ageing. Vol. 27, $N^{o} 2$, pp. 67-71.

Caballo, C.; Crespo, M.; Jenaro, C.; Verdugo, M.A.; Martínez, J.L. (2005): Factor structure of the Schalock and Keith Quality of Life Questionnaire (QOL-Q): validation on Mexican and Spanish samples. Journal of Intellectual Disability Research, Vol. 49, Part. 10, pp. 773-776.

Cabra, M.A. (2004): Discapacidad y aspectos sociales: la igualdad de oportunidades, la no discriminación y la accesibilidad universal como ejes de una nueva política a favor de las personas con discapacidad y sus familias. Algunas consideraciones en materia de protección social. Revista del Ministerio de Trabajo e Inmigración, 50, pp. 21-46.

Cabrero, J. (2007): Indicadores de discapacidad en la Encuesta de Discapacidades, Deficiencias y Estado de Salud.Rev. Esp. Salud Pública, 81, pp. 167-181.

Carbonell, A.; Aparicio, V.; Delgado, M. (2009): Efectos del envejecimiento en las capacidades físicas: implicaciones en las recomendaciones de ejercicio físico en personas mayores. Revista Internacional de Ciencias del Deporte, Vol. 5, $N^{o} 17$, pp. 118.

Carmeli, E.; Orbach, I.; Zinger-Vaknin, T.; Morad, M.; Merrick, J. (2008): Physical training and well-being in older adults with mild intellectual disability: a residential 
care study. Journal of Applied Research in Intellectual Disabilities, 21, pp. 457465.

Carr, J.; Collins, S. (2014): Ageing and dementia in a longitudinal study of a cohort with Down Syndrome. JARID, 27, pp. 555-563.

Chacón, F. (1989): Necesidad social y servicios sociales. Papeles del psicólogo, $N^{o} 41$ 42 , pp. $18-24$.

Chan, J.; Sigafoos, J.; Watego, N.; Potter, G. (2001): Adults with intellectual disability in long-term respite care: a qualitative study. Journal of Intellectual \& Developmental Disability, Vol. 26, $N^{\circ} 4$, pp. 339-344.

Chen, H.; Cohen, P.; Kasen, S.; Gordan, K.; Dufur, R.; Smailes, E. (2004): Construction and validation of a quality of life instrument for young adults. Quality of Life Research, 13, pp. 747-759.

Choi, M.; Prieto-Merino, D.; Dale, C.; Nüesch, E.; Amuzu, A.; Bowling, A.; Ebrahim, S.; Casas, J.P. (2013): Effect of changes in moderate or vigorous physical activity on changes in health-related quality of life of elderly Brittish women over seven years. Qual Life Res, 22, pp. 2011-2020. doi: 10.1007/s11136-012-0332-2

Chou, Y.C.; Schalock, R.L.; Tzou, P.Y.; Lin, L.C.; Chang, A.L.; Lee, W.P.; Chang, S.C. (2007): Quality of life of adults with intellectual disabilities who live with families in Taiwan. Journal of Intellectual Disability Research, Vol. 51, Part. 11, pp. 875-883.

Claes, C.; Van Hove, G.; Vandevelde, S.; van Loon, J.; Schalock, R.L. (2010): Personcentered planning: analysis of research and effectiveness. Intellectual and developmental disabilities. Vol. 48, $N^{\circ} 6$, pp. 432-453. 
Claes, C.; Van Hove, G.; Vandevelde, S.; van Loon, J.; Schalock, R.L. (2012): The influence of supports, environmental factors, and client characteristics on quality of life-related personal outcomes. Research in Developmental Disabilities, Vol. 33 (1), pp. 96-103.

Cleaver, S.; Ouellete-Kuntz, H.; Hunter, D. (2009): The prevalence and severity of physical mobility limitations in older adults with intellectual disabilities. Journal of Applied Research in Intellectual Disabilities, 22, pp. 477-486.

Cocks, E.; Boaden, R. (2011): A quality framework for personalised residential supports for adults with developmental disabilities. JIDR, Vol. 55, part 8, pp. 720-731.

Cooper, S.A.; McConachie, A.; Allan, M.N.; Melville, C.; Smiley, E.; Morrison, J. (2011): Neighbourhood deprivation, health inequalities and service access by adults with intellectual disabilities: a cross-sectional study. JIDR, Vol. 55, part 3, pp. 313323.

Coopus, A.M.W. (2013): People with intellectual disability: What do we know about adulthood and life expectancy? Developmental Disabilities Research Reviews, 18: 6, pp. 6-16.

Coppus, A.; Evenhuis, H.; Verberne, G-J.; Visser, F.; Oostra, B.; Eikelenboom, P.; van Gool, W.; Janssens; van Duijn, C. (2008): Survival in elderly persons with Down syndrome. JAGS, Vol. 56, $N^{o} 12$, pp. 2311-2316.

Corrales, E.; Tardón, A.; Cueto, A. (2000): Estado funcional y calidad de vida en mayores de 70 años. Psicothema, Vol. 12, $N^{\circ} 2$, pp. 171-175. 
Crossley, R.; Withers, P. (2009): Antipsychotic medication and people with intellectual disabilities: their knowledge and experiences. Journal of Applied Research in Intellectual Disabilities, 22, pp. 77-86.

Daniels, R.; van Rossum, E.; Metzelthin, S.; Sipers, W.; Habets, H.; Hobma, S.; van den Heuvel, W.; de Witte, L. (2011): A disability prevention programme for community-dwelling frail older persons. Clinical Rehabilitation, 25 (11), pp. 963-974.

Davidson, P.W.; Janicki, M.P.; Ladrigan, P.; Houser, K.; Henderson, C.M.; Cain, N.N. (2003): Associations between behavior disorders and health status among older adults with intellectual disability. Aging \& Mental Health, Vol. 7, $N^{\circ} 6$, pp. 424-430.

Davies, D.K.; Stock, S.E.; Holloway, S.; Wehmeyer, M.L. (2010): Evaluating a GPSbased transportation device to support independent bus travel by people with intellectual disability. Intellectual and Developmental Disabilities. Vol. 48, $N^{o} 6$, pp. 454-463.

Davies, N. (2011): Promoting healthy ageing: the importance of lifestyle. Nursing Standard, 25, 19, pp. 43-49.

De Ruiter, K.P.; Dekker, M.C.; Douma, J.C.H.; Verhulst, F.C.; Koot, H.M. (2008): Development of parent- and teacher-reported emotional and behavioural problems in young people with intellectual disabilities: does level of intellectual disability matter? Journal of Applied Research in Intellectual Disabilities, 21, pp. 70-80.

De Winter, C.F.; Hermans, H.; Evenhuis, H.M.; Echteld, M.A. (2015): Associations of symptoms of anxiety and depression with diabetes and cardiovascular risk factors in older people with intellectual disability. JIDR, Vol. 59, Part 2, pp. 176-185. 
Dewhurst, F.; Dewhurst, M.J.; Gray, W.K.; Orega, G.; Howlett, W.; Chaote, P.; Dotchin, C.; Longdon, A.R.; Paddick, S.M.; Walker, R.W. (2012): The prevalence of disability in older people in Hai, Tanzania. Age \& Ageing, Vol. 41 (4), pp. 517-523.

Díaz, M.D.; Martínez, B.; Calvo, F. (2002): Trastornosafectivos en el anciano. Rev. Mult. Gerontol; Vol. 12, $N^{o} 1$, pp. 19-95.

Dodd, P.; Guerin, S.; Mulvany, F.; Tyrrell, J.; Hillery, J. (2009): Assessment and characteristics of older people with intellectual disability who are not accessing specialist intellectual disability services. Journal of Applied Research in Intellectual Disabilities, 22, pp. 87-95.

Doody, C.M.; Markey, K.; Doody, O. (2011): Future need of aging people with an intellectual disability in the Republic of Ireland: lessons learned from the literature. British Journal of Learning Disabilities, 41, pp. 13-21.

Doody, C.M.; Markey, K.; Doody, O. (2013): The experiences of registered intellectual disability nurses caring for the older person with intellectual disability. Journal of Clinical Nursing, 22, pp. 1112-1123.

Dos Santos, F. H.; Gorth, S.M.; Machado, M.L. (2009): Autonomy markers in Brazilian adults with intellectual disabilities. Journal of Policy and Practice in Intellectual disabilities, Vol. 6, No3, pp. 212-218.

Dubois, M-F.; Dubuc, N.; Raîche, M.; Caron, C.D.; Hèbert, R. (2008): Correlates of the perceived needs for institutionalisation among older adults without cognitive impairment. Gerontology, 54, pp. 244-251.

Dunne, E.; Wrosch, C.; Miller, G.E. (2011): Goal disengagement, functional disability, and depressive symptoms in old age. Health Psychology, Vol. 30, $N^{\circ} 6$, pp. 763-770. 
Dykens, E.M. (2013): Aging in rare intellectual disability syndromes. Developmental Disabilities Research Reviews, 18, pp. 75-83.

Esbensen, A.J. (2016): Sleep problems and associated comorbidities among adults with Down Syndrome. JIDR, Vol.60, Part I, pp. 68-79.

Evenhuis, H.; Schoufour, J.; Echteld, M. (2013): Frailty and intellectual disability: a different operationalization? Developmental Disabilities Research Reviews, 18, pp. $17-21$.

Fagerström, C.; Hellström, A. (2011): Sleep complaints and their association with comorbidity and health-related of quality of life in an older population in Sweden. Aging \& Mental Health, Vol. 15, $N^{\circ} 2$, pp. 204-213.

Fahey, A.; Walsh, P.N.; Emerson, E.; Guerin, S. (2010): Characteristics, supports, and quality of life of Irish adults with intellectual disability in life-sharing residential communities. Journal of Intellectual \& Developmental Disability, 35 (2), pp. 66-76.

FEAPS MADRID (2007): Las personas con necesidades de apoyo generalizado: guía de identificación de indicios de envejecimiento y orientaciones para la determinación de apoyos. Cuadernos de Atención de Día, $N^{\circ} 3$, pp. 21-42.

Fernández-Ballesteros, R. (2001): Environmental conditions, health and satisfaction among the elderly: Some empirical results. Psicothema, Vol. 13, $N^{o} 1$, pp. 40-49.

Fernández-Ballesteros, R.; Caprara, M.G.; Iñiguez, J.; García, L.F. (2005): Promoción del envejecimiento activo: efectos del programa <<vivir con vitalidad〉>. Rev. Esp. Geriatr. Gerontol., 40 (2), pp. 92-102. 
Fernández-Ballesteros, R.; Zamarrón, M.D.; López, M.D.; Molina, A.; Díez, J.; Montero, P.; Schettini, R. (2010): Envejecimiento con éxito: criterios y predictores. Psicothema, Vol. 22, $N^{o} 4$, pp. 641-647.

Fernández-Mayoralas, G.; Rojo, F.; Abellán, A.; Rodríguez, V. (2003): Envejecimiento y salud. Diez años de investigación en el CSIC. Rev. Mult. Gerontol., 13 (1), pp. 4346.

Finlay, W.M.L.;Rohleder, P.; Taylor, N.; Culfear, H. (2014): 'Understanding' as a practical issue in sexual health education for people with intellectual disabilities: a study using two qualitative methods. Health Psychology. Advanced online publication. http://dx.doi.org/10.1037/hea0000128

Foley, K-R; Girdler, S.; Downs, J.; Jacoby, P.; Bourke, J.; Lennox, N.; Einfeld, S.; Llewellyn, G.; Parmenter, T.R.; Leonard, H. (2014): Relationship between family quality of life and day occupations of young people with Down Syndrome. Soc Psychiatry Psychiatr Epidemiol, 49, pp. 1455-1465.

Fuller-Thompson, E.; Brennenstuhl, S.; Hurd, M. (2011): Comparison of disability rates among older adults in aggregated and separate Asian American/Pacific Islander subpopulations. American Journal of PublicHealth, Vol. 101, $N^{o} 1$, pp. 94-100.

Garaigordobil, M.; Pérez, J.I. (2007): Self-concept, self-esteem and psychopathological symptoms in persons with intellectual disability. The Spanish Journal of Psychology, Vol. 10, $N^{o} 1$, pp. 141-150.

García-Altés, A.; Pinilla, J.; Peiró, S. (2006): Aproximaciones a los pesos de calidad de vida de los <<años de vida ajustados por calidad $>>$ mediante el estado de salud autopercibido. Gaceta Sanitaria, 20 (6), pp. 457-464. 
Giné, C.; Vilaseca, R.; Gràcia, M.; Mora, J.; Orcasitas, J.R.; Simón, C.; Torrecillas, A.M.; Beltran, F.S.; Dalmau, M.; Pro, M.T.; Balcells-Balcells, A.; Mas, J.M.; Adam-Alcocer, A.L.; Simó-Pinatella, D. (2013): Spanish family quality of life Scales: under and over 18 years old. Journal of Intellectual \& Developmental Disability, 38(2), pp. 141-148.

Giraldez-García, C.; Forjaz, M.J.; Prieto-Flores, M-E; Rojo-Perez, F.; FerandezMayoralas, G.; Martinez-Martin, P. (2013): Individual's perspective of local community environment and health indicators in older adults. Geriatr Gerontol Int, 13, pp. $130-138$.

Gispert, R.; Clot-Razquin, G.; March, J.; Freitas, A.; Busquets, E.; Ruíz-Ramos, M.; Rivero, A. (2009): Prevalencia de la discapacidad en España por Comunidades Autónomas: el papel de los factores individuales y del entorno geográfico en su variabilidad. Rev. Esp. Salud Pública, 83, pp. 821-834.

Gispert, R.; Clot-Razquin, G.; Rivero, A.; Freitas, A.; Ruíz-Ramos, M.; Ruíz, C.; Busquets, E.; Argimón, J.M. (2008): El perfil de la dependencia en España: un análisis de la encuesta de discapacidades de 1999. Rev. Esp. SaludPública, 82, pp. 653-665.

Gispert, R.; Ruíz-Ramos, M.; Barés, M.A.; Viciana, F.;Clot-Razquin, G. (2007): Diferencias en la esperanza de vida libre de discapacidad por sexo y Comunidades Autónomas en España. Rev. Esp. Salud Pública, 81, pp. 155-165.

Glaesser, R.S.; Perkins, E.A. (2013): Self-Injurious behavior in older adults with intellectual disabilities. Social Work, Vol. 58, N³, pp. 213-221.

Gómez, L.E.; Arias, B.; Verdugo, M.A.; Navas, P. (2012): Application of the Rasch rating scale model to the assessment of quality of life of persons with intelectual 
disabilities. Journal of Intellectual and Developmental Disability, Vol. 37 (2), pp. 141-150.

Gómez, L.E.; Verdugo, M.A.; Arias, B.; Navas, P. (2008): Evaluación de la calidad de vida en personas mayores y con discapacidad: la escala FUMAT. Intervención Psicosocial, Vol. 17, No2, pp. 189-199.

Gómez-Vela, M.; Sabet, E. (2000): Calidad de vida. Evolución del concepto y su influencia en la investigación y en la práctica. Salamanca, Investigaciones del INICO.

Gullberg, M.T.; Hollman-Frisman, G. (2010): Reference values for the Quality of Life Index in the general Swedish population 18-80 years of age. Qual. Life Res., 19, pp. 751-760.

Gurland, B.; Teresi, J.A.; Eimicke, J.P.; Maurer, M.S.; Reid, M.C. (2014): Quality of life impacts on 16-year survival of an older ethnically diverse cohort. Int J Geriatr Psychiatry, 29, pp. 533-545.

Hahn, J.E.; Aronow, H.U. (2011): Reliability and validity analysis of the Stay Well and Healthy! Health risk appraisal for persons with intellectual and developmental disabilities. JARID, 24, pp. 341-350.

Hanna, L.M.; Taggart, L.; Cousins, W. (2011): Cancer prevention and health promotion for people with intellectual disabilities: an exploratory study of staff knowledge. JIDR, Vol. 55, part 3, pp. 281-291.

Hart, R.P.; Bean, M.K. (2011): Executive function, intellectual decline and daily living skills. Aging, Neuropsychology and Cognition, 18, pp. 64-85. 
Hartley, S.; MacLean, W. (2007): Staff-averse challenging behaviour in older adults with intellectual disabilities. Journal of Applied Research in Intellectual Disabilities, 20, pp. 519-528.

Hawton, A.; Green, C.; Dickens, A.P.; Richards, S.H.; Taylor, R.S.; Edwards, R.; Greaves, C.J.; Campbell, J.L. (2011): The impact of social isolation on the health status and health-related quality of life of older people. Qual Life Res, 20, pp. 5767.

Hayes, S.; McGuire, B.; O’Neill, M.; Oliver, C.; Morrison, T. (2011): Low mood and challenging behavior in people with severe and profound intellectual disabilities. JIDR, Vol. 55, part 2, pp. 182-189.

Heller, T. (2009): Envejecimiento y discapacidad intelectual. Siglo Cero, Vol.40, $N^{\circ} 229$, pp. 67-78.

Henderson, C.M.; Acquilano, J.; Meccarello, J.; Davidson, P.; Robinson, L. (2009): Health status and activities of daily living and walking in older people with intellectual disabilities. Journal of Policy and Practice in Intellectual Disabilities, Vol. 6, $N^{\circ} 4$, pp. 282-286.

Hermans, H.; Evenhuis, H.M. (2013): Factors associated with depression and anxiety in older adults with intellectual disabilities: results of the healthy ageing and intellectual disabilities study. Int J Geriatr Psychiatry, 28, pp. 691-699.

Hernández Posada, A. (2004): Las personas con discapacidad: su calidad de vida y la de su entorno. Aquichan, Vol. 4, $N^{\circ} 4$, pp. 60-65.

Herps, M.A.; Buntinx, W.H.E.; Schalock, R.L.; van Breukelen, G.J.P.; Curfs, L.M.G. (2016): Individual support plans of people with intellectual disabilities in residential 
services: content analysis of goals and resources in relation to client characteristics. JIDR, Vol.60, Part.3, pp. 254-262.

Hinz, A.; Kohlmann, T.; Stöbel-Richter, Y.; Zenger, M.; Brähler, E. (2014): The quality of life questionnaire EQ-5D-5L: psychometric properties and normative values for the general German population. Qual Life Res, 23, pp. 443-447.

Holburn, S.; Cea, C.D.; Coull, L.; Goode, D. (2007): Personal vs. proxy focus group's perspectives on quality of life. Journal of Policy and Practice in Intellectual Disabilities, Vol. 4, No3, pp. 210-212.

Holland, T. (2011): The future for research in intellectual disabilities. JIDR, Vol. 55, Part 1, pp. 1-3.

Hsu, Y.; Alfermann, D.; Lu, F.J.H.; Lin, L.L. (2013): Pathways from fear of falling to quality of life: the mediating effect of the self-concept and physical independence. Aging \& Mental Health, Vol. 17, N ${ }^{o}$, pp. 816-822.

Hulbert-Williams, L.; Hastings, R.P.; Crowe, R.; Pemberton, J. (2011): Self-reported life events, social support and psychological problems in adults with intellectual disabilities. JARID, 24, pp. 427-436.

Iacono, T.; Bigby, C.; Carling-Jenkings, R.; Torr, J. (2014): Taking each day as it comes: staff experiences of supporting people with Down Syndrome and Alzheimer's disease in group homes. JIDR, Vol. 58, Part 6, pp. 521-533.

IMSERSO (2015): Informe estatal de personas con valoración del grado de discapacidad (informe a 31/12/2015). Ministerio de Sanidad, Política Social e Igualdad. 
Instituto Nacional de Estadística (2008): Panorámica de la discapacidad en España. Encuesta de discapacidad, autonomía personal y situaciones de dependencia. Boletín informativo del Instituto Nacional de Estadística. Cifras INE.

Instituto de Normalización Previsional (2004): Deficiencias propias del envejecimiento. Chile.

Instituto Nacional de Estadística (2008): EDAD. Notas de prensa.

Instituto Nacional de Estadística (2014): Proyección de la población de España 20142064. Notas de prensa. 28 de Octubre de 2014.

Jansen, J.; Rozeboom, W.; Penning, C.; Evenhuis, H.M. (2013): Prevalence and incidence of myocardial infarction and cerebrovascular accident in ageing persons with intellectual disability. Journal of Intellectual Disability Research, Vol.57, Part 7, pp. 681-685.

Janicki, M.P.; Davidson, P.W.; Henderson, C.M.; McCallion, P.; Taets, J.D.; Force, L.T.; Sulkes, S.B.; Fragenberg, E.; Ladrigan, P.M. (2002): Health characteristics and health services utilization in older adults with intellectual disability living in community residences. Journal of Intellectual Disability Research, Vol. 46, Part. 4, pp. 287-298.

Jiang, Y.; Hesser, J.E. (2006): Associations between health-related quality of life and demographics and health risks. Results from Rhode Island's 2002 behavioral risk factor survey.Health and Quality of Life Outcomes, 4:14.

Jordán de Urríes, B.F. (2010): Empleo con apoyo. Educación y Futuro, 23, pp. 31-42. 
Kahan, J.; Mitchell, J.; Kemp, B.; Adkins, R. (2006): The results of a 6-month treatment for depression on symptoms, life satisfaction, and community activities among individuals aging with a disability. Rehabilitation Psychology, Vol. 51, $N^{o} 1$, pp. 1322.

Källstrand-Eriksson, J.; Baigi, A.; Buer. N.; Hildingh, C. (2012): Perceived visionrelated quality of life and risk of falling among community living elderly people. Scandinavian Journal of Caring Sciences, pp. 433-439. doi: 10.1111/j.14716712.2012.01053.x

Karas, D.J.; Costain, G.; Chow, E.W.C.; Bassett, A.S. (2014): Perceived burden and neuropsychiatric morbidities in adults with 22q11.2 deletion syndrome. Journal of Intellectual Disability Research, Vol.58, Part2, pp.198-210.

Kober, R.; Eggleton, I.R.C. (2005): The effect of different types of employment on quality of life. Journal of Intellectual Disability Research, Vol. 49, Part. 10, pp. 756-760.

Kostka, T.; Jachimowicz, V. (2010): Relationship of quality of life to dispositional optimism, health locus of control and self-efficacy in older subjects living in different environments. Qual. Life Res., 19, pp. 351-361.

Krinsky-McHale, S.J.; Silverman, W. (2013): Dementia and mild cognitive impairment in adults with intellectual disability: Issues of diagnosis. Developmental Disabilities Reviews 18; pp. 31-42.

Lee, J.C.; Hasnain-Wynia, R.; Lau, D.T. (2012): Delay in seeing a doctor due to cost: disparity between older adults with and without disabilities in the United States. HSR, 47:2, pp. 698-720. 
Lehman, B.A.; Bos, A.E.R.; Rijken, M.; Cardol, M.; Peters, G-J. Y.; Kok, G.; Curfs, L.M.G. (2013): Ageing with an intellectual disability: the impact of personal resources on well-being. Journal of Intellectual Disability Research, Vol. 57, part 11, pp. $1068-1078$.

Levasseur, M.; Desrosiers, J.; Whiteneck, G. (2010): Accomplishment level and satisfaction with social participation of older adults: association with quality of life and best correlates. Qual. Life Res., 19, pp. 665-675.

Lifshitz, H. (2002): Attitudes toward aging in adult and elderly people with intellectual disability. Educational Gerontology, 28, pp. 745-759.

Lin, C-C; Li, C-I; Chang, C-K; Liu, C-S; Lin, C-H; Meng, N-H; Lee, Y-D; Chen, F-N; Li, T-C (2011): Reduced health-related quality of life in elders with frailty: a crosssectional study of community-dwelling elders in Taiwan. PLoS ONE, Vol. 6, Issue 7, e21841.

Lim, J-Y; Lee, H-H; Hwang, Y-H (2011): Trust on doctor, social capital and medical care use of the elderly. Eur J Health Econ, 12, pp. 175-188.

Lloyd, B.P.; Kennedy, C.H. (2014): Assessment and treatment of challenging behavior for individuals with intellectual disability: a research review. JARID, 27, pp. 187199.

Lorenz, R. (2009): Indicators of preclinical disability: women's experiences of an aging body. Journal of Women \& Aging, 21, pp. 138-151.

Lucas-Carrasco, R. (2012): Life satisfaction in persons with intellectual disabilities. Research in Developmental Disabilities, Vol. 33 (4), pp. 1103-1109. 
Lund, E.M.; Hammond, M. (2014): Single-session intervention for abuse awareness among people with developmental disabilities. Sex Disabil, 32, pp. 99-105.

Madrigal, A.; Pereyra, C.; Calvo, J.; Uría, H. (2007): Envejecimiento de las personas con discapacidad intelectual. Boletín sobre el envejecimiento, Publicaciones del IMSERSO.

Maes, B.; Van Puyenbroeck, J. (2008): Adaptation of Flemish services to accommodate and support the aging of people with intellectual disabilities.Journal of Policy and Practice in Intellectual Disabilities, Vol. 5, No 4, pp. 245-252.

Makhija, S.K.; Gilbert, G.H.; Clay, O.J.; Matthews, J.; Sawyer, M.; Allman, R.M. (2011): Oral health-related quality of life and life-space mobility in communitydweelling older adults. JAGS, 59, pp. 512-518.

Marks, B.; Sisirak, J.; Chang, Y-C. (2013): Efficacy of the HealthMatters Program Trainthe-Trainer Model. Journal of Applied Research in Intellectual Disabilities, 26, pp. 319-334.

Marrugat, M.L. (2005): La familia cuidadora y su incidencia en la calidad de vida de las personas dependientes. Rev. Mult. Gerontol., 15 (3), pp. 171-177.

Martínez, B.; Díaz, M.D.; Alonso, J.M.; Calvo, F. (2006): Evolución del envejecimiento poblacional y respuesta sociosanitaria. Rev. Mult. Gerontol; Vol. 16, No 1, pp.26-31.

McCarron, M.; Lawlor, B.A. (2003): Responding to the challenges of ageing and dementia in intellectual disability in Ireland. Aging \& Mental Health, Vol. 7, $N^{\circ} 6$, pp. 413-417. 
McCausland, D.; McCallion, P.; Cleary, E.; McCarron, M. (2016): Social connections for older people with Intellectual Disability in Ireland: Results from Wave One of IDS-TILDA. JARID, 79, pp. 71-82.

McClean, B.; Grey, I. (2012): A component analysis of positive behavior support plans. Journal of Intellectual and Developmental Disability, Vol. 37 (3), pp. 221-231.

McConkey, R.; Mulvany, F.; Barron, S. (2006): Adult persons with intellectual disabilities on the island of Ireland. Journal of IntellectualDisabilityResearch, Vol. 50, part.3, pp. 227-236.

McGlinchey, E.; McCallion, P.; Burke, E.; Carroll, R.; McCarron, M. (2013): Exploring the issue of employment for adults with and intellectual disability in Ireland. Journal of Applied Research in Intellectual Disabilities, 26, pp- 335-343.

McGrath, J.A.; O’Malley, M.; Hendrix, T.J. (2011): Group exercise mode and healthrelated quality of life among healthy adults. Journal of AdvancedNursing, Vol. 67 $N^{o} 3$, pp. 491-500.

Meadows, G.; Burguess, P. (2009): Perceived need for mental health care: findings from the 2007 Australian Survey of Mental Health and Wellbeing. Australian and New Zealand Journal of Psychiatry, 43, pp. 624-634.

Meadows, G.; Burgess, P.; Bobevski, I.; Fossey, E.; Harvey, C.; Liaw, S.T. (2002): Perceived need for mental health care: influences of diagnosis, demography and disability. Psichological Medicine, 32, pp. 299-309.

Meadows, G.; Harvey, C.; Fossey, E.; Burguess, P. (2000): Assesing perceived need for mental health care in a community survey: development of the Perceived Need for Care Questionnaire (PNCQ). Soc. Psychiatr. Epidemiol., 35, pp. 427-435. 
Medeiros, K.; Rojahn, J.; Moore, L.L.; van Ingen, D.J.(2014): Functional properties of behaviour problems depending on level of intellectual disability. JIDR, Vol. 58, part 2, pp. 151-161.

Mercier, C.; Picard, S. (2011): Intellectual disability and homelessness. JIDR, Vol. 55, part 4, pp. 441-449.

Millán-Calenti, J.C.; Meleiro, L.; Quintana, J.; López-Rey, M.J.; Vázquez de la Parra, P.; López-Sande, A. (2008): Discapacidad intelectual y envejecimiento: un nuevo reto para el siglo XXI. Rev. Esp. Geriatr. Gerontol., 38 (5), pp. 266-274.

Ministerio de Sanidad, Servicios Sociales e Igualdad; IMSERSO (2015): Informe 2014. Las personas mayores en España. Datos estadísticos estatales y por Comunidades Autónomas. Colección Documentos. Serie Documentos Estadísticos, $N^{o} 22079$.

Mirón, J.A.; Alonso, M.; Serrano, A.; Sáenz, M.C. (2008): Calidad de vida relacionada con la salud en personas con discapacidad intelectual en España. Rev. Panam. SaludPública, 24 (5), pp. 336-344.

Mitchell, J.; Adkins, R; Kemp, B. (2006): The effects of aging on employment of people with and without disabilities. RCB; Vol. 49, $N^{o} 3$, pp. 157-165.

Molzahn, A.; Skevington, S.M.; Kalfoss, M.; Makaroff, K.S. (2010): The importance of facets of quality of life to older adults: an international investigation. Qual. Life Res., 19, pp. 293-298.

Momtaz, Y.A.; Ibrahim, R.; Hamid, T.A.; Yahaya, N. (2011): Sociodemographic predictors of elderly's psychological well-being in Malasya. Aging \& Mental Health, Vol.15, $N^{o} 4$, pp. 437-445. 
Moreno, J. (2004): Mayores y calidad de vida. Portularia, 4, pp. 187-198.

Murray, A.L.; McKenzie, K. (2013): Estimating the severity of intellectual disability in adults: a Mokken Scaling analysis of the Learning Disability Screening Questionnaire. Psychological Assessment, Vol.25, 3, pp. 1002-1006.

Navarro, Y.; Torrico, E.; López, M.J. (2010): Programa de intervención psicosexual en personas con discapacidad intelectual. Educación y Diversidad, 4 (2), pp. 75-92.

Navas, P.; Uhlmann, S.; Berástegui, A. (2015): Envejecimiento activo y discapacidad intelectual. Colección Investigación. Ministerio de Educación, Cultura y Deporte. Fundación Síndrome de Down Madrid. CNIIE.

Neely-Barnes, S.; Marcenko, M.; Weber, L. (2008): Does choice influence quality of life for people with mild intellectual disabilities? Intellectual and Developmental Disabilities, Vol. 46, $N^{o} 1$, pp. 12-26.

Noonan, P.; Emerson, E.; Lobb, C.; Hatton, C.; Bradley, V.; Schalock, R.L.; Moseley, C. (2010): Supported accommodation for people with intellectual disabilities and quality of life: an overview. Journal of Practice in Intellectual Disabilities, Vol. 7, $N^{o} 2$, pp. 137-142.

Nota, L.; Ferrari, L.; Soresi, S.; Wehmeyer, M. (2007): Self-determination, social abilities and the quality of life of people with intellectual disability. Journal of Intellectual Disability Research, Vol. 51, Part. 11, pp. 850-865.

Nota, L.; Soresi, S.; Perry, J. (2006): Quality of life in adults with an intellectual disability: the evaluation of quality of life instrument. Journal of Intellectual Disability Research, Vol. 50, Part. 5, pp. 371-385. 
O’Brien, P.; McConkey, R.; García-Iriarte, E. (2014): Co-researching with people who have intellectual disabilities: insights from a National Survey. JARID, 27, pp. 65-75.

O'Brien, P.; Thesing, A.; Tuck, B.; Capie, A. (2001): Perceptions of change, advantage and quality of life for people with intellectual disability who left a long stay institution to live in the community. Journal of Intellectual \& Developmental Disability, Vol. 26, $N^{o} 1$, pp. 67-82.

Observatorio de personas mayores - IMSERSO (2011): Estudio Longitudinal Envejecer en España. El proyecto ELES. Boletín sobre envejecimiento. Ministerio de Sanidad, Política Social e Igualdad.

Observatorio Estatal de la Discapacidad (2015): Informe Olivenza 2014, sobre la situación y la evolución de la discapacidad en España. Informes, Estudios e Investigación. Ministerio de Sanidad, Servicios Sociales e Igualdad.

Olatunde, O.; White, C.; Smith, M.P. (2010): Life expectancy and disability-free life expectancy estimates for Middle Super Output Areas; England, 1999-2003. Health Statistics Quarterly, 47, pp. 33-65.

Olesen, S.C.; Berry, H.L. (2011): Community participation and mental health during the retirement in community sample of Australians. Aging \& Mental Health, Vol. 15, $N^{o} 2$, pp. 186-197.

Oliva-Moreno, J.; López-Bastida, J.; Worbes-Cerezo, M.; Serrano-Aguilar, P. (2010): Health related quality of life of Canary Island citizens. BMC PublicHealth, 10, pp. $675-684$.

OMS: Estrategia y plan de acción mundiales sobre el envejecimiento y la salud 20162020: hacia un mundo en el que todas las personas puedan vivir una vida prolonga- 
da y sana. 69 $9^{\mathrm{a}}$ Asamblea Mundial de la Salud. Punto 13.4 del orden del día. A69/A/CONF./8. 24 de mayo de 2016.

Otero, A.; Zunzunegui, M.V.; Rodríguez-Laso, A.; Aguilar, M.D.; Lázaro, P. (2004): Volumen y tendencias de la dependencia asociada al envejecimiento en la población española. Rev. Esp. SaludPública. 78, pp 201-213.

Paredes, D. (2010): Bienestar emocional y expresión conductual en las personas con discapacidad intelectual. Educación y Diversidad, 4 (2), pp. 51-60.

Patja, K.; Iivanainen, M.; Vesala, H.;Oksanen, H.; Ruoppilla, I. (2000): Life expentancy of people with intellectual disability: a 35-year follow-up study. Journal of Intellectual Disability Research, Vol. 44, Part. 5, pp. 591-599.

Patti, P.; Amble, K.; Flory, M. (2010): Placement, relocation and end of life issues in aging adults with and without Down's syndrome: a restrospective study. Journal of Intellectual Disability Research, Vol. 54, Part. 6, pp. 538-546.

Perri, J.; Allen, D.G.; Pimm, C.; Meek, A.; Lowe, K.; Groves, S.; Cohen, D.; Felce, D. (2013): Adults with intellectual disabilities and challenging behavior: the costs and outcomes of in- and out-of-area placements. Journal of Intellectual Disability Research, Vol.57, Part2, pp. 139-152.

Petry, K.; Maes, B., Vlaskamp, C. (2009): Measuring the quality of life of people with profound multiple disabilities using the QOL-PMD: first results. Research in Developmental Disabilities, Vol. 30, Nº, pp. 1394-1405.

Phillips, S.M.; Wòjcicki,T.R.; McAuley, E. (2013): Physical activity ad quality of life in older adults: an 18-months panel analysis. Qual Life Res, 22, pp. 1647-1654. 
Pikora, T.J.; Bourke, J.; Bathgate, K.; Foley, K-R; Lennox, N.; Leonard, H. (2014). PLOS ONE, Vol.9, 5, pp. 1-8.

Pin, T.; Zin, M.S.; Chiang, P.; Heok, E. (2011): Religion, health beliefs, and the use of mental services by the elderly. Aging \& Mental Health, Vol. 15, $N^{\circ} 2$, pp. 143-149.

Reid, K.A.; Smiley, E.; Cooper, S.A. (2011): Prevalence and associations of anxiety disorders in adults with intellectual disabilities. JIDR, Vol.55, Part 2, pp. 172-181.

Ribes, R.; Sanuy, J. (2000): Evaluación del envejecimiento psicológico en las personas con discapacidad psíquica. Rev. Mult. Gerontol, Vol. 10, Nº, pp. 242-248.

Richardson, T.M.; Simning, A.; He, H.; Conwell, Y. (2011): Anxiety and its correlates among older adults accessing aging services. Int $J$ Geriatr Psychiatry, 26, pp. 3138.

Robles, M.A. (2007): Incidencia y prevalencia del Síndrome de Down. Revista de Síndrome de Down, Vol. 24, pp. 68-70.

Rodríguez-Marín, J.; Pastor, M.A.; López-Roig, S. (1993): Afrontamiento, apoyo social, calidad de vida y enfermedad. Psicothema, Vol. 5, Suplemento, pp. 349-372.

Rodríguez-Porrero, C. (2000): Discapacidad y calidad de vida. Rev. Mult. Gerontol., 10 (2), pp. 66-91.

Samuel, P.S.; Hobden, K.L.; LeRoy, B.W.; Lacey, K.K. (2012): Analysing family service needs of typically underserved families in the USA. JIDR, Vol. 56, part 1, pp. 111-128.

Samuel, P.S.; Rillota, F.; Brown, I. (2012): The development of family quality of life concepts and measures. JIDR, Vol. 56, part 1, pp. 1-16. 
Schalock, R.L. (2004): The concept of quality of life: what we know and do not know. Journal of Intellectual Disability Research, Vol. 48, Part. 3, pp. 203-216.

Schalock, R.L. (2004): The emerging disability paradigm and its implications for policy and practice. Journal of Disability Policy Studies, Vol. 14, N4, pp. 204-215.

Schalock, R.L.; Brown, I.; Brown, R.; Cummins, R.A.; Felce, D.; Matikka, L.; Keith, K.D.; Parmenter, T. (2002): Conceptualization, measurement, and application of quality of life for persons with intellectual disabilities: report of an international panel of experts. Mental Retardation, Vol. 6, pp.457-470.

Schalock, R.L.; Luckasson, R.A. (2004): American Association on Mental Retardation's definition, classification, and system of supports and its relation to international trends and issues in the field of intellectual disabilities. Journal of Policy and Practice in Intellectual Disabilities, Vol. 1, $N^{o} 3 / 4$, pp. 136-146.

Schalock, R.L.; Luckasson, R.A.; Shogren, K.A.; Borthwick-Duffy, S.; Bradley, V.; Buntinx, W.H.E.; Coulter, D.L.; Craig, E.M.; Gomez, S.C.; Lachapelle Y.; Reeve, A.; Snell, M.E.; Spreat, S.; Tassé, M.J.; Thompsom, J.R.; Verdugo, M.A.; Wehmeyer, M.L.; Yeager, M.H. (2007): The renaming of mental retardation: understanding the change to the term intellectual disability. Intellectual and Developmental Disabilities, Vol. 45, $N^{\circ}$, pp. 116-124.

Schalock, R.L.; Verdugo, M.A. (2006): Revisión actualizada del concepto de calidad de vida. En M.A. Verdugo (Dir.): Cómo mejorar la calidad de vida de las personas con discapacidad. Instrumentos y estrategias de evaluación. Salamanca, Amarú, pp. 2941. 
Schalock, R.L.; Verdugo, M.A. (2007): El concepto de calidad de vida en los servicios y apoyos para personas con discapacidad intelectual. GID, Artículos del Grupo de Investigación sobre Discapacidad, pp. 1-18.

Schalock, R.L.; Verdugo, M.A.; Gómez, L.E.; Reinders, H.S. (2016): Moving us toward a theory of individual quality of life. American Journal on Intellectual and Developmental disabilities, Vol. 121, $N^{\circ} 1$, pp.1-12.

Shaw, K.; Cartwright, C.; Craig, J. (2011): The housing and support needs of people with an intellectual disability into older age. JIDR, Vol. 55, part 9, pp. 895-903.

Schoufour, J.D.; Mitnitski, A.; Rockwood, K.; Evenhuis, H.M.; Echteld, M.A. (2015): Predicting 3-year survival in older people with intellectual disabilities using a Frailty Index. JAGS, 63, pp. 531-536.

Simoes, C.; Santos, S. (2016): Comparing the quality of life of adults with and without intellectual disability. JIDR, Vol.60, Part.4, pp. 378-388.

Smulders, E.; Enkelaar, L.; Weerdesteyn, V.; Geurts, A.C.H.; van Schrojenstein Lantman-deValk, H. (2013): Falls in older persons with intellectual disabilities: fall rate, circumstances and consequences. Journal of Intellectual Disability Research, Vol. 57, Part12, pp. 1173-1182.

Snell, M.E.; Luckasson, R.; Borthwick-Duffy, S.; Bradley, V.; Buntinx, W.H.E.; Coulter, D.L.; Craig, E.M.; Gomez, S.C.; Lachapelle, Y.; Reeve, A.; Schalock, R.L.; Shogren, K.A.; Spreat, S.; Tassé, M.J.; Thompsom, J.R.; Verdugo, M.A.; Wehmeyer, M.L.; Yeager, M.H. (2009): Characteristics and needs of people with intellectual disability who have higher IQs. Intellectual and Developmental Disabilities, Vol. 47, $N^{o} 3$, pp. 220-233. 
Solís, P. (2014): Calidad de vida y necesidades percibidas en personas con discapacidad intelectual que envejecen. Tesis doctoral. Facultad de Psicología, Universidad de Oviedo.

Souto, M. (2015): Necesidades percibidas en personas con Parkinson. Tesis doctoral. Facultad de Psicología, Universidad de Oviedo.

Stainton, T.; Brown, J.; Crawford, C.; Hole, R.; Charles, G. (2011): Comparison of community residential supports on measures of information \& planning; access to \& delivery of supports; choice \& control; community connections; satisfaction; and, overall perception of outcomes. JIDR, Vol. 55, part 8, pp. 732-745.

Stewart. T.L.; Chipperfield, J.G.; Ruthig, J.C.; Heckhausen, J. (2013): Downward social comparison and subjective well-being in late life: the moderating role of perceived control. Aging \& Mental Health, Vol. 17, $N^{\circ} 3$, pp. 375-385.

Stmadová, I.; Cumming, T.M.; Knox, M.; Parmenter, T. (2014): Building an inclusive research team: the importance of team building and skills training. JARID, 27, pp. $13-22$.

Sullivan, M.; Kempen, G.; Van Sonderen, E.; Ormel, J. (2000): Models of healthrelated quality of life in a population of community-dwelling Dutch elderly. Quality of life Research, 9, pp. 801-810.

Sun, X.; Lucas, H.; Meng, Q.; Zhang, Y. (2011): Associations between living arrangements and health-related quality of life of urban elderly people: a study from China. Qual. Life. Res., 20, pp. 359-369. 
Sutherland, D.; van der Meer, L.; Sigafoos, J.; Mirfin-Veitch, B.; Milner, P.; O’Reilly, M.F.; Lancioni, G.E.; Marschik, P.B. (2014): Survey of AAC needs for adults with intellectual disability in New Zealand. J Dev Phys Disabil, 26, pp. 115-122.

Tassé, M.J.; Wehmeyer, M.L. (2010): Intensity of support needs in relation to coocurring psyquiatric disorders. Exceptionality, 18, pp. 182-192.

Thompsom, J.R.; Bradley, V.J.; Buntinx, W.H.E.; Schalock, R.; Shogren, K.A.; Snell, M.; Wehmeyer, M.L.; Borthwick-Duffy, S.; Coulter, D.L.; Craig, E.M.; Gomez, S.C.; Lachapelle, Y.; Luckasson, R.A.; Reeve, A.; Spreat, S.; Tassé, M.J.; Verdugo, M.A.; Yeager, M.H. (2009): Conceptualizing supports and the support needs of people with intellectual disability. Intellectual and Developmental Disabilities, Vol. 47, $N^{\circ} 2$, pp. $135-146$.

Thompson, D.J.; Ryrie, I.; Wright, S. (2004): People with intellectual disabilities living in generic residential services for older people in the UK. Journal of Applied Research in Intellectual Disabilities, 17, pp. 101-108.

Thorpe, L.; Davidson, P.; Janicki, M. (2001): Healthy ageing: adults with intellectual disabilities: Biobehavioural issues. Journal of Applied Research in Intellectual Disabilities, 14, pp. 218-228.

Troutman, M.; Nies, M.A.; Bentley, M. (2011): Measuring successful aging in southern black older adults. Educational Gerontology, 37, pp. 38-50.

Turk, J. (2012): Mental health needs in adolescents with intellectual disabilities: crosssectional survey of a service sample. JARID, Vol. 25 (3), pp. 252-261.

Turner, R.; Spencer, M.; Williams, K. (2010): Lay meanings of health among rural older adults in Appalachia. The Journal of Rural Health, 27, pp. 13-20. 
Tyrer, F.; McGrother, C.W.; Thorp, C.F.; Taub, N.A.; Bhaumik, S.; Cicchetti, D.V. (2008): The Leicestershire intellectual disability tool: a simple measure to identify moderate to profound intellectual disability. Journal of Applied Research in Intellectual Disabilities, 21, pp. 268-276.

Urquijo, S.; Monchietti, A.; Krzemien, D. (2008): Adaptación a la crisis vital del envejecimiento: rol de los estilos de personalidad y de la apreciación cognitiva en adultos mayores. Anales de psicología, Vol. 24, N², pp. 299-311.

Üstün, T.B.; Chatterji, S.; Kostanjsek, N.; Rehm, J.; Kennedy, C.; Epping-Jordan, J.; Saxena, S.; von Korff, M.; Pull, C. (2010): Developing the World Health Organization Disability Assessment Schedule 2.0. Bull World Health Organ, 88, pp. 815823.

Van De Wouw, E.; Evenhuis, H.M.; Echteld, M. (2013): Comparison of two types of Actiwatch with polysomnography in older adults with intellectual disability: A pilot study. Journal of Intellectual \& Developmental Disability, Vol. 38, 3, pp. 265-273.

Van Loon, J.; Claes, C.; Vandevelve, S.; Van Hove, Schalock, R.L. (2010): Assessing individual support needs to enhance personal outcomes. Exceptionality, 18, pp. 193202.

Verbrugge, L.; Yang, L-S. (2002): Aging with disability and disability with aging. Journal of Disability Policy Studies, Vol. 12, N4, pp. 253-267.

Verdugo, M.A. (1995): Personas con discapacidad. Perspectivas psicopedagógicas y rehabilitadoras. Madrid, Siglo Veintiuno de España Editores, Cap. 11, pp. 515-551.

Verdugo, M.A. (2003): Aportaciones de la definición de retraso mental (AAMR, 2002) a la corriente inclusiva de las personas con discapacidad. SID: Ponencia presentada 
en el Congreso La respuesta a las necesidades educativas especiales en una escuela vasca inclusiva: San Sebastián, Octubre de 2003.

Verdugo, M.A.; Arias, B.; Ibáñez, A.; Schalock, R.L. (2010): Adaptation and psychometric properties of the Spanish version of the Supports Intensity Scale (SIS). AJIDD, Vol. 115, Nº, pp. 496-503.

Verdugo, M.A.; Gómez, L.E.; Arias, B.; Navas, P. (2012): Evidencias de validez del modelo de calidad de vida de ocho dimensiones y aplicación de la escala INTEGRAL en distintos países. En Verdugo, M.A.; Canal, R.; Jenaro, C.; Badia, M.; Aguado, A.L.: Aplicación del paradigma de calidad de vida a la intervención con personas con discapacidad intelectual desde una perspectiva integral. Publicaciones del INICO, pp. 11-26.

Verdugo, M.A.; Jordán de Urríes, B.; Jenaro, C.; Caballo, C.; Crespo, M. (2006): Quality of life of workers with an intellectual disability in supported employment. Journal of Applied Research in Intellectual Disabilities, 19, pp. 309-316.

Verdugo, M.A.; Rodríguez, A.; Sánchez, M.C. (2009): Familias y personas con discapacidad intelectual en proceso de envejecimiento. Obra Social Caja Madrid, Editorial Síntesis.

Virués-Ortega, J.; de Pedro-Cuesta, J.; Seijo-Martínez, M.; Saz, P.; Sánchez-Sánchez, F.; Rojo-Pérez, F.; Rodríguez, F.; Mateos, R.; Martínez-Martín, P.; Mahillo, I.; Gascon-Bayarri, J.; Garre-Olmo, J.; García, F.J.; Fernández-Mayoralas, G.; Bermejo-Pareja, F.; Bergareche, A.; Almazan-Isla, J.; del Barrio, J.L. (2011): Prevalence of disability in a composite $\geq 75$ year-old population in Spain: a screening survey 
based on the International Classification of Functioning. BMC Public Health, 11, pp. 176-187.

Walker, R.; Luszcz, M.; Gerstorf, D.; Hoppmann, C. (2011): Subjective well-being dynamics in couples from the Australian Longitudinal Study of Aging. Gerontology, 57, pp. 153-160.

Wan, M.; Schalock, R.L.; Verdugo, M.A:; Jenaro, C. (2010): Examining the factor structure and hierarchical nature of the quality of life construct. AJIDD, Vol. 115, $N^{o} 3$, pp. 218-233.

Wang, H-M.; Patrick, D.L.; Edwards, T.C.; Skalicky, A.M.; Zeng, H-Y; Gu, W-W (2012): Validation of the EQ-5D in a general population sample in urban China. Qual. Life Res., 21, pp. 155-160.

Wark, S.; Hussain, R.; Edwards, H. (2014): The training needs of staff supporting individuals ageing with intellectual disability. JARID, 27, pp. 273-288.

Wehmeyer, M.L.; Buntinx, W.H.E.; Lachapelle, Y.; Luckasson, A.; Schalock, R.L.; Verdugo, M.A.; Borthwick-Duffy, S.; Bradley, V.; Craig, E.M.; Coulter, D.L.; Gomez, S.C.; Reeve, A.; Shogren, K.A.; Snell, M.E.; Spreat, S.; Tassé, M.J.; Thompsom, J.R.; Yeager, M.H. (2008): The intellectual disability construct and its relation to human functioning. Intellectual and developmental disabilities, Vol. 46, $N^{\circ} 4$, pp. $311-318$

Whitehouse, M.; Tudway, J.; Look, R.; Stenfert, B. (2006): Adapting Individual Psychotherapy for adults with intellectual disabilities: a comparative review of the cognitive-behavioral and psychodynamic literature. Journal of Applied Research in Intellectual Disabilities, 19, pp. 55-65. 
Willman, A.; Petzäll, K; Östnerg, A-L; Hall-Lord, M.L. (2013): The psycho-social dimension of pain and health-related quality of life in the oldest old. Scand H Caring Sci, 27, pp. 534-540. doi: 10.1111/j.1471-6712.2012.01062.x

Won, P.K.S.; Wong, D.F.K.; Schalock, R.L.; Chou, Y-C (2011): Initial validation of the Quality of Life Questionnaire - Intellectual Disabilities (CQOL-ID): a cultural perspective. JIDR, Vol. 55, part 6, pp. 572-580.

Yaffe, K.; Lindquist, K.; Vittinghoff, E.; Barnes, D.; Simonsick, E.; Newman, A.; Satterfield, S.; Rosano, C.; Rubin, S.; Ayonayon, H.; Harris, T. (2010): The effect of maintaining cognition on risk of disability and death. JAGS, Vol. 58, $N^{o 5}$, pp. 889894.

Zakrajsek, A.G.; Hammel, J.; Scazzero, J.A. (2014): Supporting people with intellectual and developmental disabilities to participate in their communities through support staff pilot intervention. JARID, 27, pp. 154-162

Zigman, W.B. (2013): Atypical aging in Down Syndrome. Developmental Disabilities Research Reviews, 18, pp. 51-67. 
15. ANEXOS

15.1. ANEXO 1: ENTREVISTA PERSONAL Y FAMILIAR

ENTREVISTA PERSONAL

\author{
CALIDAD DE VIDA Y \\ NECESIDADES PERCIBIDAS EN \\ EL PROCESO DE ENVEJECIMIENTO \\ DE LAS PERSONAS CON DISCAPACIDAD
}

Antonio-León Aguado Díaz

$\mathbf{y}$

\title{
María de los Ángeles Alcedo Rodríguez
}

Departamento de Psicología

Universidad de Oviedo

Plaza Feijoo, s/n - 33003 - Oviedo

Tel: 98-5103284 / Fax: 98-5104144

E-mail: aaguado@uniovi.es
SAPRE

Sociedad Asturiana de Psicología de la Rehabilitación Asturcón, 18 - 33006 - Oviedo

Tel / Fax: 985-244266

E-mail: sapre@cop.es y alaguado@cop.es 


\section{FICHA PERSONAL (RESUMEN)}

- Nombre y apellidos:

- Dirección:

- Población:

- Código postal:

- Teléfono

- Fecha de aplicación:

- Lugar de aplicación:

- Cumplimentada por:

- Entrevistador:

- Tipo de discapacidad:

- Causa de la discapacidad:

- Edad de adquisición:

- Asociación:

- Convivencia (Precisar el tipo de convivencia, en especial el tipo de residencia):

- Necesidades percibidas (Señalar las más importantes):

- Observaciones:

- Número de orden: 


\section{DATOS PERSONALES}

1. Número de orden:

2. Lugar de aplicación de la entrevista:

\begin{tabular}{|l|l|l|l|}
\hline 1. Domicilio particular & 2. Residencia & 3. Centro social & 4. Centro de trabajo \\
\hline 5. Domicilio de otro familiar & 6. Asociación & 7. Centro de día & 8. Otro: \\
\hline
\end{tabular}

3. Entrevista cumplimentada por:

\begin{tabular}{|l|l|l|l|}
\hline 1. Autoaplicada & 2. Familiar & 3. Amigo & 4. Personal de la asociación \\
\hline 5. Trabajador social & 6. Personal del centro & 7. Vecino & 8. Otro: \\
\hline
\end{tabular}

4. Género (de la persona con discapacidad entrevistada):

$$
\text { 1. Hombre }
$$

2. Mujer

5. Fecha de nacimiento:

6. Edad:

7. Estado civil:

\begin{tabular}{|l|l|}
\hline 1. Soltero & 2. Casado \\
\hline 3. En pareja & 4. Separado/a Divorciado/a \\
\hline 5. Viudo/a & 6. Otros: \\
\hline
\end{tabular}

8. Lugar de nacimiento:

9. Lugar de residencia:

Población:

10. Nivel cultural:

\begin{tabular}{|l|l|}
\hline 1. Sin alfabetizar & $\begin{array}{c}\text { 2. Neolector (lee y escribe sin forma- } \\
\text { ción académica alguna) }\end{array}$ \\
\hline $\begin{array}{c}\text { 3. Primario (Primarios, CEP, GE, } \\
\text { Bach. Elemental, EGB, FPI) }\end{array}$ & $\begin{array}{c}\text { 4. Medio (BUP, COU, PREU, ESO, } \\
\text { FPII) }\end{array}$ \\
\hline 5. Diplomado (Diplomaturas) & 6: Título superior (Licenciaturas) \\
\hline
\end{tabular}

11. Tipo de discapacidad: (En caso de varias, señalar la discapacidad principal)

\begin{tabular}{|l|l|}
\hline 1. Discapacidad intelectual & 2. Discapacidad física \\
\hline 3. Deficiencia visual & 4. Deficiencia auditiva \\
\hline 5. Trastornos mentales & 6. Enfermedad de Alzheimer \\
\hline 7. Enfermedad de Parkinson & 8. Autismo \\
\hline
\end{tabular}

12. Causa de la discapacidad:

\begin{tabular}{|l|l|}
\hline 1. Desconocida & 2. Congénita y/o perinatal \\
\hline 3. Enfermedad antes de los 5 años & 4. Enfermedad posterior \\
\hline 5. Accidente de tráfico & 6. Accidente laboral \\
\hline 7. Otros accidentes: & 8. Otras causas: \\
\hline
\end{tabular}


13. Diagnóstico o descripción de la discapacidad: (En caso de varias, señalarlas todas indicando cuál es la discapacidad principal ó $1^{\mathrm{a}}$, la $2^{\mathrm{a}}, 3^{\mathrm{a}}$, etc.)

(Es muy necesario contestar bien esta pregunta):

\begin{tabular}{|c|c|}
\hline 110. Síndrome de Down & 310. Ceguera completa \\
\hline \multirow{2}{*}{$\begin{array}{l}\text { 190. Discapacidad intelectual, defi- } \\
\text { ciencia o retraso mental }\end{array}$} & 320. Ceguera parcial \\
\hline & 340. Retinosis pigmentaria \\
\hline 211. Lesión medular & 390. Otra deficiencia visual \\
\hline 212. Amputación & 410. Sordera total \\
\hline 213. Secuelas de poliomielitis & 420. Hipoacusia \\
\hline \multirow{2}{*}{$\begin{array}{l}\text { 219. Otra discapacidad física sin afec- } \\
\text { tación cerebral }\end{array}$} & 490. Otra deficiencia auditiva \\
\hline & 520. Esquizofrenia \\
\hline 221. Esclerosis múltiple & 590. Otro trastorno mental \\
\hline 222. Fibromialgia & 610. Enfermedad de Alzheimer \\
\hline \multirow{2}{*}{$\begin{array}{l}\text { 223. Artrosis, artritis y enfermedades } \\
\text { reumatológicas }\end{array}$} & 710. Enfermedad de Parkinson \\
\hline & 810. Autismo \\
\hline 229. Otra discap. física por enfermedad & 910. Epilepsia \\
\hline 231. Parálisis cerebral & 920. Problemas de conducta \\
\hline 232. Accidente cerebro-vascular & \multirow[t]{2}{*}{ 990. Otra: } \\
\hline $\begin{array}{l}\text { 239. Otra discapacidad física con afec- } \\
\text { tación cerebral }\end{array}$ & \\
\hline
\end{tabular}

14. Edad de adquisición de la discapacidad (si no se sabe, aproximada):

15. ¿Está reconocido oficialmente como minusválido?

\begin{tabular}{|l|l|}
\hline 1. Sí & 2. No \\
\hline
\end{tabular}

16. Grado de minusvalía asignado:

17. Nivel o cualificación profesional:

\begin{tabular}{|l|l|}
\hline 1. Ama de casa & 2. No ha trabajado \\
\hline 3. Cualificación profesional baja & 4. Cualificación profesional media \\
\hline 5. Cualificación profesional alta & 6. Autónomo, artesano, empresario o similar \\
\hline 7. Otras: &
\end{tabular}

18. Situación laboral actual:

\begin{tabular}{|l|l|}
\hline 1. Ama de casa & 2. En activo \\
\hline 3. En paro y/o sin empleo & 4. Jubilado/a \\
\hline 5. Pensionista & 6. Otra: \\
\hline
\end{tabular}

19. Ingresos:

\begin{tabular}{|l|l|}
\hline 1. Sin ingresos & 2. Sin ingresos fijos \\
\hline 3. Salario laboral & 4. Pensión no contributiva \\
\hline 5. Pensión contributiva & 6. Otras pensiones: \\
\hline 7. Otros ingresos: & 8. Otras situaciones: \\
\hline
\end{tabular}

20. ¿Viven sus padres?

\begin{tabular}{|l|l|}
\hline 1. Viven los dos & 2. Vive su padre \\
\hline 3. Vive su madre & 4. No vive ninguno de los dos \\
\hline
\end{tabular}

En su caso, edades de sus padres: 
21. ¿Cuántos hermanos tiene?

En el caso de que estén vivos, edades de sus hermanos:

22. ¿Cuántos hijos tiene?

En su caso, edades de sus hijos:

23. ¿Con quién vive? (Concretar el tipo de convivencia, el tipo de residencia, etc.)

\begin{tabular}{|l|l|}
\hline 01. Sólo & 02. Con su cónyuge o pareja \\
\hline 03. Con su cónyuge e hijos & 04. Con sus hijos \\
\hline 05. Con sus padres & 06. Con sus padres y hermanos \\
\hline 07. Con sus hermanos & 08. Con otros parientes \\
\hline 09. Con otras personas & 10. En una pensión o similar \\
\hline 11. En una institución tutelar & 12. En un piso asistido \\
\hline 13. En un servicio residencial público & 14. En un servicio residencial privado \\
\hline 15. En un centro para personas con discapacidad & 16. En otra institución \\
\hline 17. En otra situación (concretar): & \\
\end{tabular}

24. Indíquenos, por favor, las preocupaciones y/o las necesidades que sean importantes para $\mathrm{Vd}$. (Puede marcar más de una respuesta):

2410 Tema de su salud personal:

\begin{tabular}{|l|l|}
\hline 2411. Estado de salud general & 2412. Cuidados personales diarios \\
\hline 2413. Limitaciones funcionales personales & 2414. Dependencia \\
\hline 2415. Dificultades para tomar la medicación & 2416. Dificultades para acudir al tratamiento \\
\hline 2417. Dolores & 2418. Aceptación de mi situación \\
\hline 2419. Otras: & \\
\end{tabular}

2420 Recursos económicos:

\begin{tabular}{|l|l|}
\hline 2421. Situación económica familiar & 2422. Independencia económica \\
\hline 2423. Subvenciones & 2424. Pensión \\
\hline 2425. Encontrar un puesto de trabajo & 2426. Incapacidad laboral \\
\hline 2427. Otras: &
\end{tabular}

2430 Recursos asistenciales sanitarios:

\begin{tabular}{|l|l|}
\hline 2431. Asistencia sanitaria hospitalaria & 2432. Asistencia sanitaria domiciliaria \\
\hline 2433. Dispositivos de apoyo y protésicos & 2434. Tratamiento de fisioterapia \\
\hline 2435. Falta de información sobre estos recursos & 2436. Calidad de la asistencia sanitaria \\
\hline 2437. Más y mejores instalaciones sanitarias & 2438. Asistencia en salud mental \\
\hline 2439. Otras: & \multicolumn{2}{|l}{} \\
\hline
\end{tabular}

2440 Recursos de servicios sociales:

\begin{tabular}{|l|l|}
\hline 2441. Servicios de alojamiento & 2442. Ayuda a domicilio \\
\hline 2443. Apoyo en las gestiones administrativas & 2444. Más y mejores instalaciones sociales \\
\hline 2445. Falta de información sobre estos recursos & 2446. Calidad de la asistencia social \\
\hline 2447. Servicios de apoyo al ocio y tiempo libre & 2448. Asesoramiento jurídico \\
\hline 2449. Otras: &
\end{tabular}


2450 Existencia de barreras:

\begin{tabular}{|l|l|}
\hline 2451. Barreras sociales & 2452. Barreras arquitectónicas \\
\hline 2453. Aceptación por parte de la familia & 2454. Aceptación por parte de la sociedad \\
\hline 2455. Ayudas técnicas & 2456. Escasez de voluntariado \\
\hline 2457. Facilidad de transporte & 2458. Accesibilidad edificios públicos \\
\hline 2459. Otras: &
\end{tabular}

2460 Otras preocupaciones y/o necesidades:

\begin{tabular}{|l|l|}
\hline 2461. Salida del domicilio familiar & 2462. Futuro de la familia \\
\hline 2463. Escasez de relaciones personales & 2464. Protección jurídica \\
\hline 2465. Dónde y con quién vivir en el futuro & 2466. Avances tecnológicos \\
\hline 2467. Problemas sociales & 2468. Problemas del movimiento asociativo \\
\hline 2469. Otras: &
\end{tabular}

25. Indíquenos, por favor, las soluciones que Vd. considera necesarias. (Puede marcar más de una respuesta):

2511. Ayuda para cuidados personales diarios

2513. Incremento de la ayuda familiar

2515. Reserva de puestos de trabajo

2517. Más y mejores instalaciones sanitarias

2519. Profesionales más especializados

2521. Mejora de apoyos y prótesis

2523. Fisioterapia en la Seguridad Social

2525. Apoyo legal y administrativo

2512. Subida de las pensiones

2514. Promoción del empleo protegido

2516. Incremento de las subvenciones

2518. Adelantar la jubilación

2520. Calidad de la asistencia sanitaria

2522. Asistencia psicológica

2524. Más y mejor información

2527. Mejora de los servicios de alojamiento

2529. Mejora de la asistencia a domicilio

2526. Más información sobre recursos

2531. Servicios de apoyo al ocio y tiempo libre

2533. Supresión de barreras arquitectónicas

2535. Programas de cambio de actitudes

2537. Más y mejores ayudas técnicas

2539. Aceptación por parte de la familia

2528. Más y mejores instalaciones sociales

2530. Calidad de la asistencia social

2532. Centros de día

2534. Campañas de imagen

2536. Promoción de voluntariado

2541. Incremento de la participación asociativa

2543. Promoción de viviendas adaptadas

2538. Aceptación por parte de la sociedad

2540. Garantías de futuro

2542. Facilidades de transporte

2545. Otras:

2544. Apoyo a los cuidadores informales

26. Indíquenos, por favor, las medidas o apoyos institucionales que Vd. echa en falta. (Puede marcar más de una respuesta):

\begin{tabular}{|l|l|}
\hline $\begin{array}{l}\text { 2621. Coordinación entre las distintas adminis- } \\
\text { traciones }\end{array}$ & $\begin{array}{l}\text { 2622. Incrementar los recursos de las aso- } \\
\text { ciaciones }\end{array}$ \\
\hline 2623. Actividades culturales & 2624. Actividades de formación \\
\hline 2625. Apoyo de la Comunidad & 2626. Apoyo de los Ayuntamientos \\
\hline 2627. Apoyos en el entorno & 2628. Igualdad de oportunidades \\
\hline 2629. Otras: & \\
&
\end{tabular}

27. ¿Qué piensa sobre su futuro? (Puede marcar más de una respuesta): 
2705. Soledad

2707. Pocas ganas de vivir

2709. Mal, negro

2711. Bien, sin problemas

2713. Resuelto

2715. Preocupación por los hijos

2717. Otros:
2706. Vida independiente

2708. Con preocupación, futuro incierto

2710. Vivir con calidad de vida

2712. Aburrimiento

2714. Dependerá del asociacionismo

2716. Autonomía personal

28. Marque con una cruz cualquiera de los siguientes problemas que sean aplicables a su caso. (Puede marcar hasta seis problemas):

\begin{tabular}{|l|l|}
\hline 2801. Problemas de salud & 2802. Inseguridad \\
\hline 2803. Ideas de suicidio & 2804. Ansiedad, tensión, estrés \\
\hline 2805. Problemas sexuales & 2806. Miedo a casi todo \\
\hline 2807. No encontrar salida a mi situación & 2808. No poder hacer amistades \\
\hline 2809. Malas condiciones en el hogar & 2810. No poder divertirme \\
\hline 2811. Sentimientos de inferioridad & 2812. Alcoholismo \\
\hline 2813. Insomnio & 2814. Drogas \\
\hline 2815. Timidez & 2816. Problemas de memoria \\
\hline 2817. Incapaz de tomar decisiones & 2818. Pocas ganas de vivir \\
\hline 2819. Depresión & 2820. Miedo a la muerte \\
\hline 2821. Soledad & 2822. Aburrimiento \\
\hline 2823. Otros & \\
& \\
\hline
\end{tabular}

29. Me considero una persona como las demás, ni mejor ni peor.

\begin{tabular}{|l|l|l|l|}
\hline 1. Totalmente en desacuerdo & 2. Muy en desacuerdo & 3. Muy de acuerdo & 4. Totalmente de acuerdo \\
\hline
\end{tabular}

30. La religión es importante para mí.

\begin{tabular}{|l|l|l|l|}
\hline 1. Totalmente en desacuerdo & 2. Muy en desacuerdo & 3. Muy de acuerdo & 4. Totalmente de acuerdo \\
\hline
\end{tabular}

31. Soy practicante.

\begin{tabular}{|l|l|l|l|}
\hline 1. Totalmente en desacuerdo & 2. Muy en desacuerdo & 3. Muy de acuerdo & 4. Totalmente de acuerdo
\end{tabular}

32. Estoy satisfecho/a con mi situación actual.

\begin{tabular}{|l|l|l|l|}
\hline 1. Totalmente en desacuerdo & 2. Muy en desacuerdo & 3. Muy de acuerdo & 4. Totalmente de acuerdo
\end{tabular}

33. Me preocupa el futuro.

\begin{tabular}{|l|l|l|l|}
\hline 1. Totalmente en desacuerdo & 2. Muy en desacuerdo & 3. Muy de acuerdo & 4. Totalmente de acuerdo
\end{tabular}

34. Me encuentro satisfecho/a conmigo mismo/a.

\begin{tabular}{|l|l|l|l|} 
1. Totalmente en desacuerdo & 2. Muy en desacuerdo & 3. Muy de acuerdo & 4. Totalmente de acuerdo \\
\hline
\end{tabular}

35. Mi vida afectiva es satisfactoria y gratificante.

\begin{tabular}{|l|l|l|l|}
\hline 1. Totalmente en desacuerdo & 2. Muy en desacuerdo & 3. Muy de acuerdo & 4. Totalmente de acuerdo \\
\hline
\end{tabular}

36. Me siento a gusto en el ambiente en el que vivo.

\begin{tabular}{|l|l|l|l|}
\hline 1. Totalmente en desacuerdo & 2. Muy en desacuerdo & 3. Muy de acuerdo & 4. Totalmente de acuerdo \\
\hline
\end{tabular} 
37. Tengo problemas familiares importantes.

\begin{tabular}{|l|l|l|l|}
\hline 1. Totalmente en desacuerdo & 2. Muy en desacuerdo & 3. Muy de acuerdo & 4. Totalmente de acuerdo \\
\hline
\end{tabular}

38. Me siento satisfecho/a con mis relaciones familiares.

\begin{tabular}{|l|l|l|l|}
\hline 1. Totalmente en desacuerdo & 2. Muy en desacuerdo & 3. Muy de acuerdo & 4. Totalmente de acuerdo
\end{tabular}

39. Creo que mi familia me apoya lo suficiente.

\begin{tabular}{|l|l|l|l|}
\hline 1. Totalmente en desacuerdo & 2. Muy en desacuerdo & 3. Muy de acuerdo & 4. Totalmente de acuerdo
\end{tabular}

40. En caso de no vivir con mi familia, ha sido por decisión propia.

\begin{tabular}{|l|l|l|l|}
\hline 1. Totalmente en desacuerdo & 2. Muy en desacuerdo & 3. Muy de acuerdo & 4. Totalmente de acuerdo \\
\hline
\end{tabular}

41. Considero satisfactorio el trato que recibo.

\begin{tabular}{|l|l|l|l|} 
1. Totalmente en desacuerdo & 2. Muy en desacuerdo & 3. Muy de acuerdo & 4. Totalmente de acuerdo \\
\hline
\end{tabular}

42. Tengo amigos.

\begin{tabular}{|l|l|l|l|} 
1. Totalmente en desacuerdo & 2. Muy en desacuerdo & 3. Muy de acuerdo & 4. Totalmente de acuerdo \\
\hline
\end{tabular}

43. Considero satisfactorias mis relaciones de amistad.

\begin{tabular}{|l|l|l|l|}
\hline 1. Totalmente en desacuerdo & 2. Muy en desacuerdo & 3. Muy de acuerdo & 4. Totalmente de acuerdo
\end{tabular}

44. Dispongo de la intimidad necesaria para contactar y relacionarme con la gente. $\quad$ v44

\begin{tabular}{|l|l|l|l|}
\hline 1. Totalmente en desacuerdo & 2. Muy en desacuerdo & 3. Muy de acuerdo & 4. Totalmente de acuerdo
\end{tabular}

45. Mis relaciones sociales son como las de los demás.

\begin{tabular}{|l|l|l|l|}
\hline 1. Totalmente en desacuerdo & 2. Muy en desacuerdo & 3. Muy de acuerdo & 4. Totalmente de acuerdo
\end{tabular}

46. Me encuentro satisfecho/a con mi situación actual.

\begin{tabular}{|l|l|l|l|}
\hline 1. Totalmente en desacuerdo & 2. Muy en desacuerdo & 3. Muy de acuerdo & 4. Totalmente de acuerdo \\
\hline
\end{tabular}

47. Considero suficientes los ingresos de que dispongo en la actualidad.

\begin{tabular}{|l|l|l|l|}
\hline 1. Totalmente en desacuerdo & 2. Muy en desacuerdo & 3. Muy de acuerdo & 4. Totalmente de acuerdo \\
\hline
\end{tabular}

48. Dispongo de vivienda propia.

\begin{tabular}{|l|l|l|l|}
\hline 1. Totalmente en desacuerdo & 2. Muy en desacuerdo & 3. Muy de acuerdo & 4. Totalmente de acuerdo \\
\hline
\end{tabular}

49. Mi vivienda reúne las condiciones adecuadas.

\begin{tabular}{|l|l|l|l|}
\hline 1. Totalmente en desacuerdo & 2. Muy en desacuerdo & 3. Muy de acuerdo & 4. Totalmente de acuerdo
\end{tabular}

50. Necesito adaptar mi vivienda.

\begin{tabular}{|l|l|l|l|}
\hline 1. Totalmente en desacuerdo & 2. Muy en desacuerdo & 3. Muy de acuerdo & 4. Totalmente de acuerdo \\
\hline
\end{tabular}


51. El lugar (barrio o zona) en que resido reúne las condiciones adecuadas.

\begin{tabular}{|l|l|l|l|} 
1. Totalmente en desacuerdo & 2. Muy en desacuerdo & 3. Muy de acuerdo & 4. Totalmente de acuerdo
\end{tabular}

52. Son necesarias adaptaciones en el lugar en que resido.

\begin{tabular}{|l|l|l|l|}
\hline 1. Totalmente en desacuerdo & 2. Muy en desacuerdo & 3. Muy de acuerdo & 4. Totalmente de acuerdo
\end{tabular}

53. Tengo carnet de conducir.

\begin{tabular}{|l|l|l|l|}
\hline 1. Totalmente en desacuerdo & 2. Muy en desacuerdo & 3. Muy de acuerdo & 4. Totalmente de acuerdo
\end{tabular}

54. Dispongo de coche propio.

\begin{tabular}{|l|l|l|l|}
\hline 1. Totalmente en desacuerdo & 2. Muy en desacuerdo & 3. Muy de acuerdo & 4. Totalmente de acuerdo
\end{tabular}

55. Necesito algún tipo de ayuda técnica personal.

\begin{tabular}{|l|l|l|l|}
\hline 1. Totalmente en desacuerdo & 2. Muy en desacuerdo & 3. Muy de acuerdo & 4. Totalmente de acuerdo \\
\hline
\end{tabular}

56. Dispongo de las ayudas técnicas personales necesarias.

\begin{tabular}{|l|l|l|l|}
\hline 1. Totalmente en desacuerdo & 2. Muy en desacuerdo & 3. Muy de acuerdo & 4. Totalmente de acuerdo
\end{tabular}

57. Actualmente mi capacidad para cuidar de mí mismo/a presenta un grado:

\begin{tabular}{|l|l|l|l|l|}
\hline 1. Muy bajo & 2. Bajo & 3. Intermedio & 4. Alto & 5. Muy alto \\
\hline
\end{tabular}

58. Mi capacidad para ocuparme del bienestar de mi familia presenta un grado:

\begin{tabular}{|l|l|l|l|l|}
\hline 1. Muy bajo & 2. Bajo & 3. Intermedio & 4. Alto & 5. Muy alto \\
\hline
\end{tabular}

59. Mi capacidad para relacionarme y comunicarme con la gente presenta un grado:

\begin{tabular}{|l|l|l|l|l|}
\hline 1. Muy bajo & 2. Bajo & 3. Intermedio & 4. Alto & 5. Muy alto \\
\hline
\end{tabular}

60. Mi autonomía para realizar tareas domésticas presenta un grado:

\begin{tabular}{|l|l|l|l|l|}
\hline 1. Muy bajo & 2. Bajo & 3. Intermedio & 4. Alto & 5. Muy alto \\
\hline
\end{tabular}

61. Mi autonomía para realizar actividades básicas, como vestirme desvestirme, comer e higiene personal, presenta un grado:

\begin{tabular}{|l|l|l|l|l|}
\hline 1. Muy bajo & 2. Bajo & 3. Intermedio & 4. Alto & 5. Muy alto \\
\hline
\end{tabular}

62. Mi autonomía para levantarme y acostarme presenta un grado:

\begin{tabular}{|l|l|l|l|l|}
\hline 1. Muy bajo & 2. Bajo & 3. Intermedio & 4. Alto & 5. Muy alto \\
\hline
\end{tabular}

63. Mi autonomía para cambiar la posición de mi cuerpo presenta un grado:

\begin{tabular}{|l|l|l|l|l|}
\hline 1. Muy bajo & 2. Bajo & 3. Intermedio & 4. Alto & 5. Muy alto \\
\hline
\end{tabular}

64. Mi autonomía para moverme y desplazarme dentro y fuera del hogar presenta un grado:

\begin{tabular}{|l|l|l|l|l|}
\hline 1. Muy bajo & 2. Bajo & 3. Intermedio & 4. Alto & 5. Muy alto \\
\hline
\end{tabular}


65. Mi autonomía para utilizar transportes públicos presenta un grado:

\begin{tabular}{|l|l|l|l|l|}
\hline 1. Muy bajo & 2. Bajo & 3. Intermedio & 4. Alto & 5. Muy alto \\
\hline
\end{tabular}

66. Mi control de esfínteres presenta un grado:

\begin{tabular}{|l|l|l|l|l|}
\hline 1. Muy bajo & 2. Bajo & 3. Intermedio & 4. Alto & 5. Muy alto \\
\hline
\end{tabular}

67. Realizo frecuentemente algún tipo de ejercicio físico o actividad deportiva.

\begin{tabular}{|l|l|l|l|}
\hline 1. Totalmente en desacuerdo & 2. Muy en desacuerdo & 3. Muy de acuerdo & 4. Totalmente de acuerdo \\
\hline
\end{tabular}

68. Me encuentro satisfecho/a con mi vida sexual actual.

\begin{tabular}{|l|l|l|l|}
\hline 1. Totalmente en desacuerdo & 2. Muy en desacuerdo & 3. Muy de acuerdo & 4. Totalmente de acuerdo \\
\hline
\end{tabular}

69. Normalmente tomo decisiones en aspectos de mi vida diaria, como elección del tipo de comida y vestido, o dónde y con quién salir.

\begin{tabular}{|l|l|l|l|}
\hline 1. Totalmente en desacuerdo & 2. Muy en desacuerdo & 3. Muy de acuerdo & 4. Totalmente de acuerdo
\end{tabular}

70. La calidad de mis hábitos alimenticios presenta un grado:

\begin{tabular}{|l|l|l|l|l|}
\hline 1. Muy bajo & 2. Bajo & 3. Intermedio & 4. Alto & 5. Muy alto \\
\hline
\end{tabular}

71. Puedo elegir ahora, o en el futuro, dónde y con quién vivir.

\begin{tabular}{|l|l|l|l|}
\hline 1. Totalmente en desacuerdo & 2. Muy en desacuerdo & 3. Muy de acuerdo & 4. Totalmente de acuerdo \\
\hline
\end{tabular}

72. Tengo metas y objetivos importantes en mi vida.

\begin{tabular}{|l|l|l|l|}
\hline 1. Totalmente en desacuerdo & 2. Muy en desacuerdo & 3. Muy de acuerdo & 4. Totalmente de acuerdo
\end{tabular}

73. Considero que tengo buen control personal.

\begin{tabular}{|l|l|l|l|}
\hline 1. Totalmente en desacuerdo & 2. Muy en desacuerdo & 3. Muy de acuerdo & 4. Totalmente de acuerdo \\
\hline
\end{tabular}

74. En general me siento satisfecho/a y contento/a con la vida.

\begin{tabular}{|l|l|l|l|}
\hline 1. Totalmente en desacuerdo & 2. Muy en desacuerdo & 3. Muy de acuerdo & 4. Totalmente de acuerdo
\end{tabular}

75. Sigo habitualmente tratamiento farmacológico.

\begin{tabular}{|l|l|l|l|}
\hline 1. Totalmente en desacuerdo & 2. Muy en desacuerdo & 3. Muy de acuerdo & 4. Totalmente de acuerdo \\
\hline
\end{tabular}

76. Personalmente considero que mi estado de salud presenta un grado:

\begin{tabular}{|l|l|l|l|l|}
\hline 1. Muy bajo & 2. Bajo & 3. Intermedio & 4. Alto & 5. Muy alto \\
\hline
\end{tabular}

77. Prestaciones que recibe de alguno de los siguientes servicios de atención sociosanitaria. (Puede marcar más de una respuesta):

\begin{tabular}{l|l|l|l|l|} 
1. Ninguna & 2. Rehabilitación & 3. Fisioterapia & 4. Salud mental & 5. Otros:
\end{tabular}

78. Me encuentro satisfecho/a con la atención que recibo en dichos servicios.

\begin{tabular}{|l|l|l|l|}
\hline 1. Totalmente en desacuerdo & 2. Muy en desacuerdo & 3. Muy de acuerdo & 4. Totalmente de acuerdo \\
\hline
\end{tabular}


79. ¿Cómo se podría mejorar la atención y la asistencia que recibe?

(Puede marcar más de una respuesta):

\begin{tabular}{|c|c|c|c|c|}
\hline $\begin{array}{c}\text { 1. Servicios más } \\
\text { especializados }\end{array}$ & $\begin{array}{c}\text { 2. Personal } \\
\text { mejor formado }\end{array}$ & $\begin{array}{c}\text { 3. Trato más } \\
\text { humano }\end{array}$ & $\begin{array}{c}\text { 4. No necesita } \\
\text { mejorar }\end{array}$ & 5. Otras: \\
\hline
\end{tabular}

80. Practico frecuentemente algún tipo de hobby o actividad de ocio.

\begin{tabular}{|l|l|l|l|}
\hline 1. Totalmente en desacuerdo & 2. Muy en desacuerdo & 3. Muy de acuerdo & 4. Totalmente de acuerdo
\end{tabular}

81. ¿Cuál de ellas? (Puede marcar más de una respuesta):

\begin{tabular}{|c|c|c|c|c|c|}
\hline 1. Leer, escuchar música, cine & \multicolumn{3}{|c|}{ 2. Actividades deportivas } & 3. Viajar & 4. Estudiar \\
\hline \multicolumn{2}{|c|}{ 5. Salir con amigos, fiestas, discoteca } & 6. Ninguna & \multicolumn{3}{|c|}{ 7. Otras: } \\
\hline
\end{tabular}

82. ¿En qué le gustaría ocupar su tiempo libre?

(Puede marcar más de una respuesta):

\begin{tabular}{|c|c|c|c|c|c|}
\hline 1. Leer, escuchar música, cine & \multicolumn{3}{|c|}{ 2. Actividades deportivas } & 3. Viajar & 4. Estudiar \\
\hline \multicolumn{2}{|c|}{ 5. Salir con amigos, fiestas, discoteca } & 6. Ninguna & \multicolumn{3}{|c|}{ 7. Otras: } \\
\hline
\end{tabular}

83. Creo que es bueno que las personas que presentan problemas como el mío se reúnan y formen asociaciones para ayudarse y apoyarse mutuamente.

\begin{tabular}{|l|l|l|l|}
\hline 1. Totalmente en desacuerdo & 2. Muy en desacuerdo & 3. Muy de acuerdo & 4. Totalmente de acuerdo \\
\hline
\end{tabular}

84. Explique las razones para el asociacionismo. (Puede marcar más de una):

\begin{tabular}{|l|l|l|l|}
\hline 1. Ninguna & 2. Apoyo & 3 Fuerza, unión & 4. Otras: \\
\hline
\end{tabular}

85. Dispongo de información sobre los recursos sociales disponibles.

\begin{tabular}{|l|l|l|l|}
\hline 1. Totalmente en desacuerdo & 2. Muy en desacuerdo & 3. Muy de acuerdo & 4. Totalmente de acuerdo \\
\hline
\end{tabular}

86. ¿Qué tipo de apoyo recibe? (Puede marcar más de una respuesta):

\begin{tabular}{|l|l|l|l|l|}
\hline $\begin{array}{c}\text { 1. Apoyo informal (amigos/as, } \\
\text { vecinos/as, familia) }\end{array}$ & $\begin{array}{c}\text { 2. Apoyo formal (ayuda a domicilio, cen- } \\
\text { tro, expertos, técnicos) }\end{array}$ & $\begin{array}{c}\text { 3. Institución especializa- } \\
\text { da }\end{array}$ \\
\hline 4. Centros de día & 5. Programas de respiro & 6. Ninguno & 7. Otros: \\
\hline
\end{tabular}

87. Considero que la intensidad o frecuencia de estos apoyos es la adecuada.

\begin{tabular}{|l|l|l|l|}
\hline 1. Totalmente en desacuerdo & 2. Muy en desacuerdo & 3. Muy de acuerdo & 4. Totalmente de acuerdo \\
\hline
\end{tabular}

88. ¿Qué piensa de estos apoyos / servicios que recibe?

\begin{tabular}{|c|c|c|c|c|}
$\begin{array}{c}\text { 1. Atención } \\
\text { inmejorable }\end{array}$ & $\begin{array}{c}\text { 2. Buena } \\
\text { atención }\end{array}$ & $\begin{array}{c}\text { 3. Atención deficiente, } \\
\text { necesita mejorar }\end{array}$ & $\begin{array}{c}\text { 4: Muy mal } \\
\text { servicio }\end{array}$ & 5. Otras: \\
\hline
\end{tabular}

89. ¿Cómo se podría mejorar la asistencia que recibe? (Puede marcar más de una respuesta)

\begin{tabular}{|c|c|c|c|c|}
\hline $\begin{array}{c}\text { 1. Servicios más } \\
\text { especializados }\end{array}$ & $\begin{array}{c}\text { 2. Personal mejor } \\
\text { formado }\end{array}$ & $\begin{array}{c}\text { 3. Trato más } \\
\text { humano }\end{array}$ & $\begin{array}{c}\text { 4: No necesita } \\
\text { mejorar }\end{array}$ & 5. Otras: \\
\hline
\end{tabular}


90. Suelo participar en actividades de tipo comunitario.

\begin{tabular}{|l|l|l|l|}
\hline 1. Totalmente en desacuerdo & 2. Muy en desacuerdo & 3. Muy de acuerdo & 4. Totalmente de acuerdo
\end{tabular}

91. Las barreras arquitectónicas de mi entorno presentan un grado:

\begin{tabular}{|l|l|l|l|l|} 
1. Muy bajo & 2. Bajo & 3. Intermedio & 4. Alto & 5. Muy alto \\
\hline
\end{tabular}

92. Las limitaciones de acceso a la vida comunitaria impuestas por esas barreras presentan un grado:

\begin{tabular}{|l|l|l|l|l|}
\hline 1. Muy bajo & 2. Bajo & 3. Intermedio & 4. Alto & 5. Muy alto \\
\hline
\end{tabular}

93. Me siento respetado/a y aceptado/a por la sociedad.

\begin{tabular}{|l|l|l|l|}
\hline 1. Totalmente en desacuerdo & 2. Muy en desacuerdo & 3. Muy de acuerdo & 4. Totalmente de acuerdo \\
\hline
\end{tabular}

94. ¿Tiene alguna otra consideración que añadir? 


\section{ENTREVISTA FAMILIAR}

95. Grado de parentesco de quien cumplimenta esta parte:

96. Indíquenos, por favor, las preocupaciones y/o las necesidades que sean importantes para la familia. (Puede marcar más de una respuesta):

9610 Tema de su salud personal:

\begin{tabular}{|l|l|}
\hline 9611. Estado de salud general & 9612. Cuidados personales diarios \\
\hline 9613. Limitaciones funcionales personales & 9614. Dependencia \\
\hline 9615. Dificultades para tomar la medicación & 9616. Dificultades para acudir al tratamiento \\
\hline 9617. Dolores & 9618. Aceptación de mi situación \\
\hline 9619. Otras: &
\end{tabular}

9620 Recursos económicos:

\begin{tabular}{|l|l|}
\hline 9621. Situación económica familiar & 9622. Independencia económica \\
\hline 9623. Subvenciones & 9624. Pensión \\
\hline 9625. Encontrar un puesto de trabajo & 9626. Incapacidad laboral \\
\hline 9627. Otras: &
\end{tabular}

9630 Recursos asistenciales sanitarios:

\begin{tabular}{|l|l|}
\hline 9631. Asistencia sanitaria hospitalaria & 9632. Asistencia sanitaria domiciliaria \\
\hline 9633. Dispositivos de apoyo y protésicos & 9634. Tratamiento de fisioterapia \\
\hline 9635. Falta de información sobre estos recursos & 9636. Calidad de la asistencia sanitaria \\
\hline 9637. Más y mejores instalaciones sanitarias & 9638. Asistencia en salud mental \\
\hline 9639. Otras: & \\
\hline
\end{tabular}

9640 Recursos de servicios sociales:

\begin{tabular}{|l|l|}
\hline 9641. Servicios de alojamiento & 9642. Ayuda a domicilio \\
\hline 9643. Apoyo en las gestiones administrativas & 9644. Más y mejores instalaciones sociales \\
\hline 9645. Falta de información sobre estos recursos & 9646. Calidad de la asistencia social \\
\hline 9647. Servicios de apoyo al ocio y tiempo libre & 9648. Asesoramiento jurídico \\
\hline 9649. Otras: &
\end{tabular}

9650 Existencia de barreras:

\begin{tabular}{|l|l|}
\hline 9651. Barreras sociales & 9652. Barreras arquitectónicas \\
\hline 9653. Aceptación por parte de la familia & 9654. Aceptación por parte de la sociedad \\
\hline 9655. Ayudas técnicas & 9656. Escasez de voluntariado \\
\hline 9657. Facilidad de transporte & 9658. Accesibilidad edificios públicos \\
\hline 9659. Otras: & \\
\hline
\end{tabular}


9660 Otras preocupaciones y/o necesidades:

\begin{tabular}{|l|l|}
\hline 9661. Salida del domicilio familiar & 9662. Futuro de la familia \\
\hline 9663. Escasez de relaciones personales & 9664. Protección jurídica \\
\hline 9665. Dónde y con quién vivir en el futuro & 9666. Avances tecnológicos \\
\hline 9667. Problemas sociales & 9668. Problemas del movimiento asociativo \\
\hline 9669. Orab:
\end{tabular}

9669. Otras:

97. Indíquenos, por favor, las soluciones que Vds. consideran necesarias. (Puede marcar más de una respuesta):

\begin{tabular}{|l|l|}
\hline 9711. Ayuda para cuidados personales diarios & 9712. Subida de las pensiones \\
\hline 9713. Incremento de la ayuda familiar & 9714. Promoción del empleo protegido \\
\hline 9715. Reserva de puestos de trabajo & 9716. Incremento de las subvenciones \\
\hline 9717. Más y mejores instalaciones sanitarias & 9718. Adelantar la jubilación \\
\hline 9719. Profesionales más especializados & 9720. Calidad de la asistencia sanitaria \\
\hline 9721. Mejora de apoyos y prótesis & 9722. Asistencia psicológica \\
\hline 9723. Fisioterapia en la Seguridad Social & 9724. Más y mejor información \\
\hline 9725. Apoyo legal y administrativo & 9726. Más información sobre recursos \\
\hline 9727. Mejora de los servicios de alojamiento & 9728. Más y mejores instalaciones sociales \\
\hline 9729. Mejora de la asistencia a domicilio & 9730. Calidad de la asistencia social \\
\hline 9731. Servicios de apoyo al ocio y tiempo libre & 9732. Centros de día \\
\hline 9733. Supresión de barreras arquitectónicas & 9734. Campañas de imagen \\
\hline 9735. Programas de cambio de actitudes & 9736. Promoción de voluntariado \\
\hline 9737. Más y mejores ayudas técnicas & 9738. Aceptación por parte de la sociedad \\
\hline 9739. Aceptación por parte de la familia & 9740. Garantías de futuro \\
\hline 9741. Incremento de la participación asociativa & 9742. Facilidades de transporte \\
\hline 9743. Promoción de viviendas adaptadas & 9744. Apoyo a los cuidadores informales \\
\hline 9745. Otras: & \\
\hline
\end{tabular}

98. Indíquenos, por favor, las medidas o apoyos institucionales que Vds. echan en falta. (Puede marcar más de una respuesta):

\begin{tabular}{|l|l|}
\hline $\begin{array}{l}\text { 9821. Coordinación entre las distintas adminis- } \\
\text { traciones }\end{array}$ & $\begin{array}{c}\text { 9822. Incrementar los recursos de las aso- } \\
\text { ciaciones }\end{array}$ \\
\hline 9823. Actividades culturales & 9824. Actividades de formación \\
\hline 9825. Apoyo de la Comunidad & 9826. Apoyo de los Ayuntamientos \\
\hline 9827. Apoyos en el entorno & 9828. Igualdad de oportunidades \\
\hline 9829. Otras: & \\
\hline
\end{tabular}


99. ¿Qué piensan sobre el futuro de su hijo/a, hermano/a o familiar?

(Puede marcar más de una respuesta):

\begin{tabular}{|l|l|}
\hline 9901. Nada, no pienso en el futuro & 9902. Vivir al día \\
\hline 9903. Seguir viviendo & 9904. Triste \\
\hline 9905. Soledad & 9906. Vida independiente \\
\hline 9907. Pocas ganas de vivir & 9908. Con preocupación, futuro incierto \\
\hline 9909. Mal, negro & 9910. Vivir con calidad de vida \\
\hline 9911. Bien, sin problemas & 9912. Aburrimiento \\
\hline 9913. Resuelto & 9914. Dependerá del asociacionismo \\
\hline 9915. Preocupación por los hijos & 9916. Autonomía personal \\
\hline 9917. Otros: &
\end{tabular}

100. ¿Tienen alguna otra consideración que añadir? 


\title{
ENTREVISTA A INSTITUCIONES
}

\author{
CALIDAD DE VIDA Y \\ NECESIDADES PERCIBIDAS EN \\ EL PROCESO DE ENVEJECIMIENTO \\ DE LAS PERSONAS CON DISCAPACIDAD
}

\section{Antonio-León Aguado Díaz}

\section{$\mathbf{y}$}

María de los Ángeles Alcedo Rodríguez

Departamento de Psicología

SAPRE

Universidad de Oviedo

Plaza Feijoo, s/n - 33003 - Oviedo

Tel: 98-5103284 / Fax: 98-5104144

E-mail: aaguado@uniovi.es
Sociedad Asturiana de Psicología de la Rehabilitación Asturcón, 18 - 33006 - Oviedo Tel / Fax: 985-244266

E-mail: sapre@cop.es y alaguado@cop.es 


\section{FICHA DE LA INSTITUCIÓN (RESUMEN)}

Nota: Esta entrevista puede ser cumplimentada por el personal directivo de la institución y por cualquier profesional que tenga experiencia en la atención a las personas con discapacidad mayores de 45 años.

- Denominación de la institución:

- Dirección:

- Población:

- Código postal:

- Teléfono:

- Fecha de aplicación:

- Lugar de aplicación:

- Cumplimentada por:

- Entrevistador:

- Especialización:

- Ámbito territorial:

- Federación con:

- Principales necesidades percibidas:

- Observaciones:

- Número de orden: 


\section{DATOS DE LA INSTITUCIÓN}

101. Número de orden:

102. Lugar de aplicación de la entrevista:

\begin{tabular}{|l|l|l|l|}
\hline 1. Sede de la asociación & 2. Residencia & 3. Centro social & 4. Domicilio de otro familiar \\
\hline 5. Domicilio particular & 6. Centro de trabajo & 7. Centro de día & 8. Otro: \\
\hline
\end{tabular}

103. Entrevista cumplimentada por:

\begin{tabular}{|l|l|l|l|}
\hline 1. Director & 2. Presidente & 3. Directivo & 4. Personal de la asociación \\
\hline 5. Trabajador social & 6. Profesional & 7. Cuidador & 8. Otro: \\
\hline
\end{tabular}

104. Sede de la institución:

Población:

1. Menos de diez mil habitantes

2. Más de diez mil habitantes

105. Tipo de discapacidad/es a la que atiende. (En su caso, puede marcar varias):

\begin{tabular}{|l|l|}
\hline 01. Retraso mental & 02. Discapacidad física \\
\hline 03. Deficiencia visual & 04. Deficiencia auditiva \\
\hline 05. Trastornos mentales & 06. Enfermedad de Alzheimer \\
\hline 07. Enfermedad de Parkinson & $08.3^{\mathrm{a}}$ edad \\
\hline 09. Parálisis cerebral & 10. Autismo \\
\hline 11. Otras: & \\
\hline
\end{tabular}

106. Descripción de los asociados:

\section{Aproximadamente, ¿de cuántos asociados mayores de 45 años dis- ponen?

Profesionales con los que cuenta:

\begin{tabular}{|c|c|c|c|}
\hline 01. Trabajador social & 02. Profesor & 03. Profesor de apoyo & 04. Monitor de tiempo libre \\
\hline 05. Técnico rehabilitador & 06. Fisioterapeuta & 07. Cuidador & 08. Personal administrativo \\
\hline 09. Logopeda & 10. Médico & 11. Enfermero / ATS & 12. Personal auxiliar \\
\hline 13. Psicólogo & 14. Abogado & 15. Pedagogo & 16. Personal de limpieza \\
\hline 17.Educador social & 18. Conductor & 19. Personal de cocina & 20. Personal mantenimiento \\
\hline $\begin{array}{l}\text { 21. Terapeuta, monitor } \\
\text { ocupacional, de taller }\end{array}$ & $\begin{array}{l}22 \text { Técnico de apo- } \\
\text { yo al empleo }\end{array}$ & \multicolumn{2}{|l|}{ 23. Otros: } \\
\hline
\end{tabular}


107. Tipo de servicios que presta a sus asociados:

\begin{tabular}{|l|l|l|l|}
\hline 01. Rehabilitación & 02. Dpto. trabajo social & 03. Atención logopédica & 04. Atención psicológica \\
\hline 05. Podólogo & 06. Servicio de comida & 07. Alojamiento & 08. Asistencia médica \\
\hline 09. Gimnasio & 10. Lavandería & 11. Ocio y tiempo libre & 12. Servicio de limpieza \\
\hline 13. Biblioteca & 14. Hidroterapia & 15. Alfabetización & 16. Ayudas asistenciales \\
\hline $\begin{array}{l}\text { 17. Fisioterapia } \\
\begin{array}{l}\text { 21. Terapia ocupa- } \\
\text { cinal }\end{array}\end{array}$ & $\begin{array}{l}\text { 22. Empleo, actividad } \\
\text { laboral }\end{array}$ & 23. Otros: & 20. Información y orientación \\
\hline
\end{tabular}

108. Tipo de alojamiento de que disponen sus asociados (concretar las distintas modalidades):

109. Indíquenos, por favor, las preocupaciones y/o las necesidades que sean importantes para la institución:

1110 Tema de su salud personal:

\begin{tabular}{|l|l|}
\hline 1111. Estado de salud general & 1112. Cuidados personales diarios \\
\hline 1113. Limitaciones funcionales personales & 1114. Dependencia \\
\hline 1115. Dificultades para tomar la medicación & 1116. Dificultades para acudir al tratamiento \\
\hline 1117. Dolores & 1118. Aceptación de mi situación \\
\hline 1119. Oras:
\end{tabular}
1119. Otras:

1120 Recursos económicos:

\begin{tabular}{|l|l|}
\hline 1121. Situación económica familiar & 1122. Independencia económica \\
\hline 1123. Subvenciones & 1124. Pensión \\
\hline 1125. Encontrar un puesto de trabajo & 1126. Incapacidad laboral \\
\hline 1127. Otras: & \\
\hline
\end{tabular}

1130 Recursos asistenciales sanitarios:

\begin{tabular}{|l|l|}
\hline 1131. Asistencia sanitaria hospitalaria & 1132. Asistencia sanitaria domiciliaria \\
\hline 1133. Dispositivos de apoyo y protésicos & 1134. Tratamiento de fisioterapia \\
\hline 1135. Falta de información sobre estos recursos & 1136. Calidad de la asistencia sanitaria \\
\hline 1137. Más y mejores instalaciones sanitarias & 1138. Asistencia en salud mental \\
\hline 1139. Otras: & \multicolumn{2}{|l}{} \\
\hline
\end{tabular}

1140 Recursos de servicios sociales:

\begin{tabular}{|l|l|}
\hline 1141. Servicios de alojamiento & 1142. Ayuda a domicilio \\
\hline 1143. Apoyo en las gestiones administrativas & 1144. Más y mejores instalaciones sociales \\
\hline 1145. Falta de información sobre estos recursos & 1146. Calidad de la asistencia social \\
\hline
\end{tabular}


1147. Servicios de apoyo al ocio y tiempo libre 1148 . Asesoramiento jurídico 1149. Otras:

1150 Existencia de barreras:

\begin{tabular}{|l|l|}
\hline 1151. Barreras sociales & 1152. Barreras arquitectónicas \\
\hline 1153. Aceptación por parte de la familia & 1154. Aceptación por parte de la sociedad \\
\hline 1155. Ayudas técnicas & 1156. Escasez de voluntariado \\
\hline 1157. Facilidad de transporte & 1158. Accesibilidad edificios públicos \\
\hline 1159. Otras: & \\
\hline
\end{tabular}

1160 Otras preocupaciones y/o necesidades:

\begin{tabular}{|l|l|}
\hline 1161. Salida del domicilio familiar & 1162. Futuro de la familia \\
\hline 1163. Escasez de relaciones personales & 1164. Protección jurídica \\
\hline 1165. Dónde y con quién vivir en el futuro & 1166. Avances tecnológicos \\
\hline 1167. Problemas sociales & 1168. Problemas del movimiento asociativo \\
\hline 1169. Atención integral e individualizada & 1170. Necesidad de más profesionales \\
\hline 1171. Formación y reciclaje del personal & 1172. Coordinación entre las instituciones \\
\hline 1173. Otras: & \multicolumn{2}{|l}{} \\
\hline
\end{tabular}

110. Indíquenos, por favor, las demandas que plantean con mayor frecuencia sus asociados:

\begin{tabular}{|c|c|}
\hline 1201. Ayudas médicas & 1202. Ayudas económicas \\
\hline 1203. Ayuda a domicilio & 1204. Apoyo institucional \\
\hline 1205. Apoyo de las distintas administraciones & 1206. Ayuda a las familias \\
\hline 1207. Apoyo a cuidadores & 1208. Apoyo afectivo al discapacitado \\
\hline 1209. Participación, que se les escuche & 1210. Relaciones afectivas, de amistad \\
\hline 1211. Fomento de la Calidad de Vida & 1212. Más y mejores instalaciones \\
\hline 1213. Servicios residenciales & 1214. Centros de día \\
\hline 1215. Inserción laboral & 1216. Actividades de ocio y tiempo libre \\
\hline 1217. Alternativas ocupacionales & 1218. Programas de respiro \\
\hline 1219. Tutorización & 1220. Rehabilitación \\
\hline 1221. Tratamiento psicológico & 1222. Formación \\
\hline 1223. Profesionales más especializados & 1224. Trato más humano \\
\hline 1225. Más información & 1226. Más recursos técnicos y materiales \\
\hline $\begin{array}{l}\text { 1227. Disminución de la relación discapacita- } \\
\text { do/profesional }\end{array}$ & 1228. Supresión de barreras arquitectónicas \\
\hline 1229. Supresión de barreras sociales & 1230. Favorecer la vida independiente \\
\hline 1231. Apoyo e implicación de las familias & 1232. Más personal y mejores servicios \\
\hline
\end{tabular}

111. Indíquenos, por favor, las soluciones que Vds. consideran necesarias:

\begin{tabular}{|l|l|}
\hline 1311. Ayuda para cuidados personales diarios & 1312. Subida de las pensiones \\
\hline 1313. Incremento de la ayuda familiar & 1314. Promoción del empleo protegido \\
\hline 1315. Reserva de puestos de trabajo & 1316. Incremento de las subvenciones \\
\hline
\end{tabular}




\begin{tabular}{|c|c|}
\hline 1317. Más y mejores instalaciones sanitarias & 1318. Adelantar la jubilación \\
\hline 1319. Profesionales más especializados & 1320. Calidad de la asistencia sanitaria \\
\hline 1321. Mejora de apoyos y prótesis & 1322. Asistencia psicológica \\
\hline 1323. Fisioterapia en la Seguridad Social & 1324. Más y mejor información \\
\hline 1325. Apoyo legal y administrativo & 1326. Más información sobre recursos \\
\hline 1327. Mejora de los servicios de alojamiento & 1328. Más y mejores instalaciones sociales \\
\hline 1329. Mejora de la asistencia a domicilio & 1330. Calidad de la asistencia social \\
\hline 1331. Servicios de apoyo al ocio y tiempo libre & 1332. Centros de día \\
\hline 1333. Supresión de barreras arquitectónicas & 1334. Campañas de imagen \\
\hline 1335. Programas de cambio de actitudes & 1336. Promoción de voluntariado \\
\hline 1337. Más y mejores ayudas técnicas & 1338. Aceptación por parte de la sociedad \\
\hline 1339. Aceptación por parte de la familia & 1340. Garantías de futuro \\
\hline 1341. Incremento de la participación asociativa & 1342. Facilidades de transporte \\
\hline 1343. Promoción de viviendas adaptadas & 1344. Apoyo a los cuidadores informales \\
\hline $\begin{array}{l}\text { 1345. Disminución de la relación discapacita- } \\
\text { do/profesional }\end{array}$ & $\begin{array}{l}\text { 1346. Más actividades ocupacionales, más y } \\
\text { mejores recursos comunitarios }\end{array}$ \\
\hline 1347. Atención individualizada & 1348. Incremento de la atención sanitaria \\
\hline 1349. Programas adecuados de intervención & 1350. Coordinación entre instituciones \\
\hline
\end{tabular}

112. Indíquenos, por favor, las medidas o apoyos institucionales que echa en falta la institución:

\begin{tabular}{|l|l|}
\hline $\begin{array}{l}\text { 1421. Coordinación entre las distintas adminis- } \\
\text { traciones }\end{array}$ & $\begin{array}{c}\text { 1422. Incrementar los recursos de las aso- } \\
\text { ciaciones }\end{array}$ \\
\hline 1423. Actividades culturales & 1424. Actividades de formación \\
\hline 1425. Apoyo de la Comunidad & 1426. Apoyo de los Ayuntamientos \\
\hline 1427. Apoyos en el entorno & 1428. Igualdad de oportunidades \\
\hline $\begin{array}{l}\text { 1429. Tener en cuenta la opinión de los profe- } \\
\text { sionales }\end{array}$ & $\begin{array}{c}\text { 1430. Reorganización de los servicios socia- } \\
\text { les }\end{array}$ \\
\hline 1431. Creación de centros y recursos necesarios & $\begin{array}{c}\text { 1432. Mayor implicación de la administra- } \\
\text { ción }\end{array}$ \\
\hline 1433. Otras: \\
\hline
\end{tabular}


113. ¿Qué piensan sobre el futuro de la atención a sus asociados?

\begin{tabular}{|l|l|}
\hline 1501. Nada, no pienso en el futuro & 1502. Vivir al día \\
\hline 1503. Seguir viviendo & 1504. Triste \\
\hline 1505. Soledad & 1506. Vida independiente \\
\hline 1507. Pocas ganas de vivir & 1508. Con preocupación, futuro incierto \\
\hline 1509. Mal, negro & 1510. Vivir con calidad de vida \\
\hline 1511. Bien, sin problemas & 1512. Aburrimiento \\
\hline 1513. Resuelto & 1514. Dependerá del asociacionismo \\
\hline 1515. Preocupación por los hijos & 1516. Autonomía personal \\
\hline $\begin{array}{l}\text { 1517. Más y mejor preparación de los profesio- } \\
\text { nales }\end{array}$ & $\begin{array}{l}\text { 1518. Mayor especialización y personaliza- } \\
\text { ción loservicios }\end{array}$ \\
\hline 1519. Necesidad de apoyos especiales & 1520. Sercicios específicos \\
\hline 1521. Atención personalizada & 1522. Más implicación de la admnistración \\
\hline 1523. Otrata
\end{tabular}

1523. Otras:

114. ¿Qué piensan sobre el futuro de la atención a las personas con discapacidad mayores de 45 años?

\begin{tabular}{|c|c|}
\hline 1601. Nada, no pienso en el futuro & 1602. Vivir al día \\
\hline 1603. Seguir viviendo & 1604. Triste \\
\hline 1605. Soledad & 1606. Vida independiente \\
\hline 1607. Pocas ganas de vivir & 1608. Con preocupación, futuro incierto \\
\hline 1609. Mal, negro & 1610. Vivir con calidad de vida \\
\hline 1611. Bien, sin problemas & 1612. Aburrimiento \\
\hline 1613. Resuelto & 1614. Dependerá del asociacionismo \\
\hline 1615. Preocupación por los hijos & 1616. Autonomía personal \\
\hline $\begin{array}{l}\text { 1617. Más y mejor preparación de los profesio- } \\
\text { nales }\end{array}$ & $\begin{array}{l}\text { 1618. Mayor especialización y personaliza- } \\
\text { ción loservicios }\end{array}$ \\
\hline 1619. Necesidad de apoyos especiales & 1620. Sercicios específicos \\
\hline 1621. Atención personalizada & 1622. Más implicación de la admnistración \\
\hline
\end{tabular}

115. ¿Tienen alguna otra consideración que añadir? 